\title{
Dietary fats and arterial thrombosis
}

Citation for published version (APA):

Hornstra, G. (1980). Dietary fats and arterial thrombosis. [Doctoral Thesis, Maastricht University]. Rijksuniversiteit Limburg. https://doi.org/10.26481/dis.19800926gh

Document status and date:

Published: 01/01/1980

DOI:

10.26481/dis.19800926gh

Document Version:

Publisher's PDF, also known as Version of record

\section{Please check the document version of this publication:}

- A submitted manuscript is the version of the article upon submission and before peer-review. There can be important differences between the submitted version and the official published version of record.

People interested in the research are advised to contact the author for the final version of the publication, or visit the DOI to the publisher's website.

- The final author version and the galley proof are versions of the publication after peer review.

- The final published version features the final layout of the paper including the volume, issue and page numbers.

Link to publication

\footnotetext{
General rights rights.

- You may freely distribute the URL identifying the publication in the public portal. please follow below link for the End User Agreement:

www.umlib.nl/taverne-license

Take down policy

If you believe that this document breaches copyright please contact us at:

repository@maastrichtuniversity.nl

providing details and we will investigate your claim.
}

Copyright and moral rights for the publications made accessible in the public portal are retained by the authors and/or other copyright owners and it is a condition of accessing publications that users recognise and abide by the legal requirements associated with these

- Users may download and print one copy of any publication from the public portal for the purpose of private study or research.

- You may not further distribute the material or use it for any profit-making activity or commercial gain

If the publication is distributed under the terms of Article $25 \mathrm{fa}$ of the Dutch Copyright Act, indicated by the "Taverne" license above, 


\section{DIETARY FATS AND ARTERIAL THROMBOSIS}

\section{G.HORNSTRA}

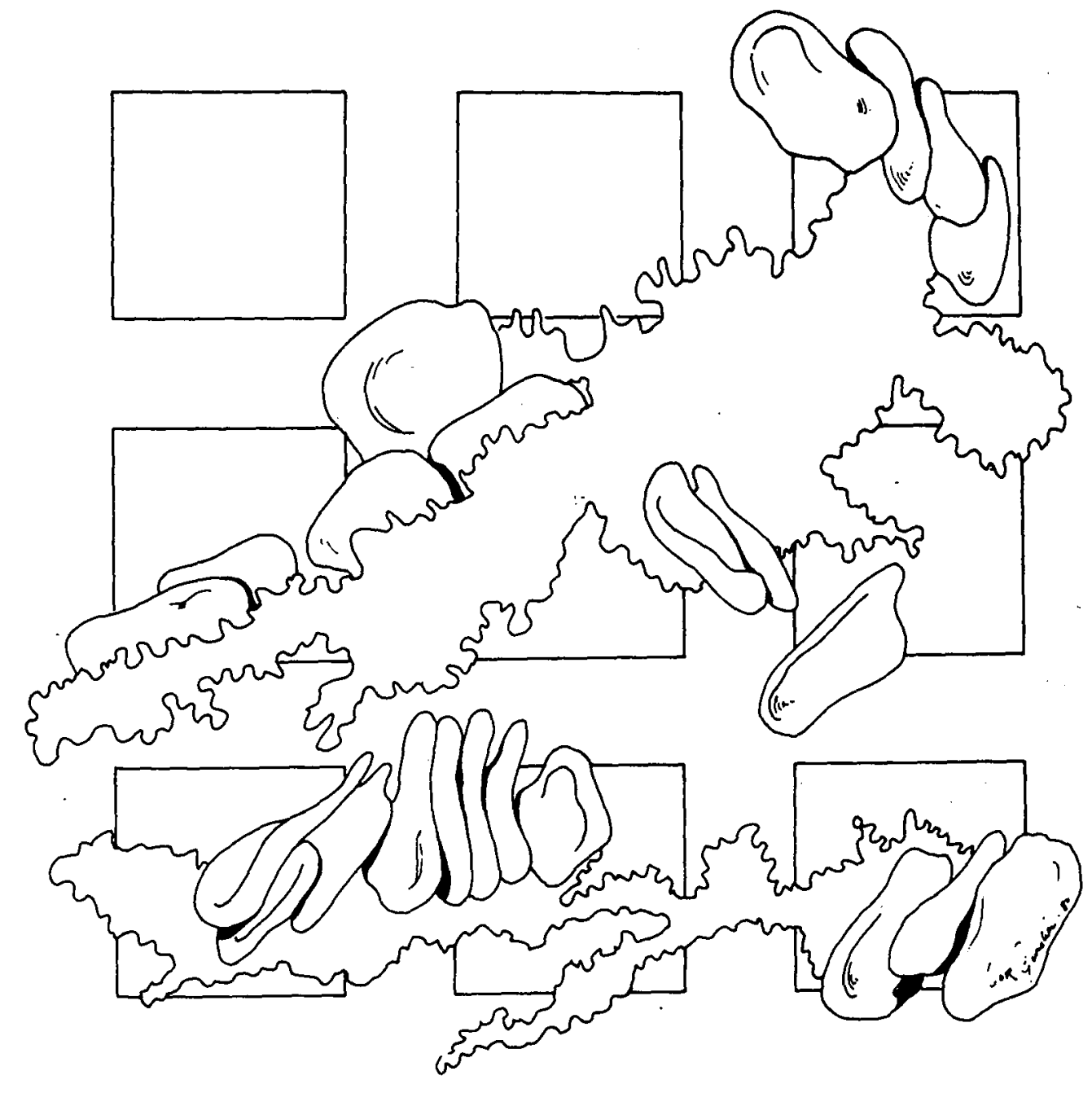


Het verschijnen van dit proefschrift werd mede mogelijk gemaakt door steun van de Nederlandse Hartstichting. 


\title{
DIETARY FATS AND ARTERIAL THROMBOSIS
}

\author{
Proefschrift \\ ter verkrijging van de graad van \\ Doctor in de Geneeskunde aan de \\ Rijksuniversiteit Limburg te Maastricht, \\ op gezag van de Rector Magnificus \\ Prof. Dr. W.H.F.W. Wijnen, \\ hoogleraar in de Fakulteit der Geneeskunde, \\ volgens het besluit van het College van Dekanen \\ in het openbaar te verdedigen in \\ de Aula van de Universiteit op \\ vrijdag 26 september 1980 \\ des namiddags te 16.00 uur
}

door G. Hornstra

geboren te Wolvega 
Promotor : Prof. Dr. H.C.Hemker

Referenten : Prof. Dr. J.F. Mustard, Hamilton, Canada Prof. Dr. A. Nord $\varnothing y$, Troms $\phi$, Noorwegen Dr. F. ten Hoor, Vlaardingen

Prof. Dr. R.S. Reneman, Maastricht 
Scientific work is teamwork and I was fortunate enough to receive a considerable amount of internal and external encouragement and practical assistance in the completion of the work described in this thesis. The spontaneous assistance of many fine colleagues at the Unilever research laboratory, Vlaardingen, is one of the best recollections I have of the years I worked for this research establishment.

I wish to record my gratitude to Jan Don, Edward Haddeman and Yvonne Gielen who assisted me with most of the experimental work and thank Wil Arentz and Elly Christ for performing many of the biochemical determinations.

Thanks are also due to Koos Zaalberg and Rijk Lussenburg who performed most of the statistical computations and also to Hans Kleinekoort who supervised animal care.

Construction of the Filtragometer would have been impossible without the help of Leo de Snayer, Erik Berends and Gë Groenewegen.

In regard to the production of the manuscript, I would like to thank Gerard Duran for his linguistic advice and proofreading, Cor Gardien and Koos Smit for drawing the graphs and illustrations and Wim Timmer and Aad Marks for providing the photographs.

Also outside the Unilever research organisation, may offered their help and assistance.

I am particularly grateful to Prof. Jan Sixma (Utrecht) and Prof. C.Haanen (Nijmegen) for giving me permission to study some of their patients and to the brethren of the Maria Toevlucht Abbey (Zundert) for participating in filtragometer studies.

I am also greatly indebted to Prof.0.Turpeinen and Prof.M.Karvonen (Helsinki) for giving me the opportunity to participate in their unique dietary experiment and to Prof.Barry Lewis and Dr.ATan Chait (London) for their expert help with this study.

My sincere thanks are also due to Prof.Dr.H.Hess (Munich), Or.H.Rieger (Munich) and Dr.Alan Fleischman (Montclair, USA) for the experiments we carried out together.

Also the valuable discussions I had with Prof.Coen Hemker and Prof.Rob Zwaal as well as with Drs.Rietje Dam, Foppe ten Hoor, Dick Nugteren and 
Toine Vergroesen have been very much appreciated.

Finally I would like to express my appreciation to the Management of the Unilever research laboratory for giving me the opportunity to study medicine.

Tenslotte wil ik jou, Netty, bedanken voor de wijze

waarop je het mij mogelijk gemaakt hebt deze studie te volgen, het onderzoek te verrichten en dit proefschrift te schrijven.

Jij, Marco, Sil en ik - we hebben veel in te halen. 
For in much wisdom

is much grief:

and he that increaseth knowledge

increaseth sorrow.

EccT. $1: 18$

Want in veel wijsheid

is veel verdriet,

en als iemand kennis vermeerdert, vermeerdert hij smart.

Pred. $1: 18$ 
is partly based on the following papers

1. Hornstra,G.: Method to determine the degree of ADP-induced platelet aggregation in circulating rat blood ('Filter-loop technique'). Brit.J.Haemato1. 19: 321-329 (1970).

2. Hornstra,G.: Degree and duration of prostaglandin $E_{1}$-induced inhibition of platelet aggregation in the rat. Eur.J.Pharmacol. 15: 343-349 (1971).

3. Hornstra,G. and Vendelmans-Starrenburg,A.: Induction of experimental arterial occlusive thrombi in rats. Atherosclerosis 17: 369-382 (1973).

4. Hornstra,G., Lewis, B., Chait,A., Turpeinen,0., Karvonen,M.J. and Vergroesen,A.J.: Influence of dietary fat on platelet function in men'. Lancet i: 1155-1157 (1973).

5. Hornstra,G. and Haddeman,E.: Prostaglandins, essential fatty acids, platelet function and thrombosis. Thromb.Res.4, Supp1.1.: 91-92 (1974).

6. Hornstra,G. and ten Hoor,F.: The filtragometer : a new device for measuring platelet aggregation in venous blood of man. Thrombos. Diathes. haemorrh. 34: 531-544 (1975).

7. Hornstra,G. and Lussenburg,R.N.: Relationship between the type of dietary fatty acid and arterial thrombosis tendency in rats. Atherosclerosis 22: 499-516 (1975).

8. Hornstra,G. and Haddeman,E.: Diet-induced changes in arterial thrombosis not primarily mediated by arachidonate peroxidation. Biblthca haemat. 45: 9-13 (1973).

9. Hornstra,G., Haddeman,E. and Don,J.A.: Blood platelets do not provide endoperoxides for vascular prostacyclin production. Nature 279: 66-68 (1979).

10. Hornstra,G. and Hemker,H.C.: Clot-promoting effect of platelet-vesse1 wall interaction: influence of dietary fats in relation to arterial thrombus formation in rats. Haemostasis 8: 211-226 (1979).

11. Hornstra,G., Christ-Hazelhof,E., Haddeman,E., Nugteren,D.H. and ten Hoor,F.: Fish oil feeding lowers thromboxane - and prostacyclin production by rat platelets and aorta and does not result in the formation of prostaglandin $I_{3}$. Submitted for publication. 
1. DIETARY FATS, ARTERIAL THROMBOSIS AND ATHEROSCLEROSIS. A SHORT INTRODUCTION

2. BIOCHEMICAL PHYSIOLOGY OF DIETARY FATS 8

2.1. Structure and nomenclature of fatty acids 8

2.2. Fatty acid synthesis 10

2.2.1. Chain elongation 10

2.2.2. Desaturation 11

2.3. Essential fatty acids 13

2.4. Fatty acid degradation 13

2.5. Fatty acid derivatives 14

2.5.1. Triglycerides 15

2.5.2. Phospholipids 15

2.5.3. Cholesterol esters 16

2.6. Fat absorption 16

2.7. Plasmatic transport of fatty acids 18

2.8. Functions of fatty acids 19

2.8.1. Function in biomembranes 20

2.8.2. Function as prostaglandin precursors 21

2.8.3. Some other functions of fatty acids 24

2.9. Lipid metabolism of platelets 24

2.10. References 25

3. PROCESSES INVOLVED IN ARTERIAL THROMBUS FORMATION AND ITS REGULATION 33

3.1. Introduction 33

3.2. The role of vessel-wall induced clotting in platelot aggregation following vascular injury $\quad 34$

3.2.1. Methodology 34

3.2.2. Effect of blood platelets on vessel-wall induced clotting $\$ 36$

3.2.3. Effect of vascular prostacyclin on vessel-wall induced clotting

3.2.4. Tentative characterization of the clotting process initiated by damaged vascular tissue 38

3.2.5. Vessel-wall induced platelet reactions : role of Thromboxane $\mathrm{A}_{2}$ and ADP 
3.2.6. Vessel-wall induced platelet reactions: role of thrombin

3.2.7. Thrombin, the key substance in thrombus formation following vascular injury?

3.3. Platelet- and vessel wall prostaglandins : their role in thromboregulation

3.3.1. Platelet prostaglandins and thromboxanes 47

3.3.2. Vascular prostaglandin $I_{2}$

3.3.3. Interaction between platelet thromboxane $A_{2}$ and vascular $\mathrm{PGI}_{2}$

3.3.3.1. Effect of blood platelets on the formation of vascular prostacyclin

3.3.3.2. Effect of collagen-activated blood platelets on vascular prostacyclin formation

3.3.3.3. Effect of platelets, producing different amounts of endoperoxides, on vascular prostacyclin production

3.3.3.4. Mechanism by which the $\mathrm{PGI}_{2}$-synthesis of indomethacin-treated tissue is restored 56

3.3.3.5. Effect of platelets on the recovery of $\mathrm{PGI}_{2}$-production by indomethacin-treated vascular tissue upon incubation in plasma

3.3.3.6. Discussion and conclusion

3.4. Summary 60

3.5. References

4. EFFECT OF DIETARY FATS ON ARTERIAL THROMBOSIS AND PLATELET FUNCTION - A LITERATURE REVIEW

4.1. Introduction

4.2. Effect of dietary fats on arterial thrombus formation in vivo

4.2.1. Effects observed on using acute techniques

4.2.2. Effects observed when using semi-chronic techniques

4.2.3. Effects obtained on using chronic thrombosis models

4.2.4. Conclusion 
4.3. Effect of dietary fats on in vitro thrombotic platelet functions

4.3.1. Effect of a single fat dose 78

4.3.2. Effect of prolonged fat feeding 81

4.3.3. Conclusion 83

4.4. References 83

5. NEW EXPERIMENTAL MODELS FOR THE INVESTIGATION OF ARTERIAL THROMBOSIS TENDENCY AND PLATELET AGGREGABILITY 92

5.1. Introduction 92

5.2. Measurement of arterial thrombosis tendency in rats 93

5.2.1. Preparation of the aorta loop 93

5.2.2. Animals and insertion procedure 94

5.2.3. Determination of arterial thrombosis tendency 95

5.2.4. Measurement of thrombus growth-rate 96

5.2.5. Histological investigation of growing thrombi and mechanism of thrombus formation 97

5.2.6. Behavioural and hematological changes after loop insertion

5.2.7. Importance of platelet function in arterial thrombus formation

5.2.7.1. Effect of prostaglandin $E_{1}$ on arterial thrombus formation

5.2.7.2. Effect of aspirin on arterial thrombosis tendency 104

5.2.7.3. Arterial thrombosis tendency of rats with a hereditary defect of the platelet release reaction

5.2.8. Contribution of clotting to arterial thrombogenesis

5.2.9. Effect of atherosclerotic and thrombotic risk factors on arterial thrombus formation 106

5.2.10. Summary

5.3. Measurement of platelet aggregation in circulating arterial rat blood

5.3.1. Principle of the filter loop technique

5.3.2. Description of the filter system

5.3.3. Measurement and calculation of degree of 
5.3.3.1. Dose-response curve ADP

5.3.3.2. Course of the aggregation index after repeated administration of $A D P$

5.3.4. Effect of aggregation measurements on the concentration of circulating platelets

5.3.4.1. Influence of single aggregation measurement on the concentration of circulating platelets

5.3.4.2. Influence of repeated aggregation measurements on the concentration of circulating platelets

5.3.5. Application of the filter-loop technique 115

5.3.5.1. Effect of prostaglandin $E_{1}$

5.3.5.2. Effect of two serum lipid-lowering drugs

5.3.5.3. Other applications

5.3.6. Summary

118

5.4. Measurement of spontaneous aggregation in flowing venous blood of man

5.4.1. Description of the Filtragometer 119

5.4.2. Concise description of some introductory mode1 experiments

5.4.3. Measuring technique in man

5.4.4. Description of the aggregation curve and definition of aggregation parameters

5.4.5. Scanning electron microscopy of the filter 123

5.4.6. Origin of the measured aggregates 124

5.4.7. Reproducibility of the filtragometer response 127

5.4.8. Effect of anticoagulant on aggregation response 129

5.4.9. Effect of platelet aggregation-inhibiting drugs on filtragometer response

5.4.9.1. Effect of prostaglandin $E_{1}$ ex vivo 130

5.4.9.2. Effect of oral aspirin

5.4.10. Relationship between filtragometer response and other hematological parameters

5.4.11. Filtragometer response in some disease states and its relation to some thrombotic risk factors 135

5.4.12. Summary 
6. EFFECT OF TYPE AND AMOUNT OF DIETARY FAT ON ARTERIAL THROMBUS FORMATION IN RATS

6.1. Introduction

6.2. Effect of increasing amounts of dietary sunflowerseed $0 i 1$ on arterial thrombus formation

6.3. Comparison of the effect of different dietary fats and oils on arterial thrombus formation in rats

6.3.1. Relationship between arterial thrombosis tendency and dietary fatty acid composition

6.3.2. Arterial thrombosis tendency as a function of the amount of absorbed fatty acids

6.4. Comparison of the antithrombotic effect of oleic and linoleic acids.

6.5. Further evidence for the prothrombotic effect of dietary saturated fatty acids

6.6. Comparison of the effect of cis and trans fatty acids on arterial thrombus formation

6.7. Summary

6.8. References

7. LOCATION OF DIETARY FAT EFFECT ON ARTERIAL THROMBUS FORMATION

7.1. Introduction

7.2. Effect of sunflowerseed oil (SO) and hydrogenated coconut oi] ( $\mathrm{HCO}$ ) on blood coagulation

7.2.1. Whole blood clotting time

7.2.2. Plasma recalcification clotting time (PCT)

7.2.3. Activated partial thromboplastin time (APTT) 162

7.2.4. Prothrombin time (PT)

7.2.5. Platelet factor 3 (PF 3)

7.2.6. Vessel-wall induced clotting

7.3. Effect of the dietary fat type on platelet aggregability 169

7.3.1. Platelet aggregation in vitro

7.3.2. Platelet aggregation in circulating arterial blood 173 7.3.2.1. ADP-induced aggregation 173

7.3.2.2. Spontaneous platelet aggregation 176

7.4. Possible mechanisms by which dietary fats affect arteriat thrombosis tendency 
8. THE SIGNIFICANCE OF PROSTAGLANDIN-LIKE SUBSTANCES IN THE DIETARY FAT EFFECTS ON ARTERIAL THROMBOGENESIS

8.1. Introduction

8.2. Essential fatty acid (EFA-) deficiency in arterial thrombogenesis

8.2.1. Effect of EFA-deficiency on arterial thrombosis

8.2.2. Platelet function in EFA-deficiency

8.2.2.1. Platelet adhesion 188

8.2.2.2. Platelet shape change 189

8.2.2.3. Platelet aggregation and release

8.2.3. Effect of EFA-deficiency on coagulation and platelet factor 3

8.2.4. Discrimination between prostaglandin-dependent and prostaglandin-independent functions of EFA in arterial thrombogenesis

8.2.5. Summary

8.3. The role of the thromboxane-prostacyclin balance in dietary-fat induced changes in arterial thrombus formation

8.4. General summary

8.5. References

9. EFFECT OF FISH OIL FEEDING ON ARTERIAL THROMBOSIS, PLATELET FUNCTION AND BLOOD CLOTTING IN RATS

9.1. Introduction

9.2. Effect of dietary fish oil on arterial thrombus formation 204 9.2.1. Comparison of cod-liver oil with sunflowerseed oil

9.2.2. Comparison of two different fish oils with respect to their antithrombotic effect

9.2.3. Effect of low-cholesterol fish oil on arterial thrombogenesis compared with that of sunflowerseed oil

9.2.4. Conclusion

9.3. Effect of dietary fish oil on platelet aggregation in vitro

9.4. Effect of fish-oil feeding on some coagulation parameters 209 9.4.1. Vessel-wall induced clotting 209

9.4.2. Activated partial thromboplastin time (APTT) 210 
9.4.3. Prothrombin time (PT)

9.5. Bleeding time : comparison between the effect of dietary

fish oils and sunflowerseed oil

9.6. Effect of fish vil feeding on platelet thromboxane

production and the vascular formation of prostacyclin-like material

212

9.6.1. Effect of fish oil feeding on platelet MDA- and vascular PGI-formation

9.6.2. Dose-response effect of dietary fish oil on platelet MDA and vascular PGI formation

9.7. Fish-oil feeding and formation of prostaglandins of the 3-series

9.7.1. Methodology

9.7.2. Conversion of arachidonic (AA) and timnodonic (TA) acid by platelet cyclo-oxygenase and lipoxygenase 218 .

9.7.2.1. Conversion of exogenous fatty acids by platelets

9.7.2.2. Conversion of endogenous $A A$ and $T A$ in activated platelets

9.7.3. Prostacyclin- and $\mathrm{PGI}_{3}$-formation by vascular tissue of rats fed a cod-liver oil containing diet 220

9.7.4. Effect of fish oil feeding to EFA-deficient animals on the formation of platelet-and vascular prostaglandins

9.8. General discussion 225

9.9. Summary 228

9.10. References 229

10. EFFECT OF DIFFERENT DIETARY FATS ON PLATELET LIPID PROFILE AND FATTY ACID COMPOSITION. CONSEQUENCES FOR PLATELET PROSTAGLANDIN PRODUCTION AND MEMBRANE FLUIDITY 234

10.1. Introduction 234

10.2. Experimental procedure

10.2.1. Animals, diets and platelet preparation

10.2.2. HHT and HETE measurements

10.2.3. Platelet phospholipid analysis

10.2.4. Phospholipid fatty acid composition

10.3. HHT and HETE production of collagen-activated blood platelets 
10.3.1. Collagen-induced aggregation

10.3.2. HHT production of collagen-activated blood platelets

10.3.3. HETE production of collagen-activated blood platelets

242

10.3.4. Relationship between HHT and HETE formation

10.3.5. Relationship between platelet HHT formation and collagen-induced aggregation

244

10.4. Platelet phospholipid analysis

10.4.1. Platelet protein content

10.4.2. Platelet phospholipid content

248

10.4.3. Platelet phospholipid class distribution

248

10.4.4. Fatty acid composition of platelet phospholipids

251

10.5. Relationship between the arachidonic acid content of platelet phospholipids and the HHT production of activated platelets

10.5.1. Absolute $A A$ content

259

10.5.2. Relative $A A$ content

261

10.5.3. Conclusions

10.6. Possible consequences of platelet lipid profile and fatty acid composition for membrane fluidity

10.6.1. Unsaturation index

10.6.2. Saturation index

10.6.3. Cholesterol-phospholipid ratio

10.6.4. Discussion

10.7. Summary

10.8. References

11. EFFECT OF DIETARY LINOLEIC ACID ON PLATELET FUNCTION IN MEN

11.2.1. Experimental groups and diets

11.2.2. Experimental procedure

11.5. Effect of decreasing the dietary linoleic acid content on platelet aggregation in men

11.6. The long-term thromboprotective effect of dietary 
linoleic acid. Hypothesis concerning a role of adipose tissue linoleate

11.6.1. Modulation of the prothrombotic effect of a saturated fat diet in rats by prefeeding an antithrombotic diet

11.6.2. The possible role of adipose tissue linoleate in long-term thromboprotection. A hypothesis 236

11.7. Possible mechanisms by which linoleic acid lowers platelet aggregability and arterial thrombosis tendency 288

11.8. Summary 289 11.9. References 290

12. SUMMARY AND CONCLUDING REMARKS 295

VOEDINGSVETTEN EN ARTERIËLE THROMBOSE 
$\mathrm{AA}$

APTT

$B F$

BHT

CLO

co

cps

D-LA

EDTA

EFA

en\%

FFA

FO

$\mathrm{HCO}$

HEPE

HETE

HHT

HHTE

HSO

i.u. or I.U. international unit

J

:LA

$\alpha$ LA

LO

LPC

LPE

LPO

butterfat

cod-1iver oil

cyclo-oxygenase

centipoise

free fatty acid(s)

linseed oil

Tyso lecithin

lipoxygenase arachidonic acid $(20: 4(n-6)$

activated partial thromboplastin time

butylated hydroxy toluene

dihomo- $\gamma-1$ inolenic acid $(20: 3(n-6))$

ethylenediamine tetraacetic acid

essential fatty acid(s)

$\%$ of digestible energy

fish oil of unknown origin

hydrogenated coconut oil

12-L-hydroxyeicosapentaenoic acid

12-L-hydroxytetraenoic acid

12-L-hydroxyheptadecatrienoic acid

12-L-hydroxyheptadecatetraenoic acid

hydrogenated soyabean oil

Joule (1 Cal 4.184 J)

linoleic acid $(18: 2(n-6))$

$\alpha$ linolenic acid $(18: 3(n-3))$

Tyso phosphatidyl ethanolamine 


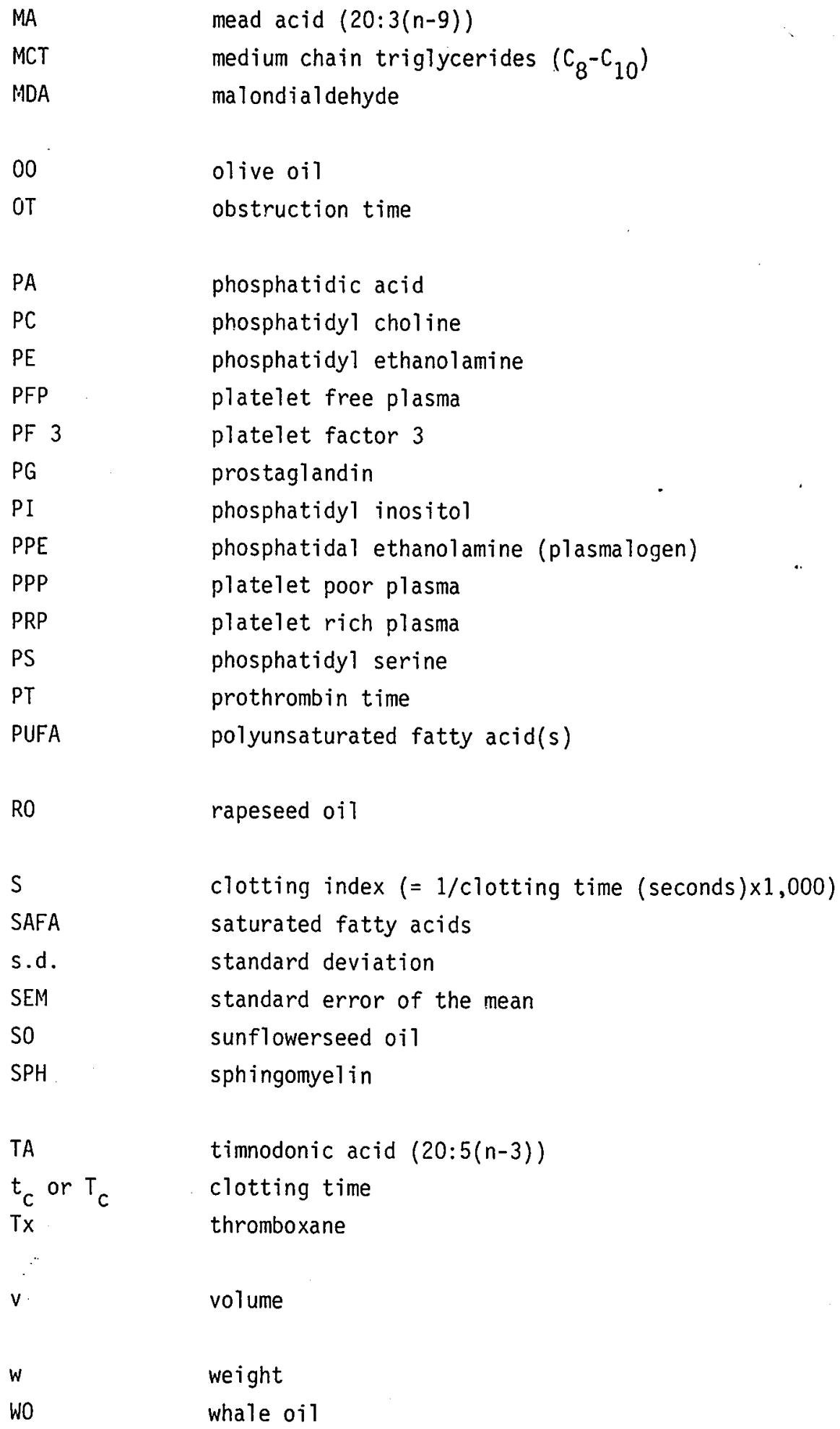




\section{DIETARY FATS, ARTERIAL THROMBOSIS AND ATHEROSCLEROSIS}

\section{A SHORT INTRODUCTION}

Thrombosis, the process of intravascular blood clotting, results in the formation of a thrombus, which might impair or even block the circulation of blood through a part of the vascular system. Thrombus formation occurs in the veins as well as in the arteries. Although in both cases, the basic processes - reaction of blood platelets and blood clotting-are similar, the relative contribution of each of these processes differs considerably, leading to a distinctly different morphology of venous and arterial thrombi.

The pathological and clinical implications of such thrombi are also different. Obstruction of the venous circulation causes stasis phenomena, which might cause a disabling condition but, in itself, it is hardly ever fatal. Mortality caused by venous thrombosis is mainly due to fragmentation of the thrombus (embolization). These emboli are swept away by the venous blood stream and after having passed the heart, they may obstruct part of the pulmonary circulation and have fatal consequences. Due to arterial thrombosis, the arterial blood supply might be obstructed resulting in malfunction or even death not only of the downstream tissue but, provided this tissue is of vital importance, also of the entire organism. Mortality from arterial thrombosis is higher than from venous thrombosis, especially in the younger age groups. This can mainly be attributed to the fact that arterial thrombosis is the major lethal complication of atherosclerosis (1-3), a disease characterized by narrowing of the arterial lumen caused by fatty depositions in the vascular wall. Moreover, there is increasing morphological (4-7) and experimental (8-12) evidence that arterial thrombosis is also important as a cause of atherosclerosis. This view has been challenged by Benditt (37) on the basis of his findings (38) and those of others $(39,40)$, indicating that the atherosclerotic plaque is of monoclonal origin whereas cells organizing a thrombus would be polyclonal. Recently, Pearson and co-workers demonstrated an increasing monocionality with increasing organization of thrombi (41). This finding provides objective evidence for the role of thrombosis in the formation of human atherosclerotic plaques. However, biochemical studies of the type and origin of lipid in atherosclerotic plaques (13-17) convincingly show that other factors are important as well. Morphological work on monkeys yielded the same indication (18). Consequently, although arterial 
thrombosis plays a major role in atherogenesis, it cannot be considered to be the sole important factor in the generation of this condition (19).

Arterial thrombosis depends on two factors: vascular injury and the reaction of circulating blood towards this injury (Fig.1.1.). As a result of vascular damage, blood inside the vessel is no longer protected from contact with subendothelial structures. This subendothelium is highly attractive for blood platelets, which readily adhere to it and so become activated to produce and release substances causing passing platelets to aggregate with adhered ones. The newly aggregated platelets al so become activated and initiate a self-propagating process of aggregation and activation. These platelet reactions lead to the formation of a fragile platelet mass, the so-called white thrombus.

Vascular damage also initiates blood clotting. This clotting response is enhanced by activated blood platelets and the fibrin formed reinforces the fragile platelet mass to a stabilized thrombus of great pathological significance. There is evidence to believe that thrombin, generated as a result of vessel-wall induced clotting, is of key importance in white thrombus formation because its local presence has been shown to be essential for platelet aggregation induced by damaged vascular tissue (Chapter 3).

There are two more ways in which blood platelets participate in atherogenesis (Fig.1.1.). Upon activation, they also release a so-called mitogenic factor stimulating the proliferation of medial smooth muscle cells (20) and their migration into the mural thrombus. These processes are considered to be of key importance in the formation of advanced atherosclerotic lesions (21). Moreover, activated platelets release serotonin, which induces endothelial contraction, thereby facilitating lipid infiltration into the arterial wall and thrombus formation $(22,23)$.

In experimental animals it has been demonstrated very convincingly that platelets play a key role in atherogenesis (24-27). This implies that decreasing the platelet activation level and lowering the arterial thrombosis tendency will be beneficial in the prevention of atherosclerosis and its complications.

One of the major manifestations of atherosclerosis is coronary artery disease (CAD) which, when complicated by an occlusive arterial thrombus, may cause myocardial infarction (34). Mortality profiles show that after 


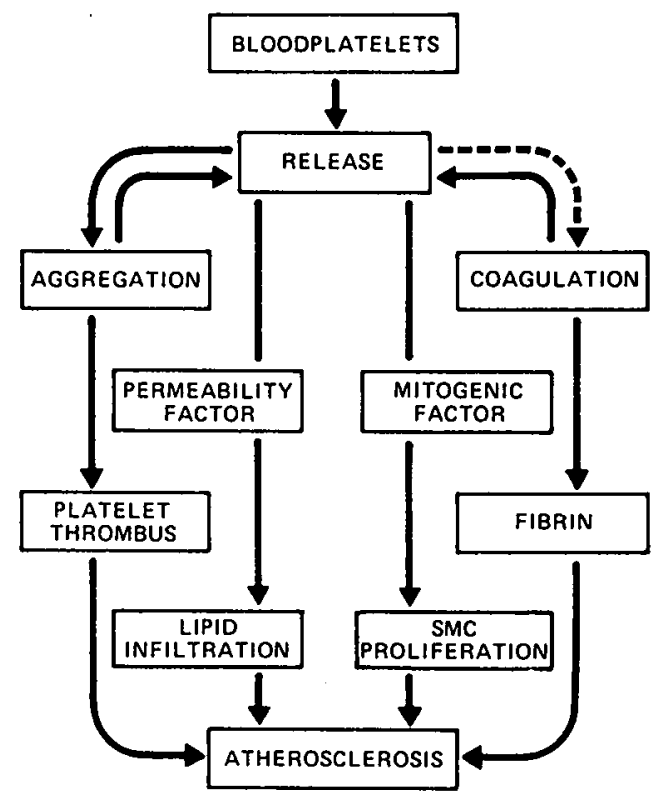

Fig.1.1. Role of biood platelets in atherogenesis. SMC : smooth muscle cel1. For further explanation : see text.

the onset of acute myocardial infarction, there is a high primary death to 11. Secondary prevention in patients who survived a first infarction either by diet, by anticoagulation or by lipid-lowering drugs - is difficult and shows only a modest success at best. Therefore, special emphasis should be placed on the primary prevention of CAD.

There is a large body of literature data showing the epidemiological relationship between diet - the type of dietary fat in particular - and atherosclerotic diseases in Western societies (for a review, see reference 28). Moreover, it is now generally accepted that the type and amount of dietary fat can influence the genesis and course of experimental atherosclerosis (29-33). Since atherosclerosis and arterial thrombosis were shown to be related phenomena, it would be interesting to know whether dietary fats are also able to modify arterial thrombosis.

Before 1970, no systematic investigations were performed in this field, possibly because of the lack of suitable techniques at that time. The development of the aorta-1oop technique, the filter-loop technique and the filtragometer (Chapter 5) enabled us to perform these studies.

Although our investigations (Chapters 6, 7, 9 and 11) and those of others, 
clearly show that saturated fats are prothrombotic and dietary polyunsaturated fatty acids antithrombotic in animals as well as in man, there is still no consensus as to the efficacy of such a diet in decreasing. coronary risk (35). Unfortunately, it is highly unlikely that proof of this efficacy will ever be produced, not only because 'numbers necessary to do a pure diet-heart trial are too large to attempt such a program' (36), but also because the huge number of data indicating the beneficial effect of such a diet will prevent this trial from being accepted by any ethical committee. Another convincing approach might therefore be the unravelling of mechanisms by which the type of dietary fat affects atheroscierosis, arterial thrombosis and ultimately platelet thrombotic functions. The experiments reported in Chapters 7-11, were devised to contribute to the elucidation of these mechanisms.

\section{References.}

1. Owren,P.: Nutrition and thrombosing atherosclerosis. Biblth. Nutr. Dieta 6 : 156-182 (1964).

2. Harland,W.A. and Holburn, A.M.: Coronary thrombos is and myocardial infarction. Lancet ii: 1158-1159 (1966).

3. Sinapius,D.: Beziehungen zwischen Koronarthrombosen und Myokardinfarkten. Dtsch. Med.Wschr. 97: 443-448 (1972).

4. Duguid,J.B.: Thrombosis as a factor in the pathogenesis of coronary atherosclerosis. Am.J.Pathol.Bacteriol. 58: 207-212 (1946).

5. Heggtveit,H.A.: Atheromatous transformation of intracardiac mural thrombi. Am.J.Pathol. 52: 70a (1968).

6. Likar,I.N., Likar,L.J., Robison,R.W. and Gouvelis,A.: Microthrombi and intimal thickening in bovine coronary arteries. Arch.Pathol. 87: 146-153 (1969).

7. Fulton,W.F.M.: Coronary thrombotic occlusion in myocardial infarction and thrombus in the pathogenesis of atherosclerosis. In: Carlson,L.A., Paoletti,R., Sirtori,C.R. and Weber,G. (Eds.): International conference on atherosclerosis. Raven Press, New York (1978), pp. 75-89.

8. Friedman,M. and Byers,S.0.: Experimental thrombo-atherosclerosis. J.Clin. Invest. 40: 1139-1152 (1961).

9. Hand,R.A. and Chandler,A.B.: Aetherosclerotic metamorphosis of autologous pulmonary thromboemboli in the rabbit. Am.J.Pathol.40:469-486(1962).

10. Sumiyoshi,A., More,R.H. and Weigensberg,B.I.: Aortic fibro-fatty type 
atherosclerosis from thrombus in normolipidemic rabbits. Atherosclerosis 18: 43-57 (1973).

11. Moore,S.: Thrombosis and atherosclerosis. Thromb. Diathes.haemorrh., Supp 1. 60: 205-212 (1974).

12. Woolf,N.: Thrombosis and atherosclerosis. Adv.Exp.Med.Biol. 104: 145-167 (1978).

13. Newman,H.A.I. and Zilversmit,D.B.: Quantitative aspects of cholesterol flux in rabbit atheromatous lesions. J.Biol.Chem. 237: 2078-2084 (1962).

14. Smith,E.B.: Quantitative and qualitative comparisons of the lipids in platelets, aortic intima and mural thrombi. Cardiovasc. Res. 1: 111-115 (1967).

15. Weigensberg,B.I., More,R.H. and Sumiyoshi,A.: Lipid profile in the evolution of experimental atherosclerotic plaques from thrombus. Lab. Invest 33: 43-50 (1975).

16. Craig,I.H., Bell,F.P. and Schwarz,C.J.: Thrombosis and atherosclerosis: the organization of pulmonary thromboembol $i$ in the pig. Individual phospholipids, fatty acid composition of lecithin, sphingomyelin, esterified cholesterol and ${ }^{3} \mathrm{H}$-cholesterol specific activity. Exp.Mol. Pathol. 18: 290-304 (1973).

17. Craig,I.H., Bell,F.P., Goldsmith,C.H. and Schwarz,C.J.: Thrombosis and atherosclerosis: the organization of pulmonary thromboemboli in the pig. Macroscopic observations, protein, DNA and major lipids. Atherosclerosis 18: 277-300 (1973).

18. Prathap,K.: The natural history of platelet-rich mural thrombi in systemic arteries of hypercholesterolemic monkeys: light and electron microscope observations. J.Pathol. 110: 203-212 (1973).

19. Born,G.V.R. and others in: Wolfe,S. (ed.): The artery and the process of arteriosclerosis: pathogenesis. Adv.Exp.Med.Biol. 16A: 175-184 (1971). Plenum Press, New York, London.

20. Ross,R., Glomset,J.A., Kariya,B. and Harker,L.A.: A platelet-dependent serum factor that stimulates the proliferation of arterial smooth muscle cells in vitro. Proc.Nat.Acad.Sci. USA 71: 1207-1210 (1974).

21. Ross,R. and Glomset,J.A.: The pathogenes is of atherosclerosis. New Engl.J.Med. 295: 369-377 and 420-425 (1976).

22. Shimamoto,T.: Contraction of endothelial cells as a key mechanism in atherogenesis and treatment of atherosclerosis with endothelial cell relaxants. In: Schettler,G. and Weizel,A.: Atherosclerosis.III. Springer Verlag, Berlin, Heidelberg, New York (1974), pp. 64-82.

23. Shimamoto,T.: Drugs and foods on contraction of endothelial cells as 
a key mechanism in atherogenesis and treatment of atherosclerosis with endothelial cell relaxants (cyclic AMP phosphodiesterase inhibitors). Adv.Exp.Med.Biol. 60: 77-105 (1975).

24. Harker,L.A., Ross, R., STichter,S.J. and Scott, C.R.: Homocystine-induced arteriosclerosis. The role of endothelial cell injury and platelet response in its genesis. J.C1in. Invest. 58: 731-741 (1976).

25. Moore,S., Friedman,R.J., Singal,D.P., Gauldie,J. and Blajchman,M.: Inhibition of injury-induced thrombo-atherosclerotic lesions by antiplatelet serum in rabbits. Thromb.Diathes.haemorrh. 35: 70-81 (1976).

26. Friedman,R.J., Stemerman,M.B., Wenz,B., Moore,S., Gauldie,J., Gent,M. , Tiel1,M.L. and Spaet,T.H.: The effect of thrombocytopenia on experimental arteriosclerotic lesion formation in rabbits. Smooth muscle cell proliferation and re-endothelialization. J.Clin. Invest.60: 1191-1201 (1977).

27. Fuster, V. and Bowie,E.J.W.: The von Willebrand pig as a model for atherosclerosis research. Thromb. Haemostas. 39: 322-327 (1978).

28. Stamler,J.: Diet-related risk factors for human atherosclerosis: hyperlipidemia, hypertension, hyperglycemia - current status. Adv. Exp. Med.Biol. 60: 125-158 (1975).

29. Gottenbos,J.J. and Thomasson,H.J.: Aorta atheromatos is in rabbits on feeding cholesterol or fats. Coll. Int.Centr.Nat.Rech.Sci. 99: 221-239 (1961).

30. Vles,R.0., Büller,J., Gottenbos,J.J. and Thomasson,H.J.: Influence of type of dietary fat on cholesterol-induced atherosclerosis in the rabbit. J.Atherosc].Res. 4: 170-183 (1964).

31. Malmros, H.: Dietary prevention of atherosclerosis. Lancet i i: 479-484 (1969).

32. Howard,C.F., Jr.: The relationship of diet and atherosclerosis in diabetic Macaca nigra. Adv. Exp.Med.Biol.60: 13-31 (1975).

33. Wissler,R.W. and Vesselinovitch,D.: The effects of feeding various dietary fats on the development and regression of hypercholesterolemia and atherosclerosis. Adv.Exp.Med.Biol. 60: 65-76 (1975).

34. Chandier,A.B., Chapman, I., Erhardt,L.R., Roberts,W.C., Schwartz,C.J., Sinapius,D., Spain,D.M., Sherry,S., Ness,P.M. and Simon,T.L.: Coronary thrombosis in myocardial infarction. Report of a workshop on the role of coronary thrombosis in the pathogenesis of acute myocardial infarction. Am.J.Cardiol. 34: 823-833 (1974).

35. Mann,G.V.: Diet-heart: end of an era. New Engl.J.Med. 297: 644-650(1977). 36. Vogt,T.M.: Diet-heart era: premature obituary ? New Engl.J.Med. 298: 
ERRATUM

De grafleken $3 a$ en $3 b$ staan per abuis afgedrukt op pagina 8; dit moet zijn pagina 11 . 
107 (1978).

37. Benditt,E.P.: Evidence for a monoclonal origin of human atherosclerotic plaques and some implications. Circulation 50: 650-652 (1974).

38. Benditt,E.P. and Benditt,J.M.: Evidence for a monoclonal origin of human atherosclerotic plaques. Proc.Nat1.Acad.Sci USA 70: 1753-1756 (1973).

39. Pearson,T.A., Wang,A., Solez,K. and Heptinstall,R.H.: Clonal characteristics of fibrous plaques and fatty streaks of human aortas. Am.J.Pathol. 81: 379-388 (1975).

40. Pearson,T.A., Dillman,J., Solez,K. and Heptinstall,R.H.: Clonal markers in the study of the origin and growth of human atherosclerotic lesions. Circ.Res. 43: 10-18 (1978).

41. Pearson,T.A., Solez,K., Dillman,J. and Heptinstall,R.H.: Monoclonal characteristics of organizing arterial thrombi: significance in the origin and growth of human atherosclerotic plaques. Lancet $i: 7-11$ (1979). 


\section{BIOCHEMICAL PHYSIOLOGY OF DIETARY FATS}

Dietary fats mainly consist of fatty acids esterified to glycerol. For a long time, they have been considered as a condensed source of energy but this view changed completely after the structural and metabolic functions of fatty acids had been recognized.

\subsection{Structure and nomenclature of fatty acids}

Al though some naturally occurring branched-chain and even ring-chain fatty acids are known, the majority of fatty acids consists of an aliphatic chain of carbon atoms $\left(-C_{-}\right)$with a terminal carboxyl group $(-\mathrm{COOH})$. In saturated fatty acids, all available C-bonds are occupied by hydrogen atoms (-H, Fig.2.1.). In unsaturated fatty acids, not all free $\mathrm{C}$-bonds are 'saturated' with $\mathrm{H}$-atoms, resulting in a double bond between two adjacent $\mathrm{C}$-atoms $\left(-{ }^{\mathrm{H}} \mathrm{C}=\mathrm{C}^{\mathrm{H}}-\right)$. Mono-unsaturated fatty acids contain one unsaturated bond and polyunsaturated fatty acids, two or more (Fig.2.2.). Double bonds may have a cis- or trans-configuration. In the cis-configuration, the H-atoms immediately adjacent to the double bonds are located on the same side of the C-chain plane. In the trans-configuration, these $\mathrm{H}$-atoms are situated on opposite sides of this plane. (Fig.2.3.). Natural oils and fats contain fatty acids with almost exclusively cis-isomers. However, small amounts of trans fatty acids are present in certain animal fats, while the oil of Aquilegia Vulgaris is relatively rich in columbinic acid, which has a trans-double bond between the 13th and the 14th C-atom (Fig.2.4. see Chapter 8, section 2.4.). In natural fatty acids, two double bonds are practically always separa-

(A)

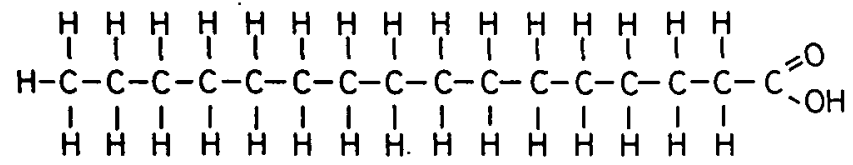

(B) n. $12345 \rightarrow$ etc. etc. $\longleftarrow \Delta_{5} \Delta_{4} \Delta_{3} \Delta_{2} \Delta_{1}$ etc. $\delta \gamma \beta \alpha$

(C)

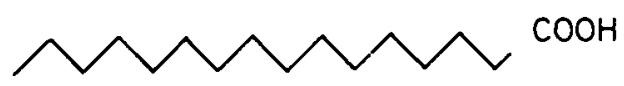

Fig.2.1. Composition and structure of palmitic acid (16:0)

A. extensive notation; B. numbering of C-atoms; C. simplified notation. 
a

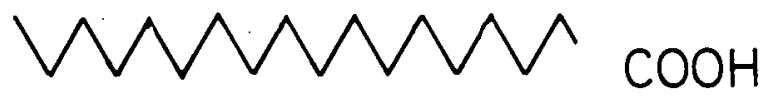

$b$

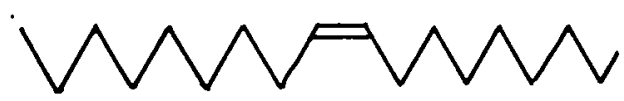

$\mathrm{COOH}$

C

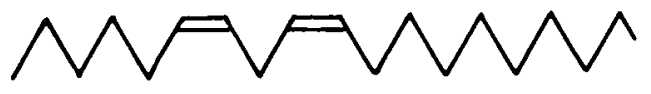

\section{$\mathrm{COOH}$}

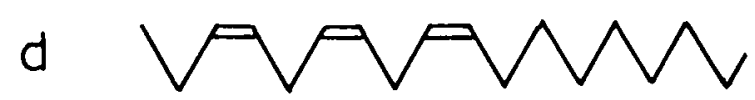

$\mathrm{COOH}$

Fig. 2.2. Structure of some common fatty acids

a. stearic acid (18:0); b. oleic acid $(18: 1(n-9))$;c. linoleic acid $(18: 2(n-6)) ;$ d. $\alpha-1$ inolenic acid $(18: 3(n-3))$.

ted by one methylene group $\left(-\mathrm{C}^{\mathrm{H}}=\mathrm{C}^{\mathrm{H}}-\mathrm{CH}_{2}-\mathrm{C}^{\mathrm{H}}=\mathrm{C}^{\mathrm{H}}-\right)$. Moreover, they contain almost exclusively an even number of $\mathrm{C}$-atoms. Depending on the length of this $\mathrm{C}$-chain, fatty acids are designated as short-chain-( $\leq 6 \mathrm{C}$-atoms), medium-chain- ( 8 or $10 \mathrm{C}$-atoms) or long-chain fatty acids (12 or more (-atoms).

The systematic designation is rather complex and, therefore, trivial names are more frequently used. For practical purposes, we will denote fatty acids as $x: y(n-z)$, in which $x$ is the total number of $c$-atoms, $y$ the number of double bonds and $z$ the position of the first $C$-atom (counted from the terminal methyl group) involved in a double bond. Fig.2.2. gives some examples of fatty acid structures and their notation. The structure of the fatty acids is an important determinant of their
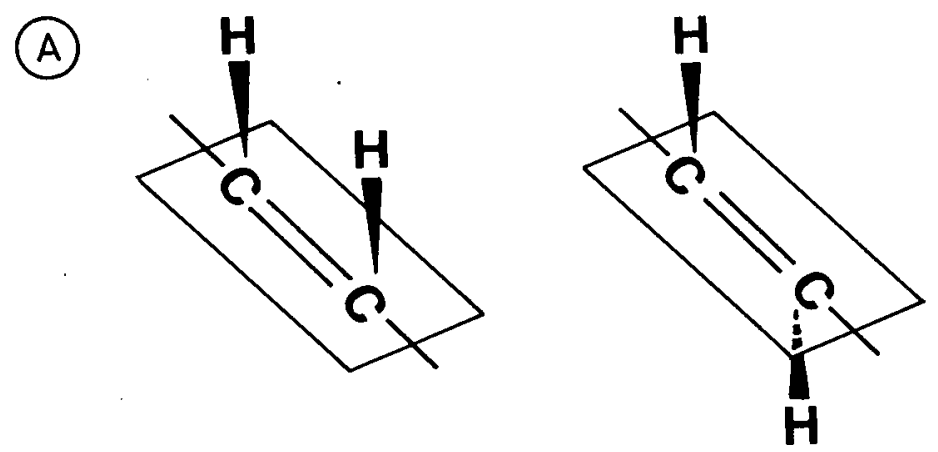

(B).

Fig.2.3. Cis (A) and trans (B) configuration of double bonds. 


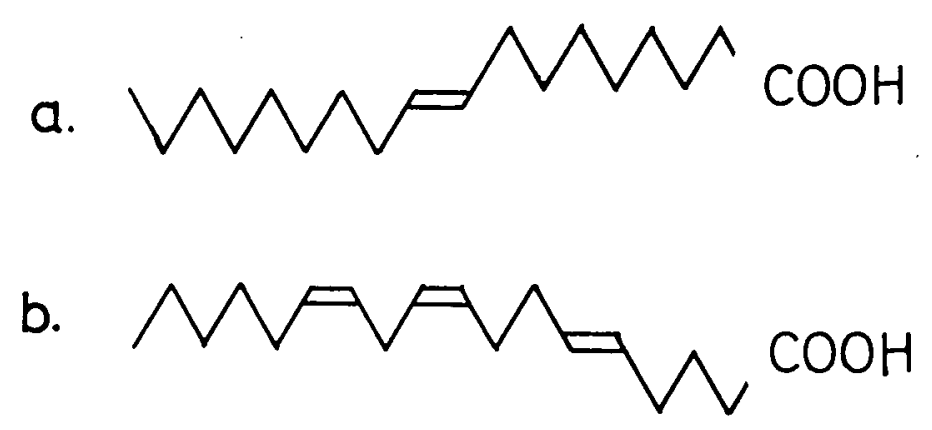

Fig.2.4. Structure of some fatty acids containing a trans double bond. a. elaidic acid; b. columbinic acid.

physical properties and thereby of their structural functions. The physical properties of acids containing trans double bonds resemble those of saturated fatty acids more closely than those of cis compounds.

\subsection{Fatty acid synthesis}

Depending on the special requirement of various tissues, the body needs an ever-changing variety of different fatty acids. To meet this demand, it is not completely dependent on a certain dietary fatty acid intake, because the body is able to synthesize a great variety of fatty acids itself, starting mainly from pyruvate, a product of carbohydrate metabolism. The major product of this pathway of de novo fatty acid synthesis is palmitic acid $(16: 0)$.

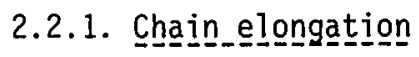

The greater part of palmitic acid is converted into stearic acid $(18: 0)$ by chain elongation. This reaction - and the formation of longer-chain saturated fatty acids - is catalysed by an elongase enzyme system and results in the incorporation of two methylene groups from malonyl COA into the fatty acid chain just proximal to the carboxyl group:

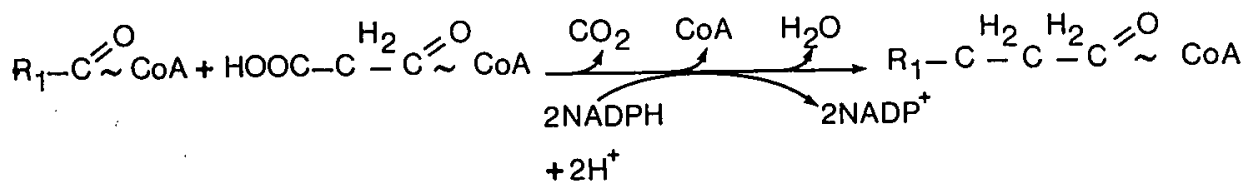


The elongase system contains 3 different enzymes, which are located on the membranes of the endoplasmatic reticulum. Another fatty acid chain -elongation system is located in the mitochondria. It differs from the microsomal system in that it does not use malonyl COA but acetyl CoA. Therefore, this pathway can be considered as the reverse route of the catabolic process of $\beta$-oxidation (see section 2.4.). Polyunsaturated fatty acids (PUFA's) are better elongated than saturated fatty acids (SAFA's), especially when the double bonds are located closely to the carboxyl groups. It is not known whether different elongase systems are required for the elongation of different chain lengths (1).

\subsubsection{Desaturation}

Starting from mainly stearic acid (18:0), the body can produce quite a number of long-chain (poly-) unsaturated fatty acids by the alternating action of a desaturase enzyme complex and the elongase described. For this purpose, various desaturases are available, which are microsomal enzyme complexes allowing the introduction of double bonds into fatty acid molecules (2). For their activity, they require a reduced pyridine nucleotide and molecular oxygen. They act only on activated fatty acids (acyl CoA) according to the following overall reaction:

$$
\begin{aligned}
& \mathrm{R}_{1}-\mathrm{C}_{2}-\mathrm{C}_{2}-\mathrm{R}_{2} \sim \mathrm{COA}+\mathrm{NAD}(\mathrm{P}) \mathrm{H}+\mathrm{H}^{+}+\mathrm{O}_{2} \longrightarrow \\
& \mathrm{R}_{1}-\mathrm{C}^{\mathrm{H}}=\mathrm{C}^{\mathrm{H}}-\mathrm{R}_{2} \sim \mathrm{COA}+\mathrm{NAD}(P)^{+}+2 \mathrm{H}_{2} \mathrm{O}
\end{aligned}
$$

The various desaturases all act on a specific site of the fatty acid molecule. The $\Delta_{9}$-desaturase introduces a double bond into a saturated fatty acid between the 9 th and the 10th carbon atom, counted from the carboxyl group (the $\Delta_{9,10}$-position, see Fig.2.1.B.). The $\Delta_{6}$-desaturase does the same between the 6 th and the 7 th $\mathrm{C}$-atom but oniy in those fatty acids which have already a double bond at the $\Delta_{9,10}$-position. The $\Delta_{5}$-desaturase introduces a double bond between the 5 th and the 6 th $\mathrm{C}$-atom. It needs a substrate fatty acid already desaturated in the $\Delta_{11,12}$ - and $\Delta_{8,9}$ - position. Also, a $\Delta_{4}$-desaturase has been described, being highly specific for substrate fatty acids with double bonds at the $\Delta_{13,14}$, $\Delta_{10,11^{-}}$and $\Delta_{7,8}$-positions. It introduces a double bond between the 4 th and the 5th $\mathrm{C}$-atom, again counted from the carboxyl group.

So far, no other desaturases have been found in mammalian tissue and the 
conditions mentioned above therefore imply that

- no double bonds can be introduced between $c_{1}$ and $c_{9}$ (counted from the terminal methyl group)

- any further double bond is introduced between the carboxyl group and the nearest double bond present.

Consequentiy, starting from an (n-9) fatty acid, only another (n-9) fatty acid can be formed and from an (n-7) fatty acid only another ( $n-7)$ fatty acid. Therefore, endogenously formed polyunsaturated fatty acids can be classified as members of the $(n-9)$ - or the (n-7)-family. Fig.2.5. shows the major steps of the biosynthesis of these families.

The desaturase enzyme system is stimulated by dietary carbohydrates and SAFA's. Insulin has also been reported to have a stimulating effect, which is most probably indirect. To attain an optimum activity,

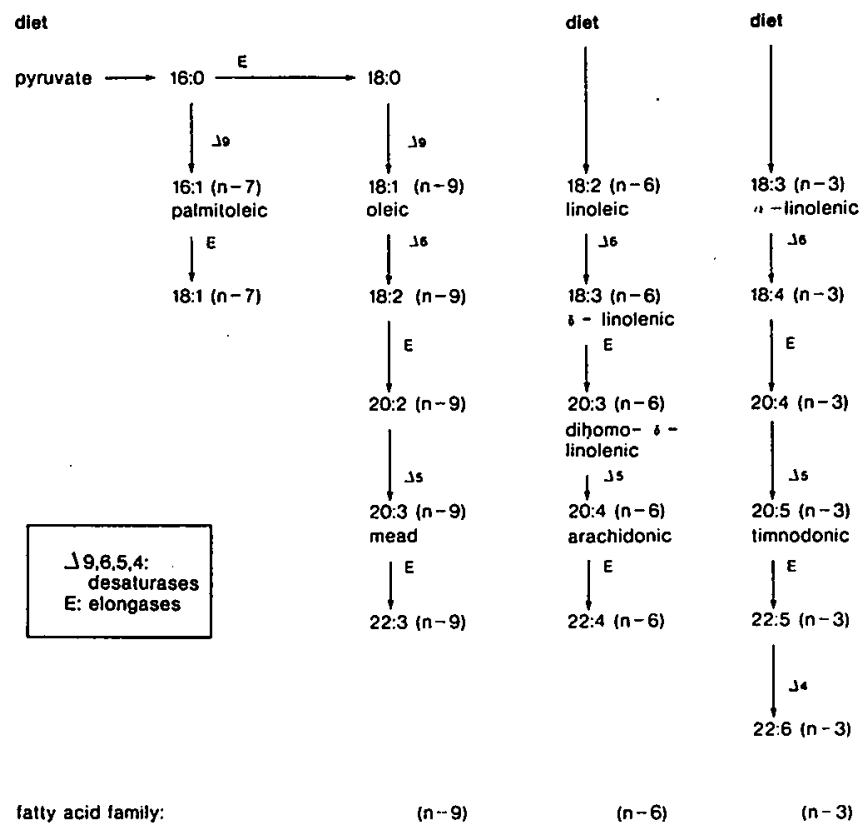

Fig.2.5. Major biosynthetic pathways of fatty acids. 
the desaturase enzym complex requires the presence of certain cytoplasmic proteins. These proteins most probably act as fatty-acid binding proteins and may regulate the supply of fatty acids (or its CoA esters) to the enzyme. For PUFA synthesis, $\Delta_{6}$-desaturase activity is rate-limiting. The affinity of substrate fatty acids for this enzyme is higher, the higher the number of double bonds. Therefore, desaturation of 1 inoleic acid $(18: 2(n-6))$ is inhibited by $\alpha-1$ inolenic acid $(18: 3(n-3))$ and other long-chain PUFA's (3). Only when these fatty acids are present in minute amounts, can oleic acid $(18: 1(n-9))$ become desaturated and chain-elongated. This occurs in essential fatty acid deficiency (vide infra) and results in the formation of mead acid, 20:3(n-9) (4).

\subsection{Essential fatty acids}

Saturated fatty acids and fatty acids of the (n-9) and (n-7) families are insufficient to maintain normal life in mammals. This was shown as early as 1929 by Burr and Burr (5), who observed that rats, after feeding them a rigidly fat-free diet, developed severe deficiency symptoms and ultimately died. This deficiency could be cured only by administering small amounts of oils containing polyunsaturated fatty acids of the $(n-3)$ and/or $(n-6)$ series. Similar results were obtained in a wide variety of animal species and in man (6-8). Obviously, mammals need (n-3) and/or ( $n-6)$ fatty acids and because they lack $\Delta_{12}$ and $\Delta_{15}$ - desaturases (present in plants), they depend for these fatty acids on dietary intake. Therefore, these fatty acids are called essential fatty acids (EFA's). Fig.2.5. shows the major steps of the metabolism of $18: 2(n-6)$, linoleic acid, and 18:3(n-3), $\alpha-1$ inolenic acid.

\subsection{Fatty acid degradation}

Fatty acid degradation occurs for the greater part by a process known as $\beta$-oxidation. This process is located in the mitochondria and only 'activated' fatty acids (esterified with $C O A$ ) can be oxidized. Activation of fatty acids requires energy and takes place in the cyptoplasm. The activated fatty acids enter the mitochondria as carnitine esters after which they are converted back into CoA-esters. Fatty acid oxidation yields a multiple of the energy invested in their activation. 
By a complex process, in which various enzymes and cofactors are involved, the fatty acyl (e.g. 16:0)-COA is dehydrogenated at the $\alpha$ - and $\beta$-carbon atoms (See Fig.2.1.), hydrated and dehydrogenated again, after which a 2-carbon fragment (acetyl COA) is split off. The remainder of the molecule (14:0 COA) enters a second degradation cycle -- etc, until the fatty acid molecule is degraded completely. The $\beta$-oxidation of unsaturated fatty acids requires some additional reactions, the nature of which still gives rise to some controversy (10). The electrons removed in the two hydrogenation steps travel to oxygen via the respiratory chain, accompanied by oxidative phosphorylation of ADP. The acetyl CoA formed enters the Krebs cycle and is oxidized to $\mathrm{CO}_{2}$ and $\mathrm{H}_{2} \mathrm{O}$. In this way, one molecule of palmitic acid yields 131 molecules of ATP, which represents $40 \%$ of the standard free energy of the oxidation reaction.

\subsection{Fatty acid derivatives}

Fatty acids, especially the long-chain types, have strong deterging properties and are very toxic for the organism. Therefore, under norma 1 circumstances, tissue free fatty acid levels are very low. Most fatty acids are present as triglycerides -serving as a general reserve (adipose tissue)- or as (mainly membrane-) phospholipids performing a structural function or acting as quickly mobilizable precursor substances (e.g. for prostaglandins).

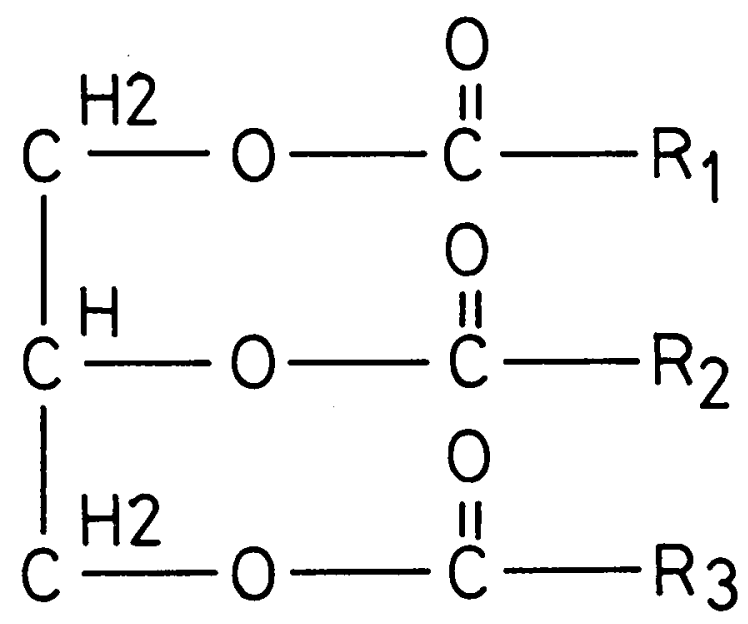

Fig.2.6. Structure of triglyceride molecule. $R_{1}, R_{2}$ and $R_{3}$ : fatty acids residues. 


\subsubsection{Triglycerides}

Triglycerides (triacyglycerols) are esters of glycerol and fatty acids. One molecul of glycerol can bind 3 fatty acid molecules (Fig.2.6.). These fatty acids may be similar or (partly) different. In the body, triglycerides constitute the major fatty acids depot located in the adipose tissue. When the body requires fatty acids, adipose tissue triglycerides are hydrolyzed by the action of a hormone-sensitive lipase. (See section 2.7.).

\subsubsection{Phospholipids}

Phospholipids have a glycerol backbone, like triglycerides, but in the 3-position it is esterified to phosphoric acid. Hydrocarbon groups are attached to the 1- and 2-positions. At the 2-position, this group is largely a (poly-)unsaturated fatty acid ; at the 1-position, it usually is a saturated fatty acid. Sometimes, the hydrocarbon chain is attached to the 1-position of the glycerol moiety via an ether linkage, forming an alkyl ether phosphoglyceride. Plasmalogens are alkyl ether phosphoglycerides in which the ether-linked alkyl chain contains a double bond between the $\Delta_{1}$ and $\Delta_{2}$ positions. The greater part of the phosphoric acid groups form diesters with the hydroxyl groups of choline, ethanolamine, serine or inositol. The major phospholipid classes and the codes used in this thesis, are shown in Table 2.1.

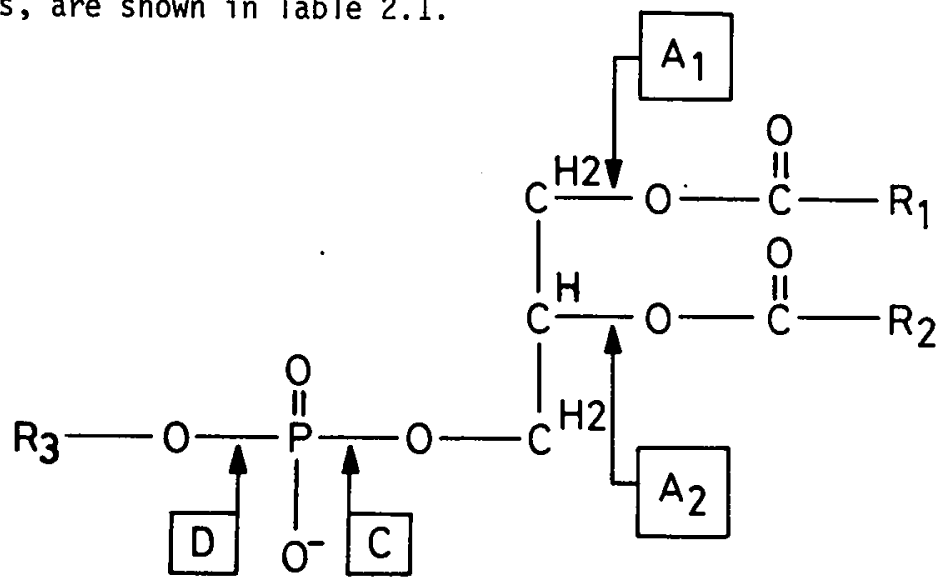

Fig.2.7. Structure of phospholipid molecule. $R_{1}$ and $R_{2}$ : fatty acid residues; $R_{3}$ : alcohol group.

$A_{1}, A_{2}, C$ and $D:$ site of action of respective phospholipases. 
Table 2.1. Survey of major phospholipid classes

\begin{tabular}{lll}
\hline Name & Alcohol group & Code \\
\hline Phosphatidyl choline & choline & PC \\
Phosphatidyl ethanolamine & ethanolamine & PE \\
Phosphatidyl serine & serine & PS \\
Phosphatidyl inositol & inositol & PI \\
Phosphatidic acid & - & PA \\
Phosphatidal ethanolamine & ethanolamine & PPE \\
(plasmalogen) & & \\
\hline
\end{tabular}

For practical purposes, sphyngomyel in (SPH) is also regarded as a phospholipid, although it does not fit our general description of such a compound. In fact, it is a sphyngolipid, a sphyngosine derivative, containing one amide-linked (mainly saturated or mono-unsaturated) long-chain fatty acid and a phosphorylcholine group (as in PC) attached to the terminal hydroxyl group of sphyngosine.

Phospholipids (including SPH) can be hydrolyzed by special enzymes which, according to their sites of action, are called phospholipase- $A_{1},-A_{2},-C$ or -D (See Fig.2.7.). Sphyngomyelinase is a C-type phospholipase.

\subsubsection{Cholesterol esters}

Cholesterol is the major sterol in the human body. It serves quite a number of important functions which are not relevant here. However it is briefly mentioned because, in esterified form, it is one of the fatty acid 'carriers'. Cholesterol esters contain mainly polyunsaturated fatty acids, esterified to the 3- $\beta$-hydroxyl group of the steroid ring system and has been suggested as a fatty acid donor for cyclo-oxygenase -and lipoxygenase activity in the adrenal cortex (11). Moreover, cholesterol is the precursor of bile acids, which are important in fat absorption. It is also an important component of cell membranes and plasma lipoproteins.

\subsection{Fat absorption}

Vegetable or animal fats contain over $99 \%$ triglycerides. Depending on 
their origin, the fatty acid composition of the dietary oils and fats is highly different (Tables 6.2. and 9.1.). Since dietary triglycerides cannot be absorbed as such, they must first be hydrolyzed, which is accomplished by lipolytic enzymes produced mainly by the pancreas, but also by pharyngeal and intestinal glands. To allow these lipases optimum access to the triglycerides, the fat globules in the chyme, measuring about $100 \mathrm{~nm}$ in diameter, are emulsified by conjugated bile acids. These compounds lower the average diameter of the lipid globule to about $5 \mathrm{~nm}$, thereby increasing the accessible surface area of the lipids some 400 times. This increases the efficiency of the lipases, which split the triglycerides usually into 2-monoglycerides and two fatty acids. These substances would be able to penetrate the brush border of the intestinal epithelial cells simply by diffusion but they are hardly able to reach these celis because in view of their hydrophobic nature, they cannot pass through the thin water barrier between the glycocalix and the microvilli. Again, the conjugated bile salts have an important function here. Because of their amphiphatic nature (polar head and non-polar tail (12)), they form mixed micelles containing monoglycerides, fatty acids, cholesterol and lipid-soluble vitamins. These negatively charged micelles are able to penetrate the intervillous space. Here, the monoglycerides, fatty acids etc. diffuse out of the micelles into the intestinail mucosal cells. The conjugated bile salts can be absorbed in the ileum later and enter the enterohepatic circulation.

Inside the intestinal mucosal cells, monoglycerides and fatty acids are resynthesized into triglycerides which, together with small amounts of phospholipids and cholesterol, are 'packed' by a negatively charged B-1ipoprotein to form a chylomicron with a diameter of $2 \mathrm{~nm}$. After a proteinaceous meal, another type of particle forms : the very low density lipoprotein (VLDL). This is also the principal vehicle for dietary cholesterol absorption and transportation. Chylomicra and VLDL are able to diffuse through the basolateral membrane of the villous epithelium and enter the terminal lacteals. Via the thoracic duct, which drains into the left internal jugular vein, they finally enter the circulation.

Short- and medium-chain fatty acids are directly absorbed from the intestinal epithelium into the intestinal capillaries and when bound to plasma proteins, they are transported via the portal vein towards the liver. 


\subsection{Plasmatic transport of fatty acids}

Fatty acids are transported either as free fatty acids (vide infra) or in the form of triglycerides, phospholipids and cholesterol esters. These latter compounds are poorly soluble in their transportation medium, the blood plasma. Lipid particles, made up of physically combined lipid and protein complexes, the lipoproteins, make transportation possible. Non-esterified fatty acids are also transported with the blood, largely bound to plasma proteins and to albumin in particular.

Dietary long-chain fatty acids, esterified into triglycerides or cholesterol esters and incorporated in chylomicra and VLDL are transported to adipose tissue and to the liver. On entering the adipose tissue, the lipoprotein triglycerides are hydrolyzed by a lipoprotein lipase. The fatty acids released enter the adipocytes where they are resynthesized into and stored as triglycerides.

Chylomicra entering the liver are also attacked by a lipoprotein lipase. The fatty acids released -together with fatty acids synthesized de novo by the liver from carbohydrates- are resynthesized to triglycerides and incorporated into VLDL, which are transported to the adipose tissue where their triglyceride fatty acids are transferred into the adipocytes and stored as triglycerides. The remaining low-density lipoproteins chiefly contain cholesterol esters and are of minor importance for fatty acid transportation. The same holds for high-density lipoproteins.

When needed somewhere in the body, fatty acids can be released from adipose tissue triglycerides by means of a hormone- (adrenaline, noradrenaline, ACTH, glucagon) sensitive triglyceride lipase. The resulting diglycerides are further catabolized by a diglyceride lipase, which also degrades the resulting monoglycerides. The fatty acids released enter the bloodstream and bind physically to plasma proteins (mainly albumin) in non-esterified form. There are at least 3 'classes' of fatty acid binding sites, the 'tight' one being saturated at a molar fatty acid/albumin ratio of about 2 , occurring at a plasma free fatty acid concentration of about 1200 umor.1. ${ }^{-1}(13)$.

Albumin-bound, non-esterified fatty acids are in equilibrium with unbound free fatty acids. Usually, plasma free fatty acid (FFA) concentrations indicate the sum of the protein-bound and unbound fatty acids. It should be realized that the protein-bound free fatty acids are much less

'aggressive' than the free fatty acids, the concentration of which is 
generally very low. However, under certain conditions (e.g. myocardial infarction), fatty acid mobilization may become so massive that the binding capacity of the plasma proteins is exceeded and the plasma FFA-level increases considerably (14). The possible implication of this condition for platelet function and arterial thrombogenesis will be discussed in Chapter 11 .

\subsection{Functions of fatty acids}

The oldest recognized function of fatty acids is to serve as a source of energy. In Western societies, about $40 \%$ of the digestible energy ( energy $\%$, en\%) is supplied by dietary fats. Carbohydrates are also an important source of energy and from this point of view it should be able to replace dietary fat completely. However, prolonged feeding of a fat-free diet causes growth retardation, dermatitis, impaired reproduction and a great many other pathological conditions ultimately leading to death (5-7). This syndrome could only be cured by administration of polyunsaturated fatty acids of the $(n-6)$ and $(n-3)$ families, which were named essential fatty acids (EFA's).

It should be noted that the EFA-activity of both fatty acid families differs considerably and is also different for the various EFA-deficiency symptoms (9). EFA-deficiency not only occurs in animals but also in man $(8,15)$. The minimum human EFA requirement has been estimated to be between 1 and 5 en\% but there is still no consensus of opinion on this aspect (16).

The EFA-deficiency syndrome is a convenient starting point for discussing the possible functions of fatty acids. The increased permeability of the skin to water (17), the enhanced capillary fragility and permeability (18), the higher erythrocyte fragility (19) and the enhanced mitochondrial swelling (20) all point to an important structural and functional role in relation to biomembranes. Moreover, EFA's appeared to be the ultimate dietary precursors of prostaglandins and related compounds $(21,22)$. Membrane structure and function as well as prostaglandin metabolism have important implications for the regulation of thrombus formation. Therefore, these functions will be dealt with in some detail. 


\subsubsection{Function in biomembranes}

Fatty acids may be in the fluid or in the crystalline state, depending on the environmental temperature being above or below their melting points respectively. In the crystalline phase, the fatcy acid molecules are closely packed resulting in a rigid arrangement compared to the liquid state where the molecular arrangement is largely determined by the environment.

When incorporated in phopholipids, fatty acids are important constituents of cellular membranes, which serve not only as bounderies between individual cells, but also compartmentalize several major biochemical processes within the cell.

Phospholipids, SPH including, contain a polar head-group and two non -polar tails. Due to this 'amphiphatic' character and as a result of thermodynamic forces, phospholipids, when contacted with water, form structures composed of molecular bilayers with an internal hydrophobic phase and the polar heads exposed on the surface. When these structures separate two aqueous compartments they have properties very similar to those of natural cellular membranes. Under this condition, the inter- and intramolecular interaction of hydrophobic and hydrophylic groups result in a conformation and mobility of the hydrocarbon chains which is either sinilar to that in the crystalline state or adopts an intermediate 'liquid -crystalline' phase. The temperature at which the hydrocarbon core of a phospholipid bilayer changes from a rigid crystalline to a more fluid liquid-crystalline phase is called the phase transition temperature. This temperature is much lower than the meiting points of the fatty acids incorporated, and is determined by their chain lenghts and degree of unsaturation as well as by the nature of the phospholipid head-groups. It is now generally agreed that mammalian cellular membranes indeed consist of a phospholipid bilayer with cholesterol- and (non-structural) protein molecules 'floating' in this lipid 'sea' (23). The degree of fluidity of this lipid sea is determined by various factors e.g. the physical state (crystalline or liquid-crystalline) of the phospholipid-hydrocarbon groups. Because of the less rigid arrangement of these groups above the phase transition temperature, membranes are more 'fluid' in the liquid-crystalline than in the crystalline state, thus allowing a greater mobility of certain membrane proteins serving as receptor sites. Therefore, membrane fluidity may determine, at least in part, receptor availability and -efficiency temperature, membranes are more 'fluid' in the liquid-crystalline than 
in the crystalline state, thus allowing a greater mobility of certain membrane proteins serving as receptor sites. Therefore, membrane fluidity may determine, at least in part, receptor availability and -efficiency and, as a result, modulate a great number of membrane-located processes. Membrane fluidity is affected by the relative proportion of the different phospholipid classes, the chain length and degree of unsaturation of their fatty acid residues and the membrane cholesterol content (24-26). Since these latter two factors can be influenced by diet, one may expect a dietary effect on membrane fluidity and on the processes depending on it. Thus it has been shown that dietary fat-induced changes in membrane fatty acid composition influenced the cooperativity of certain allosteric membrane-bound enzymes (27). Similar effects were observed when membrane fluidity was altered by cholesterol feeding (28). Cholesterol incorporation in platelet plasma membranes has been shown to lower their fluidity (29), to enhance the sensitivity of the platelet to certain aggregating agents (85) and to increase their production of aggregation-promoting thromboxane $A_{2}(30)$.

Above the phase transition temperature, the mobility of the phospholipid -hydrocarbon groups is determined by the viscosity of their micro-environment. Therefore, membrane micro-viscosity may be regarded as being equivalent to the inverse of membrane fluidity. Membrane micro-viscosity can be determined by techniques such as nuclear magnetic resonance, electron spin resonance and fluorescence polarization, using a probe inserted into the hydrophobic core of the membrane.

\subsubsection{Function_a as_prostaglandin_precursors}

Prostaglandins (PG's) are a group of structuraliy related compounds of great physiological importance, implicated in such vital processes as blood-pressure regulation, hemostasis, reproduction, inflammation etc. They are produced in almost every tissue of the body and because most of them are broken down during one single passage through lungs or $1 \mathrm{i}$ ver, they closely resemble local hormones.

Structurally, $P G^{\prime}$ s can be considered as derivatives of the hypothetical compound prostanoic acid which is characterized by $20 \mathrm{C}$-atoms, arranged as a cyclopentane ring carrying two side-chains, one of which is terminated by a carboxyl group and the other by a methyl group (Fig.2.8.). Therefore, PG's are cyclic fatty acids, each consisting of 
20-C atoms. Depending on the structure of the cyclopentane ring, PG's are divided into 'families', indicated by the capitals A to I. Each family consists of a 1-, a 2- and a 3-series, depending on the number of double bonds in their two side-chains (1,2 or 3, see Fig.2.8.).

The striking similarity in the molecular shapes of arachidonic acid and prostaglandin $E_{2}$ led to the discovery that $P G$ 's are synthesized from essential fatty acids $(21,22)$. The 1- and 2- series were shown to be derived from dihomo- $\gamma-1$ inolenic acid $(20: 3(n-6))$ and arachidonic acid $(20: 4(n-6))$ respectively, while timnodonic acid $(20: 5(n-3))$ appeared to be the direct precursor of the 3-series $P G^{\prime} s$ (31). In animals, these long-chain polyunsaturated fatty acids are formed from linoleic acid $(18: 2(n-6))$ or $\alpha-1$ inolenic acid $(18: 3(n-3))$. These two essential fatty acids can, therefore, be regarded as the ultimate dietary precursors of all PG's and their derivatives.

For the greater part, the precursor fatty acids are not available as such. Most of them have to be released from phospholipids $(32,33)$ by means of phospholipases, the exact nature of which is still a controversial point (See Chapter 3). Cholesterol esters have also been mentioned as possible fatty acid donors, especially in the adrenal cortex (11). Recently, attention has been drawn to the importance of tissue free fatty acids as substrates for PG-synthesis (34).

The first step in this synthesis is the peroxidation of (released) precursor fatty acids into a PG-hydroperoxide,PGG. $(35,36)$. The enzyme involved (prostaglandin endoperoxide synthase or cyclo-oxygenase, $\mathrm{CO}$ ) has also a peroxidase activity (37). As a result, $P G G$ is immediately converted

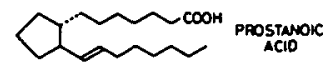

PG-FAMLES

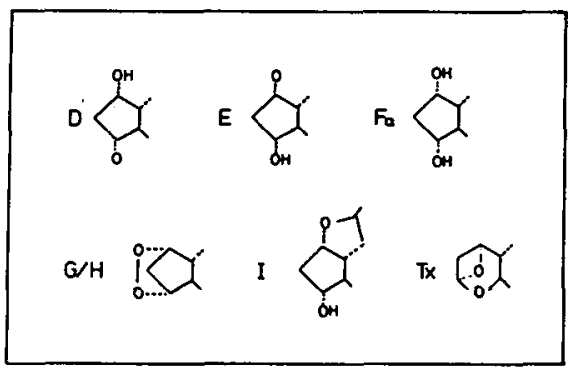

Fig.2.8. Structural features of some prostaglandin families. 
into PGH. The CO-enzyme system is present in virtualiy all tissues and is a so-called self-destructive enzyme (38) because it is inactivated by the compound it produces (39). It is inhibited by non-steroidal anti - inflammatory drugs such as aspirin and indomethacin (40-42). The degree of inhibition is not the same for the various inhibitors, while a given inhibitor is not always equally effective in all tissues $(43,44)$. This provides the possibility of a specific differential inhibition of $\mathrm{CO}$ in the various tissues, which is likely to be therapeutically important.

The PG-endoperoxide PGH has only a short half-life because it is converted by various - mostly membrane bound - isomerases into other PG's (35-36) or into thromboxanes (45), a series of compounds characterized by an oxane- instead of a cyclopentane ring (Fig.2.8.). The activities of the different isomerases are quantitatively different in the various tissues resulting in a different profile of end-products (46).

In blood platelets, the vast majority of the PG-endoperoxides are converted into thromboxanes (45). In the vessel wall, PG's of the I-family predominate $(47,48)$. Since these platelet- and vascular compounds are of great importance for hemostasis and thrombosis, their formation, effects and metabolism will be discussed in some more detail in Chapter 3.

The amounts of PG's formed depend on the availability of their substrate fatty acids (See Chapter 10) as well as on the efficiency of the enzyme -substrate interaction $(31,38)$. Since in most tissues, the arachidonic acid content is much higher than that of dihomo- $\gamma-1$ inolenic acid, and because timnodonic acid is a poor substrate for the $\mathrm{CO}$ enzyme system $(31,50,51)$, the 2 -series are likely to be the most important PG's quantitatively and are, therefore, studied most extensively.

The majority of the PG-effects are mediated by changes in the intraceliular level of adenosine-3'-5'-monosphate (CAMP), following PG-binding to specific receptors at the surface of the target cells $(49,95)$. cAMP is also implicated in PG-synthesis; it has a stimulating effect in some cells and an inhibitory effect in other ones (52). An example of a cAMP-mediated PG-effect is the antilipolytic action of PGE's observed by Steinberg and co-workers (53), which is possibly of great importance for the regulation of plasma free fatty acid levels. 


\subsubsection{Some_other functions of fatty açids}

Although outside the scope of the present study, some other important functions of fatty acids deserve further attention. There is ample evidence that polyunsaturated fatty acids are implicated in a great many transport processes e.g. in the removal of triglycerides and cholesterol from the liver $(54,55,94)$ and in cholesterol excretion via the bile (56). Dietary polyunsaturated fatty acids have also been shown to reduce the net synthesis of fatty acid synthetase, possibly leading to a reduction of the synthesis of saturated fatty acids (57). These effects of polyunsaturated fatty acids may contribute to their benefical effect on atherosclerosis $(58,59)$. Apart from atherosclerosis, there are many other diseases in which (a defective ?) fatty acid metabolism is involved (cancer, multiple sclerosis, cystic fibrosis, diabetes mellitus see ref. 60-63). This underlines the importance of fatty acids in maintaining normal health.

Polyunsaturated fatty acids have also been shown to be good substrates for a cytoplasmatic enzyme - with properties of a lipoxygenase - present in blood platelets, leukocytes and mast cells $(64,65)$. The function of the resulting hydroxy acids are largely unknown but the arachidonate product of platelet lipoxygenase is known to be involved in the regulation of the Tx-synthase $(66)$, in leukocyte chemotaxis $(67,68)$ and in irreversible platelet aggregation (69).

Recently, arachidonic acid was shown to be the precursor fatty acid of leukotrienes, a group of non-cyclized $\mathrm{C}_{20}$ - carboxylic acids with one or two oxygen substituents and three conjugated double bonds, produced by polymorphonuclear leukocytes (70). It has been proposed that leukotriene $A$, an unstable intermediate in the formation of leukotriene $B$, is the direct precursor of SRS-A, the slow-reacting substance of anaphylaxis, an important mediator in asthma and other immediate hypersensitivity reactions.

\subsection{Lipid metabolism of platelets}

Blood platelets have an active lipid metabolism. They are capable of de novo synthesis of fatty acids and phospholipids (71-78) and activily exchange these substances with those from the surrounding plasma (79-81). 
Although they contain only few mitochondria, fatty acid oxidation is yet an important source of energy (82).

Since platelets lack one or more components of the methyl-sterol demethylase system $(83,84)$, they are unable to synthesize cholesterol and although cholesterol biosynthesis in megakaryocytes has been reported, the most likely possibility of altering the platelet cholesterol content is via an exchange with the surrounding medium (85).

Platelet lipid metabolism is greatly stimulated upon platelet activation with aggregating agents (86-92). This strongly indicates that 1 ipid metabolism is of primary importance in platelet function, which has been confirmed by the discovery of the functional implications of platelet fatty acid peroxidation (93). Since this latter pathway is likely to be affected by dietary lipids, it will be discussed in detail in Chapter 3.

\subsection{References}

1. Sprecher,H. and James,A.T.: Biosynthesis of long-chain fatty acids in mammalian systems. In: Emken,E.A. and Dutton,H.J. (Eds): Geometrical and positional fatty acid isomers. American $0 i 1$ Chemist's Society (1979) pp. 303-338.

2. R.Jeffcoat: The biosynthes is of unsaturated fatty acids and its control in mammalian liver. In: Campbell,P.N. (Ed): Essays in Biochemistry 15: $1-36$ (1980).

3. Brenner,R.R. and Peluffo,R.0.: Regulation of unsaturated fatty acid biosynthesis.I. Effect of unsaturated fatty acids of 18 carbons on the microsomal desaturation of linoleic acid into $\gamma$-linolenic acid. Biochim. Biophys. Acta 170: 471-479 (1969).

4. Mead,J.F.: The metabolism of the polyunsaturated fatty acids. In: Holman,R.T. (Ed): Progress in the Chemistry of fats and other 1ipids. Oxford, Pergamon, 9: 161-189 (1971).

5. Burr,G.0. and Burr,M.M.: Deficiency disease, produced by the rigid exclusion of fat from the diet. J.Biol.Chem.82: 345-367 (1929).

6. Aaes-Jørgensen,E.: Essential fatty acids. Physiol.Rev.41: 1-51 (1961).

7. Holman,R.T.: Essential fatty acid deficiency. In: Holman,R.T. (Ed): Progress in the chemistry of fats and other lipids. Volume 9, No 2. Pergamon Press, London. 275-348 (1971).

8. Hansen,A.E., Wiese,H.F., Boelsche,A.N., Haggard,M.E., Adam,D.J.D. and 
Davis,H.: Relation of linoleic acid to infant feeding: a review. Acta Paediat. 51, Suppl. 137 (1962).

9. Houtsmulter,U.M.T.: Differentiation in the biological activity of polyunsaturated fatty acids. In Galli,C., Jacini,G. and Pecile,A. (Eds): Dietary lipids and postnatal development. Raven Press, New York (1973) pp. 145-155.

10. Kunau,W-H. and Dommes, P.: Degradation of unsaturated fatty acids. Identification of intermediates in the degradation of cis-4-decenoy1CoA by extracts of beef 1 iver mitochondria. Eur.J.Biochem. 91: 533-544 (1978).

11. Boyd,G.: Dietary effects on certain adrenal cortical functions. Nutr.Metabol, Supplement (in press).

12. Haertiy,G.S. (1936), cited in Gitler,C.: Plasticity of biological membranes. Ann.Rev.Biophys. Bioeng. 1: 51-92 (1972).

13. Connor,W.E., Hoak,J.C. and Warner,E.D.: Plasma free fatty acids, hypercoagulability and thrombosis. In: Sherry,S., Brinkhous, K.M., Genton,E. and Stengle,J.M. (Eds): Thrombosis. Nat.Acad.Sci.Washington D.C. p.p. 355-373 (1969).

14. Spector,A.A.: Transport and ultilization of free fatty acids. Annals N.Y. Acad.Sci. 149: 768-783 (1968).

15. Holman,R.T.: Essential fatty acid deficiency in humans. In: Galli,C., Jacini,G. and Pecile,A. (Eds): Dietary lipids and postnatal development. Raven Press, New York (1973) p.p. 127-143.

16. Crawford,M.A., Hassam,A.G. and Rivers, J.P.W.: Essential fatty acid requirements in infancy. Am.J.Clin.Nutr. 31: 2181-2185 (1978).

17. Basnayake,V. and Sinclair,H.M.: The effect of deficiency of essential fatty acids upon the skin. In: Popjak and Le Breton (Eds): Biochemical problems of lipids. London, Butterworth, (1956) p.p. 476-484.

18. Kramár,J. and Levine,V.E.: Influence of fats and fatty acids on the capillaries. J.Nutr.50: 149-160 (1953).

19. Mac Millan,A.L. and Sinclair,H.M.: The structure and function of essential fatty acids. Proc. Intern. Conf.Biochem. Problems of Lipids, London, Butterworth (1958) p.208.

20. Hayashida,T. and Portman, 0.W.: Swelling of liver mitochondria from rats fed diets deficient in essential fatty acids. Proc.Soc.Expt1.Biol. Med. 103: 656-659 (1960).

21. Van Dorp,D.A., Beerthuis,R.K., Nugteren,D.H. and Vonkeman,H.: The biosynthesis of prostaglandins. Biochim. Biophys.Acta 90: 204-207 (1964).

22. Bergström,S., Danielsson,H. and Samuelsson,B.: The enzymatic formation 
of prostaglandin $E_{2}$ from arachidonic acid. Biochim.Biophys. Acta 90: 207-210 (1964).

23. Singer,S.J. and Nicholson,G.L.: The fluid mosaic model of the structure of cell membranes. Science 175: 720-731 (1972).

24. Ladbrooke,B.D. and Chapman,D.: Thermal analysis of lipids, proteins and biological membranes. A review and summary of some recent studies. Chem. Phys.Lipids, 3: 304-356 (1969).

25. Jakobson,K. and Papahadjopoulos,D.: Phase transitions and phase separations in phospholipid membranes induced by changes in temperature, $\mathrm{pH}$ and concentration of bivalent cations. Biochemistry 14: 152-161 (1975).

26. Demel,R.A. and de Kruyff,B.: The function of sterols in membranes. Biochim. Biophys. Acta 457: 109-132 (1976).

27. Bloj,B., Morero,R.D., Farías,R.N. and Trucco,R.E.: Membrane lipid fatty acids and regulation of membrane bound enzymes. Biochim. Biophys. Acta 311: 67-69 (1973).

28. Bloj,B., Morero,R.D. and Farias,R.N.: Membrane fluidity, cholesterol and allosteric transitions of membrane bound $\mathrm{Mg}^{2+}$-APTase, $\left(\mathrm{Na}^{+}+\mathrm{K}^{+}\right)-$ APTase and acetyl cholinesterase from rat erythrocytes. FEBS Lett. 38: 101-105 (1973).

29. Shattil,S.J. and Cooper,R.A.: Membrane microviscosity and human piatelet function. Biochem. 15: 4832-4837 (1976).

30. Stuart,M.J., Gerrard,J.M. and White,J.G.: Effect of cholesterol on production of thromboxane $B_{2}$ by platelets in vitro. New Engl.J.Med. 302: 6-10 (1980).

31. Struyck,C.B., Beerthuis,R.K., Pabon,H.J.J. and van Dorp,D.A.: Specificity of the enzyme conversion of polyunsaturated fatty acids into prostaglandins. Recl.Trav.Chim.Pays-Bas 85: 1233-1250 (1966).

32. Vonkeman,H. and van Dorp,D.A.: The action of prostaglandin synthetase on 2-arachidonyl-lecithin. Biochim. Biophys. Acta 164: 430-432 (1968).

33. Lands,W.E.M. and Samuelsson,B.: Phospholipid precursors of prostaglandins. Biochim. Biophys. Acta 164: 426-429 (1968).

34. Lagarde,M., Guichardant,M. and Dechavanne,M.: Human platelet $\mathrm{PGE}_{1}$ and dihomogammalinolenic acid. Comparison to $\mathrm{PGE}_{2}$ and arachidonic acid. Progr.Lip.Res. (in press).

35. Hamberg,M. and Samuelsson,B.: Detection and isolation of an endoperoxide intermediate in prostaglandin biosynthesis. Proc. Natl.Acad.Sci. USA 70: 899-903 (1973).

36. Nugteren, D.H. and Hazelhof,E.: Isolation and properties of interme- 
diates in prostaglandin biosynthesis. Biochim. Biophys. Acta 326: 448-461 (1973).

37. Van der Ouderaa,F.J., Buytenhek,M., Nugteren,D.H. and van Dorp,D.A.: Purification and characterization of prostaglandin endoperoxide synthetase from sheep vesicular glands. Biochim. Biophys. Acta 487: 315-331 (1977).

38. Lands,W.E.M., LeTellier,P.R., Rome,L.H. and Vanderhoek,J.Y.: Inhibition of prostaglandin biosynthesis in: Samuelsson,B. and Bernhard,S. (Eds): Adv. in the Biosciences 9: 15-28 (1973).

39. Egan,R.W., Paxton,J. and Kuehi,F.A.Jr.: Mechanism for irrevesible self-deactivation of prostaglandin synthetase. J.Biol.Chem. 251: 7329-7335 (1976).

40. Ferreira,S.H., Moncada,S. and Vane,J.R.: Indomethacin and aspirin abolish prostaglandin release from the spleen. Nature (New Biology) 231: 237-239 (1971).

41. Smith,J.B. and Willis,A.L.: Aspirin selectively inhibits prostaglandin production in human piatelets. Nature (New Biology) 231: 235-237 (1971).

42. Roth,G.J., Stanford,N. and Majerus,P.W.: Acetylation of prostaglandin synthetase by aspirin. Proc.Nat1.Acad.Sci.USA 72: 3073-3076 (1975).

43. Burch,J.W., Baenziger,N.L., Stanford,N. and Majerus,P.W.: Sensitivity of fatty acid cyclooxygenase from human aorta to acetylation by aspirin. Proc.Nat1.Acad.Sci.USA 75: 5181-5184 (1978).

44. Massotti,G.,Poggesi,L., Galanti,G., Abbate,R. and Neri Serneri, G.G.: Differential inhibition of prostacyclin production and platelet aggregation by aspirin. Lancet ii: 1213-1216 (1979).

45. Hamberg,M., Svensson,J. and Samuelsson,B.: Thromboxanes, a new group of biologically active compounds derived from prostaglandin endoperoxides. Proc.Nat1.Acad.Sci.USA 72: 2994-2998 (1975).

46. Pace Asciak,C.R.: Oxidative biotransformations of arachidonic acid. Prostaglandins 13: 811-817 (1977).

47. Moncada,S., Gryglewski,R., Bunting,S. and Vane,J.R.: An enzyme isolated from arteries transforms prostaglandin endoperoxides to an unstable substance that inhibits platelet aggregation. Nature 263: 663-665 (1976).

48. De Deckere,E.A.M., Nugteren,D.H. and ten Hoor,F.: Prostacyclin is the major prostaglandin released from the isolated perfused rabbit and rat heart. Nature 268: 160-163 (1977).

49. Miller,0.V. and Gorman,R.R.: Evidence for distinct prostaglandin $I_{2}$ and $D_{2}$ receptors in human platelets. J.Pharmacol.Exp. Ther. 210: 
134-140 (1979).

50. Needleman,P., Raz,A., Minkes,M.S., Ferrendelli,J.A. and Sprecher,H.: Triene prostaglandins: prostacyclin and thromboxane biosynthesis and unique biological properties. Proc.Nat1.Acad.Sci.USA 76: 944-948 (1979).

51. Gryglewski,R.J., Salmon,J.A., Ubatuba,F.B., Weatheriy,B.C., Moncada,S. and Vane,J.R.: Effect of all cis 5,8,11,14,17 eicosapentaenoic acid and $\mathrm{PGH}_{3}$ on platelet aggregation. Prostaglandins 18: 453-478 (1979).

52. Samuelsson,B., Goldyne,M., Granström,E., Hamberg,M., Hammarström,S. and Malmsten,C.: Prostaglandins and thromboxanes. Ann. Rev.Biochem. 47: 997-1029 (1978).

53. Steinberg,D., Vaughan,M., Nestel,P.J., Strand,0. and Bergström,S.: Effects of prostaglandin on hormone-induced mobilization of free fatty acids. J.Clin. Invest. 43: 1533-1540 (1964).

54. Sinclair,A.J. and Collins,F.D.: Fatty livers in rats deficient in essential fatty acids. Biochim.Biophys. Acta 152: 498-510 (1968).

55. Nørby,J.G.: Effects of giving a fat free diet for up to 10 weeks on the male weanting rat. Br.J.Nutr. 19: 209-224 (1965).

56. Danielsson,H.: Present status of reseach on catabolism and excretion of cholesterol. In: Paoletti,R. and Kritchevsky,D. (Eds): Adv.Lip. Res. I. New York, Academic Press. p.p. 335-385 (1963).

57. Volpe,J.J. and Vagelos,P.R.: Mechanisms and regulation of biosynthes is of saturated fatty acids. Physiol.Rev. 56: 339-417 (1976).

58. Thomasson,H.J.: Dietary fat and atherosclerosis. In: Dols,M.J.L.(Ed): The physiological and nutritional role of fats in human nutrition. Westerbaan, The Haque, p:p. 92-103 (1963).

59. Malmros,H.: Dietary prevention of atherosclerosis. Lancet ii: 479-484 (1969).

60. Kitada,S., Hays,E.F. and Mead,J.F.: Characterization of a lipid mobilizing factor (LMF) from tumors. Progr.Lipids Res., in press.

61. Millar,J.H.D., Zilka,K.J., Langman,M.J.S., Wright,H.P., Smith,A.D., Belin,J. and Thompson,R.H.S.: Double blind trial of linoleate supplementation of the diet in multiple sclerosis. Br.Med.J. 1: 765-768 (1973).

62. Chase,H.P. and Dupont,J.: Abnormal levels of prostaglandins and fatty acids in blood of children with cystic fibrosis. Lancet $i i: 236-238$ (1978).

63. Houtsmuller, A.J., van Hal-Ferwerda,J., Zahn, K.J. and Henkes, H.E.: Favourable influences of linoleic acid on the progression of diabetic micro and macro-angiopathy. Progr.Lip. Res. (in press). 
64. Nugteren,D.H.: Arachidonate lipoxygenase in blood platelets. Biochim. Biophys. Acta 380:299-307 (1975).

65. Borgeat,P., Hamberg,M. and Samuelsson, B.: Transformation of arachidonic acid and homo- $\gamma-1$ inolenic acid by rabbit polymorphonuclear leucocytes. Monohydroxy acids from novel lipoxygenases. J.Biol.Chem. 251: 7816-7820 (1976).

66. Hammarström,S. and Falardeau,P.: Resolution of prostaglandin endoperoxide synthase and thromboxane synthase of human platelets. Proc. Nat1.Acad.Sci. USA 74: 3691-3695 (1977).

67. Turner,S.R., Tainer,J.A. and Lynn,W.S.: Biogenesis of chemotactic molecules by the arachidonate system of platelets. Nature 257: 680-681 (1975).

68. Goetz1,E.J., Woods,J.M. and Gorman,R.R.: Stimulation of human eosinophil and neutrophil polymorphonuclear leucocyte chemotaxis and random migration by 12 -L-hydroxy-5,8,10,14-eicosatetraenoic acid. J.Clin. Invest.59: 179-183 (1977).

69. Dutilh,C.E., Haddeman,E., Jouvenaz,G.H., ten Hoor,F. and Nugteren,D.H.: Study of the two pathways for arachidonate oxygenation in blood platelets. Lipids 14: 241-246 (1979).

70. Samuelsson,B., Borgeat,P., Hammarström,S. en Murphy,R.C.: Introduction of a nomenclature: Leukotrienes. Prostaglandins 17: 785-787 (1979).

71. Deykin,D. and Desser,R.K.: The incorporation of acetate and palmitate into lipids by human platelets. J.Clin. Invest. 47: 1590-1602 (1968).

72. Cohen,P., Derksen, A. and van den Bosch,H.: Pathway of fatty acid metabolism in human platelets. J.Clin. Invest. 49: 128-139 (1970).

73. Hoak,J.C., Spector,A.A., Fry,G.L. and Barnes,B.C.: Localization of free fatty acids taken up by human platelets. Blood 40: 16-22 (1972).

74. Chambaz,J., Béréziat,G., Pépin,D. and Polonovski,J.: Turnover of platelet arachidonic and linoleic acids. Biochimie 61: 127-130 (1979).

75. Lucas,C.T., Call II,F.L. and Williams,W.J.: The biosynthesis of phosphatidylinositol in human platelets. J.Clin. Invest. 49: 1949-1955 (1970).

76. Majerus,P.W., Baenziger,N.L. and Brody,G.N.: Lipid metabolism in human platelets. Ser. Haemat. IV: 59-74 (1971).

77. Spector,A.A., Hoak,J.C., Warner,E.D. and Fry,G.L.: Utilization of long-chain free fatty acids by human platelets. J.Clin. Invest. 49: 1489-1496 (1970).

78. Cohen,P., Broekman,M.J., Verkley, A. ,Lisman,J.W.W. and Derksen, A.: Quantification of human platelet inositides and the influence of ionic 
environment on their incorporation of orthophosphate ${ }^{32} \mathrm{p}$. J.Clin. Invest. 50: $762-772$ (1971).

79. Joist,H.J., Dolezel,G., Lloyd,J.V. and Mustard,J.F.: Phospholipid transfer between plasma and platelets in vitro. Blood 48: 199-211 (1976).

80. Bērēziat, G., Chambaz,J., Trugnan,G., Pêpin,D. and Polonovski,J.: Turnover of phospholipid linoleic and arachidonic acids in human platelets from plasma lecithins. J.Lipid.Res. 19: 495-500 (1978).

81. Chambaz,J., Robert,A., Wolf,C., Bërêziat,G. and Polonovski,J.: Different acylation and accumulation in free form of arachidonic acid or its sodium salt in human platelets. Thromb.Res. 15: 743-753 (1979).

82. Gross,R. and Schneider,W.: Energy metabolism in: Johnson,S.A. (Ed): The circulating platelet. Academic Press, New York \& London p.p. 123-188 (1971).

83. Derksen, A. and Cohen, P.. Extensive incorporation of $\left[2 .-{ }^{14} \mathrm{C}\right]$ Mevalonic acid into cholesterol-precursors by human platelets in vitro. J.Biol. Chem. 248: 7396-7403 (1973).

84. Derksen,A.: Failure of rhesus platelets and arterial tissue to convert preformed $\left({ }^{14} \mathrm{C}\right)$ lanosterol to $\left({ }^{14} \mathrm{C}\right)$ cholesterol in vivo. In: Derksen, $A$. Studies on lipid metabolism in human platelets. Thesis, Fox Run Press, Topsfield, Mass. USA. p.p. 45-53 (1975).

85. Shattil, S.J., Anaya-Galindo,R., Bennett,J., Colman,R.W. and Cooper, R.A.: Platelet hypersensitivity induced by cholesterol incorporation. J.Clin. Invest. 55: 636-643 (1975).

86. Deykin,D. and Snyder,D.: Effect of epinephrine on platelet lipid metabolism. J.Lab.Clin.Med. 82: 554-559 (1973).

87. Lloyd,J.V., Nishizawa,E.E., Haldar,J. and Mustard,J.F.: Changes in 32 p-labelling of platelet phospholipids in response to ADP. Brit.J. Haematol. 23: 571-585 (1972).

88. Lloyd,J.V., Nishizawa,E.E., and Mustard,J.F.: Effect of ADP - induced shape change on incorporation of ${ }^{32} p$ into platelet phosphatidic acid and mono-, di- and triphosphatidylinositol. Brit.J.Haematol. 25: 77-99 (1973).

89. Lloyd,J.V., Nishizawa,E.E., Joist,H.J. and Mustard,J.F.: Effect of ADP - induced aggregation on ${ }^{32} \mathrm{PO}_{4}$ incorporation into phosphatidic acid and the phosphoinositides of rabbit platelets. Brit.J.Haematol. 24: 589-604 (1973).

90. Lloyd,J.V. and Mustard,J.F.: Changes in ${ }^{32}$ p-content of phosphatidic acid and the phosphoinositides of rabbit platelets during aggregation 
induced by collagen or thrombin. Brit.J.Haematol. 26: 243-253 (1974).

91. Deykin,D.: Altered lipid metabolism in human platelets after primary aggregation. J.Clin. Invest. 52: 483-492 (1973).

92. Leung,N.L., Kinlough-Rathbone,R.L. and Mustard,J.F.: Incorporation of ${ }^{32} \mathrm{PO}_{4}$ into phospholipids of blood platelets. Brit.J.Haematol. 36 : 417-425 (1977).

93. Marcus,A.J.: The role of lipids in platelet function: with particular reference to the arachidonic acid pathway. J.Lipid.Res. 19: 793-826 (1978).

94. Jackson,R.L., Taunton,0.D., Morrisett,J.D. and Gotto,A.M.Jr.: The role of dietary polyunsaturated fat in lowering blood cholesterol in man. Circ.Res. 42: 447-453 (1978).

95. Siegle,A.M., Smith,J.B. and Silver,M.J.: Specific binding sites for prostaglandin $\mathrm{D}_{2}$ on human platelets. Biochem.Biophys.Res.Comm.90: 291-296 (1979). 


\subsection{Introduction}

Arterial thrombosis results from an imbalance between thrombus formation and thrombus dissolution. This chapter deals with processes involved in thrombus formation.

The formation of an arterial thrombus is triggered by the disruption of the endothelial barrier between blood and subendothelium. Endothelial damage sufficient to initiate a thrombotic response, can be caused by factors such as chronic hypercholesterolemia (1), chronic homocysteinemia (2), smoking (3), hypertension (4), wall shear forces (5) etc.. Exposure of the subendothelium to blood results in the simultaneous occurrence of two closely interrelated processes : the response of blood platelets towards their activation and blood clotting. Platelet activation may lead to the formation of a fragile platelet thrombus via a series of frequently reviewed processes (6-8). In brief, circulating platelets adhere to subendothelial tissue - collagen, microfibrils, basement membrane - which may become blood-exposed after vessel-trauma, rupture, of an atherosclerotic plaque, etc.. Adhered platelets release some of their constituents, such as adenine nucleotides, serotonin, $\mathrm{Ca}^{++}$and adrenaline. Adenosine diphosphate (ADP), made available by this release reaction, causes blood platelets to aggregate: passing platelets stick to the adhered ones, thus forming a mural platelet thrombus which, being unstable, is easily embolized. The platelet release reaction is also induced by platelet aggregation ; so the formation of mural and circulating platelet thrombi is a self-propagating process.

Since vascular tissue has thromboplastic activity (9), vessel wall damage is likely to trigger extrinsic clotting. Moreover, subendothelial collagen, while interacting with one of the contact factors (Factor XII, ref. 10,11 ) or with platelets (12), triggers the intrinsic coagulation system, which is also initiated by platelets per se when activated by low amounts of ADP (13). Coagulation is accelerated by platelet factor 3 (PF3) a platelet-phospholipoprotein-associated clot-promoting entity which is normally inactive (14) but which becomes available upon platelet activation $(15,16)$.

The contribution of coagulation to the process of arterial thrombus for- 
mation has long been regarded to be of secondary importance. This contribution would be confined to reinforcement of the fragile white platelet thrombus by fibrin. However, as will be demonstrated below, evidence is becoming available indicating that coagulation is of primary importance here, because thrombin formation appeared to be a prerequisite for the platelet aggregation response upon vessel wall damage.

In recent years, much progress has been made in the elucidation of biochemical events following platelet activation and which are associated with the platelet release reaction. Moreover, the antithrombotic properties of the intact vessel wall can now be explained in biochemical terms. This knowledge resulted in the formulation of a homoiostatic concept of the regulation of thrombosis (17) which will be discussed in detail. Experiments will be described which throw quite some doubt on the validity of this concept.

\subsection{The role of vessel-wall induced clotting in platelet aggregation} following vascular injury

\subsubsection{Methodology}

Rats are bled under ether anesthesia by puncturing the abdominal aorta. The blood is collected in citrate; platelet-rich plasma (PRP) and platelet-poor plasma (PPP) are prepared by differential centrifugation. (For details, reference is made to Chapter 7 , section 2). The aortas are rapidly removed, cleaned from adhering tissue, opened longitudinally and kept in an ice-cold Krebs-Henseleit buffer ( $\mathrm{KH}$, see ref. 136).50 $\mu$ ] PRP or PPP and $450 \mu \mathrm{la}{ }^{++}$containing saline $\left(0.5 \times 10^{-6} \mathrm{~mol}^{-1} 1^{-1} \mathrm{CaCl}_{2}\right.$ in $0.154 \mathrm{~mol} .1^{-1} \mathrm{NaCl}$ ) are placed into the cuvette of an aggregometer. The temperature is maintained at $37.5^{\circ} \mathrm{C}$ and the stirring speed is $600-700$ rev. $\min ^{-1}$. After $3 \mathrm{~min}$, a small piece of tissue, diameter $3 \mathrm{~mm}$, is punched out of the aorta, transferred into the cuvette while light transmission is recorded continuously. Fibrin formation is indicated by a decrease in light transmission, which is very clearly observed in PPP. (Fig.3.1.A). This decrease is followed by a rapid increase when the fibrin fibres become twisted around the stirring bar. When the vascular tissue passes the light beam, the tracing shows spikes. In PRP, fibrin formation is not always clearly visible, due to the high turbidity of the solution. 


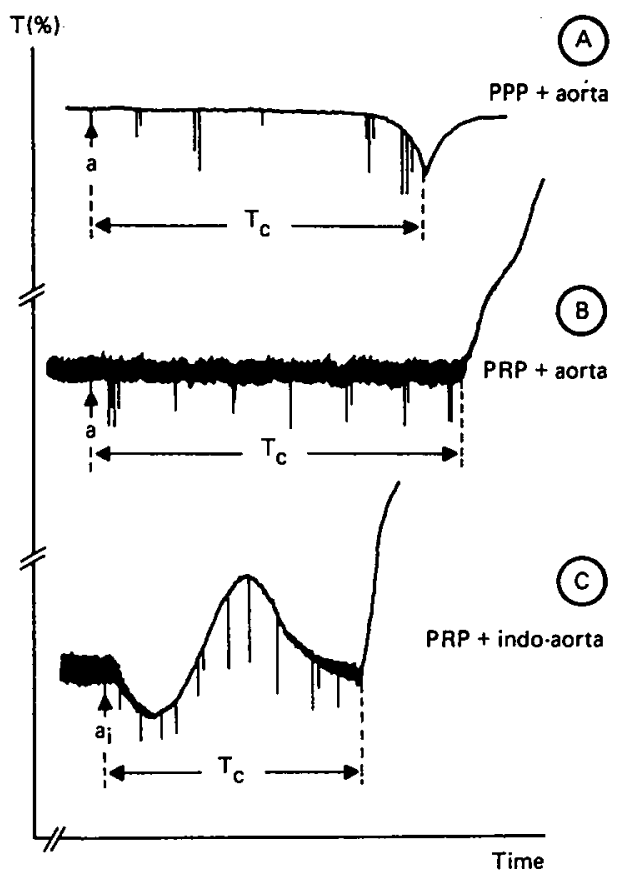

Fig.3.1. Clotting-induced changes in light transmission $(T)$ in platelet-poor plasma (A) and platelet-rich plasma preceded (C) or not (B) by platelet aggregation.

a : aorta. $a_{i}$ : aorta pretreated with indomethacin (indo-aorta). $\mathrm{T}_{\mathrm{c}}$ : clotting time.

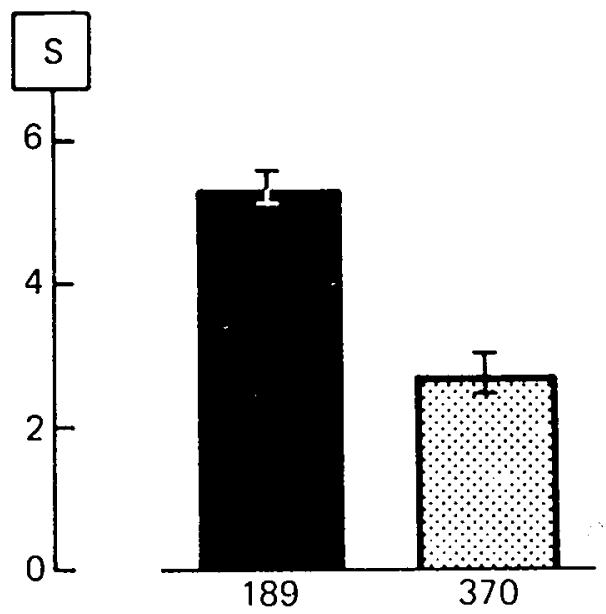

Fig.3.2. Effect of presence of blood platelets on vessel-wall induced clotting, indicated by clotting index $S=1,000 / t_{c}$ (seconds). Figures below bars are clotting times (seconds) calculated from mean S-values. PRP PPP 
However, the subsequent increase in transmission is more pronounced than in PPP, because platelets are trapped in the fibrin strands twisting around the stirring bar (Fig 3.1.B). The time lapse (seconds) between tissue addition and the moment of clotting is called the clotting time, $t_{c}$, which, for statistical reasons, is indicated by the clotting index $S=1 / t_{c} \times 1,000 . S$ is higher, the higher the clotting tendency of the plasma. Initially, measurements were discontinued after a clotting time of 1,200 sec had been reached. The S-value of these measurements was taken as 0.83 . In later experiments, the $\mathrm{Ca}^{++}$-content of the saline was increased to $0.65 \times 10^{-6} \mathrm{~mol} .1^{-1}$, which prevented the occurrence of these long clotting times.

\subsubsection{Effect__of_blood_platelets_on_vessel_wall_induçed_clotting}

To establish whether the presence of platelets is a prerequisite for vessel-wall induced coagulation, clotting times were determined upon incubation of aortic tissue in PRP and PPP respectively. Clotting occurred in both media but, as evaluated by Student's t-test, in PRP it was significantly enhanced as compared with PPP (Fig.3.2, $P_{2}<0.01$, which means that the probability (two sided) for the observed difference to be ascribed to chance, is less than $1 \%$, see ref.137).

Although the pieces of vascular tissue used provide a thrombogenic surface, platelets not in direct contact with the vessel wall are not activated, as can be concluded from the absence of platelet shape change and aggregation (Fig.3.1.B). This would indicate that for their clot-promoting effect to become operative, platelets need not become activated. However, it is likely that the adhered and thereby activated platelets are responsible for the clot-promoting effect observed.

When, immediately upon tissue addition, aggregation is triggered by adding $\operatorname{ADP}\left(3.5 \times 10^{-5} \mathrm{~mol} .1^{-1}\right.$, final concentration) coagulation is significantly enhanced $\left(P_{2}<0.05, F i g .3 .3.\right)$. Since $A D P$ in itself has never been shown to affect blood clotting, this strongly suggests that activated platelets have a stronger clot-promoting effect than non-activated ones.

As is also evident from Fig. 3.3, vessel-wall induced clotting in Fawn-Hooded (FH) rats (See section 3.2.5.) is significantily $\left(P_{2}<0.01\right.$, 
Student's two-samples test) higher as compared with normal Wistar rats. This has been confirmed in later experiments and requires further investigation.

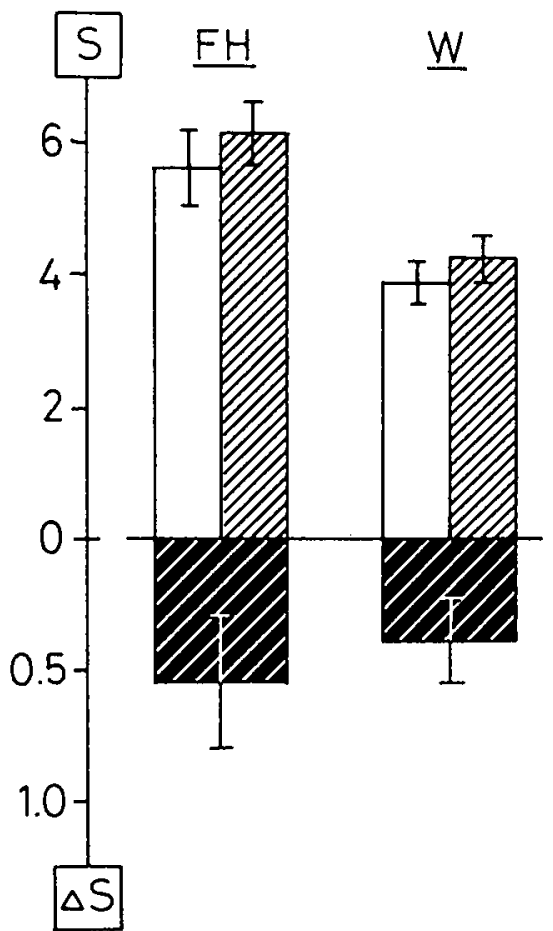

Fig.3.3. Effect of ADP-induced platelet aggregation on vessel-wall induced clotting of PRP (S). Experiments carried out with material from Fawn-Hooded rats ( $F H, n=12)$ and Wistar rats ( $W, n=12)$. Mean \pm SEM. $\triangle S$ Difference caused by ADP administration.

$\square$ No ADP UPA ADP added DIA Difference,

\subsubsection{Effect of vascular prostacyclin on vessel-wall induced clotting}

Vascular tissue produces prostacyclin (Prostaglandin $I_{2}, P I_{2}$, see section 3.3.2.) which is a very active inhibitor of platelet aggregation. To investigate whether $\mathrm{PGI}_{2}$ also affects vessel-wall induced clotting, aortas were pre-incubated in $\mathrm{KH}-$ buffer, containing indomethacin $\left(2 \mu \mathrm{g} \cdot \mathrm{ml}^{-1}\right)$, aspirin $\left(100 \mu \mathrm{g} \cdot \mathrm{ml}^{-1}\right)$ or tranylcypromine $\left(500 \mu \mathrm{g} \cdot \mathrm{ml}^{-1}\right)$, which are substances known to inhibit vascular prostacycl in production (18). This resulted in a generalized activation of the blood platelets in the cuvette as indicated by their shape change and aggregation (Fig 3.1.C.) and also in a significantly enhanced clotting response. 
(for indomethacin, see Fig.7.7.A and B).

As will be demonstrated in more detail later (Chapter 8, section 2.3.), a lack of $\mathrm{PGI}_{2}$-precursors in the vascular tissue occurring in essential fatty acid (EFA-) deficiency and resulting in a low prostacycl in production (19), is also associated with platelet shape change and aggregation upon addition of an aortic piece to PRP. Besides, the clotting response is enhanced as compared with normal tissue. This difference became greatly reduced after pretreatment of normal and EFA-deficient aortas with indomethacin, thereby preventing any effect of vascular prostacyclin (Fig.8.7.). These observations show that prostacyclin probabiy inhibits vessel-wall induced clotting by diminishing the activation of blood platelets and, as a consequence, also their clot-promoting activity. Compatible with these results are the recently published observations of Bunting and Moncada (20) that prostacyclin inhibits kaolin and collagen-stimulated clotting in blood and PRP but not in PPP.

\subsubsection{Tentative characterization of the clotting process initiated by_damagaged vas}

Only preliminary investigations have been carried out to come to a characterization of the vessel-wall induced clotting process. When compared with rat-brain thromboplastin, damaged tissue of rat aorta induced similar clotting indices in human VII-deficient plasma, which were about $60 \%$ lower than in a standard plasma (Fig.3.4). When human vascular tissue was used (obtained from surgical patients), the clotting response in human VII-deficient plasma was about $40 \% 1$ ower than that obtained with a standard plasma. Both results indicate that in the vessel-wall induced clotting a clearly extrinsic component is involved. This is in line with the fairly well documented tissue-factor activity of the vessel-wall (for a review: see ref.9).

This finding was confirmed in preliminary experiments with a rabbit-raised fibrinogen- and complement-free antiserum against human-brain thromboplastin (prepared and provided by Dr.K.van Ginkel, Amsterdam), which was shown to be ineffective in the APTT-test. Pieces of vascular tissue from rat or man were incubated in $50 \mu 1$ antithromboplastin or control serum, diluted with $450 \mu$ l Tris buffer $\left(10 \mathrm{mmol.1} \mathrm{l}^{-1}\right)$ in saline (pH 7.3), containing $4 \mathrm{mmol}^{-1} \mathrm{1}^{-1} \mathrm{Ca}{ }^{++}$, in a stirred cuvette at $700 \mathrm{rev} \cdot \mathrm{min}^{-1}$ and $37^{\circ} \mathrm{C}$. After incubation for 3 and 15 minutes, $50 \mu l$ aliquots of the 

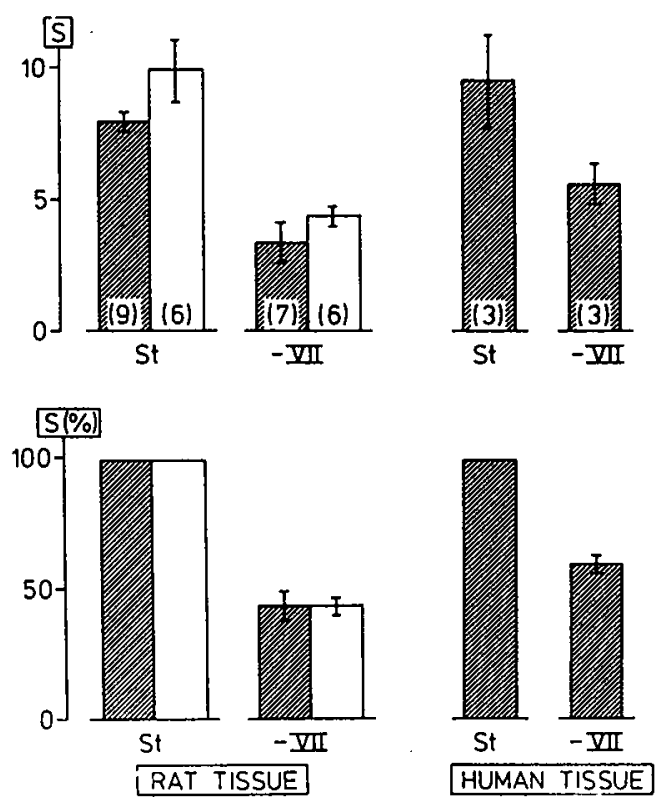

Fig.3.4. Effect of VII-deficient plasma (human) on clotting induced by damaged vascular tissue ( $)$ and rat-brain thromboplastin ( $\square$ ). Upper row : clotting indicated by the mean clotting index $S \pm S E M$ Lower row : clotting response in VII-deficient plasma calculated as $\% \pm$ SEM of the S-value, obtained with standard plasma $(=100 \%)$. St : standard plasma. -VII : VII-deficient plasma.

incubate were transferred into an aggregometer cuvette, containing $450 \mu 1 \mathrm{Tris} / \mathrm{saline}$ buffer with $\mathrm{Ca}^{++}\left(4 \mathrm{mmol} . \mathrm{I}^{-1}\right)$ and $50 \mu \mathrm{l}$ standard rat or human platelet-free plasma, which had been pre-incubated for 3 min. at $37.5^{\circ} \mathrm{C}$ and a stirring rate of 700 rev.min. $^{-1}$. The clotting response. was recorded and calculated as the clotting index $\mathrm{S}$ (section 3.2.1.).

In Fig. 3.5, the white bars represent the clotting responses of the control incubate. The shaded bars refer to the clotting reaction upon addition of the antithromboplastin incubate. The difference between these responses in \% of the control $S$-value is indicated by the black bars and it can be seen that the clotting potency of rat and human tissue is greatly diminished (but not blocked) upon pre-incubation with antithromboplastin antibodies.

The fact that neither the VII-deficient plasma nor the thromboplastin antibodies are able to prevent vessel-wall induced clotting completely, suggests that in this clotting process, also an intrinsic component 


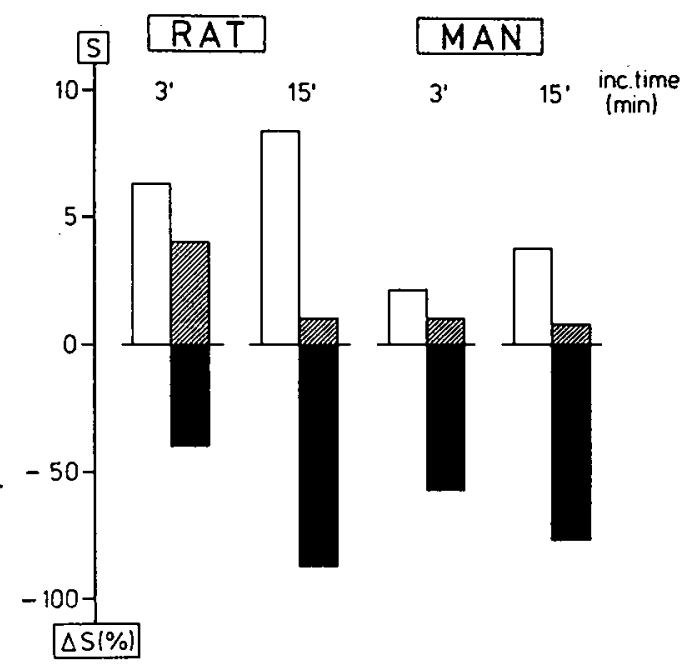

Fig.3.5. Effect of an antithromboplastin antiserum on the clotting potency of rat and human vascular tissue.

$\square$ Tissue incubated with control serum. Tissue incubated with antiserum. Difference in clotting response. $S=$ clotting index : 1,000/clotting time (seconds).

is involved. This is also suggested by studies of VIII, IX, XI and XII-deficient plasmas (human), which also showed a lower clotting response with rat aortic tissue than a human standard plasma. The combined character of vessel-wall induced clotting (intrinsic and extrinsic) is also underlined by the significant correlation existing between vessel-wall induced clotting and PT as well as APTT, as was observed in a study of dietary fish-oil induced changes in vessel-wall induced clotting (Fig.3.6.). However, more experiments are needed for a further characterization of this clotting process.

\subsubsection{Vesse1-wall induced_platelet reactions_: role of Thromboxane $A_{2}$ and ADP}

Clotting of PRP, brought about by a piece of vascular tissue producing little or no prostacyclin, is preceded by platelet shape change and aggregation (Fig.3.1.). The time course of these platelet reactions very much resembles that of collagen-induced aggregation (Fig 7.10.), which is known to be mediated by ADP released by (21) and Thromboxane $A_{2}$, 

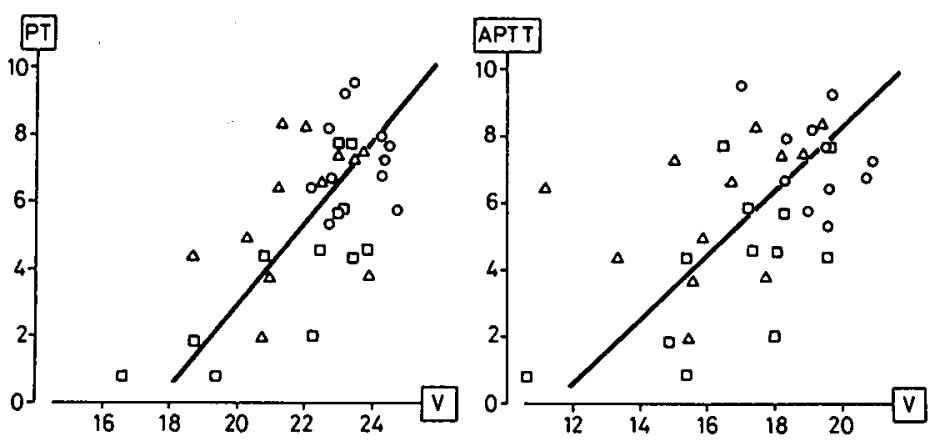

Fig.3.6. Relationship between vessel-wall induced clotting (V) and prothrombin time (PT, left) and activated partial thromboplastin time (APTT, right). Values indicated as clotting index $S$.

PT : $Y=-21.67+1.23 X ; n=35 ; r=0.64 ; P<0.001$

APTT : $Y=-10.73+0.95 x ; n=35 ; r=0.50 ; P<0.01$

o animals fed a diet containing 50 en\% sunflowerseed oil (SO).

a animals fed a diet containing 45 en\% cod-liver $0 i 1+5$ en $\%$ so.

$\Delta$ animals fed a diet containing 45 en\% of another fish oi $1+5$ en\% so.

$\left(\mathrm{TXA}_{2}\right)$ produced by activated blood platelets (22) and which can be inhibited by aspirinization of the blood platelets (23-25).

To investigate the role of platelet $A D P$ and $\mathrm{TXA}_{2}$ in the aggregation of PRP following exposure to damaged vascular tissue, PRP was pre-incubated with aspirin $\left(0.55 \times 10^{-3} \mathrm{~mol} .7^{-1}\right.$ in saline) or with saline for $1 \mathrm{~h}$ at room temperature. Subsequently, aggregation was measured in $50 \mu 1$ PRP diluted with $440 \mu \mathrm{l} \mathrm{Ca}^{++}$- containing saline, (Payton Dual Channel aggregometer) on addition of one piece of indomethacin-treated vascular tissue (+ $10 \mu 1$ saline), $10 \mu 1$ adenosine diphosphate (ADP, $0.25 \times 10^{-6}$ mol. $l^{-1}$, final concentration), $10 \mu l$ of a collagen-in-saline suspension $\left(5.6 \times 10^{-6} \mathrm{~g} \text { protein.m }\right]^{-1}$, final concentration) or $10 \mu 1$ thrombin ( $0.09 \mathrm{NIH}-\mathrm{u} . \mathrm{ml}^{-1}$, final concentration).

The results of this study are shown in Fig 3.7. from which it is evident that the aggregation induced by injured vascular tissue and by thrombin, , is not significantly affected by aspirin treatment of the PRP. The collagen- and ADP- induced aggregation was significantly impaired, thus showing the effectiveness of the aspirin dose used to block platelet $\mathrm{TxA}_{2}$ production. These results strongly suggest that vessel-wall induced aggregation is not mediated by $\mathrm{TxA}_{2}$ and/or ADP.

However, it has been repeatedly shown that the aspirin effect can be overcome by simply increasing the trigger strength, thereby inducing the 


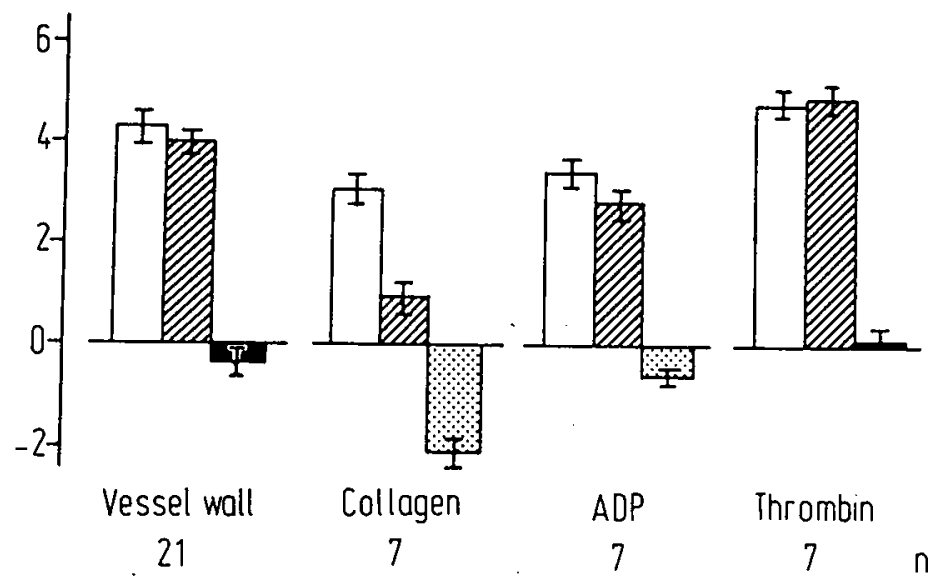

Fig.3.7. Aggregation (arbitrary units) of normal ( $\mathbb{Z}$ ) and aspirintreated ( $\square$ ) PRP of Wistar rats, induced by different stimuli. Mean \pm SEM. Difference, not significant Difference, $P_{2}<0.01$.

release of ADP independently of platelet thromboxane production $(25,26)$. Therefore, the aspirin experiment was repeated with PRP obtained from FH-rats. This strain of rats has a hereditary defect of the platelet release reaction : their dense granules, which, in normal animals, contain ATP, ADP, $\mathrm{Ca}^{++}$, seretonin, pyrophosphate and antiplasmin (2/), seem to be empty, thus leading to reduced platelet nucleotide and serotonin contents $(28,29)$. This defect is thought to be the underlyina mechanism of the bleeding tendency observed in these animais (29), because the collagen-induced aggregation is highly impaired $(28,29)$. However, collagen-induced platelet $\mathrm{TXA}_{2}$ - production is normal in $\mathrm{FH}$-rats, judging from the production of a $\mathrm{TXA}_{2}$-metabolite, malondialdehyde (MDA), upon

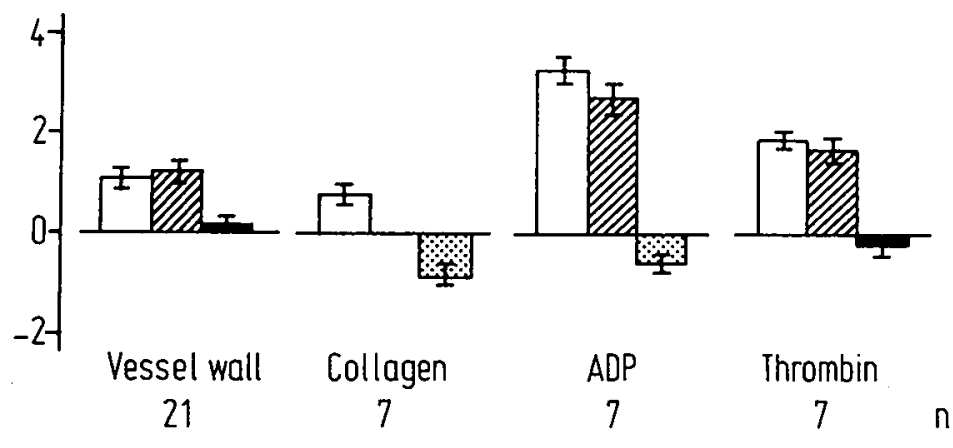

Fig.3.8. Aggregation (arbitrary units) of normal ( $\square$ ) and aspirintreated ( $)$ ) PRP of Fawn-Hooded rats, induced by various stimuli. Mean \pm SEM.

Difference, not significant. $\quad$ Difference, $P_{2}<0.001$ 
supramaximal triggering with collagen (FH:1.33 \pm 0.048 ; Wistar $1.30 \pm 0.069$ nmol MDA. $10^{-9}$ platelets, $n=9$ ).

As is shown in Fig 3.8., the results obtained with FH-PRP are identical to those obtained with Wistar rats. Pre-incubation of PRP with an aspirin dose high enough to block the collagen-induced aggregation completely and inhibit the ADP-induced aggregation significantly, did not modify vessel-wall and thrombin-induced aggregation.

The role of released ADP was further investigated by measuring the aggregation of PRP induced by a piece of indomethacin-treated rat aorta in the presence and absence of the ADP dephosphorylating enzyme apyrase (30) and the ADP transphosphorylating system creatine phosphate, creatine phosphokinase (CP/CPK, see ref 31$)$. These ADP scavengers appeared to inhibit platelet aggregation only in doses about two times higher than those needed to block a comparable degree of aggregation induced by added ADP. (for CP/CPK : see Fig.3.9.).

These results demonstrate that neither $\mathrm{TxA}_{2}$ nor ADP plays an important mediatory role in the aggregation of platelets induced by damaged vascular tissue.
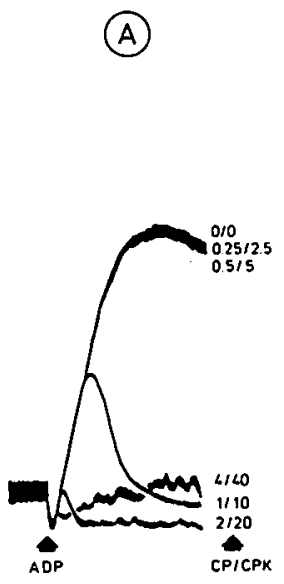

(B)

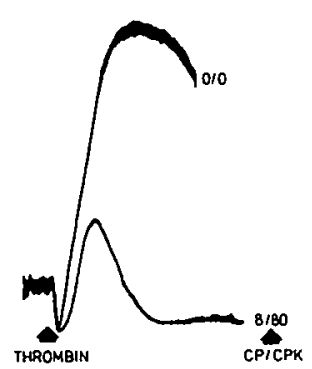

(C)

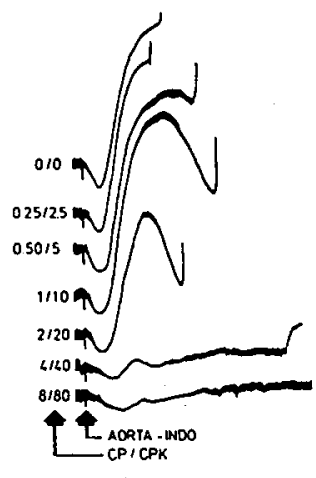

Fig.3.9. Effect of ADP scavenging on platelet aggregation induced by ADP (A), Thrombin (B) or damaged vascular tissue, pretreated with indomethacin (C). Tracings (superimposed) show increase in light transmission due to aggregation, followed by clotting ( $C$ onty).

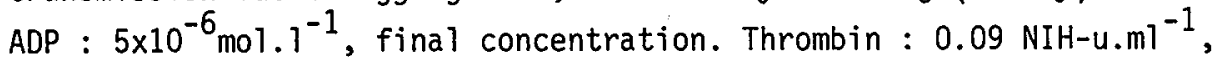
final concentration. $C P$ : Creatine phosphate in mmol. $1^{-1}$, final concentration. CPK : Creatine phosphokinase in $u \cdot \mathrm{ml}^{-1}$, final concentration 


\subsubsection{Vessel-wal1 induced platelet reactions : role of thrombin}

As shown in Figs. 3.7. and 3.8, the aggregation induced by damaged vascular tissue closely resembles that of thrombin as far as the effect of aspirin is concerned. Since the PRP/vessel-wall interaction triggers a clotting response, the preceding platelet reactions may be mediated by thrombin formed during this clotting response. We tested this hypothesis by measuring vessel-wall induced aggregation and clotting of PRP in the presence of increasing amounts of hirudin (ex Pentapharm, Basle, Switzerland), which is a specific thrombin-inactivating polypeptide and does not modify platelet aggregation induced by ADP (Fig.3.10.). It appeared that this substance very effectively blocked platelet aggregation when added to PRP in doses only slightly effective in lowering the clotting response (Fig.3.10, see also Table 3.1, page 60). It is therefore concluded that platelet aggregation occurring upon exposure to damaged vascular tissue is mediated by thrombin, generated as a result of vessel-wall induced clotting. Since ADP scavengers had also some inhibitory effect on vessel-wall induced platelet reactions, a supporting role of ADP, released from adherent platelets and/or froii non-adherent platelets activated by the generated thrombin, cannot be excluded (32).

(A)

(B)
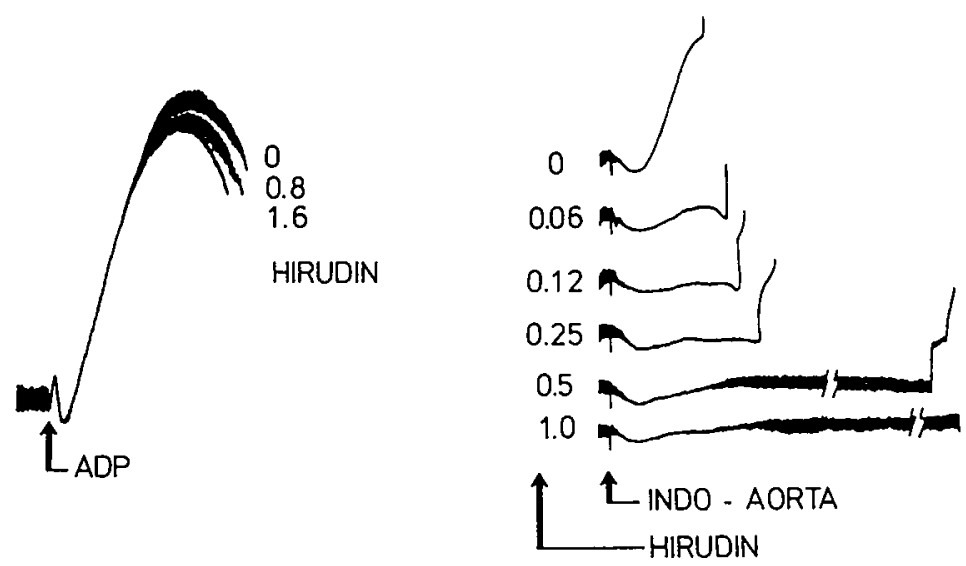

Fig.3.10. Effect of hirudin (antithrombin units per $\mathrm{ml}$, final concentration) on platelet aggregation induced by $\operatorname{ADP}\left(A, 1 \times 10^{-6} \mathrm{~mol} .1^{-1}\right.$, final concentration) and a piece of aortic tissue, pretreated with indomethacin $\left(2 \mu \mathrm{g} \cdot \mathrm{ml}^{-1}\right)$ to block prostacyclin formation (B). Tracings show increase in light transmission due to aggregation, followed by clotting (B only). 


\subsubsection{Ihrombin the key substance in thrombus formation following vasscular injury}

We demonstrated that injured vessel wall can clot plasma, most probably by activating the extrinsic and intrinsic coagulation pathways. If we consider our findings in the light of literature data, the following picture emerges as to the process resulting from the interactions between damaged vessel wall and blood constituents (Fig.3.11.). In the first reaction phase, the endothelial injury causes the adhesion of blood platelets to subendothelial structures, followed by the activation of the adhered platelets. Tissue factor activity of the injured blood vessel triggers the extrinsic pathway of coagulation, leading to the formation of activated factor $X$ in close proximity to adhered blood

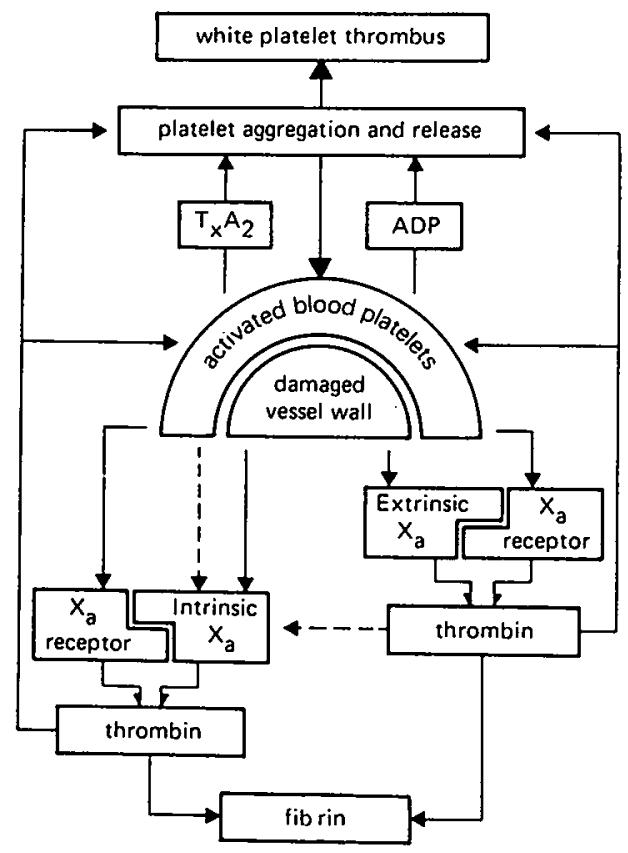

Fig.3.11. Processes possibly involved in thrombus formation, following vascular injury. For details, see under section 3.2.7.

platelets. These platelets, following activation, have disclosed specific receptors for activated factor $x$, as a result of which $x_{a}$ binds to their surface (33-35). There is substantial evidence that activated factor $V$ acts as this receptor $(36,37)$.

Together with platelet membrane phospholipids and $\mathrm{Ca}^{++}, \mathrm{V}_{\mathrm{a}}$ accelerates the $x_{a}$-mediated proteolysis of prothrombin to thrombin at the platelet 
surface. Although, initially, the amount of thrombin generated in this way is only very smal1, the local concentration will be sufficient to uncover $x_{a}$ receptors on fresh platelets. These have, in the meantime, concentrated around the vascular injury due to the aggregating activity of $\mathrm{TXA}_{2}$ produced by, and ADP released from the adhered platelets. This enables $X_{a}$ to produce more thrombin. By activating factor VIII, thrombin may promote its own formation via the intrinsic clotting pathway (9), which is also initiated by the injured vessel wall. Via these positive feedback mechanisms, the local thrombin concentration is boosted.

Since thrombin is a very potent platelet aggregation and releasing agent, it cooperates with $\mathrm{TXA}_{2}$ and ADP in the production of a 'white platelet thrombus', the growth of which will be counteracted by prostacyclin generated in the vessel wall from endogenous precursors (see sections 3.3.2. and 3.3.3.). The white thrombus has a fragile structure and embolizes very easily. However, thrombin also mediates the formation of fibrin which consolidates the fragile platelet mass to a stable arterial thrombus of great pathological significance.

For a long time, the participation of coagulation in arterial thrombogenes is has been considered to be of secondary importance. However, it is now gradually becoming clear that white thrombus formation and blood clotting are two intimately linked processes equally important in arterial thrombogenesis.

It is possible that the ineffectiveness of anticoagulants to prevent myocardial infarction and other arterial thrombotic events, as reported in the older literature $(38,39)$, resulted from too low a level of anticoagulation, but also positive reports have been published (38). Recently, a well-designed study was undertaken to investigate the effect of anticoagulant withdrawal from postmyocardial infarction patients aged 60 years and older. A significantly higher reinfarction rate was observed in the group in which anticoagulant therapy was discontinued. Bleeding complications were only slightly enhanced in the group in which treatment was continued, resulting in a lower overall mortality in this group (40). Our finding may provide an explanation for this beneficial effect of anticoagulants in the secondary prevention of myocardial infarction. 


\subsection{Platelet- and vessel wall prostaglandins: their role in thromboregulation}

\subsubsection{Platelet_prostaglandins and thromboxanes}

Kloeze (41) was the first to show that prostaglandins are very active modulators of platelet aggregation in vitro: prostaglandin $E_{1}\left(P_{1} E_{1}\right)$ had a strong inhibitory effect while $\mathrm{PGE}_{2}$ was slightly stimulating. Of the later discovered natural prostaglandins, only $\operatorname{PGD}_{2}(42,43)$ and prostacyclin ( $P I_{2}$, see section 3.3.2.) were shown to be potent antiaggregants. Since Kloeze's observations, confirmed in later studies by himself and other researchers ( 44-46), circulating prostaglandins have been considered as possible regulators of platelet aggregation and, consequently, of thrombus formation.

In 1970, Smith and Willis demonstrated that activated platelets, simultaneously with their release reaction, produce prostaglandins themselves, $\mathrm{PGE}_{2}$ in particular (47). After they had discovered that pre-incubation of the platelets with aspirin not only blocked the platelet release reaction but their prostaglandin production as well (48), they postulated that $\mathrm{PGE}_{2}$ produced by platelets upon their activation, mediates therelease reaction of these platelets and, consequently, also their involvement in aggregation and thrombus formation. Since PG's had been shown to be formed from certain long-chain polyunsaturated fatty acids $(49,50)$ liberated from phospholipids $(51-53)$, these findings implied that platelet triggering should result in the activation of a phospholipase, presumably of the $A_{2}$-type, because polyunsaturated fatty acids preferabiy occupy the 2-position. Later studies indeed demonstrated the presence of phospholipase $A_{2}$ in platelets $(54,75)$. Phospholipase $A_{1}$ was present as well $(55,56)$.

However, a mediatory role of endogenously formed $\mathrm{PGE}_{2}$ in the plateletrelease reaction was not in line with the finding that exogenous $\mathrm{PGE}_{2}$ did not induce platelet-release and aggregation. Therefore, a short-lived intermediate was proposed in the conversion of arachidonic acid into $\mathrm{PGE}_{2}$. Such an intermediate was indeed isolated and characterized by Dutch and Swedish workers. $(61,57,58)$. In fact, two intermediates were found which, because of their molecular configuration, were called cyclic 
endoperoxides and named $\mathrm{PGG}_{2}$ (a hydroperoxide) and $\mathrm{PGH}_{2}$. They were shown to be synthesized from arachidonic acid (AA) by an enzyme complex, prostaglandin synthase or cyclo-oxygenase $(C O)$. The enzyme complex also appeared to have peroxidase activity (59) so that $P G G_{2}$ is very rapidly converted into $\mathrm{PGH}_{2}$. The endoperoxides were able to aggregate blood platelets and their formation was blocked by aspirin and other non-steroidal anti-inflammatory drugs as a result of Co-inactivation. Moreover, they appeared to be labile substances which are quickly metabolized to either the 'classical' $P G^{\prime} s\left(E_{2}, D_{2}, F_{2 \alpha}\right.$, etc.) or to three different platelet-inactive compounds containing 3 (malondialdehyde, MDA), 17 (12-hydroxyheptadecatrienoic acid, HHT) or 20 (PHD, later called $\mathrm{TXB}_{2}$ ) carbon atoms (60).

However, the hypothesis that endogenously formed endoperoxides mediate platelet-release and aggregation could not be maintained for a long time because the endoperoxide levels often correlated negatively with the degree in which these platelet reactions occurred. In fact, these studies suggested the existence of a highly unstable, very potent endoperoxide derivative, which was indeed confirmed in later studies (22). On theoretical and experimental grounds, the structure of this substance was proposed to contain an oxane ring and because of its very potent prothrombotic effect, it was named Thromboxane $A_{2}\left(T \times A_{2}\right)$. $\mathrm{TxA}_{2}$ appeared to be formed from $\mathrm{PGH}_{2}$ by an isomerase-type of enzyme (Tx-synthase) and to have a very strong platelet-activating effect. Its action is, however, limited by its lability because it is very actively hydrated to $\mathrm{TXB}_{2}$ (which appeared identical to $\mathrm{PHD}$ ) and is most probably also catabolized to HHT and MDA $(62,100)$. Because of their high affinity for Tx-synthase, platelet endoperoxides are almost completely ultilized for Tx-formation. Only when the Tx-synthase is blocked, are endoperoxides also converted into the classical PG's or may even escape from the platelet (63). It should be realized that, apart from platelet $A A$, the other PG-precursor fatty acids may also be expected to become converted via the same pathways. Dihomo- $\gamma-7$ inolenic acid $(20: 3(n-6))$ and timnodonic acid $(20: 5(n-3))$ have indeed been shown to be converted to prostaglandins of the 1- and 3- series respectively (64). Timnodonic acid appeared to be a poor substrate; this aspect will be discussed in more detail in Chapter 9. $\mathrm{PGH}_{1}$ is not converted by Tx-synthase, possibly because it lacks the $\Delta_{5}$ double bond $(65,91)$. Since $A A$ is by far the most abundant PG-precursor present in platelets, PG's of the 2-series dominate. 


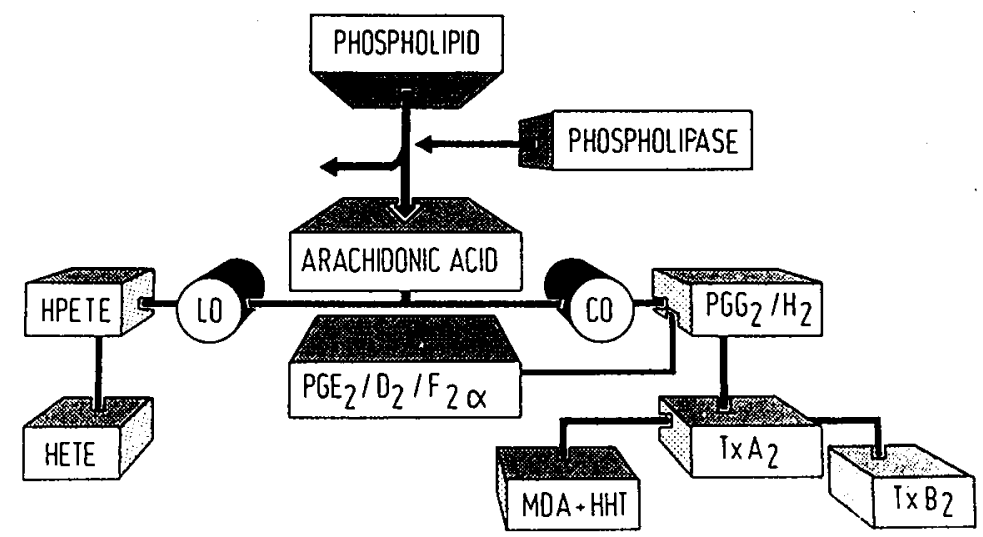

Fig.3.12. Metabolic pathway of arachidonic acid upon platelet activation. LO : Lipoxygenase. CO : cyclo-oxygenase.

Platelet $A A$, when liberated upon phospholipase activation, is not only converted by $\mathrm{CO}$, but also by another platelet enzyme. This enzyme - a lipoxygenase (LO) - converts AA via a hydroperoxy intermediate (HPETE, 12-hydroperoxyeicosatetraenoic acid) into a hydroxy acid (HETE, 12-hydroxyeicosatetraenoic acid).

The platelet L0-products would be involved in Tx-synthase regulation (66) in leukocyte chemotaxis $(67,68)$ and in irreversible platelet aggregation (69). Several c0-products have been shown to have chemotactic properties as well (70).

The major effect of $\mathrm{TxA}_{2}$ is the induction of platelet aggregation which can occur independently of the platelet-release reaction (124-126). Moreover, $\mathrm{TXA}_{2}$ is a potent vasoconstrictor (22) and will, therefore, probabiy contribute to primary hemostasis (84). Fig. 3.12. summarizes AA metabolism upon platelet stimulation.

There is still some discussion about the mechanisms by which fatty acids are liberated from platelet phospholipids, and about the specifity of these mechanisms as far as donor-phospholipid classes and releasable fatty acids are concerned. An arachidonic-acid specific phospholipase $A_{2}$ has been mentioned as being the enzyme responsible for AA release (71). other investigators hold the view that a phosphatidyl-inositol (PI) specific phospholipase $C$ (in combination with a diglyceride lipase) is reponsible for AA-liberation upon platelet triggering (72). Again others stress the importance of the PI-specific phospholipase, combined with a phosphatidic acid-activated phospholipase $A_{2}(56,73,74)$. Similar controversies exist about the major AA-donor-phospholipid class : 
PC (71) PI $(72,75)$ as well as PE $(76,77)$ have been mentioned, which may be connected with the different species investigated.

It is generally agreed that phospholipases require $\mathrm{Ca}^{++}$for their activity. One of the first effects of platelet activation (except when epinephrine is used as a platelet trigger) is platelet shape change. This phenomenon coincides with a redistribution of intra-cellular $\mathrm{Ca}^{++}$ stores resulting in an increase in cytoplasmatic $\mathrm{Ca}^{++}(78)$. However, it is suggested that this $\mathrm{Ca}^{++}$originates from a pool different from the one involved in the release reaction (79). Since the PI-specific phospholipase $C$ requires less $\mathrm{Ca}^{++}$for its activation (80) than phospholipase $\mathrm{A}_{2}$ (74), it is likely that PI is primarily involved in AA-liberation. A further increase of the cytoplasmatic $\mathrm{Ca}^{++}$-concentration might occur as a result of a $\mathrm{Ca}^{++}$-ionophore-like activity of Thromboxane $\mathrm{A}_{2}$ (81). Moreover, lysophosphatidic acid, accumulating following platelet activation (82), would be implicated in releasing intracellular, membrane-bound $\mathrm{Ca}^{++}(83)$.

It is very likely that modulation of platelet functions by prostaglandins, endoperoxides and thromboxanes is mediated by changes in platelet CAMP levels. A first indication in this direction was obtained by Robison and co-workers (135) and later studies clearly showed that inhibition of platelet activation coincides with an increased platelet cAMP level $(86,87)$. There is sound evidence that cAMP exerts its effects on platelets through stimulation of (a) protein-kinase(s), thereby altering the activity of key enzymes in platelet membrane and cytoplasma (88). Accumulation of CAMP results, for instance, in $\mathrm{Ca}^{++}$sequestration and inhibits (thereby ?) the phospholipase-mediated release of arachidonic acid and, consequently, also $\mathrm{TXA}_{2}$ formation $(89,90)$. The prostaglandin cyclic endoperoxides $\mathrm{PGG}_{2}$ and $\mathrm{PGH}_{2}$ and $\mathrm{TXA}_{2}$ are potent inhibitors of platelet cAMP accumulation. They promote, therefore, their own formation because they neutralize the CAMP-mediated inhibition of arachidonate release.

\subsubsection{Vasculalar_prostaglandin $I_{2}$}

Although the vessel-wall does produce some $\mathrm{TxA}_{2}$ (92), the major vascular prostaglandin is prostacyclin, $\mathrm{PGI}_{2}(98,119)$. This substance was discovered by Moncada and co-workers (93), who demonstrated that it is 
enzymatically formed from $\mathrm{PGH}_{2}$ and that its activities are the reverse of those of $\mathrm{TXA}_{2}$ : it causes vasodilation, inhibits platelet aggregation and -adhesion and stimulates platelet adenylcyclase, leading to a marked accumulation of CAMP $(94-96,115)$.

The enzyme prostacyclin synthase is inhibitid by lipid peroxides $(97,99)$. Prostacyclin formation can also be inhibitid by inactivation of the vascular cyclo-oxygenase enzyme system (18), which was shown to be less sensitive towards aspirin than the platelet enzyme (107). The formation of $\mathrm{PGI}_{2}$ in vivo can be influenced by various blood-borne factors such as lipoproteins (127), prostaglandins (128), B-thromboglobulin (a platelet-specific protein which is released upon platelet activation, see ref. 129), albumin-bound fatty acids (130) and other factors (131-134).

Prostacyclin is a rather unstable substance (t $\frac{1}{2}$ ca 2-3 min. in circulating blood, ref. 102) but is not inactivated in the pulmonary circulation $(102,103)$. Its major degradation product is 6 -keto-PGF $1 \alpha$.

Although the vessel-wall generates ADP-ase activity as we11 $(101,104)$, the major contribution to its antithrombotic properties is due to its production of prostacyclin (105).

\subsubsection{Interaction between platelet thromboxane $A_{2}$ and vascular $P G I_{2}$}

The striking opposite effects of $\mathrm{TXA}_{2}$ and $\mathrm{PGI}_{2}$ on platelet aggregation and cyclic nucleotide levels gave rise to the concept that the balance between the two compounds would regulate platelet aggregability and so determine arterial thrombosis tendency $(93,106,116)$. However, as will be demonstrated in Chapters 8 and 9 , arterial thrombosis tendency can be modified by dietary means without changing the $\mathrm{TXA}_{2} / \mathrm{PGI}_{2}$ ratio.

A prerequisite for the validity of the balance concept is the proof that vascular $\mathrm{PGI}_{2}$ is able to reach the circulating platelets. Therefore, the findings of Gryglewski et al. (108) and Moncada and co-workers (109) that prostacyclin indeed circulates in the body, were very important in this respect.

The concept of prostacyclin being a circulating hormone has recently been contested by different groups (110-112) and there is still no unanimity on this point. Moreover, the importance of possibly circulating $P G I_{2}$ as a constant platelet-deactivator might be doubtful because the phenomenon of agonist-specific desensitization has been recognized for prostaglandin 
-mediated effects on platelet adenylcyclase $(113,114)$.

Another contradictory facet concerns the transfer of endoperoxides, formed in activated platelets, to the vessel-wall where it would be used to produce prostacyclin. As stated before, indomethacin inhibits platelet and vessel-wall cyclo-oxygenase and thus prevents the formation of the prostaglandin endoperoxide $\mathrm{PGH}_{2}$. Because of the absence of precursor, endogenous $\mathrm{PGI}_{2}$ production of indomethacin-treated vascular tissue does not take place. Bunting and co-workers showed that if vascular tissue pretreated with indomethacin is incubated in platelet-rich plasma, its $P G I_{2}$-production is restored (94). On the basis of this observation it has been suggested - and is, in fact, now generally accepted - that activated blood platelets can be a source of exogenous endoperoxides stimulating the vascular prostacyclin formation and consequently limiting the growth of a platelet thrombus (117). Since, in our opinion, the experimental data on which this highly elegant homoiostatic concept is based, is rather circumstantial and easy to criticize, we decided to perform some well-controlled experiments to support this so-called 'stealing hypothesis'. From these experiments we must conclude that under normal conditions, blood platelets do not provide endoperoxides for vascular prostacyclin production.

\subsubsection{Effect of blood platelets on the formation of vascular prosta- cyclin.}

Male Wistarrats, specific pathogen-free, mean body weight about $300 \mathrm{~g}$, were bled under ether anesthesia by puncturing the abdominal aorta. The blood was collected in sodium citrate $(3.8 \mathrm{w} / \mathrm{v} \% 1$ part +9 parts of blood) and PRP and platelet-poor plasma (PPP) were prepared by differential centrifugation. (For experimental details : see Chapter 7, section 2). Aortas were removed, cleaned from adjacent tissue, opened longitudinally and kept in Krebs-Henseleit buffer with or without indomethacin $\left(2 \mu \mathrm{g} . \mathrm{ml}^{-1}\right)$ for at least $60 \mathrm{~min}$ at $0^{\circ} \mathrm{C}$. A small piece of tissue (diameter $3 \mathrm{~mm}$, dry weight $\sim 100 \mu \mathrm{g}$ ) was punched out of the aorta and incubated immediately in $200 \mu 1$ of either PPP or PRP in a gently shaken plastic vial for 3 min at room temperature. Measurement of the prostacyclin-content of the incubate was based on the inhibiting effect of the incubate on ADP-induced aggregation of blood platelets. To this end, the incubate was centrifuged 


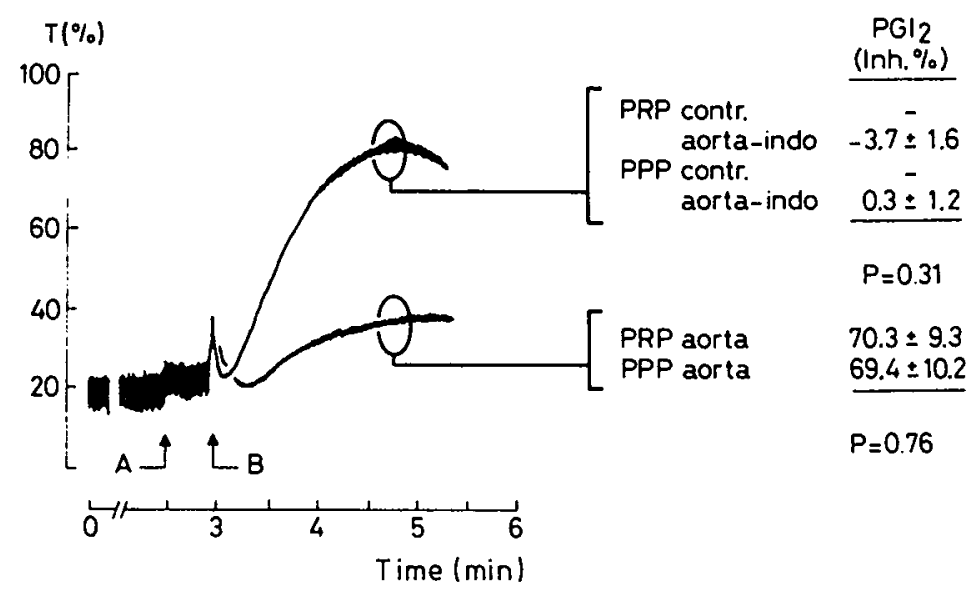

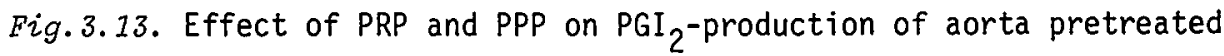
or not with indomethacin (indo). For experimental details, see section 3.3.3.1.

$A$ : addition of incubate under investigation. $B$ : addition of standard ADP-dose. $T$ : light transmission.

$\mathrm{PGI}_{2}$-content of incubate expressed as percentage inhibition (Inh \%) of ADP-induced aggregation. Mean \pm SEM; $n=7$

(45 s; Beckman 152 Microfuge) and 1 min after termination of incubation $50 \mu 1$ was added to an aggregometer cuvette (Born/Michel) containing $0.75 \mathrm{ml}$ saline $\left(0.85 \mathrm{w} / \mathrm{v} \% \mathrm{NaCl}, 7\right.$ parts $+\mathrm{CaCl}_{2} 4 \times 10^{-3} \mathrm{~mol} .1^{-1}, 1$ part $)$ and $0.1 \mathrm{ml}$ rat PRP, which had been pre-incubated $\left(37^{\circ} \mathrm{C}\right)$ for $2.5 \mathrm{~min}$. Thirty seconds after incubate addition, $0.1 \mathrm{ml}$ ADP was added to a final concentration of $2.5 \times 10^{-7} \mathrm{~mol} . \mathrm{7}^{-1}$.

Incubation of normal aortic tissue resulted in the production of an aggregation-inhibiting principle with typical prostacyclin characteristics (19). No significant difference in $\mathrm{PGI}_{2}$ production was observed on incubation with either PPP or PRP (Fig.3.13.). Indomethacin-treated tissue did not produce prostacyclin, irrespective of whether it had been incubated in PPP or PRP (Fig.3.13.). Similar results were obtained with Tonger incubation times (up to $12 \mathrm{~min}$ ) and/or using human PPP and PRP as incubation media.

Prostacyclin formation of normal aortas was considerably stimulated and that of indomethacin-treated aortas completely restored when $\mathrm{PGH}_{2}$ was added to the incubation medium ( $1 \mu \mathrm{g} . \mathrm{ml}^{-1}$ final concentration), thus showing the responsiveness of the tissue to exogenous precursor in the present experimental conditions. Therefore, it can be concluded that PRP, gentiy shaken at room temperature for 3-12 min, does not supply the 
vascular wall with endoperoxides for prostacyclin synthesis.

3.3.3.2. Effect of collagen-activated blood platelets on vascular prostacyclin formation.

In the previous experiment, PRP-activation by damaged tissue might have been insufficient to trigger arachidonate peroxidation. Therefore, in the next series of experiments, platelet endoperoxide production was triggered by collagen. $P G I_{2}$ formation by normal and indomethacin-treated aortic tissue was assessed on incubation in PRP during aggregation induced by a collagen dose that caused platelets to produce endoperoxides (measured as malondialdehyde) and to release part of their granule content (118.). Aggregation of rat PRP (platelet count $\left.1,7 \times 10^{6} \cdot \mu 7^{-1}\right)$ was triggered by collagen $\left(5.6 \times 10^{-6}\right.$ g protein. $\mathrm{m}^{-1}$ final concentration). At the beginning of aggregation (delay time $60 \mathrm{~s}$ ), aortic tissue was added. Aggregation was quantified as the \% change in transmission 3 min after adding the tissue. Prostacyclin production was determined by measuring the difference in collagen-induced aggregation after tissue addition compared with control aggregations without added tissue.

The results (Fig.3.14.) show that indomethacin-treated aortic tissue is unable to produce prostacyclin even if it is uncubated in a suspension of collagen-activated blood platelets.

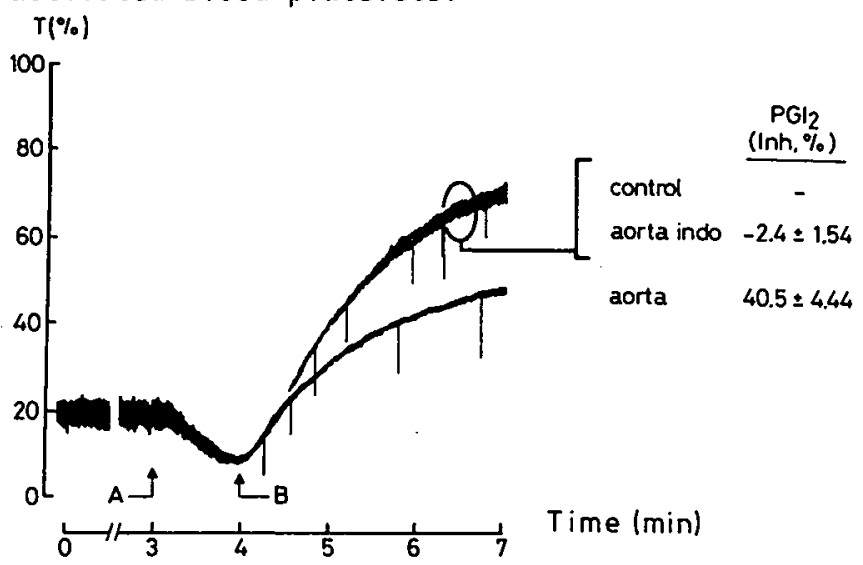

Fig.3.14. Failure of indomethacin-treated vascular tissue (aorta-indo) to produce prostacyclin ( $P \mathrm{GI}_{2}$, expressed as percentage inhibition (Inh \%) of collagen-induced aggregation) when incubated with collagenactivated PRP. Mean \pm SEM; $n=16$

A : addition of collagen. B : addition of piece of vascular tissue. 
3.3.3.3. Effect of platelets, producing different amounts of endoperoxides, on vascular prostacyclin production.

Investigations were carried out to establish whether the prosta-

cyclin production of vascular tissue not treated with indomethacin could be influenced by incubation in PRP producing different amounts of endoperoxides. For this, we used platelets and aortas of normal rats and animals deficient in essential fatty acids (EFA). Platelets of these latter animals, when triggered by collagen, aggregate less than normal platelets $(85,120$, see also Chapter 8 , section 2.2.3.) and produce only small amounts of endoperoxides and thromboxanes $(19,120)$. Their vascular prostacyclin production is lower than in normal animals $(19,118)$, but thromboxane (120) and prostacyclin synthase (19) are present in normal amounts.

If platelet endoperoxides stimulate vascular prostacyclin formation, ore would expect more $P G I_{2}$ to be formed on incubation of vascular tissue with collagen-activated normal than EFA-deficient PRP. However, Fig.3.15. shows that neither normal nor EFA-deficient aortic tissue produces more $\mathrm{PGI}_{2}$ on incubation with collagen-activated normal PRP than with collagen-activated EFA-deficient PRP.

Because normal as well as EFA-deficient vascular tissue can easily be stimulated to produce more $\mathrm{PGI}_{2}$ merely by adding exogenous $\mathrm{PGH}_{2}$ to the

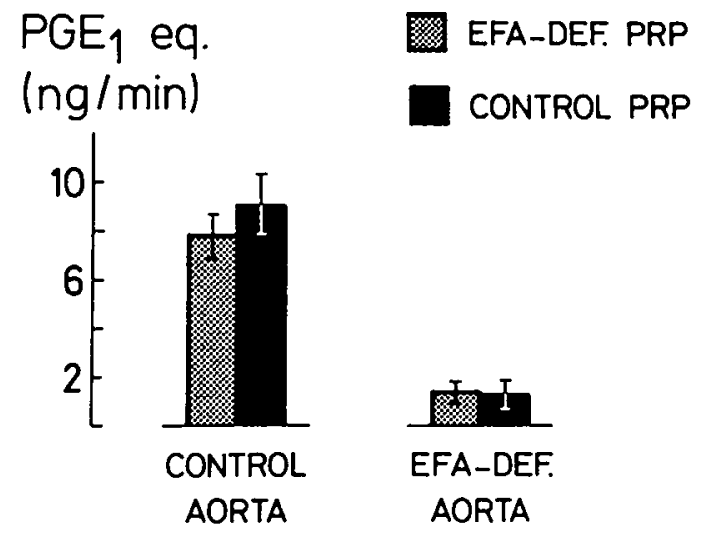

Fig. 3.15. Prostacyclin production (expressed as $P G E_{1}$-equivalents) of control- and EFA-deficient aortic tissue on incubation with collagenaggregated PRP of normal and EFA-deficient rats. Dose-response curves of $P_{G E}$ were constructed for normal and EFA-deficient PRP. Mean $\pm S E M$; $n=11$. The difference in $P G I_{2}$-formation between EFA-deficient and control aortas is highly significant $\left(\mathrm{P}_{2}<0.001\right)$. 
incubation medium, it is highly unlikely that activated blood platelets contribute to vascular prostacyclin synthesis by providing cyclic endoperoxides.

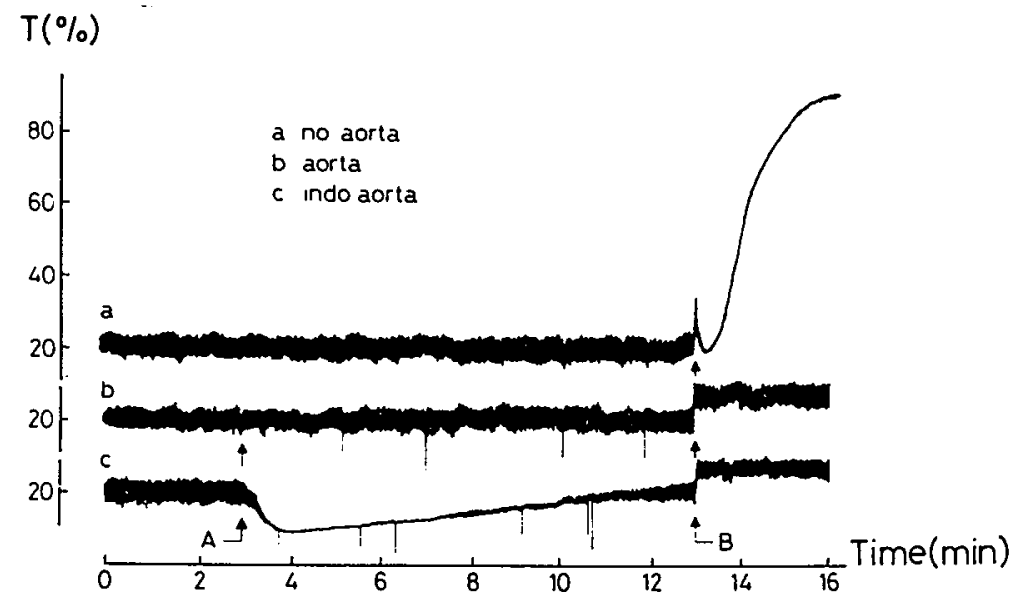

Fig. 3.16. Effect of normal and indomethacin-treated aortic tissue on percentage light transmission (T) of PRP and ADP-induced aggregation $(T, \%)$ in PRP. Tracings are superimposed.

A : tissue addition. $B$ : tissue removal, ADP-addition.

3.3.3.4. Mechanism by which the $\mathrm{PGI}_{2}$-synthesis of indomethacin-treated tissue is restored.

As shown by Bunting et a1. (94) and confirmed by others $(121,122)$, indomethacin-treated tissue prevents aggregation when incubated in PRP. We could also confirm this observation (Fig 3.16.). A piece of indomethacin -treated rat aorta was added to a stirred rat PRP dilution and the change in transmission recorded continuously. When after $10 \mathrm{~min}$, the tissue was removed and $\operatorname{ADP}\left(0.1 \mathrm{ml}, 2.5 \times 10^{-6}\right.$ mol. $\left.1^{-1}\right)$ added to the $P R P$, no aggregation was observed (Fig.3.16.). Aggregation did occur, however, when the platelet mixure was stirred without added aorta. The course of the change in light transmission occurring upon addition of a piece of indomethacin -treated vascular tissue to PRP-causing rapid activation of the blood platelets, followed by a gradual deactivation- suggests a progressively increasing prostacyclin formation, which might be due either to a 'washout' of the indomethacin from the cyclo-oxygenase enzyme system or to an endoperoxide transfer from platelets to vessel wall. To find this out, the endogenous prostacyclin production of indomethacin-treated tissue was measured after pre-incubation under, different conditions. 
To this end, pieces of indomethacin-treated vascular tissue were added to an aggregometer cuvette containing $0.8 \mathrm{ml}$ saline $+\mathrm{CaCl}_{2}$ and $0.1 \mathrm{ml} \mathrm{PRP}$, PPP or Krebs-Henseleit buffer. This mixure had been pre-incubated for $3 \mathrm{~min}$ at $37^{\circ} \mathrm{C}$, while stirred at 1,000 rev.min ${ }^{-1}$. After $10 \mathrm{~min}$, the tissue was removed, rinsed in Krebs-Henseleit buffer and incubated in $200 \mu 1$ Tris buffer $\left(0.02 \mathrm{~mol} . \mathrm{l}^{-1}, \mathrm{pH} \mathrm{7.2)}\right.$ at room temperature in a gently shaken vial. After 3,10 and $20 \mathrm{~min}, 50-\mu 1$ portions of the incubate were assessed for their $\mathrm{PGI}_{2}-1$ ike activity on the basis of their inhibiting effect on ADP-induced aggregation.

When, after tissue incubation in PRP, the cyclo-oxygenase was still blocked by indomethacin, no prostacyclin production would be expected. However, substantial amounts of endogenous $\mathrm{PGI}_{2}-1$ ike activity were detected in the incubate (Fig.3.17.). This is not due to 'late' conversion of stored, platelet-derived $\mathrm{PGH}_{2}$, as essentially similar results were obtained after incubation for $10 \mathrm{~min}$. of indomethacin-treated tissue in a stirred PPP dilution or in a dilution of Krebs-Henseleit buffer. Endogenous $\mathrm{PGI}_{2}$ production could be prevented only when the first as well as the second incubation was carried out in a saline milieu, containing indomethacin

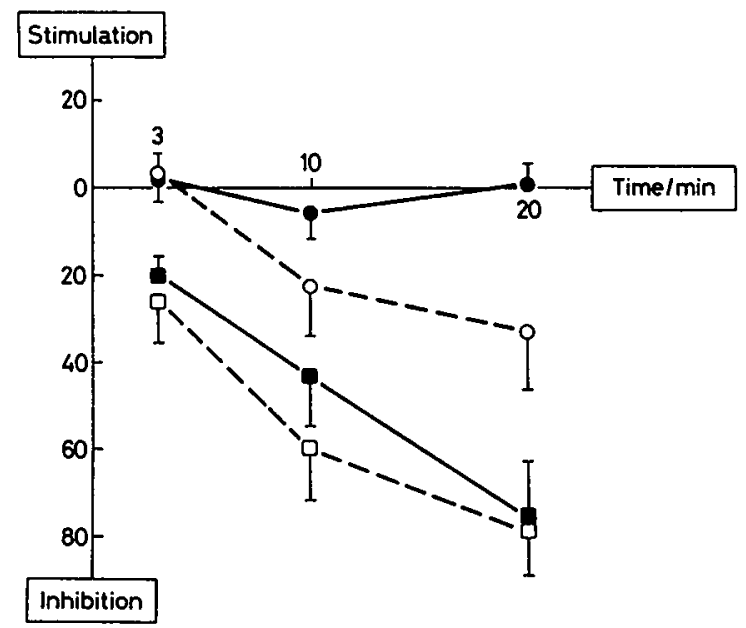

Fig.3.17. Endogenous $\mathrm{PGI}_{2}$-production (percentage inhibition of ADP-induced aggregation) of indomethacin-treated vascular tissue after pre-incubation under various conditions. For experimental details, see under 3.3.3.4.. Results are mean \pm SEM, $n=7$.

Symbols First incubate Second incubate

$\begin{array}{lll}-\square- & \text { PRP } & \text { TRIS/saline } \\ -\therefore-0- & \text { PPP } & \text { TRIS/saline } \\ --0--- & \text { KH-buffer } & \text { TRIS/saline } \\ -\bullet- & \text { KH-buffer + indo } & \text { TRIS/sal ine + indo }\end{array}$


Indomethacin added to PRP or PPP $\left(2 \mu \mathrm{g} \cdot \mathrm{ml}^{-1}\right)$ did not prevent reactivation of vascular cyclo-oxygenase (not shown), most probably because the added indomethacin is bound to plasma proteins, resulting in too low a 'free' indomethacin concentration. There was no appreciable difference between the use of PRP or PPP during the first incubation on subsequent endogenous $P G I_{2}$ production by the tissue. This again demonstrates that platelets do not have a special effect on reactivation of vessel wall cyclo-oxygenase. In this respect, plasma seems superior to buffer, probably because the strong affinity of indomethacin for plasma proteins facilitates its removal from vascular cyclo-oxygenase.

\subsubsection{Effect of platelets on the recovery of $P G I_{2}$-production by indomethacin-treated vascular tissue upon incubation in plasma.}

In our first experiment (Fig.3.13.), we were unable to detect $\mathrm{PGI}_{2}$ production by indomethacin-treated aortas incubated in PRP or PPP. Obviously, the incubation condition in our last experiment (temperature $37^{\circ} \mathrm{C}$ instead of room temperature; time 10 instead of $3 \mathrm{~min}$; plasma mixing by stirring instead of shaking) enhanced the removal of indomethacin from vessel wall cyclo-oxygenase.

The time-course of indomethacin washout -as indicated by the restoration of $\mathrm{PGI}_{2}$-production of indomethacin-treated tissue- was measured as follows. Pieces of aortic tissue, pre-treated or not with indomethacin were incubated in $1 \mathrm{ml}$. human PRP at constant $\mathrm{pH}(7.4)$, temperature $\left(37^{\circ} \mathrm{C}\right)$ and stirring rate ( $1000 \mathrm{rev} \cdot \mathrm{min}^{-1}$ ). After incubation for $2,6,10$ and 14 minutes, $100 \mu 1$ samples were taken and centrifuged to remove the platelets. One minute after sampling, $50 \mu 1$ of the supernatant was added to an indifferent $P R P$ in order to measure its $P G I_{2}$-content as indicated by its inhibiting potency on the aggregation induced by a standard dose of ADP. During aggregation, the $\mathrm{pH}$ was kept between 7.4 and 7.6. As shown in Fig.3.18. A, the indomethacin-treated aorta starts producing measurable amounts of $\mathrm{PGI}_{2}$ after incubation for about $6 \mathrm{~min}$. If this prostacyclin is formed from platelet-derived endoperoxides, no $\mathrm{PGI}_{2}$-production is expected to occur when platelet-poor plasma is used as an incubation medium. However, incubation of tissue in PPP gave about similar results (Fig.3.18.B). In no case did the presence of platelets in the incubation medium promote vascular $\mathrm{PGI}_{2}$ formation. 
(A)

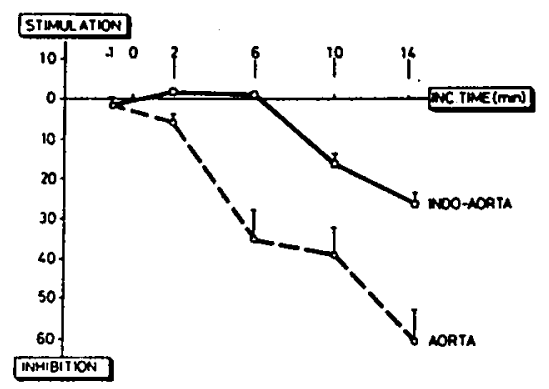

(B)

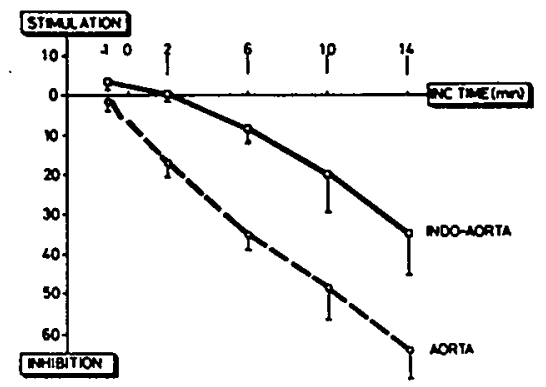

Fig.3.18. Effect of aortic incubates on ADP-induced aggregation $(\% \pm$ SEM, $n=6)$. For experimental details, see section 3.3.3.5. A : incubation with PRP. $B$ : incubation with PPP.

\subsubsection{Discussion and conclusion.}

We demonstrated that under a variety of conditions, blood platelets do not enhance vascular prostacyclin production. Some time ago, Needleman and co-workers reached a similar conclusion. They only noted an endoperoxide transfer from platelets to the vessel-wall when the thromboxane synthase in the platelets was blocked (63). So as a therapeutic concept, the 'stealing hypothesis' seems highly valid because inhibition of $\mathrm{TXA}_{2}$ synthesis would not only lower the aggregation of blood platelets but - via a stimulation of vascular $\mathrm{PGI}_{2}$-production it is also expected to enhance the antithrombotic properties of the vessel wa11. Recently, Marcus reported that endoperoxide transfer from platelets to cultured endothelial cells does occur, but only if the cells have been detached from their culture dishes and stirred together with the platelets in a $1: 130$ ratio. (123). The physiological relevance of this observation is, however, rather questionable. We conclude that, under physiological conditions, blood platelets do not provide the vessel wall with endoperoxides for prostacyclin formation. The direct implication of our findings is that activated blood platelets do not inhibit their own participation in white thrombus formation and that this homoiostatic concept must therefore be refuted. 


\section{4.- Sunmary}

Arterial thrombus formation results from two interrelated processes: the response of blood platelets towards their activation and blood clotting. Both processes are initiated by disruption of the endothelial barrier between blood and subendotheTium. Evidence is presented that thrombin, generated as a result of vessel-wall induced clotting, is of paramount importance for the platelet aggregation reaction following vascular injury. The rapidly increasing knowledge of biochemical processes following platelet activation and the discoveries of a platelet prothrombotic substance (Thromboxane $\mathrm{A}_{2}$ ) and a vascular antithrombotic compound (Prostacyclin) formed from the same precursor, prostaglandin $\mathrm{H}_{2}$, resulted in the concept that a balance between both substances may determine arterial thrombosis tendency and also be implicated in a homoiostatic system to limit thrombus formation. Starting from results of the experiments presented in this chapter and in Chapters 8 and 9, the general validity of these concepts must be questioned.

Table 3.1. Effect of hirudin on platelet aggregation and clotting of PRP, induced by indomethacin-treated vascular tissue (mean \pm SEM ; $n=5$ ). ATU : antithrombin units. f.c. : final concentration. $\triangle T$ : increase in light transmission due to aggregation of PRP.

$S$ : clotting index $=1,000 /$ clotting time (seconds).

\begin{tabular}{lll}
\hline $\begin{array}{l}\text { Hirudin dose } \\
\left(\times 10^{-2} \text { ATU. ml }^{-1} \text { f.c. }\right)\end{array}$ & $\begin{array}{l}\text { Aggregation } \\
(\Delta T, \%)\end{array}$ & $\begin{array}{l}\text { Coagulation } \\
(\mathrm{S})\end{array}$ \\
\hline 0 & $19.0 \pm 2.37$ & $6.28 \pm 0.284$ \\
3.125 & $1.6 \pm 1.03$ & $4.89 \pm 0.442$ \\
6.25 & $3.2 \pm 3.01$ & $4.53 \pm 0.603$ \\
12.5 & 0 & $3.31 \pm 0.480$ \\
25 & 0 & $1.43 \pm 0.333$ \\
50 & 0 & $1.06 \pm 0.254$ \\
\hline
\end{tabular}

\subsection{References}

1. Ross, R. and Harker,L.: Hyperlipidemia and atherosclerosis Science 193 : 1094-1100 (1976).

2. Harker,L.A., Slichter,S.J., Scott,C.R,: Homocysteinemia : vascular 
injury and arterial thrombosis. New Eng7.J.Med.291:537-543 (1974).

3. Mustard,J.F. and Murphy,E.N.: Effect of smoking on blood coagulation and platelet survical in man. Brit. Med.J. 1 : 846-849 (1963)

4. Elemer,G. and Gabbiani,G.: Modifications of aortic intima during hypertension. Role of angiotensin and mineralocorticoids. in Carison, L.A., Paoletti,R., Sirtori,C. and Weber,G.(Eds): International Conference on atherosclerosis. Raven Press, New York (1978). pp. 553-560.

5. Fry,D.L.: Acute vascular endothelial changes associated with increased blood velocity gradients. Circ.Res. 22: 165-197 (1968).

6. French,J.E.: The fine structure of experimental thrombi. in : Sherry,S., Brinkhous, K.M., Genton,E. and Stengle,J.M. (Eds): Thrombosis. National Acad.Sci. Washington pp. 300-320 (1969).

7. Mustard,J.F. and Packham,M.A.: Factors influencing platelet function: adhesion, release and aggregation. Pharmacol.Rev. 22: 97-187 (1970).

8. Weiss,H.J.: Platelet physiology and abnormalities of platelet function. N.Engi.J.Med. 293 : 531-541 and 580-588 (1975).

9. Nemerson,Y. and Pitlick,F.A.: The tissue factor pathway of b? nod coagulation in : Spaet,T.H. (Ed.): Progress in haemostasis and thrombosis 1 : 1-37, Grune and Stratton, New York and London (1972).

10. Niewiarowski,S., Bankowski,E. and Rogowicka,I.: Studies on the absorption and activation of the Hageman factor (factor XII) by collagen and elastin. Thromb.Diathes.haemorrh. 14: 387-400 (1965).

11. Wilner,G.D., Nossel,H.L. and Le Roy,E.C.: Activation of Hageman factor by collagen. J.Clin. Invest 47: 2608-2615 (1968).

12. Walsh,P.N.: The effects of collagen and kaolin on the intrinsic coagulant activity of platelets. Evidence for an alternative pathway in intrinsic coagulation not requiring Factor XII. Brit.J.Haematol 22 : 393-405 (1972).

13. Walsh,P.N.: The role of platelets in the contact phase of blood coagulation. Brit.J.Haemato1.22: 237-254 (1972).

14. Fantl,P. and Ward,H.A.: The thromboplastic component of intact blood is present in masked form. Austr.J.Exp.Biol.Med.Sci. 36: 499-504 (1958).

15. Sixma,J.J. and Nijessen,J.G.: Characteristics of platelet factor 3 release during ADP-induced aggregation. Comparison with 5-hydroxytryptamine release. Thromb. Diath.haemorrh.24:206-213 (1970).

16. Joist,J.H., Dolezel,G., Lloyd,J.V., Kinlough-Rathbone,R.L. and Mustard,J.F.: Platelet factor-3 availability and the platelet release reaction. J.Lab.Clin.Med. 84: 474-482 (1974).

17. Moncada,S. and Vane,J.R.: Unstable metabolites of arachidonic acid 
and their role in haemostasis and thrombosis. Brit.Med.Bu11.34: 129-135 (1978).

18. Gryglewski,R.J., Bunting,S., Moncada,S., Flower,R.J. and Vane,J.R.: Arterial walls are protected against deposition of platelet thrombi by a substance (PGX) which they make from prostaglandin endoperoxides. Prostaglandins 12: 685-713 (1976).

19. Hornstra,G., Haddeman,E. and Don,J.A.: Some investigations into the role of prostacyclin in thromboregulation. Thromb. Res. 12: 367-374 (1978).

20. Bunting,S. and Moncada,S.: Prostacyclin, by preventing platelet activation, prolongs activated clotting time in blood and platelet rich plasma and potentiates the anticoagulant effect of heparin - in press.

21. Hovig,T. and Holmsen, H.: Release of a platelet-aggregation substance (adenosine diphosphate) from rabbit blood platelets induced by saline "extracts" of tendon. Thromb. Diathes.haemorrh. 9: 264-278 (1963).

22. Hamberg,M., Svensson, J. and Samuelsson,B.: Thromboxanes, a new group of biologically active compounds, derived from prostaglandin endoperoxides. Proc.Nati.Acad.Sci.USA : 72 : 2994-2998 (1975).

23. O'Brien,J.R.: Effects of salicylates on human platelets. Lancet $i$ : 799-783 (1968).

24. Weiss,H.J., Aledort,L.M. and Kochwa,S.: The effects of salicylates on the hemostatic properties of platelets in man. J.Clin. Invest. 47 : 2169-2180 (1968).

25. Zucker,M.B. and Peterson,J.: Effect of acetylsalicylic acid, other nonsteroidal anti-inflammatory agents and dipyridamole on human blood platelets. J.Lab.Clin.Med. 76 : 66-75 (1970).

26. Fukami,H.M., Holmsen,H. and Bauer, J.: Thrombin-induced oxygen consumption, malondialdehyde formation and serotonin-secretion in human platelets. Biochim.Biophys. Acta 428 : 253-256 (1976).

27. Holmsen, H.: Platelet secretion. Current concepts and methodological aspects in : Platelet function testing. DHEW-Publication No (NIH) 78-1087, US Department of Health, Education and Welfare (1978) pp. 112-132.

28. Raymond,S.L. and Dodds,W.J.: Characterization of the Fawn-Hooded rat as a model for hemostatic studies. Thromb.Diath.heamorrh. 33 : 361-369 (1975).

29. Tschopp,T.B., and Zucker,M.B.: Hereditary defect in platelet function in rats. Blood $40: 217-226$ (1972). 
30. Ardlie,N.G., Perry,D.W., Packham,M.A. and Mustard,J.F.: Influence of apyrase on stability of suspensions of washed rabbit platelets. Proc.Soc.exptl.Biol.Med. 136 : 1021-1023 (1971).

31. Izrael, V., Zawilska,K., Jaisson,F., Levy-Toledano,S. and Caen,J.: Effect of vast removal of plasmatic ADP by the creatine phosphate and creatine phosphokinase system on human platelet function in vitro. In : Platelets : production, function, transfusion and storage. pp. 187-196 Grune and Stratton, New York (1974).

32. Packham,M.A., Guccione,M.A., Chang,P.L. and Mustard,J.F.: Platelet aggregation and release : effects of low concentrations of thrombin or collagen. Am.J.Physiol. $225: 38-47$ (1973).

33. Dahlbäck,B. and Stenflo,J.: Binding of bovine coagulation factor $x_{a}$ to platelets. Biochemistry $17: 4938-4945$ (1978).

34. Miletich,J.P., Jackson,C.M. and Majerus, P.W.: Interaction of coagilation factor $X_{a}$ with human platelets. Proc.Natl.Acad.Sci.USA 74 : 4033-4036 (1977).

35. Miletich,J.P., Jackson,C.M. and Majerus,P.W.: Properties of the factor $X_{a}$ binding site on human platelets. J.biol.Chem. 253 : 6908-6916 (1978).

36. Miletich,J.P., Majerus,D.W. and Majerus,P.W.: Patients with congenital factor $V$ deficiency have decreased factor $x_{a}$ binding sites on their platelets. J.Clin. Invest. 62 : 824-831 (1978).

37. Østerud,B., Rapaport,S.I. and Lavine, K.K.: Factor V activity of platelets : evidence for an activated factor $V$ molecule and for.a platelet activator. Blood 49 : 819-834 (1977).

38. Douglas,A.S.: Anticoagulant therapy in coronary artery disease. in : Sherry,S. et al. (Eds):Thrombosis. Nat.Acad.Sci., Washington D.C. pp. 690-704 (1969).

39. Wright,I.S.: Comment on anticoagulant therapy in coronary artery disease. ibid. pp. 705-707.

40. de Vries,W.A., Tyssen,J.P.G., Loeliger,E.A. en Roos, J.: Het effect van het staken van een langdurige antistollingsbehandeling wegens myocardinfarct bij ouderen; een dubbelblind onderzoek ( $A$ double blind investigation into the effect of anticoagulant withdrawal in postmyocardial infarction patients). Ned.Tijdschr.Geneesk. 123 : 1211-1212 (1979).

41. Kloeze,J.: Influence of prostaglandins on platelet adhesiveness and platelet aggregation. in : Bergström,S. and Samuelsson, B. (Eds.): Prostaglandins. Almqvist and Wiksel1, Stockholm 1967 pp. 241-252. 
42. Smith,J.B., Ingerman,C.M. and Silver,M.J.: Formation of prostaglandin $\mathrm{D}_{2}$ during endoperoxyde-induced platelet aggregation. Thromb.Res. 9 : 413-418 (1976).

43. Oelz,0., Oelz,R., Knapp,H.R., Sweetman,B.J. and Oates,J.A.: Biosynthesis of prostaglandin $D_{2}$. I. Formation of prostaglandin $D_{2}$ by human platelets. Prostaglandins 13 : 225-234 (1977).

44. Kloeze,J.: Prostaglandins and platelet aggregation in vivo. I. Influence of $\mathrm{PGE}_{1}$ and $\omega$-homo-PGE 1 on transient thrombocytopenia and of $\mathrm{PGE}_{1}$ on the $L_{50}$ of ADP. Thromb. Diathes.haemorrh. $23: 286-292$ (1970). II : Influence of $\mathrm{PGE}_{1}$ and $P \mathrm{PF}_{1 \alpha}$ on platelet thrombus formation induced by an electric stimulus in veins of the rat brain surface. Ibid pp. 293-298.

45. Shio,H. and Ramwel1,P.: Effect of prostaglandin $E_{2}$ and aspirin on the secondary aggregation of human platelets. Nature (New Biology) 236 : 45-46 (1972).

46. Emmons,P.R., Hampton,R.J., Harrison,M.J.G., Honour,A.J. and Mitche11, J.R.A.: Effect of prostaglandin $E_{1}$ on platelet behaviour in vitro and in vivo. Brit.Med.J. 2 : 468-472 (1967).

47. Smith,J.B. and Willis,A.L.: Formation and release of prostaglandins by platelets in response to thrombin. Br.J.Pharmacol. 40 : $545 \mathrm{P}-546 \mathrm{P}$ (1979).

48; Smith,J.B. and Willis,A.L.: Aspirin selectively inhibits prostaglandin production in human platelets. Nature (New Biology) 231 : 235-237 (1971).

49. Van Dorp,D.A., Beerthuis,R.K., Nugteren,D.H. and Vonkeman,H.: The biosynthesis of prostaglandins. Biochim.Biophys. Acta 90 : 204-207 (1964).

50. Bergström,S., Danielsson,H. and Samuelsson,B.: The enzymatic formation of prostaglandin $E_{2}$ from arachidonic acid. Biochim. Biophys. Acta 90 : 207-210 (1964).

51. Vogt,W. and Distelkötter,B.: Release of prostaglandin from frog intestine. in : Bergström,S. and Samuelsson,B. (Eds): Prostaglandins. Almqvist and Wiksell, Stockholm 1967 pp. 237-240.

52. Vonkeman, H. and Van Dorp,D.A.: The action of prostaglandin synthethase on 2-arachidonyl-lecithin. Biochim.Biophys. Acta $164: 430-432$ (1968).

53. Lands,W.E.M. and Samueisson,B.: Phospholipid precursors of prostaglandins. Biochim.Biophys. Acta 164 : 426-429 (1968).

54. Trugnan,G., Bérēziat,G., Manier,M.C. and Polonovski,J.: Phosphol ipase 
activities in subcellular fractions of human platelets. Biochim. Biophys. Acta 573 : 61-72 (1979).

55. Smith,J.B. and Silver,M.J.: Phospholipase $A_{1}$ of human bloodplatelets. Biochem.J. 131 : 615-618 (1973).

56. Béréziat,G.: Are phospholipases involved in platelet activation ? Agents and actions 9 : 390-399 (1979).

57. Nugteren,D.H., and Hazelhof,E.: Isolation and properties of intermediates in prostaglandin biosynthesis. Biochim.Biophys. Acta 326 : 448-461 (1973).

58. Hamberg,M. and Samuelsson,B.: Detection and isolation of an endoperoxide intermediate in prostaglandin biosynthesis. Proc.Natl.Acad.Sci.USA. 70 : 899-903 (1973).

59. Van der Ouderaa, F.J., Buytenhek,M., Nugteren,D.H. and van Dorp,D.A.: Purification and characterization of prostaglandin endoperoxide synthethase from sheep vesicular glands. Biochim.Biophys. Acta. 487 : 315-331 (1977).

60. Hamberg,M. and Samuelsson,B.: Prostaglandin endoperoxides. Nove1 transformation of arachidonic acid in human platelets. Proc. Nat1. Acad.Sci. USA 71 : 3400-3404 (1974).

61. Willis,A.L. and Kuhn,D.C. : A new potential mediator of arterial thrombosis whose biosynthesis is inhibited by aspirin. Prostaglandins, 4 : 127-130 (1973).

62. Diczfalusy,U., Falardeau,P. and Hammarström,S.: Conversion of prostaglandin endoperoxides to $C_{17}$-hydroxy acids catalyzed by human platelet thromboxane synthetase. FEBS Letts. 84 : 271-274 (1977).

63. Needleman,P., Wyche,A. and Raz,A.: Platelet and blood vessel arachidonate metabolism and interactions. J.Clin. Invest. 63 : 345-349 (1979).

64. Struyk,C.B., Beerthuis,R.K., Pabon,H.J.J. and van Dorp,D.A.: Specificity of the enzyme conversion of polyunsaturated fatty acids. Rec.Trav. Chim. Pays Bas. 85 : 1233-1250 (1966).

65. Needleman,P., Minkes,M. and Raz,A.: Thromboxanes : selective biosynthesis and distinct biological properties. Science 193 : 163-165 (1977).

66. Hammarström, S. and Falardeau,P.: Resolution of prostaglandin endoperoxide synthase and thromboxane synthase of human platelets. Proc. Nat1.Acad.Sci. USA 74 : 3691-3695 (1977).

67. Turner,S.R., Tainer,J.A. and Lynn,W.S.: Biogenesis of chemotactic molecules by the arachidonate lipoxygenase system of platelets. Nature 257 : 680-681 (1975).

68. Goetz1,E.J., Woods,J.M. and Gorman,R.R.: Stimulation of human eosinophi1 
and neutrophil polymorphonuclear leucocyte chemotaxis and random migration by 12-L-hydroxy-5,8,10,14-eicosatetraenoic acid. J.Clin. Invest. $59:$ 179-183 (1977).

69. Dutilh,C.E., Haddeman,E., Jouvenaz,G.H., ten Hoor,F. and Nugteren,D.H.: Study of the two pathways for arachidonate oxygenation in blood platelets. Lipids 14 : 241-246 (1979).

70. Kitchen,E.A., Boot,J.R. and Dawson,W.: Chemotactic activity of Thromboxane $B_{2}$, prostaglandins and their metabolites for polymorphonuclear leucocytes. Prostaglandins $16: 239-244$ (1978).

71. Bills,T.K., Smith,J.B. and Silver,M.J.: Metabolism of ${ }^{14}$ C-arachidonic acid by human platelets. Biochim. Biophys. Acta 424 : 303-314 (1976).

72. Bell,R.L., Kennerly,D.A., Stanford,N. and Majerus,P.W.: Diglyceride lipase : A pathway for arachidonate release from human platelets. Proc.Nat1.Acad.Sci. USA 76 : 3238-3241 (1979).

73. Lapetina,E.G. and Cuatrecasas,P.: Stimulation of phosphatidic acid production in platelets precedes the formation of arachidonate and parallels the release of serotonin. Biochim.Biophys. Acta 573 : 394-402 (1979).

74. Lapetina,E.G. personal communication.

75. Schoene,N.W. and Iacono,J.M.: The influence of phospholipase $A_{2}$ on prostaglandin production in platelets. Adv.Prost. Thromb.Res. 2 : 763-766 (1976).

76. Blackwe11,G.J., Duncombe,W.G., Flower,R.J., Parsons,M.F. and Vane,J.R.: The distribution and metabolism of arachidonic acid in rabbit platelets during aggregation and its modification by drugs. Brit.J.Pharmacol. 59 : 353-366 (1977).

77. Etienne,J., Grüber,A. et Polonovski,J.: L'activitê phospholipasidique des plaquettes de rat. Biochimie 61 : 433-435 (1979).

78. Le Breton,G.C., Dinerstein,R.J., Roth,L.J. and Feinberg,H.: Direct evidence for intracellular divalent cation redistribution associated with platelet shape change. Biochem.Biophys.Res.Comm. $71:$ 362-370 (1976).

79. Le Breton,G.C. and Dinerstein,R.J.: Effect of the calcium antagonist TMB-6 on intracellular calcium redistribution associated with platelet shape change. Thromb. Res. $10: 521-523$ (1977).

80. Mauco,G., Chap,H. and Douste Blazy,L.: Characterization and properties of a phosphatidylinositol phosphodiesterase (phospholipase C) from platelet cytosol. Febs Lett. 100: 367-370 (1979).

81. Gerrard,J.M. cited by Smith,J.B.: Lipid-membrane interaction of 
platelets and coagulation with the arterial wall. Adv. Expt1.Med. Biol. 104 : 343-348 (1977).

82. Mauco,G., Chap,H., Simon,M.F. and Douste-Blazy,L.: Phosphatidic and lysophosphatidic acid production in phospholipase $C$ and thrombin - treated platelets. Possible involvement of a platelet lipase. Biochimie 60 : 653-661 (1978).

83. Gerrard,J.M., Kindom,S.E., Peterson,D.A., Peller,J., Krantz,K.E. and White,J.G.: Lysophosphatidic acids. Influence on platelet aggregation and intracellular calcium flux. Am.J.Pathol. 96 : 423-438 (1979).

84. Mestel,F., Oetliker,0., Beck,E., Felix,R., Imback,P. and Wagner,H.P.: Severe bleeding associated with defective thromboxane synthetase. Lancet i : 157 (1980).

85. Hornstra, G. and Haddeman,E.: Prostaglandins, essential fatty acids, platelet function and thrombosis. Thromb.Res. 4, Suppl.1, 91-92 (1974).

86. Mills,D.C.B. and Smith,J.B.: The influence on platelet aggregation of drugs that affect the accumulation of adenosine $3^{\prime}: 5^{\prime}-$ cyclic monophosphate in platelets. Biochem.J. 121: 185-196 (1971).

87. Salzman,E.W. and Levin,L.: Cyclic $3^{\prime}, 5^{\prime}$-adenosine monophosphate in human blood platelets. J.Clin. Invest. 50 : 131-141 (1971).

88. Assaf,S.A. : Cyclic AMP-mediated phosphorylation reactions in the regulation of blood platelet aggregation. Int.J.Biochem. $7: 535-540$ (1976).

89. Lapetina,E.G., Schmitges,C.J., Chandrabose,K. and Cuatrecasas, P.: Cyclic adenosine $3^{\prime}, 5^{\prime}$-monophosphate and prostacyclin inhibit membrane phospholipase activity in platelets. Biochem.Biophys.Res.Comm. 74 : 828-835 (1977).

90. Minkes,M., Stanford,N., Chi, MM-Y., Roth,G., Raz, A., Needleman,P. and Majerus,P.: Cyclic adenosine $3^{\prime}, 5^{\prime}$-monophosphate inhibits the availability of arachidonate to prostaglandin synthetase in human platelet suspensions. J.Clin.Invest. 59 : 449-454 (1977).

91. Diczfalusy,U. and Hammarström,S.: A structural requirement for the conversion of prostaglandin endoperoxides to thromboxanes. Febs. Lett. 105 : 291-295 (1979).

92. Ally,A.I. and Horrobin,D.F.: Thromboxane $A_{2}$ in blood vessel walls and its physiological significance : relevance to thrombosis and hypertension. Prost. and Med. 4 : 431-438 (1980).

93. Moncada,S., Gryglewski,R.J., Bunting,S., and Vane,J.R.: An enzyme isolated from arteries transforms prostaglandin endoperoxides to an unstable substance that inhibits platelet aggregation. Nature 263 : 
663-665 (1976).

94. Bunting,S., Gryglewski,R.J., Moncada,S. and Vane,J.R.: Arterial walls generate from prostaglandin endoperoxides a substance (prostaglandin $X$ ) which relaxes strips of mesenteric and coeliac arteries and inhibits platelet aggregation. Prostaglandins 12 : 897-913 (1976).

95. Gorman,R.R., Bunting,S. and Miller,0.V.: Modulation of human platelet adenyl cyclase by prostacyclin. Prostaglandins 13 : 377-388 (1977).

96. Tateson,J.E., Moncada,S. and Vane,J.R.: Effects of prostacycl in (PGX) on cyclic AMP concentrations in human platelets. Prostaglandins 13 : 389-399 (1977).

97. Moncada,S., Gryglewski,R.J., Bunting,S. and Vane,J.R.: A lipid peroxide inhibits the enzyme in blood vessel microsomes that generates from prostaglandin endoperoxides the substance (prostaglandin $X$ ) which prevents platelet aggregation. Prostaglandins 12 : 715-737 (1976).

98. De Deckere,E.A.M., Nugteren,D.H. and ten Hoor,F.: Prostacyclin is the major prostaglandin released from the isolated perfused rabbit and rat heart. Nature $268: 160-163$ (1977).

99. Salmon,J.A., Smith,D.R., Flower,R.J., Moncada,S. and Vane,J.R.: Further studies on the enzymatic conversion of prostaglandin endoperoxides into prostacyclin by porcine aorta microsomes. Biochim. Biophys. Acta $523^{\circ}$ : 250-262 (1978).

100. Yoshimoto,T., Yamamoto,S., Okuma,M. and Hayaishi,0.: Solubilization and resolution of thromboxane synthesizing system from microsomes of bovine blood platelets. J.Biol.Chem. 252 : 5871-5874 (1977).

101. Heins, A du P., van den Berg,D.J., Potgieter,G.M. and Retief,F.P.: The inhibition of platelet aggregation by an aorta intima extract. Thromb. Diathes.haemorrh. 32 : 417-431 (1974).

102. Dusting,G.J., Moncada,S. and Vane,J.R.: Disappearance of prostacycl in in the circulation of the dog. Brit.J.Pharmacol. $62: 414-415 P(1977)$.

103. Dusting,G.J., Moncada,S. and Vane,J.R.: Recirculation of prostacyclin $\left(P G I_{2}\right)$ in the dog. Brit.J.Pharmacol. $64: 315-320$ (1978).

104. Lieberman,G.E., Lewis,G.P. and Peters,T.J.: A membrane-bound enzyme in rabbit aorta capable of inhibiting adenosine diphosphate-induced platelet aggregation. Lancet ii : 330-332 (1977).

105. Bunting,S., Moncada,S. and Vane,J.R.: Antithrombotic properties of vascular endothelium. Lancet ii : 1075-1076 (1977).

106. Horton,E.W.: Molecular insight into thrombosis. Nature $263: 637$ (1976).

107. Burch,J.W., Baenziger,N.L., Stanford,N. and Majerus,P.W.: Sensitivity of fatty acid cyclo-oxygenase from human aorta to acetylation by 
aspirin. Proc.Nat1.Acad.Sci. USA 75 : 5181-5184 (1978).

108. Gryglewski,R.J., Korbut,R. and 0cetkiewicz,A.C.: Generation of prostacyclin by lungs in vivo and its release into the arterial circulation. Nature 273 : 765-767 (1978).

109. Moncada,S., Korbut,R., Bunting,S. and Vane,J.R.: Prostacyclin is a circulating hormone. Nature 273 : 767-768 (1978).

110. Smith,J.B., Ingerman,C.M. and Silver,M.J.: Normal bleeding times in rabbits containing antibodies that bind prostacyclin $\left(\mathrm{PGI}_{2}\right)$. Thromb.Haemostas. $42: 7$ (1979).

111. Haslam,R.J. and McClenaghan,M.D.: An assay for activators of platelet adenylate cyclase present in rabbit blood: Evidence that prostacyclin $\left(P I_{2}\right)$ is not a circulating hormone. Thromb. Haemostas. $42: 117$ (1979).

112. E.Christ-Hazelhof and Nugteren, D.H.: Personal communication.

113. Cooper,B., Schafer,A. I., Puchalsky,D. and Handin,R. I. : Desensitization of prostaglandin-activated platelet adenylcyclase. Prostaglandins 17 : 561-571 (1979).

114. Miller,0.V. and Gorman,R.R.: Evidence for distinct prostaglandin $\mathrm{I}_{2}$ and $\mathrm{D}_{2}$ receptors in human platelets. J.Pharmacol.Exp.Ther. 210 : 134-140 (1979).

115. Weiss,H.J. and Turitto,V.T.: Prostacyclin (Prostaglandin I,, PGI,) inhibits platelet adhesion and thrombus formation on subendothelium. Blood 53 : 244-250 (1979).

116. Gorman,R.R., Fitzpatric,F.A. and Miller,0.V.: Reciprocal regulation of human platelet CAMP levels by Thromboxane $A_{2}$ and prostacyclin. Adv.Cycl.Nucl.Res. 9 : 597-609 (1978).

117. Moncada,S. and Vane,J.R.: Unstable metabolites of arachidonic acid and their role in haemostasis and thrombosis. Brit.Med.Bull. 34 : 129-135 (1978).

118. Hornstra,G. and Haddeman,E.: Diet-induced changes in arterial thrombosis not primarily mediated by arachidonate peroxidation. Biblthca haemat. $45: 9-13$ (1978).

119. Needleman,P., Kulkarni,P.S. and Raz,A.: Coronary tone modulation: Formation and actions of prostaglandin endoperoxides and thromboxanes. Science 195 : 409-412 (1977).

120. Bult,H. and Bonta,I.L.: Rat platelets aggregate in the absence of endogenous precursors of prostaglandin endoperoxides. Nature 264 : 449-451 (1976).

121. Myatt,L. and Elder,M.G.: Inhibition of platelet aggregation by a placental substance with prostacyclin-like activity. Nature 268 : 
159-160 (1977).

122. Weksler,B.B., Marcus,A.J. and Jaffe,E.A.: Synthes is of prostaglandin $I_{2}$ (prostącyclin) by cultured human and bovine endothelial cells. Proc.Nat.Acad.Sci. USA 74 : 3922-3926 (1977).

123. Marcus,A.J., Weksler,B., Jaffe,E., Safier,L., UlIman,H., Broekman,M., Dorso,C. and Brown,S.: Arachidonic acid metabolism in platelets and endothelial cells. Progr.Lipid Res. (in press).

124. Kinlough-Rathbone,R.L., Reimers,H.J., Mustard,J.F. and Packham,M.A.: Sodium arachidonate can induce platelet shape change and aggregation which are independent of the release reaction. Science $192: 1011$ $-1012(1976)$.

125. Ingerman,C.M., Smith,J.B., Shapiro,S., Sedar,A. and Silver,M.J.: Hereditary abnormality of platelet aggregation attributable to nucleotide storage pool deficiency. Blood 52 : 332-344 (1978).

126. Meyers,K.M., Seachord,C.L., Holmsen,H., Smith,J.B. and Prieur,D.J.: A dominantrole of thromboxane formation in secondary aggregation of platelets. Nature $282: 331-333$ (1979).

127. Nord $\varnothing y, A .$, Svensson,B., Wiebe,D. and Hoak,J.C.: Lipoproteins and the inhibitory effect of human endothelial cells on platelet function. Circ.Res. 43 : 527-534 (1978).

128. Tomasi,V., Meringolo,C., Bartolini,G. and Orlando,M.: Biosynthesis of prostacyclin in rat liver endothelial cells and its control by prostaglandin $E_{2}$. Nature 273 : 670-671 (1976).

129. Hope,W., Martin,T.J., Chesterman,C.N. and Morgan,F.J.: Human $\beta$-thromboglobul in inhibits $\mathrm{PGI}_{2}$ production and binds to specific site in bovine aortic endothelial cells. Nature $282: 210-212$ (1979).

130. Nord $\varnothing y, A$. and Svensson, B.: The simultaneous effect of albumin bound fatty acids on platelets and endothelial cells. Thromb.Res. 15 : 215-226 (1979).

131. McIntyre,D.E., Pearson,J.D. and Gordon,J.L.: Localization and stimulation of prostacyclin production in vascular cells. Nature 271 : 549-551 (1978).

132. Moretti,R.L. and Abraham,S.: Stimulation of microsomal prostaglandin synthesis by a blood plasma constituent which augments antoregulation and maintenance of vascular tone in isolated rabbit hearts. Circ. Res. 42 : 317-323 (1978).

133. Remuzzi,G., Livio,M., Cavenaghi,A.E., Marchesi,D., Mecca,G., Donati, M.B. and Gaetano,G. de : Unbalanced prostaglandin synthesis and plasma factors in uraemic bleeding. A hypothesis. Thromb. Res. 13 : 
531-536 (1978).

134. Saeed,S.A., McDonald-Gibson,W.J., Cuthbert,J., Copas, J.L., Schneider, C., Gardiner,P.J., Butt,N.M. and Collier,H.O.J.: Endogeneous inhibitor of prostaglandin synthetase. Nature $270: 32-36$ (1977).

135. Robison,G.A., Arnold,A. and Sartman,R.C.: Divergent effects of epinephrine and prostaglandin $E_{1}$ on the level of cyclic AMP in human blood platelets. Pharmacol.Res.Comn.1: 325-332 (1969).

136. Krebs,H.A. und Henseleit,K.: Untersuchungen über die Harnstoffbilduńg in Tierkörper. Hoppe-Seiler's Z.Phys.Chem. 210: 33-66 (1932).

137. Dixon,W.J. and Massey,F.J.: Introduction to statistical analysis. McGraw Hi11, London (1957). 
4. EFFECT OF DIETARY FATS ON ARTERIAL THROMBOSIS AND PLATELET

\section{FUNCTION - A LITERATURE REVIEW}

\subsection{Introduction}

As discussed in Chapter 1, arterial thrombosis is the main letha? complication of atherosclerosis. Moreover, there is increasing morphological and experimental evidence that arterial thrombosis plays also a role in the atherogenetic process. $(42,46,47,74)$. Epidemioiogical studies clearly indicate that the type of dietary fat has a certain influence on coronary artery disease (CAD), being one of the manifestations of atherosclerosis $(18,23,27,63)$. It is now generally accepted that the type and amount of dietary fat can affect the genesis and course of experimental atherosclerosis in animals. $(17,48,70)$. Human prospective studies have also shown that the diets low in long-chain saturated fatty acids and enriched in linoleic acid, are beneficial for CAD-prevention $(36,41,67,82)$. Atherosclerosis is a multifactorial disease (14). Therefore, the dietary fats might - at least in part - be effective through their influence on arterial thrombosis and thrombotic platelet functions.

When we started our investigations, the effect of dietary fatty acid compositions on arterial thrombus formation had not yet been investigated systematically. One of the reasons might have been the lack of a suitable in vivo model of arterial thrombogenesis. The body of information available at that time was mainly based on acute experiments - although 'diet' is a chronic factor - with models, the relevance of which to arterial thrombus formation is questionable. A screening of the available literature in this field was, nevertheless, thought appropriate, because earlier knowledge had to serve as a frame of reference for our own research. A more recent review has been published by Renaud (103).

Three of the processes implicated in arterial thrombus formation - adhesion, release and aggregation - are strictiy platelet-bound; in the fourth process - coagulation - the platelets play a contributory role. Consequently, for a study of the possible mechanisms by which 
dietary fats affect arterial thrombogenesis, investigations into platelet function are indispensable. Therefore, before starting our experimental work, we screened the literature also on this point.

The majority of the experiments to be discussed below were published before 1972. Later studies relevant to our field of interest and the work of Renaud at al. $(52,53,92,104)$ will be dealt with while discussing our owr findings.

\subsection{Effect of dietary fats on arterial thrombus formation in vivo}

Results of studies concerning the effects of dietary fats on arterial thrombus formation in vivo depend to a certain extent on the techniques used. These techniques, which have been reviewed before $(28,51)$, can be roughiy subdivided into acute and (semi-) chronic ones. The acute techniques are particularly useful in the search for drugs or treatments interfering with thrombotic platelet functions, whereas the chronic and semi-chronic ones are most suitable for experiments in relation to complete thrombus formation.

\subsubsection{Effects_observed_on using açute technigues}

One group of acute techniques comprises the production of intravascular platelet thrombi by injecting thrombogenic substances.

Nord $\varnothing y$ and Chandler (96), inducing intravascular aggregation in rats by injection of ADP into the vena cava inferior, found thrombosis in histological sections of lung tissue excised shortly after the injection. Light- and electron microscopy of these thrombi revealed them to consist of aggregated platelets with intact membranes and internal structure. Fibrin was not observed (93). Feeding rats diets containing $10 \%$ saturated fat (hydrogenated coconut 0.11 ) and $1 \%$ cholesterol, considerably increased thrombosis incidence as compared with feeding a low (unsaturated) fat diet (97). Daily oral administration of $50 \mathrm{mg}$ linseed oil to the animals on the saturated fat diet did not modify the high incidence of thrombosis. In later experiments (100) with lower ADP doses, the thrombogenicity was compared for diets containing $10 \%$ hydrogenated coconut fat $(10 \mathrm{CF}), 40 \%$ hydrogenated coconut fat ( $40 \mathrm{CF}$ ) 
and $32 \%$ hydrogenated coconut fat $+8 \%$ cottonseed oil ( $8 \mathrm{CO})$ or $8 \%$ linseed oil ( $8 \mathrm{LO})$. After feeding for one day, thrombosis incidence in all groups was nat significantly different. After 5-6 weeks, however, it was significantly higher in the $40 \mathrm{CF}$ group than in the other groups; the latter did not differ significantly from each other. Electron microscopical investigation showed that in the 10 and $40 \mathrm{CF}$ groups, thrombi contained zones of platelet membrane fusion, which was not observed in the 8 CO and 8 LO groups (94).

By direct observation of the microcirculation in the hamster cheek pouch, Cullen and Swank (25) observed slowing of the blood flow and even complete stasis after intravenous infusion of gelatin and high-molecular-weight dextran. The same changes were observed on inducing al imentary lipemia by feeding cream via a stomach tube; this treatment was also shown to increase blood viscosity in the hamster (91). This thrombogenic state (58) was caused by aggregation of red blood cells (rouleaux formation) and by the occurrence of platelet aggregates.

Wexier (57) observed local thrombotic reactions on ligation of a carotid artery in arieriosclerotic rats. Hyperlipemia, induced by supplementing the stock diet with $15 \%$ coconut oil and $2 \%$ cholesterol, did not modify the thrombotic response to this injury.

\subsubsection{Effects observed when using semi_chronic technigues}

Most semichronic thrombosis models utilize the intra-arterial insertion of foreign material. Techniques based on the application of arteriovenous shunts and arterial protheses also belong to this group. Pearl and Friedman (107) observed that feeding dogs an unspecified hypercholesterolemic diet resulted in engraved thrombotic complications on intra-arterial insertion of a metal wire. Evans and Irvine (32) showed that increased platelet adhesiveness is associated with a reduction of the long-term patency of Dacron ${ }^{\circledR}$ femoropopliteal bypass grafts in men. They found that linseed and maize oil, $2 \times 5 \mathrm{ml}$ daily for 1 month, failed ta reduce platelet adhesiveness in vitro (modified glass bead column technique (50)). Because of the increasing number of shunt-bearing patients, a clinical trial on the use of antithrombotic dietary fats to 
increase graft patency should be considered.

Downie et al. (29) connected a bifurcated flow chamber to arteriovenous shunts and quantified thrombotic deposits by weighing. Murphy et al:(86), using this technique in pigs, showed that the pattern and distribution of these deposits were strikingly similar to those in early atheroscierosis at comparable sites in the vascular tree. Later, it was demonstrated (59) that the structure of the deposits resembled intravascular platelet thrombi. Using the Downie technique, Mustard et al. (89) showed that enrichement of a normal stock diet with lard (final fat content 11.5\%), lard + cholesterol $(0.5 \%$ ) or uncooked egg yolk (final dietary fat and cholesterol content 7.3 and $0.5 \%$, respectively), significantiy increased thrombotic deposits in pigs. There were no significantly different effects between the three dietary groups, although the deposits in the egg yolk group were 3 times as heavy as in the lard groups in spite of the fat content being lower. Unfortunately, this study was not continued, so it is not known whether the higher thrombogenicity of egg yolk as compared with lard is real and, if so, whether this is due to differences in fatty acid composition or to another factor.

Mathues et ar.(78) used the same technique in rabbits fed a stock diet as such or supplemented with $6 \%$ coconut oil and $2 \%$ cholesterol. The enrichement significantly increased the amount of thrombotic deposits, which could be prevented by intravenous infusion of phosphatidyl serine, 30 min prior to the experiment. This antithrombotic effect of phosphatidyl serine was also observed by Mustard et al. (90) and is thought to be due to its anticoagulatory effect (87) in combination with its inhibiting action on the platelet release reaction (95). However, when added to platelet-rich plasma $(1 \mathrm{mg} / \mathrm{ml})$, phosphatidyl serine induces mild, reversible aggregation (66).

\subsubsection{Effects obtained_on using chronic_thrombosis models}

From a physiological point of view, diet-induced thrombosis seems to be the better chronic thrombosis model. The diet normally used and originally applied by Thomas and Hartroft ( 80 ) contains $40 \%$ butter, $5 \%$ cholesterol, $2 \%$ cholic acid and $0.3 \%$ thiouracil. When fed to rats for 3-4 months, it produces thrombosis in about $50 \%$ of the animals, whereas 
myocardial infarction is observed in about $25 \%$. As reviewed by Howard and Gresham (60), this type of diet produces hypercoagulability (81), hyperlipidemia and hyperlipoproteinemia (61), it does not affect platelet stickiness, but increases the platelet count. The type of fat determines the thrombogenicity of the diet : butter, lard, hydrogenated coconut oil, cocoa butter, hydrogenated groundnut $0 i 1$ and maize oil being thrombogenic, groundnut oil being nonthrombogenic. Extrapolation of these findings to a normal dietary situation is hardly possible because of the diet being highly atypical and causing widely different pathological effects.

A simpler dietary thrombosis model was devised by Ball et al. (3) who used a diet high in fat $(23 \%$ lard), low in protein ( $8 \%$ casein) and well-balanced as to vitamins and minerals. Ad libitum feeding of a selected strain of mice (4) for about 7 weeks resulted in a high incidence of organized atrial piatelet-fibrin thrombi, which became lethal in $75 \%$ of the animals after 13 weeks. Thrombosis was preceded by atrial subendothelial edema, endothelial vacuolization, thickening of basement membrane and villous projections from vascular endothelial cells (75). Endothelial edema completely regressed on refeeding a normal diet. Under this regimen, thrombosis did not occur although the other lesions persisted (22).

Another feature attributed to the aforementioned diet is a severe, chronic anemia (5), which is readily reversible on refeeding a norma? diet (6). Ashburn et al.(2) showed that prevention of anemia by intraperitoneal injections of red cells also prevented the development of atrial thrombi. It is very likely that combined local and general hypoxia (due to endothelial edema and anemia respectively) are the thrombogenic factors on feeding this type of diet. As low-protein diets are generally associated with anemia (1), protein deficiency seems a prerequisite for the thrombogenic effect. The dietary fat level $(6,28$ and $40 \%$ ) did not clearly affect thrombosis frequency during a 12-week feeding period. Only when the experimental time was extended to 56 weeks, was thrombosis incidence highest in the 40-per cent fat group, whereas no appreciable difference was observed between the low- and medium-fat diets (21). Using this thrombosis model, Wicks et al.(56) tested nine different dietary oils and fats for their thrombogenic effect (hydrogenated coconut $0 i 1$, cod-liver $0 i 1$, Wesson $0 i 1$, linseed 
0i1, olive oil, lard, maize oil, butter and cocoa butter). Although these fats had different effects on the frequency of atrial thrombosis and ventricular myocardial necrosis and calcification, little correlation existed between the fatty acid composition of the fats and their activity in producing these lesions. Maguire and Doran (77) showed that on feeding a diet high (25\%) in lard and marginal (18\%) in proteins, mural endocardial (atria and ventricles) thrombi develop in mice as well as in rats. In rats, this diet caused hypercholesterolemia and initially a sharp rise in triglycerides, followed by a marked decrease and the establishment of a new level at only $40 \%$ of the starting value.

Frost (37), inducing hypercholesterolemia in rabbits by feeding a diet containing $2 \%$ cholesterol for 2-3 weeks, observed numerous platelets adhering to the wall of the abdominal aorta and of the carotid arteries, using the scanning electron microscope. He also saw enhanced endothelial separation and adhesion of drop-like bodies, probably fat droplets. In control animals, these lesions were not found. It is evident from this study that increased thrombogenes is will decrease the average circulation time of platelets. Mustard and Murphy (88) used this concept as early as 1962 for their studies of the effect of dietary fats on the half-life and turnover of circulating platelets in volunteers receiving either a low-fat (21 en\% mainly vegetable fat) or a high-fat diet (37-39 en\% containing mainly maize oil or animal fats (egg yolk and dairy fats) for 3 weeks. Platelet half-life was shortest and platelet turnover greatest on feeding the high-animal fat diet. The high vegetable fat diet gave a shorter platelet half-life than the low vegetable fat diet. Platelet turnover was least on the low fat diet, but the difference with the high-vegetable fat diet was not significant.

\subsubsection{Conclusion}

In conclusion it can be stated that the rather scarce information as to the effects of dietary fats on experimental arterial thrombosis indicates that saturated fats enhance thrombus formation whereas unsaturated fats do not or are even antithrombotic. Similar indications have been obtained in some human in vivo studies $(44,82)$. 


\subsection{Effect of dietary fats on in vitro thrombotic platelet functions}

Most in vitro work has been done in venous blood and should in fact not be included in this review on arterial thrombosis. However, several studies have been carried out in relation to arterial thrombus formation and atherosclerosis. We therefore did include them, but it is questionable whether 'venous' platelets are suitable for such a study, because there is evidence that their adenosine diphosphate (ADP) sensitivity is higher than that of 'arterial' platelets $(15,45)$.

\subsubsection{Effect_of_a_single_fat_dose}

Moolten et al.(83) observed that alimentary lipemia was associated with increased platelet stickiness as measured by the glass wool braid technique (84). They offered normal, atherosclerotic and diabetic volunteers a low-fat diet or a diet containing $36 \mathrm{~g}$ animal fat (cream and eggs) or maize $0 i 1$. In all instances platelet-to-glass adhesion measured 2-5 $h$ after the meal, was increased as compared with the fasting state. The effect of the animal fat diet was greatest, while the effects of the low-fat and maize oil diets hardly differed. The effects were qualitativeiy similar in all three groups of volunteers; only minor quantitative differences were observed.

Böhle et al.(9) performed the same kind of experiments in normal men and in patients with increased platelet aggregation (mainly atherosclerotics), who were given $50 \mathrm{~g}$ butterfat, olive $0 i 1$, maize oil or 1 inseed oil after overnight fasting. Platelet aggregation was determined by the PAT test of Breddin and Bauke (16) in which aggregates formed during rotation of the upper layer of sedimented citrated blood are quantified. In normal volunteers, fat-loading did not modify platelet aggregation, although it resulted in distinct hyperlipemia. In patients with increased platelet aggregation, fat-loading produced a somewhat higher degree of lipemia than in the normal volunteers. Butter and olive oil (both low in polyunsaturated fatty acids) caused a slight decrease in platelet aggregability, whereas maize oil and linseed $0 i 1$, which are rick in polyunsaturated fatty acids, normalized the high aggregation values completely for a period of at least $8 \mathrm{~h}$. Horlick (55) fed normal and 
atherosclerotic volunteers a high-fat breakfast containing $75 \mathrm{~g}$ of mixed animal fats (butter, eggs, cream and bacon). He measured the platelet stickiness by the glass wool braid technique of Moolten and Vroman (modified) in the fasting state and after 2,4 and $6 \mathrm{~h}$ after the meal. In the normal group, no change in platelet stickiness was observed, whereas there was a significant increase in the atherosclerotic group 2 and $4 \mathrm{~h}$ after the meal.

Using the Chandler loop (20), Dubber et al.(30) and Ferguson et al. $(33,34)$ showed that $3 \mathrm{~h}$ after a single dose of $270 \mathrm{~g}$ double cream $(95 \mathrm{~g}$ fat) was given to norma? Europeans, the formation of platelet thrombi in citrated platelet-rich plasma was retarded as compared with a fat-free breakfast. In African and Asian populations, however, the same fat load did not change the formation of artificial thrombi. It should be noted that thrombogenesis in the chandler loop is due to thrombin formation (31); so the results obtained with this technique are more related to coagulation than to thrombotic platelet function. Philp and Payling Wright (76) also studied the effect of alimentary lipemia on platelet function. They induced lipemia by a fatty meal consisting of bacon, fried bread, butter, eggs and double cream. Platelet stickiness in blood collected after overnight fasting and 2-2.5 $\mathrm{h}$ after the meal, was measured by the rotating bulb technique (54). In this study, lipemia was associated with a significantly increased platelet stickiness as compared with that in the fasting state. Adenosine, a well-known inhibitor of platelet aggregation (13), reduced platelet retention in fasting blood strikingly. This inhibiting effect was also present in lipemic blood, but was considerably diminished.

Gromnatskii (40), using the same technique for measuring platelet aggregation, induced lipemia in 20 normal volunteers by giving them 350-400 $\mathrm{mi}$ sour cream, which significantly increased the platelet stickiness. Besterman et al. (8) reported an increased platelet stickiness (Wright rotator) after a fatty breakfast $(50 \mathrm{~g})$ in normal as well as ischemic subjects.

Kloeze (69) induced postprandial hyperlipemia by giving fasting rats coconut 0 il, soyabean 0il, maize oil, linseed 0il, whale oil or butterfat by stomach tube in a single dose of $6 \mathrm{mg} / \mathrm{cm}^{2}$ body surface/day for 4 days. 
Three $h$ after the last load, blood was drawn by venepuncture for measuring lipemia and platelet adhesiveness in citrated blood (glass bead column technique of Hellem (49)). Although striking differences were observed in the degree of lipemia, the adhesiveness values did not differ significantiy.

Lipemia can also be produced by intravenous administration of fat emulsions, a technique which is used clinically to an increasing extent. Lipofundin ${ }^{\circledR}$, an emulsion of cottonseed oil, when administered to rabbits ( $290 i l / \mathrm{kg}$ body weight), decreased the circulating platelet count significantly, but produced an inconsistent effect on platelet retention in the rotating bulb (72). When added to blood in vitro, it invariably produced a significant increase in platelet aggregation ( 35 ). Later investigations of Pfleiderer et al. (24), which included emulsions of a great number of fatty acids and vegetable and mineral oils, revealed that all emulsions added to citrated platelet-rich plasma or citrated blood, increased platelet stickiness. Extensive electron microscopical and biochemical studies showed that this aspecific effect of lipid emulsions is the result of a two-step process : adhesion of the fat particles to and their phagocytosis by the platelets (85). The latter phase is associated with a considerable loss of platelet ATP (62), which might be responsible for the increase in platelet stickiness. Surface-active agents (phospholipids, albumin) are inhibitory to these processes.

Deiniger (26), connecting an isolated cat heart to the arterial circulation of a donor anima1, showed that infusion of Lipofundin ${ }^{\circledR}$ into the coronary arteries decreased the heart function due to the formation of occlusive platelet thrombi. This formation could be prevented by pre-incubation of the emulsion with post-heparin plasma (19). Decreased heart function was also observed in dogs after acute lipemia induced by infusion of a 10-percent sesame oil emulsion or of lipemic plasma (73).

Kapp et az. (64) using the glass bead test (49), observed a progressive decrease in platelet adhesiveness on Intralipid ${ }^{\circledR}$ (a 20-per cent emulsion of soyabean $0 i 1)$ infusion $(500 \mathrm{ml})$ to normal fasting volunteers. In: addition of the emulsion to citrated blood (10 and $20 \mathrm{~g} / 1 \mathrm{blood}$ ) induced a dose-dependent increase in platelet adhesiveness. They speculated that the discrepancy in results between in vivo and in vitro administration may be due to the release in vivo of a platelet-stickiness-reducing agent. 


\subsubsection{Effect_of prolonged_fat_feeding}

Kloeze (69), feeding $50 \mathrm{en} \%(-27$ weight $\%$ ) coconut oil, soyabean oil, maize oil, linseed oil, whale oil or butterfat to rats for 1,2 or 5 weeks, observed no differences in the platelet adhesiveness in whole citrated blood (glass bead test) between the six groups after overnight fasting. Nord $\phi y$ (99), using the modified glass bead test (50), measured ADP-induced platelet adhesiveness in citrated platelet-rich plasma of rats fed a normal stock diet (control group) or a saturated fat diet containing 10\% hydrogenated coconut $0 i 1$ and $1 \%$ cholesterol for 4 months. During the last month, animals on the saturated fat diet were daily administered $80 \mathrm{mg}$ maize oil, linseed oil or water. Platelet adhesiveness was higher in the saturated fat and water groups than in the control group. Maize oil supplementation increased platelet adhesiveness further, whereas linseed oil administration decreased it to nearly the control level. Roughly, the effect of these dietary fats on the formation of experimental venous thrombi (98) was analogous.

Kloeze et al. (71) performed similar experiments in rabbits which were offered diets containing $14 \%$ hydrogenated coconut $011,10 \%$ hydrogenated coconut oil $+4 \%$ safflower or linseed oil. After 18 and 62 weeks' feeding, platelet adhesiveness determined by the modified glass bead test (50) was not significantly different. In an earlier investigation (65), rabbits were fed a 1:1 mixture of maize and coconut oil (15\% fat in the diet), while another group was fed these dietary fats separately during a) ternate periods of 10 weeks. After 2 years' feeding, the atheroma index in the alternately fed group was twice as high as that in the group fed the fat mixture. However, no difference in platelet adhesiveness was observed.

Mathues et al.(78) fed rabbits either a stock diet as such or supplemented with $6 \%$ coconut 013 and $2 \%$ cholesterol for 3-7 weeks. Platelet adhesiveness determined in native platelet-rich plasma (glass bead test) was significantly higher in the supplemented group than in the control group. No difference was observed in artificial thrombus formation in the Chandler loop. Phosphatidyl serine, infused 30 min prior to blood collection, normalized the high adhesion values in the fat/cholesterol group completely. 
McDonald and Edgill (79) showed that the enhanced platelet stickiness (citrated platelet-rich plasma in the rotating bulb) in patients with ischemic heart disease could be decreased by lowering the dietary fat intake. Mustard and Murphy (88) did not find significant effects on the platelet adhesive index (glass wool braid) of diets containing either $21 \mathrm{en} \%$ mixed vegetable fats, 37 en\% vegetable fats (mainly maize oil) or 39 en\% mixed animal fats, fed for 4 weeks to normal volunteers. Owren et al. (105) showed that maize oil, cod-liver oil and safflower oil in doses of $100 \mathrm{ml} /$ day were rather ineffective in changing the increased platelet adhesiveness in atherosclerotic patients (modified glass bead test (50))while soyabean oil normalized it within 3 days. Linseed oil was reported to be extremely beneficial in this respect, but this was revoked later (106). In a clinical trial on patients with coronary heart disease, Borchgrevink et al.(10), using the same technique, did not see any effect of daily doses of 10-30 $\mathrm{ml}$ linseed or maize oil on platelet adhesiveness, nor did the mortality and the reinfarction rate differ between the two groups (11). Bentzen et al. (7) measured the platelet adhesiveness with the glass bead column technique in a group of elderly patients (average age 75) before and after 1-5 weeks' treatment with one daily dose of $20 \mathrm{ml}$ oil containing either $55 \%$ rinolenic acid or $52 \%$ linoleic acid, the rest being about similar. In the linolenic acid group, they observed a very significant decrease in platelet retention after 1 week, but a significant increase after 3 weeks' treatment. Aftel 4 weeks, platelet retention was still elevated but after 5 weeks no difference existed as compared with the pre-experimental value. This 'rebound'-phenomenon is not explained. In the linoleic acid group, no significant change was seen after 1 week, but after 3 weeks platelet retention had dropped significantly. After 4 weeks, this drop was even more pronounced, but after 5 weeks all differences had disappeared.

Geill and Dybkaer (38) treated female patients for 2 periods of 8 weeks with $15 \mathrm{ml}$ of a fatty acid mixture containing $56 \%$ linolenic acid, $20:$ : oleic acid, $14 \% 1$ inoleic acid and $10 \%$ saturated fatty acid. Platelet adhesion (glass bead columns) was not affected significantly but tended to increase. Nord $\varnothing y$ and Rødset (101), giving 20 healthy volunteers diets containing $40 \%$ soyabean $0 i 1$ or MCT-oil, did not observe significant differences in ADP-, collagen- and thrombin-induced platelet aggregation (turbidimetric technique $(12,102)$ as compared with the pre-experimental 
values, nor were dietary effects in platelet electrophoretic mobility found. The technique they used for this latter determination (39) fails, however, to discriminate between 'normal' and 'atherosclerotic' platelets, in contrast to the technique used by Hampton and Mitchell (43). This is probably due to differences in the potential gradients applied (68) and therefore an effect of the dietary fats on this parameter cannot be excluded. Platelet factor 3 (PF-3) activity decreased significantly in the soyabean oil group, while in the MCT group it increased slightly. The same tendency in PF-3 activity was found after exposure of platelets to kaolin, ADP, and freezing and thawing.

\subsubsection{Conclusion}

In sum, it can be stated that in the literature, there is no unanimity as to the effect of dietary fats on in vitro platelet stickiness, no matter whether the fats are administered as a single oral load by intravenous infusion or by continuous feeding. The conflicting results cannot be ascribed to differences in fatty acid composition but may be due the different techniques used. This is all the more likely as in vitro platelet studies are disturbed by technical artifacts. Moreover, the interpretation of in vitro findings is very difficult. For instance, a low platelet aggregation in vitro does not necessarily imply that all the platelets have a low thrombosis tendency. On the contrary, it is very well possible that due to thrombogenesis in vivo, the most active platelets are involved in aggregate and thrombus formation and that only the less active ones remain as single platelets in the circulation. Therefore, any in vitro technique should first be checked on its indicative value in relation to thrombosis tendency.

\subsection{References.}

1. Aschkenasy,A.: On the pathogenesis of anaemias and leucopenias induced by protein deficiency.Amer.J.clin.Nutr. 5: 14-25(1957).

2. Ashburn,A.D.; Weaver,M.M. and Summers,P.A.: Effects of red blood cell injections on diet-induced atrial thrombosis in Swiss mice. Amer.J.Anat.133: 341-348 (1972). 
3. Ball,C.R.; Williams,W.L. and Collum,J.M.: Cardiovascular lesions in Swiss mice fed a high fat-low protein diet with and without betaine supplementation. Anat.Rec. 145:49-59 (1963).

4. Ball,C.R.; Clower,B.R.; Williams,W.L., and Jackson,M.: Dietary-induced atrial thrombosis in mice. Arch.Path.80:391-396 (1965).

5. Ball,C.R.: Hematologic studies of mice fed a thrombogenic diet. Arch.Path. 85:547-553 (1968).

6. Ball,C.R.; Westin,D.C., and Jackson,M.: Anemia induced by thrombogenic diet and remission after normal diet. Arch.Path.90:117-124 (1970).

7. Bentzen,A.J.; Jacobsen,P.A., and Munck-Petersen,S.: An investigation of the platelet adhesiveness by Hellem's method in elderly patients under longterm psychiatric care, on a controlled diet with an unsaturated fatty acid load. Geront.clin., Basel 14:217-234 (1972).

8. Besterman,E.; Myat,G., and Travadi,V.: Diurnal variations of platelet stickiness compared with effects produced by adrenalin. Brit.med. J. 1:597-600 (1967).

9. Böhle,E.; Bauke,J.; Harmuth,E. und Breddin,K.: Untersuchungen über die Agglutination der Blutplättchen nach Zufuhr verschiedener Nahrungsfette. KTin. Wschr. 43:555-562 (1965).

10. Borchgrevink,C.F.; Berg,K.J.; Skaga,E.; Skjaeggestad, H.: Effect of linseed $0 i 1$ on platelet adhesiveness and bleeding timc in patients with coronary heart disease. Lancet $i \mathrm{i}: 980-982$ (1965).

11. Borchgrevink,C.F.; Berg,K.J.;Skaga,E., and Skjaeggestad, 0 .: Absence of prophylatic effect of linolenic acid in patients with coronary heart disease. Lancet ij:187-189 (1966).

12. Born,G.V.R.: Aggregation of blood platelets by adenosine disphosphate and its reversal. Nature, Lond.194:927-929 (1962).

13. Born,G.V.R. and Cross,M.J.: The aggregation of blood platelets. J.Physiol., Lond. 168:178-195 (1963).

14. Born,G.V.R. and others: Thrombogenic mechanisms in atherosclerosis. in : S.Wolfe (Ed): The artery and the process of atherosclerosis : pathogenesis. Adv.Exp.Med.Biol. 16A:175-184. Plenum Press New York, London (1971).

15. Bottecchia,D. and Doni,M.G.: Artero-venous differences in blood platelet clumping by ADP. Experientia 29:211-212 (1973).

16. Breddin,K. und Bauke,J.: Thrombocytenagglutination und Gefässkrankheiten. Blut 11:144-165 (1965).

17. Malmros,H.: Dietary prevention of atherosclerosis. Lancet $i \mathrm{i}: 479-484$ (1969). 
18. Heyden,S.: Epidemiological data on dietary fat intake and atherosclerosis with an appendix on possible side-effects. In : Vergroesen,A.J. (Ed.): The role of fats in human nutrition. Academic Press London, New York, San Francisco.(1975) pp. 43-113.

19. Bschor,F. und Deiniger,R.: Einfluss der Hyperlipämie auf die Thrombogenese im Coronarsystem des isolierten Katzenherzens. Klin. Wschr.42:435-450 (1964).

20. Chandler,A.B.: In vitro thrombotic coagulation of blood. Lab. Invest. $7: 110-115$ (1958).

21. Clower,B.R.: Relation of levels of dietary fat to atrial thrombosis in RF mice.J.Atheroscler. Res. 8:885-890 (1968).

22. Clower,B.R. and Lockwood,W.R.: Light and electron microscopy of diet-induced atrial thrombosis in Swiss mice. II. Recovery on return to a balanced diet. Amer.J.Path.66:65-82 (1972).

23. Stamler,J.: Epidemiology of coronary heart disease. Med.Clin. North Amer. $57: 5-46$ (1973).

24. Pfleiderer,T.; Morgenstern,E., and Weber,E.: Über die Wirkung von Lipidemulsionen auf Blutplättchen.1.Zunahme der Plättchenaggregation unter dem Einfluss verschiedener Lipidemulsionen in vitro. Thromb.Diath.haemorrh.22:513-524 (1969).

25. Cullen,C.F. and Swank,R.L.: Intravascular aggregation and adhesiveness of the blood elements associated with alimentary lipemia and injections of large molecular substances. Effect on blood-brain barrier. Circulation 9:335-346 (1954).

26. Deiniger,R.: Einfluss von Fettinfusionen auf Leistung und Sauerstoffverbrauch des isoliert durchströmten Herzens. Arch.exp. Path.Pharmakol. 245:414-426 (1963).

27. Renaud,S., Morazain,R., McGregor,L. and Baudier,F.: Dietary fats and platelet functions in relation to atherosclerosis and coronary heart disease. Haemostasis 8 :234-251 (1979).

28. Didisheim,P.: Animal models useful in the study of thrombosis and antithrombotic agents; in Spaet:Progress in hemostasis and thrombosis, vol.1,pp.165-197 (Grune \& Stratton, New York 1972).

29. Downie,H.G.; Murphy,E.A.; Rowse1],H.C., and Mustard,J.F.: Extra corporeal circulation : a device for the quantitative study of thrombus formation in flowing blood. Circulat. Res.12:441-448 (1963).

30. Dubber,A.H.C.; Rifkin,B.; Gale,M.; McNicol,G.P., and Douglas,A.S.: The effect of fat feeding on fibrinolysis, 'Stypven' time and platelet aggregation. J.Atheroscler. Res. 7:225-235 (1967). 
31. Engelberg,H.: Studies with the Chandler Rotating Loop. Evidence that thrombin generation is responsible for the formation of the artificial in vi.tro thrombi. Thromb. Diath.haemorrh.22:344-350 (1969).

32. Evans,G. and Irvine,W.T.: Long-term arterial graft patency in relation to platelet adhesiveness, biochemical factors and anticoagulant therapy. Lancet ii:353-355 (1966).

33. Ferguson,J.C.; Mackay,N., and MCNicol,G.P.: Effect of feeding fat on fibrinolysis. 'Stypven' time and platelet aggregation in Africans, Asians and Europeans. J.clin.Path.23:580-585 (1970).

34. Ferguson,J.C.; Mackay,N., and McNicol,G.P.: Effect of feeding fat on fibrinolysis, 'Stypven' time and platelet aggregation in elderly Africans. J.clin.Path.25:574-576 (1972).

35. Pfleiderer,T.; Kommerel1,B. und Barth,P.: Über die Wirkung einer Fettemulsion auf menschliche Thrombocyten in vitro. Verh.dtsch. Ges.inn.Med.71:741-744 (1965).

36. Dayton,S.; Pearce,M.L.; Hashimoto,S., and Dixon,W.J.: A controlled clinical trial of a diet high in unsaturated fat in preventing complications of atherosclerosis. Circulation 40, Supplement II: $1-63$ ( 1969).

37. Frost,H.: Zur Pathogenese obliterierender Arterienprozesse bei Hypercholesterinämie. Thromb. Diath.haemorrh.22:351-359 (1969).

38. Geill, T. and Dybkaer,R.: The effect of linolenic acid orally on platelet adhesiveness and fibrinogen concentration. Scand.J.clin. Lab. Invest.23:256-258 (1969).

39. Gröttum,K.A.: Influence of aggregating agents on electrophoretic mobility of blood platelets from healthy individuals and from patients with cardiovascular diseases. Lancet $i$ : 1406-1408 (1968).

40. Gromnatskii,N.I.: Viscous metamorphosis of platelets and functional changes in the blood clotting system under influence of alimentary 1ipemia. Bull.exp.Biol.Med.USSR 71:518-519 (1971).

41. Leren,P.: The Osio diet-heart study. Circulation 42:935-942 (1970).

42. Haerem, J.W.: Sudden coronary death : the occurrence of platelet aggregates in the epicardial arteries of man. Atherosclerosis 14: 417-432 (1971).

43. Hampton,J.R., and Mitchell,J.R.A.: A transferable factor causing abnormal platelet behaviour in vascular disease. Lancet ii:764-768 (1966).

44. Hansen,P.F.T.; Geill,T., and Lund,E.: Dietary fats and thrombosis. Lancet i i:1193-1194 (1962). 
45. Zyablitskii,V.M.: Changes in adhesiveness and aggregation of platelets after passage of blood through the lungs. Bull.exp.biol.Med. USSR 68:1073-1075 (1969).

46. Harland,W.A., and Holburn,A.M.: Coronary thrombosis and myocardial infarction. Lancet ii:1158-1159 (1966).

47. Heggtveit,H.A.: Atheromatous transformation of intracardiac mural thrombi. Amer.J.Path. 52:70a (1968).

48. Weber,G.: Regression of arterial lesions : facts and problems in : Carlson,L.A.; Paoletti,R.; Sirtori,C., and Weber,G.: International Conference on Atherosclerosis. Raven Press, New York, (1978) pp.1-13.

49. Hellem,A.J.: The adhesiveness of human blood platelets in vitro (University Press, 0slo 1960).

50. Hellem,A.J.; Ödegaard,A.E., and Skårhegg,B.A.: Investigations on adenosine diphosphate (ADP) induced platelet adhesiveness in vitro. Thromb. Diath. haemorrh.10:61-70 (1963).

51. Henry,R.L.: Methods for inducing experimental thrombosis. An annotated bibliography. Angiology, Baltimore 13:554-577 (1962).

52. Renaud,S.: Thrombogenicity and atherogenicity of dietary fatty acids in rat. J.Atheroscler. Res.8:625-636 (1968).

53. Renaud,S.; Allard,C., and Latour,J.G.: Influence of the type of dietary saturated fatty acid on lipemia, coagulation and the production of thrombosis in the rat. J.Nutr.90:433-440 (1966).

54. Wright,H.P.: The adhesiveness of blood platelets in normal subjects with varying concentrations of anticoagulants. J.Path.Bact.53: 255-262 ( 1941).

55. Horlick,L.: Platelet adhesiveness in normal persons and subjects with atherosclerosis. Effect of high fat meals and anticoagulants on the adhesive index. Amer.J.Cardiol.8:459-470 (1961).

56. Wicks,M.S.; Ball,C.R., and Williams,W.L.: Relation of types of dietary fat to cardiovascular damage in mice. Amer.J.Anat. 124: 481-490 (1969).

57. Wexler,B.C.: Carotid artery occlusion in rats with and without arteriosclerosis. Angiology,Baltimore 19:554-572 (1968).

58. Wessler,S.: The role of stasis in thrombosis; in Sherry, Brinkhous, Genton and Stengle:Thrombosis,pp.461-468 (Nat.Acad.Sci., Washington (1969).

59. Hovig,T.; Jørgensen,L.; Rowse11,H.C., and Mustard,J.F.: The structure of thrombus-like deposits formed in extra corporeal shunts. Amer.J.Path.59:75-99 (1970). 
60. Howard,A.N. and Gresham,G.A.: The dietary induction of thrombosis and myocardial infarction. J.Atheroscler.Res.4:40-56 (1964).

61. Howard,A.N.; Gresham,G.A., and Lindgren,F.T.: Lipoprotein studies on rats fed thrombogenic and atherogenic diets. J.Atheroscler. Res. 8:739-743 (1968).

62. Weber,E.; Pfleiderer,T.; Feder,V. und Morgenstern,E.: Uber die Wirkung von Lipidemulsionen auf Blutplättchen. III. Verhalten von ATP,Glykogen und Glucoseverbrauch. Thromb. Diath. haemorrh.23:99-109 (1970).

63. Kannel,W.B.: Results of the epidemiologic investigation of ischaemic heart disease: Illustrated by the Framingham study; in de Haas, Hemker and Snellen:Ischaemic heart disease,pp.272-310 (University Press, Leiden (1970).

64. Kapp,J.P.; Duckert,F., and Hartmann,G.: Platelet adhesiveness and serum lipids during and after Intralipid ${ }^{\circledR}$-infusions. Nutr.Metab. 13:92-99 (1971).

65. Vles,R.0. and Kloeze,J.: Effects of feeding alternately mâize oil and coconut $0 i l$ on atherosclerosis in rabbits. J.Atherosc?er.Res.7: 59-68 (1967).

66. Kerr,J.W.; Pirrie,R.;MacAulay,I., and Bronte Stuart,B.: Platelet aggregation by phospholipids and free fatty acids. Lancet $i: 1296-1299$ (1965).

67. Turpeinen,0.: Liet and coronary events. J.Amer.diet.Ass.52: 209-213 (1968).

68. Tomich,E.G.: Effects of potential gradient on the electrophoretic mobility of human blood platelets in the presence of ADP or noradrenal ine. Biochem. Pharmaco1.21:3201-3203 (1972).

69. Kloeze,J.: Influence des graisses alimentaires sur l'adhésivité des plaquettes; in Extrait des journées de diabétologie de 1'Hôtel-Dieu, pp.227-233 (Flammarion, Paris 1966).

70. Thomasson,H.J.: Über die biologische Wirkung von Nahrungsfetten; in Fette in der Medizin, 5.Folge, pp.19-21 (Pallas Verlag,Lochham 1965).

71. Kloeze,J.; Houtsmuller,U.M.T., and V1es,R.0.: Influence of dietary fat mixtures on platelet adhesiveness, atherosclerosis and plasma cholesterol content in rabbits. J.Atheroscler.Res.9:319-334 (1969).

72. Kommerel1,B.; Barth,P., and Pfleiderer, $\Gamma .:$ Coagulation changes with intravenous administration of fat after blocking the RES. Thromb. Diath.haemorrh.15:381-389 (1966).

73. Kuo,P.T.; Whereat,A.F.; Altman,A.A. and West,J.W.: Effects of fat 
on coronary circulation in dogs. Circulat.Res.8:1157-1163 (1960).

74. Likar,I.N.; Robis.on, R.W.; Likar,L.J., and Gouvelis, A.: Microthrombi and intimal thickening in bovine coronary arteries. Arch.Path.87: 146-153 (1969).

75. Lockwood,W.R.; Clower,B.R., and Hetherington, F.: Light and electron microscopy of diet-induced atrial thrombosis in TS mice.I.Primary changes in the endocardium. Amer.J.Anat.125:185-200 (1969).

76. Philp,R.B. and Payling Wright,H.: Effect of adenosine on platelet adhesiveness in fasting and lipaemic bloods. Lancet ii:208-209(1965).

77. Maguire,K.F. and Doran,G.A.: Surface morphology of endocardial thrombus induced by a high fat diet. Amer.J.Anat.135:153-157 (1972).

78. Mathues,J.K.; Wolff,C.E.; Cevallos,W.H., and Holmes,W.L.: Platelet adhesiveness and thrombosis in rabbits on an atherogenic diet. Med.exp. 18:121-128 (1968).

79. McDonald,L. and Edgi11,M.: Dietary restriction and coagulability of the blood in ischaemic heart disease. Lancet $i i: 996-998$ (1958).

80. Thomas, W.A. and Hartroft,W.S.: Myocardial infarction in rats fed diets containing high fat, cholesterol, thiouracil and sodium cholate. Circulation 19:65-72 (1959).

81. Merskey,C. and Woh $1, H .:$ Changes in blood coagulation and fibrinolysis in rats fed atherogenic diets. Thromb.Diath.haemorrh.10:295-303 (1964).

82. Miettinen,M.;Turpeinen,0.; Karvonen,M.J.; Elosuo,R., and Paavilainen,E.: Effect of cholesterol-lowering diet on mortality from coronary heart disease and other causes. A twelve-year trial in men and women. Lancet ii:835-838 (1972).

83. Moolten,S.E.; Jennings,P.B., and Solden,A.: Dietary fat and platelet adhesiveness in arteriosclerosis and diabetes. Amer.J.Cardio1.11: 290-300 (1963).

84. Moolten,S.E. and Vroman,L.: The adhesiveness of blood platelets in thromboembolism and hemorrhagic disorders.I.Measurement of platelet adhesiveness by the glass wool filter. Amer.J.clin.Path.19:701-709 (1949).

85. Morgenstern,E.; Pfleiderer,T.; Zebisch,P. und Weber,E.: Über die Wirkung von Lipidemulsionen auf Blutplättchen. II.Licht- und electronenmikroskopische Studien. Thromb. Diath.haemorrh.22:525-543 (1969).

86. Murphy,E.A.; Rowsel1,H.C.; Downie,H.G.; Robinson,G.A., and Mustard, J.F.: Encrustation and atherosclerosis: the analogy between early ill live lesions and deposits which occur in extra corporeal circulation. J.canad.med.Ass.87:259-274 (1962). 
67. Mustard,J.F.: Effects of intravenous phospholipid containing phosphatidyl serine on blood clotting with particular reference to the Russell's viper venom time. Nature, Lond.196:1063-1065 (1962).

88. Mustard,J.F. and Murphy,E.A.: Effect of different dietary fats on blood coagulation, platelet economy and blood lipids. Brit.med.J.i: 1651-1655 (1962).

89. Mustard,J.F.; Rowsell,H.C.; Murphy,E.A., and Downie,H.G.: Diet and thrombus formation : quantitative studies using an extra corporeal circulation in pigs. J.clin. Invest.42:1783-1789 (1963).

90. Mustard,J.F.; Glynn,M.F.; Nishizawa,E.E., and Packham,M.A.: Platelet surface interactions : relationship to thrombosis and hemostasis. Fed.Proc.26:106-114 (1967).

91. Swank,R.L.: Effects of high fat feedings on viscosity of blood. Science 120:427-428 (1954).

92. Renaud,S. and Godu,J.: Induction of large thrombi in hyperlipemic rats by epinephrine and endotoxin. Lab. Invest.21:512-518 (1969).

93. Nathaniel,E.J.H. and Chandler,A.B.: Electron microscopic study of adenosine diphosphate-induced platelet thrombi in the rat.

J.U1trastruct.Res. 22:348-359 (1968).

94. Nathaniel,E.J.H.; Nathaniel,D.R.; Nordфy,A.F., and Chandler,A.B.: Electron microscopic observations of platelets in rats fed on different fat diets. J.U1trastruct.Res.38:360-370 (1972).

95. Nishizawa,E.: Phopholipid, blood coagulation, platelet aggregation and thrombosis. Fed.proc. 24:154 (1965).

96. Nord $\varnothing y, A$. and Chandler,A.B.: Platelet thrombosis induced by adenosine diphosphate in the rat. Scand.J.Haemat.1:16-25 (1964).

97. Nordøy,A. and Chandler,A.B.: The influence of dietary fats on the adenosine diphosphate induced platelet thrombosis in the rat.

Scand. J. Haemat. 1:202-211 (1964).

98. Nord $\not y, A .:$ The influence of saturated fats, cholesterol, corn oil and linseed $0 i 1$ on experimental venous thrombosis in rats. Thromb. Diath.haemorrh.13:244-256 (1965).

99. Nord $\varnothing y, A_{\text {. }}$ : The influence of saturated fat, cholesterol, corn oil and linseed $0 i 1$ on the ADP-induced platelet adhesiveness in the rat. Thromb.Diath. haemorrh. 13:543-549 (1965).

100. Nordøy, A.; Haml in,J.T.; Chandler,A.B., and Newland,H.: The influence of dietary fats on plasma and platelet lipids and ADP-induced platelet thrombosis in the rat.Scand.J.Haemat.5:458-473 (1968).

101. Nord $\phi y, A$. and R $\varnothing d s e t, J . M .:$ The influence of dietary fats on platelets 
in man. Acta med.scand. 190:27-34 (1971).

102. O'Brien,J.R.: Platelet aggregation.II. Some results from a new method of study. J.clin.Path.15:452-455 (1962).

103. Renaud, S:Dietary fats and thrombosis. Biblthca Nutr.Dieta 25:92-101 (1977).

104. Renaud,S.: The recalcification plasma clotting time. A valuable general clotting test in man and rats. Canad.J.Physiol. Pharmacol. 47:689-693 (1969).

105. Owren,P.A.; Hellem,A.J., and Ödegaard,A.: Linolenic acid for the prevention of thrombosis and myocardial infarction. Lancet $i i_{\text {: }}$ 975-978 (1964).

106. Owren,P.A.; Hellem,A.J., and Ödegaard,A.: Linolenic acid and platelet adhesiveness. Lancet i i:849-850 (1965).

107. Pearl,F., and Friedman,M.: Experimental coronary thromboatherosclerosis in the dog. Arch.Path. 77:370-377 (1964). 
5. NEW EXPERIMENTAL MODELS FOR THE INVESTIGATION OF ARTERIAL THROMBOSIS TENDENCY AND PLATELET AGGREGABILITY

\subsection{Introduction}

Research into the effects of nutritional factors on arterial thrombus formation and its underlying processes, requires reliable, (semi-) chronic quantitative in vivu techniques to measure arterial thrombosis tendency and platelet function. Although numerous techniques to induce experimental thrombosis were available when starting our project (1), none of them met our specific requirements. Therefore, we devised the aorta-loop technique for investigations with rats, which

- is simple and inexpensive,

- produces a high thrombosis incidence but a low mortality rate,

- allows the process of thrombus formation to be estabiished in a simple way,

- results in a thrombus, the structure and composition of which are comparable with those of arterial thrombi in man.

The aggregation of blood platelets is of pivotal importance in arterial. thrombogenesis and a considerable number of techniques has been developed to determine the degree of experimentaliy induced platelet aggregation $(2-6)$. However, since it was our aim to relate our aggregation findings with the results of the arterial thrombosis measurements, we needed a technique which enables the measurement of platelet aggregability in circulating arterial blood. Since such a technique was not available, the filter loop technique was developed, suitable for the measurement of platelet aggregation in circulating arterial blood of rats.

Although this technique is very useful for animals, it appeared unsuitable for humans. Therefore, the Filtragometer $\left.{ }^{(}\right)$was developed to measure spontaneous platelet aggregation in flowing venous blood.

Since these three techniques are of essential importance for our research work, they will be described and discussed in detail. 


\subsection{Measurement of arterial thrombosis tendency in rats}

This method is based on the insertion of a loop-shaped polyethylene cannula (the aorta loop) into the abdominal aorta. At places where the cannula is in permanent contact with the vessel wall, endothelial damage and flow disturbances result in the formation and growth of a thrombus, which reaches an occlusive state after about 5 days.
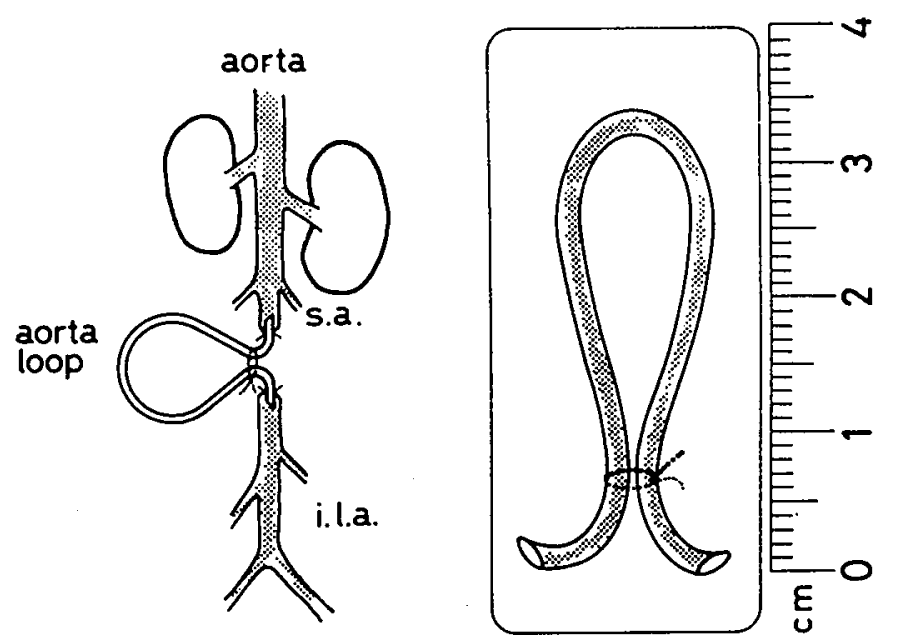

Fig.5.1. Aorta loop and site of insertion.

s.a.: spermatic arteries. i.l.a.: iliolumbar arteries.

\subsubsection{Preparation of the aorta loop}

The aorta loop (Fig.5.1.) is bent from an approx. 20-cm piece of polyethylene cannula, bore $1.00 \mathrm{~mm}$, external diameter $2.00 \mathrm{~mm}$ (Portex ${ }^{\circledR}$ PP 120, Portland Plastics Ltd, Hythe, Kent, England) under a stream of

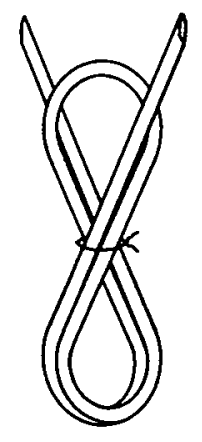

a

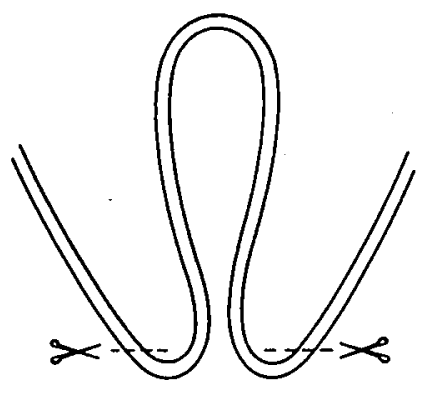

b

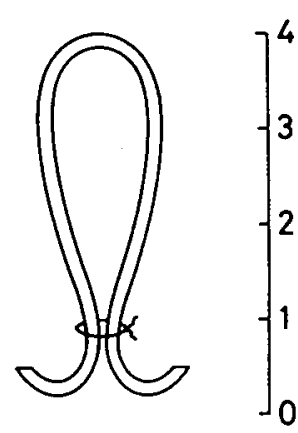

C

Fig. 5.2. Preparation of aorta loop. For details, see under section 5.2.1. 
hot water and fastened with a central ligature (Fig.5.2.a). On the day of use, the central ligature is untied and the loop cut as shown in Fig. 5.2.b. Finally, the loop is provided with another ligature (Fig.5.2.c). After preparation, the loop is siliconized with a solution of Siliclad ${ }^{\circledR}$ (Clay Adams, B and D Company, Parsippany, N.J., U.S.A.) $1: 20$ and filled with a heparin (Vitrum $\otimes$, Apotheksvarucentralen Vitrum A.B., Stockholm, Sweden) solution in physiological saline (500 I.U.m $\left.{ }^{-1}\right)$.

\subsubsection{Animals and insertion procedure}

Male Wistar rats, specific pathogen-free (S.P.F.), hody weight approx. $300 \mathrm{~g}$, are anesthetized by intraperitoneal administration of pentobarbital sodium ; $40 \mathrm{mg} . \mathrm{kg}^{-1}$ body weight (Nembutal ${ }^{\circledR}$, Abbott, Saint Rémy sur Avre, France). To the left of the median line, the abdominal skin from the costal border to the thigh is shaven and disinfected with tincture of iodine. Approximately $5 \mathrm{~mm}$ to the left of the median line, starting at the costal border, a $3 \mathrm{~cm}$ long caudad incision is made. From the renal arteries to the common iliac arteries, the aorta is detached from the surrounding tissue. Subsequently, the part of the aorta bounded by the spermatic and iliolumbar arteries is carefully cleaned. Into this part, the loop is introdiced. To this end, the aorta is clamped above the spermatic arteries and below the iliolumbar arteries. The aorta is incised $3 \mathrm{~mm}$ below the spermatic arteries and one end of the loop is inserted craniadly and fastened with a previously applied, loose ligature. The aorta is incised again, caudally from the first incision, as near as possible to the inserted part of the loop, and provided with another loose ligature. The upper clamp is monentarily opened in order to replace the heparin solution by blood, after which the free end of the cannula is inserted caudadly into the aorta and fastened. Care should be taken that the ends of the loop do not block the branches of the spermatic and iliolumbar arteries. Inclusion of air bubbles must be prevented.

The two clamps are removed so that the blood flow through the aorta, via the loop, is restored. The muscle layer is sutured and the skin clamped in such a way that the loop partly projects from the body. Between the muscle layer and the skin, some Terramycin ${ }^{\circledR}$ ointment (Pfizer Corporation, Brussels, Belgium) is spread. To prevent the loop from being bitten, a plastic-coated cardboard collar (7) is put around the neck of the animal. 
The outer diameter of the collar was approx. $12 \mathrm{~cm}$, inner diameter $2.5-3.0 \mathrm{~cm}$. Unless otherwise stated, the animals were fed a commercial pellet diet ad Zibitum (Muracon $1{ }^{\circledR}$, Trouw \& Co, Amsterdam).

\subsubsection{Determination of arterial thrombosis tendency}

As the loop projects from the body and is made of translucent material, the blood flow can be checked without difficulty. If the flow is satisfactory, the colour of the blood is light-red. After the loop has become blocked, the colour rapidly changes from light-red via dark-red to blue or black.

The period between insertion and complete obstruction of the loop is called the obstruction time (OT) and is a measure of the arterial thrombosis tendency of the animal: the longer the OT, the lower the thrombosis tendency. For most experiments, it is sufficient to check the loop twice daily.

A more accurate determination of the moment of obstruction can be realized by measuring the temperature of the surface of the loop. To this end, an Ellab thermocouple, type $K 8$ (Elektrolaboratoriet, Copenhagen) is bent into the same curve as the projecting part of the loop, after which they are tied together with small strips of Parafilm (American Can Company, Marathon Products, Neenhah, Wisconsin, U.S.A.) The rats are restrained (8) and loop and rectal (thermocouple RM-4) temperatures are recorded on an Ellab Strip Chart Recorder, type Z 8. Fig. 5.3. shows the temperature recording at the moment a loop becomes obstructed.

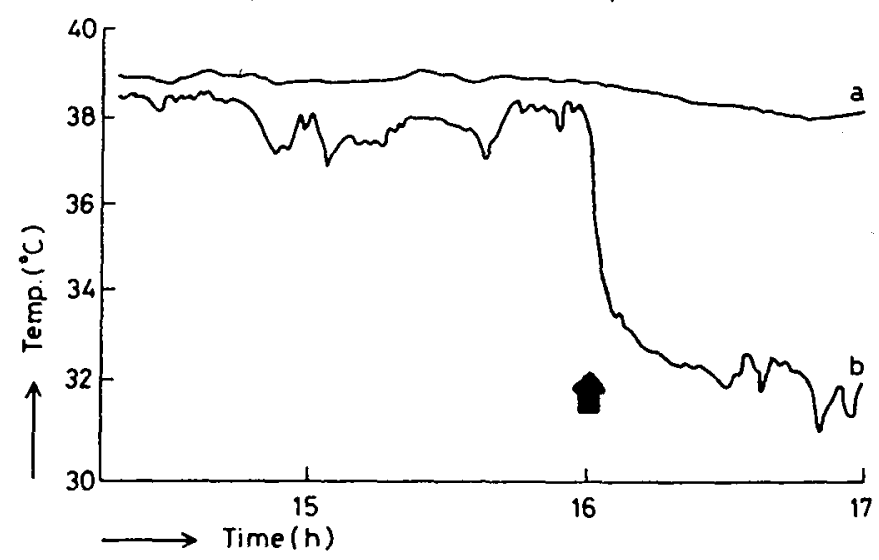

Fig.5.3. Course of rectal (a) and loop (b) temperatures on obstruction of the loop (arrow). Time is clock-time. 
When the rats are fed a normal stock diet, the obstruction time (OT) is about 5 days. Once the loops have become obstructed, the animals do not die because, in the meantime, collateral vessels have developed which take over the blood supply to the hind quarters of the animal. Therefore, it remains possible to take blood samples for plasma and blood cell analyses after OT determination.

Within each experimental group, the OT values showed a log-normal pattern so that for a statistical evaluation of the results, logarithmic transformation of the OT was necessary.

\subsubsection{Measurement of thrombus growth-rate}

Aorta loops were inserted in 32 animals; $1,2,3$, and 4 days later, 8 animals were killed per day. The aortas were perfused with saline, opened longitudinally and the thrombi, which were always lorater against the proximal and distal cannula tips, were removed with the aid of a zeiss binocular microscope (magn. 10x). After drying under vacuum for at least $24 \mathrm{~h}$ over silica gel, the thrombi were weighed, using a Cahn Electrobalance ${ }^{8}$, Model G (Cahn Instrument Company, Paramount, California, U.S.A.). Experimental time was restricted to 4 days, because it was shown that,

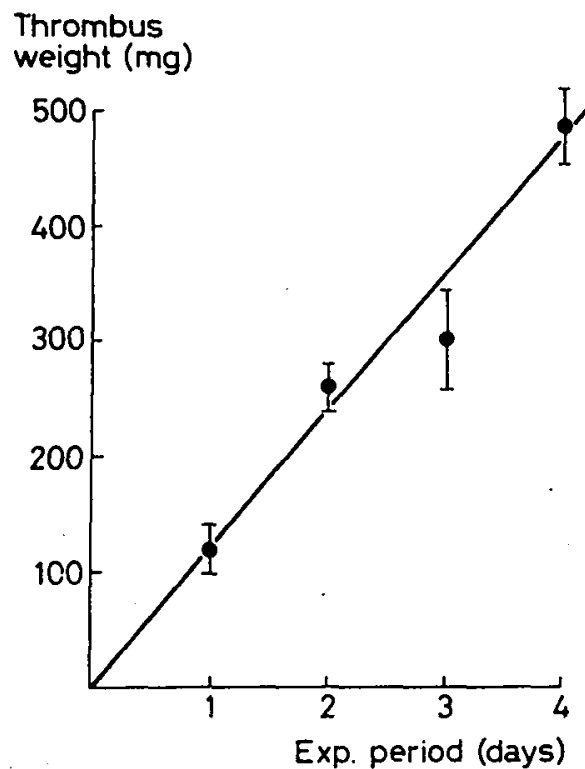

Fig. 5.1. Thrombus weight ( $\mathrm{mg}+\mathrm{SEM}$ ) as a function of experimental period (days). $Y=118 X ; r=0.72 ; P<0.001 ; n=32$. Each point represents the mean of eight measurements. 
in most animals, the aortas were totally obstructed after 5 days. In these cases, it was impossible to remove the affixed blood clot from the thrombus.

Fig. 5.4. gives the average thrombus weight 1 to 4 days after 1oop insertion. Statistical evaluation of the results showed that the relationship between thrombus weight and experimental time was positive and linear.

\subsubsection{Histological investigation of growing thrombi and mechanism of thrombus formation}

In 12 animals, aorta loops were inserted. From 1 up to 6 days after insertion of the loop, 2 animals were killed each day; after opening their abdomen longitudinally, the animals were placed in a Formol-calcium mixture after Baker (9) for $24 \mathrm{~h}$ at $4^{\circ} \mathrm{C}$. Parts of the aorta proximally and distally from the loop were removed and embedded in Paraplast (Sherwood Medical Industries Inc., St.Louis, Miss., U.S.A.). Transversal serial sections of $6 \mu \mathrm{m}$ were stained as follows: Harris' hematoxylin azophloxin (10), Masson's trichrome stain (modif. Goldner) (10), Mallory's PTAH method for fibrin (9), Neubert's stain for smooth muscle cells (10), Von Kossa's stain for calcium (10) and Perls' method for hemosiderin (9).

The inserted aorta loop causes endothelial damage: the underlying tissue is denuded and platelets adhere to the affected sites (Fig.5.5.). Twenty

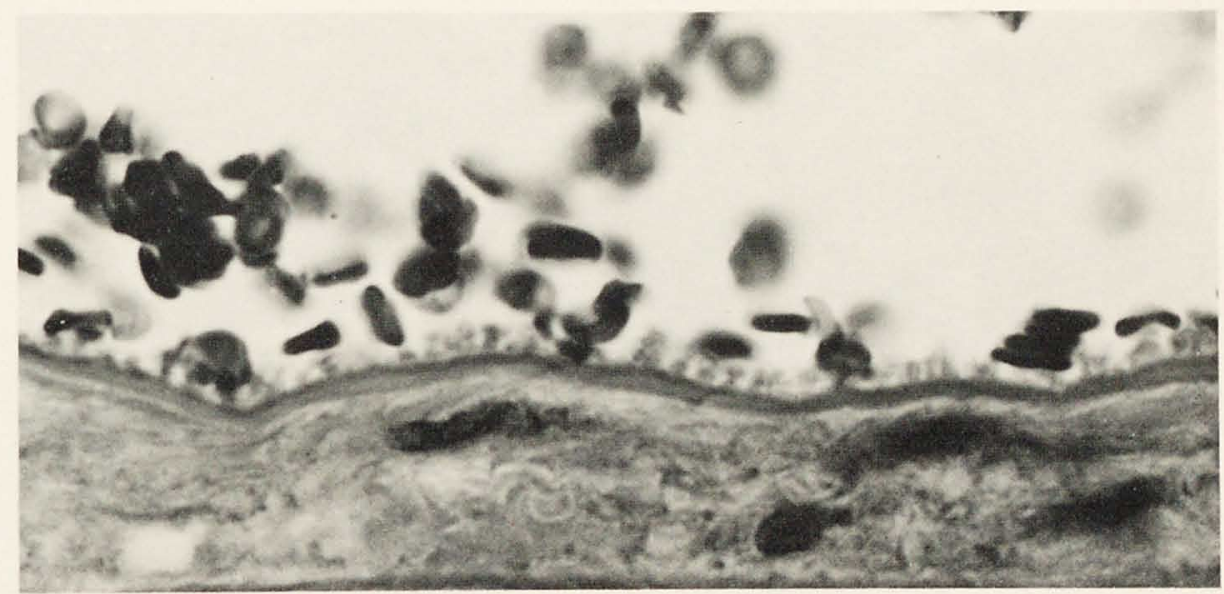

Fig.5.5. Adhesion of platelets to denuded aortic wal1. Some erythrocytes are seen in the vascular lumen (Masson, 1300x). 
- four hours after insertion of the aorta loop, large thrombi are already found at both ends of the loop. The platelets nearest to the vessel wall are swollen and have lost their internal structure. In the interstices of the platelet thrombus, numerous erythrocytes are trapped, while accumulations of polynuclear leukocytes are observed on the surface of the aggregates (Fig.5.6.). Strands of fibrin are present among the platelets. The thrombus is not homogeneous but contains several histologically different layers. The vessel wall is degenerated by the pressure of the loop and damaged by the tapered end of the loop.

After 2 and 3 experimental days, the thrombi, the area of attachment to the vessel wall and the amount of fibrin have increased. The thrombus material is invaded by polynuclear leukocytes and mononuclear cells (Fig.5.7.). The trailing ends of the thrombi can be followed for a considerable distance into the vascular lumen. After 4 experimental days, the vessel wall beneath the thrombus is necrotic and in adjacent parts, the smooth muscle cells in the media show proliferation and mitosis, while the endothelial cells of the aorta are swollen and pyknotic.

After 5 and 6 experimental days, smooth muscle cells, fibroblasts and macrophages penetrate into the thrombus and endothelization of the thrombus starts (Fig.5.8.). Some hemosiderin and calcium appeared to be present.

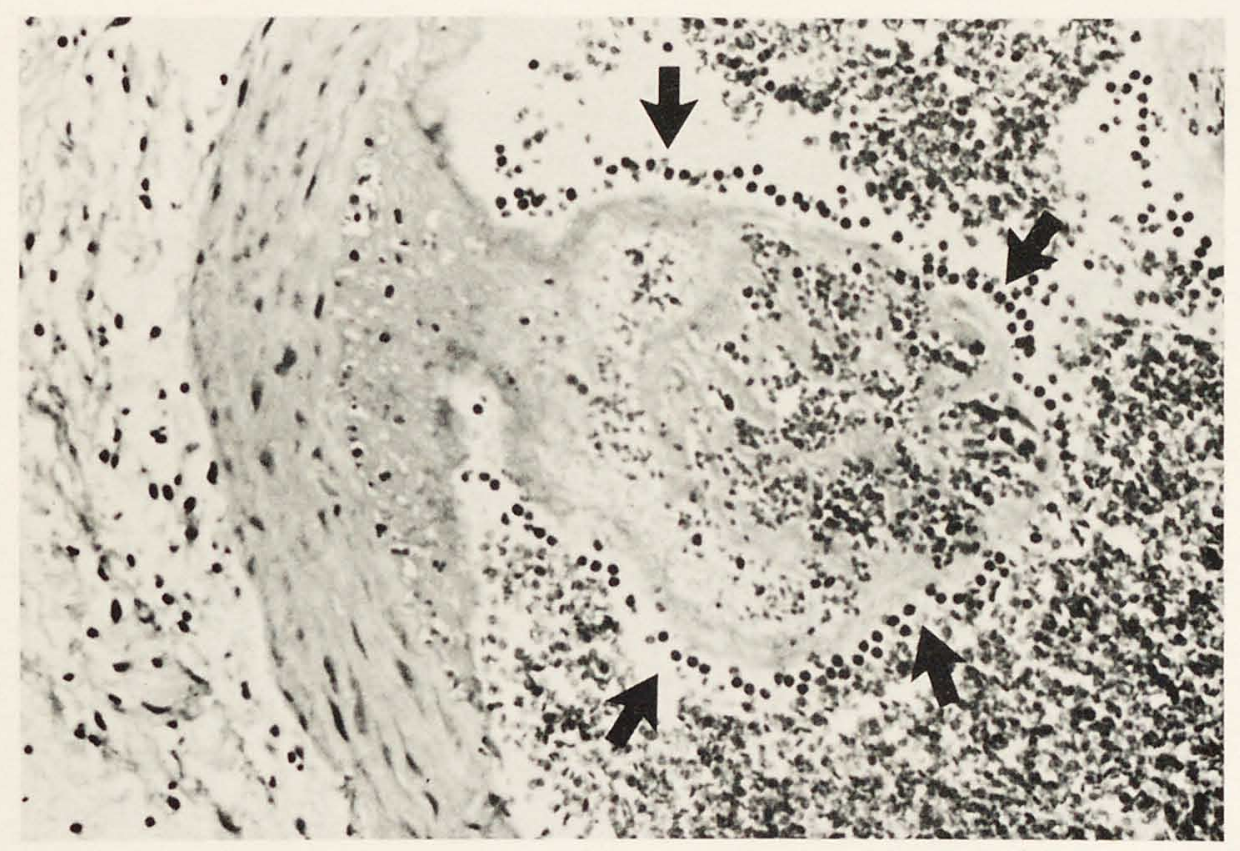

Fig.5.6. Polynuclear neutrophils (arrons) on the surface of a one-day thrombus (Masson, 208x). 


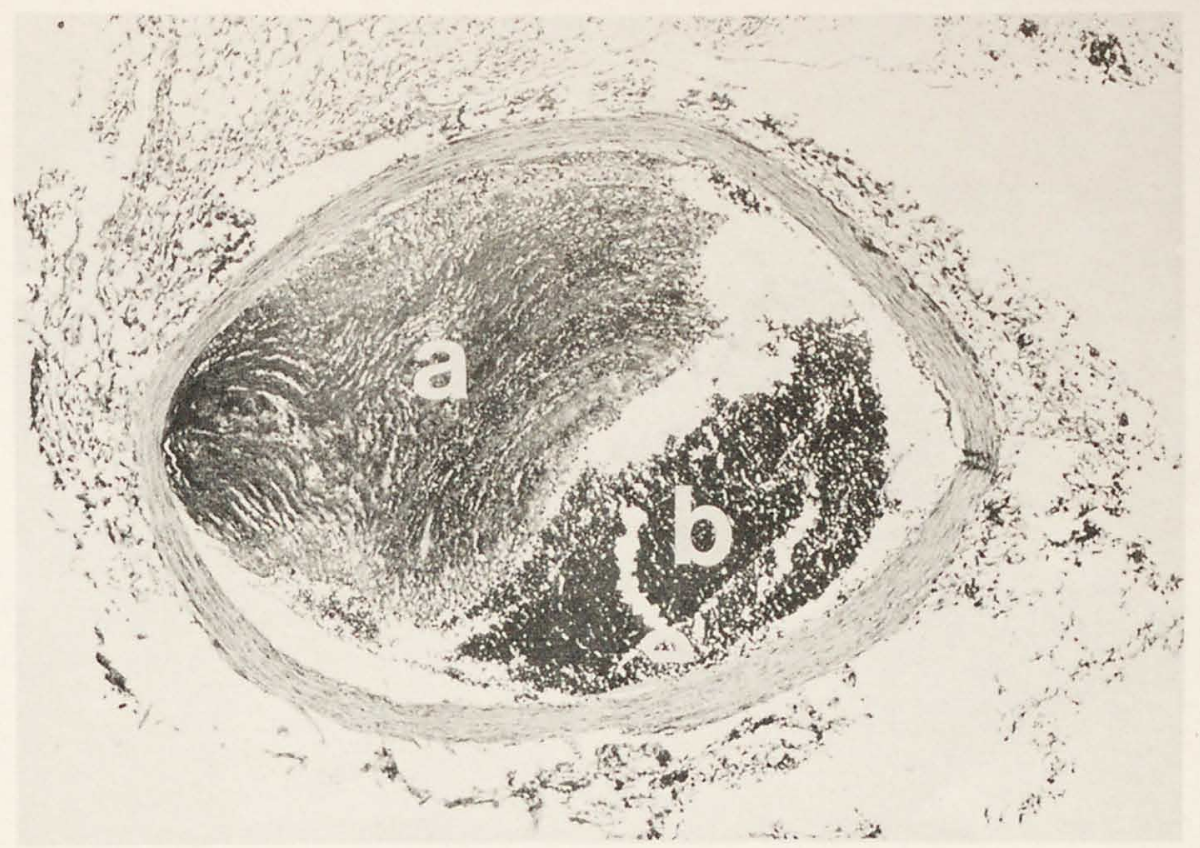

Fig. 5.7. Thrombus after 3 days. (a) Thrombus, invaded by polynuclear leukocytes and mononuclear cel1s. (b) Erythrocytes. (Masson, 55x).

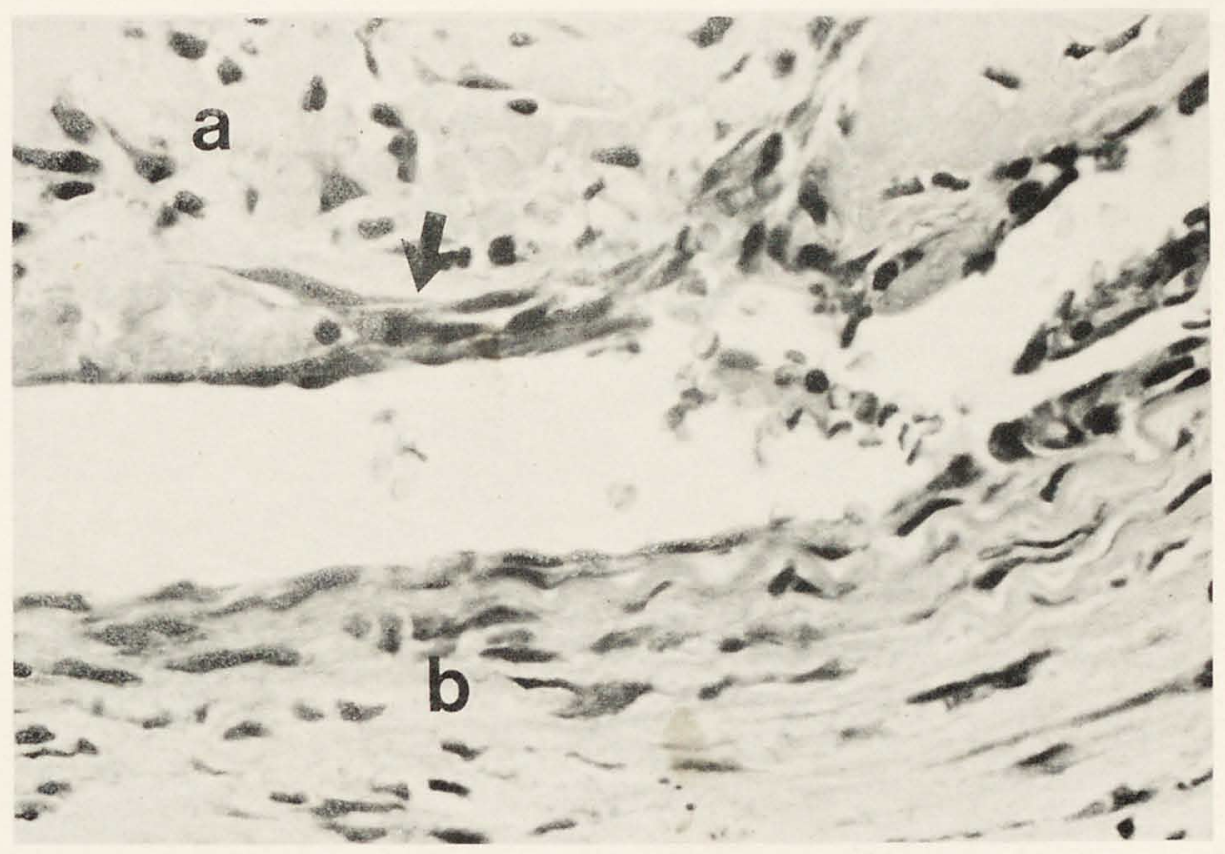

Fig.5.8. Smooth muscle cell and mitosis (arrow) in endothelialized 6-day thrombus. (a) Thrombus; (b) Aortic wal1 (Masson, 546x). 
Conclusion : the structure of the thrombi induced by the insertion of an aorta loop in rats is similar, in comparative phases of development, to that of natural arterial thrombi in man (11) and animals (12).

In this model, endothelial damage seems to be the initiating stimulus for thrombus formation. In rabbits it was shown, however, that endothelial damage alone does not produce thrombosis but results in the formation of a platelet 'pseudo-endothelium' followed by layering of leukocytes, disappearance of platelets and formation of a new endothelial layer (77). It is most probable that the turbulent flow, which will also occur as a result of aorta cannulation, contributes significantly to the formation of the obstructing thrombus (20). The red blood cells should also be considered as a contributory factor in thrombus formation. This is suggested from scanning electron microscopy of the early stage of thrombus formation after loop insertion(Fig.5.9.). Platelets adhering to the inner arterial wall form pseudopodia in which red cells seem to be trapped. Sometimes, platelets adherent to erythrocytes are observed. It might be assumed that the trapped red cells together with the adhered platelets are the source of ADP contributing to the aggregation of passing blood platelets on the adhered mass.

An important role of erythrocytes in early thrombus formation was also suggested by Kloeze (44), who showed that venous platelet thrombi induced by electrical stimuli generally settled around a central plug of red blood cells. Moreover, Arfors, Born and co-workers $(21,78,79)$ provided evidence that the presence of erythrocytes is a prerequisite for normal hemostasis. It seems, therefore, important to pay more attention to the role of erythrocytes in thrombogenesis.

As endothelial injury may also trigger the local formation of fibrin (80), thrombus growth in the present model might be enhanced by platelet aggregation, induced by fibrin polymerization and the subsequent association of platelets with the polymerizing fibrin, which was shown to occur in vitro (81).

\subsubsection{Behavioura]_and hematological_changes after_loop_insertion}

After loop insertion, food consumption decreases considerably. Restoration takes place rather slowly, as can be seen from Table 5.1. This is 


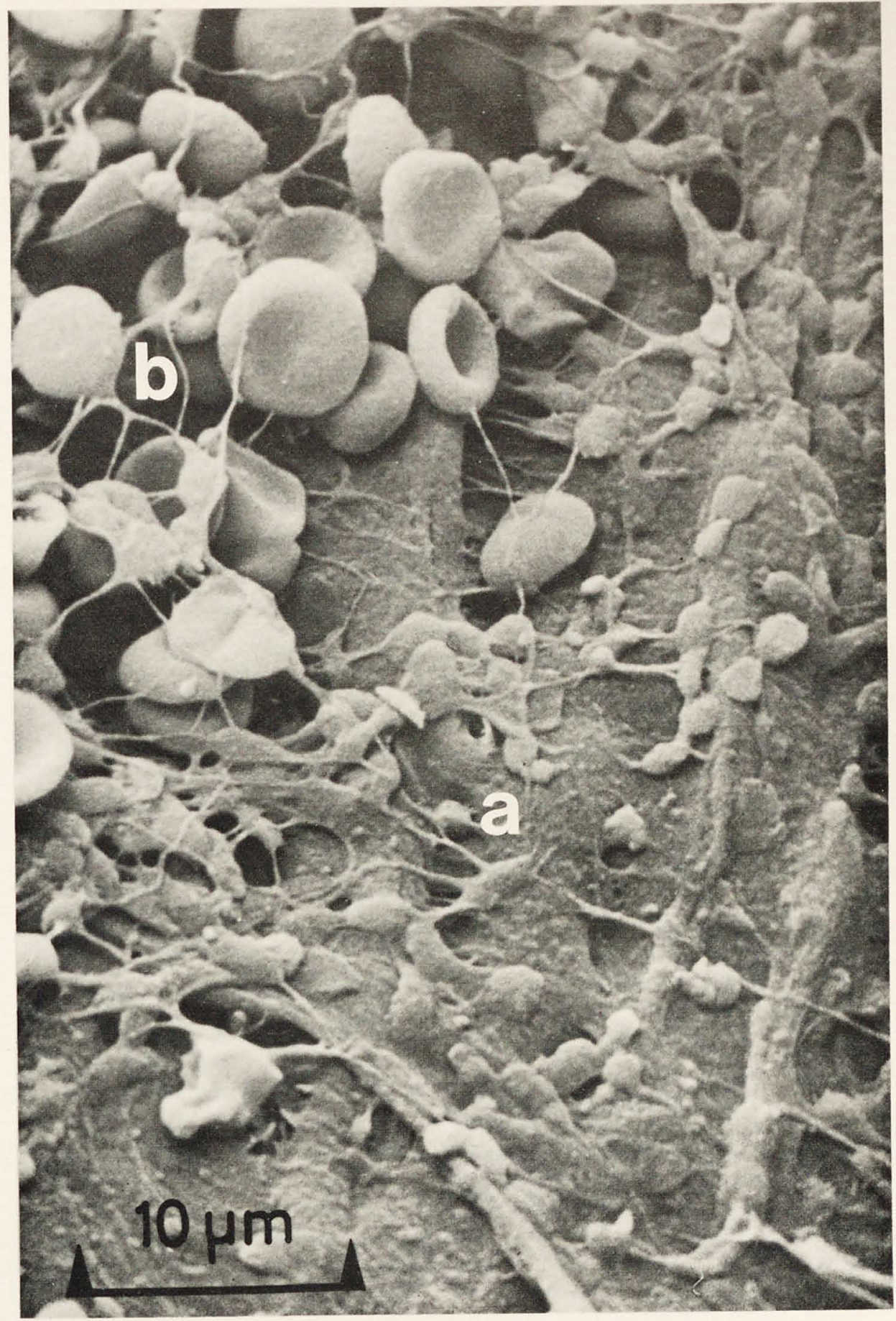

Fig.5.9. Scanning electron microscopic picture of early thrombus formation. (a) Platelets, adhered to damaged vascular wall. (b) Erythrocytes, interconnected by platelet pseudopodia. 
not due to the cardboard collar, because in sham-operated rats having such a device, food consumption completely normalized within 3 days.

Table 5.1. Food consumption after aorta-loop insertion (\% of pre-operative value \pm SEM).

\begin{tabular}{lll}
\hline Day & $n$ & $\%$ \\
\hline 1 & 59 & $20.4 \pm 2.03$ \\
2 & 55 & $28.7 \pm 1.83$ \\
3 & 55 & $38.7 \pm 1.77$ \\
4 & 54 & $41.1 \pm 1.89$ \\
\hline
\end{tabular}

To investigate hematological changes after loop insertion, three days before and 1 to 4 days after loop insertion, blood samples were taken from the tail of 36 animals. The hemoglobin content was determined according to the hemicyanin method. Total erythrocyte, thrombocyte and leukocyte counts were carried out with a coulter counter, model "A". For the differentiation of the leukocytes, blood smears were stained after May Grünwald-Giemsa and 200 cells were counted.

The hematological data (Table 5.2.) show the normal postoperative changes (13). The decrease in hemoglobin content and the number of erythrocytes are due to the loss of blood during and after the operation. Surgical trauma and thrombosis cause an increase of neutrophils, whereas the number of thrombocytes tends to decrease during the first postoperative day after which it increases again.

\subsubsection{Importance of platelet function in arterial thrombus formation}

Platelet aggregation is a prerequisite for arterial thrombogenesis. Therefore, any change in platelet aggregability might be expected to affect arterial thrombosis tendency. To test the usefulness of the aorta loop technique, we investigated the effect of prostaglandin $E_{1}$ and aspirin, two inhibitors of platelet aggregation (14-16). The importance of the platelet-release reaction was investigated, using animals suffering from a hereditary defect of this platelet property $(90,31)$.

5.2.7.1. Effect of prostaglandin $E_{1}$ on arterial thrombus formation.

Rats were provided with aorta loops and prepared for thermometric obstruc- 


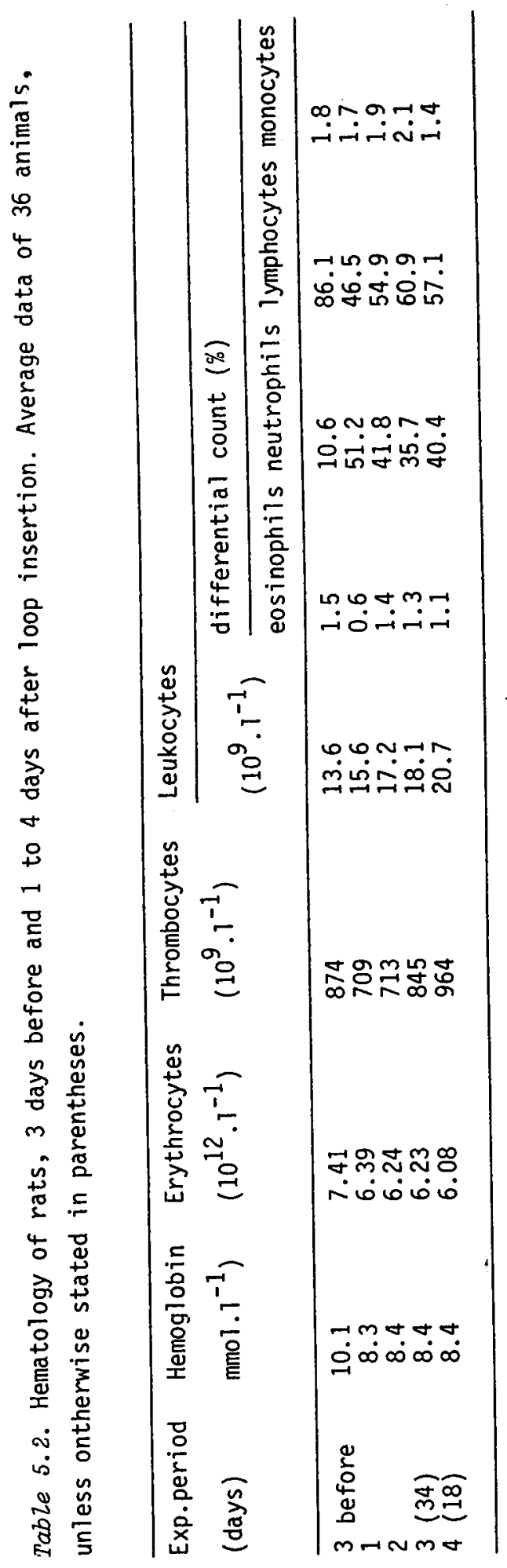


tion determination. In 48 rats, a cannula (Portex PP 50) was inserted into the right atrium via the right jugular vein (17) and in 14 animals, via the left carotid artery, a small cannula (Portex PP 25) was introduced into the aorta and pushed down until the cannula tip was positioned just between the left renal artery and the proximal tip of the aorta. loop. Via these cannulae, the rats were infused $\left(0.88 \mathrm{ml}^{-1}\right)$ with :

- group $1(n=28)$ phosphate-buffered saline ( $\mathrm{pH} 7.42)$ intravenously,

- group $2(n=20) P_{1}$ in saline $\left(10 \mu \mathrm{g} \cdot \mathrm{h}^{-1}\right)$ intravenously,

- group $3(n=5)$ saline intra-arterially,

- group $4(n=9) P G E_{1}$ in saline $\left(10 \mu \mathrm{g} \cdot \mathrm{h}^{-1}\right)$ intra-arterially.

Table 5.3. Influence of $\mathrm{PGE}_{1}\left(10 \mu \mathrm{g}\right.$.animal $\left.{ }^{-1} \cdot \mathrm{h}^{-1}\right)$ given intravenously (i.v.) and intra-arterially (i.a.) on the obstruction time of aorta loops (OT).

\begin{tabular}{lccccc}
\hline \multirow{2}{*}{ Parameter } & \multicolumn{2}{l}{ Control } & & \multicolumn{2}{c}{$P G E_{1}$} \\
\cline { 2 - 3 } & i.v. & i.a. & & i.v. & i.a. \\
\hline n & 28 & 5 & & 20 & 9 \\
Log OT & 2.107 & 2.076 & & 2.204 & 2.408 \\
SEM & 0.0351 & 0.0776 & & 0.0305 & 0.0700 \\
OT (h) & 128.1 & 119.0 & & 160.1 & 255.7 \\
\hline
\end{tabular}

The influence of $\mathrm{PGE}_{1}$ on arterial thrombus formation is shown in Table 5.3. The two control groups did not differ significantly; therefore, they were combined into one control group ( $\log$ OT $=2.103 \pm 0.0316 ; 0 \mathrm{~T}=126.6 \mathrm{~h}$, $n=33$ ). Intravenous infusion of $10 \mu \mathrm{g} P G E_{1}$ per animal per hour resulted in a significant increase of the OT $\left(P_{2}<0.05\right)$. When the same amount of $P G E_{1}$ was infused intraarterially, the increase in OT was significantly higher than on intravenous administration $\left(P_{2}<0.01\right)$. The discrepancy between the antithrombotic effect of $\mathrm{PGE}_{1}$ on intravenous and intraarterial administration is most probably due to the rapid inactivation of $\mathrm{PGE}_{1}$ in the lungs (18).

5.2.7.2. Effect of aspirin on arterial thrombosis tendency.

Groups of 12 rats were fed adequate diets containing increasing amounts of acetylsalicylic acid. After 4 weeks' feeding, aorta loops were inser- 


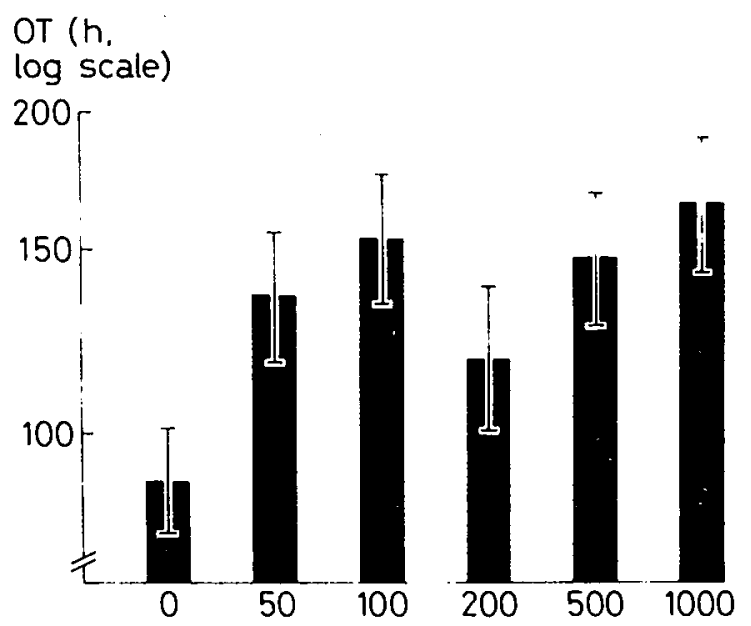

Fig.5.10. Effect of dietary aspirin (mg. $4184 \mathrm{~kJ}^{-1}$ indicated on X-axis) on arterial thrombus formation in rats (OT \pm SEM; $n=12$ ).

ted and arterial thrombosis tendencies measured. The results are shown in Fig.5.10., which clearly demonstrates that aspirin inhibits arterial

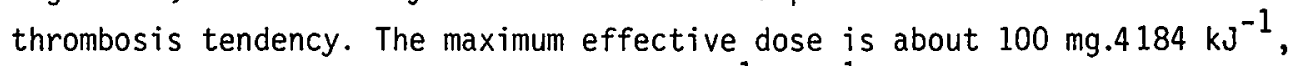
which is equivalent to about $15 \mathrm{mg}$.anima ${ }^{-1}$. day ${ }^{-1}$.

5.2.7.3. Arterial thrombosis tendency of rats with a hereditary defect of the platelet release reaction.

As discussed in Chapter 3, section 2.5, Fawn-Hooded (FH) rats have a hereditary defect of the platelet release reaction. Obstruction times measured in $15 \mathrm{FH}$ rats appeared to be 26.5 days ( $\log$ OT $(h)=2.80 \pm 0.056$ ) which is significantly longer $\left(P_{2}<0.001\right)$ than the average ot in a group of 16 control rats ( $\log$ OT $(h)=1.90 \pm 0.037,0 T \sim 3.5$ days). This clearly indicates the importance of platelet release and aggregation for arterial thrombus formation.

\subsubsection{Contribution of clotting_to_arterial_thrombogenesis}

Histoiogical examinations showed that the developing thrombus contains strands of fibrin (section 5.2.5.). To establish the relative importance of the clotting process in arterial thrombus formation, OT's were determined in rats which, from $5 \mathrm{~h}$ after loop insertion onwards, were intra- 


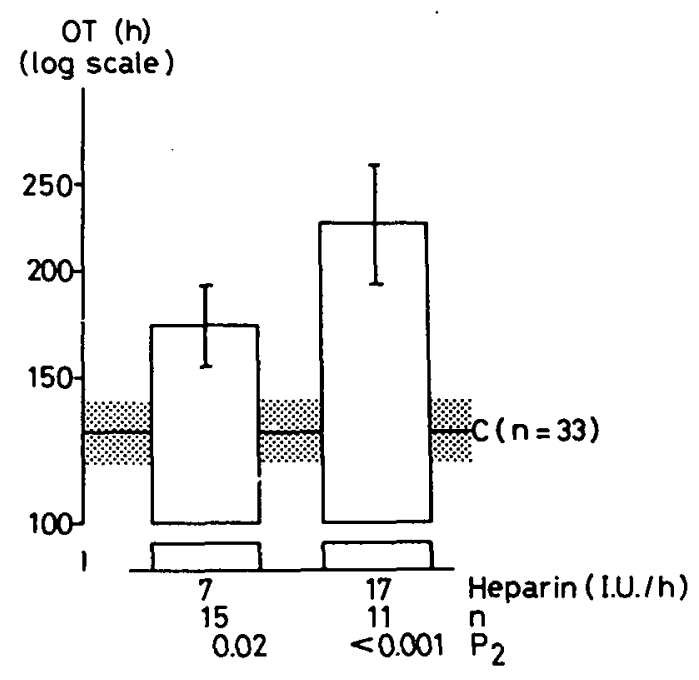

Fig.5.11. Effect of continuous intravenous infusion $\left(0.88 \mathrm{ml} . \mathrm{h}^{-1}\right)$ of heparin (I.U.h $h^{-1}$ ) in phosphate-buffered saline on arterial thrombosis tendency in rats (OT \pm SEM). The control group (C) was infused with saline only and is indicated by the fat line (mean) and the shaded area $( \pm$ SEM).

venously infused $\left(0.88 \mathrm{ml} . \mathrm{h}^{-1}\right)$ with heparin, 7 or 17.6 I.U. per animal per hour. Immediately before starting infusion, a priming dose of heparin (30 and 100 I.U., respectively) was injected intravenously. As shown in Fig.5.11., both heparin doses prolonged the OT's significantly compared to those of a control group. The difference between the two heparin groups was not significant. These results demonstrate that anticoagulation with heparin significantly lowers arterial thrombosis tendency.

\subsubsection{Effect of atherosclerotic and thrombotic_risk factors on arterial} thrombus formation

Some of the major atherosclerotic risk factors are age, sex and hypercholesterolemia $(22,23)$. The use of oral contraceptives is also associated with an enhanced risk of thromboembolic complications $(24,25)$. Finally, hypercoagulation is considered an important risk factor in relation to thrombotic complications of atherosclerosis (26).

Uzunova and co-workers demonstrated that OT's decrease with increasing

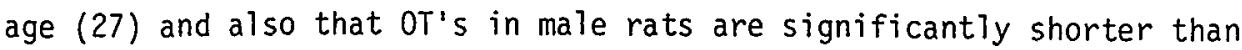


in female animals. This appeared to be connected with the effect of gonadal hormones $(27,28)$.

Working with a hypercholesterolemic strain of rats, Kim and co-workers (29) showed that these animals had shorter obstruction times than normocholesterolemic controls. This enhanced arterial thrombosis tendency was associated with hypercoagulability. Roncaglioni et al. (30) observed that treatment of female rats with oral contraceptives caused an enhanced tendency to thrombotic occlusion of an aorta loop. The delayed onset of a hypercoagulable state, induced by the treatment of rats with adriamycin, was associated with a significant reduction in the occlusion time of aorta loops (31).

\subsubsection{Summary}

The aorta-10op technique provides a useful tool for measuring arterial thrombosis tendency in rats. The technique is relatively simple and inexpensive. Thrombosis frequency is $100 \%$ and the incidence of mortality is negligible. Compounds influencing platelet aggregation and blood coagulation, affect the arterial thrombosis tendency in a predictable manner. Moreover, known risk factors for atherosclerosis and thrombosis were shown to be associated with enhanced arterial thrombosis as measured by the aorta-loop technique.

\subsection{Measurement of platelet aggregation in.circulating arterial rat blood}

\subsubsection{Principle of the filter loop technigue}

After insertion of an aorta loop (section 5.2), the arterial circulation of anesthetized rats is passed through an extracorporeal filter as described by Swank et al. (6) for in vitro experiments. Before and behind this filter the blood pressure is measured continuously. Test solutions are infused before the filter. On inducing platelet aggregation, e.g. by administering an adenosine diphosphate (ADP) solution, the aggregates obturate the filter, as a result of which the pressures before and behind the filter change. These pressure changes are a measure of the obstruction of the filter and consequently of the degree of aggregation. 


\subsubsection{Description of the fi]ter system}

The filter system (Fig.5.12.) is connected to the circulation of the animals via a polyethylene aorta loop (see section 5.2.), which is inserted the day preceding the experiment. Portex vinyl tube no.4E (internal diameter $2 \mathrm{~mm}$ ) is used as a connecting tube. The two pressure transducers (Statham, type P23-Db) are connected to the system by glass 4-way connection pieces. The blood pressures are recorded by a two-channel recorder. The filter (Veco, Eerbeek, The Netherlands) consists of a round, nickel filter plate (diameter $12 \mathrm{~mm}$, pore width $20 \mu \mathrm{m}$ ), provided with a support screen. By means of two Teflon rings (internal diameter $9 \mathrm{~mm}$ ), the filter is fitted leak-proof in a metal filter holder (Millipore Swinny Hypodermic Adapter, Cat. No. XX 300 1200). Assembly of the filter is done under water to prevent inclusion or air bubbles. Close to the proximal connection of the filter system to the aorta loop, two thin cannulea (Portex PP 50) are introduced to administer the substances to be investigated. The places of introduction are sealed with quick-drying plastic glue. After assembly, the whole system (internal volume ca. $2 \mathrm{ml}$ ) is siliconized witr siliclad $1: 20$ and filled with a $0.9 \% \mathrm{NaCl}$-solution containing $5001 . \mathrm{U} \cdot \mathrm{ml}^{-1}$ heparin (Vitrum). To prevent the influence of temperature changes on the aggregation process, the system is embedded in a heating block

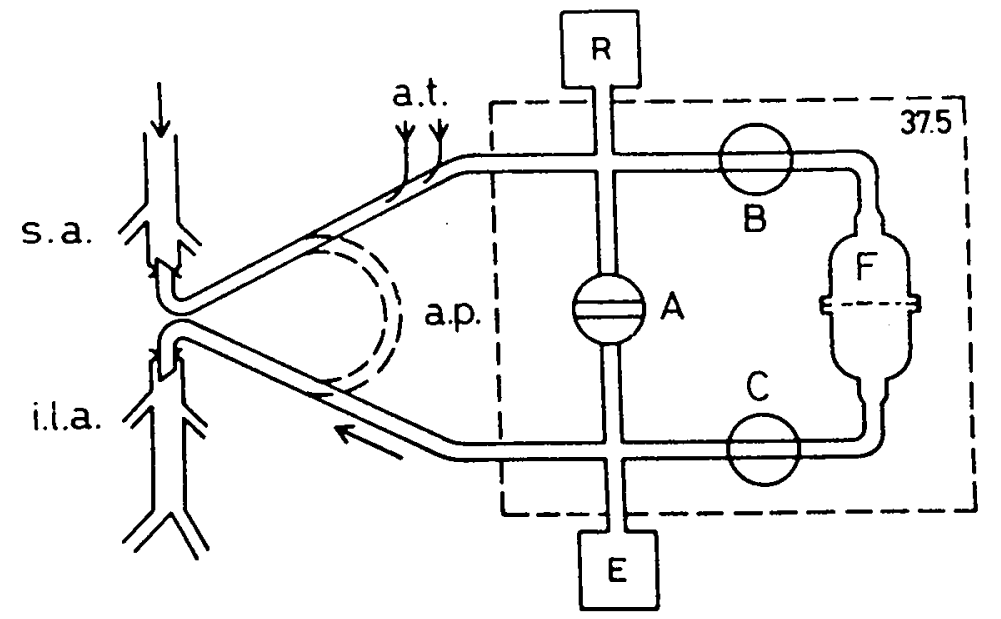

Eig.5.12. Schematic drawing of apparatus for measuring platelet aggregation in circulating arterial blood. R: recording of reference pressure, $E$ : recording of experimental pressure; $A, B$, and $C$ : valves; $F$ : filter; s.a.: spermatic arteries; a.p.: aorta loop (cut through); i.1.a.: iliolumbar arteries; a and $t$ : thin cannulae for infusing ADP and substances under investigation. 
which is kept at $37.5^{\circ} \mathrm{C}$ by warm water circulation.

After connection of the filter system to the arterial circulation of the animal, valve $A$ (Fig.5.12.) is opened slowly and the blood allowed to flow through the bypass. In most cases, the blood pressure will drop, which can be prevented by placing an oxygen hood over the animal's head. This device is not removed during the entire experiment. After levelling of the blood pressure, valves $B$ and $C$ are opened and valve $A$ is closed. The blood now flows through the filter. As a result of the internal resistance of the filter, the pressure before the filter is usually somewhat higher $(4-10 \mathrm{~mm} \mathrm{Hg})$ than behind it. For the rest, the filter has no appreciable influence on the blood circulation for hours. Obstruction as a result of spontaneous aggregation does only occur under certain dietary conditions (see Chapter 7, section 3.2.2.), and is only temporary. Therefore, it does not affect the aggregation measurements.

\subsubsection{Measurement_and_calculation of degree_of_aggregation}

Ten minutes after the filter has been included in the circulation of the rat, the first aggregation measurement can be performed. The ADP (adenosine-5-diphosphate trisodium salt, Boehringer, Mannheim, G.F.R.) used to induce aggregation is stored as a stock solution of $50 \mu \mathrm{g} \cdot \mathrm{ml}^{-1}$ at $-20^{\circ} \mathrm{C}$. Every day, this solution is diluted to the correct ADP-concentration and

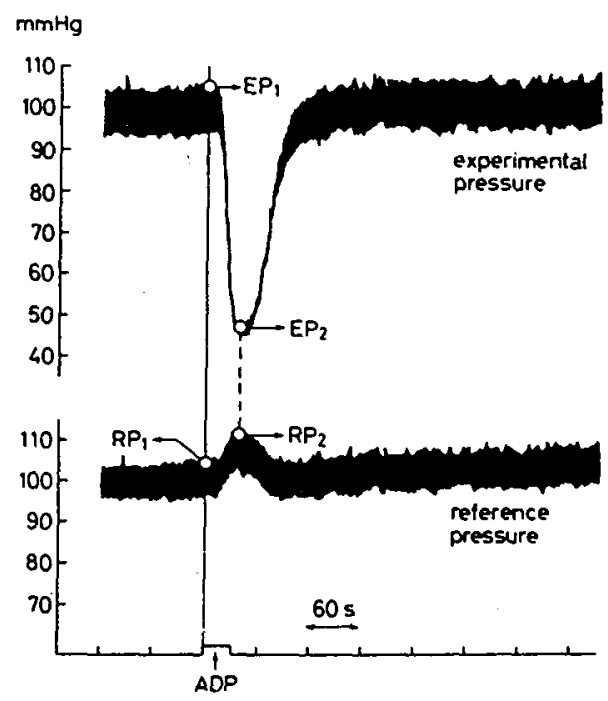

Fig.5.13. Recording of an aggregation measurement. For explanation of $E P_{1}$ and $E P_{2}$ and $R P_{1}$ and $R P_{2}$, see under section 5.3.3. 
kept in melting ice until use. No decay of the ADP-solution takes place within one day. It is administered by means of an infusion device (Unita, Braun, Melsungen, G.F.R.) at a rate of $0.1 \mathrm{ml} . \mathrm{min}^{-1}$ for $30 \mathrm{~s}$. Dependent on the ADP-concentration, more or fewer thrombocytes aggregate, as a result of which the filter is obturated rapidly or slowly, completely or partly, while the blood pressures before and behind the filter change and the pulse wave behind the filter diminishes (Fig.5.13.). The pressure changes consist of an increase in the reference pressure (RP = the systolic blood pressure before the filter) and a fall in the experimental pressure (EP = the systolic blood pressure behind the filter).

For practical purposes an aggregation index $A$ was defined as

$$
A=100 \times\left(1-\frac{E P_{2}}{R P_{2}} \times \frac{R P_{1}}{E P_{1}}\right)
$$

which is, in fact, the maximum pressure difference over the filter caused by ADP-administration expressed as a percentage of the reference pressure $\mathrm{RP}_{2}$ and corrected for small variations in reference and experimental pressures immediately before the administration of ADP.

After completion of the ADP-administration, the pressure benind the filter rapidly increases, as does the pulse wave. This indicates a cleaning of the filter as a result of disaggregation. Usually, the pressure returns to its initial level within a few minutes, after which the next measurement can take place. The time between two consecutive measurements has been standardized at $10 \mathrm{~min}$, because normalization of the concentration of circulating platelets takes about 6-8 $\mathrm{min}$ (see section 5.3.4.).

\subsubsection{Dose-response curve ADP.}

Aggregation measurements were performed on seven groups of 10 male Wistar rats, which were given ADP-doses varying from 0.0125 to $0.4 \mathrm{\mu g}$ per $30 \mathrm{~s}$. Each determination was performed twice on the same animal. The results are given in Table 5.4 .

For the $0.0175-0.2 \mu \mathrm{g} \mathrm{ADP.} 30 \mathrm{~s}^{-1}$ range, the correlation between log dose $A D P$ and the first as well as the second aggregation index is positive and does not deviate significantly from a straight line. Moreover, there is no significant difference between the two regression lines; so the first and second aggregation measurements carried out on the same animal, are reproducible.

The maximum value of $A$ appears to be 75 instead of 100 , as might be 
Table 5.4. Aggregation index (A) on administering varying doses of ADP twice to the same rat $(n=10)$.

\begin{tabular}{|c|c|c|}
\hline \multirow{2}{*}{$\begin{array}{l}\text { ADP dose } \\
\left(\mu g .30 \mathrm{~s}^{-1}\right)\end{array}$} & First measurement & Second measurement \\
\hline & $A_{1} \pm S E M$ & $A_{2} \pm S E M$ \\
\hline $\begin{array}{l}0.0125 \\
0.0175 \\
0.025 \\
0.05 \\
0.1 \\
0.2 \\
0.4\end{array}$ & $\begin{array}{l}11.8 \pm 4.4 \\
16.6 \pm 6.1 \\
24.6 \pm 7.8 \\
48.9 \pm 7.2 \\
58.3 \pm 6.1 \\
75.0 \pm 3.9 \\
73.2 \pm 2.9\end{array}$ & $\begin{array}{l}10.7 \pm 3.7 \\
12.6 \pm 4.5 \\
31.2 \pm 7.3 \\
42.6 \pm 8.1 \\
62.0 \pm 3.9 \\
75.3 \pm 4.1 \\
70.1 \pm 3.0\end{array}$ \\
\hline
\end{tabular}

expected on theoretical grounds. This is at least partly due to the fact that the residual arterial pressure after complete obstruction of the aorta is still $10-20 \mathrm{~mm} \mathrm{Hg}$.

During aggregation, $0.8-2 \times 10^{5}$ molecules of ADP can be taken up per human platelet $(32,33)$. This implies that both the flow-rate and the thrombocyte concentration in the blood can influence the ADP-induced aggregation for at a higher flow-rate, more thrombocytes are passing per unit of time than at a lower rate and, consequently, less ADP per thrombocyte is available. In our experiments, the thrombocyte concentration varied between 616,700 and $1,316,600 . \mu 7^{-1}$ (mean 957,700. I $^{-1}$; $n=14$ ). The flow-rate in the filter at the start of an experiment could not be measured exactly, but the mean value in 10 experiments was approximately $10 \mathrm{ml} \cdot \mathrm{min}^{-1}$ (between 8 and $18 \mathrm{ml} \cdot \mathrm{min}^{-1}$ ). It is probable that these individual differences in flow-rate and thrombocyte concentration are responsible for the relatively wide range in $\mathrm{A}$ (see Table 5.4.). Also a difference in the rate of disaggregation caused by differences in the amount of ADP-splitting enzymes in the plasma of the animals (34) may play a role.

\subsubsection{Course of the aggregation index after repeated administration of ADP.}

When the number of measurements on the same animal is extended, a significant decrease in aggregation index is observed. This was investigated

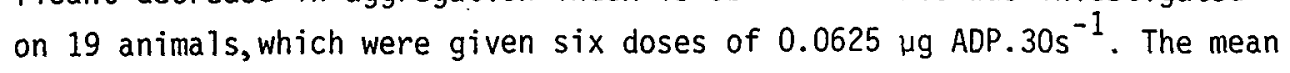


Table 5.5. Mean aggregation index after administration of six doses of $0.0625 \mu \mathrm{g}$ ADP per $30 \mathrm{~s}$ to the same animal. $A_{1}=$ first aggregation index of each series.

\begin{tabular}{lccllll}
\hline \multirow{2}{*}{ Aggregation index } & \multicolumn{6}{l}{ Dose no. } \\
\cline { 2 - 7 } & 1 & 2 & 3 & 4 & \multicolumn{1}{l}{5} & \multicolumn{1}{l}{6} \\
\hline $\begin{array}{l}\text { Absolute } \\
\% \text { of } A_{1}\end{array}$ & 57.5 & 57.0 & 53.3 & 48.5 & 41.5 & 34.8 \\
\hline
\end{tabular}

aggregation indices are shown in Table 5.5, both as absolute values and as percentages of the first aggregation index $\left(A_{1}\right)$. The correlation between dose number and absolute as well as proportional aggregation index is significant, negative, and rectilinear. However, the significance does not occur until after the fifth measurement. The mean aggregation index has been represented graphically in Fig. 5.14, together with values obtained for some individual animals. The figure clearly shows that great differences exist in the time when the aggregation index starts to decrease. The decrease was observed for all ADP-doses tested.

This decrease in aggregation index after repeated ADP-administrations (see Table 5.5.) is probably not due to thrombocytopenia (see section

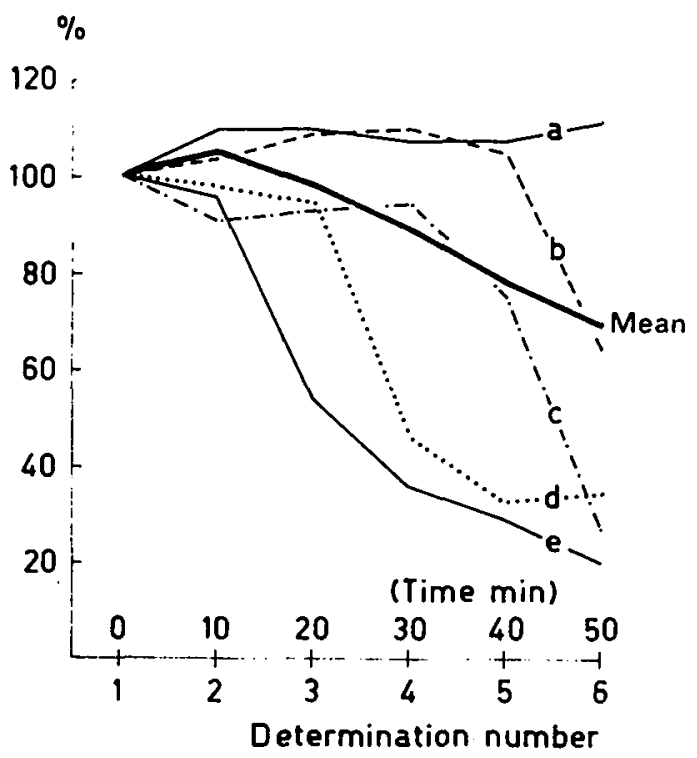

Fig.5.14. Mean aggregation index, together with some individual values (a-e), after administration of six doses of $0.0625 \mu \mathrm{g}$ ADP per $30 \mathrm{~s}$ to the same animal $(n=19)$. Results are plotted as a percentage of the first aggregation index of each experiment. 
5.3.4.2.). This certainly applies to the first five measurements (Table 5.6.). The influence of a slight increase in the flow-rate of the blood, found during a series of measurements, on the aggregation index is not known.

In human plasma, ADP is degraded in vitro to adenosine monophosphate (AMP) and adenosine (35). Although nothing is known about the in vivo degradation of ADP in the circulation of the rat, the AMP and adenosine concentration in the circulation probably increases on repeated ADPadministration. According to Cuthbertson and Milis (36), these two metabolites of ADP do not influence the ADP-induced thrombocyte aggregation in the rat in vitro, in contrast to other animals. Constantine (37), however, observed that adenosine did inhibit the aggregation in citrated rat plasma. Born and Philp (38), moreover, found that adenosine inhibits the formation of platelet thrombi induced by mechanical damage of blood vessels of the cerebral cortex of rats. Thus, ADP-metabolites could contribute to decreased ADP-sensitivity of the platelets after repeated aggregation measurements on the same animal.

Constantine (37), O'Brien (39), Rozenberg and Holmsen (40) and Busfield and Tomich (41) observed that pre-incubation of thrombocytes (rat, rabbit) with ADP inhibits the ADP-induced aggregation. This phenomenon may also be one of the causes of a decreasing aggregation in repeated measurements on the same animal, as represented in Fig.5.14. and Table 5.5.

\subsubsection{Effect of aggregation measurements on the concentration of circu= lating platelelets}

Microscopic investigations showed that the material obstructing the filter when ADP is infused consisted mainly of thrombocytes. Moreover, blood smears taken behind the filter during ADP-infusion before the filter, contained fewer and much smaller platelet aggregates than the smears taken simultaneousiy before the filter. During ADP-administration, the concentration of blood platelets before the filter is also significantly higher than behind it. In 11 animals, these concentrations were 865,000 and 772,100 platelets. $\mu 1^{-1}$. respectively (phase-contrast microscopy). It is therefore assumed that the changes in pressure before and behind the filter, induced by ADP-administration, are mainly caused by thrombocyte aggregation. 
5.3.4.1. Influence of single aggregation measurement on the concentration of circulating platelets.

As a result of the ADP-induced platelet aggregation, the concentration of circulating thrombocytes drops temporarily. To investigate this effect, circulating platelets were counted in 10 animais, 10, 5, and $1 \mathrm{~min}$ before administration of $0.0625 \mu \mathrm{g} A D P$ per $30 \mathrm{~s}(\bar{A}=50.3)$ and every $2 \mathrm{~min}$ for a period of $20 \mathrm{~min}$ after ADP-administration. The mean course of the thrombocyte concentration is shown in Fig.5.15. During the entire experimental period, the thrombocyte concentration does not differ significantly from the initial value. The values obtained 2 and 4 min after ADP-administration, however, do differ significantly. This difference probably indicates trapping of aggregated platelets on the filter and of partly disaggregated platelet clumps in the capillary bed, followed by a release of the trapped platelets (see also ref.42). Although the rise in platelet count 4 min after ADP-administration does not lead to a thrombocyte concentration that is significantly higher than the initial value, the resultant overshooting may indicate fragmentation of part of the platelets as a result of the experimental procedure and/or temporary release into the circulation of a hitherto sequestered group of platelets.

5.3.4.2. Influence of repeated aggregation measurements on the concentration of circulating platelets.

In 11 animals, thrombocyte counts were performed directly before each

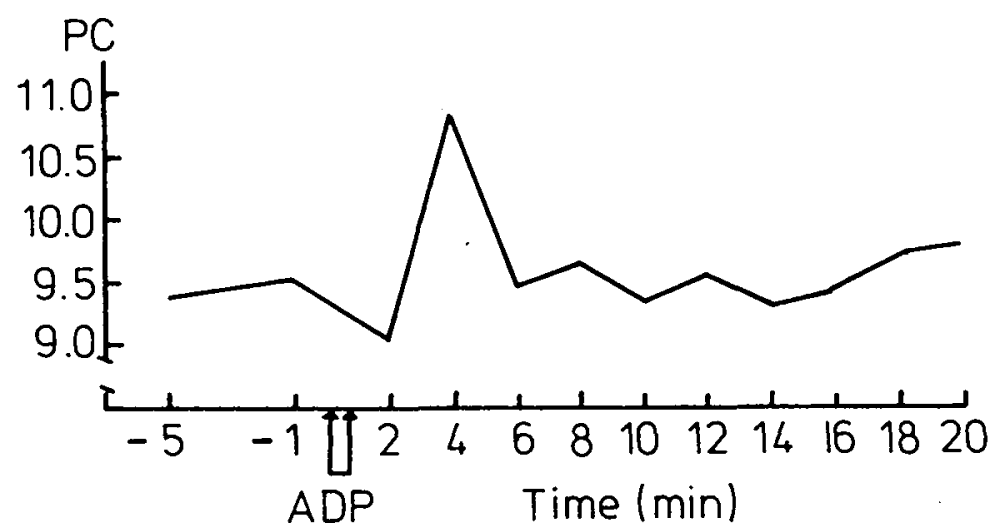

Fig.5.15. Concentrations of circulating platelets ( $P C \times 10^{5} . \mu 1^{-1}$ ) before and after aggregation upon administration of $0.0625 \mu \mathrm{g} \mathrm{ADP} .30 \mathrm{~s}^{-1}$ $(n=10)$. Blood samples were taken in front of the filter. 
Table 5.6. Number of circulating blood platelets (per $\mu$ l blood) after administration of six doses of $0.1 \mu \mathrm{g}$ ADP per $30 \mathrm{~s}$ to the same animal $(n=11)$. Bloos samples were taken before the filter.

\begin{tabular}{ll}
\hline Dose no. & Platelet count \pm SEM \\
\hline 1 & $865,900 \pm 75,300$ \\
2 & $775,800 \pm 82,580$ \\
3 & $926,300 \pm 84,340$ \\
4 & $840,900 \pm 72,040$ \\
5 & $857,600 \pm 81,340$ \\
6 & $680,500 \pm 75,780$ \\
\hline
\end{tabular}

aggregation measurement, administering six doses of $0.1 \mu \mathrm{g}$ ADP per $30 \mathrm{~s}$. The results are given in Table 5.6. There are no significant differences between the platelet concentrations observed in the first five measurements. The drop in platelet concentration seen during the sixth determination is significant.

\subsubsection{Application of the filter-loop technigue}

Only substances, such as ADP, that induce platelet aggregation immediately can be used to trigger aggregation, because the aggregates must have been formed before the reaction mixture passes the filter. Therefore, it appeared impossible to use collagen as an aggregation inducer. The use of thrombin is also impossible, as the animal has to be anticoagulated to prevent clotting on the filter. Arachidonic acid, however, has been used successfully to trigger aggregation.

\subsubsection{Effect of prostaglandin $E_{1}$.}

Prostaglandin $E_{1}\left(P E_{1}\right)$ was shown by Kloeze to be an effective inhibitor of platelet aggregation, both in vitro (14) as well as in vivo $(43,44)$. Because of the rapid inactivation of $\mathrm{PGE}_{1}$ in vivo (18), its aggregation inhibiting effect is reported to be of short duration (19). The filter -ioop technique appeared particularly useful for obtaining exact information as to the degree and duration of the aggregation inhibiting action of $\mathrm{PGE}_{1}$, not only upon infusion with the extracorporeal system together with ADP, but also when administered via other routes (45). 
When mixed with $A D P, P G E_{1}$ inhibited the ADP-induced aggregation in a dose-dependent way. The duration of the inhibiting effect was less than $10 \mathrm{~min}$. The same applied to the effect of intravenously (jugular vein) and intra-arterially (extracorporeally behind the filter) administered $P G E_{1}$. When given subcutaneously or intramuscularly, the inhibiting effect of $\mathrm{PGE}_{1}$ lasted somewhat longer, which is most probably due to the rather slow absorption rate. When $\mathrm{PGE}_{1}$ was administered intraperitoneally, an unexpected phenomenon was observed.

In 2 groups of 10 animals, 18 consecutive aggregation measurements per animal were performed using the same dose of ADP. One min before the second measurement, $25 \mu \mathrm{PGE}_{1}$ in saline was injected intraperitoneally. In the control group, only saline was injected. Degree and duration of the $\mathrm{PGE}_{1}$-induced aggregation inhibition were calculated by correcting the course of the aggregation in the experimental group in relation to that in the control group. The results of this experiment are given in Fig.5.16. from which it appears that $P_{G E}$ exercises a biphasic aggregation inhibiting action. There is substancial evidence that only the first phase of the inhibition is caused by $\mathrm{PGE}_{1}$ itself and that the second can be ascribed to a substance released from intraperitoneal mast cells upon $\mathrm{PGE}_{1}$ administration (45).

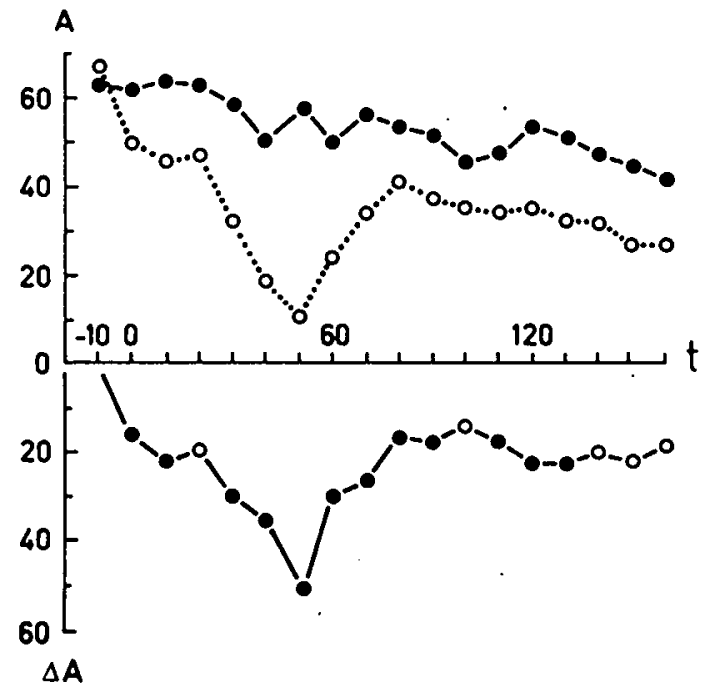

Fig.5.16. Course of aggregation index (A) upon repeated ADP administration and aggregation inhibiting effect $(\triangle A)$ of $25 \mu \mathrm{PGE}_{1}$ in $0.25 \mathrm{ml}$ saline administered intraperitoneally.

$A:$ - - saline. ……... $P G E_{1}$ in saline. $\triangle A:$ significant $\left(P_{2}<0.05\right)$

o not significant $\left(P_{2}>0.05\right)$. t: time $(\min )$ after $P_{G E}$ or saline administration $(n=10)$. 
5.3.5.2. Effect of two serum 1ipid-lowering drugs.

Atromid-S (ethyl-2-(p-chlorophenoxy)-2-methylpropionate) and Ronicol (B-pyridylcarbinol) are serum lipid-lowering substances $(46,47)$ with inhibiting effects on platelet aggregation (48-50) although this is not generally confirmed $(51,52)$. To investigate the effect of these drugs in circulating arterial blood, animals were given Atromid-s, $0.3 \%(w / v)$ in the diet, or Ronicol, $20 \mathrm{mg}$ twice daily orally, or nothing (control group). Drug administration continued for 3-5 weeks, after which ADP induced aggregation was measured by means of the filter-loop technique, using 3 different doses of ADP. The results (Fig.5.17.) showed that Atromidand Ronicol decreased the ADP-sensitivity of the blood platelets significantly $\left(P_{2}<0.01\right)$. Atromid-S tended to be somewhat more active than Ronicol $\left(0.05<P_{2}<0.1\right)$.

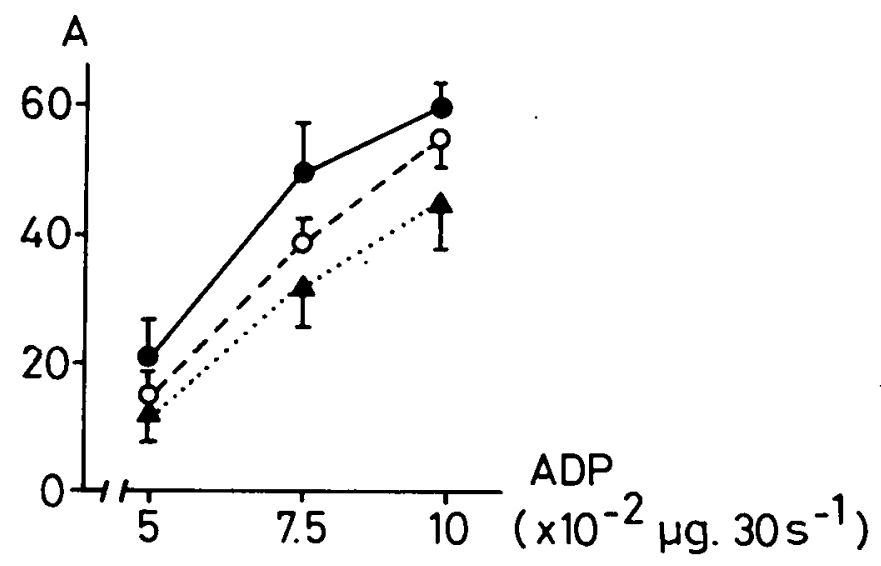

Fig.5.17. ADP-induced aggregation of blood platelets in circulating arterial blood (A) of rats $(n=18)$ fed $0.3 \% \mathrm{w} / \mathrm{w}$ Atromid $(\boldsymbol{\Lambda . . . . . . 4 )}$ or given $20 \mathrm{mg}$ Ronicol twice daily $(0-\ldots-0)$ for 3-5 weeks. Mean \pm SEM. $\multimap$ control group.

5.3.5.3. Other applications.

The filter-loop technique has also been adopted by other investigators, not only for rats (53) but, after minor modifications, also for dogs (54) and monkeys (55). In these experiments, the technique was successfully used for drug-screening. 


\subsubsection{Summary}

To enable the investigation of platelet aggregability in relation to arterial thrombosis, a technique was developed to measure the ADP-induced platelet aggregation in circulating arterial blood. The advantage of this method is that aggregation is measured in whole blood (containing all aggregation modulating factors, including the short-lived) and under conditions of arterial flow. The major limitation of the technique is that only substances can be used that induce platelet aggregation immediately, without a time lag. The technique has been applied by us and others and appeared particularly useful for the screening of aggregation -affecting drugs (ex vivo) and treatments (in vivo).

\subsection{Measurement of spontaneous aggregation in flowing venous blood of} man

The filter-loop technique is difficult to apply in humans because its use requires arterial punction. This procedure often leads to spasm and consequently to a low blood flow. Moreover, it has a high incidence of

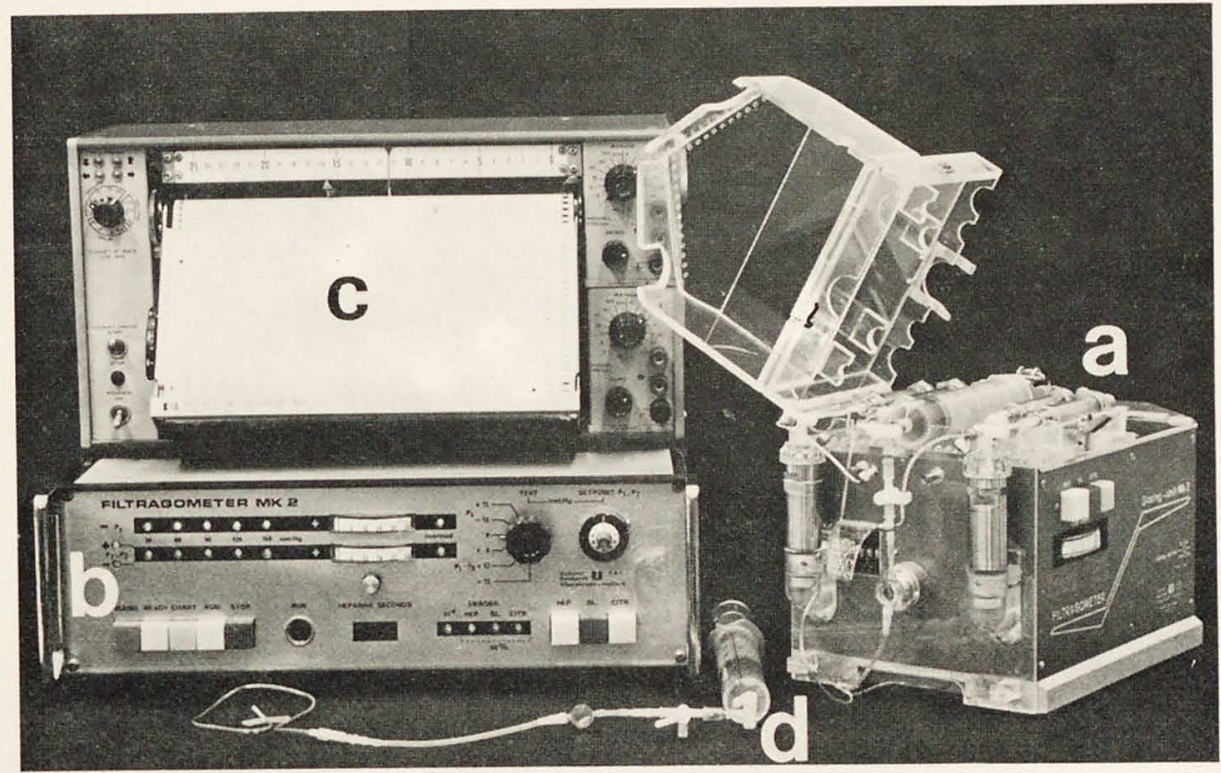

Fig.5.18. Filtragometer.

a: dosing unit; b: electronics compartment; $c$ : recorder; $d$ : needle, tubing with mixing chamber, filter with 3-way stopcocks and syringe. 


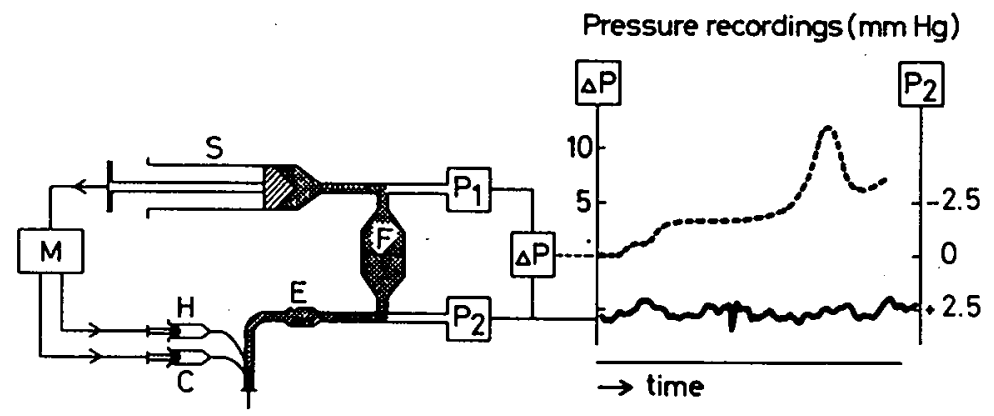

Fig. 5. 19. Diagram of filtragometer.

M: Motor; S: Syringe; F: Filter; E: Mixing Chamber; H: Heparin infusion; $C$ : Citrate infusion.

For explanation of $P_{1}, P_{2}$ and $\Delta P$, see section 5.4.1.

thrombotic complications (56). Therefore, we developed a venous modification of the technique, for which a new device, the Filtragometer ${ }^{\circledR}$, was constructed (Fig.5.18.).

\subsubsection{Description of the Fil tragometer}

A diagram of the filtragometer is given in Fig. 5.19. By means of a motor $(M)$ driven syringe $\left(S, P l a s t i p a k, 50 \mathrm{ml}, B-D\right.$. Company or Monoject ${ }^{\circledR}$, $60 \mathrm{ml}$, Sherwood Medical Industries Inc., Deland, Florida) blood is drawn from a cubital vein via a mixing chamber ( $E, 0.40 \mathrm{ml}$ ) with a magnetic stirrer (1600 rev.min ${ }^{-1}$ ) through a nickel filter ( $F$, diameter $6 \mathrm{~mm}$; diameter of the apertures $20 \mu \mathrm{m}$, ex Veco, Eerbeek, The Netherlands) at a flow-rate of $2.25 \mathrm{ml} . \mathrm{min}^{-1}$. The filter, part of the afferent connecting tube (Portex PE4, outer diameter $3 \mathrm{~mm}$, inner diameter $2 \mathrm{~mm}$ ) and the pressure transducers (vide infra) are enclosed in a Perspex cabinet, heated by warm air to keep the blood at $37^{\circ} \mathrm{C}$. The filter house is connected to the afferent tube and the syringe by two plastic three-way stopcocks (K-75, Pharmaseal Laboratories, Glendale, California 91201, U.S.A.), the free ends of which are connected to pressure transducers (Statham $P$ :23 Ia) to measure the pressure before $\left(P_{2}\right)$ and after $\left(P_{1}\right)$ the filter. The pressure difference $\triangle P$ and the reference pressure $P_{2}$ are recorded on a two-channel recorder (Moseley Strip Chart recorder, 7100 BM, Hewlett Packard). At constant flow-rate, $\Delta P$ is a measure of filter occlusion, and thus of the degree of aggregation, whereas $P_{2}$ indicates a possible flow obstruction. The distal end of the connecting tube is supplied with a male Luer adaptor 
(605/L, B-D Company), proximal to which needles (14 gauge) are inserted for infusion of heparin $\left(H, 0.1 \mathrm{ml}^{-m_{n}}{ }^{-1}, 112.5\right.$ I.U. $\mathrm{ml}{ }^{-1}$ saline) or sodium citrate solution ( $C, 0.1 \mathrm{ml} . \mathrm{min}^{-1}, 7.6 \mathrm{w} / \mathrm{v} \%$ in distilled water). The whole system is siliconized (Siliclad) and primed with a $3.8 \mathrm{~W} / \mathrm{v} \%$ sodium citrate solution. All solutions are filtered before use (Millipore GSWP $04700,0.22 \mu \mathrm{m})$.

\subsubsection{Concise description_of some introductory model_experiments}

In model experiments, in which Rheomacrodex or a suspension of latex particles (mean diameter $25 \mu \mathrm{m}$ ) in Rheomacrodex was drawn through the filter, it was shown that the filtragometer reacts reproducibly to a standard obstruction (Fig.5.20). Knowing the concentration of the latex particles and assuming a homogeneous suspension, the number of obstructed pores can be calculated at any given time and be related to the pressure ratio over the filter. From these experiments it appeared that $\Delta P$ already starts rising when only $5 \%$ of the filter area is obstructed and that, at $\Delta P=5 \mathrm{~mm} \mathrm{Hg}$, the proportional filter occlusion is about $25 \%$ (Fig.5.21.).

From in vitro experiments, in which PRP was drawn through the filter and different doses of ADP were infused to induce various degrees of aggre-

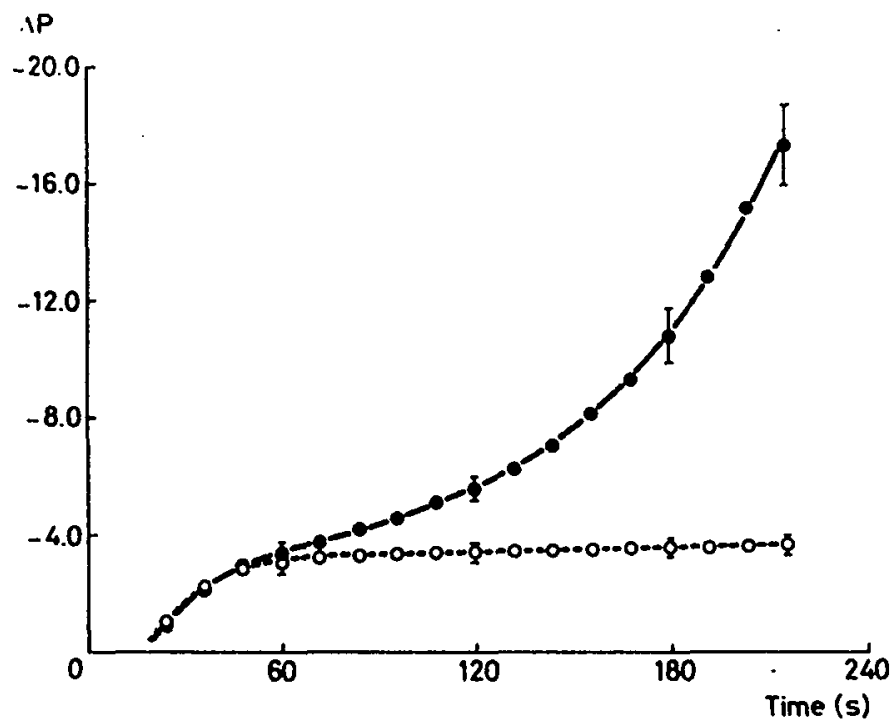

Fig.5.20. Time-course of pressure gradient over filter ( $\triangle \mathrm{P}, \mathrm{mm} \mathrm{Hg} \pm \mathrm{SEM}$ ) resulting from filter occlusion. - - o-- Rheomacrodex drawn through filtragometer; —- Rheomacrodex plus latex particles; $(n=10)$. 


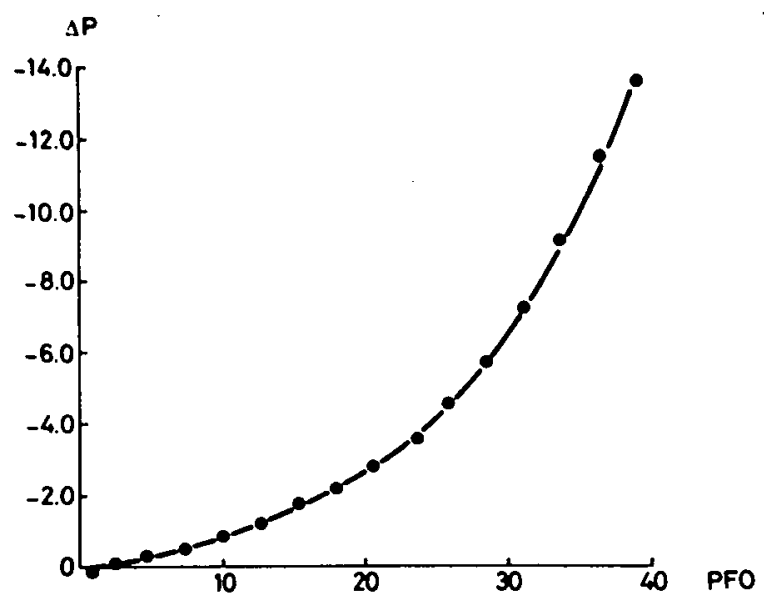

Fig.5.21. Relation between pressure gradient over the filter ( $\triangle \mathrm{P}, \mathrm{mm} \mathrm{Hg})$ and proportional filter occlusion (PF0, \%). For experimental details see section 5.4.2.

gation, the filtragometer response -indicated by the inverse value of the aggregation time, $t_{A}$ (time needed to obtain a standardized obstruction, see section 5.4.4)- was negatively related to the number of single platelets in the aggregated PRP and positively related to the number of aggregates larger than $100 \mathrm{\mu m}^{3}$ (Fig.5.22.). From these experiments it can be concluded that the filtragometer is able to quantify different degrees of platelet aggregation. With the same experimental set-up (PRP and ADP), the fairly obvious effects on platelet aggregation of stirring-rate, flow-rate and platelet count were demonstrated. Also in the in vivo mea-
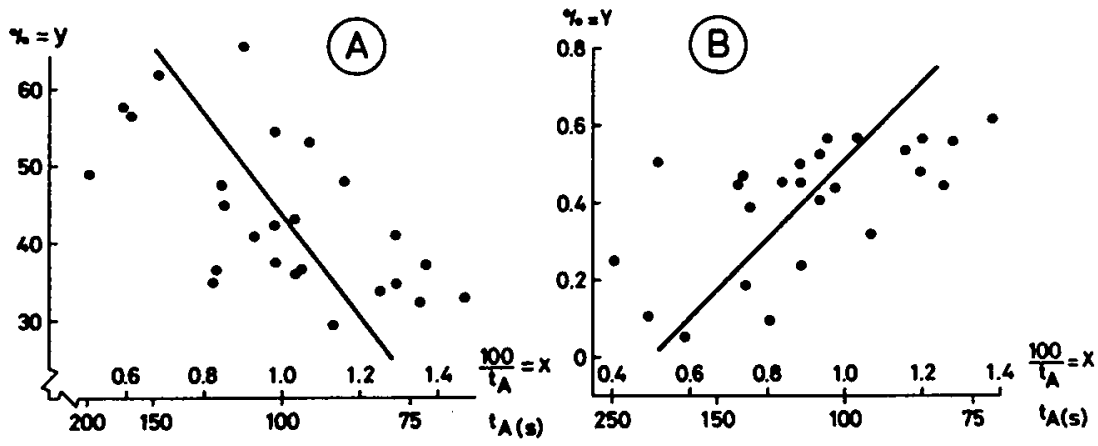

Fig. 5.22. Relationship between filtragometer response $\left(t_{A}\right.$; see section $5.4 .4)$ and $\%$ of single platelets (A) or $\%$ of aggregates $>100 \mu^{3}$ (B) in PRP.

A: $X=1.56-0.015 Y ; r=-0.59 ; n=24 ; P<0.01$.

$B: X=0.50+0.970 Y ; r=0.62 ; n=25 ; P<0.001$. 
surements, the blood flow appeared to be an important determinant of the filtragometer response, as was the filter diameter. Moreover, the temperature of the blood was very important: at $37^{\circ} \mathrm{C}$, the filtragometer response was only about $85 \%$ of that at room temperature (temperature of the blood at the filter approximately $30^{\circ} \mathrm{C}$ ).

\subsubsection{Measuring technigue in man}

Immediately prior to starting the measurement, the citrate infusion ( $C$, Fig.5.19.) is switched on to prevent inclusion of air bubbles while the system is being connected to the venous circulation. Inclusion of air bubbles should be strictly avoided because most of them do not pass the filter and thus reduce the effective filter area and initiate thrombotic phenomena at the air/blood interface (57). The selected vein is punctured with a metal needle (Microlance $18 \mathrm{G} \mathrm{1.5,} \mathrm{Luer,} \mathrm{B-D} \mathrm{Company} \mathrm{or} \mathrm{Butterfly,}$ $19 \mathrm{G}, 30 \mathrm{~cm}$, Abbott Laboratories No. 8488, Luer). Since venous compression was found to increase the filtragometer response, puncturing is carried out under minimal stasis. The first drops of blood are allowed to drain away, after which the system is connected to the needle, the suction pump started, the citrate infusion switched off and the heparin infusion switched on. When $\Delta P$ reaches $5 \mathrm{~mm} \mathrm{Hg}$, heparin. is switched off and the citrate infusion started again. When no further information is wanted, the suction pump is stopped after removal of the needle. If red blood clots are observed on the filter, the results of the measurements cannot be used.

\subsubsection{Description_of the__aggregation_curve_and definitition_of_aggregation parameters}

The start of the measurement is indicated by an upward deflection of the tracing (Fig.5.23.). From this moment, blood is drawn from the arm and heparin administered (final concentration 5 I.U. $\mathrm{ml}^{-1}$ ). Due to the resistance of the system, a small pressure difference builds up, which increases as the viscous blood replaces the priming citrate solution. A further increase in $\Delta \mathrm{P}$ indicates that platelet aggregates are obstructing the filter. This has been confirmed by scanning electron microscopy (see Fig.5.24.). A downward deflection marks the moment when $\Delta P$ equals $5 \mathrm{~mm} \mathrm{Hg}$. At this 


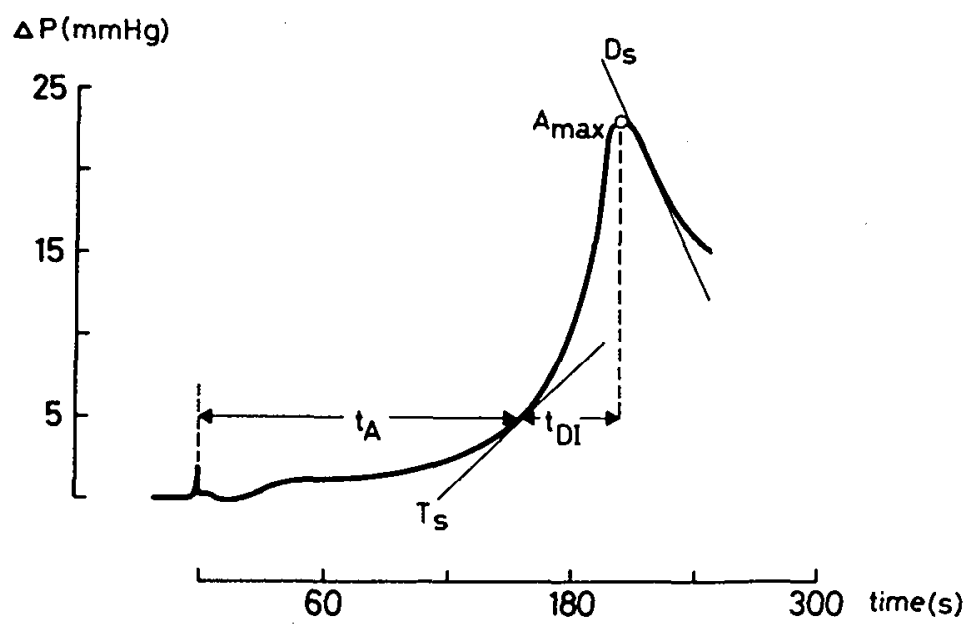

Fig.5.23. Schematic representation of aggregation curve.

$t_{A}$ : aggregation time; $T_{S}$ : aggregation velocity; $A_{\max }$ : maximum aggregation; $t_{D I}$ : disaggregation induction time; $D_{S}$ : disaggregation velocity.

moment, heparin is replaced by citrate and after a short period, the decrease in $\Delta P$ indicates cleaning of the filter by disaggregation. From the $\Delta P$-curve, the following parameters can be calculated:

- the aggregation time, $t_{A}$, which is the time (s) necessary to reach a $\Delta P$-value of $5 \mathrm{~mm} \mathrm{Hg}$.

- the aggregation velocity, $T_{S}$, defined as $\operatorname{tg} \alpha$, where $\alpha$ is the angle between the tangent to the curve at $\Delta \mathrm{P}=5 \mathrm{~mm} \mathrm{Hg}$ and the horizontal (=time) axis.

- the maximum aggregation, $A_{\max }$, which is the maximum height of the aggregation curve in $\mathrm{mm} \mathrm{Hg}$.

- the disaggregation induction time, $t_{D I}$, being the time (s) between termination of heparin infusion and start of disaggregation.

- disaggregation velocity, $D_{S}$. which is the angle of the downward slope of the curve after $A_{\text {max }}$ has been reached.

For most purposes, $t_{A}$ appeared to be the most practical aggregation parameter.

\subsubsection{Scanning_electron microscopy of the fil ter}

Aggregation measurements were carried out as described in section 5.4.3. At $\Delta \mathrm{P}=5 \mathrm{~mm} \mathrm{Hg}$, a $2 \%$ glutaraldehyde solution in phosphate-buffered saline $\langle\mathrm{pH} \mathrm{7.4)} \mathrm{was} \mathrm{drawn} \mathrm{through} \mathrm{the} \mathrm{filter,} \mathrm{the} \mathrm{blood} \mathrm{supply} \mathrm{being} \mathrm{terminated.}$ 
After 2 min of glutaraldehyde perfusion, the filter was taken out and placed in a fresh glutaraldehyde solution for another $15 \mathrm{~min}$. After being washed and dehydrated with acetone, the filters were cut into two parts, which were being glued to a specimen stub in such a way that both the downstream side of the filter could be observed. The material was coated with carbon and gold layers of about 10 and $50 \mathrm{~nm}$ respectively, and investigated with a Cambridge Stereoscan electron microscope $\$ 4$ at an acceleration voltage of $10 \mathrm{kV}$.

From the photographs (Fig.5.24.) it is evident that filter occlusion is mainly the result of platelet aggregates in which red cells are trapped. Fibrin is not observed. A larger magnification shows that the aggregated platelets are closely packed but retain their individual shape. They seem to be swollen but platelet fusion has not taken place. The aggregated platelets have only a few pseudopodia except for those which have stuck to the filter material.

A large number of aggregates sticks to the filter material without blocking the filter pores and consequently do not contribute to the measured degree of aggregation. As the passable area of the filter (total surface area of the pores relative to the total surface area of the filter) is only $3-4 \%$, the real degree of aggregation is much higher than corresponding to the observed pressure changes. Therefore, a filter with a passable area of about $50 \%$ was introduced later on.Both filters gave comperable results.

\subsubsection{Origin of the measured_aggregates}

From the scanning electron microscopic pictures (Fig.5.24.) it is clear that the filtragometer response is caused by occlusion of the filter by platelet aggregates. It is not exactly known where these aggregates are formed but there is evidence that, at least in part, they are already formed in vivo. Intravascular aggregates have been shown to occur in rabbits (58), mice (59), rats (60), and man (61-63).

In this respect, also the observations of Solis et al.(64) are relevant. They observed particles with diameters between 13 and $80 \mu \mathrm{m}$ in venous as

Fig. 5.24. Scanning electron microscopic pictures of a partly occluded filter (tilt $0^{\circ}$ ).

a. upstream side; b. larger magnification of a; c. downstream side;

d. larger magnification of $c$. 

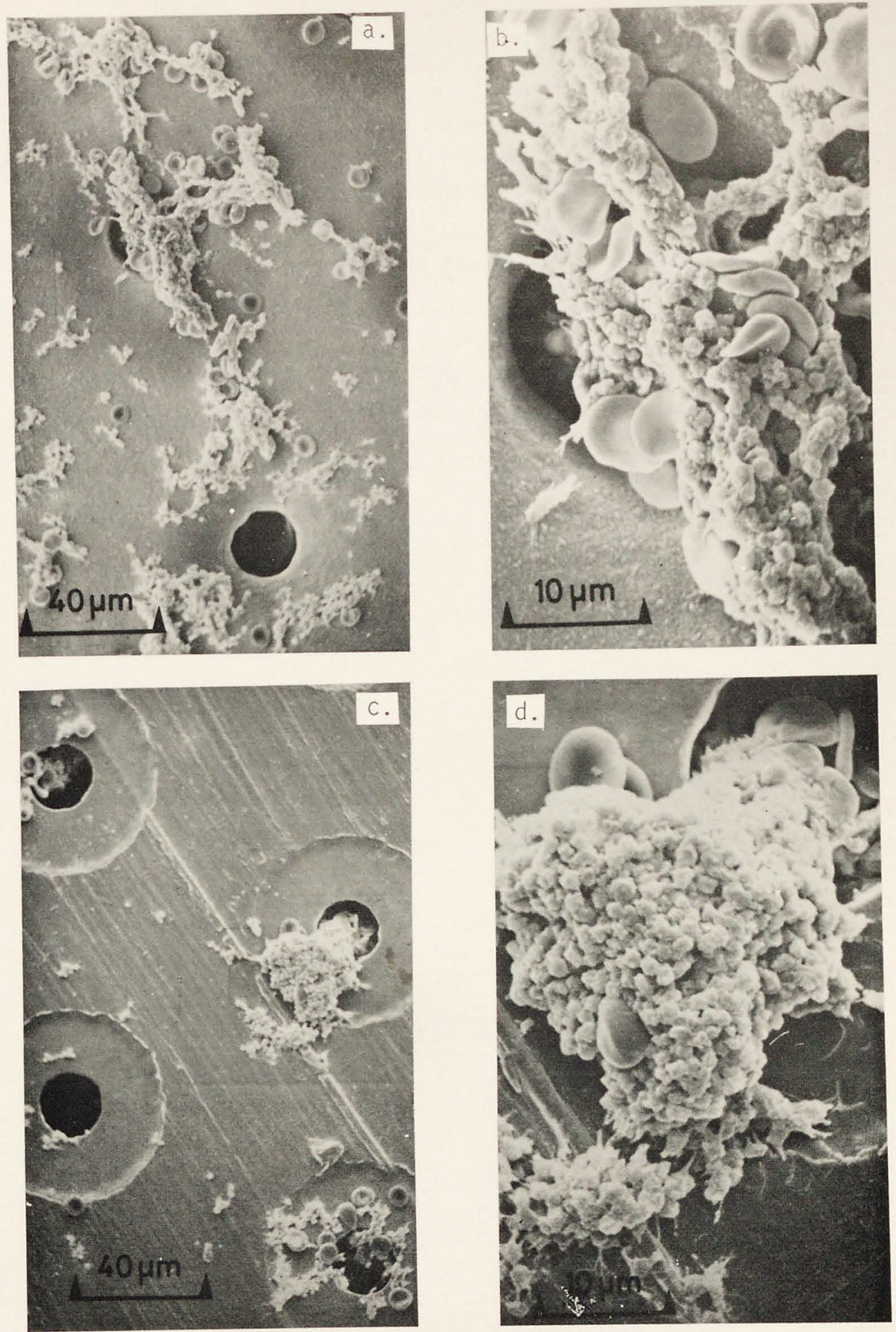
well as in arterial rat blood and also showed that, in venous blood, these particles dramatically increased in number in response to ADP injection in the carotid artery. Since we know that intra-arterially injected ADP causes immediate platelet aggregation (section 5.3), these findings suggest that intra-arterially formed aggregates are not, or very ineffectively trapped in the peripheral circulation so that aggregates, measured on the venous side, may very well reflect arterial thrombotic phenomena.

On the analogy of what was shown for the glass bead column (65), red cell and/or platelet damage possibly (and probably) occurring in the filtragometer, may, at least in part, be responsible for the aggregation measured in the filtragometer. However, a negative relationship between hematocrit and platelet aggregation has been established (Fig.5.28.) whereas a positive one is expected if red cell ADP would be a major aggregation stimulus. Moreover, infusion of apyrase, an enzyme that rapidly degrades ADP (66) did not inhibit the aggregation response in the filtragometer. Therefore, a contributory role of ADP - liberated from erythrocytes - to the aggregation measured with the filtragometer, is rather unlikely.

If platelet aggregation would indeed be initiated inside the filtragometer, the stirring rate in the mixing chamber will have a certain effect, as was shown in the PRP/ADP model system. However, in four anticoagulated
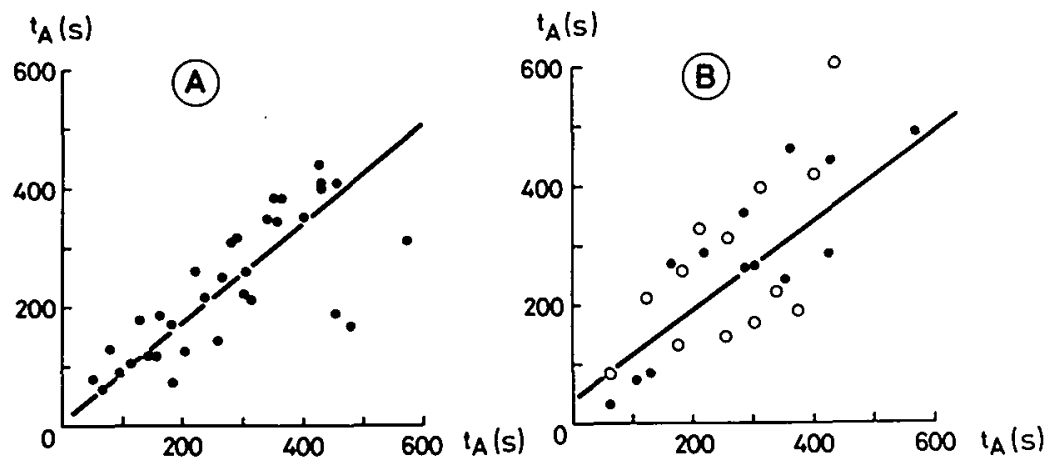

Fig.5.25. Reproducibility of platelet aggregation measured with two filtragometers.

A. Measurement at 20 min intervals. Abscissa: Filtragometer 1; ordinate: Filtragometer 2.

$Y=11+0.82 X ; r=0.74 ; P<0.001$.

B. Measurement at 1 week interval. Each set of measurements performed with the same filtragometer. - filtragometer 1; o filtragometer 2 . $Y=40.5+0.81 X ; r=0.75 ; P<0.001$. 
subjects, no aggregation-inducing effect of mixing was observed. On the contrary, mixing seemed to lower the aggregation response somewhat, which might be. due to dispersion of the aggregates already present (with mixing: $\log t_{A}=2.01 \pm 0.108, t_{A}=103 \mathrm{~s}$; without mixing: $\log t_{A}=1.87 \pm 0.120$, $\left.t_{A}=74 \mathrm{~s}\right)$.

We conclude that it is highly probable that the filtragometer measures at least. for the greater part, the degree of platelet aggregation in the blood before it enters the apparatus. However, formation of aggregates within the filtragometer cannot be excluded completely, especially because the temperature of the blood appears to affect the filtragometer response (section 5.4.2.), and because the geometry of the filtragometer system has been shown to affect the (dis-)aggregation values.

\subsubsection{Reproducibilitty of the filtragometer response}

Measurements with two different filtragometers at intervals of $20 \mathrm{~min}$ and one week gave reproducible aggregation times (Fig.5.25.).

The stability of the filtragometer response was tested by measuring platelet aggregation 7 times in 21 volunteers at weekiy intervals. These subjects did not use drugs known to affect platelet stickiness and did not change their way of living to any great extent during the experimental period. Table 5.7. gives the mean values of the 7 consecutive measurements. In 4 individuals, disaggregation did not occur once or twice ( 6 cases in all), hence $A_{\max }$ and $t_{D I}$ could not be measured; and a comparison of the mean values has been carried out with 17 instead of with 21 individuals. The mean values have been compared by multiple analysis of variance, which showed that significant differences could not be indicated for any of the 4 criteria. Therefore, a steady state may be assumed during the experimental period. For each aggregation parameter, the mean and standard deviations were calculated from each individual series of 7 measurements. The standard deviations per individual were directly proportional to their mean values, so that there is no justification to calculate an average standard deviation. Davies (82) showed that, in such a case, a logarithmic transformation of the data leads to standard deviations which are independent of the mean values. Therefore, logarithmic transformation has been adopted as standard procedure. The mean and average standard 

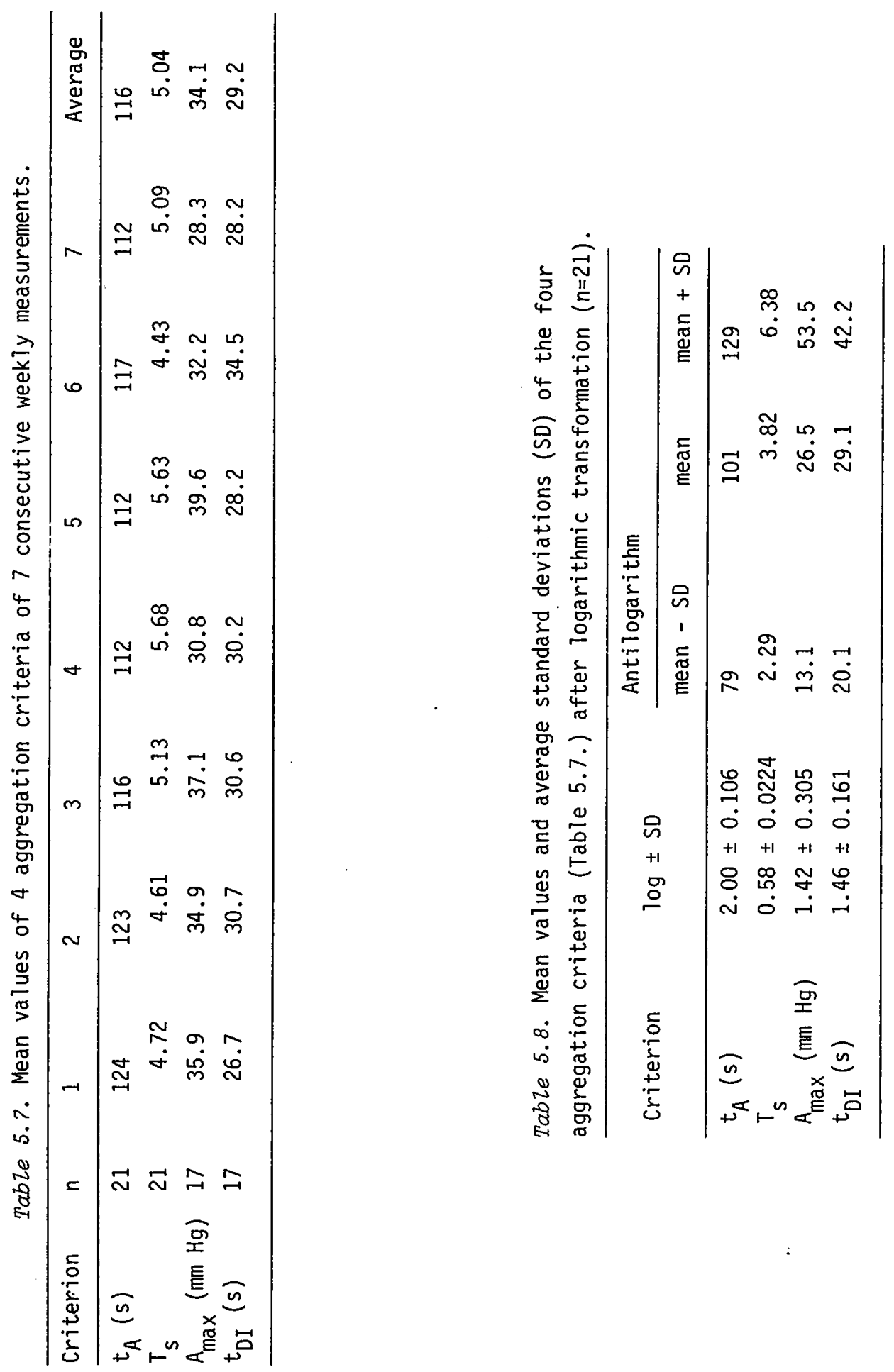
deviations of each aggregation parameter after log-transformation are given in Table 5.8. It is evident that, except for $t_{A}$, reproducibility is not so good. Since model experiments showed the filtragometer to react reproducibly to a standard filter obstruction (see section 5.4.2.), the present finding indicates that platelet aggregation show large fluctuations. This is also suggested by studies of the interrelationship between the aggregation criteria.

When the aggregate supply to the filter and the rate of disaggregation are constant, $t_{A}$ and $T_{S}$ should be closely correlated. In model experiments, using the PRP/ADP system, a high correlation coefficient was found $\left(\log t_{A}=218.7-0.047 \log T_{s} ; r=-0.88 ; n=181\right)$. This indicates that, in these model experiments, we measured a phenomenon that approximates a steady state. In human experiments, however, the relationship between $t_{A}$ and $T_{S}$ is less clear. In a separate study comprising 162 observations, the regression equation almost equalled that for the PRP experiments $\left(\log t_{A}=213.3-0.044 \log T_{S}\right)$, but the correlation coefficient was only $-0.64(n=162)$. This indicates that, in a given subject, the aggregation tendency of $\mathrm{platelets}$ in venous blood may vary from $\mathrm{ml}$ to $\mathrm{ml}$. This hampers the establishment of an average level of platelet aggregability in the individual. To diminish the influence of these physiological variations, repeated measurements are required. It also implies that a better impression of the mean aggregation tendency is obtained according as blood sampling is done more slowly as a result of which fluctuations become averaged.

\subsubsection{Effect_of anticoagulant_on aggregation response}

It appeared impossible to measure platelet aggregation in native blood without interference by clotting. Therefore, heparin, sodium citrate and hirudin were compared for their effects on the filtragometer response. In a first experiment, two aggregation measurements were carried out in 12 volunteers with an interval of about $15 \mathrm{~min}$. In one measurement, the standard measuring procedure was applied (first heparin is infused, followed by sodium citrate after $\Delta P$ has reached the $5 \mathrm{~mm} \mathrm{Hg}$ value); in the other measurement,citrate was used from the beginning. The aggregation responses were compared, using Student's paired samples test.

In a second experiment, two aggregation measurements were carried out 
with an interval of about $15 \mathrm{~min}$, in each of 12 volunteers. In one measurement, the standard heparin/citrate was applied and in the other,hirudin (ex Pharmachemie, Haarlem, The Netherlands) in a final concentration of $0.1 \mathrm{mg} . \mathrm{ml}^{-1}$ blood was used instead of heparin. The aggregation responses were compared using Student's paired samples test. The results of these experiments are shown in Table 5.9.

Since no disaggregation occurs in the citrate system, in the first experiment only the aggregation time and slope were calculated. It can be seen that aggregation is less pronounced when using citrate as an anticoagulant and that no differences are observed when heparin or hirudin is used. The lower response in the citrate experiments will be due to the low calcium level of the plasma. Since heparin and hirudin give the same response, any specific effect of heparin on platelet aggregation in the concentration used seems unlikely, al though heparin has repeatedly been shown to cause platelet aggregation in whole blood in vitro $(83,84)$ as well as in vivo $(85,86)$.

A specific effect of heparin on the filtragometer response is also very unlikely because in 6 hemophilia patients (for whom the use of an anticoagulant is not necessary) the use of heparin was not associated with a significantly different filtragometer response, then when the same amount of saline was infused (heparin: $\log t_{A}=2.06 \pm 0.196, t_{A}=116 \mathrm{~s}$; saline $\left.: \log t_{A}=1.96 \pm 0.078, t_{A}=92 \mathrm{~s}\right)$.

\subsubsection{Effect_of_platelet_aggregation-inhibiting drugs on fil fraggometer response}

5.4.9.1. Effect of prostaglandin $E_{1}$ ex vivo.

In 21 male and female volunteers, two subsequent aggregation measurements were carried out with an interval of about $15 \mathrm{~min}$. In nine subjects, the heparin/citrate system was applied and in 12 volunteers, only citrate was used as anticoagulant. In each subject, one measurement was performed without prostaglandin $E_{1}\left(P G E_{1}\right)$, whereas in the other measurement, the heparin (heparin/citrate system) or the citrate (citrate system) contained $\mathrm{PGE}_{1}$, providing a final concentration of $0.10 \mu \mathrm{g} . \mathrm{ml}^{-1}$ blood. All measurements and calculations were performed without knowing in which experiments 


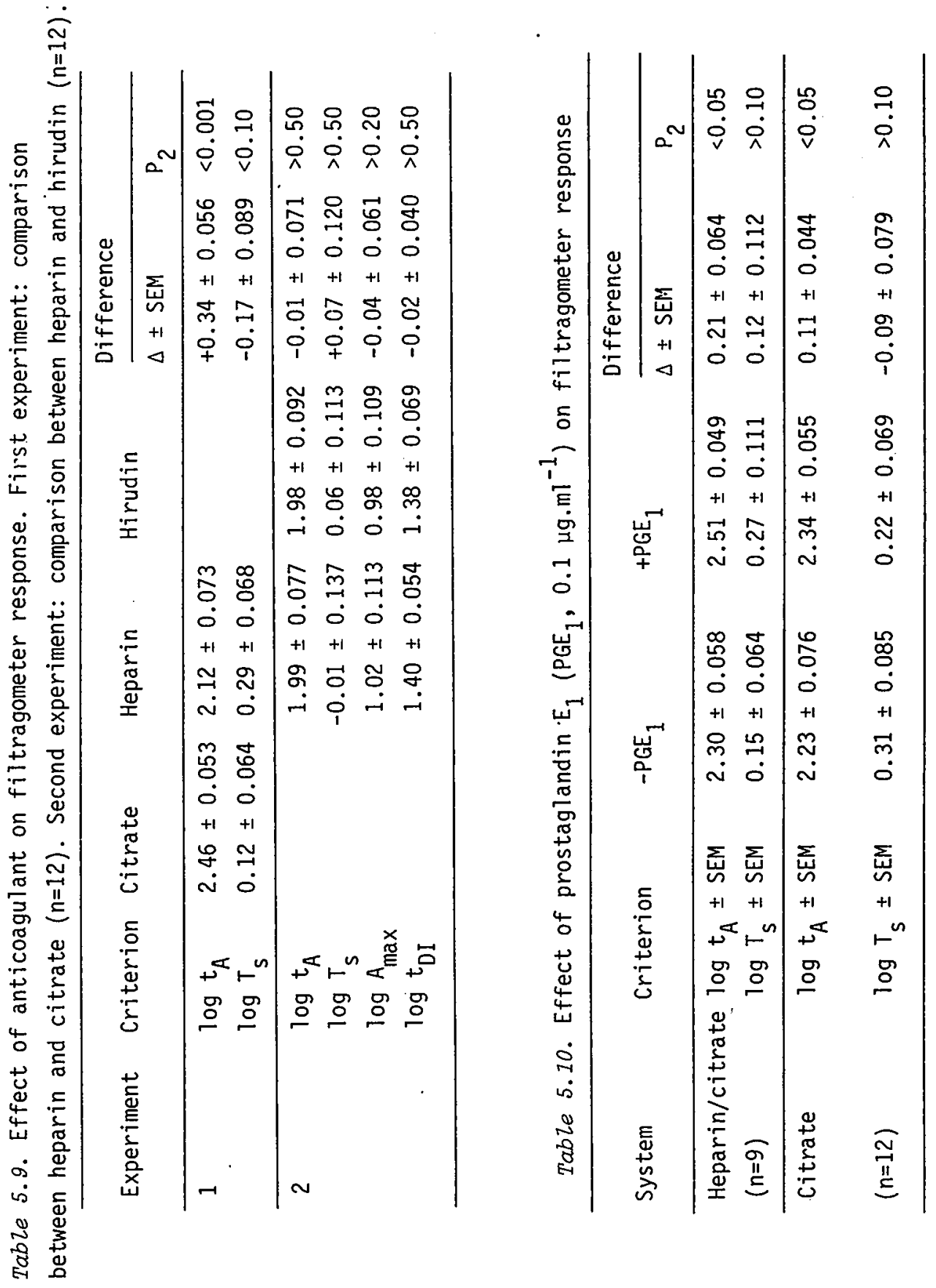


$P G E_{1}$ had been administered. The results were statistically analysed, using Student's paired samples test. The results are given in Table 5.10. Because no disaggregation occurs in the citrate system, only aggregation time and slope were calculated. In both systems, $\mathrm{PGE}_{1}$ leads to a modest but significant prolongation of the aggregation time, pointing to an inhibition of aggregation. In neither of the two systems did $\mathrm{PGE}_{1}$ alter the aggregation slope significantly.

\subsubsection{Effect of oral aspirin.}

Aggregation was measured in 22 male volunteers after one overnight fast. In the evening of the same day, they received $1 \mathrm{~g}$ acetylsalicylic acid or $1 \mathrm{~g}$ of a placebo (mainly potato starch and lactose). The next morning, the measurements were repeated for which the other arm was taken. Bleeding times were measured simultaneously by means of a device described by Praga et al.(69). A11 measurements and calculations were done without knowing which subjects had received aspirin. The differences between the two groups before and after aspirin or placebo administration were evaluated statistically using Student's two sample test.

No significant differences between the two groups were observed before aspirin or placebo administration (Fig.5.26.). However, after administration, $t_{A}$ was significantly longer $\left(P_{2}=0.02\right)$ and $T_{S}$ and $A_{\max }$ were lower $\left(P_{2}=0.07\right)$ in the aspirin group than in the placebo group. These results
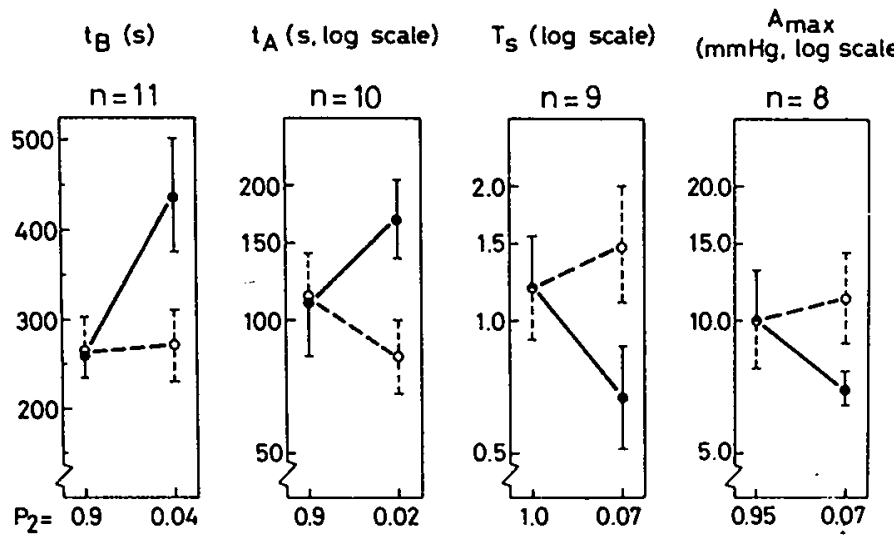

Fig.5.26. Effect of placebo ( ---0$)$ and aspirin (- $-\bullet)$ on bleeding time $\left(t_{B}\right)$ and platelet aggregation parameters in men; mean \pm SEM.

First values: premedication; second values: postmedication. 
show that aspirin, administered orally, inhibits platelet aggregation as measured with the filtragometer. In later experiments, it was found that aspirin also significantly enhanced disaggregation of aggregates trapped on the filter. These findings are in agreement with the prolongation of the bleeding time (Fig.5.26.).

Since aspirin was reported to inhibit the formation of experimental venous $(87,88)$ and arterial $(89$, see also section 5.2 .7 .2 .) thrombi in vivo, our findings indicate that the filtragometer is able to detect changes in thrombosis tendency in vivo.

\subsubsection{Relationship between fi]tragometer response_and other hematological parameters}

Within individuals, the filtragometer response does not correlate significantly with the PAT-1 test of Breddin and Bauke (67), the platelet retention test of Wright (2) and the aggregation test of Wu and Hoak (63). Moreover, no significant correlation was observed in relation to platelet survival time (68).

A slight but significant correlation exists between some filtragometer criteria and the Ivy bleeding time measured with the Praga device (69). This correlation improves after treatment with aspirin or a placebo (Fig. 5.27.).
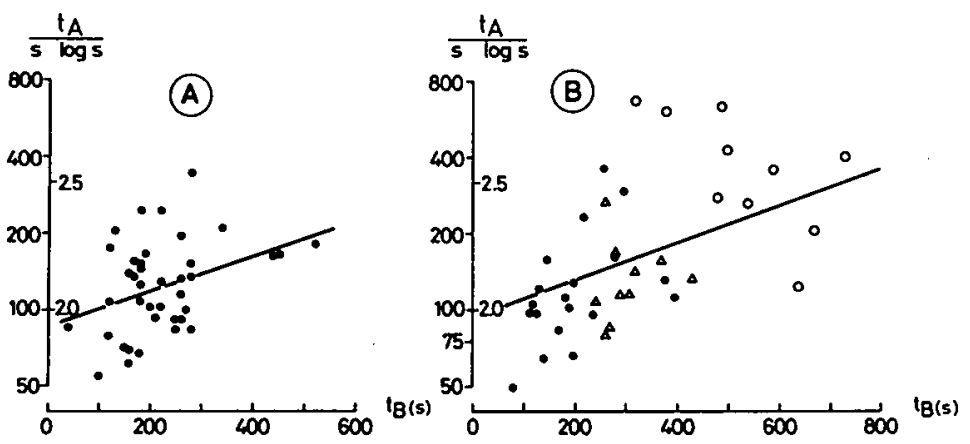

Fig.5.27. Relationship between bleeding time $\left(t_{B}, s\right)$ and aggregation time $\left(t_{A}, s\right)$.

$A$ : control series (pretreatment values of $B$ ) $\log t_{A}=1.94+0.0007 t_{B}$; $r=0.357 ; n=39 ; P<0.05$.

B: $-18 \mathrm{~h}$ after placebo $(n=19) ; \quad \Delta 18 \mathrm{~h}$ after $1 \mathrm{~g}$ aspirin $(n=10)$;

$018 \mathrm{~h}$ after $1.5 \mathrm{~g}$ aspirin $(n=10) ; \log t_{A}=1.97+0.0007 t_{B}$;

$r=0.55 ; n=39 ; P<0.001$. 

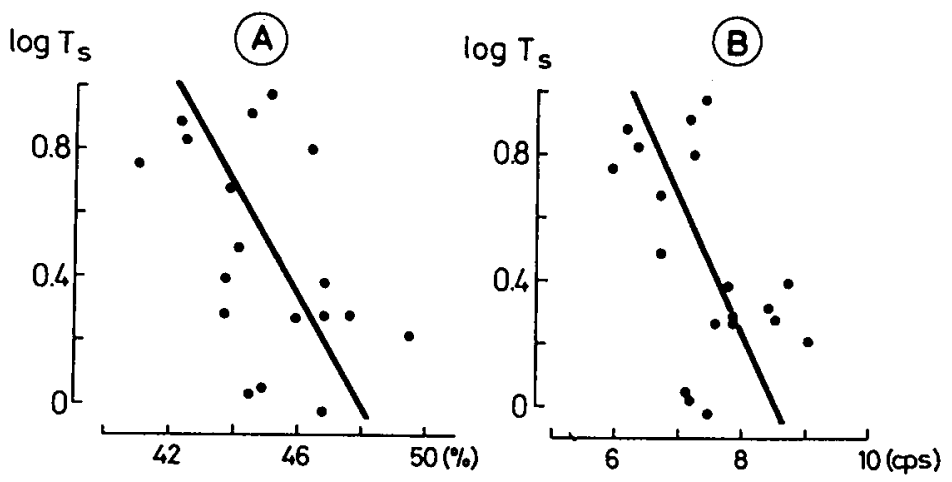

Fig.5.28. Relationship between filtragometer response $\left(T_{S}\right)$ and hematocrit $(\%, A)$ or blood viscosity) (cps, B).

$A: \log T_{S}=9.22-0.19(\%) ; r=-0.49 ; n=18 ; P<0.05$.

$B: \log T_{S}=3.70-0.43$ (cps); $r=-0.51 ; n=19 ; P<0.05$.

In normal individuals, the filtragometer response is negatively related to hematocrit and whole blood viscosity (Fig.5.28.), which suggests that red cells may counteract aggregation by preventing platelets to collide. This has also been observed with the screen filtration pressure technique (70); it stresses the necessity for a physiological milieu when investigating platelet function in relation to physiological phenomena.

A positive relationship has been found between the filtragometer response and the shear-induced platelet aggregation in normal volunteers (71; Fig.5.29.) as well as in patients suffering from peripheral arterial disease $(71)$.
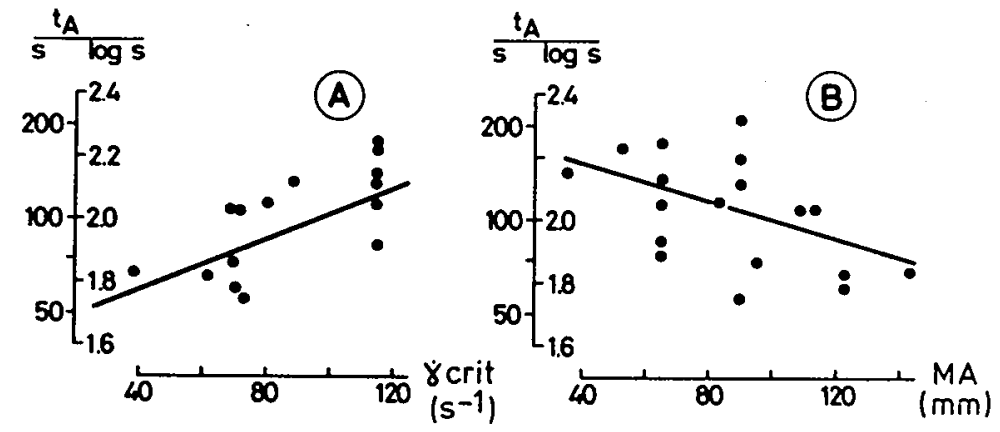

Fig.5.29. Relationship between filtragometer response (aggregation time, $\left.t_{A}\right)$ and shear-induced platelet aggregation measured according to Klose (71). A: Relationship with critical shear-rate $\left(\dot{\gamma}\right.$ crit, $\left.s^{-1}\right)$.

$. \log t_{A}=1.61+0.004(\dot{\gamma}$ crit $) ; r=0.71 ; n=15 ; P<0.01$.

$B$ : Relationship with maximum amplitude (MA,mm)

$\log t_{A}=2.28-0.003(M A) ; r=-0.52 ; n=18 ; P<0.05$. 


\subsubsection{Filtragometer response in some_disease_states_and_its relatation.}

\section{to some thrombotic r risk factors}

No significantly different filtragometer response has been observed in patients deficient in coagulation factors VIII, IX, X, and XII, but patients suffering from von Willebrand's disease, Glanzmann's thrombasthenia, Hermanski-Pudlak syndrome and uremia, showed a diminished filtragometer response (i.e. a longer aggregation time).

Male patients suffering from angina pectoris have an increased aggregation tendency and a decreased disaggregation tendency compared with healthy controls (Fig.5.30.A). These patients have a significantly higher aggregation tendency than female angina pectoris patients (Fig.5.30. B).

In acute myocardial infarction, a highly increased filtragometer response has been reported by Fleischman et az. (72) but these findings could not yet be confirmed by others (Hugenholz,P.: Personal Communication). Patients with a history of myocardial infarction show an increased aggregation tendency (Fig.5.31.) and a diminished frequency and degree of disaggregation. The filtragometer response has been reported to be significantly enhanced in acute stroke (72), in stress (73) and in diabetes mellitus (74). Smoking was shown to increase the filtragometer response (75) but we were unable

(A)

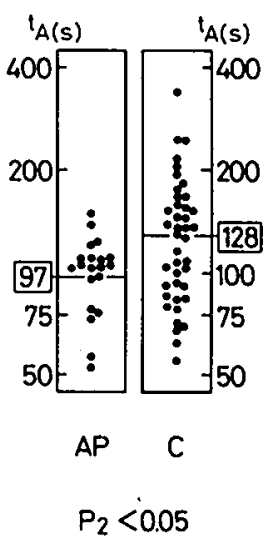

(B)

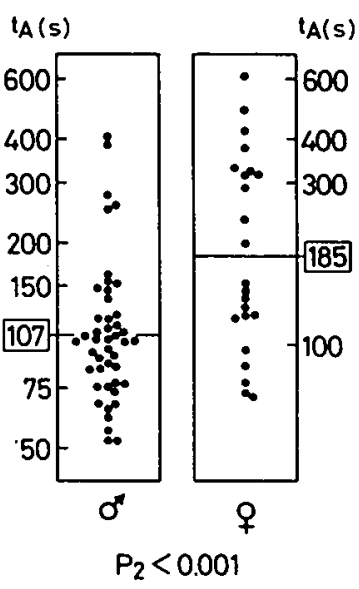

Fig.5.30. Filtragometer response (aggregation time, $t_{A}$, log scale) in angina pectoris patients.

A: Comparison between angina pectoris patients (AP) and controls (C).

B: Comparison between male $\left(\sigma^{\prime}\right)$ and female ( $q$ ) AP-patients. 
(A)

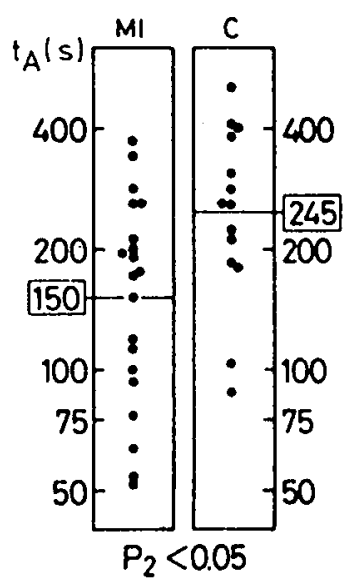

(B)

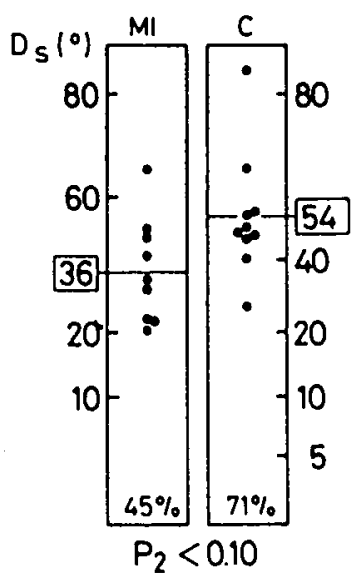

Fig.5.31. Filtragometer response in patients with a history of myocardial infarction. MI: post-MI patients; $\mathrm{C}$ : control subjects; $\mathrm{A}$ : aggregation time $\left(t_{A}, \log s c a l e\right) ; B$ : disaggregation velocity $\left(D_{S}, \log\right.$ scale $)$. Disaggregation was observed in only $45 \%$ of the post MI-patients and in $71 \%$ of the control subjects.

to confirm this finding. Finally, the use of oral contraceptives was associated with a higher filtragometer response $(76)$. It should be noted that, in most cases discussed so far, the overlap between experimental and control groups is considerable.

\subsubsection{Summary}

The filtragometer appears to be a suitable instrument for measuring the degree of platelet aggregation in flowing venous blood of man. The measurement takes little time and requires only $5-10 \mathrm{ml}$ blood. Individual results are obtained directly. Considering the fact that substances inhibiting platelet aggregation, diminish the filtragometer response whereas conditions known to be associated with an enhanced thrombosis tendency are accompanied by increased filtragometer values, this instrument is presumably suitable for measuring thrombosis tendency in humans.

\subsection{References}

1. Henry,R.L.: Methods for inducing experimental thrombosis. An annotated bibliography. Angiology 13: 554-577 (1962). 
2. Wright,H.P.: The adhesiveness of blood platelets in normal subjects with varying concentrations of anti-coagulants. J.Pathol.Bacteriol.53: 255-262 (1941).

3. Hellem,A.J.: The adhesiveness of human blood platelets in vitro. Scand.J.Clin. Invest. 12, Suppl. 51 (1960).

4. Born,G.V.R.: Aggregation of blood platelets by adenosine diphosphate and its reversal. Nature 194: 927-929 (1962).

5. O'Brien,J.R.: Platelet aggregation.II. Some results from a new method of study. J.Clin.Pathol. 15: 452-455 (1962).

6. Swank,R.L., Roth,J.G. and Janssen,J.: Screen filtration pressure method and adhesiveness and aggregation of blood cells. J.Appl.Physiol.19: 340-346 (1964).

7. Einheber,A., Wren,R.E., Carter,D. and Rose,L.R.: A simple collar device for the protection of skin grafts in mice. Lab.An.Care 17: 345-348 (1967).

8. Van de Graaf,H.M.: A method for limiting the activity of rats. Z.Versuchstierk. 8: 246-247 (1966).

9. Everson Pearse,A.G.: Histochemistry, Churchill, London (1968).

10. Romeis,B.: Mikroskopische Technik. 01denbourg, Munich, Vienna (1968).

11. Gould,S.E.: Pathology of the heart and blood vessels. Thomas, Springfield, I11. (1968).

12. Smith,H.A. and Jones,Th.E.: Veterinary Pathology. Lea and Febiger, Philadeiphia, Penn. (1968).

13. Eastham,R.D.: Clinical Haematology, Wright, Bristol (1966).

14. Kloeze,J.: Influence of prostaglandins on platelet adhesiveness and platelet aggregation. In: S.Bergström and B.Samuelsson: Prostaglandins. Almqvist and Wiksell, Stockholm, pp. 241-252 (1967).

15. Weiss,H.J. and Aledort,L.M.: Impaired platelet/connective tissue reaction in man after aspirin ingestion. Lancet $i i$ : 495-497 (1967).

16. O'Brien,J.R.: Effect of salicylates on human platelets. Lancet $i$ : 779-783 (1968).

17. Popovic, $V$. and Popovic,P.: Permanent cannulation of aorta and vena cava in rats and ground squirrels. J.Appl.Physiol.15: 727-728 (1960).

18. Ferreira,S.H. and Vane,J.R.: Prostaglandins: their disappearance from and release into the circulation. Nature 216: 868-873 (1967).

19. Chandra Sekhar,N.: Inhibition of platelet aggregation by prostaglandins. Blood 30: 554 (1967).

20. Stein,P.D. and Sabbah,H.N.: Measured turbulence and its effect on thrombus formation. Circ.Res. 35: 608-614 (1974).

21. Born,G.V.R. and Wehmeier,A.: Inhibition of platelet thrombus formation 
by chlorpromazine acting to diminish haemolysis. Nature $282: 212-213$ (1979).

22. Stamler,J.: Epidemiology of coronary heart disease. Med.Clin. North Amer. 57: 5-46 (1973).

23. Kannel,W.B.: Some lessons in cardiovascular epidemiology from Framingham. Am.J.Cardiol. 37: 269-282 (1976).

24. Editorial: Oral contraceptives and health. Lancet i: 1147-1148 (1974).

25. Mann,J.I. and Inman,W.H.W.: Oral contraceptives and death from myocardial infarction. Brit.Med.J. 2: 245-248 (1975).

26. Meade,T.W., Chakrabarti,R., Haines,A.P., North,W.R.S., Stirling,Y., Thompson,S.G. and Brozovic,M.: Haemostatic function and cardiovascular death: early results of a prospective study. Lancet $i$ : 1050-1054 (1980).

27. Uzunova,A.D., Ramey,E.R. and Ramwell,P.W.: Effect of testosterone, sex and age on experimentaliy induced arterial thrombosis. Nature 261: 712-713 (1976).

28. Uzunova,A.D., Ramey,E.R. and Ramwell,P.W.: Gonadal hormones and pathogenesis of occlusive arterial thrombosis. Am.J.Physiol. 234: H 454 - H 459 (1978).

29. Kim,W.M., Merskey,C., Deming,Q.B., Ade1,H.N. and Wel insky,H.: Hyperlipidemia, hypercoagulability and accelerated thrombosis. Studies in congenitally hyperlipidemic rats and in rats and monkeys with induced hyperl ipidemia. Blood 47: 275-285 (1976).

30. Roncaglioni,M.C., Di Minno,G., Pangrazzi,J., Reyers, I., Mussoni,L. and Donati,M.B.: Increased prostacyclin activity in vascular tissue from rats on prolonged treatment with oral contraceptives. Thromb. Haemostas. 42: 7 (1979).

31. Delaini,F., Poggi,A., Colombo,T., Kornblintt,L., Reyers, I., Mussoni,L. and Donati,M.B.: Adriamycin induces a delayed hypercoaguiable and prothrombotic state in rats. Thromb. Haemostas. 42: 456 (1979).

32. Born,G.V.R.: Uptake of adenosine and of adenosine diphosphate by human blood platelets. Nature 206: 1121-1122 (1965).

33. Hampton,J.R. and Mitchell,J.R.A.: An estimate of the number of adenosine diphosphate binding sites on human platelets. Nature 211: 245-246 (1966).

34. Hawkey,C.W. and Symons, C.: Variation in ADP-induced platelet aggregation in vitro in primates as a result of differences in plasma ADP inhibitor levels. Thrombos.Diatines.haemorrh. 19: 29-35 (1968).

35. Ireland,D.M. and Mills,D.C.B.: Degradation of adenosine diphosphate in plasma. Biochem.J. 92: $30 \mathrm{P}$ (1964). 
36. Cuthbertson,W.F.J. and Mills,D.C.B.: Some factors influencing platelet clumping. J.Physiol.169: 9P (1963).

37. Constantine,J.W.: Aggregation and adhesion of rat platelets. Nature 214: 1084-1086 (1967).

38. Born,G.V.R. and Philp,R.B.: Effects of adenosine analogues and of heparin on platelet thrombi in non-1ipaemic and lipaemic rats. Brit. J.Expt1. Pathol. 46 : 569-576 (1965).

39. O'Brien,J.R.: Changes in platelet membranes, possibly associated with platelet stickiness. Nature 212: 1057-1058 (1966).

40. Rozenberg,M.C. and Holmsen,H.: Adenosine nucleotide metabol ism of blood platelets. IV. Platelet aggregation in response to exogenous ATP and ADP. Biochim.Biophys.Acta 157: 280-288 (1968).

41. Bushfield,D. and Tomich,E.G.: Acute intravascular haemolysis and platelet behaviour. Nature 218: 696-697 (1968).

42. Born,G.V.R. and Cross,M.J.: Effect of adenosine diphosphate on the concentration of platelets in circulating blood. Nature 197:

974-976 (1963).

43. Kloeze,J.: Prostaglandins and platelet aggregation in vivo.I. Influence of $P G E_{1}$ and $w$-homo $P G E_{1}$ on transient thrombocytopenia and of $P G E_{1}$ on the $\mathrm{LD}_{50}$ of ADP. Thrombos.Diathes haemorrh.33: 286-292 (1970).

44. Kloeze,J.: Prostaglandins and platelet aggregation in vivo II. Influence of $P G E_{1}$ and $P G F_{1 \alpha}$ on platelet thrombus. formation induced by an electric stimulus in veins of the rat brain surface. Thrombos.Diathes.haemorrh. 33: 293-298 (1970).

45. Hornstra, G.: Degree and duration of prostaglandin $E_{1}$-induced inhibition of platelet aggregation in the rat. Eur.J.Pharmacol. 15: 343-349 (1971).

46. Butterfie]d,W.J.H. and others: Symposium on Atromid. J.Atheroscler. Res. 3: 341-755 (1963).

47. Shimamoto, T. and Numano,F. (Eds.): Atherogenesis. Excerpta Medica Foundation, Amsterdam (1969).

48. Symons,C., De Toszeghi,A. and Cook, I.J.Y.: Effect of ethylchlorophenoxy -isobutyrate with or without androsterone on platelet stickiness. Lancet i: 233-243 (1964).

49. Glynn,M.F., Murphy,E.A. and Mustard,J.F.: Effect of clofibrate on platelet economy in man. Lancet ii: 447-448 (1967).

50. Yamazaki,H.: Changes in blood coagulability, platelet count and platelet aggregation induced by endotoxin or exercise, and the prevention of these changes by pyridinolcarbamate. In:(47) pp. 93-95 51. O'Brien,J.R. and Heywood,J.B.: A comparison of platelet stikiness 
tests during an Atromid-S trial. Thrombos.Diathes.haemorrh. 16: 768-777 (1966).

52. Henry,R.L.: Effect of pyridinolcarbamate on specific components of hemostasis in Crutz's model. In:(47) p. 75-81.

53. Muirhead,C.R.: The filter-loop technique as a method for measuring platelet aggregation in the flowing blood of the rat; the inhibitory activity of 5-oxo-1-cyclopentene-1-heptanoic acid (AY-16,804) on platelet aggregation. Thrombos.Diathes.haemorrh. 30: 138-147 (1973).

54. Broersma,R.J., Dickerson,G.D. and Sullivan,M.S.: The determination of platelet aggregation by filtration pressure in circulating dog blood. Thrombos.Diathes. haemorrh. 29: 201-210 (1973).

55. Ambrus,J.L.: Personal Communication.

56. Machleder,H.I., Sweeny,J.P. and Barker,W.F.: Pulseless arm after brachial artery catheterization. Lancet i: 407-409 (1972).

57. Warren,B.A., Philp,R.B. and Inwood,M.J.: The ultrastructural morphology of air embolism: platelet adhesion to the interphase and endothelial damage. Brit.J.Expt1.Pathol.54: 163-172 (1973).

58. Maca,R.D., Fry,G.L. and Hoak,J.C.: New method for detection and quantification of circulating platelet aggregates. Microvasc.Res.4: 453-457 (1972).

59. Jørgensen,L., Haerem,J.W. and Moe,N.: Platelet thrombosis and non-traumatic injury in mouse aorta. Thrombos.Diathes.haemorrh. 29: 470-489 (1973).

60. Haft,J.I. and Fani,K.: Intravascular platelet aggregation in the heart, induced by stress. Circulation 47: 353-358 (1973).

61. Haerem,J.W.: Sudden coronary death: the occurrence of platelet aggregates in the epicardial arteries of man. Atherosclerosis 14: 417-432 (1971).

62. Haerem,J.W.: Platelet aggregates and mural microthrombi in the early stages of acute, fatal coronary disease. Thrombos.Res.5: 243-249 (1974).

63. Wu,K.K. and Hoak,J.C.: New method for quantitative detection of platelet aggregates in patients with arterial insufficiency. Lancet $i i$ : 924-926 (1974).

64. Solis,R.T., Wright,C.B. and Gibbs,M.B.: A model for quantitating in vivo platelet aggregation. Biblth. Anat.12: 223-228 (1973).

65. McPherson,V.J., Zucker,M.B., Friedberg,N.M. and Rifkin,P.L.: Platelet retention in glass bead columns: further evidence for the importance of ADP. Blood 44, 411-425 (1977).

66. Ardlie,N.G., Perry,D.W., Packham,M. and Mustard,J.F.: Influence of apyrase on stability of suspensions of washed rabbit platelets. 
Proc.Soc.expt1.Biol.Med. 136: 1021-1023 (1971).

67. Breddin,K. und Bauke,J.: Thrombozytenagglutination und Gefässkrankheiten. Blut 11: 144-165 (1965).

68. Aster,R.H. and Jandl, J.H.: Platelet sequestration in man.I.Methods. J.Clin. Invest. 43: 843-855 (1964).

69. Praga,C., Valentini,L., Maiorano,M. and Cortellaro,M.: A new automatic device for the standardized Ivy bleeding time. Adv.Exp.Med.Biol. 34: 271-279 (1972).

70. Dha11,D.P. and Matheson,N.A.: Platelet aggregate filtration pressure. A method of measuring platelet aggregation in whole blood. Cardiovasc. Res. 3: 155-160 (1969).

71. Klose,H.J., Rieger,H. and Schmid-Schönbein,H.: A rheological method for the quantification of platelet agrregation (PA) in vitro and its kinetics under defined flow conditions. Thrombos.Res. 7: 261-272 (1975).

72. Fleischman,A.I., Bierenbaum,M.L., Justice,D., Stier,A. and Sullivan, A.S.: In vivo platelet function in acute myocardial infarction, acute cerebro-vascular accidents and following surgery. Thrombos.Res.6: 205-207 (1975).

73. Fleischman,A.I., Bierenbaum,M.L. and Stier, A.: Effect of stress due to anticipated minor surgery upon in vivo platelet aggregation in humans. J.Human Stress, March 1976, pp. 33-37.

74. Fleischman,A.I., Bierenbaum,M.L., Stier, A., Somol,H. and Watson,P.B.: In vivo platelet function in diabetes mellitus. Thrombos. Res. 9: 467-471 (1976).

75. Bierenbaum,M.L.: Personal Communication.

76. Bierenbaum,M.L., Fleischman, A. I., Stier, A., Watson,P., Somol, H. , Naso, A.M. and Binder,M.: Increased platelet aggregation and decreased high-density lipoprotein cholesterol in woman on oral contraceptives. Am.J.Obstet.Gynecol. 134: 638-641 (1979).

77. Baumgartner,H.R.: The role of blood flow in platelet adhesion, fibrin deposition and formation of mural thrombi. Microvasc. Res. 5: 167-179 (1973).

78. Arfors,K.E. and Bergqvist,D.: The red cell in the hemostatic process. Microvasc.Res. 11: 430 (1976).

79. Born,G.V.R., Bergqvist,D. and Arfors,K.E.: Evidence for inhibition of platelet activation in blood by a drug effect on erythrocytes. Nature 259: 233-235 (1976).

80. Ashford,T.P. and Freiman,D.G.: The role of endothelium in the initial phases of thrombosis. An electron microscopic study. Amer.J.Patho1.50: 


\section{7-273 (1967).}

81. Niewiarowski,S., Regoeczi,E., Stewart,G.J., Senyi,A.F. and Mustard, J.F.: Platelet interaction with polymerizing fibrin. J.Clin. Invest. 51: 685-700 (1972).

82. Davies,0.L.: Design and analysis of industrial experiments. 0liver and Boyd, Edinburg p. 44-45 (1954).

83. Copley,A.L. and Robb,T.P.: Studies on platelets.II. The effect of heparin on platelet count in vitro. Am.J:Clin.Pathol.12: 416-423 (1942).

84. Holdrinet,A., Ewals, M. and Haanen, C.: A simple method for measuring platelet aggregation. Results in von Willebrand's disease and uraemia. Thrombos.Diathes. haemorrh. 22: 174-191 (1966).

85. Fidlar,E. and Jaques,L.B.: The effect of commercial heparin on the platelet count. J.Lab.Clin.Med. 33: 1410-1423 (1948).

86. Eika,C. and Godal,H.: Thrombocytopenia in rabbits induced by heparin, protamine and polybrene. Scand.J.Haematol. 8: 481-486 (1971).

87. Renaud,S. and Godu,J.: Thrombosis prevention by acetylsalicylic acid in hyperlipemic rats. Can.Med.Ass.J. 103: 1037-1040 (1970).

88. Kricheff, I.I., Zucker,M.B., Tschopp,T.B. and Kolodjiez,A.: Inhibition of thrombosis on vascular catheters in cats. Radiology 106: 49-51 (1973).

89. Danese,C.A. and Haimov,M.: Inhibition of experimental thrombosis in dogs with platelet-deaggregating agents. Surgery 70: 927-934 (1971).

90. Tschopp, T.B. and Zucker,M.B.: Hereditary defect in platelet function in rats. Blood 40: 217-226 (1972).

91. Raymond,S.L. and Dodds,W.J.: Characterization of the Fawn-Hooded rat as a model for hemostatic studies. Thromb. Diath.haemorrh. 33: 361-369 (1975). 
6. EFFECT OF TYPE AND AMOUNT OF DIETARY FAT ON ARTERIAL THROMBUS FORMATION

IN RATS

\subsection{Introduction}

As demonstrated in Chapter 1 , there is a close relationship between arterial thrombosis and atherosclerosis. Since experimental atherosclerosis is influenced by the type of dietary fat, the effect of the dietary fatty acid composition on arterial thrombus formation was investigated. To this end, 3- to 5-week-old male Wistar rats (specific pathogen-free, SPF.) were fed adequate diets, the composition of which, is given in Table 6.1. The carbohydrate moiety of the diets was isocalorically replaced by various amounts of different oils and fats, as indicated in the separate experiments.

Aorta loops were inserted after feeding for 8-12 weeks (Chapter 5, section 2.). The loops were checked for obturation twice daily. Obstruction times (OT) were calculated in hours and, because of skew distribution, transformed to their logarithmic values. Regressions were calculated

Table 6.1. Composition of a diet containing $50 \mathrm{en} \%$ fat

\begin{tabular}{lcc}
\hline Ingredients & g. $4184 \mathrm{~kJ}^{-1}$ & en\% \\
\hline Casein & 62.0 & 23 \\
Minerals & 5.4 & \\
Vitamin mix 5 & 1.0 & \\
Sawdust & 20.0 & 27 \\
Corn starch & 77.1 & 50 \\
Experimental fat & 53.8 & 100 \\
\hline Total & 219.3 & 100 \\
\hline
\end{tabular}

II: g. $4184 \mathrm{~kJ}^{-1}: \mathrm{KCl} 0.350, \mathrm{MgHPO}_{4}-\mathrm{H}_{2} \mathrm{O} 0.956, \mathrm{KH}_{2} \mathrm{PO}_{4} 0.475, \mathrm{KHCO}_{3}$ $0.719, \mathrm{C}_{6} \mathrm{H}_{5} \mathrm{Na}_{3} \mathrm{O}_{7}-2 \mathrm{H}_{2} \mathrm{O} 0.711, \mathrm{CaCO}_{3} 2.014, \mathrm{MnHC}_{6} \mathrm{H}_{5} \mathrm{O}_{7} 0.0756, \mathrm{C}_{6} \mathrm{H}_{5} \mathrm{FeO}{ }_{7}$ $-5 \mathrm{H}_{2} \mathrm{O} 0.0439, \mathrm{Cu}_{2} \mathrm{C}_{6} \mathrm{H}_{6} \mathrm{O}_{3} 0.0036, \mathrm{Zn}_{3}\left(\mathrm{C}_{6} \mathrm{H}_{5} \mathrm{O}_{7}\right)_{2}-2 \mathrm{H}_{2} \mathrm{O} 0.0125, \mathrm{KIO}_{3} 0.00007$ $\xi: \mathrm{g} .4184 \mathrm{~kJ}^{-1}$ : choline 0.250 , vitamin $\mathrm{E} 0.020$, calcium silicate 0.05 , myoinositol 0.025 , vitamin $B_{12} 0.000005$, vitamin $A 0.0077$ niacin 0.005 , pantothenic acid 0.005 , riboflavin 0.0015 , thiamin 0.0015 , vitamin $D$ 0.00125 , vitamin $K 0.000227$, vitamin $B_{6} 0.0005$, folic acid 0.00025 , biotin 0.00005 , made up to 1.00 with sucrose. 
using the least-squares method.

Because vegetable oils rich in polyunsaturated fatty acids were shown to inhibit experimental atherogenesis $(1,2)$, experiments were started with sunflowerseed oil, which contains over $60 \%$ linoleic acid.

\subsection{Effect of increasing amounts of dietary sunflowerseed oil on arterial} thrombus formation

Eight groups of 12 animals, 5 weeks old, were fed diets containing 2.5 to $60 \%$ of digestible energy (en\%) sunflowerseed $0 i 1$ (s0) at the expense of carbohydrates. After 12 weeks, arterial thrombosis tendencies were measured. A significantly positive linear relationship was observed between the logarithm of the dietary So content and the logaritm of the obstruction time (Fig.6.1.).

This antithrombotic effect may be due to the increasing amount of dietary So or to the decreasing carbohydrate content of the diet. Therefore, in a following experiment, the dietary fat content was kept constant (60 en\%) but the amounts of So were varied by replacing it with various amounts of hydrogenated coconut oil ( $\mathrm{HCO}$ ) or butterflat (BF). In both experimental

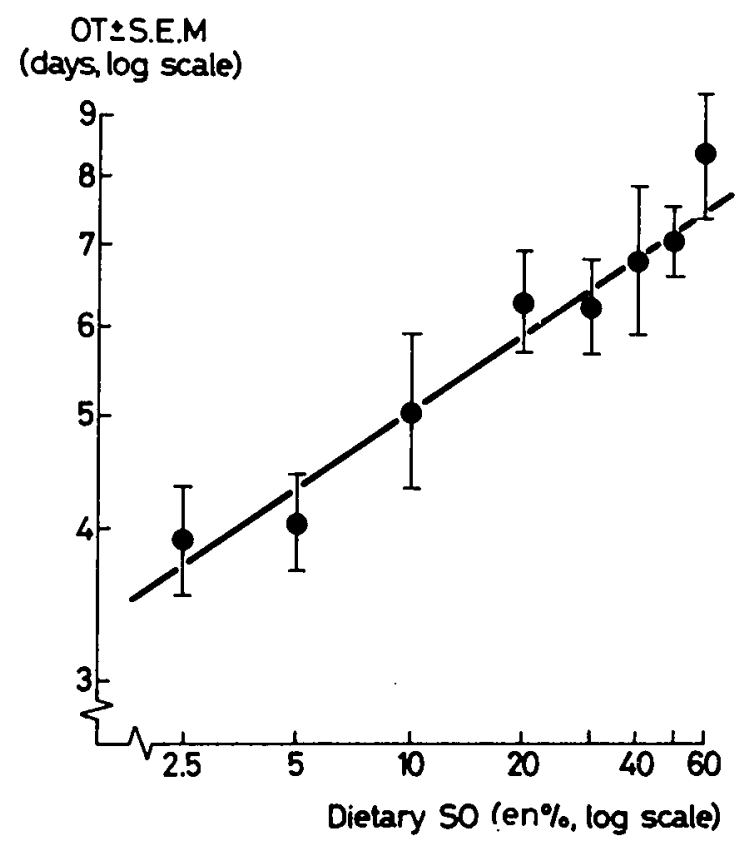

Fig.6.1. Effect of increasing dietary sunflowerseed oil (SO) content on arterial thrombosis tendency (OT) in rats. $\log$ OT (days) = $0.481+0.228(\log$ en\% SO $) r=0.96 ; \mathrm{P}<0.001$. Each point represents the mean OT ( \pm SEM) of 10-12 animals. 
OTะS.E.M.

(days, log scale)
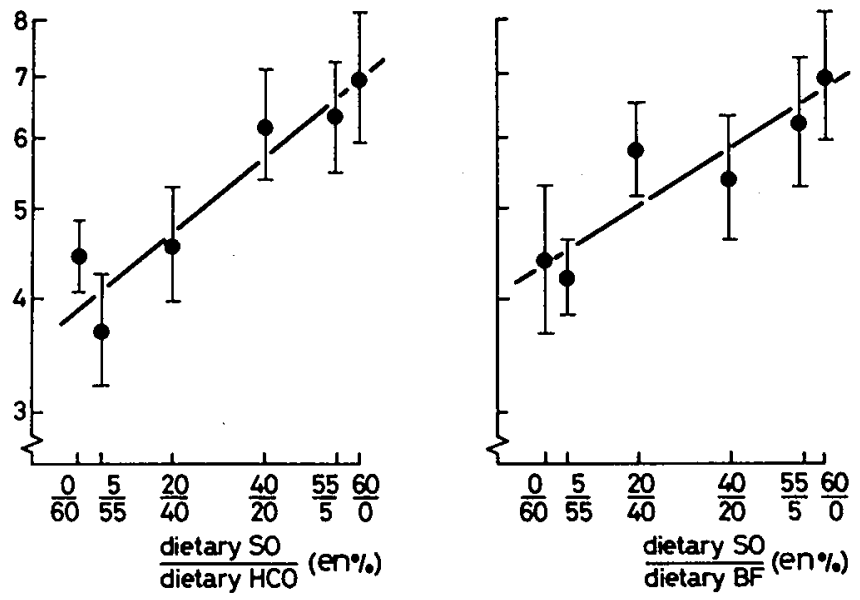

Fig.6.2. Effect of increasing amounts of sunflowerseed oil (SO), mixed with hydrogenated coconut oil ( $\mathrm{HCO}$, left) or butterfat (BF, right) on arterial thrombosis tendency in rats. $n=9-11$ SO/HCO : $\log$ OT (days) $=0.59+0.004$ en\% SO $r r=0.94 ; P<0.01$ SO $/ \mathrm{BF}: \log$ OT (days) $=0.64+0.003$ en $\%$ SO $r=0.91 ; P<0.02$

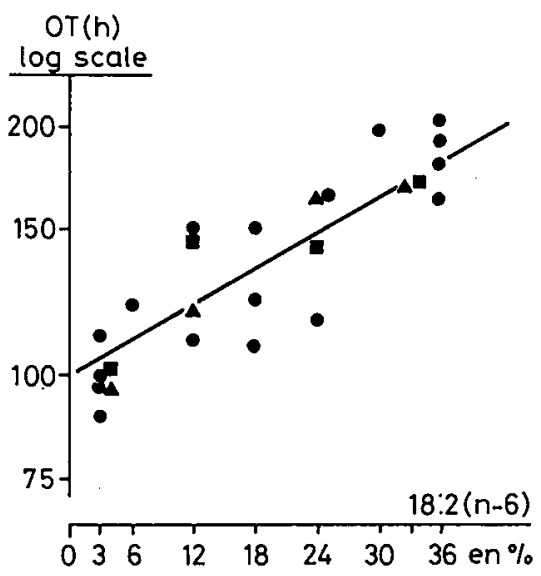

Fig.6.3. Relationship between dietary linoleic acid content and thrombogenicity (OT). Each point represents the mean of 10-16 animals. $\log$ OT $(h)=1.99+0.007$ en\% linoleic acid, $r=0.87 ; P<0.001$

- sunflowerseed oil

$\Delta+$ hydrogenated coconut 0 il

- + butterfat 
series, a positive rectilinear relationship was observed between the dietary so content and the diet-induced thrombosis tendency (Fig.6.2.). This strongly indicates that sunflowerseed oil has an antithrombotic effect.

A comparison between the fatty acid composition of sunflowerseed oil, hydrogenated coconut oil and butterfat (Table 6.2., fats No. 11-13) suggests that linoleic acid may be responsible for the antithrombotic effect of sunflowerseed oil. This suggestion is further supported by the significant positive relationship existing between the amount of dietary linoleic acid and the OT-increasing effect of the diet (Fig.6.3.), no matter whether sunflowerseed $0 i 1$ is the only dietary fat or whether it is mixed with hydrogenated coconut oil or butterfat.

\subsection{Comparison of the effect of different dietary fats and oils on arterial thrombus formation in rats}

Five-week-old male Wistar rats (SPF) were fed (for 9 weeks) diets containing $50 \mathrm{en} \%(-24 \mathrm{w} / \mathrm{w} \%)$ of fats with a different fatty acid composition (Table 6.2., fats No. 1-11). During the last two days of the last week, the food consumption of all animals was measured and the faeces were collected to determine fat absorption. To this end, the faeces of 3 animals were pooled and the faecal fatty acids extracted after saponification. After weighing, the faecal fatty acids were pooled per group and identified by gas-liquid chromatography. Fat absorption was calculated by subtracting the excreted from the ingested fat. No correction was applied for endogenous fat production. Absorption of fatty acids was calculated in the same way. Arterial thrombus formation was determined as described above and the optimum relationship between OT and the fatty acids absorbed was established by means of a multiple regression analysis.

\subsubsection{Relationship_between_arterial thrombosis tendency and dietary fattyy açid_composition}

The mean OT and log OT values of the various dietary groups are given in Table 6.3. Statistical analysis (Newman-Keuls multiple range test (4)) showed that the dietary fats which are not connected by the same line 


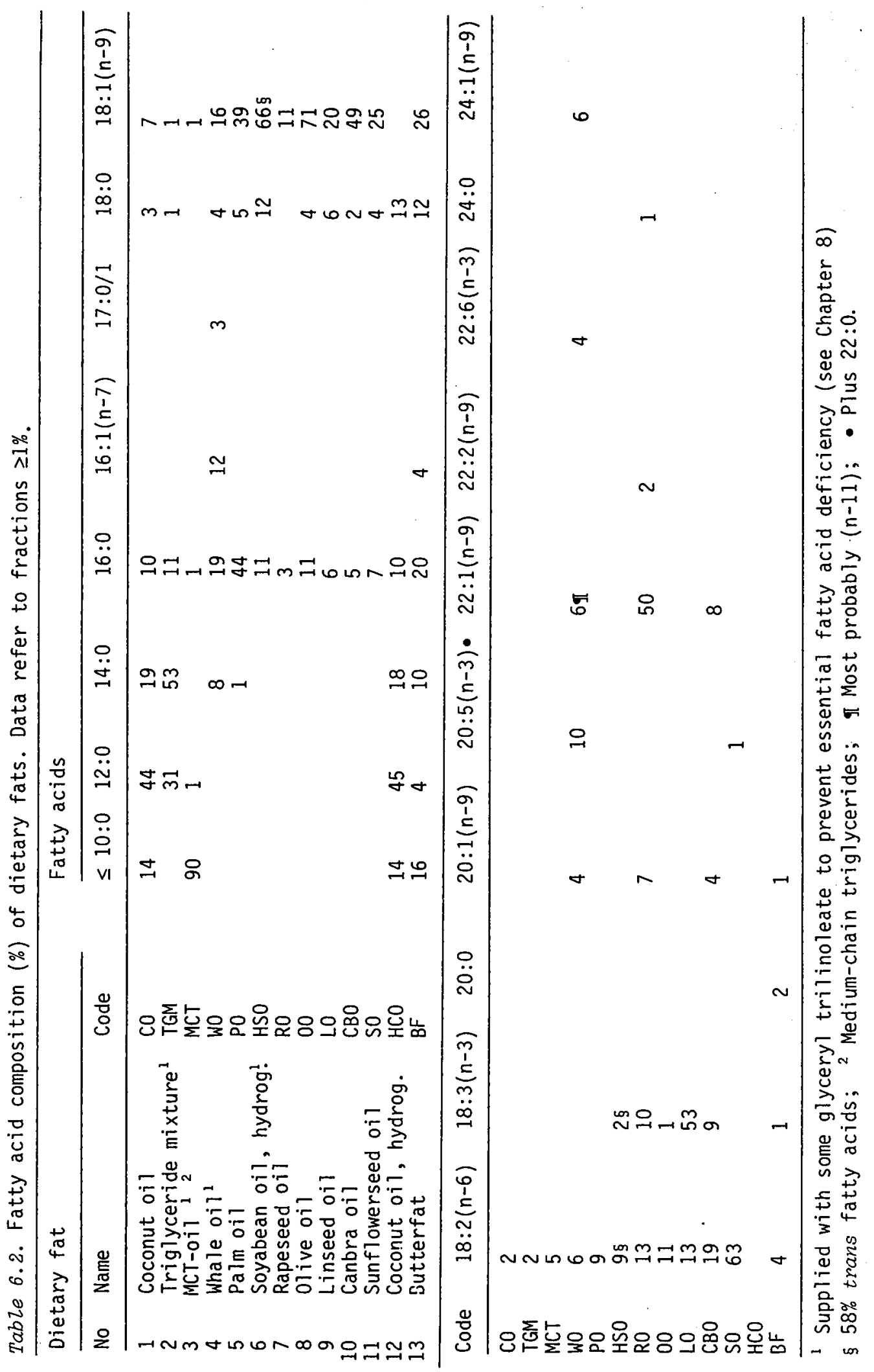


Table 6.3. Arterial thrombosis tendency (OT) in rats fed diets containing 50 en\% of differents fats for 9 weeks.

\begin{tabular}{lccr}
\hline Dietary fat & No. of animals & log OT \pm SEM & OT(h) \\
\hline CO & 12 & $2.13 \pm 0.04$ & 134 \\
TGM $^{1}$ & 12 & $1.81 \pm 0.05$ & 65 \\
MCT $^{1}$ & 12 & $1.89 \pm 0.07$ & 77 \\
WO $^{1}$ & 10 & $2.04 \pm 0.08$ & 111 \\
PO & 12 & $2.29 \pm 0.05$ & 195 \\
HSO & 11 & $2.10 \pm 0.04$ & 127 \\
RO & 8 & $2.33 \pm 0.08$ & 214 \\
OO & 10 & $2.16 \pm 0.04$ & 145 \\
LO & 8 & $2.27 \pm 0.03$ & 186 \\
CBO & 12 & $2.28 \pm 0.05$ & 191 \\
SO & 12 & $2.24 \pm 0.05$ & 173 \\
\end{tabular}

1 Supplied with some glyceryl trilinoleate, to prevent essential fatty acid deficiency.

as shown in the diagram below induce systematically different average $\log$ OT values, the confidence of this statement being at least $90 \%$. $\begin{array}{llllllllll}\text { TMG MCT WO HSO } & \text { CO } & 00 & \text { SO } & \text { LO } & \text { CBO } & \text { PO } & \text { RO }\end{array}$
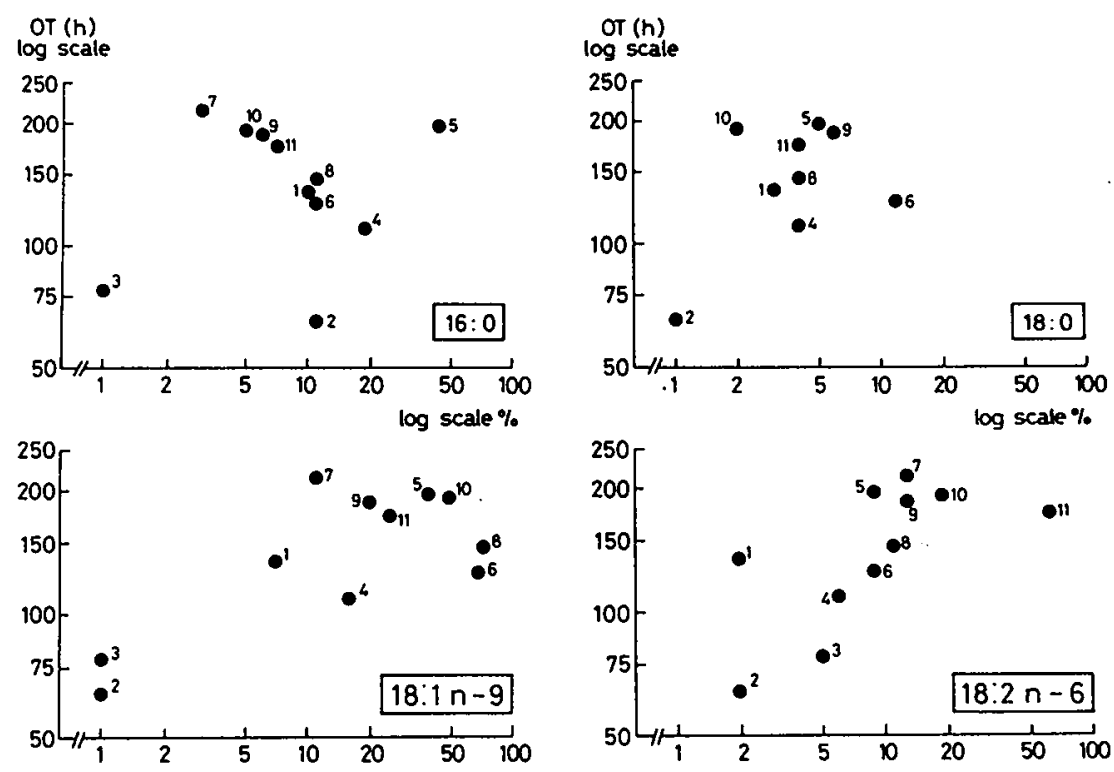

Fig.6.4. Relationship between dietary content of some fatty acids and arterial thrombosis tendency (OT). Numbers refer to the dietary fats given in Table 6.2 . 
Table 6.2. Shows that only four fatty acids $(16: 0,18: 0,18: 1$ and 18:2) are present in at least nine of the dietary fats. Using the rank correlation test of Spearman (3) -chosen to diminish the possibility of spurious correlations- a significant rank correlation between OT and dietary fatty acid concentration was found only for linoleic acid $(r=0,72 ; P<0.05)$. However, the results given in Fig. 6.4. indicate that OT may also be related to the 16:0 content of the dietary oils. The fact that this relationship is not significant may be ascribed to the possibility that the $0 T$ is not a function of a single fatty acid and that it may also be influenced by the absorbed amount of fatty acids.

As food consumption and fat absorption are considerably influenced by the type of dietary fatty acids $(4,5)$, a further investigation into their relationship with OT was done on the basis of the absorbed amounts of fatty acids (Table 6.4.).

\subsubsection{Arterial_thrombosis tendency_as_a function_of the amount of}

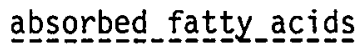

By means of a multiple regression analysis, we tried to describe the average $\log$ OT of a dietary group as a function of the average absorbed amount of one or more fatty acids.

From 10 independent variables (the different fatty acids occurring in more than one dietary fat), the multiple regression analysis computer program selects all the combinations of a given number of independent variables exceeding a predetermined multiple correlation coefficient ( $R$ ) and also selects the combination which has the highest multiple correlation coefficient.

When only one independent variable is used, it appears that $10 \mathrm{~g}$ OT is best described as a function of the absorbed amounts of 14:0 ( $R=0.66)$. However, this is caused by only one dietary fat (Fig.6.5.A; TGM), which makes the validity of this relationship very doubtful.

The same holds for the results obtained by adding a second variable $(8: 0+10: 0)$ which indeed increases the $R$ value $(0.87)$ significantly $(P<0.01)$, but this again is caused mainly by one of the dietary fats (MCT).

Addition of a third $(18: 0)$ and a fourth $(12: 0)$ variable results in an 
Table 6.4. Total food intake, relative fat and fatty acid absorption and absorbed amount of dietary fatty acids. (Values $<20 \mathrm{mg}$. day ${ }^{-1}$ are not included)

\begin{tabular}{|c|c|c|c|c|c|c|c|}
\hline \multirow{2}{*}{$\begin{array}{l}\text { Dietary } \\
\text { fat }^{1}\end{array}$} & \multirow{2}{*}{$\begin{array}{l}\text { Food intake } \\
\text { g.anima }{ }^{-1} \\
\text { day }^{-1}\end{array}$} & \multirow{2}{*}{\multicolumn{2}{|c|}{$\begin{array}{l}\text { e Relative } \\
1 \text {. absorption } \\
\text { of fat }(\%)\end{array}$}} & \multicolumn{4}{|c|}{ Fatty acids absorbed mg.animal ${ }^{-1}$} \\
\hline & & & & $\begin{array}{l}\leq 10: 0 \\
(100) \S\end{array}$ & $\begin{array}{l}12: 0 \\
(99)\end{array}$ & $\begin{array}{l}14: 0 \\
(94)\end{array}$ & $\begin{array}{l}16: 0 \\
(94)\end{array}$ \\
\hline $\begin{array}{l}\text { CO } \\
\text { TGM } \\
\text { MCT } \\
\text { WO } \\
\text { PO } \\
\text { HSO } \\
\text { RO } \\
00 \\
\text { LO } \\
\text { CBO } \\
\text { SO }\end{array}$ & $\begin{array}{l}12.8 \\
12.4 \\
13.3 \\
10.3 \\
12.7 \\
11.6 \\
10.0 \\
12.0 \\
10.8 \\
12.2 \\
13.8\end{array}$ & $\begin{array}{l}98.0 \\
96.1 \\
99.7 \\
97.8 \\
91.8 \\
90.8 \\
91.6 \\
98.9 \\
98.6 \\
97.2 \\
97.1\end{array}$ & & $\begin{array}{r}418 \\
2814\end{array}$ & $\begin{array}{r}1339 \\
919 \\
31\end{array}$ & $\begin{array}{r}579 \\
1533 \\
\\
190 \\
34\end{array}$ & $\begin{array}{r}286 \\
309 \\
36 \\
464 \\
1174 \\
234 \\
79 \\
311 \\
158 \\
155 \\
215\end{array}$ \\
\hline $\begin{array}{l}\text { Dietary } \\
\text { fat }^{1}\end{array}$ & $\begin{array}{l}18: 0 \\
(90)\end{array}$ & $\begin{array}{l}18: 1 \pi \\
(97)\end{array}$ & $\begin{array}{l}18: 2^{\bullet} \\
(99)\end{array}$ & $\begin{array}{l}18: 3 \dagger \\
(99)\end{array}$ & $\begin{array}{l}20: 111 \\
(96)\end{array}$ & $\begin{array}{l}22: 1 \pi \\
(87)\end{array}$ & Rest \\
\hline $\begin{array}{l}\text { CO } \\
\text { TGM } \\
\text { MCT } \\
\text { WO } \\
\text { PO } \\
\text { HSO } \\
\text { RO } \\
\text { OO } \\
\text { LO } \\
\text { CBO } \\
\text { SO }\end{array}$ & $\begin{array}{r}93 \\
20 \\
\\
94 \\
138 \\
258 \\
\\
113 \\
140 \\
40 \\
108\end{array}$ & $\begin{array}{r}224 \\
21 \\
36 \\
400 \\
1184 \\
1710 \\
253 \\
2051 \\
525 \\
1425 \\
827\end{array}$ & $\begin{array}{r}61 \\
62 \\
169 \\
202 \\
270 \\
305 \\
327 \\
331 \\
338 \\
561 \\
2049\end{array}$ & $\begin{array}{r}38 \\
245 \\
20 \\
1386 \\
266\end{array}$ & 162 & 1050 & $935^{2}$ \\
\hline
\end{tabular}

1 See Table 6.2 ; $\$$ values in brackets indicate the relative fatty acid absorption ; ${ }^{2}$ Mainly $16: 1(n-7), 22: 0$ and $22: 1(n-11)$.

$\Uparrow(n-9) ; \quad \bullet(n-6) ;+(n-3)$

$R$ value of 0.94 , which cannot be further improved significantly by including more variables.

A careful screening of the results of the multiple regression analysis used in this experiment showed (6) that, at least for up to two independent variables, the regression equation describes $\log$ OT as a function of dietary fats rather than as a function of constituent fatty acids. This is due mainiy to the fairly specific fatty acid composition of the dietary fats selected for this experiment.

It should also be realized that the independent variables used in this 

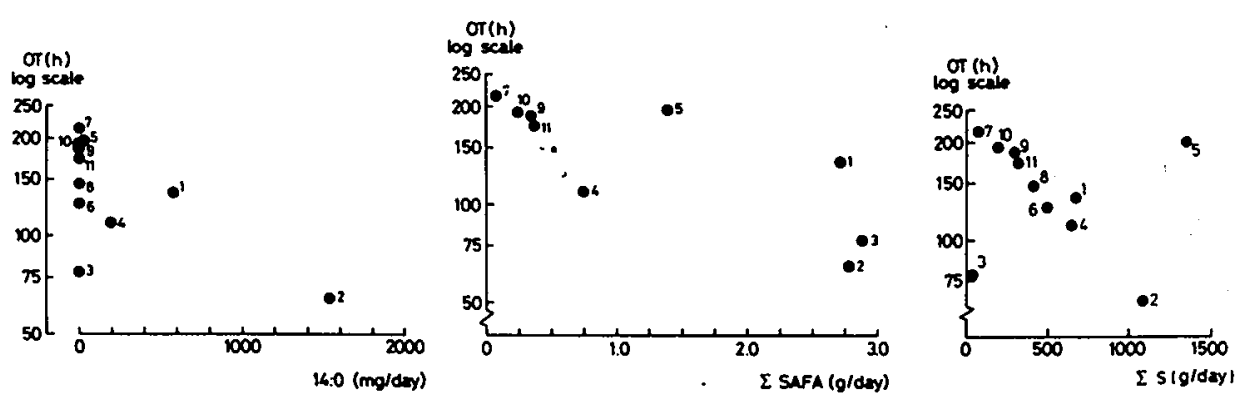

Fig.6.5. Relationship between the amount of fatty acids absorbed and arterial thrombosis tendency (mean values per animal). Numbers refer to the dietary fats given in Table 6.2.

A : Relationship between 14:0 and OT.

$B$ : Relationship between the total amount of saturated fatty acids ( $\Sigma$ SAFA) and OT.

C : Relationship between the sum of half the amount of $14: 0$ and the total amount of long-chain saturated fatty acids $(\Sigma S)$ and $0 T$.

regression analysis must be considered as descriptive and not as explanatory variables for $\log$ OT.

It is striking that $\log$ OT can best be described as a function of the absorbed amount of saturated fatty acids.(SAFA). This has also been suggested in the literature $(7,8)$ and is further supported by the significant relationship between $\log$ OT and the total absorbed amount of SAFA (Fig.6.5.B ; R=0,75; $P<0.05$ ).

From this figure it is evident that PO, CO, MCT and TGM do not fit very well: the OT's they induce seem to be too high for their SAFA-content. Three of these fats are the only ones containing 8:0, 10:0 and 12:0 (Table 6.2.), which suggests that these fatty acids are non-thrombogenic. This suggestion is consistent with the inability of 12:0 to enhance the ADP-induced platelet aggregation in vitro. In this system, 14:0 is moderately effective while 16:0 and 18:0 are highly effective (9).

Starting from these data from the literature, an attempt was made to improve the correlation between $\log$ OT and the absorbed amount of SAFA by assuming that 14:0 is only half as thrombogenic as 16:0 and 18:0. Therefore, the sum of the absorbed amount of SAFA was replaced by the sum of half the absorbed amount of 14:0 and the absorbed amount of all longer -chain saturated fatty acids $(\Sigma S)$. When this parameter is plotted against 
$\log$ OT, a perfect fit is obtained, except for MCT and PO (Fig.6.5.C).

It should be noted that almost all the fatty acids of MCT (8:0 and 10:0) are metabolized quite differently from the fatty acids with longer carbon chains. Absorption and early metabolism of $8: 0$ and 10:0 seem to be related more to carbohydrates, so that MCT-feeding can be considered as low -fat feeding, which is known to induce a low OT (Fig.6.1., see also ref. 10). The reason why $P O$ is an exeption is not yet known. When $\log O T$ is plotted against $\Sigma S$, calculated on the basis of dietary fatty acid composition or on the basis of absorbed fatty acids, almost identical relationships are obtained. Consequently, it is sufficient to relate arterial thrombosis tendency to dietary fatty acid composition.

In sum,this experiment indicates that dietary saturated fatty acids with 14 or more carbon atoms are thrombogenic, which implies that their replacement with unsaturated fatty acids will decrease dietary thrombogenicity.

\subsection{Comparison of the antithrombotic effect of oleic and linoleic acids}

To establish whether all unsaturated fatty acids are equally effective as to this 'passive' antithrombotic effect, the most common unsaturated fatty acids, oleic acid $(18: 1(n-9))$ and linoleic acid $(18: 2(n-6))$ were compared as for their effects on arterial thrombosis tendency. Four groups of 12 male Wistar rats (SPF) were fed diets containing 50 en\% of fat mixtures obtained by mixing hydrogenated palm oil with olive oil, safflowerseed $0 i 1$ and unhardened palm oil in such a way that the final mixtures contained 10 or $40 \%$ saturated acids (mainty palmitic acid) and 30 or $50 \% 1$ inoleic acid, the rest being oleic acid. If linoleic and oleic acid should have the same effect on arterial thrombosis tendency, the obstruction times would not be influenced by the dietary oleic/linoleic acid ratio so that, at a given saturated fat level, there would be no difference in arterial thrombus formation. This was investigated after feeding for 8 weeks. The results are given in Fig.6.6.

Statistical evaluation of these results shows that, at each saturated fat level, thrombosis tendency is lower (OT significantly longer) in the group receiving the diet highest in 1 inoleic acid $\left(P_{2}<0.05\right.$; analysis of variance). This finding demonstrates that linoleic acid, apart from 
before saturated fats can be considered prothrombotic. Some evidence was already obtained in the experiments described in sections 6.3 and 6.4 . In both experimental series, the dietary carbohydrate content was kept constant. In section 6.3, arterial thrombosis tendency appeared to be related to the dietary long-chain saturated fatty acid content (Fig.6.5.C). However, this might have been due to the fact that largely fats high in long-chain saturated fatty acids contain only a small amount of antithrombotic linoleic acid. The evidence mentioned in section 6.4. is, therefore, more convincing : at constant dietary carbohydrate and linoleic acid contents, the arterial thrombosis tendency is higher, the higher the dietary long-chain saturated fatty acid content. Nevertheless, another experiment was performed in order to investigate the effect of dietary long-chain saturated fatty acids.

Rats, fed a commercial stock diet, were given an experimental diet containing 5 en\% sunflowerseed oil supplemented or not with 55 en\% hydrogenated coconut oil. At the beginning of the feeding period (control) and 4 and 8 weeks later, OT's were measured in part of the animals. It then appeared that after the change in diet, the OT decreased to about the same final value. However, the OT-decrease occurred more rapidly in the group receiving the HCO-supplemented diet. (Fig.6.7.). Therefore, it can be concluded that dietary fats rich in long-chain saturated fatty acids enhance arterial thrombosis tendency.

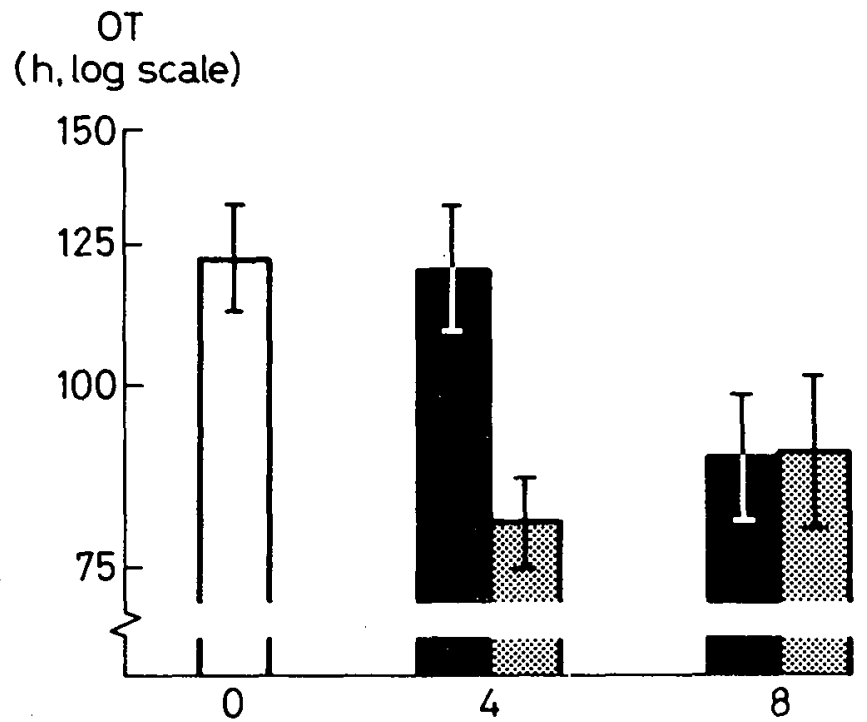

Fig.6.7. Accelerating effect of saturated fat on the increase of thrombosis tendency in rats, following dietary changes (OT \pm SEM)

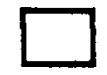
stock diet 


\subsection{Comparison of the effect of cis and trans fatty acids on arterial} thrombus formation

The organoleptic and physicochemical properties of natural oils used for the production of edible fats are improved by hydrogenation. This technological process reduces the number of double bounds and at the same time converts variable amounts of cis double bounds into their trans isomers (see Chapter 2, section 1.). These trans fatty acids have slightly different physical properties as compared to their cis isomers. Results of physiological and biochemical studies suggest that the properties of the trans monoenoic fatty acids are intermediate between those of saturated and cis-mono-unsaturated fatty acids $(11,12)$.

However, there are no indications that the molecular configuration around the double bonds influences the effect of unsaturated fatty acids on thrombogenesis. The hydrogenated soyabean oit used in the experiment described in section 6.3. contained unsaturated fatty acids about $58 \%$ of which had the trans-configuration. Nevertheless, this dietary group fits perfectly the curve showing the relationship between the amount of dietary saturated fatty acids absorbed and arterial thrombosis tendency (Fig.6.5.C). In a further experiment, we compared the obstruction time in rats fed a diet containing 50 en\% olive oil (80\% oleic acid) or a mixture of olive oil and hydrogenated olive oil contaning $40 \%$ oleic acid and $40 \%$ elaidic acid (as triglycerides; elaidic acid is the trans isomer of oleic acid, see Fig. 2.4.). After 8 weeks' feeding, the obstruction times did not differ significantly:

cis oleic acid : $\log$ OT $=2.10 \pm 0.040 ; n=12 ;$ OT $=125 \mathrm{~h}$

trans oleic acid: $\log$ OT $=2.02 \pm 0.058 ; n=11 ;$ OT $=104 \mathrm{~h}$ It is, therefore, highly likely that there is no difference between the antithrombotic effect of cis and trans unsaturated fatty acids.

\subsection{Summary}

A model used to quantify arterial thrombosis tendency in rats, showed that dietary fats rich in long-chain saturated fatty acids promote arterial thrombogenesis. Dietary linoleic acid (and most probabiy also $\alpha-1$ inolenic acid) has a specific antithrombotic effect whereas mono-unsaturated fatty acids behave neutral in this respect and decrease arterial thrombosis tendency only if they replace long-chain saturated fatty acids. No 
significant difference was observed between the antithrombotic effect of cis fatty acids and their trans isomers.

\subsection{References}

1. Malmros,H.: Dieteray preventions of atherosclerosis. Lancet ii: 479-484 (1969).

2. Büller,J., and Vies,R.0.: Dietary fats and atherosclerosis in the rabbit. Voeding 27 : 223-231 (1966).

3. Spearman,Ch.: The proof and measurement of association between two things. Amer.J.Psychol.15: 7214-7217 (1906).

4. Carroll,K.K.: Digestibility of individual fatty acids in the rat. J.Nutr. 64: 399-410 (1958).

5. Carroll,K.K. and Richards,J.F.: Factors affecting digestibility of fatty acids in the rat. J.Nutr.64: 411-424 (1958).

6. Hornstra,G. and Lussenburg,R.N.: Relationship between the type of dietary fatty acid and arterial thrombosis tendency in rats. Atherosclerosis 22 : 499-516 (1975).

7. Hornstra,G.: Dietary fats and arterial thrombosis. Haemostasis 2 : 21-52 (1973/74).

8. Renaud,S. and Gautheron,P.: Dietary fats and experimental (cardiac and venous) thrombosis. Haemostasis 2: 53-72 (1973/74).

9. Hoak,J.C., Spector,A.A., Fry,G.L. and Warner,E.D.: Effect of free fatty acids on ADP-induced aggregation. Nature (London) 228: 1330-1332 (1970).

10. Hornstra,G.: The influence of dietary sunflowerseed $0 i 1$ and hardened coconut $0 i 1$ on intra-arterial occlusive thrombosis in rats. Nutr. Metabol. 13: 140-149 (1971).

11. Houtsmuller,U.M.T.: Biochemical properties of trans-fatty acids. Proc. 13th World Congress ISF, Symp. 3, pp. 79-97, ITERG, Paris (1976).

12. Vies,R.0., Gottenbos,J.J. et van Pypen,P.L.: Aspects nutritionnels des huiles de soja hydrogénées et de leurs acides gras insaturés isomériques. Bibl. Nutr. et Dieta 25: 186-196 (1977). 


\subsection{Introduction}

As discussed in Chapter 3, arterial thrombus formation results from platelet reactions and blood coagulation, both initiated - and possibly modulated - by the vessel wall. In order to 'locate' the dietary fat effect on arterial thrombogenesis, investigations were carried out into the effects of dietary fats on blood clotting and several thrombotic platelet functions. Most of these experiments were done with diets containing 50 or $60 \mathrm{en} \%$ sunflowerseed oil (SO) -an example of a linoleic acid-rich, antithrombotic vegetable oil- or hydrogenated coconut oil ( $\mathrm{HCO}$ ), which is highly saturated and has prothrombotic properties (Chapter 6). In order to prevent essential fatty acid deficiency (Chapter 8), the HCO-diet was always enriched with 5 en\% so. These experimental diets invariably induce a significant difference in arterial thrombosis tendency, as shown in Fig.7.1.

\subsection{Effect of sunflowerseed oil (SO) and hydrogenated coconut oil (HCO)}

\section{on blood coagulation}

Blood for whole blood and plasma clotting time studies was bbtained by a clean venepuncture of the exposed external jugular vein of ether-anesthe-

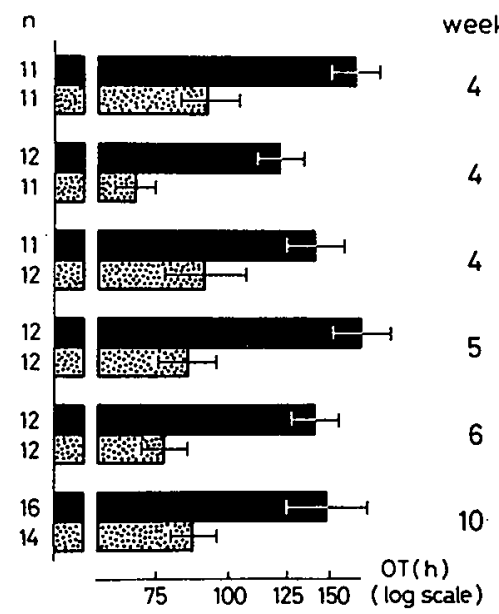

Fig.?.1. Arterial thrombosis tendency (OT) in rats fed $\mathrm{SO}(\square$ )and $\mathrm{HCO}$ ( diets for 4-10 weeks. 
tized rats after overnight fasting. The puncture was made with a $18 \mathrm{G}$ siliconized disposable needle. After 3-5 drops of blood had drained away, a syringe, prefilled or not with one part of a $3.8 \%$ (w/v) sodium citrate solution, was connected to the needle. Nine parts of blood were drawn into the syringe so slowly that the vessel wall did not collapse: onto the needle. After careful mixing, the anticoagulated blood was transferred into a plastic or siliconized glass tube for further processing as described for the various tests.

For the measurement of activated partial thromboplastin time (APTT), prothrombin time (PT) and vessel-wall induced clotting, blood was obtained by puncturing the abdominal aorta of ether-anesthesized animals after overnight fasting. The puncture needle (18 G) was connected to a siliconized vinyl tube (Portex, $4 \mathrm{E}$, length $15 \mathrm{~cm}$, i.d. $2 \mathrm{~mm}$ ). Blood was collected in a calibrated plastic tube containing $1 \mathrm{ml} 3.8 \%(\mathrm{w} / \mathrm{v})$ sodium citrate. From each animal, $9 \mathrm{ml}$ of blood was taken. After careful mixing and standing for at least 10 min (room temperature), PRP was prepared by centrifugation for $20 \mathrm{~min}$ at $190 \times \mathrm{g}$. The PRP was treated as described for the different tests.

\subsubsection{Whole_blood_clotting_time}

The clotting time of native blood was measured with the so-called rotating loop technique devised by Chandler (1). A piece of transparent plastic tubing, length $32,5 \mathrm{~cm}$, i.d. $2.3 \mathrm{~mm}$; o.d. $3.9 \mathrm{~mm}$, was filled with $0.5 \mathrm{ml}$ of freshly drawn native blood. The tube was bent and both ends were tightly connected using a somewhat wider piece of tubing (i.d. $3.8 \mathrm{~mm}$; o.d. 5.8 $\mathrm{mm}$ ). The loop so obtained was placed at an angle of $30^{\circ}$ on a device rotating it at 15 rev.min ${ }^{-1}$. The device is placed in a cabinet at $37^{\circ} \mathrm{C}$, which is also used to prewarm the tubing. Gravity keeps the fluid blood in the lower part of the rotating loop. However, when the blood clots, it suddenly starts rotating at the same speed as the loop. The time between blood sampling and the very onset of rotation of the blood, is taken as the clotting time.

This test measures blood clotting in a dynamic situation and, therefore reflects, to some extent, the in vivo situation. Clotting is preceded by visible platelet aggregation and the clot formed resembles a typical white-headed, red-tailed thrombus. Platelet aggregation was shown to 
Table 7.1. Whole blood clotting time ( \pm SEM) in Chandler's rotating loop, measured in native blood of rats fed $\mathrm{SO}$ or $\mathrm{HCO}$-containing diets $(n=14-16)$

\begin{tabular}{llll}
\hline Feeding period & \multicolumn{4}{l}{ Whole blood clotting time } \\
\cline { 2 - 4 } (weeks) & SO & HCO & $P_{2}$ \\
\hline 4 & $138 \pm 2.2$ & $147 \pm 6.5$ & $>0.10$ \\
8 & $150 \pm 4.8$ & $157 \pm 12.5$ & $>0.10$ \\
\hline
\end{tabular}

result from thrombin formation (2). Measurements were done after feeding for 4 and 8 weeks. No differences were observed between the two groups (Table 7.1.).

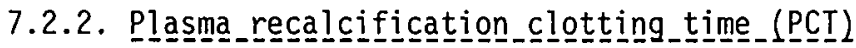

In 1969, Renaud published this clotting test enabling him to demonstrate a relationship between PCT and thrombosis tendency in rats as well as in man (3). We decided to use this test to screen the inirinsic clotting system upon feeding different diets.

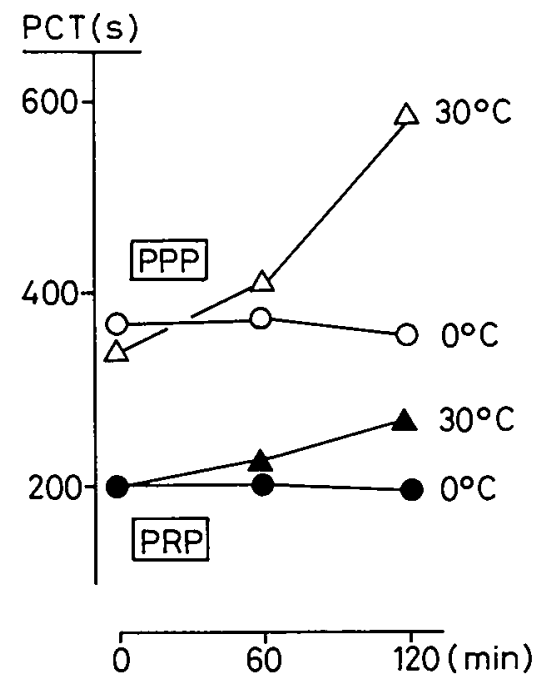

Fig.7.2. Effect of plasma storage temperature $\left({ }^{\circ} \mathrm{C}\right)$ and time (min) on recalcification plasma clotting time (PCT, 5 ). Each point represents the mean of 4 determinations.

Open symbols: platelet-poor plasma. Closed symbols: platelet-rich plasma $\left(0.3 \times 10^{9} \mathrm{pl} . \mathrm{ml}^{-1}\right)$. 
Freshly drawn citrated blood $(2.0 \mathrm{ml})$ was transferred to a siliconized glass tube and centrifuged at $130 \mathrm{xg}$ for $10 \mathrm{~min}$. Approximately $0.3 \mathrm{ml}$ of the citrated platelet-rich plasma (PRP) was collected and stored in another siliconized glass tube. The rest of the blood was centrifuged again (10 min at $4000 \mathrm{xg}$ ) in order to obtain platelet-poor plasma (PPP). After counting its platelet content (using a Coulter Counter model FN) $50 \mu 1$ of the PRP was diluted with autologous PPP to a platelet concentration of about $3 \cdot 10^{5} \cdot \mu 7^{-1}$. This whole procedure was performed at $0^{\circ} \mathrm{C}$ since storage at $30^{\circ} \mathrm{C}$ (the temperature used by Renaud) was shown to prolong the clotting time considerably, especially in PPP (Fig.7.2.).

The actual clotting test is performed by transferring $0.1 \mathrm{ml}$ PRP, PRP diluted with PPP or PPP, into a clear plastic tube which is placed in a waterbath $\left(37.5^{\circ} \mathrm{C}\right.$ ). After a warming-up period of $30 \mathrm{~s}, 0.2 \mathrm{ml} \mathrm{\textrm {CaCl } _ { 2 }}$ $\left(10^{-2}\right.$ mol. $\left.1^{-1}\right)$ is added while a stopwatch is started. Mixing is performed by gently rotating the tube. One min later and then after every $10 \mathrm{~s}$, the tube is carefully removed from the waterbath and tilted slightly to check the fluidity of the plasma. The end-point is attained when the plasma becomes a solid mass.

The PCT measures the intrinsic clotting pathway and is greatly influenced by the number of platelets present (Fig.7.3., see also ref. 3 ). Therefore, by comparing the clotting time of PPP with that of PRP or its dilution,
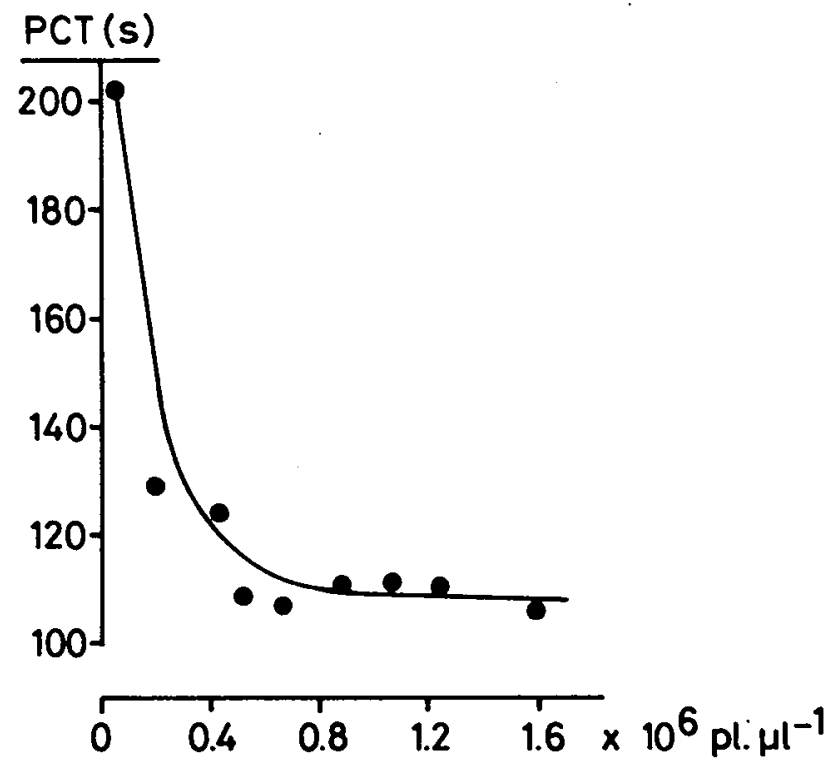

Fig.7.3. Effect of platelet count on recalcification plasma clotting time (PCT). Each point represents the mean of 3-7 determinations. Different platelet counts were obtained by diluting PRP with autologous PPP. 
an indication of the clot-promoting effect of the platelets can be obtained as well.

Measurements were carried out after 15 weeks' feeding. The results (Fig. 7.4.) show that there is no difference between the groups. This is not in agreement with the results published by Renaud and co-workers. They clearly demonstrated that the type of dietary fat greatly influenced the PCT of PRP, which appeared to be due to a certain influence on the clot-promoting effect of the blood platelets. A striking relationship was also observed for the thrombosis tendency induced by the different dietary fats $(4-6)$. However, it should be noted that these researchers used an extremely hyperlipemic diet which was shown to cause enhanced blood clotting $(7,8)$. Moreover, their thrombosis model depends on endotoxin-induced activation of factor XII in the venous circulation (9) and, therefore, more applies to venous thrombosis for which the importance of enhanced coagulation is generally acknowledged.

When PCT measurements were carried out in the same samples at the same time and laboratory by ourselves and the Renaud group, none of us was able to discriminate between SO- and $\mathrm{HCO}$-fed animals on the outcome of this clotting test. We conclude, therefore, that in the dietary fat effect on

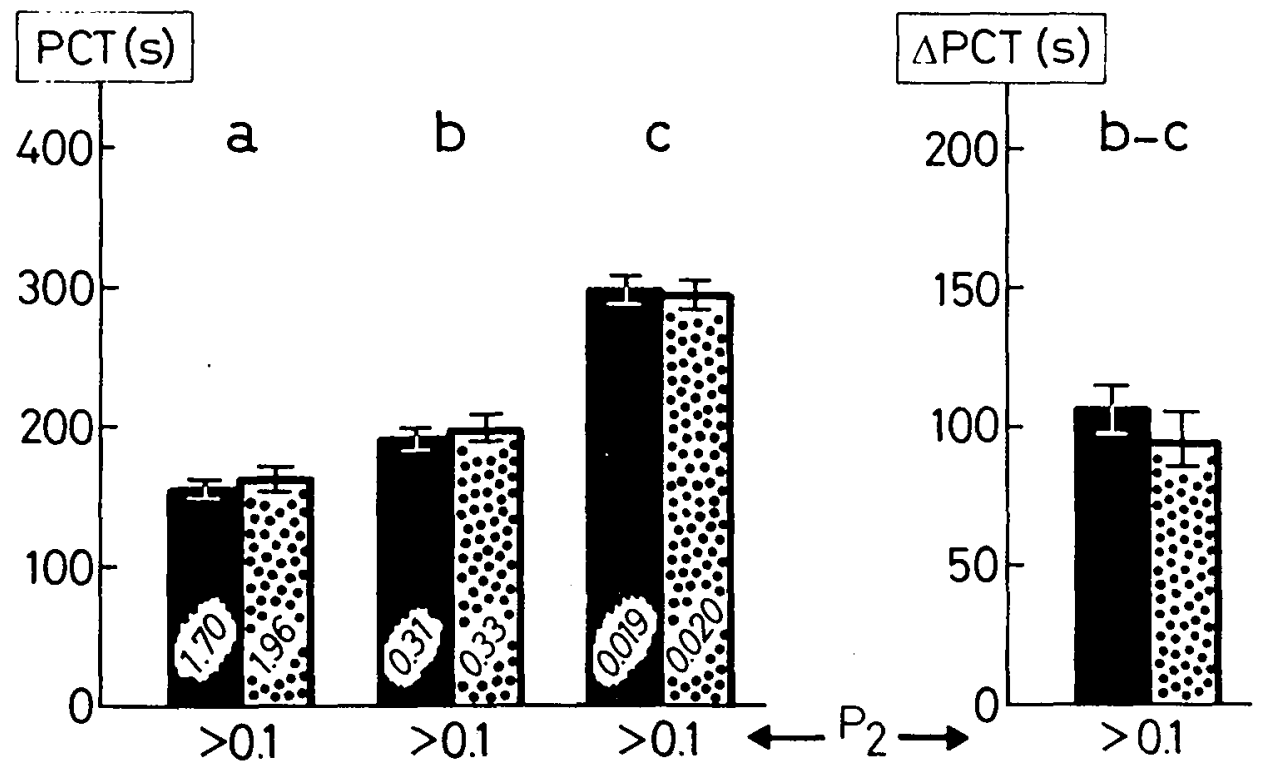

Fig.7.4. Recalcification plasma clotting times (PCT, $S \pm \operatorname{SEM}$ ) in PRP (a), PRP diluted with autologous PPP (b) and in PPP (c) of rats fed SO or HCO

(b-c) indicates clot-promoting effect of platelets. Numbers in bars $\times 10^{6}$ refer to platelet concentration per $\mu 1$ plasma. 
arterial thrombosis tendency, blood clotting as reflected by the PCT-test, does not play a significant role.

\subsubsection{Activateded_partial thromboplastin time_(APIT)}

In order to investigate the intrinsic pathway of coagulation APTT's were measured in platelet-free plasma (PFP) after high-speed centrifugation $(16,000 \times \mathrm{g}$ for $20 \mathrm{~min})$ of PPP. A standard PFP was prepared in the same way from a pool of 15 stock animals after overnight fasting. The test was performed in PFP, diluted to $20 \%$ with a Tris buffer $\left(10^{-3}\right.$ mol. $1^{-1}$ in saline) at $\mathrm{pH} 7.35$. The activation mixture consisted of inositin, $50 \mathrm{mg} \cdot \mathrm{ml}^{-1}, 0.2 \mathrm{ml}$; kaolin, $100 \mathrm{mg}$ and Tris/saline buffer, $19.8 \mathrm{ml}$. Clotting was measured in an aggregometer (Payton Dual Channel) at $37.5^{\circ} \mathrm{C}$ in siliconized glass tubes. Transmitted light was recorded continuously while the reaction mixture was stirred with a siliconized metal bar at 500 rev. $\min ^{-1}$. $0.1 \mathrm{ml}$ Tris/saline buffer, $0.1 \mathrm{ml}$ plasma dilution and $0.1 \mathrm{ml}$ activation mixture were incubated for $2 \mathrm{~min}$, after which $0.1 \mathrm{ml}$ $\mathrm{CaCl}_{2}\left(0.033 \mathrm{~mol}^{-1}\right)$ was added. Clotting times were calculated from the recorder tracings as indicated in Fig.7.5. Because of skew distribution, these clotting times ( $t_{c}$, seconds) were converted to the clotting index $S=1 / t_{c} \times 1,000$. This clotting index $S$ is higher, the stronger the clotting response. Results (Table 7.2.) are also expressed in percentages of the $S$ values obtained witii standard PFP. After 4 months' feeding, the difference between the groups was not signifirant (Student's iwi-sample test)

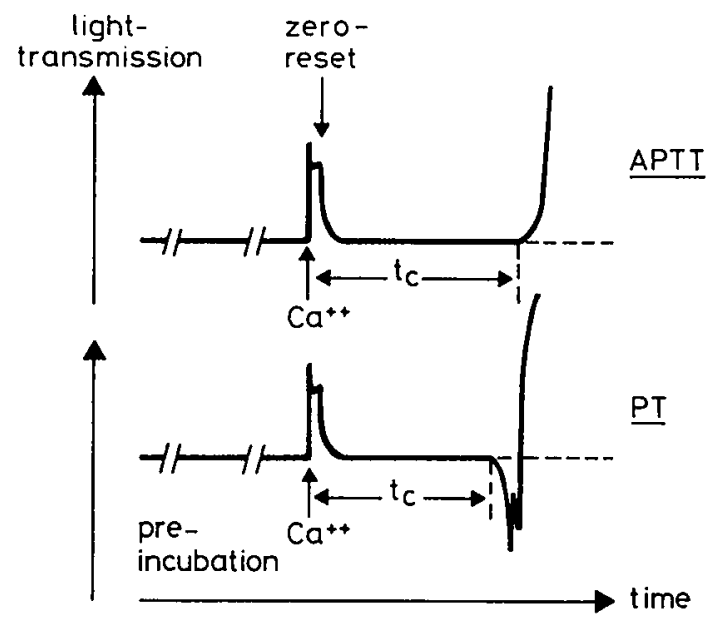

Fig.7.5. Aggregometer tracings obtained when measuring APTT (upper tracing) and PT (lower tracing) in platelet-free plasma. $t_{c}$ : clotting time. 
Table 7.2. Clotting index S, calculated from activated partial thromboplastin times (APTT) and prothrombin times (PT), measured in platelet-free plasma of rats fed $\mathrm{SO}-(n=9)$ or $\mathrm{HCO}-(n=10)$ containing diets. Results are also given in $\%$ of values obtained in plasma of animals fed a stock diet (APTT: $S=20.0 \pm 1.60 ;$ PT: $S=31.9 \pm 0.47 ; n=8$ )

\begin{tabular}{|c|c|c|c|c|}
\hline \multirow{2}{*}{ Parameter } & \multicolumn{2}{|l|}{ APTT } & \multicolumn{2}{|l|}{ PT } \\
\hline & so & $\mathrm{HCO}$ & so & $\mathrm{HCO}$ \\
\hline $\begin{array}{l}\mathrm{S} \\
\%\end{array}$ & $\begin{aligned} 27.3 & \pm 2.05 \\
147 & \pm 16.5\end{aligned}$ & $\begin{aligned} 24.6 & \pm 1.41 \\
131 & \pm 9.5\end{aligned}$ & $\begin{array}{ll}28.6 & \pm 0.62 \\
89 & \pm 2.3\end{array}$ & $\begin{aligned} 27.7 & \pm 0.40 \\
87 & \pm 1.3\end{aligned}$ \\
\hline
\end{tabular}

a)though clotting of plasma of the HCO group tended to be less than that in the so group. It is striking to note that, compared with the stock diet, both experimental diets seem to enhance intrinsic clotting, judging from a significantly higher $S$ value $\left(P_{2}<0.05\right)$.

\subsubsection{Prothrombin time_(PI)}

PT's were measured with the one-stage technique, using a rat-brain thromboplastin preparation to trigger the extrinsic clotting system. Rat-brain thromboplastin was prepared according to a procedure described by Owren and Aas (10) and modified by Muller (11). The preparation was diluted with Michaelis buffer (12) to give a clotting time of about 14 seconds (clotting index $S=71.4$ ) with undiluted standard rat PFP. PT measurements were performed in PFP, diluted to $20 \%$ with the Tris/saline buffer. Plasma

Table 7.3. Platelet count (A), platelet factor 3 activity (B), availability (C) and content (D) measured in rat platelets on feeding a diet containing SO or HCO for 8 weeks $(n=16)$. ST = stypven time; $\mathrm{fr} / \mathrm{th}=$ freezing and thawing.

\begin{tabular}{|c|c|c|c|c|}
\hline Parameter & Unit & SO & $\mathrm{HCO}$ & $P_{2}$ \\
\hline A. Platelet count & $\times 10^{6} \cdot \mu 7^{-1}$ & $0.30 \pm 0.021$ & $0.32 \pm 0.011$ & $>0.10$ \\
\hline B. ST, saline & $\begin{array}{l}\mathbf{s} \\
\%\end{array}$ & $\frac{31.1}{100} \pm 0.83$ & $\begin{array}{c}32.9 \\
100\end{array}$ & $\begin{array}{l}>0.10 \\
.\end{array}$ \\
\hline C. ST, collagen & $\stackrel{s}{\%}$ of saline & $\begin{array}{ll}22.9 & \pm 0.74 \\
74 & \pm 1.5\end{array}$ & $\begin{array}{ll}26.9 & \pm 1.01 \\
82 & \pm 1.9\end{array}$ & $\begin{array}{l}<0.01 \\
<0.01\end{array}$ \\
\hline D. ST, $3 \times \mathrm{fr} / \mathrm{th}$. & $\begin{array}{l}s \\
\%\end{array}$ of saline & $\begin{array}{ll}13.9 & \pm 0.43 \\
45 & \pm 1.9\end{array}$ & $\begin{array}{ll}14.0 & \pm 0.32 \\
43 & \pm 1.7\end{array}$ & $\begin{array}{l}>0.10 \\
>0.10\end{array}$ \\
\hline
\end{tabular}


dilution $(0.15 \mathrm{ml})$ and $0.15 \mathrm{ml}$ of the rat-brain thromboplastin preparation were preincubated for $1 \mathrm{~min}$ at $37.5^{\circ} \mathrm{C}$ and a stirring rate of 500 rev.min $^{-1}$ in a siliconized glass cuvette of the Payton Dual Channel aggregometer. Coagulation was triggered by adding $0.15 \mathrm{ml} \mathrm{CaCl}_{2}\left(0.033 \mathrm{~mol}^{-1}\right)$. Clotting times were calculated from the aggregometer tracings as shown in Fig.7.5. PT's were converted to their S-values (see 7.2.3.) and expressed in percentages of the values obtained in standard PFP. The difference between both groups (Table 7.2.) was not significant (Student's two-sample test). Compared with a stock diet, the experimental diets significantly reduced extrinsic clotting.

\subsubsection{Platelet factoror 3 (PF 3)}

At various stages in the coagulation cascade, activated platelets contribute to the clotting process by providing a phospholipid surface on which the activated clotting factors are concentrated and properly positioned towards each other (13). This property of (activated) platelets is called platelet factor 3 (PF 3). It can be measured in a system in which the available phospholipid surface limits the coagulation reaction. In such a system, any additional phospholipid surface becoming available causes a reduction in clotting time. Clotting is initiated by direct activation of factor $X$, using a snake venom (Russell's Viper Venom, RVV). In this way, any direct influence of the intrinsic/extrinsic activation system is prevented (14). The clotting time measured with RVV is called the Stypven Time (ST). The RVV reagent is prepared fresh daily. $0.5 \mathrm{mg}$ RVV (Wellcome) is dissolved in $5 \mathrm{ml} \mathrm{CaCl} \mathrm{Cl}_{2}\left(0.015 \mathrm{~mol}^{-1}\right)$ and diluted $(1: 20)$ in the same $\mathrm{Ca}^{++}$-solution. This working solution is kept at room temperature.

In a first experiment, the PF 3 activity, content and availability were determined in PRP, diluted with autologous PPP to a platelet concentration of about $\left.0.3 \times 10^{6} \cdot \mu\right]^{-1}$. PF3 activity and availability were measured by transferring $0.1 \mathrm{ml}$ of the PRP + PPP dilution into a siliconized glass tube containing $0.05 \mathrm{ml}$ of saline (for the measurement of PF3 activity) or a collagen suspension in saline (for measuring PF3 availability). The tubes were placed on a device at an angle of about $8.5^{\circ}$ and rotated longitudinally at $30 \mathrm{rev} . \mathrm{min}^{-1}$. After $10 \mathrm{~min}, 0.1 \mathrm{ml}$ of the mixture was transferred into another siliconized glass tube and placed in a waterbath 
at $37.5^{\circ} \mathrm{C}$. After $1 \mathrm{~min}, 0.1 \mathrm{ml}$ of the RVV reagent was added while a stopwatch was started. After rotating the tube (mixing!), fibrin formation was checked by using an oese. The moment the first fibrin strand appeared was taken as end-point. ST's obtained upon saline incubation ( PF3 activity) were taken as 100\%. ST's obtained after collagen addition ( PF3 availability) were expressed in $\%$ of PF3 activity. To measure the PF 3 content, the PRP + PPP dilution was frozen in a mixture of solid $\mathrm{CO}_{2}$ and acetone $\left(-64^{\circ} \mathrm{C}\right)$ and subsequently thawn in water at $37^{\circ} \mathrm{C}$. This procedure was repeated 3 times in order to lyse the platelets and make all their PF3 available. ST's were measured and expressed as described for PF3 activity and availability. PF3 availability is better and the content higher, the lower the ST-values.

The results obtained after 8 weeks' feeding, are shown in Table 7.3. PF3 activity (B) and content (D) do not differ for both groups; however, PF3 availability (C) is significantly lower in the thrombogenic HCO group. This unexpected finding was confirmed in a second experiment in which PF3 availability after 8 weeks' feeding was measured in citrated whole blood and followed in time after activation. One $\mathrm{ml}$ of freshly drawn citrated blood was divided over 2 siliconized glass tubes containing $0.05 \mathrm{ml}$ of saline or a suspension of collagen in saline. The tubes were
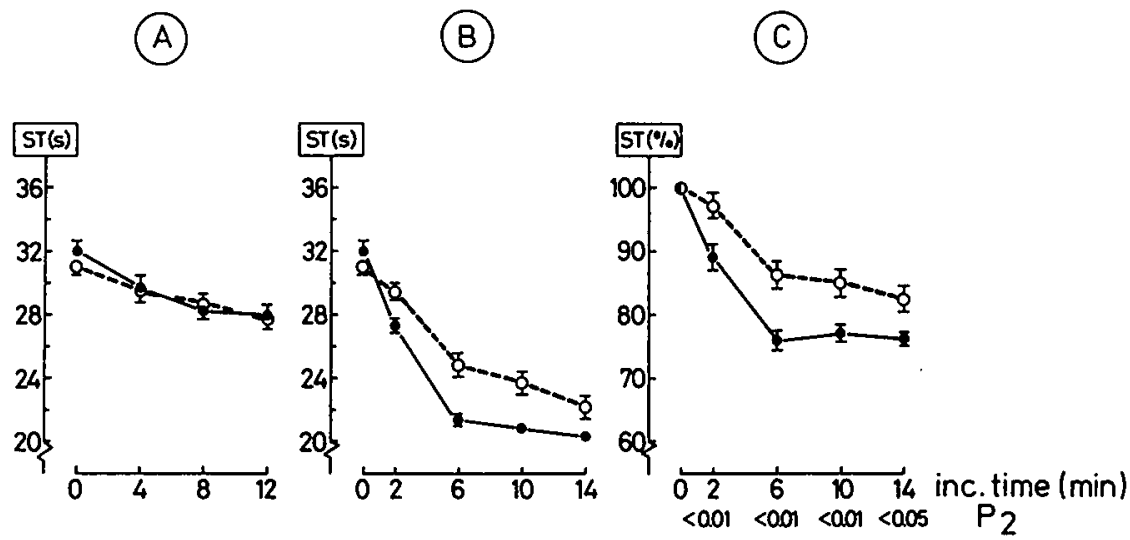

Fig.7.6. Platelet factor 3 availability in citrated blood of rats fed SO-(-—) or HCO-(--O-- ) containing diets for 8 weeks.

A. Course of Stypven time (ST, S \pm SEM) upon incubation with saline (control series).

B. Course of ST ( $S \pm$ SEM) on incubation with a collagen suspension in saline.

C. Collagen-induced PF3 availabi?ity (\% \pm SEM.) after correction for non-specific platelet activation as described in the text. 
placed on the rotator and after $0,4,8$, and 12 minutes (saline, control) or $2,6,10$, and 14 minutes(collagen) ST's were measured in $0.1 \mathrm{ml}$ samples as described above. Due to platelet activation, PF3 becomes available causing the ST to decrease. This is shown in Fig.7.6., sections $A$ and $B$ for saline and collagen-activation respectively.

Fig.7.6.C shows the time course of PF 3 availability upon activation with collagen. Results are corrected for non-specific collagen-independent PF3 availability, by expressing the ST's in \% of the values calculated from the control (saline) series. It is evident that the HCO diet is associated with a significantly lower PF3 availability as compared with the so diet.

It has been shown that a slight degree of platelet lysis -which is inevitable when handling platelets- causes the ST to decrease considerably $(15,16)$. Our results are not corrected for possible lysis so that the difference observed may be explained by the possibility that HCO platelets are more lysis-resistant than so platelets. This has not yet been investigated.

From these studies it can be concluded that PF3 activity and content are not different for both groups. Since feeding the HCO-containing diet results in a zower PF3 availability of blood platelets upon their activation by collagen as compared to feeding the so-diet, whereas it causes a higher arterial thrombosis tendency, it is unlikely that changes in PF3 are involved as a causal factor in the dietary-fat induced changes in arterial thrombosis tendency.

\subsubsection{Vessel-wall induced clotting}

Blood clotting can be initiated by vessel-wall damage. As indicated in Chapter 3, this clotting process is of extrinsic as well as intrinsic origin and platelets definitively contribute to it, particularly so after activation. Prostacyclin $\left(P \mathrm{PI}_{2}\right)$ was shown to inhibit vessel-wall induced clotting by inhibiting platelet activation.

In order to investigate the possible relationship between arterial thrombosis tendency and vessel-wall induced clotting, three groups of rats were fed diets in which $50 \%$ of the digestible energy was provided by sunflowerseed oil (SO, mainly linoleic acid), linseed oil (LO, mainly 
$\alpha$-linolenic acid) or hydrogenated coconut oil (HCO, mainly saturated fatty acids, see Table 6.2.). After 3 months, arterial thrombosis tendency was determined in $50 \%$ of the animals. In the other animals, the aortic wall-induced clotting in autologous PRP was measured, as described in Chapter 3 section 2.1.

The results confirm the differences in arterial thrombosis tendency found on earlier occasions (Chapter 6). They also indicate differences in the mean clotting response of each group the saturated fat group showing the highest and the linoleic acid-rich group, the lowest clotting tendency (Fig.7.7.A) Due to wide individual variations, the differences did not reach the level of statistical significance. However, a striking relationship was observed between arterial thrombosis tendency and vessel-wall induced clotting (Fig.7.8.), which indicates that this clotting response may contribute to arterial thrombus formation. When prostacyclin action is prevented by using indomethacin-treated aortas, coagulation in autologous PRP is enhanced in all three groups (Fig.7.7.B). In the LO group, this enhancement is very small, leading to a significantly $\left(P_{2}<0.05\right)$ lower clotting tendency than in the other groups.
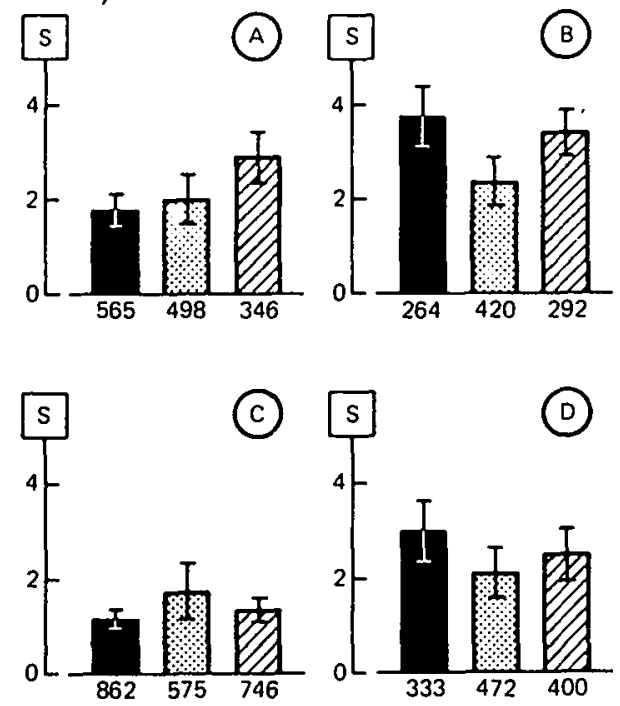

Fig.7.7. Effect of dietary fat on vessel-wall induced clotting (clotting index $S$, mean $\pm S E M)$ in Wistar rats.

A. Non-treated aortas in autologous PRP $(n=9)$

B. Indomethacin-treated aortas in autologous PRP $(n=9)$

C. Aortas in standard PPP $(n=10)$

D. Standard aorta in different PPPS $(n=7)$

Figures below bars are clotting times (s) calculated from mean $S$-values. so; Lо; Eăнo. 


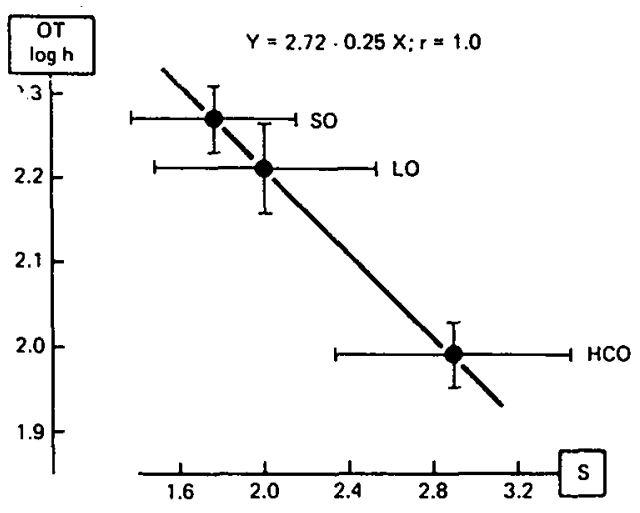

Fig. 7.8. Relationship between vessel-wall induced clotting in autologous PRP ( $\mathrm{S} \pm$ SEM) and arterial thrombosis tendency ( $\log$ OT \pm SEM) measured in different groups of animals receiving 50 en\% fat-containing diets. SO = sunflowerseed oil; LO = linseed oil; HCO = hardened coconut oil.

Since no clotting differences were observed upon incubation of non-treated aortas in standard PPP (Fig.7.7.C) or upon incubation of pieces of standard aorta in the different PPPS (Fig.7.7.D), this must be due to a low 'activation grade' of the LO platelets induced by the vessel-wall which can be either platelet- or aorta-bound. Most probably, the low 'activation grade' is caused by some platelet property, since malon dialdehyde (MDA) formation upon supramaximal triggering with collagen appeared to be significantly lower $\left(\mathrm{P}_{2}<0.01\right)$ than in the other groups (MDA production in $10^{-9}$ mol per $10^{9}$ platelets; LO: $0.78 \pm 0.055$; SO: $1.27 \pm 0.118$; HCO:

$1.44 \pm 0.080 ; n=12$, mean \pm SEM). These results are further dealt with in Chapter 8 .

In the experiment mentioned above, vessel-wall induced clotting was measured in a low $\mathrm{Ca}^{++}$- medium $\left(\mathrm{CaCl}_{2}\right.$ added to a final concentration of $\left.0.5 \times 10^{-6} \mathrm{~mol} .1^{-1}\right)$, leading to long clotting times and, as a result, to low S-values. In order to explore the dietary fat effect on vessel-wall induced clotting further, the experiment was repeated with SO- and HCO -diets and a final $\mathrm{CaCl}_{2}$ concentration of $10^{-3}$ mol. $1^{-1}$. Again, no significant difference was observed. In contrast to the previous experiment, however, the HCO group showed a tendency towards a lower clotting response $(7.05 \pm 0.204, \bar{S} \pm S E M, n=10)$ than the So group $(7.42 \pm 0.325$, $n=11$ ). Therefore, it must be concluded that the difference in arterial thrombosis tendency on feeding SO- and HCO-diets is most probably not caused by a dietary fat effect on vessel-wall induced clotting. 


\subsection{Effect of the dietary fat type on platelet aggregability}

Platelet aggregation plays a pivotal role in arterial thrombus formation. Thus, the dietary fat effects may be mediated via an effect on the platelet aggregation tendency. This aspect was investigated in depth, using again material from animals fed diets containing antithrombotic so (50 or 60 en\%) or thrombogenic HCO (45 or 55 en\%, supplied with 5 en\% so to prevent essential fatty acid deficiency). Apart from a consistent effect on arterial thrombosis tendency (Fig.7.1.), we also noted that the HCO diet invariably caused a higher whole blood platelet count than the so diet (Fig.7.9.).

\subsubsection{Platelelet_aggregation in vititro}

PTatelet aggregation in vitro was measured, using the turbidimetric technique as described by Born (17) and 0'Brien (18). To this end, $0.3 \mathrm{ml}$ PRP (obtained as described in section 7.2.) was mixed with $2.3 \mathrm{ml}$ saline and $0.2 \mathrm{ml} \mathrm{CaCl} 2_{2}$-solution $\left(7.5 \times 10^{-3} \mathrm{~mol} .1^{-1}\right)$ and incubated for $2 \mathrm{~min}$ at $37^{\circ} \mathrm{C}$ while stirring at 1,000 rev. $\mathrm{min}^{-1}$. Aggregation was then induced by adding $0.2 \mathrm{ml}$ of the following solutions:

- ADP (disodium salt, ex Sigma) 2.5 and $1.25 \mu \mathrm{g} \cdot \mathrm{ml}^{-1}$ in saline, giving a final concentration of 0.167 and $0.083 \mu \mathrm{g} . \mathrm{ml}^{-1}$, respectively.

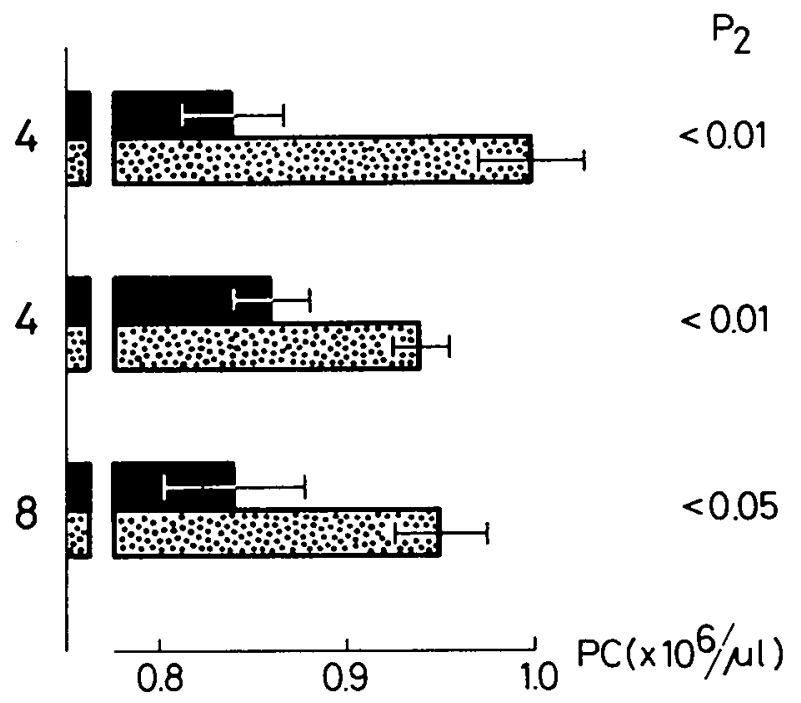

Fig.7.9. Platelet concentration (PC \pm SEM) in blood of rats fed SO ( $\square$ ) or $\mathrm{HCO}$ ( ) diets for 4 and 8 weeks $(n=12-16)$. 
- Thrombin (ex Hoffmann-La Roche and Co, Basle, Switzerland) 2.5 and 2 $\mathrm{NIH}$-units per $\mathrm{ml}$ in saline, providing a final concentration of 0.17 and $0.13 \mathrm{NIH}$-units per $\mathrm{ml}$, respectively.

- Collagen (from Achillis tendon, ex Merck, Darmstadt, West Germany) prepared as follows: $1 \mathrm{~g}$ collagen was suspended in $50 \mathrm{ml}$ saline by intermittent homogenization (U1tra Turrax, Type 45., No. 5202 Janke and Kunkel, A.G.) for $10 \mathrm{~min}$ at $0^{\circ} \mathrm{C}$. Subsequently, the suspension was centrifuged for $10 \mathrm{~min}$ at $60 \mathrm{xg}$ and $0{ }^{\circ} \mathrm{C}$. The clear supernatant was decanted, diluted 1:5 with saline, divided into $2.5 \mathrm{ml}$ portions and stored at $-20{ }^{\circ} \mathrm{C}$ until use. For aggregation measurements, this stock was diluted with saline in a ratio of $1: 3$ and $1: 5$.

All working solutions were stored in melting ice. The aggregation-induced changes in optical density of the PRP dilutions were recorded with Vitraton ${ }^{\circledR}$ equipment (Dieren,Holland). ADP- and thrombin-induced aggregation was quantified by measuring the maximal change in optical density $\left(\Delta O D_{\max }\right)$. The aggregation induced by collagen proceeds somewhat different from that initiated by ADP and thrombin. Fig.7.10. shows a typical curve. Addition of the collagen suspension (arrow) results in a slight descent of the 00 curves, due to dilution of the platelet suspension. The collagen causes the release of ADP to which the platelets react with a shape change, resulting in an $O D$ increase. The $O D$ curve passes through a maximum $\left(O D_{\max }\right)$, after which platelet aggregation causes a rapid irreversible decrease in $\mathrm{OD}$. From this curve, the following parameters were calculated:

- Aggregation induction time, $t_{a j}$, being the time ( $s$ ) lapsing between collagen addition and a decrease by 1 OD-unit (full scale 100 Units)

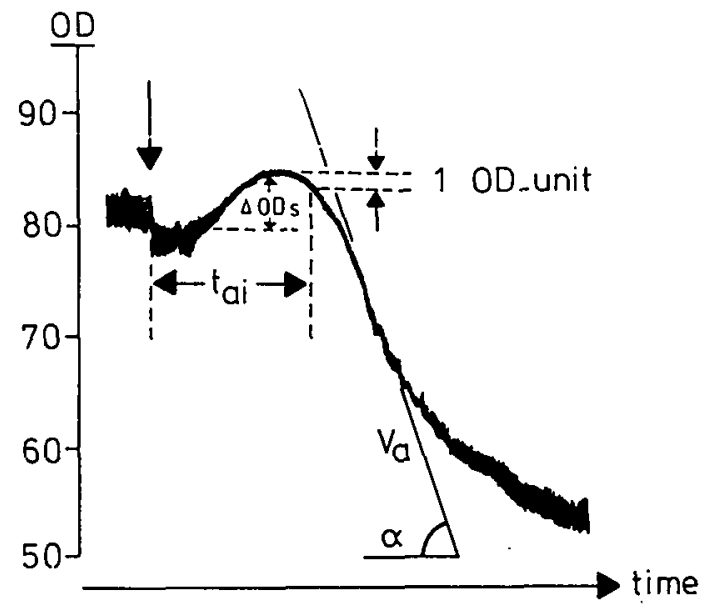

Fig.7.10. Course of Optical Density (OD) of a platelet suspension after adding collagen to the suspension (arrow). For explanation: see text. 
Table 7.4. ADP- and thrombin-induced aggregation $\left(\triangle O D_{\max } \pm S E M\right)$ in $\mathrm{PRP} / \mathrm{saline}$ dilutions of rats fed SO- $(n=12)$ or $\mathrm{HCO}(n=11)$ containing diets for 4 weeks.

\begin{tabular}{|c|c|c|c|c|}
\hline Compound & Final concentration & so & $\mathrm{HCO}$ & $P_{2}$ \\
\hline \multirow[t]{2}{*}{ ADP } & $0.167 \mu \mathrm{g} . \mathrm{ml}^{-1}$ & $27.7 \pm 1.59$ & $28.5 \pm 1.98$ & $>0.10$ \\
\hline & $0.083 \mu \mathrm{g} . \mathrm{m}^{-1}$ & $12.2 \pm 1.76$ & $8.3 \pm 1.42$ & $>0.10$ \\
\hline \multirow[t]{2}{*}{ Thrombin } & 0.17 NIH-units.m1 ${ }^{-1}$ & $37.7 \pm 2.94$ & $42.7 \pm 1.94$ & $>0.10$ \\
\hline & 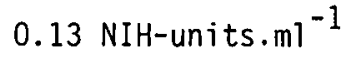 & $25.8 \pm 3.38$ & $26.7 \pm 3.45$ & $>0.10$ \\
\hline
\end{tabular}

after the curve has passed through $0 D_{\max }$.

- Aggregation velocity, $v_{a}$, which is the tangent of the angle $(\alpha)$ which is formed by the steepest slope of the aggregation curve and the horizontal (=time) axis.

- Platelet shape change, $\triangle O D_{S}$, the total increase in $0 D$ after administration of the collagen suspension.

Results obtained with ADP and thrombin after 4 weeks' feeding are given in Table 7.4. The differences between the two groups were not significant, which is not in agreement with the results obtained by Renaud and co-workers (19), who showed that thrombosis tendency was positively related to thrombin-induced aggregation and inversely related to ADP-induced aggregation. This discrepancy might be due to the different diets used (see section 7.2.2.).

Table 7.5. gives the results of collagen-induced aggregation. For both aggregation parameters $\left(t_{a j}\right.$ and $\left.v_{a}\right)$, the values for the HCO group indicate

Table 7.5. Platelet aggregation $\left(t_{a j}\right.$ and $\left.V_{a}\right)$ and platelet shape change $\left(\triangle O D_{S}\right)$ induced by collagen in PRP/saline dilutions of rats fed SO- $(n=11)$ or HCO $(n=10)$-containing diets for 4 weeks. Mean \pm SEM.

\begin{tabular}{|c|c|c|c|c|c|}
\hline \multirow{2}{*}{ Parameter } & \multicolumn{3}{|l|}{ Collagen 1:5 } & \multicolumn{2}{|l|}{ Collagen $1: 3$} \\
\hline & so & $\mathrm{HCO}$ & & so & $\mathrm{HCO}$ \\
\hline$t_{a i}(s)$ & \pm 4.4 & 112 & \pm 12.0 & \pm 4.7 & \pm 6.0 \\
\hline$(\log s)$ & $1.92 \pm 0.02$ & 2.03 & $\pm 0.04 \S$ & $1.84 \pm 0.03$ & $1.89 \pm 0.03$ \\
\hline$v_{a}(\operatorname{tg} \alpha)$ & $2.15 \pm 0.26$ & 1.66 & \pm 0.28 & $2.95 \pm 0.26$ & $2.84 \pm 0.14$ \\
\hline$\Delta 0 D_{s}$ & $3.12 \pm 0.21$ & 4.75 & $\pm 0.25 \mathbb{I}$ & $3.45 \pm 2.36$ & $4.76 \pm 0.16 \mathbb{I}$ \\
\hline
\end{tabular}

\& $P_{2}<0.05$ I $P_{2}<0.01$ 
a lower platelet aggregation (longer aggregation induction times, lower aggregation velocities). Platelet shape change $\left(\triangle O D_{s}\right)$ is significantly more pronounced in the $\mathrm{HCO}$ group $\left(\mathrm{P}_{2}<0.01\right.$, Wilcoxon's two-sample test $)$. Because of the (unexpected) tendency of platelets from the thrombogenic HCO group to aggregate to a lesser extent in response to collagen than platelets from animals receiving the antithrombotic so-diet, a second experiment was performed to collect more data on this point. Again it appeared that, especially in the lower-dose range, collagen-induced aggregation is lower in platelets from animals fed the thrombogenic HCO-diet (Fig.7.11.).

This discrepancy between in vitro and in vivo findings indicates that in vitro results should be interpreted with the utmost care. This can also be concluded from a different experiment described in detail in Chapter 8 , section 3. Briefly, rats were fed diets known to induce different arterial thrombosis tendencies. After 8 weeks, OT's were determined in $50 \%$ of the animals where in the other half, collagen-induced aggregation was measured (as well as some other platelet and vessel-wall properties, see Chapter 8). As shown in Fig.7.12., no correlation was found between arterial thrombosis tendency and collagen-induced aggregation. In separate studies (Chapters 8 and 9), similar results were obtained for ADP- and thrombin-induced aggregation measurements. Therefore, the usefuiness of in vitro aggregation tests as indicators for the arterial thrombosis tendency, is highly questionable.
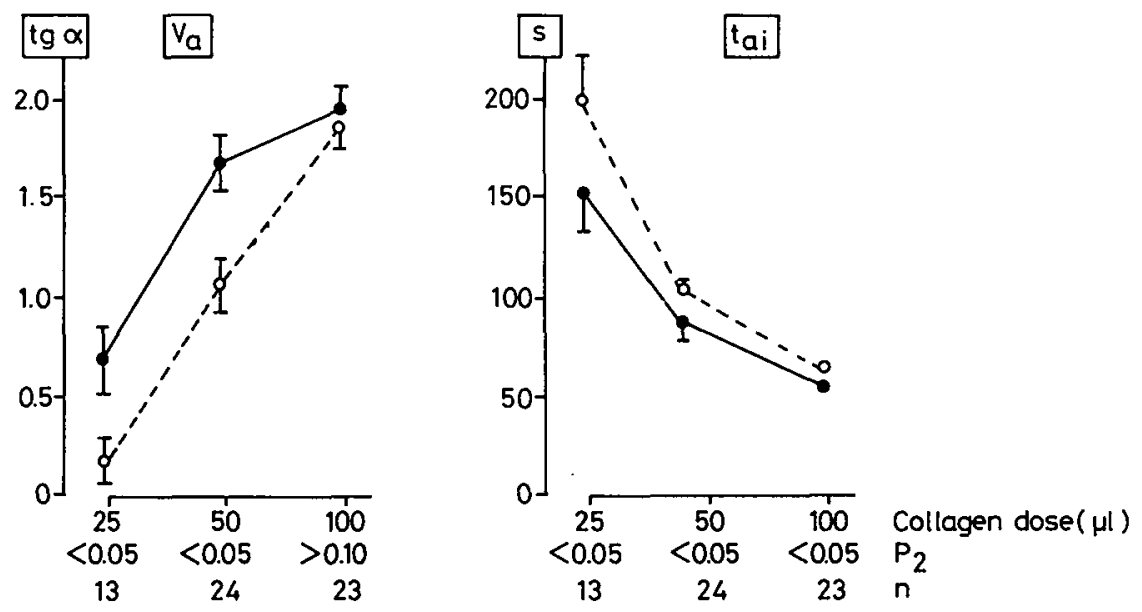

Fig.7.11. Collagen-induced aggregation velocity $\left(V_{a}, \operatorname{tg} \alpha \pm S E M\right)$ and aggregation induction time $\left(t_{a i}, s \pm S E M\right)$ of platelets of rats fed SO $(\rightarrow-)$-or HCO(-o--)-containing diets for 4 weeks. 
The lower 'activation grade' of $\mathrm{HCO}$ platelets upon collagen-triggering most probably explains the diminished collagen-induced PF 3 availability observed in these platelets (see section 7.2.5.).

\subsubsection{Platelet aggregation in circulating arterial_blood}

The main disadvantage of the aggregation technique used in the previous section is that any short-lived aggregation-affecting substance that might be present in circulating blood, will already have been inactivated when aggregation in vitro is ultimately measured. Since the discovery of Thromboxane $A_{2}$ and prostacyclin (two unstable substances with very profound effects on platelet function - see Chapter 3 ), this disadvantage became particularly manifest. The method we developed to measure platelet aggregation in circulating arterial blood (Chapter 5) does not suffer from this drawback. This is why this technique was also used to measure the dietary fat effect on platelet aggregation.

7.3.2.1. ADP-induced aggregation.

Platelet aggregation was measured (Chapter 5, section 3.) by administering

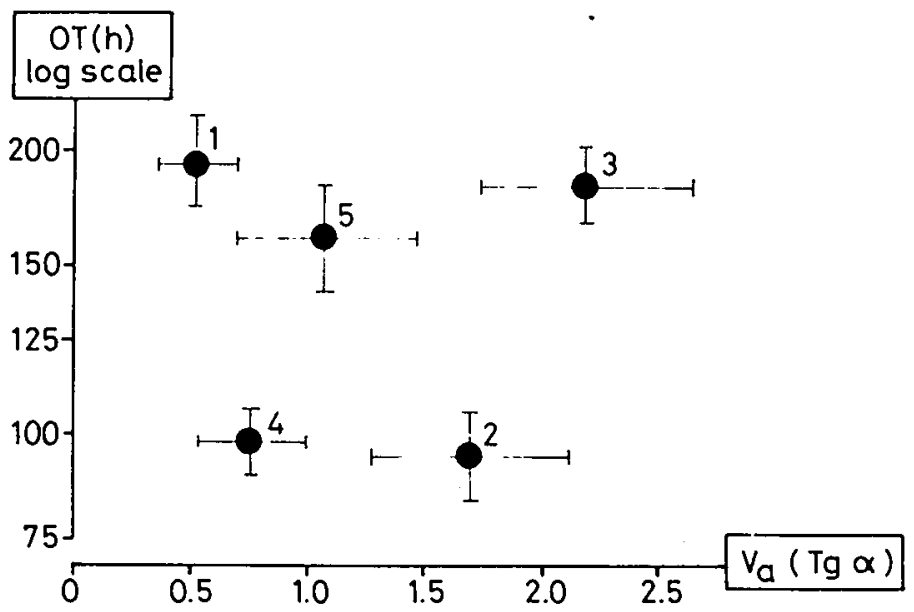

Fig.7.12. Lack of correlation between collagen-induced aggregation $\left(V_{a}, \operatorname{tg} \alpha \pm S E M\right)$ and arterial thrombosis tendency (OT, $h \pm$ SEM, log scale) in rats fed different dietary fats $(n=10-12)$.

1: 5 en\% HCO (essential fatty acid deficient); 2: 5 en\% SO (control);

3: 50 en\% S0; 4: 5 en\% SO + 45 en\% HCO; 5: 5 en\% SO + 45 en\% LO. 
Table 7.6. ADP-induced aggregation $(A \pm S E M)$ in circulating arterial blood of rats fed diets containing SO or HCO for 4 weeks $(n=13)$.

\begin{tabular}{|c|c|c|c|}
\hline \multirow{2}{*}{$\begin{array}{l}\text { ADP-dose } \\
\mu g \cdot 10^{-3} .\end{array}$} & \multicolumn{3}{|l|}{$A \pm S E M$} \\
\hline & so & $\mathrm{HCO}$ & $P_{2}$ \\
\hline $\begin{array}{l}25 \\
50\end{array}$ & $\begin{array}{l}10.4 \pm 2.60 \\
25.8 \pm 5.25\end{array}$ & $\begin{array}{l}15.1 \pm 3.10 \\
49.3 \pm 5.53\end{array}$ & $\begin{array}{l}>0.10 \\
<0.01\end{array}$ \\
\hline
\end{tabular}

2 ADP doses to the same animal with an interval of 10 minutes. The 10west dose was given first. As is evident from Table 7.6, HCO feeding causes a significantly higher ADP-response than the So-diet.

This experiment has been repeated several times, using different ADP doses and feeding periods. In total, both diets have been compared 16 times for their effect on the ADP-induced platelet aggregation in circulating arterial blood. Although the differences did not always reach the $5 \%$ significance level, in 15 cases the mean aggregation in the $\mathrm{HCO}$ group was higher than that in the comparable So group (Sign test: $\left.\mathrm{P}_{2}<0.01\right)$. Thus, it can be concluded that ADP-induced platelet aggregation measured in circulating arterial blood is higher on feeding the thrombogenic HCO-diet than when the antithrombotic SO-containing diet is given.

In order to investigate whether arterial thrombosis tendency is correlated with ADP-induced aggregation in circulating arterial blood, 6 groups of 24 animals were fed diets containing $50 \mathrm{en} \%$ of WO, HSO, RO, 00, LO or so (see Table 6.2.). In 12 animals of each group, arterial thrombosis

Table 7.7. ADP-induced aggregation $(A \pm S E M)$ in circulating blood of rats fed diets containing $50 \mathrm{en} \%$ of different fats for 9 weeks $(n=12)$.

\begin{tabular}{crrr}
\hline Dietary fat & \multicolumn{3}{l}{ ADP-dose (ng. $30 \mathrm{~s}^{-1}$ ) } \\
\cline { 2 - 4 } (see Table 6.2.) & \multicolumn{1}{l}{ 25 } & 37.5 & 50 \\
\hline WO & $6.3 \pm 1.7$ & $13.9 \pm 2.8$ & $36.2 \pm 6.1$ \\
HSO & $39.2 \pm 6.8$ & $52.2 \pm 6.4$ & $68.3 \pm 3.4$ \\
RO & $14.1 \pm 2.7$ & $33.3 \pm 5.7$ & $50.4 \pm 6.3$ \\
OO & $33.9 \pm 5.5$ & $49.0 \pm 6.0$ & $64.2 \pm 3.7$ \\
LO & $32.3 \pm 5.1$ & $44.8 \pm 5.6$ & $64.5 \pm 2.4$ \\
SO & $24.5 \pm 3.8$ & $43.5 \pm 5.7$ & $63.2 \pm 4.4$ \\
\hline
\end{tabular}


tendency was measured with the aorta-loop technique (Chapter 5, section 2.). In the other animals, aggregation was measured on infusing 3 different ADP-doses in the same animal with intervals of $10 \mathrm{~min}$. The sequence of the ADP doses varied per 4 animals. The results of the aggregation measurements are given in Table 7.7. From statistical analysis it appeared that, in each dietary group, the ADP dose-response curve did not deviate significantly from rectilinearity. Moreover, all curves ran parallel to each other. The ADP-response in the wo-group was significantly lower $\left(P_{2}<0.05\right)$ than in all other groups. Platelet aggregation in the group receiving $R O$ was systematically lower than in the groups receiving HSO, $00, L O$, and SO $\left(P_{2}<0.1\right)$.

As the ADP-response and the OT were determined in different animals (the OT results have been reported in Chapter 6 , section 3.), no direct relationship between the two parameters could be calculated. However when the mean values within each group were compared, it appeared that, in general, a high OT value coincides with a low ADP-response (Fig.7.13.). This finding strongly indicates that the dietary fat effect on arterial thrombosis tendency is, at least in part, mediated by changes in platelet aggregability. The deviating behaviour of the W0-group will be discussed further in Chapter 9.

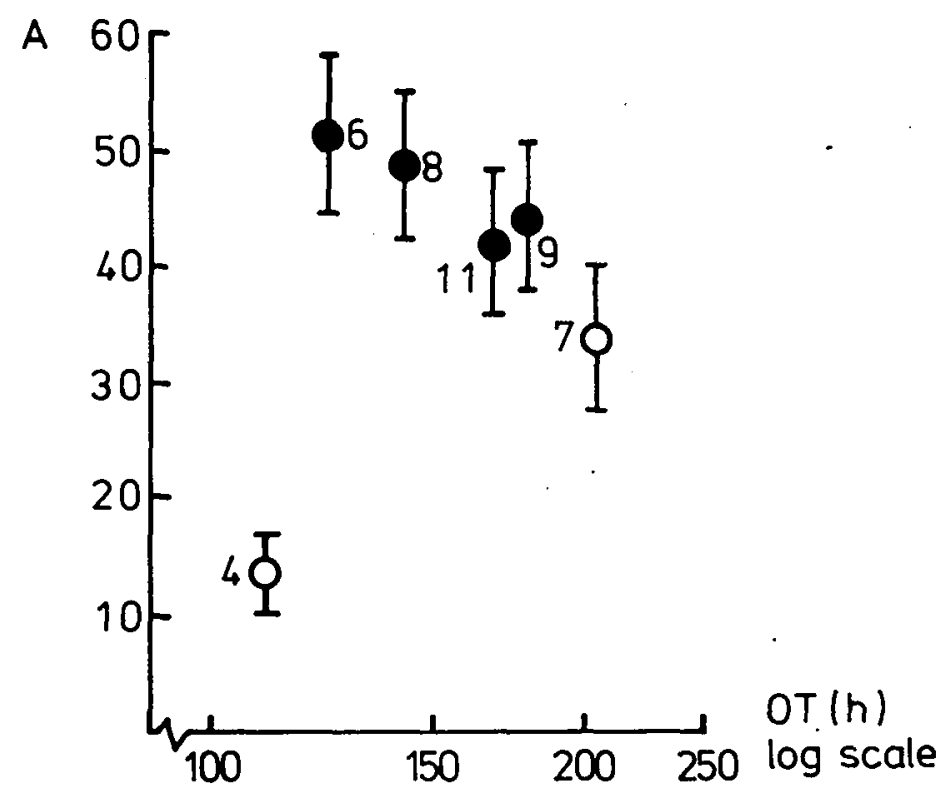

Fig.7.13. Relationship between arterial thrombosis tendency (OT) and ADP-induced aggregation in circulating blood ( $A ; 37,5 \mathrm{ng}$ ADP in $30 \mathrm{~s}$ ) of rats fed diets containing $50 \mathrm{en} \%$ of different fats for 9 weeks. Numbers refer to dietary fats mentioned in Table 6.2. 


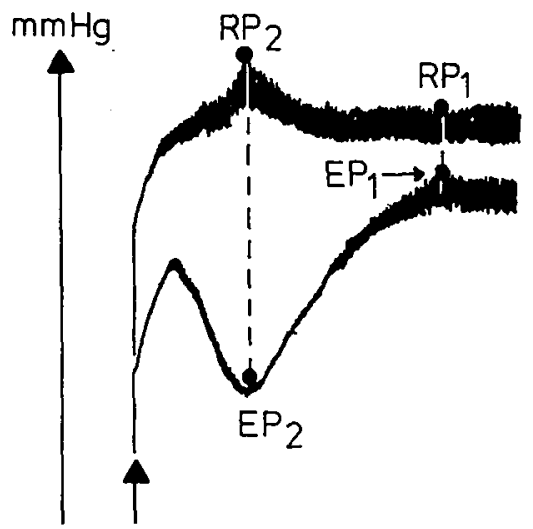

time

Fig.7.14. Location of $E P_{1}, E P_{2}, R P_{1}$ and $R_{2}$ for calculating spontaneous aggregation in circulating arterial rat blood.

At $\uparrow$, the extracorporeal system is connected to the arterial circulation.

\subsubsection{Spontaneous platelet aggregation}

To induce aggregation in circulating arterial blood of animals fed a stock diet, ADP has to be infused (Chapter 5, section 3.). However, when investigating the effects of SO- and HCO-feeding, a reversible 'wave' of spontaneous aggregation was sometimes observed immediately after the extracorporeal system had been connected. In retrospect, we observed that spontaneous aggregation occurred more frequentiy on $\mathrm{HCO}$ - than on SO-feeding. In view of this, a prospective study was carried out in which frequency and degree of spontaneous aggregation (SA) were compared in animals fed the SO- and HCO-diets for 4 weeks. The SA-degree was quantified in the same way as for ADP-induced aggregation (Chapter 5, section 3.), except that $E P_{1}$ and $R P_{1}$ were taken at their minimum difference and $E P_{2}$ and $R P_{2}$ at minimum EP (Fig.7.14.). Two experiments were performed, the results of which are given in Table 7.8 .

Table 7.8. Frequency (\%) and degree $(A \pm$ SEM) of spontaneous aggregation (SA) observed in rats fed SO- and HCO-containing diets for 4 weeks.

\begin{tabular}{|c|c|c|c|c|c|}
\hline \multirow{2}{*}{ Expt.no. } & \multirow{2}{*}{$n$} & \multicolumn{2}{|c|}{ SA frequency } & \multicolumn{2}{|l|}{ SA degree } \\
\hline & & so & $\mathrm{HCO}$ & so & $\mathrm{HCO}$ \\
\hline $\begin{array}{l}1 \\
2\end{array}$ & $\begin{array}{l}12 \\
13\end{array}$ & $\begin{array}{c}33.3 \\
0\end{array}$ & $\begin{array}{l}100 \mathrm{I} \\
76.99 ?\end{array}$ & $\begin{aligned} 39.2 & \pm 17.27 \\
& -\end{aligned}$ & $\begin{array}{l}61.2 \pm 6.33 \\
33.9 \pm 5.73\end{array}$ \\
\hline
\end{tabular}

I $P_{2}<0.01$ 
The SA-frequency was significantly higher in the HCO group than in the So-fed animals ( $P_{2}<0.01$, Student's two-sample test). Because of the great differences in SA-frequency, the differences in SA-degree could not be evaluated statistically. However, there is a distinct tendency that the SA-degree is also higher in the HCO group. The same can be concluded after including the retrospective results obtained from the experiments mentioned in section 7.3.2.1. In 103 SO-animals, the average SA-frequency and SA-degree were $15.5 \%$ and 23.8 respectively, whereas in 93 HCO-fed animals, these figures were $77.4 \%$ and 35.8 . These results allow of the conclusion that feeding the thrombogenic HCO-diet is associated with a systematically higher frequency and degree of spontaneous aggregation than when the antithrombotic so-diet is given.

Some experiments have been carried out to explain the phenomenon of spontaneous aggregation. Since platelet aggregates were already observed $14 \mathrm{~cm}$ proximal to the filter, the filter itself cannot be the cause. The extracorporeal system is primed with a rather strong heparin solution and heparin has repeatedly been reported as being an aggregation-inducing substance $(20,21)$. The spontaneous aggregation observed might, therefore, be heparin-induced. To establish this, SA was measured in HCO-fed animals in the absence and presence of heparin. The degree of spontaneous aggregation ( $S A \pm S E M)$ appeared to be significantly higher in the presence of heparin $(22.8 \pm 4.9, n=24)$ than in its absence $(9.5 \pm 2.9, n=19$, $\mathrm{P}_{2}<0.01$, Wilcoxon's two-sample test).

Within $30 \mathrm{~s}$ after starting extracorporeal circulation, blood samples were taken (14 cm proximal to the filter) for the preparation of blood smears. Moreover, the number of aggregates was counted and their sizes determined. To this end, blood was diluted $(1: 200)$ with a $1 \%(w / v)$ ammonium oxalate solution in an erythrocyte counting pipette and mixed with a pipette shaker. After shaking for $10 \mathrm{~s}$ and 3 min respectively, samples were counted in a Bürker-Türk counting chamber, using phase-contrast microscopy. Investigation of the blood smears (not quantitatively evaluated) yielded an indication that the number and sizes of the aggregates were not influenced by the absence or presence of heparin. This was confirmed by aggregate counts performed after shaking for $10 \mathrm{~s}$ (Table 7.9.). After shaking for $3 \mathrm{~min}$, however, significantly more and bigger aggregates were observed in the heparinized samples than in the native blood samples. These results strongly suggest that heparin stabilizes platelet aggregates, resulting in a less rapid break-up when mecha- 
Table 7.9. Effect of heparin (hep) on number and size of spontaneous aggregates occurring in circulating arterial blood of rats fed the HCO-diet for 1 week.

\begin{tabular}{|c|c|c|c|c|c|c|}
\hline \multirow{2}{*}{ Number of: } & \multicolumn{3}{|c|}{ Mixing time $10 \mathrm{~s}$} & \multicolumn{3}{|c|}{ Mixing time 3 min } \\
\hline & + hep & - hep & $P_{2}$ & + hep & - hep & $P_{2}$ \\
\hline Aggregates & 32 & 36 & $>0.10$ & 44 & 9 & 0.07 \\
\hline Aggregated platelets & 288 & 199 & $>0.10$ & 257 & 32 & 0.04 \\
\hline Platelets per aggregate & 7.2 & 4.8 & $>0.10$ & 5.3 & 3.6 & 0.008 \\
\hline
\end{tabular}

nically stressed (shaking of the blood dilution, passage through the filter, etc.).

The SA-inducing mechanism has not yet been elucidated. Since the aorta loop is temporarily clamped immediately before the extracorporeal system is connected, thrombin generated during this stasis period might trigger aggregation. Since the duration of this stasis period was not related to the degree of SA, this explanation seems rather unlikely.

Another explanation might be that heparin 'neutralizes' prostacyclin as reported recentiy by Saba and co-workers (22). Similar effects of heparin on $P G E_{1}$ have also been reported $(23,24)$. However, this does not explain the fact that aggregation is reversible whereas heparin remains in the vascular system throughout the experiment.

Also, the connection procedure might cause erythrocyte damage resulting in some ADP release and, consequently, cause reversible aggregation.

No investigations have been carried out into the fact whether saturated fat-feeding causes an enhanced formation of spontaneously occurring aggregates or whether the stabilizing effect of heparin is more pronounced on $\mathrm{HCO}$ feeding.

\subsection{Possible mechanisms by which dietary fats affect arterial thrombosis tendency}

The results presented so far show that the (anti)thrombotic effect of dietary fats are probably caused by their fatty acid composition. The same has been reported for atherogenesis: long-chain saturated fats 
were shown to be atherogenic whereas linoleic acid had a distinct atherosclerosis preventive effect (25-28). In the pathogenesis of atherosclerosis, the cholesterol metabolism plays an important role: hypercholesterolemic diets appeared to be atherogenic whereas the hypocholesterolemic effect of dietary linoleic acid is associated with a lower incidence of and mortality from atherosclerotic complications (29-31,39).

In rats, the saturated, thrombogenic $\mathrm{HCO}$ diet causes a higher serum cholesterol content than the linoleic acid-rich antithrombotic so diet. Since atherosclerosis and arterial thrombosis are related phenomena (Chapter 1), the dietary fat effects on arterial thrombosis might also be mediated by the plasma cholesterol content. However, this appeared highly unlikely, because no significant correlation was observed between plasma cholesterol content and the $O T$ in animals fed 8 different amounts of linoleic acid-rich SO or 5 different dietary fats. Similar results were obtained by Renaud and co-workers (6). The possible role of platelet cholesterol is discussed in Chapter 10 section 6.3.

Considering the results presented in Chapter 6 , it is tempting to speculate that linoleic acid causes the antithrombotic effect of sunflowerseed oil, but it should be realized that other components present in this and oth linoleic acid-containing fats may also play a role in this effect. Since it has been reported that the vitamin $E$ content of vegetable oils is higher, the higher their degree of unsaturation (33), and vitamin $E$ has

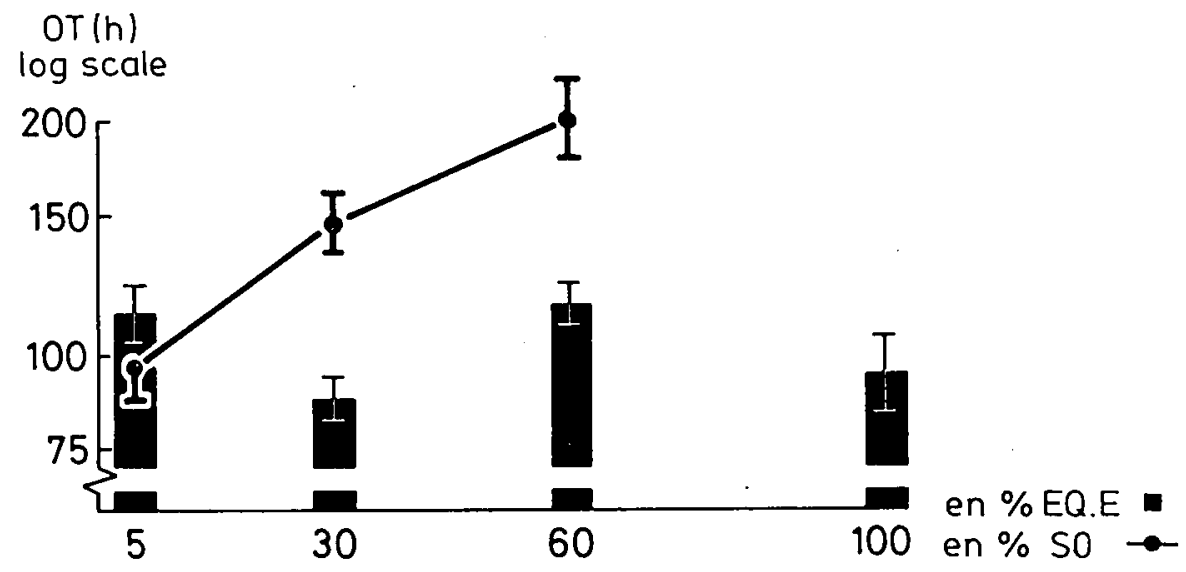

Fig.7.15. Effect of vitamin E supplementation (bars) and increasing amounts of dietary sunflowerseed oil (dots) on arterial thrombosis tendency in rats (OT \pm SEM; $n=12$ ).

Vitamin $E$ was added to a diet containing $5 \mathrm{en} \%$ SO in amounts equivalent to those present in 5, 30,60, and 100 en\% so-containing diets (en\% eq.E). 
been suggested to inhibit platelet thrombotic functions (34-38), at least part of the antithrombotic effect of linoleic acid-rich oils might be due to their relatively high vitamin $E$ content. This was investigated by comparing the OT's of animals fed 5, 30 and $60 \mathrm{en} \%$ so with those of rats fed diets containing 5 en\% SO and enriched with amounts of vitamin E equivalent to those present in diets containing 30,60 , and $100 \mathrm{en} \%$ So. The results of this study (Fig.7.15.) clearly indicate that the antithrombotic effect of sunflowerseed $0 i 1$ is not due to its vitamin $E$ content because increasing the dietaryamount of vitamin $E$ does not prolong the OT, whereas dietary SO does.

Ever since the inhibiting effect of prostaglandin $E_{1}$ on platelet aggregation was recognized (32), prostaglandins and related compounds have been implicated in the regulation of platelet function and arterial thrombosis. Since the antithrombotic fatty acids (linoleic- and $\alpha-1$ inolenic acid) are the dietary precursors of the naturally occurring prostanoids, these fatty acids may exert their thrombosis-modulating effect by influencing the prostaglandin production. This was investigated in detail, the results of which are discussed in Chapters 8,9 and 10 .

\subsection{Summary}

Although diets rich in $\mathrm{SO}$ or $\mathrm{HCO}$ induce a consistent difference in arterial thrombosis tendency, their effects on blood clotting are only marginal. Whole blood and plasma clotting times are hardly affected and the same holds for the APTT and PT. Moreover, vessel-wall induced clotting does not differ significantly. Platelet factor 3 activity and content are also similar in both groups. PF3 availability upon collagen-activation of platelets is, however, significantly depressed in the thrombogenic HCO group compared with that in the antithrombotic SO group. A1though it should be realized that the results of measurements performed in systematic blood do not necessarily reflect local processes, it seems rather unlikely that dietary-fat induced differences in blood coagulability - if present - contribute significantly to the differences in arterial thrombosis tendency observed.

In vitro platelet aggregation, induced by adenosine diphosphate (ADP) and thrombin, is similar in both groups and collagen-induced aggregation is even lower in the thrombogenic group. However, collagen-indu- 
ced shape change of platelets in vitro as well spontaneous and ADP-induced aggregation in circulating arterial blood, are significantly depressed in the antithrombotic group. Moreover, on feeding 5 different vegetable oils, a close correlation was observed between ADP-induced aggregation in circulating arterial blood and arterial thrombosis tendency. Therefore, it is highly probabie that the changes in the thrombotic properties of blood platelets constitute the basis for the dietary-fat induced changes in arterial thrombosis tendency.

Plasma cholesterol content and dietary vitamin $E$ concentration are most probably not implicated in the mechanisms by which dietary fats affect arterial thrombosis tendency. From the present studies, it became also evident that the 'classical' in vitro platelet aggregation tests have no indicative value for arterial thrombosis tendency in vivo.

\subsection{References}

1. Chandler,A.B.: In vitro coagulation of blood. Lab. Invest.7: 110-115 (1958).

2. Engelberg,H.: Studies with the Chandler Rotating Loop. Evidence that thrombin generation is responsible for the formation of the artificial in vitro thrombi. Thrombos.Diathes.haemorrh. 22: 344-350 (1969).

3. Renaud,S.: The recalcification plasma clotting time. A valuable general clotting test in man and rats. Can.J.Physiol.Pharmacol. 47: 689-693 (1969).

4. Renaud,S., Kuba,K., Goulet,C., Lemire,Y. and Allard,C.: Relationship between fatty acid composition of platelets and platelet aggregation in rat and man. Relation to thrombosis. Circ.Res. 26: 553-564 (1970).

5. Renaud,S.: Thrombogenicity and atherogenicity of dietary fatty acids in rat. J.Atheroscler. Res.8: 625-636. (1968).

6. Renaud,S., and Gautheron,P.: Dietary fats and experimental (cardiac and venous) thrombosis. Haemostasis 2: 53-72 (1973/74).

7. Merskey,C., and Marcus,A.J.: Lipids, blood coagulation and fibrinolysis Ann.Rev.Med. 14: 323-338 (1963).

8. Howard,A.N. and Gresham,G.A.: The dietary induction of thrombosis and myocardial infarction. J.Atheroscler. Res. 4: 40-56 (1964).

9. Latour,J.G., Leger,C. and Renaud,S.: Activation of Hageman factor and initiation of hepatic vein thrombosis in hyperlipemic rats. Am.J. Pathol. 76: 178-193 (1974). 
10. Owren,P.A. and Aas, K.: The control of dicumarol therapy and the quantitative determination of prothrombin and proconvertin. Scand. J.Clin. Invest. 3: 201-208 (1951).

11. Muller,A.D.: Personal Communication.

12. Sober,H.A. (Ed.): Handbook of Biochemistry. Selected data for molecular biology. Buffer solutions, J-234 No 4.

13. Zwaal,R.F.A.: Membrane and lipid involvement in blood coagulation. Biochim.Biophys. Acta 515: 165-207 (1978).

14. Hardisty,R.M. and Hutton,R.A.: Platelet aggregation and the availability of platelet factor 3. Brit.J.Haematol. 12: 764-776 (1966).

15. Joist,J.H., Dolezel,G., Lloyd,J.V., Kinlough-Rathbone,R.L. and Mustard,J.F.: Platelet factor-3 availability and the platelet release reaction. J.Lab.Clin.Med. 84: 474-482 (1974).

16. Zwaal,R.F.A., Rosing,J., Tans,G., Bevers, E.M. and Hemker,H.C.:Topological and kinetic aspects of phospholipids in blood coagulation. In:

K.G.Mann and F.B.Taylor,jr., (Eds.): The regulation of Coagulation. Elsevier/North Holland, Inc. 95-115 (1980).

17. Born,G.V.R.: Aggregation of blood platelets by adenosine diphosphate and its reversal. Nature 194: $927-929$ (1962).

18. O'Brien,J.R.: Platelet aggregation. II. Some results from a new method of study. J.Clin.Pathol. 15: 452-455 (1962).

19. Renaud,S., Kinlough,R.L., Mustard,J.F.: Relationship between platelet aggregation and the thrombotic tendency in rats fed hyperlipemic diets. Lab. Invest. 22: 339-343 (1970).

20. Eika,C.: The platelet aggregating effect of eight commercial heparins. Scand.J.Haematol. 9: 480-482 (1972).

21. Hohage,R., Hiemeyer, V.: Methodische Untersuchungen zur Plättchenaggregation bei der Ratte: 1. Verwendbarkeit vor rekalzifizierten Zitrat-Heparin-Plasma im Rahmen tierexperimenteller Untersuchungen. Thrombos.Diathes. haemorrh. 26: 393-398 (1971).

22. Saba,H.I., Saba,S.R., Blackburn,C.A., Hartmann, R.C. and Mason,R.G.: Heparin neutralization: effects upon platelets. Science 205: 499-501 (1979).

23. Hissen,W., Fleming,J.S., Bierwagen, M.E. and Pinde11, M.H.: Effect of prostaglandin $E_{1}$ on platelet aggregation in vitro and in hemorrhagic shock. Microvasc.Res. 1: 374-378 (1969).

24. Reches, A., Eldor, $A$. and Salomon, Y.: Heparin inhibits $P_{G E}$-sensitive adenylate cyclase and antagonizes $P E_{1}$ antiaggregating effect in human platelets. J.Lab.Clin.Med. 93: 638-644 (1979). 
25. Thomasson,H.J.: Dietary fat and atherosclerosis. In: Dols,M.J.L. (Ed.) : The physiological and nutritional role of fats in human nutrition. Westerbaan, The Haque. p. 92-103 (1963).

26. Malmros, H.: Dietary prevention of atherosclerosis. Lancet i i: 479-484 (1969).

27. Kritchevsky,D.: Experimental atherosclerosis in primates and other species. Ann.N.Y.Acad.Sci. 162: 80-88 (1969).

28. Vles,R.0., Gottenbos,J.J. et Van Pijpen,P.L.: Aspects nutritionnels des huiles de soja hydrogénées et de leurs acides gras insaturés isomériques. Biblthca Nutr. Dieta 25: 186-196 (1977).

29. Wissler,R.W. and Vesselinovitch,D.: Comparative pathogenetic patterns in atherosclerosis. Adv.Lipid Res. 6: 181-206 (1968).

30. Heyden,S.: Epidemiological data on dietary fat intake and atherosclerosis with an appendix on possible side-effects. In: Vergroessen, A.J. (Ed.): The role of fats in human nutrition. Acad.Press, London, New York, San Francisco (1975) pp. 43-113.

31. Miettinen,M., Turpeinen,0., Karvone,M.J., Elosuo,R. and Paavilainen, E.: Effect of cholesterol-lowering diet on mortality from coronary heart disease and other causes. A twelve-year clinical trial in men and woman. Lancet $i \mathrm{i}:$ 835-838 (1972).

32. Kloeze,J.: Influence of prostaglandins on platelet adhesiveness and platelet aggregation. In: S.Bergström and B.Samuelsson (Eds.) : Prostaglandins. Almqvist and Wiksell, Stockholm pp. 241-252 (1967).

33. Jager,F.C.: Linoleic acid intake and vitamin $E$ requirement. In: Vergroesen,A.J. (Ed.): The role of fats in human nutrition. Acad. Press, London, New York, San Francisco (1975) p. 381-432.

34. Steiner,M., Anastasi,J.: Vitamin E, an inhibitor of the platelet release reaction. J.Clin. Invest. 57: 732-737 (1976).

35. Fong,J.S.C.: Alpha-tocopherol: its inhibition of human platelet aggregation. Experientia 32: 639-641 (1976).

36. Svensson, J. and $0 \mathrm{ki}, \mathrm{T}$.: Inhibition of platelet aggregation by $\alpha$-tocopherol and its nicotinate and acetate esters. Int.J.Vit.Nutr. Res. 48: 250-254 (1978).

37. Steiner,M.: Inhibition of platelet aggregatior, by alpha-tocopherol. In: De Duve,C. and Hayashi,0. (Eds.): Tocopherol, oxygen and biomembranes. Elsevisier/North Holland Biomedical Press, Amsterdam, New York (1978) Pp.143-163.

38. Machlin,L.J., Filipski,R., Willis,A.L., Kuhn,D.C. and Brin,M.: Influence of vitamin $E$ on platelet aggregation and thrombocythemia 
in the rat. Proc.Soc.exp.Biol.Med. 149: 275-277 (1975).

39. Wissler,R.W. and Vesselinovitch,D.: The effects of feeding various dietary fats on the development and regression of hypercholesterolemia and atherosclerosis. Adv. Expt].Med.Biol. 60:65-76 (1975). 


\section{THE SIGNIFICANCE OF PROSTAGLANDIN-LIKE SUBSTANCES IN THE DIETARY}

\section{FAT EFFECTS ON ARTERIAL THROMBOGENESIS}

\subsection{Introduction}

In 1967,Kloeze described that prostaglandins influence the aggregation of blood platelets very effectively. Prostaglandin $E_{1}\left(P_{G E}\right)$ is a strong inhibitor and $\mathrm{PGE}_{2}$ a weak stimulator of platelet aggregation (1). It was also shown that $P G E_{1}$ is able to inhibit arterial thrombus formation (Chapter 5, section 2.7.1.). Since linoleic- and $\alpha-1$ inolenic acids are the ultimate dietary precursors of the prostaglandins (Chapter 2), the effect of these fatty acids on arterial thrombogenesis might be mediated by prostaglandins and/or related compounds. In order to investigate the possible role of these compounds in arterial thrombus formation, we decided to investigate the effect of essential fatty acid deficiency which is associated with a low $P G$ production in tissues $(2,3)$.

\subsection{Essential fatty acid (EFA-) deficiency in arterial thrombogenesis}

Essential fatty acid (EFA-) deficiency in animals is caused by feeding them diets lacking essential fatty acids. EFA-deficiency has been observed in a large number of animal species and in man, and found to cause a great variety of deficiency symptoms (4-6). We induced EFA - deficiency in newly weaned rats by feeding them a fat-free diet or a diet containing 5 en\% hydrogenated coconut oil for at least 3 months. Control animals received a diet with 5 en\% sunflowerseed oil.

EFA-deficiency was checked by measuring the water-vapour loss via skin and respiration, which, due to structural changes in the skin, is significantly enhanced in EFA-deficiency. Measurements were carried out according to a method described by Thomasson (7), by which a flow of dry air is blown through a cylinder containing the animals under investigation. Water vapour produced by the animal is taken up.by the air, which is fed to a measuring cylinder containing a water absorbent. From the increase in weight of this cylinder, the water-vapour release of the animal can be calculated. The results - computed per $100 \mathrm{~cm}^{2}$ body surface (8) per hour - are about twice as high for EFA-deficient than for control animals. 

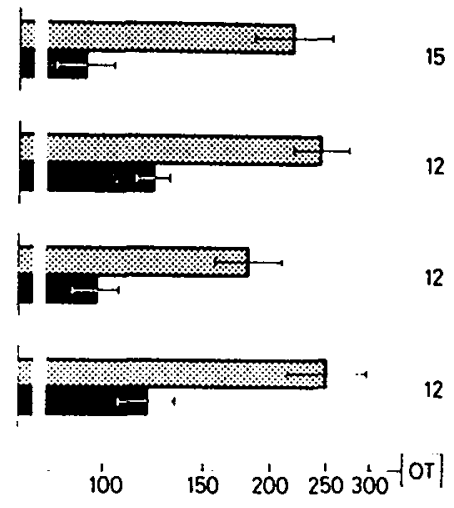

Fig.8.1. Arterial thrombosis tendency (OT, $h, \log$ scale) in EFA-deficient (国) and control ( $($ ) rats.

\subsubsection{Effect of EFA-deficiency on arterial thrombosis}

In a first series of experiments, we repeatedly observed that arterial thrombosis tendency is significantly depressed in EFA-deficient animals. Obstruction times (OT's) of aorta loops (See Chapter 5, section 2.) are invariably longer compared with those of control animals (Fig.8.1.). Feeding an EFA-free, thrombogenic diet to EFA-deficient animals does not result in a shortening of their OT'S. This is illustrated in Fig. 8.2, where the effect of additonal hydrogenated coconut oil ( $\mathrm{HCO}, \mathrm{a}$ thrombogenic fat, see Chapter 6) on the OT of EFA-deficient rats is shown. This demonstrates that the prothrombotic effect of saturated fats is prevented in EFA-deficiency. A small amount of sunflowerseed oil (SO), which cures EFA-deficiency because of its linoleic acid content, quickly normalizes arterial thrombosis tendency (Fig.8.2.).

To find the minimal EFA-requirement for normal thrombogenesis (OT $\pm 120 \mathrm{~h}$, see Chapters 5 and 6 ), newly weaned rats were fed diets containing 5 en\% $\mathrm{HCO}$, which was replaced by increasing amounts of so. Moreover, 2 groups of animals were given 30 and 60 en\% So-containing diets. OT's were measured after 12 weeks' feeding. To check EFA-deficiency, water vapour release in vivo was measured after a feeding period of 10 weeks. The fatty acid composition of plasma total lipids was also determined (gas-liquid chromatography) approximately 2 weeks after loop obstruction. Results of 


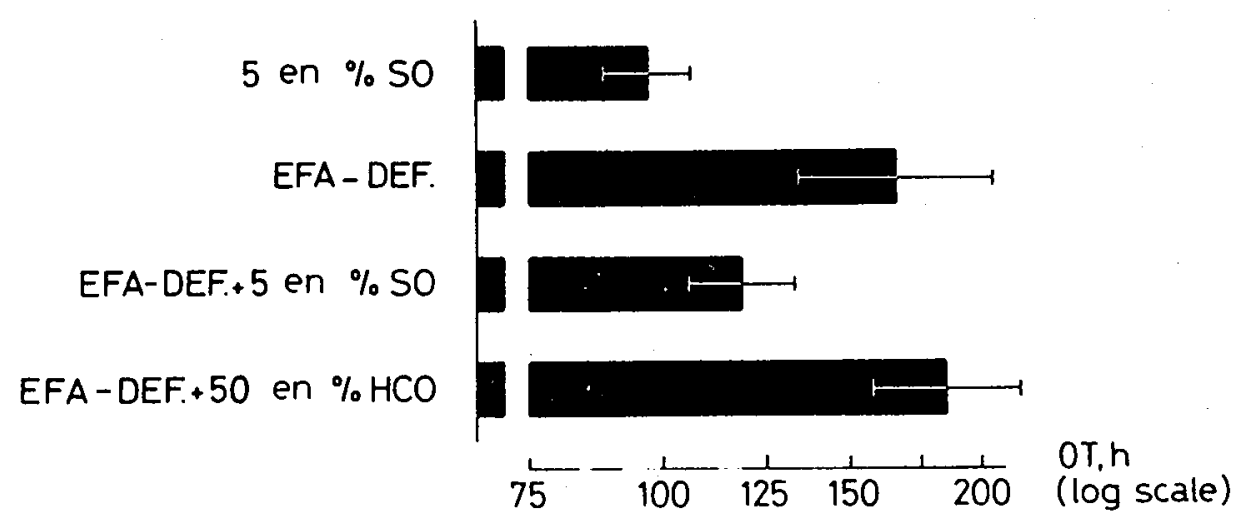

Fig.8.2. Effect of $\mathrm{SO}$ and $\mathrm{HCO}$-containing diets -fed to EFA-deficient. animals for 4 weeks - on arterial thrombosis tendency (OT \pm SEM; $n=12$ ).

OT and water-release measurements are given in Fig.8.3, from which it can be seen that 2.5-0.6 en\% So ( $\sim 1.5-0.4$ en\% linoleic acid) is sufficient to prevent EFA-deficiency changes as far as these two criteria are concerned.

There was a close inverse relationship between the $0 T$ and the plasma arachidonic- and linoleic acid contents $\left(r=-0.92 ; P_{2}<0.01\right)$, whereas the $0 \mathrm{~T}$ was positively related to the plasmatic content of mead acid

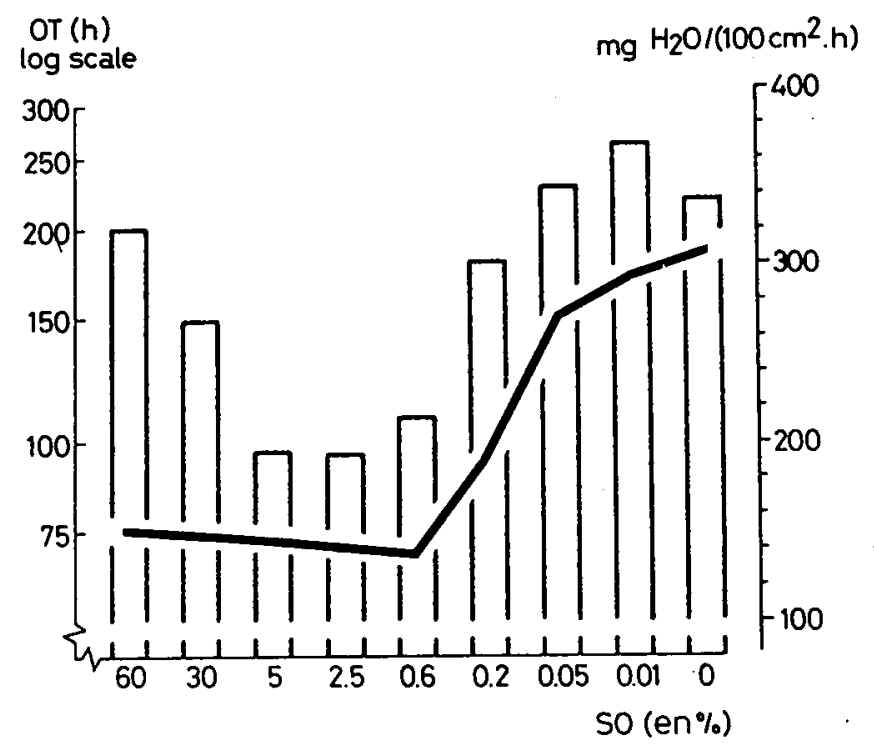

Fig. 8.3. Effect of dietary sunflowerseed oil content (en\%) on arterial thrombosis tendency ( $\mathrm{OT}$, bars) and water-vapour release in vivo ( $\mathrm{mg} \mathrm{H}_{2} \mathrm{O}$, line). Diets were fed for 12 weeks. Each group comprised 16 animals. EFA-deficiency changes are observed at dietary S0 levels below 0.6 en\% ( 20.4 en\% linoleic acid). 
$\left(20: 3(n-9) ; r=-0.96 ; P_{2}<0.001\right)$. In EFA-deficiency, this fatty acid replaces arachidonic acid ((9), see also Chapter 2$)$.

From these studies it is evident that EFA-deficiency is associated with an abnormally low arterial thrombosis tendency.

\subsubsection{P]atelet function in EFA-deficiency}

\subsubsection{Platelet adhesion.}

Platelet adhesion to a glass surface was measured with a flow-chamber technique devised by Lyman et al. (10) and Friedman and co-workers (11). The flow-chamber is covered with a microscopic slide, previously cleaned by immersion in an ethanol-ether (1:1) mixture for $48 \mathrm{~h}$, polished with a clean towel, kept overnight in ether and air-dried in a dust-free cylinder. The chamber is connected to the arterial blood circulation via an aorta loop, inserted into the animal one day before the experiment. The extracorporeal system is primed with heparinized (50 I.U.ml ${ }^{-1}$ ) saline. Immediately after connection of the flow-chamber, the blood is allowed to circulate through it for exactly $2 \mathrm{~min}$. During the first $30 \mathrm{~s}$, a blood sample is taken -proximally to the flow-chamber-for platelet counting. Subsequently, the chamber is disconnected and exactly 1 min later, the blood is removed by flushing the chamber with $10 \mathrm{ml}$ phosphate

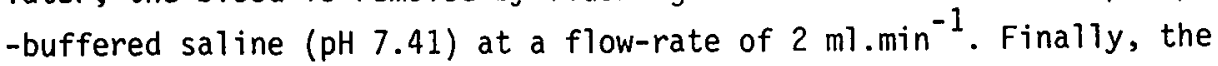
flow-chamber is flushed with $10 \mathrm{ml}$ methanol. After this fixation, the cover slide is removed and air-dried. The adhered cells are stained with Harris' Haematoxilin for $3 \mathrm{~min}$, rinsed in tap water, stained for $30 \mathrm{~min}$ with Giemsa-stain ( 3 drops. $\mathrm{m}^{-1}$ ) rinsed again and air-dried. The number of adhered cells is counted (magn. $1000 \mathrm{x}$ ) in 7 standardized microscopic fields $\left(80 \times 80 \mu^{2}\right)$ which are fixed by presettings of the microscope stage. For control animals, $48 \pm 14.2$ platelets adhered per microscopic field whereas for EFA-deficient animals, this figure was significantly lower: $5 \pm 1.3$ (mean $+\mathrm{SEM}, n=12, P_{2}<0.05$, Wilcoxon's two-sample test). The whole blood platelet count was the same for both groups $\left(0.96 \pm 0.07\right.$ and $0.95 \pm 0.05 \times 10^{6}$ platelets. $\left.\mu 7^{-1}\right)$.

At our request, platelet adhesion to a collagen-coated glass rod $(12,13)$ was measured by Dr.J.P.Cazenave, Department of Pathology, McMaster University, Hamilton, Ontario, Canada. He irivariably observed significantly lower adhesive values for EFA-deficient platelets (14). 
Table 8.1. Collagen- and ADP-induced shape change of EFA-deficient and control platelets $(n=12)$.

\begin{tabular}{|c|c|c|c|c|c|}
\hline \multicolumn{2}{|c|}{ Stimulus } & \multirow{2}{*}{$\frac{\text { Unit }}{\triangle O D}$} & \multirow{2}{*}{$\frac{\text { EFA-def. }}{9.6 \pm 0.57}$} & \multirow{2}{*}{$\frac{\text { Control }}{6.9 \pm 0.47}$} & \multirow{2}{*}{$\frac{P_{2} I}{<0.002}$} \\
\hline Colla & $\operatorname{gen}^{1} 0.05 \mathrm{ml}$ & & & & \\
\hline$A D P^{2}$ & $25 \mathrm{ng} \cdot \mathrm{ml}^{-1}$ & $\mathrm{AU}^{3}$ & $6.1 \pm 0.31$ & $5.2 \pm 0.22$ & $<0.05$ \\
\hline & $75 \mathrm{ng} \cdot \mathrm{ml}^{-1}$ & $A U$ & $8.1 \pm 0.25$ & $6.8 \pm 0.16$ & $<0.01$ \\
\hline & $125 \mathrm{ng} \cdot \mathrm{ml}^{-1}$ & $\mathrm{AU}$ & $8.0 \pm 0.37$ & $7.3 \pm 0.24$ & $<0.10$ \\
\hline
\end{tabular}

\subsubsection{Platelet shape change.}

When triggered by collagen, the shape change of EFA-deficient platelets is more pronounced than that of control platelets (Table 8.1.). This was measured during collagen-induced aggregation in vitro (See Chapter 7 , section 3.1.).

Using a light-scattering method developed by Michal $(15,16)$, the ADP-induced shape change was measured also. The results in Table 8.1. clearly show that for EFA-deficient platelets, the ADP-induced shape change is significantly enhanced in relation to that of control animals.

\subsubsection{Platelet aggregation and release.}

PRP was prepared as described in Chapter 7, section 2. and incubated at room temperature with $0.2 \mu \mathrm{Ci}{ }^{14} \mathrm{C}$-serotonin (5 HT) per ml PRP (specific activity of ${ }^{14} \mathrm{C}-5 \mathrm{HT}$ : $\left.58 \mu \mathrm{Mi} . \mathrm{mmol}^{-1}\right)$. After $30 \mathrm{~min}, 5 \mathrm{HT}$-uptake was almost complete (90-95\%) and showed no difference between both groups. Platelets in PRP dilutions (1:10 in saline) were triggered by ADP, collagen and thrombin in the aggregometer. For release measurements, $0.1 \mathrm{ml}$ samples were taken from the aggregation cuvette and $0.1 \mathrm{ml}$ EDTA ( $1 \% \mathrm{w} / \mathrm{v})$ was added to stop the reaction. The samples were centrifuged and the radioactivity of $0.1 \mathrm{ml}$ platelet-free supernatant was measured in a liquid scintillation counter. Values were corrected for initial radioactivity measured in a sample taken $30 \mathrm{~s}$ before adding the aggregating agent. No correction was made for any re-uptake of released 5HT.

Platelet aggregation was also measured in circulating arterial blood, as described in Chapter 5 , section 2. 
(A)

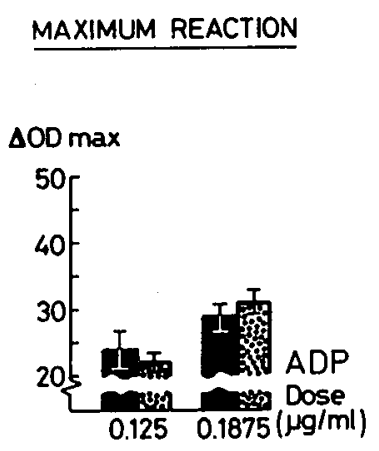

(B)

(C)
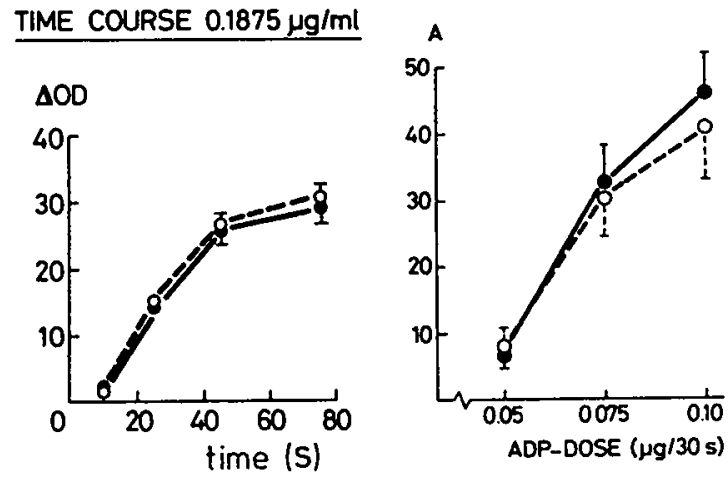

Fig.8.4. ADP-induced aggregation in vitro $(A, B, n=8)$ and in circulating arterial blood $(C, n=12$ ) in EFA-deficient (咸-O-) and control rats ( $\bullet-)$. Mean values \pm SEM.

$\triangle 0 D$ : Change in optical density (see Chapter 7, section 3.1.); A: Aggregation index (see Chapter 5, section 3.3.).

ADP induced aggregation was not different from normal in EFA-deficiency, neither in vitro, nor in circulating arterial blood (Fig.8.4.). No significant $5 \mathrm{HT}$-release was observed. Collagen induced aggregation and 5HT-release was significantly decreased in EFA-deficiency (Fig.8.5.),

(A)

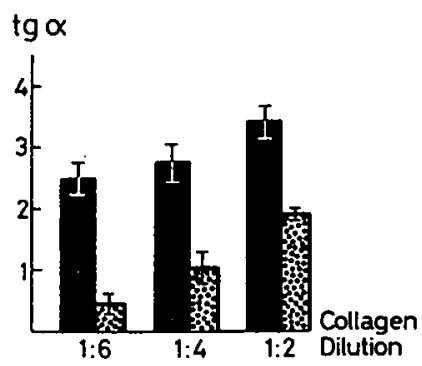

(B)

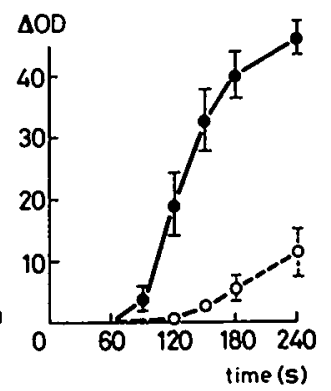

(C)

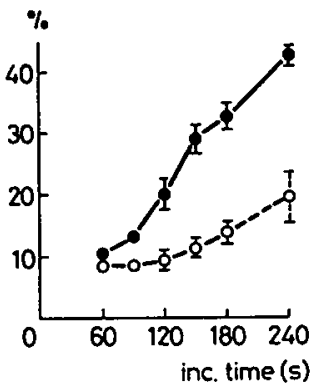

Fig.8.5. Effect of EFA-deficiency on collagen-induced aggregation and release of blood platelets in vitro.

EFA-def.: -O-; Control: - Mean values \pm SEM; $n=10$.

A: Aggregation velocity. For explanation of tgo, see Fig. 7.10.

B: Time course of collagen-induced aggregation. Collagen dilution 1:6. $\triangle O D=$ change in optical density.

C: Time course of ${ }^{14} \mathrm{C}-5 \mathrm{HT}$ release $(\%)$. Collagen dilution $1: 6$. 

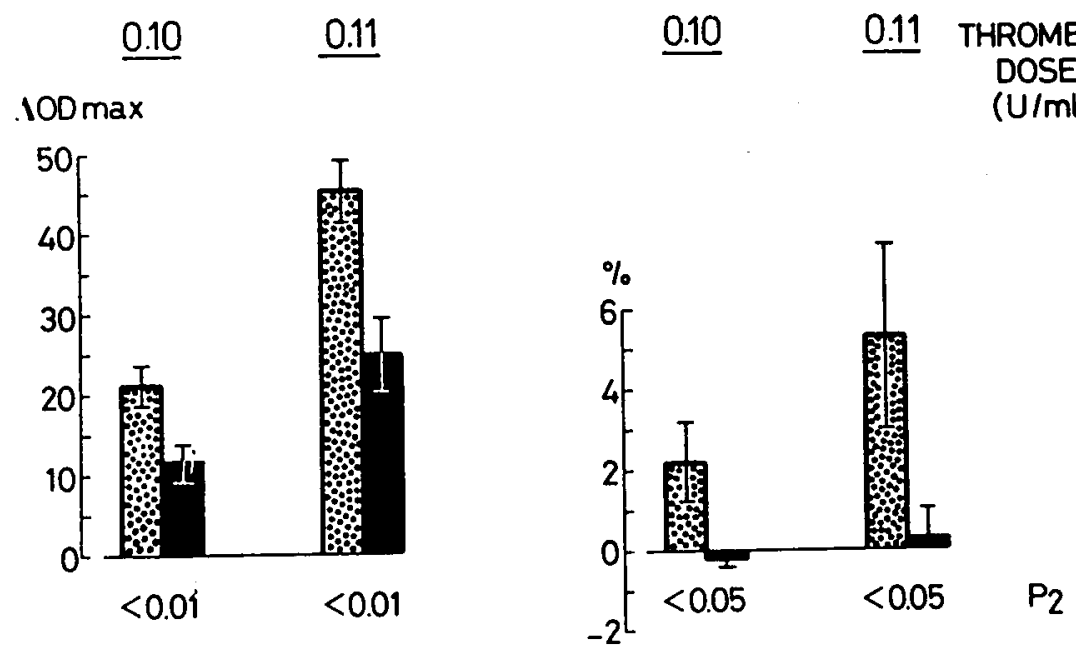

Fig.8.6. Thrombin-induced aggregation $\left(\triangle 0 D_{\max } \pm\right.$ SEM) and ${ }^{14} \mathrm{C}-5 \mathrm{HT}$-release $(\% \pm$ SEM) of platelets of EFA-deficient (m) and control ( $\square$ ) rats. $n=10$.

whereas aggregation and release induced by thrombin were enhanced for EFA-deficient platelets (Fig.8.6.).

\subsubsection{Effect_of EFA-deficiency_on_coagulation_and_platelet_factor 3 -}

Recalcification plasma clotting times (PCT, see Chapter 7, section 2.2.) are normal in EFA-deficient plasma (Fig.8.7.). Platelet factor 3 activity, content and availability (see Chapter 7, section 2.5.) are significantly

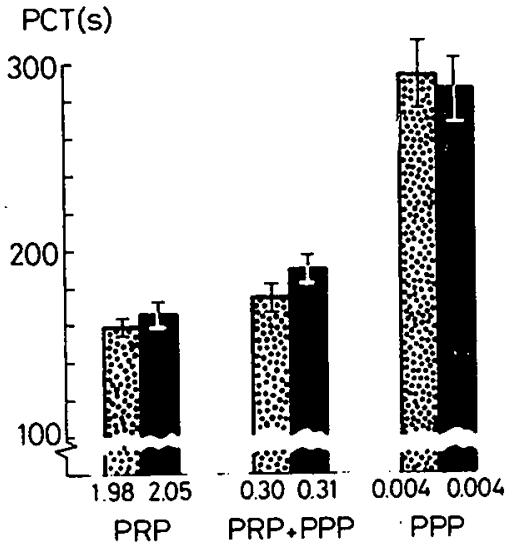

Fi.j.3.7. Recalcification plasma clotting time (PCT, $\mathrm{s} \pm$ SEM) of EFA-deficient (G) and control rats ( $\mathrm{G}$ ). Numbers under bars denote platelet concentrations $\left.\left(x 10^{6} \cdot \mu\right]^{-1}\right)$. Each group consisted of 14 animals. 

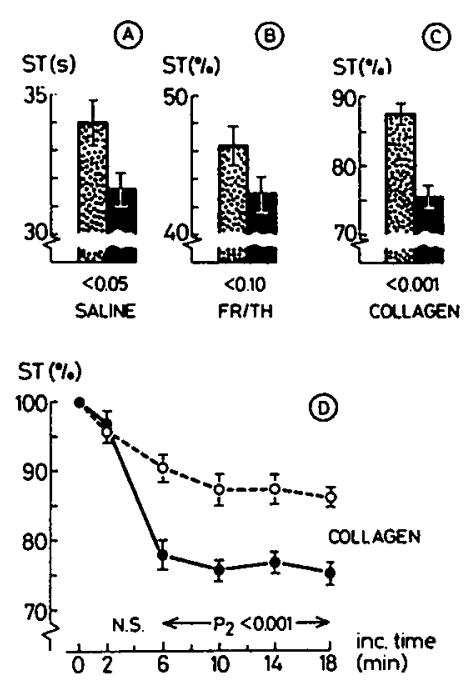

Fig.8.8. Platelet factor 3 activity (A), content (B) and availability $(C$ and $D)$ of EFA-deficient (B-O) and normal $(\square-)$ blood platelets (mean \pm SEM, $n=12$ ).

ST: Stypven time (See Chapter 7, section 2.5.); Fr/Th: platelets lysed by 3 times freezing and thawing. For experimental procedure: see text.

lower than in control animals (Fig.8.8.). Vessel-wall induced clotting (see Chapter 3, section 2.), when measured in autologous PRP, is significantly enhanced in EFA-deficiency (Fig.8.9.A). This is, at least partly, due to the lower prostacyclin production of EFA-deficient vascular tissue, because the difference in vessel-wall induced clotting greatly diminishes upon pre-treatment of the vascular tissue with indomethacin (Fig.8.9.B). When incubated in standard PPP, EFA-deficient aortas caused a more active clotting response than control tissue (Fig.8.9.C), indicating that EFA-deficient vascular tissue has a stronger clot-promoting effect than normal tissue. No differences were observed when standard tissue was incubated in EFA-deficient or control PPP (Fig.8.9.D).

8.2.4. Discrimination between prostaglandin_dependent_and_prostaglandinindegendent functions of EFA in arterial thrombogenes is

Columbinic acid, a stereo-isomer of $\gamma-1$ inolenic acid, with a trans instead of a zis double bond between the 13th and 14th carbon atom (see chapter 2, section 1.) was recently shown to possess all the functions of normal 


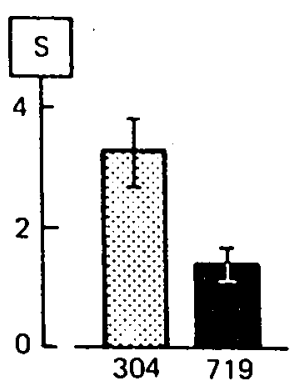

(A)

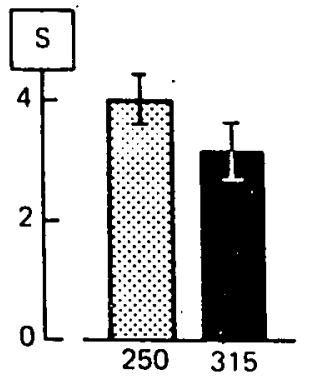

(B)

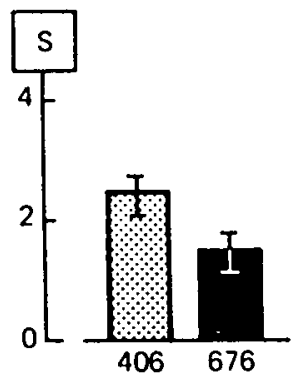

(c)

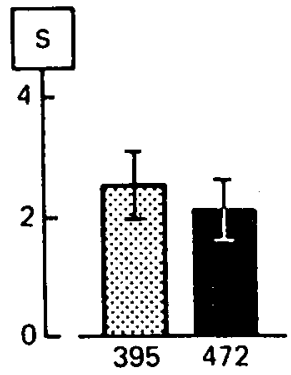

(D)

Fig.8. 9. Effect of EFA-deficiency on vessel-wall induced clotting ( mean \pm SEM).

A: non-treated aorta in autologous PRP $(n=10)$;

$B$ : indomethacin-treated aorta in autologous PRP $(n=12)$;

C: EFA-deficient and control aortas in reference PPP ( $n=7)$;

D: reference aorta in EFA-deficient and control PPP $(n=12)$. Figures below bars represent clotting times (s) calculated from mean S-values. BFA-def Control.

Vessel-wall induced clotting was measured as described in Chapter 3 , section 2.1. and is indicated by the clotting index $S=1 /$ clotting time (seconds) $\times 1,000$.

essential fatty acids, except the prostaglandin-dependent ones (17). Therefore, we used columbinic acid to investigate whether or not the disturbed arterial thrombogenesis and platelet functions observed in EFA-deficiency, are the results of a prostaglandin (PG) deficiency. To this end, rats were made EFA-deficient by feeding them a 5 en\% $\mathrm{HCO}$-containing diet. Control animals received a diet with 5 en\% SO. After 12 weeks, the EFA -deficient animals were divided into 3 groups. One group remained on the EFA-deficient diet. In the diet of the other groups, 3 en\% HCO was replaced by the methyl ester of either columbinic acid or linoleic acid.

Three weeks later, the water-vapour release in vivo was measured, while after four weeks' feeding aorta loops were inserted in all animals to determine arterial thrombosis tendency. After all loops had been obstructed, the animals were bled by puncturing the aorta just proximal to the loop and PRP was prepared for measuring collagen- and thrombin-induced aggregation. The results are given in Fig.8.10.

With respect to the normalization of the water-vapour release, columbinic acid was equally effective as linoleic acid. The same holds for thrombin -induced aggregation and these functions are, therefore, prostaglandin 

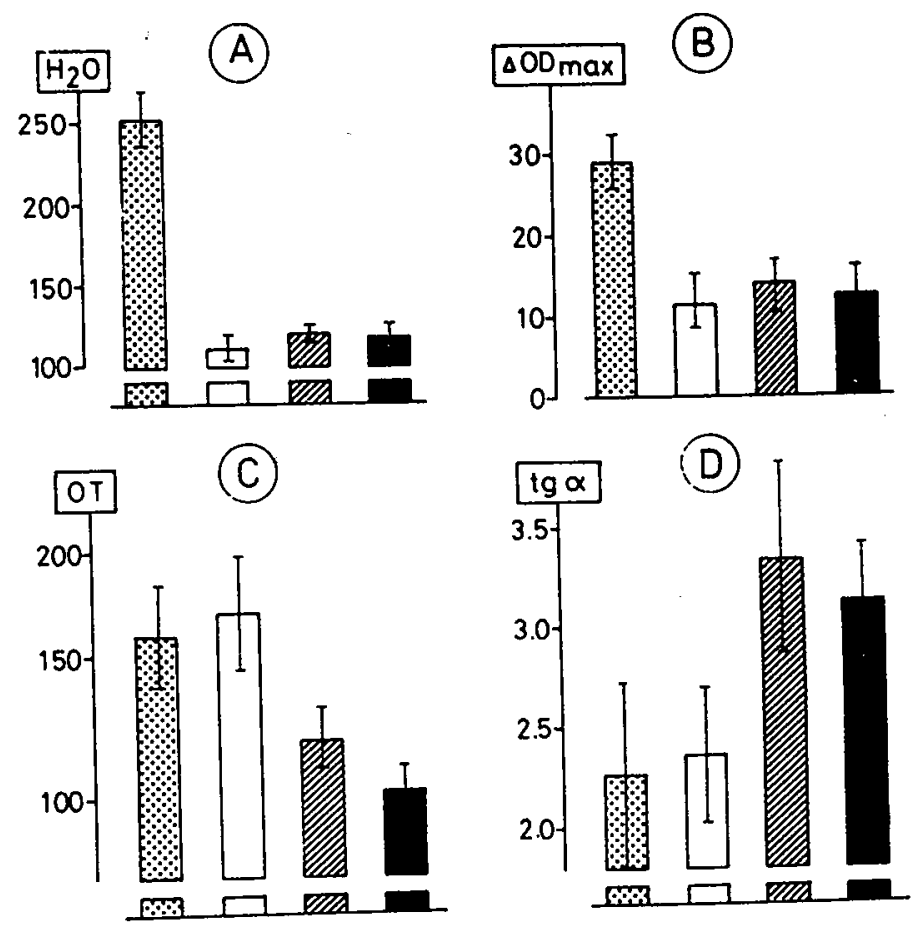

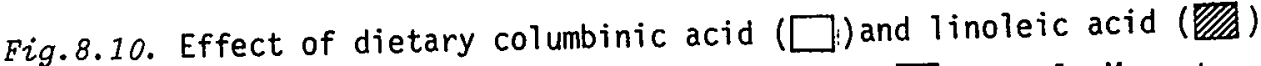
on some EFA-deficiency criteria. 3 EFA-deficient; Control. Mean \pm SEM.

A: Water release in vivo ( $\mathrm{mg} \mathrm{H}_{2} 0 . \mathrm{cm}^{-2} \cdot \mathrm{h}^{-1}$ ), $\mathrm{n}=10$.

$B$ : Thrombin-induced platelet aggregation in vitro $\left(\Delta 00_{\max }\right) ; n=8$.

$C$ : Arterial thrombosis tendency (OT, $h, \log$ scale), $n=12$.

D: Collagen-induced platelet aggregation in vitro $(\operatorname{tg} \alpha), n=8$.

-independent. Dietary linoleic acid but not columbinic acid normalized the arterial thrombosis tendency and the collagen-induced aggregation. Consequently, these functions can be considered prostaglandin-dependent.

\subsubsection{Summary}

In EFA-deficient rats, the arterial thrombosis tendency is significantly lower than in control rats. This is associated with a significantly lower platelet factor 3 activity, content and availability. Moreover, platelet adhesion and collagen-induced aggregation and serotonin-release in vitro are significantiy depressed. ADP-induced aggregation, both in vitro and in circulating arterial blood, is not different from normal. Platelet 
shape change, induced by ADP and collagen in vitro and thrombin-induced aggregation and release in vitro are significantly enhanced in EFA-deficiency, as is vessel-wall induced clotting. No difference was observed between the recalcification time of platelet-poor and platelet-rich plasma.

Feeding EFA-deficient animals with methyl ester of columbinic acid (this fatty acid shares the structural effects of essential fatty acids, but is not a prostaglandin precursor) had no effect on the disturbed arterial thrombosis tendency nor on the collagen-induced aggregation. Therefore, it can be concluded that, in our model, arterial thrombus formation is primarily regulated by prostaglandin-like substances.

\subsection{The role of the tromboxane-prostacyclin balance in dietary-fat induced changes in arterial thrombus formation}

Arterial thrombosis tendency is assumed te depend mainly on the ratio between prothrombotic Thromboxane $A_{2}\left(T \times A_{2}\right)$ produced by activated blood platelets and antithrombotic prostacyclin $\left(\mathrm{PGI}_{2}\right)$ formed in vascular tissue $(18,19$, see also Chapter 3 , section 3.$)$. Since in our thrombosis model, prostaglandin-like substances are of primary importance (section 8.2.), we decided to investigate whether the $T X A_{2} / P G I_{2}$ balance plays a significant role in dietary-fat induced changes in arterial thrombosis tendency. To this end, rats were fed diets containing 5 en\% HCO or SO (control). Due to a lack of linoleic acid, the first diet caused EFA -deficiency. Three other groups included in the study received diets containing, apart from 5 en\% sunflowerseed oil, $45 \mathrm{en} \%$ of either sunflowerseed oil (mainly ( $n-6)$ fatty acids), hydrogenated coconut oil (mainly saturated fatty acids) or linseed oil (mainly (n-3) fatty acids) (cf. Table 6.2.).

After 8 - 10 weeks' feeding, arterial thrombosis tendency was measured with the aorta loop in 50\% of all animals (Chapter 5, section 2). The other animals were used for quantifying platelet $\mathrm{TXA}_{2}$-formation and vascular $P G I_{2}$-production. For this purpose, the animals were bled by puncturing the abdominal aorta; PRP was prepared as described in Chapter 7 , section 2. Aortas were quickly removed, freed from adjacent tissue, opened longitudinally, divided into two parts and kept in Krebs-Henseleit buffer with or without indomethacin $\left(2 \mu \mathrm{g} . \mathrm{ml}^{-1}\right)$ at $0^{\circ} \mathrm{C}$ for at least $60 \mathrm{~min}$. 
Platelet $T \times A_{2}$ was measured as its stable metabolite malondialdehyde (MDA) formed upon supramaximal stimulation of a washed platelet suspension with collagen using the spectrophotometric thiobarbituric acid method $(20,21)$. Extinctions were corrected for values obtained for nor-stimulated platelets and using a standard curve obtained with MDA-bis(di)ethylacetal. The results were calculated in nmol MDA produced per $10^{9}$ platelets. The rest of the PRP was used for measuring vascular $\mathrm{PGI}_{2}$ production (vide infra) and collagen-induced aggregation. The latter results were already described in Chapter 7, section 3.1 .

Vascular prostacyclin formation was measured in two ways. In the first method, a small piece of tissue (diameter $3 \mathrm{~mm}$, dry weight approx. $100 \mu \mathrm{g}$ ) is punched from the aorta and incubated immediately in $200 \mu 10.02 \mathrm{M}$ Tris/ saline buffer, $\mathrm{pH} 7.2$ in a gently shaken vial at room temperature. After $4 \mathrm{~min}, 50 \mu \mathrm{l}$ of the incubation fluid is added to an aggregometer cuvette (Born/Michal, Mark IV) containing $0.9 \mathrm{ml}$ normal rat PRP diluted with saline to a platelet concentration of about $180,000 . \mu 1^{-1}$, preincubated at $37.5^{\circ} \mathrm{C}$ for $2.5 \mathrm{~min}$. Thirty $\mathrm{s}$ after incubate addition, $0.1 \mathrm{~m} 1 \mathrm{ADP}$ is added to a final concentration of $2.5 \times 10^{-7} \mathrm{~mol} .1^{-1}$ and the aggregation quantified in the usual way. Control measurements are performed using tissue of the same blood vessel pretreated with indomethacin. The inhibition of aggregation caused by the incubate of the non-treated tissue is converted into a $\mathrm{PGI}_{2}$-concentration by using a standard curve obtained with synthetic PGI 2 .

Unfortunately, this method does not take into account possible influences due to physiological factors such as plasma prostacyclin inhibitors/stimulators (22-25). Moreover, possible differences in platelet prostacyclin sensitivity between the groups are not taken into account either. Therefore, vascular prostacyclin production was also measured in autologous PRP. To this end, a piece of vascular tissue is added to a $1: 10$ saline dilution of autologous PRP in the aggregometer. Thirty seconds later, $A D P$ is administered and the resulting aggregation quantified by measuring the tangent to the steepest part of the aggregation curve. Due to $\mathrm{PGI}_{2}-$ formation, aggregation in the presence of normal vascular tissue is lower than that obtained on addition of a piece of indomethacin-treated aorta. For this reason, the proportional difference in aggregation induced by $A D P$ in the presence of either a piece of normal aorta or a piece of indomethacin-treated tissue, is taken as a measure of the amount of PGI 2 formed.

At the end of the experiment, it appeared that both methods gave highly 
comparable results $\left(r=0.75 ; n=45 ; P_{2}-0.001\right)$ indicating that neither plasma factors nor platelet properties interfered with the first measuring technique. Since only the values obtained by this first method could be expressed in $\mathrm{PGI}_{2}$-equivalents, these results will be reported here. It should be stressed that both the $\mathrm{TXA}_{2}$ production as well as the $\mathrm{PGI} 2$ formation are measured after stimulation of the platelets (collagen) and the vascular tissue (mechanical stress), respectively. Therefore, the results reflect production potencies rather than actual formation rates. The results of this experiment are given in Table 8.2.

Table 8.2. Effect of different dietary fats on arterial thrombosis tendency (OT), platelet MDA-formation (MDA) and vascular production of prostacyclin-like material $\left(\mathrm{PGI}_{2}\right)$. Mean \pm SEM; $n=10-12$.

\begin{tabular}{|c|c|c|c|c|}
\hline \multirow{2}{*}{ Diet } & \multicolumn{2}{|l|}{ OT } & \multirow{2}{*}{$\begin{array}{l}\text { MDA nmol per } \\
10^{9} \text { platelets }\end{array}$} & \multirow{2}{*}{$\begin{array}{l}\mathrm{PGI}_{2} \text { ng per } \\
\text { piece per min }\end{array}$} \\
\hline & $\log h$ & $\mathrm{~h}$ & & \\
\hline 5 en\% so (control) & $1.99 \pm 0.054$ & 97 & $1.21 \pm 0.059$ & $0.66 \pm 0.055$ \\
\hline 50 en\% so & $2.27 \pm 0.041$ & 187 & $1.27 \pm 0.118$ & $0.56 \pm 0.040$ \\
\hline 45 en\% $\mathrm{HCO}+5$ en\% SO & $1.99 \pm 0.037$ & 98 & $1.44 \pm 0.088$ & $0.62 \pm 0.040$ \\
\hline 45 en\% LO + 5 en $\%$ so & $2.21 \pm 0.054$ & 163 & $0.78 \pm 0.055$ & $0.32 \pm 0.050$ \\
\hline 5 en\% HCO (EFA def.) & $2.29 \pm 0.049$ & 195 & $0.55 \pm 0.072$ & $0.22 \pm 0.043$ \\
\hline
\end{tabular}

Analysis of variance revealed that platelet MDA-production and vascular $\mathrm{PGI}_{2}$-formation in the $\mathrm{LO}$ - and EFA-deficient groups are significantly depressed $\left(P_{2}<0.01\right)$ as compared with the other groups the results of which do not differ significantly from each other.

From these findings it can be concluded that the dietary linoleic acid/ saturated fatty acid ratio does not affect platelet thromboxane and vascular prostacyclin production potencies, provided the diet contains a sufficient amount of linoleic acid to prevent EFA-deficiency.

Recently, Galli and co-workers (28) confirmed these data in an experiment with rabbits fed diets containing $8 \mathrm{w} / \mathrm{w} \%$ maize oil or butter. They even noticed a significantly higher $\mathrm{PGI}_{2}$-formation in the group fed the saturated (butter) diet.

De Deckere et al.(29), measuring the 'spontaneous' prostacyclin release 
from isolated rabbit and rat hearts perfused according to a modified Langendorf technique, also noted that saturated fat feeding (35 en\% laird and hydrogenated coconut oil) does not coincide with a lower but rather with a higher vascular prostacyclin production.

All these data contrast with findings by ten Hoor and co-workers (30) obtained with a newly devised pulsatingly perfused rat-aorta preparation. Using this set-up, they demonstrated that vascular prostacyclin production is higher in relation to the dietary linoleic acid/saturated fatty acid ratio. Since this technique seems comparable to that used by de Deckere et $a$. the discrepancy between the results are most probably not attributable to the various methods used and needs, therefore, further investigation.

In Fig.8.11.A, the mean platelet MDA formation is plotted against the mean arterial thrombosis tendency from which it is evident that, in general, arterial thrombosis tendency is higher (OT is shorter), the higher the platelet MDA formation. The sunflowerseed oil group seems to be an exception because it shows a low thrombogenicity in combination with a high MDA production of the activated blood platelets. This exceptional behaviour of animals fed the sunflowerseed $0 i 1$ diet was confirmed in later studies in which another stable metabolite of $\mathrm{TxA}_{2}$ (HHT) was measured by gas chromatography and mass spectrometry (see Chapter 10, section 3.2.).

In Fig.8.11.B, the mean vascular prostacyclin formation is plotted against the mean arterial thrombosis tendency. Surprisingly, the relationship is essentially similar to that between MDA and OT. Here again, the sunflowerseed oil-fed animals behave anomalousiy.

There appeared to be a striking correlation between the MDA production of platelets and the prostacyclin production by the vessel wall (Fig.8.11.C), leaving the actual value of the $T X A_{2} / P G I_{2}$ ratio essentially unchanged irrespective of the great differences in arterial thrombosis tendencies between the groups. Consequentiy, no correlation was found between this ratio and arterial thrombosis tendency (Fig.8.11.D), which seems to be in contrast with the hypothesis that the $T \times A_{2} / P G I_{2}$ ratio determines thrombosis tendency $(18,19)$. This balance hypothesis only holds if we accept that, under the present experimental conditions, the prothrombotic effect of platelet $T_{X A_{2}}$ is far more important for arterial thrombus formation than the antithrombotic effect of vascular $\mathrm{PGI}_{2}$. 
A

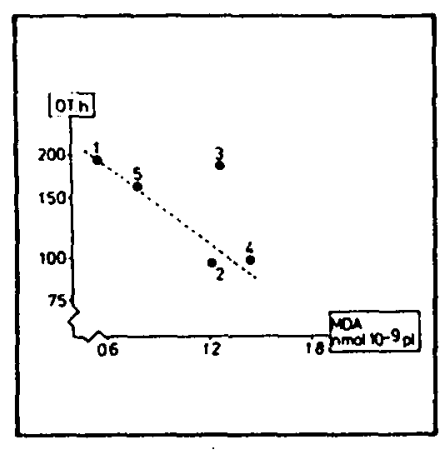

C

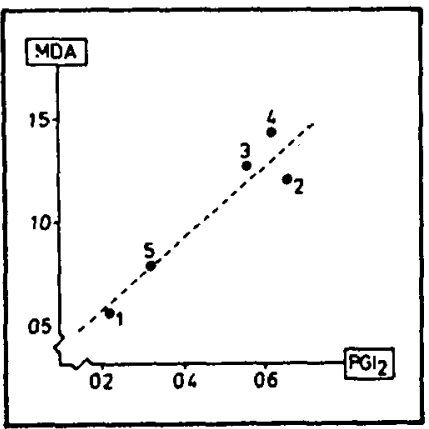

B

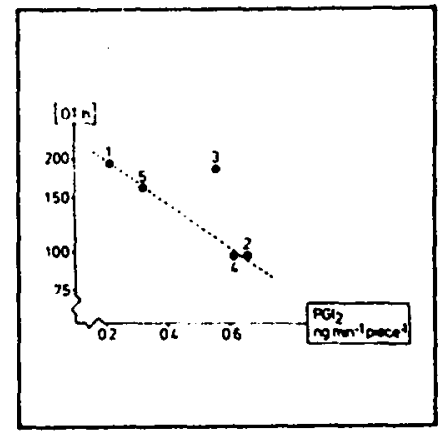

D

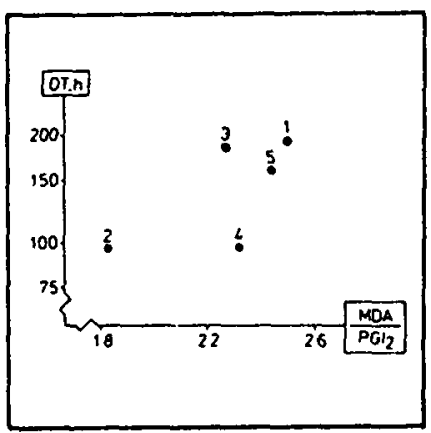

Fig. 8.11. $T \times A_{2} / P I_{2}$ balance in arterial thrombus formation. Each point represents the mean value of 10-12 animals.

Dietary groups: 1. EFA-deficient ( 5 en\% HCO); 2. Control (5 en\% SO); 3. Sunflowerseed oil (50 en\% SO); 4. Hydrogenated coconut $0 i 1$ ( $45 \mathrm{en} \%$ $\mathrm{HCO}+5$ en\% SO); 5 . Linseed oil ( 45 en\% LO + 5 en\% SO).

A: Relationship between arterial thrombosis tendency (OT) and MDA formation by activated platelets. B: Relationship between arterial thrombosis tendency (OT) and vascular $P \mathrm{PI}_{2}$ formation. $C$ : Relationship between platelet MDA formation ( $Y, n$ mol. $10^{-9}$ platelets) and vascular PGI production $\left(X, n g \cdot \min ^{-1} \cdot\right.$ piece $\left.^{-1}\right) \cdot Y=0.56+0.96 X ; r=0.57 ; n=52 ; P_{2}<0.001$.

$D$ : Relationship between arterial thrombosis tendency (OT) and the MDA/PGI ratio.

These results strongly indicate that the antithrombotic effect of an EFA-deficient diet and that of a linseed oil-containing diet is due to the diminished potency of platelets to produce $T \times A_{2}$ upon their activation. On the basis of this platelet property, animals fed a sunflowerseed oil -enriched diet may be expected to have a high thrombosis tendency. 
However, this is not the case; on the contrary, So appeared to be an antithrombotic substance. Upon So-feeding, an effective antithrombotic mechanism might, therefore, become operative, which efficiently counteracts the thrombotic properties of the blood platelets. It is possible that the classical prostaglandins from sources other than platelets and vascular tissue play an important role here, because with rats (26) and human subjects (27), urinary PG-excretion was shown to increase dose-dependently with the dietary sunflowerseed oil content (See also Chapter 11 , section 8 .).

\subsection{General summary}

In essential fatty acid deficiency, arterial thrombus formation appeared to be diminished. Normalization could be obtained with small amounts of linoleic acid but not with columbinic acid, which is able to cure the prostaglandin-independent EFA-deficiency symptoms but not the prostaglandin-dependent ones (because it is not a PG-precursor). From this finding it was concluded that in our arterial thrombosis model, prostaglandin-like substances are of primary regulatory importance.

Dietary-fat induced changes in arterial thrombosis tendency were not associated with a change in the thromboxane $A_{2}$ /prostacyclin ratio measured in collagen-activated platelets and mechanically stimulated vascular tissue in vitro. However, large differences in the levels of $\mathrm{TXA}_{2}-$ and $\mathrm{PGI}_{2}$ formation were observed on feeding different diets, the arterial thrombosis tendency being higher, the more elevated the $T \times A_{2}$ production of activated platelets. This suggests that for the regulation of arterial thrombus formation, $\mathrm{platelet} \mathrm{TXA}_{2}$ is more important than vascular $\mathrm{PGI}_{2}$.

\subsection{References}

1. Kloeze,J.: Influence of prostaglandins on platelet adhesiveness and platelet aggregation. In: S.Bergström and B.Samuelsson: Prostaglandins. Almquist and Wicksell, Stockholm (1967). pp. 241-252.

2. Van Dorp,D.: Recent developments in the biosynthesis and the analysis of prostaglandins. Ann.N.Y.Acad.Sci. 180: 181-199 (1971).

3. Tan,W.C. and Privett,0.S.: Studies on the synthesis of prostaglandins in the vesicular glands of essential fatty acid deficient and hypo- 
physectomized rats. Biochim.Biophys.Acta 296: 586-592 (1973).

4. Aaes-Jprgensen,E.: Essential fatty acids. Physiol.Rev.41: 1-51 (1961):

5. Holman,R.T.: Essential fatty acid deficiency. In: Holman,R.T.(Ed.): Progress in the chemistry of fats and other lipids, 9 (2). Pergamon Press, London (1971) pp. 275-348.

6. Mead,J.F. and Fulco,A.J.: The unsaturated and polyunsaturated fatty acids in health and disease. Charles C.Thomas, Publ. Springfield, I11. USA (1976).

7. Thomasson,H.J.: Les acides gras essentiels. Revue Française des Corps Gras. Numëro Spécial. Paris (1962).

8. Lee,M.0.: Determination of the surface of the white rat with its application to the expression of metabolic results. Am.J.Physiol. 39: 24-34 (1939).

9.Mead,J.F.: The metabolism of the polyunsaturated fatty acids. In: Holman,R.T.(Ed.): Progress in the chemistry of fats and other lipids, 9(2) Pergamon. London (1971) pip. 161-189.

10. Lyman,D.J., Klein,K.G., Brash,J.L. and Fritzinger,B.K.: The interaction of platelets with polymer surfaces.I. Uncharged hydrophobic polymer surfaces. Thrombos. Diathes.haemorrh. 23: 120-128 (1970).

11. Friedman,L. I. , Lien,H., Grabowski,E.F., Leonard,E.F. and McCord,C.W.: Inconsequentiality of surface properties of initial platelet adhesion. Trans.Amer.Soc.Artif.Int.Org. $16: 63-76$ (1970).

12. Cazenave,J.P., Packham,M.A. and Mustard,J.F.: Adherence of platelets to a collagen-coated surface: development of a quantitative method. J.Lab.Clin.Med. 82: 978-990 (1973).

13. Cazenave,J.P., Reimers,H.J., Kinlough-Rathbone,R.L., Packham,M.A. and Mustard,J.F.: Effects of sodium periodate on platelet functions. Lab.Invest. 34: 471-481 (1976).

14. Cazenave,J.P.: Personal communication.

15. Michal,F. and Born,G.V.R.: Effect of the rapid shape change of platelets on the transmission and scattering of light through plasma. Nature 231: 220-222 (1971).

16. Michal,F.: Measurement of platelet aggregation and shape change. Adv. Expt1.Med. and Biol. 34: 257-262 (1972).

17. Houtsmuller,U.M.T.: Columbinic acid, a new type of essential fatty acid. Progr.Lipid Res. (in press).

18. Moncada,S. and Vane,J.R.: Unstable metabolites of arachiaonic acid and their role in haemostasis and thrombosis. Brita.Med.Bul1. 34: 129-135 (1978). 
19. Corman,R.R.: Modulation of human platelet function by prostacyclin and thromboxane $A_{2}$. Fed.Proc. 38: 83-88 (1979).

20. Okuma,M., Steiner,M. and Baldini,M.: Studies on lipid peroxides in platelets.I. Method of assay and effect of storage. J.Lab.Clin.Med. 75: 283-296 (1970).

21. Smith,J.B., Ingerman,C.M. and Silver,M.J.: Malondialdehyde formation as an indicator of prostaglandin production by human platelets. J.Lab.C1 in.Med. 88: 167-172 (1976).

22. Saeed,S.A., McDonald-Gibson,W.J., Cuthbert, J., Copas, J.L., Schneider, C., Gardiner,P.J., Butt,N.M. and Collier,H.O.J.: Endogenous inhibitor of prostaglandin synthetase. Nature 270: 32-36 (1977).

23. Moretti,R.L. and Abraham,S.: Stimulation of microsomal prostaglandin synthesis by a blood plasma constituent which augments autoregulation and maintenance of vascular tone in isolated rabbit hearts. Circ. Res. 42: 317-323 (1978).

24. Nordфy, A., Svensson,B., Wiebe, D. and Hoak,J.C.: Lipoproteins and the inhibitory effect of human endothelial cells on platelet function. Circ.Res. 43: 527-534 (1978).

25. McIntyre,D.E., Pearson, J.D. and Gordon,J.L.: Localization and stimulation of prostacyclin production in vascular cel1s. Nature 271: 549-551 (1978).

26. Nugteren,O.H., van Evert,W.C., Soeting,W.J. and Spuy,J.H.: The effect of different amounts of linoleic acid in the diet on the excretion of urinary prostaglandin metabolites in the rat. Adv. Prostagl. Thrombox.Res. 8: 1793-1796 (1980).

27. Zöllner,N., Adam,0. and Wolfram,G.: The influence of linoleic acid intake on the excretion of urinary prostaglandin metabolites. Res. Expt1.Med. 175: 149-153 (1979).

28. Galli,C., Agradi,E., Petroni,A. and Tremoli,E.: Differential effects of dietary fatty acids on the accumulation of arachidonic acid and its metabolic conversion through the cyclo oxygenase in vascular tissue. Lipids - to be published.

29. De Deckere,E.A.M., Nugteren,D.H. and ten Hoor,F.: Influence of type of dietary fat on the prostaglandin release from isolated rabbit and rat hearts and from rat aortas. Prostaglandins 17: 947-955 (1979).

30. Ten Hoor,F., de Deckere, E.A.M., Haddeman, E., Hornstra, G. and Quadt, J.F.A.: Dietary manipulation of prostaglandin and thromboxane synthes is in heart, aorta and blood platelets of the rat. Adv. Prost. Thromb. Res. 8: $1771-1781$ (1980). 
9. EFFECT OF FISH OIL FEEDING ON ARTERIAL THROMBOSIS, PLATELET FUNCTION: AND BLOOD CLOTTING IN RATS

\subsection{Introduction}

Greenland Eskimos have an enhanced bleeding tendency (1) and mortality from acute myocardial infarction is very low (2). This latter finding might be related with their plasma lipid and lipoprotein pattern $(3,4)$. When Eskimos adopt a Western way of life, their plasma lipid and fatty acid patterns change towards that of people living in the West $(3,5)$. This largely rules out the implication of a genetic factor and strongly suggests that environmental conditions may play an important role here. Diet may be one of these factors because the genuine Eskimo diet is very different from that in Western societies $(6,7)$ : it is low in carbohydrates and rich in fat from marine animals, the fatty acid composition of which is characterized by a high content of long-chain polyunsaturated fatty acids of the $(n-3)$ family, whereas the content of $(n-6)$ fatty acids is usually very low.

Since the fatty acid composition of tissue reflects that of the diet (8-10, see also Chapter 10) it was not surprising that in Greenland Eskimos, plasma and platelet arachidonic acid appeared largely replaced with the eicosapentaenoic acid of the (n-3) family, timnodonic acid (TA) (1). This fatty acid is the precursor of prostaglandins of the 3-series $(11,12)$. Thromboxane $A_{3}\left(T \times A_{3}\right)$ possibly formed by activated platelets, has been reported to be less thrombogenic than $\operatorname{TxA}_{2}(12,13)$, which later studies showed to be due to the activity of prostaglandin $D_{3}\left(P_{3}\right)$ formed concomittantly with $\mathrm{TXA}_{3}$ upon incubation of the endoperoxide $\mathrm{PGH}_{3}$ with platelet microsomes (14). $\mathrm{PGI}_{3}$ possibly produced by the vessel wall, is equally antithrombotic as prostacyclin $\left(P G I_{2}, 15\right)$. Therefore, Dyerberg and co-workers suggested in a rather speculative paper (16) that the low thrombosis tendency in Greenland Eskimos is due to a shift in the prostaglandin production from the 2- to the 3-series, resulting. in a change of the TXA/PGI balance towards a less thrombogenic state. They also advocated a dietary enrichment with $(n-3)$ fatty acids, TA in particular, at the expense of $(n-6)$ fatty acids.

This publication had a tremendous impact because it led to the generalized idea that 'fish oils prevent from myocardial infarction'. However, upon feeding linseed oil to rats (causing the incorporation of TA in tis- 
sues (17, see also Chapter 10)) we noticed a lower production of vascular $\mathrm{PGI}_{2}$-1ike material than in control animals (Chapter 8, section 3.), which is not in agreement with Dyerberg's hypothesis.

In our systematic investigations of the effect of dietary fat type on arterial thrombogenesis, we also found that dietary whale oil (containing $10-15 \%$ TA) was equally thrombogenic as saturated vegetable fats, although, admittedly, it caused a much lower platelet aggregation tendency (Chapter 6). Unfortunately, confirmation of our whale oil results appeared impossible because, for obvious reasons, whale hunting and whale oil trading is now prohibited by law in this country. Therefore, we decided to investigate other marine oils as to their effects on arterial thrombogenesis and some of its underlying processes.

\subsection{Effect of dietary fish oil on arterial thrombus formation}

\subsubsection{Comparison_of cod-liver_oil_with_sunflowerseed_oi]}

Rats were fed adequate diets containing 5 en\% sunflowerseed oil (S0, control), 50 en\% S0 or 45 en\% cod-liver oil (CLO) +5 en\% SO (to prevent essential fatty acid deficiency). The fatty acid composition of the oils is given in Table 9.1. Since CLO rapidly autoxidizes, an antioxidant

Table 9.1. Fatty acid composition (\%) of some marine oils used in our studies (only fractions $\geq 1 \%$ are mentioned). WO : Whale oil; CLO : Cod-liver oil; FO : Fish oil of unknown origin.

\begin{tabular}{lrrr}
\hline Fatty acid & WO & CLO & FO \\
\hline $14: 0$ & 8 & 4 & 8 \\
$16: 0$ & 19 & 10 & 20 \\
$16: 1(n-7)$ & 12 & 9 & 9 \\
$17: 0$ & 1 & 1 & 2 \\
$17: 1$ & 2 & 2 & 3 \\
$18: 0$ & 4 & 25 & 17 \\
$18: 1(n-9)$ & 16 & 2 & 4 \\
$18: 2(n-6)$ & 3 & 2 \\
$18: 3(n-3)$ & 1 & 1 & 2 \\
$20: 0$ & & 2 & 2 \\
$20: 1(n-9)$ & 4 & 12 & 6 \\
$20: 5(n-3)$ & 10 & 15 & 15 \\
$22: 1(n-9) 11)$ & 6 & & 2 \\
$22: 6(n-3)$ & 4 & 10 & 4 \\
$24: 0$ & & & \\
$24: 1$ & 6 & 1 & \\
\hline
\end{tabular}


I'abite 9.2. Effect of diets containing sunflowerseed oil (SO) or cod-1iver oil (CLO) on arterial thrombosis tendency (OT, ' $h$ )

\begin{tabular}{lllr}
\hline Diet & $n$ & log OT \pm SEM & OT \\
\hline 5 en\% SO & 16 & $1.96 \pm 0.037$ & 91 \\
50 en\% SO & 14 & $2.14 \pm 0.057$ & 139 \\
45 en\% CLO +5 en\% SO & 16 & $2.45 \pm 0.076$ & 279 \\
\hline
\end{tabular}

was added to the dietary oils (Santoquin ${ }^{2}, 6$-ethoxy-2,2,4-trimethyi-1, 2-dihydroquinoline, $0.6 \mathrm{~g}$ per $\mathrm{kg}$ ).

After 8 weeks' feeding, arterial thrombosis tendency was measured in a11 animals, using the aorta-loop model (Chapter 5, section 2.). Results are given in Table 9.2. Statistical evaluation (analysis of variance followed by the Newman-Keuls test) revealed that both the CLO and the SO-enriched diets prolonged the OT's significantly as compared with the control group $\left(P_{2}<0.05\right)$. This effect was significantly more pronounced in the CLO- than in the SO-group $\left(P_{2}<0.05\right)$. This experiment clearly demonstrates that CLO has a very distinct antithrombotic effect in rats.

\subsubsection{Comparison of two different fish oils with respect to their} antithrombotic_effect

The experiment of the previous section was repeated without adding an antioxidant to the dietary fats. Also another fish oil (FO) was included, the composition of which is given in Table 9.1. Autoxidation of the oils was prevented by storing them under nitrogen in a cold $\left(-5^{0} \mathrm{C}\right)$ room. Food was prepared daily. Each experimental (SO, CLO and FO) group comprised 28 animals: 16 were used for OT measurements and 12 for the determination of other parameters, which will be reported in subsequent sections. The control (5 en\% SO) group $(n=16)$ was used for OT measurements only. The OT results are given in Fig.9.1. Although the mean OT's of the three experimental groups did not differ significantly from one another (analysis of variance), the different diets caused different responses compared with the control group: the fo effect was not significant whereas that of the other diets was (Student's two sample test). The fact that Fo contains about two times more long-chain saturated fatty acids than CLO (see Table 9.1.) might be responsible for the different results obtained for both fish oils. Another discrepancy between these oils is the difference in cholesterol content: approx. $2.2 \mathrm{mg} \cdot \mathrm{g}^{-1}$ in CLO and $6.4 \mathrm{mg} \cdot \mathrm{g}^{-1}$ 


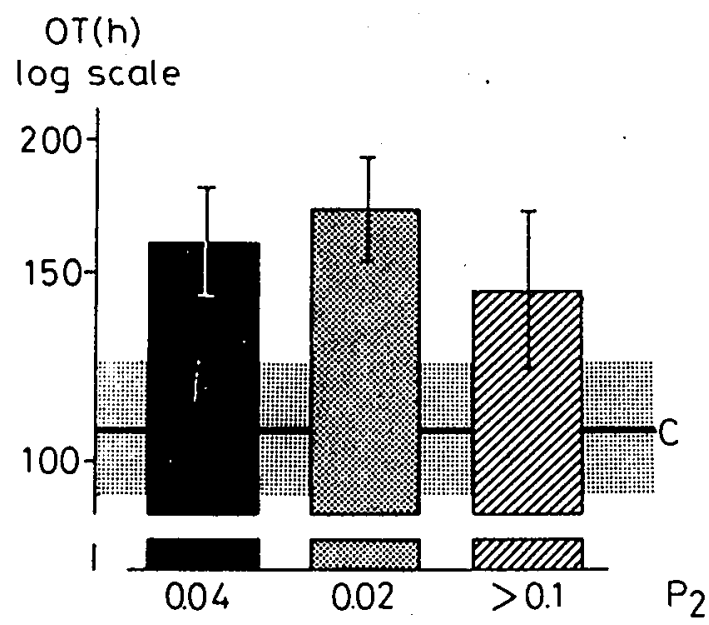

Fig. 9.1. Comparison between dietary sunflowerseed oil (SO), cod-liver oil (CLO) and another fish oil (FO) as to their effect on arterial thrombosis tendency in rats (OT \pm SEM; $n=14-16$ ).

C: Control group (5 en\% SO) fat line: mean; shaded area: SEM.; 50 en\% S0; 45 en\% CLO + 5 en\% S0; WIIA 45 en\% FO.

in F0. Since it is mainly free cholesterol which is readily taken up by platelets (18) and platelet cholesterol content has been implicated in thrombotic platelet functions (18-20, see also Chapter 10 , section 6.3.), experiments were repeated with $\mathrm{F} 0$, which had been treated with activated alumina to remove free cholesterol (21). This treatment removes free tocopherols as well. Therefore, the original amount of $\alpha$-tocopherol was added again afterwards.

\subsubsection{Effect_of_low-cholesterol_fish_oil_on_arterial_thrombogenes_is compared with that of sunflowerseed_oil}

Rats were fed adequate diets containing 5 (= control) or 50 en\% sunflowerseed oil. Five other groups were given diets which not only contained 5 en\% so but also increasing amounts (5-45 en\%) of F0, which had been pretreated in order to remove the free cholesterol. Obstruction times were measured after 8 weeks' feeding (Fig.9.2.). From the results of statistical analysis (Student's two-sample test) it was concluded that the $50 \mathrm{en} \%$ sunflowerseed oil diet prolonged the $0 \mathrm{~T}$ significantly $\left(P_{2}<0.05\right)$. None of the FO groups had an OT significantly longer than that of the control group. Even if all FO animals were combined, the mean OT-value 


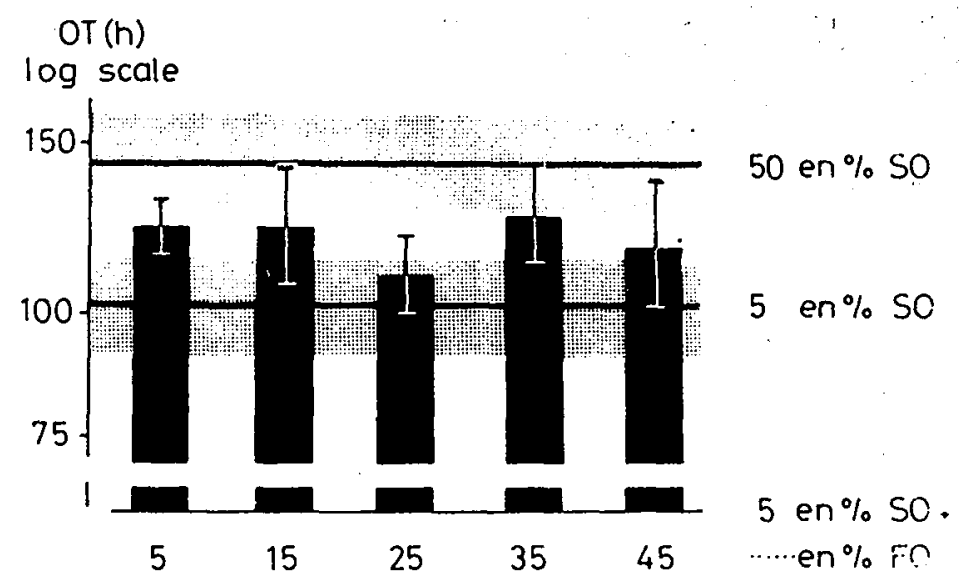

Fig. 9.2. Effect of different amounts of sunflowerseed oil (SO) and fish oil (FO) on arterial thrombosis tendency in rats (OT \pm SEM; $n=16$ ).

$(\log 0 T=2.080 \pm 0.0225 ;$ OT $=120 \mathrm{~h} ; n=79)$ was not significantly different from that of the control group $(\log$ OT $=2.007 \pm 0.048$; OT $=102 \mathrm{~h}$; $n=16)$.

\subsubsection{Conclusion}

Cod-liver oil fed to rats in a concentration of 45 en\% lowers arterial thrombosis tendency. Diets containing another fish oil with more saturated fatty acids, less $22: 6(n-3)$ and the same amount of TA as CLO, only showed a tendency to prolong the OT as compared with a standard diet. Therefore, it can be concluded that not all fish oils are equally antithrombotic. Whale oil had no antithrombotic effect at all.

\subsection{Effect of dietary fish oil on platelet aggregation in vitro}

Animals from the experiment mentioned in section 9.2.2. (50 en\% so, 45 en\% CLO + 5 en\% so and 45 en\% FO + 5 en\% SO) were bled under ether anesthesia by puncturing the abdominal aorta. PRP and PPP were prepared at room temperature, following the procedure described in Chapter 7 , section 2. The platelet count of the PRP was 'normalized' to the lowest value of each series by adding the required amount of autologous PPP. Aortas were quickly removed and treated for measurement of vascular PGI-production (Chapter 8, section 3.) and vessel-wall induced clotting 
(Chapter 3, section 2.1.). The PRP was partly used for measuring MDA formation upon triggering with collagen (Chapter 8, section 3.) as well as for the determination of vessel-wall induced clotting. In the rest of the PRP, platelet aggregation was measured (Chapter 7, section 3.1.) in a Chrono-log aggregometer, using ADP, collagen and thrombin as aggregation-inducing agents. The results are shown in Fig.9.3.

The ADP-induced aggregation did not differ significantly. Aggregation induced by thrombin was significantly higher in the fish oil groups versus the S0-group ( $P_{2}=0.06$ (FO) and $<0.001$ (CLO) respectively, Student's tivo-sample test).Both fish oil groups did not differ significantly from each other. The collagen-induced aggregation was markedly lower in the fish oil groups than in the S0-group. This effect was more pronounced in the $F O-\left(P_{2}<0.01\right)$ than in the CLO group $\left(P_{2}<0.05\right)$. The collagen-induced shape change is significantly enhanced in the fish oil groups, compared with that in the so-group. However, this only holds for the two higher collagen doses. The shape change in both fish oil groups was not significantly different from each other.

(4)

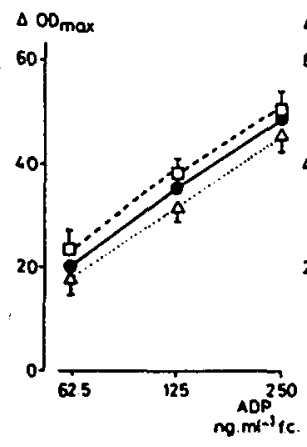

(8)

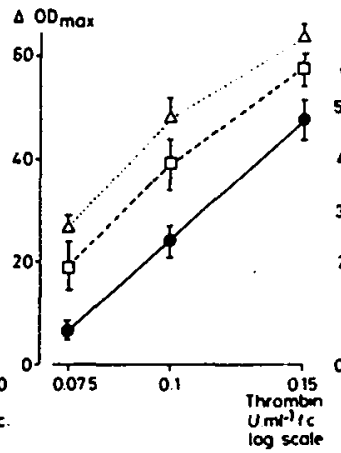

(c)

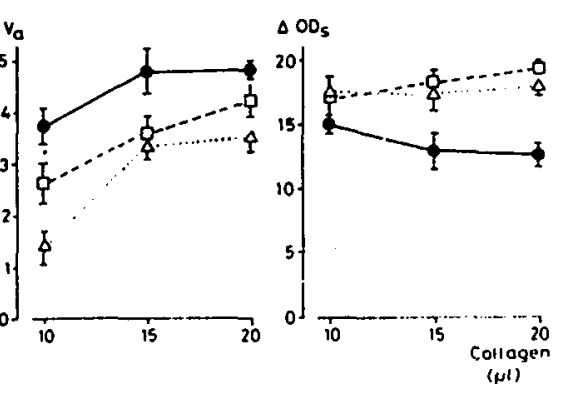

Fig.9.3. Effect of fish oil feeding on platelet aggregation in nil.m. (mean \pm SEM; $n=10$ ).

$A$ : ADP-induced aggregation $\triangle O D_{\max }$ : maximum change in optical density of PRP after ADP-addition. f.c. = final concentration in aggregation cu-

$B$ : Thrombin-induced aggregation. [vette

C: Collagen-induced aggregation. $V_{a}$ : aggregation velocity, see Chapter 7 , section 3.1. and Fig.7.10.

$D$ : Collagen-induced shape change. $\triangle O D_{s}$ : total increase in $O D$ after collagen addition.

$\longrightarrow 50$ en\% SO;

-.--- 45 en\% CLO + 5 en\% SO;

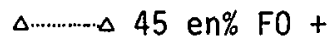

5 en\% So. 
As far as the aggregation/shape change pattern is concerned, there is a striking similarity between platelets of fish oil-fed animals and trose of EFA-deficient rats. Also in the latter, platelet shape change is enhanced, as is thrombin-induced aggregation. Collagen-induced aggregation is depressed and aggregation brought about by ADP does not differ from normal (Chapter 8, section 2.2.3.).

\subsection{Effect of fish-oil feeding on some coagulation parameters}

\subsubsection{Vessel-wall_induced_clotting}

In pilot experiments, we observed that CLO-feeding caused a significantly lower vessel-wall induced clotting response in relation to feeding a so-diet. Therefore, this phenomenon was investigated in more detail, after feeding rats diets containing SO, CLO and FO (see section 9.2.2.).
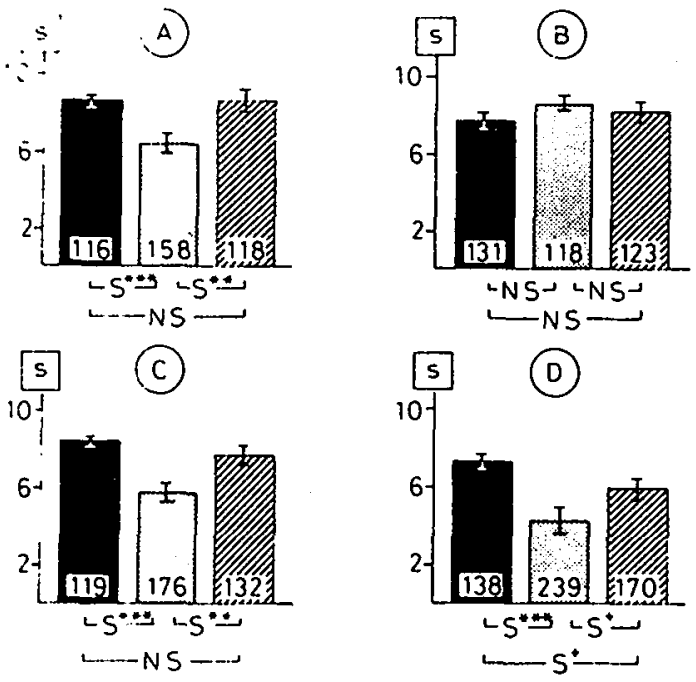

l.ig. \%.4. Vessel-wall induced clotting measured with vascular tissue, platelet-rich (PRP) and platelet-free (PFP) plasma of animals fed different diets (S \pm SEM; $n=10$ )

50 en\% so $\square 45$ en\% CLO + 5 en\% so 40 en\% F0 + 5 so. Numbers in bars represent clotting times (seconds) calculated from mean S-values ( $1 /$ clotting time (seconds) $\times 1,000)$

A. Vascular tissue in autologous PRP. B. vascular tissue in PRP of stock animals. C. vascular tissue of stock animals in different PRP's

D. vascular tissue of stock animals in different PFP's.

NS: $F_{2}>0.10 ; S^{+}: P_{2}<0.10 ; S^{\bullet \bullet}: 0.001<P_{2}<0.01 ; S^{\bullet \bullet \bullet}: P_{2}<0.001$. 
Experiments were carried out as described in Chapter 3, section 2.1, at a final $\mathrm{Ca}^{++}$-concentration of $1 \mathrm{mmol} .1^{-1}$, and results are expressed by the clotting index $S=1 /$ clotting time (seconds) $\times 1,000$. As a result, the clotting response is higher, the higher the S-value. Fig. 9.4. shows the relevant data. Statistical analyses were performed using Student's two-sample test.

Vessel-wall induced clotting in autologous PRP is significantly lower in the CLO-group as compared with both other groups, which do not differ significantly (Fig.9.4.A). This difference disappears when the aortic pieces are placed in PRP obtained from stock animals (Fig.9.4.B).

Therefore, the CLO-effect is located in the PRP and not in the aorta. This was confirmed in an experiment in which pieces of aorta from stock animals were used to activate clotting in the different PRP's: essentially, differences were similar to those observed in the first experiment (Fig.9.4.C). To find out as to whether the CLO-effect is located in the platelets or in the plasma, the experiment with aortas of stock animals was repeated in platelet-free plasma (Fig.9.4.D). It then appeared that clotting in the CLO plasma was again lower than in the other group, indicating that the lower clot-promoting effect of vascular tissue, as observed in CLO-fed animals, is located in the plasma.

\subsubsection{Activated_partial_thromboplastin_time_(APII)}

APTT's were measured as described in Chapter 7, section 2.3. Apart from the SO, CLO and FO groups, a control group was included receiving a commercial stock diet (Muracon, Trouw, Amsterdam). Results (Fig.9.5.A) are expressed in S-values (1/clotting time (seconds) $\times 1,000$ ). APTT's of plasmas from the CLO and the FO groups did not differ significantly but were markedly different from those of the control- and SO-groups $\left(P_{2}<0.001\right)$, which did not differ mutually. Consequentiy, APTT's of both fish oil groups are also significantly different from those of the So group, suggesting a less active intrinsic clotting pathway in fish oil-fed animals as compared with rats fed the so- or the control diet.

\subsubsection{Prothrombin time_(PI)}

PT-measurements were carried out in the same plasmas as the APTT's, 
(A)

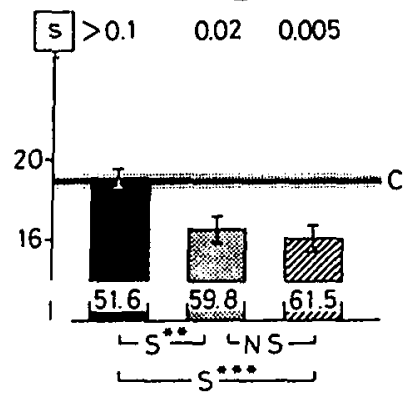

(8)

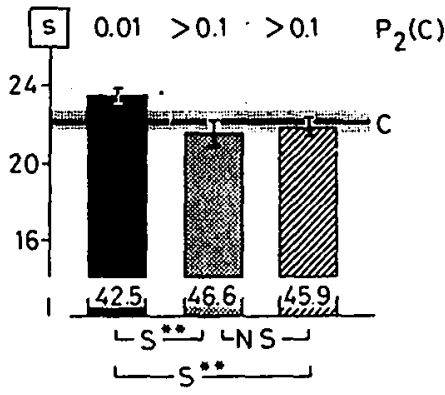

Fig.9.5. Effect of diets containing sunflowerseed oil (SO), cod-liver oil (CLO) and another fish $0 i 1$ (FO) on intrinsic (A, APTT) and extrinsic (B,PT) clotting of plasma (Mean \pm SEM; $n=10$ )

S: Clotting index $=1 /$ clotting time (seconds) $\times 1,000$.

50 en\% SO; $\square 4$ en\% CLO + 5 en\% SO; 45 en\% FO + 5 en\% SO;

$C$ : stock diet. Fat line:mean. Shaded area: SEM.

$\mathrm{P}_{2}(\mathrm{C})$ : Significance level compared with control group;

NS: $P_{2}>0.10 ; S^{\bullet \bullet}: 0.001<P_{2}<0.01 ; S^{\bullet \bullet \bullet}: P_{2}<0.001$. Numbers in bars represent clotting times (seconds) calculated from mean $S$-values.

using the method described in Chapter 7 , section 2.4. The results are depicted in Fig.9.5.B. As compared with the control group, PT in the So-group was significantly different ('Student's two-sample test). Both fish oil groups did not differ from the control group but did so from the so-group. Our conclusion is, therefore, that, as compared to a low -fat control group, CLO- and FO-feeding do not change the extrinsic pathway of coagulation whereas an So-enriched diet enhances extrinsic coagulability. When compared with a standard PFP, the PT- and APTT-results for the So-fed rats were qualitatively similar to those found in an earlier experiment (Table 7.2.).

9.5. Bleeding time: comparison between the effect of dietary fish oils and sunflowerseed oil

One of the most reliable tests for screening hemostatic platelet functions is the measurement of bleeding times. We performed the test as follows: rats were anesthetized with sodium pentobarbitone (Nembutal, $40 \mathrm{mg} \cdot \mathrm{kg}^{-1}$ intraperitoneally). The tail was transected at $3 \mathrm{~mm}$ from the tip and the distal end $(5 \mathrm{~cm})$ of the tail was immersed vertically in 
Table 3.3. Fffect of different dietary oils on bleeding time (BT,s) in rats; $n=12$.

So : 50 en\% sunflowerseed oil; CLO : 45 en\% cod-1iver oil + 5 en\% SO;

FO : 45 en\% fish oil (origin unknown) +5 en\% so.

\begin{tabular}{ll}
\hline Group & BT \pm SEM \\
\hline SO & $244 \pm 30$ \\
CLO & $372 \pm 44$ \\
FO & $346 \pm 50$ \\
\hline
\end{tabular}

saline ( $\left.\mathrm{NaCl} 9 \mathrm{~g} . \mathrm{1}^{-1}\right)$ at $37.5^{\circ} \mathrm{C}$. The period between transection and the moment bleeding stopped was taken as bleeding time. Results are given in Table 9.3. As compared with the So-group, both fish oil diets prolonged the bleeding times significantly: $C L O: P_{2}=0.03 ; F 0: P_{2}=0.09$, (Student's two-sample test).

9.6. Effect of fish oil feeding on platelet thromboxane production and the vascular formation of prostacyclin-like material

The first experiment described in this section was performed with animals fed diets containing $50 \mathrm{en} \% \mathrm{SO}$, or $45 \mathrm{en} \% \mathrm{CLO}$ or FO $+5 \mathrm{en} \%$ so. The effect of these diets on arterial thrombosis tendency has been reported in section 9.2.2. and studies concerning platelet functions and coagulation in sections 9.3. and 9.4. respectively. In a second experiment, the effect of the dietary amount of fish oil was investigated in animals used for the OT-measurements reported in section 9.2.3.

Blood for the study to be described now was collected approximately 1-2 weeks after occlusion of the loops. Methodological details on blood collection and preparation of .PRP are described in detail in Chapter 7 , section 2. Platelet thromboxane, formed upon triggering with collagen, was measured as its stable metabolite MDA, according to the method described in Chapter 8 , section 3 . It should be noted that MDA formation reflects total thromboxane production from all three prostaglandin precursors: $20: 3(n-6), 20: 4(n-6)$ and $20: 5(n-3)$.

The formation of vascular prostacyclin-like material was measured with the platelet aggregation bio-assay described in Chapter 8 , section 3 , 
using both autologous and indifferent PRP's. Essentialiy, the results obtained with both methods were similar, which excludes any difference between the groups regarding plasmatic modulators of PGI-formation and platelet PGI sensitivity. Only results obtained when using indifferent PRP for PGI quantification were compared with a $\mathrm{PGI}_{2}$ standard. Therefore, these results are given. It should be emphasized that this bio-assay method measures the total production of $P G I_{2}+P G I_{3}$ (PGI 1 is not formed because $P G H_{1}$ is not a substrate for PGI-synthase $\left.(22,23)\right)$.

\subsubsection{Effect of fish} formation

MDA and PGI measurements were carried out in material from the same animal and are, therefore, directly comparable. As shown in Fig.9.6., both CLO- and FO-feeding cause a much lower MDA and PGI formation than a diet rich in SO. The values obtained for the FO group are significantly lower than those measured for the CLO-fed animals. A significant linear correlation was observed between vascular PGI formation $(X)$ and platelet
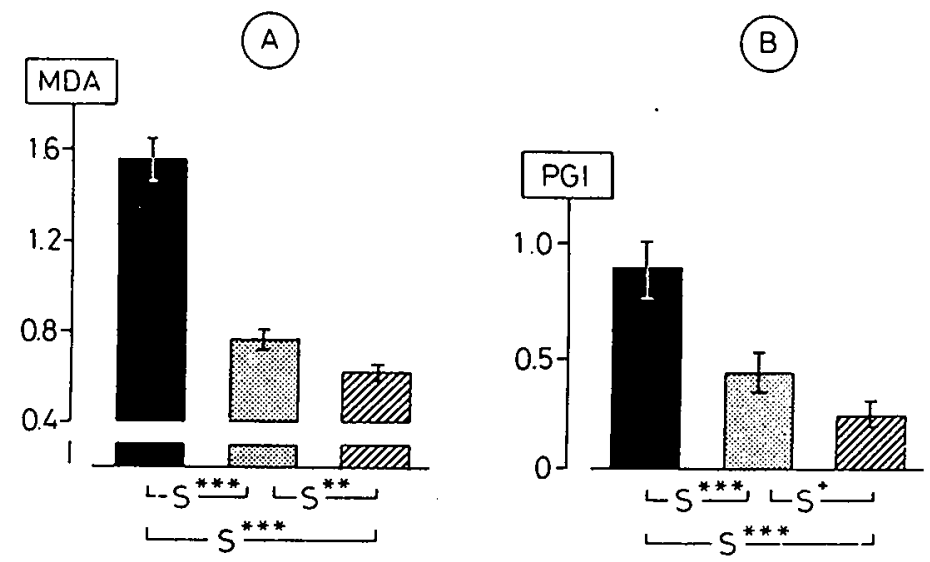

$\therefore$. 3 . Effect of fish oil feeding on the formation of platelet-and vessel-wall prostaglandins (Mean $上$ SEM).

A. Malondialdehyde (MDA, nmol. $10^{-9}$ platelets)-formation by collagenactivated blood platelets $(n=13)$.

B. Formation of prostacyclin-like material (PGI) by aortic tissue. Results expressed in $n g$ PGI $2^{-e q u i v a l e n t s . ~} \min ^{-1}$. piece of aorta ${ }^{-1} . \quad(n=11-12)$ $S^{+}: 0.10>P_{2}>0.05 ; S^{\bullet \bullet}: 0.01>P_{2}>0.001 ; S^{\bullet \bullet}: P_{2}<0.001$.

50 en\% sunflowerseed oil (SO); $\square 45$ en\% cod-1iver oil + 5 en\% so; TIII 45 en\% of another fish oil +5 en\% so. 


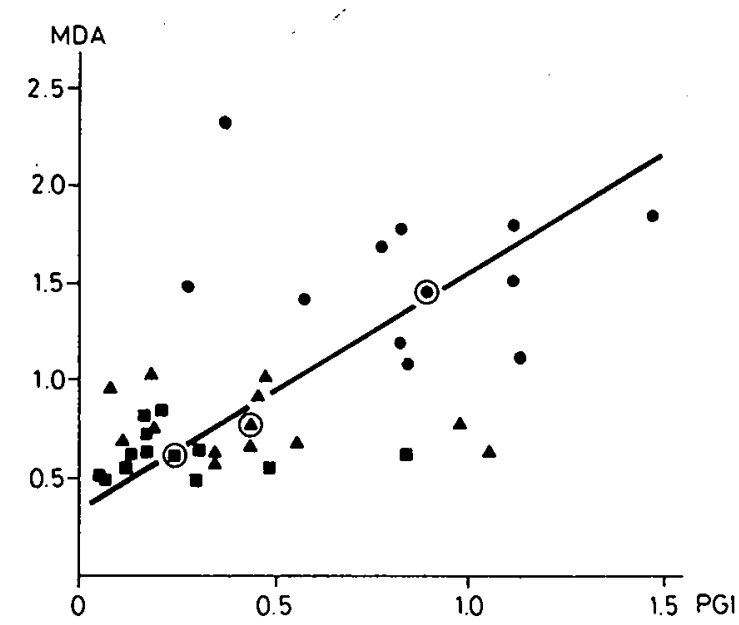

lig. $\% \%$ Intra-individual correlation between vascular PGI-production (ng $P G 2_{2}-1$ ike material.aortic piece ${ }^{-1} \cdot \min ^{-1}$ ) and platelet MDA-formation (nmol MDA. $10^{-9}$ platelets) as influenced by dietary fat type.

- 50 en\% sunflowerseed oil (SO); 45 en\% cod-liver cil + 5 en $\%$ so; 45 en\% of another fish oil + 5 en\% so.

Encircled symbols represent group means.

MDA production $(Y)$, which can be characterized by the equation $Y=0.37+1.20 \times(r=0.51 ; n=35 ; P<0.01$, see Fig.9.7. $)$.

\subsubsection{Dose-response effect of dietary fish oil on_Platelet_MDA and vasscular PGI formation}

As shown in Fig.9.8, the effect of fish $0 i 1$ on platelet MDA and vascular PGI formation, partly depends on the amount in the diet: the effect increases with the dose up to about 25 en: FO. A further 20 en: increase in the amount of dietary $F 0$ did not affect the parameters under investigation. Since platelet MDA and vascular PGI formation were determined in material from the same animal, they could be compared directly. As was the case in earlier investigations (Chapter 3 , section 3; see also section 9.6.1.), the dietary fat effect was about similar for both platelet MDA and vascular PGI, leaving the ratio between both parameters essentially unchanged (Table 9.4.).

- Measurements were carried out with material obtained from animals used earlier for OT-measurements (section 9.2.3.) so that the results could be compared directly. No significant relationship existed between OT and 

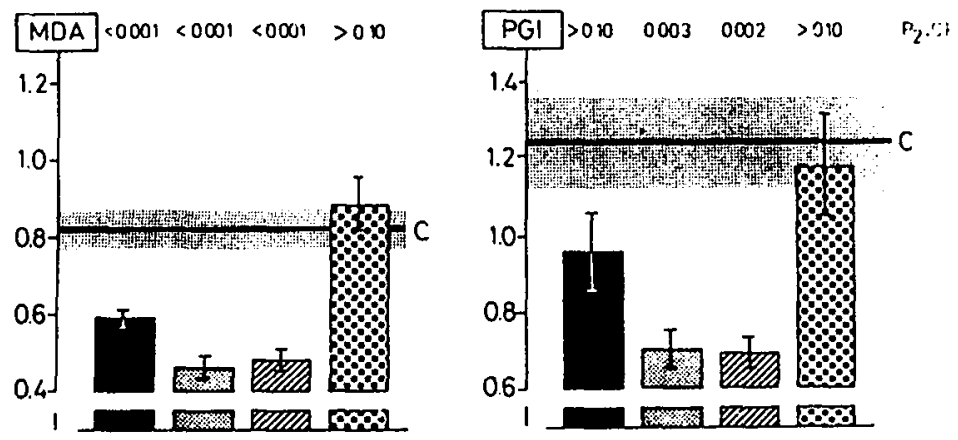

Fig.9.8. Effect of increasing amounts of dietary fish oil (FO) and sunflowerseed oil (SO) on platelet MDA (nmol. $10^{-9}$ platelets) - and vascular PGI (ng $\mathrm{PGI}_{2}$-equivalents. min ${ }^{-1}$. aortic piece ${ }^{-1}$ ) formation. (Mean values \pm SEM; $n=10)$.

$P_{2}(C)$ : Significance level of difference in relation to control group ( $C, 5$ en\% SO, fat line: mean, shaded area SEM.).

5 en\% SO + 5 en\% FO; $\square 5$ en\% SO + 25 en\% FO; WTIG en\% SO + 45 en\% FO; 50 en\% so.

either platelet MDA-formation or vascular PGI-production. This seems contradictory to the results reported in Chapter 8 , section 3 for rats fed different dietary fats. However, it should be emphasized that, in contrast to these earlier results, the OT's measured in the FO-groups of the present experiment were not significantly different from that in the control -5 en\% So- group, thus providing only a small 'response

Table 9.4. Ratio between MDA-formation by collagen-activated platelets (ng MDA. $10^{-9}$ platelets) and vascular PGI-production (ng PGI $2^{-1 \text { ike acti- }}$ vity. aortic piece ${ }^{-1} \cdot$ min $^{-1}$ ) measured in platelets and aortic tissue of rats fed diets containing various amounts of sunflowerseed oil (SO) or fish oil (FO).

Ratios were determined for each animal (10 animals per group). The group means are given \pm SFM. There were no significant differences between the groups.

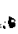

\begin{tabular}{ll}
\hline Diet : 5 en\% SO + & Ratio \\
\hline$\overline{5}$ en\% FO & $0.73 \pm 0.087$ \\
25 en\% FO & $0.70 \pm 0.086$ \\
45 en\% FO & $0.70 \pm 0.071$ \\
45 en\% SO & $0.73 \pm 0.071$ \\
\hline
\end{tabular}


area'. Moreover, it should be noted that in the previous investigation, results obtained with animals fed 50 en\% so did not fit the general relationship. Thus, a significant contribution of the so group in the present experiment is not to be expected either.

\subsection{Fish-oil feeding and formation of prostaglandins of the 3-series}

The results obtained in the previous section clearly demonstrate that fish-oil feeding decreases the formation of thrombosis influencing platelet- and vascular prostaglandins. The techniques employed so far measured the products of the arachidonic acid (AA) derived 2-series together with those of the timnodonic acid (TA) derived 3-series. In view of this it can be concluded that fish-oil feeding does not result in a complete replacement of 2-series PG's by those of the 3-series, as suggested by Dyerberg et al. (16).

In plasma and platelets of Greenland Eskimos, eating a marine diet, arachidonic acid $(20: 4(n-6))$ is for a considerable part replaced by timnodonic acid $(20: 5(n-3))$. As is shown in Table 9.5, this also holds for

Table 9.5. Fatty acid composition (percentage minor fatty acids not mentioned) of platelet and aorta phospholipids of rats fed diets containing 50 en\% sunflowerseed oil (SO) or 45 en\% cod-liver oil (CLO) +5 en\% SO.

\begin{tabular}{|c|c|c|c|c|}
\hline \multirow{2}{*}{ Fatty acids } & \multicolumn{2}{|c|}{ Platelets. } & \multicolumn{2}{|l|}{ Aorta } \\
\hline & so & CLO & so & CLO \\
\hline $\begin{array}{l}14: 0 \\
16: 0 \\
16: 1(n-7) \\
18: 0 \\
18: 1(n-9) \\
18: 2(n-6) \\
20: 1(n-9) \\
20: 4(n-6) \\
20: 5(n-3) \\
22: 0 \\
22: 1(n-9) \\
22: 4+22: 5(n-6) \\
22: 5+22: 6(n-3) \\
24: 0 \\
24: 1\end{array}$ & $\begin{array}{c}28 \\
16 \\
4 \\
7 \\
21 \\
0.5 \\
3 \\
4 \\
1 \\
2\end{array}$ & $\begin{array}{r}1 \\
29 \\
2 \\
13 \\
9 \\
5 \\
2 \\
9 \\
10 \\
1 \\
2 \\
2 \\
1 \\
6\end{array}$ & $\begin{array}{r}1 \\
27 \\
1 \\
36 \\
3 \\
7 \\
12 \\
0.4\end{array}$ & $\begin{array}{r}1 \\
28 \\
2 \\
28 \\
15 \\
7 \\
3 \\
5 \\
3\end{array}$ \\
\hline Rest & 13.5 & 8 & 4.6 & 2 \\
\hline
\end{tabular}


platelets and vascular tissue of cod-liver oil fed rats. These results were obtained by gas-liquid chromatography (GLC) of plateletand vessel-wall phospholipids. The experimental procedure for platelets is described in detail in Chapter 10, section 2.4. GLC of vascular phospholipids was performed after homogenization of aortas and lipid extraction with chloroform/methanol $(2 / 1, v / v)$. Total phospholipids were isolated by thin-layer chromatography, methylated ( $5 \%$ methanolic $\mathrm{HCl}, 3 \mathrm{~h}$, $65^{\circ} \mathrm{C}$ ) and their fatty acid spectra analyzed, using $5 \%$ polyethylene glycoladipate and $2 \%$ Apiezon columns at $185^{\circ} \mathrm{C}$ and $200^{\circ} \mathrm{C}$ respectively.

Since the formation of prostaglandin-like substances is expected to be a function of the precursor fatty acid content of phospholipids $(25,26$, cf. Chapter 10), a lower production of PG's of the 2-series may indeed be expected. Although $\mathrm{TA}$ is a poor substrate for cyclo-oxygenase $(11,13$, 27 ), the presence of considerable amounts of TA in platelets and vascular tissue of ClO-fed animals provides a potential for the generation of $P G$ 's of the 3-series. In connection herewith, we investigated the conversion of exogenous $A A$ and TA by platelet cyclo-oxygenase $(C O)$ and Tipoxygenase (LPO) and the production of $\mathrm{PGI}_{2}$ and $\mathrm{PGI}_{3}$ from endogenous precursors by the vessel wall.

\subsubsection{Methodology}

Unfortunately, the techniques used so far could not discriminate between products of the 2- and 3-series. Consequently, the contribution of the 3-series to the eicosanoids produced by activated platelets and vascular tissue upon fish-oil feeding, could not be determined. Therefore, in this experiment, we used more specific physico-chemical methods for measuring the production of the following compounds:

HHT: $(5 Z, 8 E, 10 E)$ 12-L-hydroxyheptadecatrienoic acid, HHTE: (5Z, 8E, 10E, 14Z) 12-L-hydroxyheptadecatetraenoic acid, HETE: $(5 Z, 8 Z, 10 E, 14 Z)$ 12-L-hydroxyeicosatetraenoic acid and HEPE: $(5 Z, 8 Z, 10 E, 14 Z, 17 Z)$ 12-L-hydroxyeicosapentaenoic acid. HHT and HHTE are stable cyclo-oxygenase products of AA and TA respectively, and considered to reflect $T \times A_{2}$ and $T \times A_{3}$ formation. HETE and HEPE are the lipoxygenase products of $A A$ and $T A$ respectively.

As described in detail in Chapter 10, the hydroxy acids are extracted 
from the reaction mixture with diethyl ether and determined as their silylated methyl esters by gas chromatography and mass spectrometry. In this way, the sum of HHT + HHTE and that of HETE + HEPE are determined. The HHT:HHTE and HETE:HEPE ratios were obtained by high performance liquid chromatography (HPLC) of their methyl esters on a LiChrosorb $7 \mathrm{RP} 18$ (reversed phase) column, using acetonitrile/water (70/30 v/v) and UV absorption at $232 \mathrm{~nm}$ for detection. The four hydroxy acids are fully separated under these conditions.

$\mathrm{PGI}_{2}$ and $\mathrm{PGI}_{3}$ produced from endogenous precursors by the vessel wall, were measured as their stable metabolites 6-keto-PGF $1 \alpha$ and $\Delta_{17}-6$-keto-PGF $1 \alpha$ respectively. Twelve pieces of tissue, punched from an aorta (diameter $3 \mathrm{~mm}$, dry weight approx. $100 \mu \mathrm{g}$ ) were incubated in $1 \mathrm{ml}$ phosphate-buffered saline $(\mathrm{pH} 7.4)$ for 10 min at room temperature in a shaking vial. After adding $50 \mathrm{ng}(\omega)$-homo-6-keto-PGF ${ }_{1 \alpha}$ (see ref.28) as internal standard, the mixture was acidified with citric acid $\left(0.2 \mathrm{~mol}^{-1} \mathrm{1}^{-1}\right)$ until $\mathrm{pH}$ 3-4 and the prostaglandins were extracted twice with $2 \mathrm{ml}$ ethyl acetate. Because the derivatives of 6 -keto-PGF $1 \alpha$ and $\Delta_{17^{-6-k e t o-P G F}}$ (the stable $_{1 \alpha}$ metabolites of $\mathrm{PGI}_{2}$ and $P \mathrm{PI}_{3}$ respectively) do not separate during the gas-chromatographic procedure, prepurification by argentation TLC was carried out, using the organic phase of isooctane/ethylacetate/acetic acid/water $(30 / 130 / 20 / 100, v / v / v / v)$. The zones were scraped off, eluted with methanol and the compounds were then derivatized into the pentafluorobenzoxime methyl esters (29). A second TLC step, using chloroform/methanol $90 / 6, v / v)$, was performed and the products were analyzed, after silylation, by gas chromatography with electron capture detection. Columns: $0.2 \times 180 \mathrm{~cm}$, $2 \%$ SE30 on Chromosorb WAW, $240^{\circ} \mathrm{C}, \mathrm{N}_{2} 23 \mathrm{ml} \cdot$ min $^{-1}$ and $0.25 \mathrm{~mm} \times 25 \mathrm{~m} \mathrm{SE30}$, film thickness $0.37 \mu \mathrm{m}, 240^{\circ} \mathrm{C}, \mathrm{N}_{2} 2 \mathrm{ml} \cdot \mathrm{min}^{-1}$. Chemically prepared $\Delta_{17^{-6-k e t o-P G F}} 1 \alpha$ was used to check the procedure.

\subsubsection{Conversion of arachidonic__AAL_and_timnodonic_(TA)_acid_by platelelet_cyclo-oxygenase_and_lipoxygenase}

\subsubsection{Conversion of exogenous fatty acids by platelets.}

Suspensions of rat platelets were prepared as described in Chapter 8 , section 3 . In order to measure $A A$ and $T A$ conversions, $0,2,5$, and 10 
$\mu \mathrm{g}$ of fatty acids was incubated for 5 min at $37^{\circ} \mathrm{C}$ in a stirred cuvette, containing $1 \mathrm{ml}$ phosphate-buffered saline $(\mathrm{pH} 7.4), 1,5.10^{9}$ platelets of stock ánimals and EDTA $\left(7.10^{-3} \mathrm{~mol}: 1^{-1}\right)$ to prevent platelet aggregation and conversion of endogenous fatty acids. The results, given in Fig.9.9, show that in contrast to $A A$, which is readily converted to HHT by platelet CO, TA hardly forms any $\mathrm{TXA}_{3}$ as may be concluded from the extremely small amount of HHTE measured. This confirms earlier observations that $T A$ is a poor substrate for the Co enzyme system $(11,13,27)$ : TA appeared to have been converted quite well by platelet LPO (see also ref. 30$)$.

9.7.2.2. Conversion of endogenous $A A$ and $T A$ in activated platelets.

Rats were fed diets containing 50 en\% So or 45 en\% CLO +5 en\% So. After 10 weeks, blood was collected and PRP prepared as described before

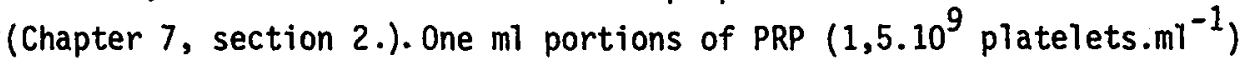
were stirred in an aggregometer at $37^{\circ} \mathrm{C}$. The platelets were activated by adding 50,100, or $200 \mu 1$ of a collagen suspension in saline, containing $160 \mu \mathrm{g}$ protein. $\mathrm{ml}^{-1}$. The reaction was stopped after. $5 \mathrm{~min}$ by transferring the mixture into $2 \mathrm{ml}$ ethanol. The hydroxy acids were analyzed as described in section 9.7.1. Results are shown in Fig.9.10. As compared

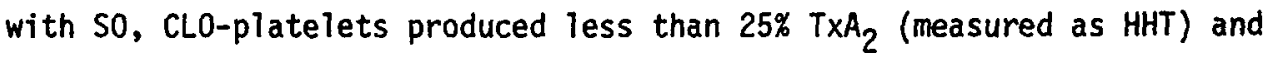
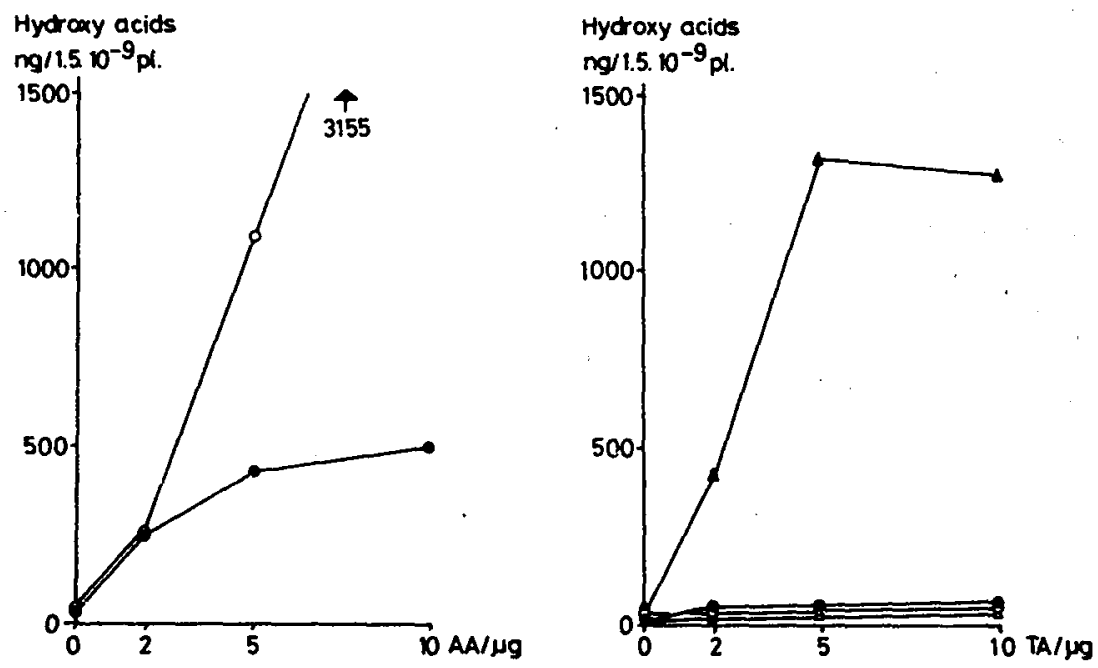

Fig.9.9. Conversion of added araçhidonic acid (AA) and timnodonic acid (TA) into hydroxy acids by rat platelet suspensions.

○ HETE ; - HHT ; $\triangle$ HHTE ; $\triangle$ HEPE.(For explanation see section 7.2.1.). 
(A)

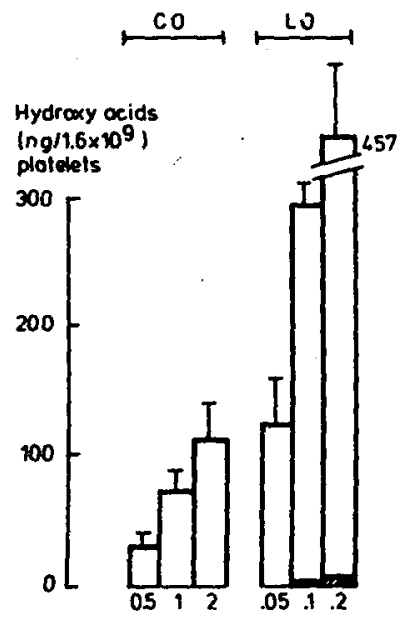

(B)
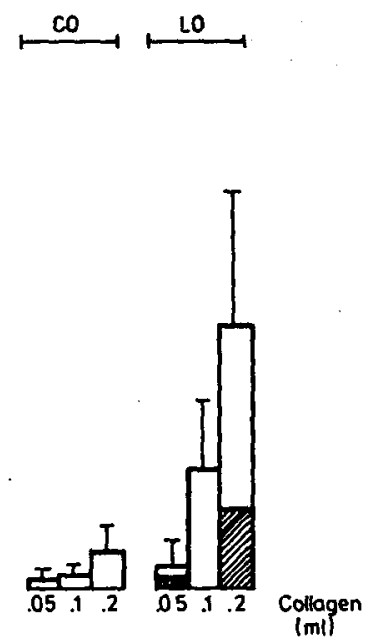

Fig.9.10. Hydroxy acids formed from endogenously liberated arachidonic acid (AA, open columns) and timnodonic acid (TA, hatched columns) by collagen-activated platelets of rats fed diets containing either $50 \mathrm{en} \%$ sunflowerseed oil (SO, A) or $45 \mathrm{en} \%$ cod-liver oil +5 en\% SO(B). Mean \pm s.d. CO: cyclo-oxygenase products: HHT and HHTE; LO: lipoxygenase products HETE and HEPE. Ratios between AA- and TA-derived products determined in separate experiments.

Significance levels of differences between $A$ and $B$ for total hydroxy acid production (Wilcoxon's two-sample test): 0.05 and $0.10 \mathrm{ml}$ collagen: $0.05<P_{2}<0.10(n=3) ; 0.20 \mathrm{ml}$ collagen : $P_{2}<0.001(n=7)$.

less than $50 \%$ of the LPO-product (measured as HETE). No significant amounts of $\mathrm{TXA}_{3}$ (measured as HHTE) were detected. The production of HEPE, on the other hand, appeared to be quite substantial. These findings confirm the conclusion from the MDA data (Figs. 9.6. and 9.8.) that fish oilffeeding coincides with a lower thromboxane formation by blood platelets upon their activation. They also demonstrate that TA liberated from phospholipids upon platelet triggering enters the LPO-pathway but hardly. serves as a substrate for platelet $c 0$.

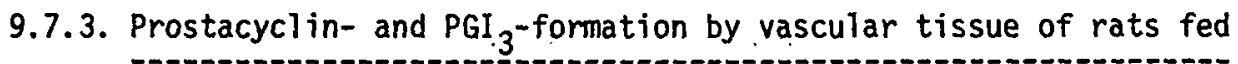
a_cod-Iiver_oil_containning_diet 
that vascular tissue of fish-oil fed rats would be unable to produce $\mathrm{PGI}_{3}$. However, vessel wall $\mathrm{CO}$ may be different from platelet $\mathrm{C} 0$, as is shown by its different sensitivity towards aspirin $(31,32)$. It cannot, therefore, be ruled out that in vascular tissue, TA is converted efficiently into $\mathrm{PGH}_{3}$ and subsequently into $\mathrm{PGI}_{3}$. To find this out, we measured the production of 6-keto-PGF ${ }_{1 \alpha}$ (stable $\mathrm{PGI}_{2}$ metabolite) and $\Delta_{17^{-6-k e t o-P G F}}$ (stable $\mathrm{PGI}_{3}$ metabolite) by vascular tissue of S0 (50 en\%) and CLO (45 en\% + 5 en\% SO)-fed rats upon incubation in phosphate-buffered saline as described in section 9.7.1. According to Table 9.6, $\mathrm{PGI}_{2}$ production by tissue of $\mathrm{CLO}$-fed rats is about $50 \%$ lower than that by tissue of rats fed the SO-diet which is in very close agreement with the bio-assay results (Fig.9.6.). No significant formation of $\mathrm{PGI}_{3}$ could be detected.

\subsubsection{Effeect of fish_oil feeding to EFA-deficient_animals on the}

\section{formation of plateletet-_and vascular_ar_prostaglandins}

As is evident from Table 9.5, animals fed a CLO-containing diet, although relatively EFA-deficient, still have appreciable amounts of arachidonic acid (AA, 20:4 (n-6)) in their platelet- and vessel wall phospholipids. Upon phospholipase activation, except for timnodonic acid (TA, 20:5 (n-3)), $A A$ will therefore be released as well. Both fatty acids, $A A$ and $T A$, compete for the cyclo-oxygenase enzyme system $(C O)$. Since $A A$ is a much better $C O$ substrate than TA $(11,13,27)$, TA is expected to be converted to a much lesser extent than $A A$, even if the latter fatty acid has been partly replaced by the former. This, in fact, is what we found in the

Table 9.6. Production of $\mathrm{PGI}_{2}$ and $\mathrm{PGI}_{3}$ (measured as 6-keto-PGF $1 \alpha$ and $\Delta_{17^{-6-k e t o-P G F}}$ respectively) by vascular tissue of rats fed diets containing 50 en\% sunflowerseed oil (SO) or 45 en\% cod-liver oil (CLO) +5 en\% SO. Mean \pm SEM; $n=6$.

\begin{tabular}{lll}
\hline \multirow{2}{*}{ Diet } & \multicolumn{2}{c}{ ng. per piece of aorta } \\
\cline { 2 - 3 } & 6-keto-PGF & $\Delta_{1 \alpha}{ }^{-6-\text { keto-PGF }_{1 \alpha}}$ \\
\hline S0 & $5.9 \pm 0.86$ & $<0.2$ \\
CLO & $2.9 \pm 0.82$ I & $<0.2$ \\
\hline
\end{tabular}

I $P_{2}<0.05$, Wilcoxon's 'two-sample test. 
previous section.

In order to investigate the potency for 3-series prostaglandins to be formed from endogenous precursors, we decided to feed a fish oil diet to essential fatty acid (EFA) deficient rats. In the tissue of these animals, $A A$ is largely replaced by mead acid (MA, 20:3(n-9), see Chapter 2, section 2.). Since $T A$ inhibits the $\Delta_{6}$-desaturase (Chapter 2, section 2.2.), MA might be expected to become replaced by dietary TA. In this light, fish-oil feeding of EFA-deficient animals is expected to result in a considerable increase in the TA/AA ratio in membrane phospholipids, thus providing greatly improved conditions for the formation of $\mathrm{TXA}_{3}$ and $\mathrm{PGI}_{3}$.

A group of newly weaned male Wistar rats were made EFA-deficient by feeding them a diet containing 5 en\% hydrogenated coconut oil ( $\mathrm{HCO}$ ), which lacks essential fatty acids (Table 6.2.). After 3 months, the animals were randomly divided into 3 groups: one group remained on the low-fat, EFA-deficient diet, one group received this diet enriched with $45 \mathrm{en} \% \mathrm{HCO}$ (at the expense of carbohydrates) and one group was offered the EFA-deficient diet enriched with $45 \mathrm{en} \%$ of a fish oil of unknown origin (FO), pretreated to remove the cholesterol. After 4 weeks' feeding, determination of transepidermal water loss ( a modernized and more specific version of the technique to measure water vapour loss via the skin'(24)) revealed that the permeability of the skin had completely normalized in the Fo group (Table 9.7.). Another 4 weeks later, platelet

Table 9.7. Effect of dietary fish oil (FO) and hydrogenated coconut oil (HCO) on the transepidermal water loss $\left(\mu 1 \mathrm{H}_{2} 0 . \mathrm{cm}^{-2}\right.$ body surface. $\mathrm{h}^{-1}$ ) of EFA-deficient rats.

From weaning on, animals were fed a diet containing 5 en\% HCO (EFA-deficient control group). After 12 weeks, the diet in two groups was enriched with $45 \mathrm{en} \%$ of $\mathrm{HCO}$ or FO at the expense of carbohydrate. Four weeks later, the measurements were performed (24). Mean \pm SEM, $n=24$.

\begin{tabular}{ll}
\hline Group & Water loss \\
\hline EFA-deficient & $2.85 \pm 0.140$ \\
do. +45 en\% HCO & $2.76 \pm 0.115$ \\
do. +45 en\% FO & $0.40 \pm 0.033$ \\
Normal I & $0.35 \pm 0.015$ \\
\hline
\end{tabular}

I Animals fed a commercial stock diet in a different experiment ; $n=120$ 
MDA-formation and vascular PGI-production were measured according to earlier described methods. Compared with the EFA-deficient control group, HCO enrichment of the diet did not affect platelet MDA-formation (Fig. 9.11.A). From the fatty acid composition of platelet total lipids and vascular phospholipids (Table 9.8.) it can be concluded that the EFA-deficiency status (indicated by the MA/AA ratio (46)) did not change upon dietary enrichment with $\mathrm{HCO}$. The FO-diet caused a significant enhancement of platelet MDA-formation, indicating that $P G^{\prime} S$ of the 3-series might have been formed. However, the platelet and vascular fatty acid compositions (Table 9.8.) show that F0-feeding also caused a considerable increase in $A A$, resulting in only a slight enhancement of the TA/MA ratio in relation to normal Fo-fed animals (Table 9.5.). Therefore, it is highly likely that the higher MDA-production observed on F0-feeding of EFA-deficient animals reflects an enhanced formation of 2-series PG's only.

F0-feeding to EFA-deficient rats also causes the vascular production of $\mathrm{PGI}_{2}$-like material to increase significantly (Fig.9.11.B). Since this coincides with a doubling of the AA-content of the vascular phospholipids (Table 9.8.) this is, most probably; not caused by any $\mathrm{PGI}_{3}$-formation. Surprisingly, HCO-enrichment of the diet - providing no additional essential fatty acids neither of the $(n-6)$ nor of the $(n-3)$ family and causing
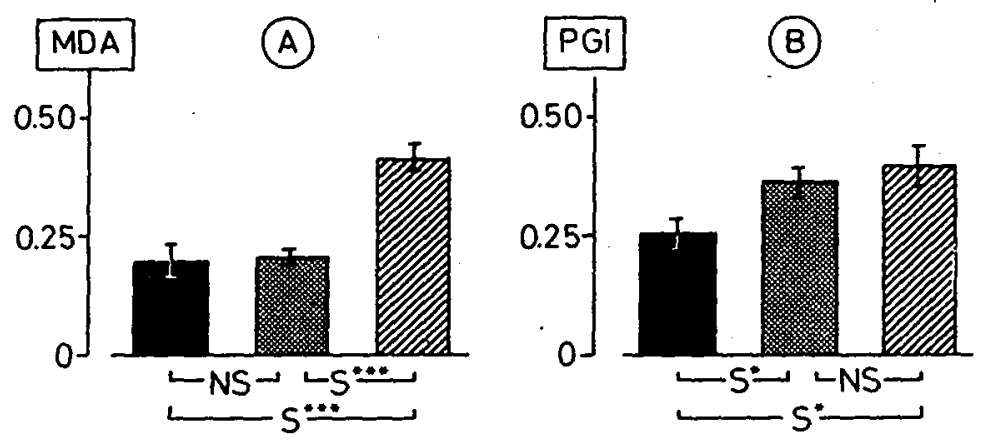

Fig.9.11. Effect of additional hydrogenated coconut oil (HCO) and fish oil (FO) on the formation of MDA (nmol. $10^{-9}$ platelets) by collagen-activated platelets and the production of $\mathrm{PGI}_{2}$-like material (ng. aortic piece ${ }^{-1} \cdot \min ^{-1}$ ) by vascular tissue of animals fed an EFA-deficient diet. (Mean \pm SEM; $n=12$ ).

5 en\% HCO for 20 weeks (EFA-deficient control group).

5 en\% HCO for 12 weeks and. 50 en\% HCO for 8 weeks.

YII 5 en\% HCO for 12 weeks and 45 en\% FO +5 en\% HCO for 8 weeks. NS: $P_{2}>0.10 ; S^{\bullet}: 0.01<P_{2}<0.05 ; S^{\bullet \bullet \bullet} P_{2}<0.001$. 
Table 9.8. Fatty acid composition (\%) of platelet total lipids and aortic phospholipids. Only fractions $\geq 1 \%$ are mentioned.

EFA-def.: 20 weeks on a diet containing 5 en\% hydrogenated coconut oil (HCO). HCO : 12 weeks on the EFA-def. diet, followed by 8 weeks on a diet containing 50 en\% $\mathrm{HCO}$.

F0 : 12 weeks on the EFA-def. diet, followed by 8 weeks on a diet containing 45 en\% FO +5 en\% HCO.

\begin{tabular}{|c|c|c|c|c|c|c|}
\hline \multirow{2}{*}{ Fatty acids } & \multicolumn{3}{|c|}{ Platelet total lipids } & \multicolumn{3}{|c|}{ Aorta phospholipids } \\
\hline & EFA-def. $H$ & $\mathrm{HCO}$ & F0 & EFA-def. & tiCO & Fo \\
\hline $\begin{array}{l}12: 0 \\
14: 0 \\
16: 0 \\
16: 1(n-7) \\
18: 0 \\
18: 1(n-9) \\
18: 2(n-6) \\
18: 3(n-3)+20: 0 \\
20: 1(n-9) \\
20: 3(n-9) \\
20: 3(n-6) \\
20: 4(n-6) \\
20: 5(n-3) \\
22: 3(n-9) I \\
24: 0+22: 4(n-6) \\
22: 5(n-6) \\
22: 5(n-3) \\
22: 6(n-3)\end{array}$ & $\begin{array}{r}2 \\
1 \\
24 \\
4 \\
13 \\
17 \\
1 \\
1 \\
1 \\
19 \\
4 \\
4 \\
\end{array}$ & $\begin{array}{r}2 \\
19 \\
2 \\
16 \\
15 \\
1 \\
1 \\
2 \\
24 \\
\\
5 \\
\end{array}$ & $\begin{array}{r}2 \\
27 \\
3 \\
14 \\
9 \\
2 \\
1 \\
1\end{array}$ & $\begin{array}{r}15 \\
6 \\
4 \\
1 \\
2 \\
1\end{array}$ & $\begin{array}{r}1 \\
2 \\
15 \\
2 \\
20 \\
18 \\
1\end{array}$ & $\begin{array}{r}1 \\
1 \\
11 \\
5 \\
1 \\
1 \\
3 \\
7\end{array}$ \\
\hline Rest & 8 & 8 & 8 & 7 & 10 & 8 \\
\hline
\end{tabular}

I Tentative identification.

almost no differences in the fatty acid composition of vascular phospholipids - yielded essentially similar results. Therefore, the considerable increase in the vascular formation of $\mathrm{PGI}_{2}-1$ ike material in this latter group is most likely due to some non-specific fat effect, which requires further investigation.

Although FO contains some linoleic acid (Table 9.1.), it is rather surprising that this fatty acid is desaturated (and elongated) so efficiently despite the presence of fairly high amounts of $T A$ and $22: 6(n-3)$. These latter fatty acids have been reported to be strong inhibitors of the $\Delta_{6}$-desaturase, the key-enzyme in the conversion of linoleic acid into arachidonic acid (47). For this reason, it seems likely that under EFA -deficiency conditions, the 'rules for desaturation' (Chapter 2, section 


\section{2) are different from normal.}

Although not conclusive, this experiment strongly suggests that even under conditions favourable for the formation of 3-series PG's, TXA 3 and $\mathrm{PGI}_{3}$ are not formed in measurable amounts. As a result, any contribution of these substances in regard to the regulation of arterial thrombogenesis is unlikely.

\subsection{General discussion}

Cod-liver oil (CLO) fed to rats, has a distinct antithrombotic effect. Another fish oil (FO) containing twice as much long-chain saturated fatty acids, equal amounts of TA: but half as much $22: 6(n-3)$, does not affect arterial thrombosis tendency significantly. Earlier experiments with whale oil, the composition of which is comperable to that of F0, also revealed no antithrombotic effect, although platelet aggregation in circulating blood was greatly reduced (Chapters 6 and 7). This indicates that in arterial thrombogenesis, apart from platelet aggregation other processes play an important regulatory role as well. Moreover, it again points to the prothrombotic effect of saturated fatty acids.

Dietary CLO and FO did behave qualitatively similar as to their effects on platelet aggregation in vitro induced by collagen and thrombin (ADP -induced aggregation was not significantly affected) although the effect of the CLO diet was somewhat more pronounced. The decreased collagen-induced aggregation is most probably the result of the lower platelet arachidonic acid content and, consequently, of the lower $\mathrm{TXA}_{2}$-formation (vide inj The enhanced response upon stimulation with thrombin is not clear. Platelet prostaglandins and thromboxanes are most probably not involved considering the fact that thrombin-induced aggregation appeared highly independent of this pathway (Chapter 8, section 2.4.). Thrombin-induced aggregation, however, has been reported to be inhibited by a phospholipase $A_{2}$ inhibitor, suggesting that some lipid-derived product might be involved nevertheless (33). Recently, it has been demonstrated (34) that activated blood platelets release a highly active aggregating agent with characteristics similar to those of PAF (platelet-activating factor). PAF is a chemical mediator released from antigen-stimulated IgE-sensitized basophils $(35,36)$ and from antigen-challenged blood, obtained from IgE-sensitized rabbits (37). PAF is very similar, if not the same, as 
1-0-alkyl-2-acetyl-on-glyceryl-3-phosphorylcholine (38) and is a very active platelet-aggregating agent $(37,39,40)$ acting independently of the release reaction and the arachidonate pathway (41). Therefore, it is of interest to investigate the relation between the dietary fat type and the PAF-pathway of aggregation in more detail, especially so because membrane-active drugs modulate PAF-induced aggregation (41) and dietary lipids are likely to modify membrane properties also (Chapter 2, section 8.1.).

As compared with a low-fat control diet, both CLO and FO diets inhibit intrinsic clotting and do not affect the extrinsic coagulation pathway. For fish-eating Eskimos, APTT's and PT's were reported to be normal (1). However, when we measured both parameters in a volunteer who had been on an Eskimo-type diet for about 6 months, a somewhat reduced intrinsic and extrinsic clotting was observed (clotting index 16 and $7 \%$ lower than that of a normal standard plasma). A marine diet is, therefore, likely to lower blood coagulability.

In CLO-fed rats, vessel-wall induced clotting is significantly depressed as compared to that of animals, fed a sunflowerseed oil-containing diet. This appeared to be due to a plasma condition so that this might be caused by the significantly lower intrinsic and extrinsic coagulabilities found in fish oil-fed animals compared with SO-fed rats.

Although the findings in regard to coagulation are about the same for CLO- and FO-fed rats, vessel-wall induced clotting is significantly different, Fo-feeding. showing no decrease vs. So-feeding. This discrepancy needs further investigation, which also holds for the cause(s) of the dietary fat-induced clotting changes.

Bleeding time is prolonged on fish-oil feeding, which may be due to the lower platelet aggregability in response to collagen. However, in EFA -deficient rats, also the platelet collagen reaction is diminished (Chapter 8, section 2.2.3.) whereas bleeding times in these animals were found to be normal. This strongly indicates that bleeding time may be determined by still another factor than platelet aggregability. It is tempting to speculate that vessel-wall induced clotting plays a role here: in EFA-deficiency it is enhanced (Chapter 8, section 2.3), thereby possibly counteracting the effect of the lower collagen-induced aggregation, especially so because the thrombin sensitivity of platelets is strikingly increased. Upon CLO-feeding, vessel-wall induced clotting is reduced, 
whereby the effect of the diminished collagen-induced aggregation is possibly potentiated. In FO-fed rats, vessel wall-induced clotting is not different from that in animals after so-feeding but the activity of the intrinsic clotting system is definitely depressed. It is striking to see that bleeding times in Fo-fed rats take an intermediate position between those after CLO- and SO-feeding (Table 9.3.). In view of this, it is very likely that the bleeding time is not only determined by the platelet/. collagen interaction, but also by (vessel-wall induced)thrombin formation.

Platelet $\mathrm{TXA}_{2}$ - and vascular $\mathrm{PGI}_{2}$-formation is considerably depressed upon fish oil feeding. The lower $\mathrm{TXA}_{2}$ formation has recently been confirmed in a human study (48) and - as in rats - it was associated with a lower platelet arachidonic acid content. Phospholipids of platelets $(1,48)$ as well as vascular tissue (Tables 9.5. and 9.8.) contain considerable amounts of timnodonic acid $(T A, 20: 5(n-3))$. Nonetheless, $\mathrm{TxA}_{3}$ and $\mathrm{PGI}_{3}$ are not formed from endogenous precursors in detectable amounts. Although the production of these compounds under extreme conditions of AA-deficiency cannot be excluded completely, a thromboregulatory role for 3-series PG's - as suggested by Dyerberg et a7. (16) - must be doubted. The lower AA-content of the platelet phospholipids observed after fishoil feeding is most probably the main reason for the lower $T \times A_{2}$-formation by these platelets upon their activation. Moreover, the competition between TA and AA for cyclo-oxygenase ( $C O$ ) may play a role here (cf. Chapter 10). Although TA is a poor substrate for $\mathrm{CO}$, it very actively blocks the active site of the enzyme leading to an inhibiting effect on AA-conversion $(42,43)$.

TA, added to a suspension of blood platelets, inhibits platelet aggregation $(14,44,45)$. This might be due to the aforementioned interference of TA with AA peroxidation by $\mathrm{CO}(13,43)$ or to the fact that TA might block platelet receptors for endoperoxides and thromboxanes (14). The physiological relevance of these experiments is, however, rather doubtful, because in vivo, TA is mainly present as albumin-bound acid, which is likely to behave quite differently from the sodium salt used in in vitro studies (57).

The resuits presented allow of the conclusion that the antithrombotic effect of CLO results from a combination of at least two processes. Due to their low AA content, platelets of CLO-fed animals cannot produce a sufficient amount of thromboxanes to maintain the platelet aggregation 
reaction after the initial stimulus has disappeared. As a result of thi.s low arjuregation tendency of the platelets, the reduced production of vascular $\mathrm{PGI}_{2}-1$ ike material has no consequences for the thrombosis tendency. In connection with the lower degree of vessel wall-induced clotting, formation of thrombin at the site of thrombosis will be reduced and, although the thrombin-sensitivity of CLO-platelets is enhanced, this may result in a lower contribution of clotting to thrombus formation and thrombus reinforcement by fibrin (see Chapter 3).

Because of their antithrombotic effect, some fish oils could be important in dietary thrombosis prevention. However, the rapid autoxidation of the highly unsaturated oils constitutes a serious problem because of the general toxicity of peroxides (49), and also because lipid peroxides inhibit prostacyclin synthase (50), which may have prothrombotic consequences and may promote atherogenesis (58). Moreover, the rapid development of rancidity will be a great drawback as to the applicability of fish oils as important dietary constituents. Finally, the potentialiy harmful effects of marine-type diets should not be overlooked, especially as far as cardiac necrosis and decreased stress tolerance are concerned (51-53). In addition, a large intake of long-chain polyenoic fatty acids of the (n-3) family is held responsible for yellow-fat disease, a generalized disorder of fatty depots observed in a wide variety of animals (54-56). Therefore, care should be taken when carrying out experiments in which human beings are given large amounts of fish oil-type fatty acids in their diets.

Dose-response studies showed that 5 en\% Fo had already a significant lowering effect on platelet MDA-formation. Such a low dose is unlikely to cause any pathological effects. Sunflowerseed oil-enriched diets caused a low arterial thrombosis tendency although platelet $\mathrm{TxA}_{2}$-formation remained norma1. It seems worthwhile investigating whether a further lowering of arterial thrombosis tendency can be obtained if, in these animals, the potency of platelets to produce $\mathrm{TXA}_{2}$ is reduced by adding some FO to the high-sunflowerseed oil diet.

\subsection{Summary}

Cod-1iver oil (CLO) fed to rats, has an antithrombotic effect which is at least as pronounced as that of sunflowerseed oil. Whale oil does not 
change arterial thrombosis tendency significantly, whereas a fish oil of unknown origin (FO) does so to some extent. The effects of FO and CLO on platelet function and plasma clotting are almost similar. Vessel-wall induced clotting, however, is depressed in CLO but normal in FO, which might be one of the reasons why $F O$ is less antithrombotic. Fish-oil feeding leads to partial replacement of platelet- and vesselwall arachidonic acid $(20: 4(n-6))$ by timnodonic acid $(20: 5(n-3))$, so that platelets produce less $T_{X A_{2}}$ upon their activation. $T \times A_{3}$ is not formed in measurable amounts. Vascular $\mathrm{PGI}_{2}$-formation is also reduced, which is not compensated for by the formation of $\mathrm{PGI}_{3}$. Our conclusion is that the antithrombotic effect of cod-liver oil is caused by a lower $\mathrm{TXA}_{2}$ formation by activated platelets, combined with a reduced vessel-wall induced clotting.

A large intake of long-chain polyunsaturated fatty acids of the (n-3) family has been reported to have rather severe pathological consequences but the fish oil effect on platelet $\mathrm{TXA}_{2}$-formation becomes already noticeable when given in relatively small doses. Such a dietary treatment could add to the antithrombotic effect of oils rich in iinoleic acid, the latter oils not being associated with a change in platelet TXA-formation.

\subsection{References}

1. Dyerberg,J. and Bang,H.O.: Heamostatic function and platelet polyunsaturated fatty acids in Eskimos. Lancet ii : 433-435 (1979).

2. Annual report from the Chief Medical Officer in Greenland 1963-1967, Cited in : Bang,H.O. and Dyerberg,J.: Plasma lipids and lipoproteins in Greenlandic West coast Eskimos. Acta Med.Scand. 192: 85-94 (1972).

3. Bang,H.O., Dyerberg,J. and Nielsen,A.: Plasma lipids and lipoprotein pattern in Greenlandic West-coast Eskimos. Lancet i: 1143-1146 (1971).

4. Dyerberg,J., Bang,H.O. and Hjørne,N.: Plasma cholesterol concentration in Caucasian Danes and Greenland West-coast Eskimos. Dan.med.Bul1. 24: 52-55 (1977).

5. Dyerberg,J., Bang,H.O. and Hjфrne,N.: Fatty acid composition of the plasma lipids in Greenland Eskimos. Am.J.Clin.Nutr. 28: 958-966 (1975).

6. Bang,H.O., Dyerberg,J. and Hiørne,N.: The composition of food consumed by Greenland Eskimos. Acta Med.Scand, 200: 69-73 (1976).

7. Bang,H.O., Dyerberg,J. and Sinclair, H.M.: An examination of food consumed by Greenland Eskimos. In press. 
8. Andreoli,V.M., Maffei,F. and Tonon,G.C.: Platelet lipid modification induced by fatty acids : experimental studies and correlations with human neuropathology. Haemostasis 2 : 118-140 (1973/1974).

9. Renaud,S., Kuba,K., Goulet,C., Lemire,Y. and Allard,C.: Relationship between fatty acid composition of platelets and platelet aggregation in rat and man. Circ. Res. 26 : 553-564 (1970).

10. Nord $\phi y, A$. and Rødset,J.M.: The influence of dietary fats on platelets in man. Acta Med.Scand. 190: 27-34 (1971).

11. Struyck,C.B., Beerthuis,R.K., Pabon,H.J.J. and van Dorp,D.A.: Specificity of the enzymic conversion of polyunsaturated fatty acids into prostaglandins. Recl. Trav.Chim. Pays Bas 85: 1233-1250 (1966).

12. Needleman,P., Minkes,M. and Raz,A.: Thromboxanes : selective biosynthesis and distinct biological properties. Science 193: 163-165 (1976).

13. Needleman,P., Raz,A., Minkes,M.S., Ferrendelli,J.A. and Sprecher,H.: Triene prostaglandins : prostacyclin and thromboxane biosynthesis and unique biological properties. Proc.Nat1.Acad.Sci.USA 76: 944-948 (1979).

14. Gryglewski,R.J., Salmon,J.A., Ubatuba,F.B., Weatherly,B.C., Moncada,S. and Vane,J.R.: Effects of al1-cis- 5,8,11,14,17 - eicosapentaenoic acid and $\mathrm{PGH}_{3}$ on platelet aggregation. Prostaglandins 18: 453-478 (1979).

15. Nidy,E.G. and Johnson,R.A.: Synthesis of prostaglandin PGI ${ }_{3}$. Tetrahedron Lett. 27: 2375-2378 (1978).

16. Dyerberg,J., Bang,H.O., Stoffersen,E., Moncada,S. and Vane,J.R.: Eicosapentaenoic acid and prevention of thrombosis and atherosclerosis ? Lancet ii: 117-119 (1978).

17. Crawford,M.A., Casperd,N.M. and Sinclair,A.J.: The long chain metabolites of linoleic and linolenic acids in liver and brain in herbivores and carnivores. Comp. Biochem. Physio1. 54B: 395-401 (1976).

18. Shattil,S.J., Anaya-Galindo,R., Bennet,J., Colman,R.W. and Cooper,R.A.: Platelet hypersensitivity induced by cholesterol incorporation. J.Clin. Invest. 55: 636-643 (1975).

19. Shattil,S.J., Bennet,J.S., Colman,R.W. and Cooper,R.A.: Abnormalities of cholesterol-phospholipid composition in platelets and low-density lipoproteins of human hyperbetal ipoproteinemia. J.Lab.Cl in. Med.89: 341-353 (1977).

20. Stuart,M.J., Gerrard,J.M. and White,J.G.: Effect of cholesterol on production of thromboxane $B_{2}$ by platelets in vitro. New Engl.J.Med. 
302: 6-10 (1980).

21. Jager,F.J.: High linoleic acid intake and Vitamin $E$ requirement in rats. Nutr. et Dieta $11: 270-279$ (1969).

22. Isakson,P.C., Raz,A., Denny,S.E., Pure,E. and Needleman,P.: A novel prostaglandin is the major product of arachidonic acid metabolism in rabbit heart. Proc.Natl.Acad.Sci.USA 74: 101-105 (1977).

23. Needleman,P., Bronson,S.D., Wyche,A., Sivakoff,M. and Nicolaou,K.C.: Cardiac and renal prostaglandin $I_{2}$. Biosynthesis and biological effects in isolated perfused rabbit tissues. J.Clin. Invest. 61: 839 -849 (1978).

24. Van der Beek,A.: Trans Epidermal Water Loss, a useful criterion for the determination of the EFA-status in experimental animais. To be published.

25. Vonkeman,H. and van Dorp,D.A.: The action of prostaglandin synthetase on 2-arachidonyl-1ecithin. Biochim. Biophys. Acta 164: 430-432 (1968).

26. Lands,W.E.M. and Samuelsson,B.: Phospholipid precursors of prostaglandins. Biochim.Biophys. Acta 164: 426-429 (1968).

27. Smith,D.R., Weatherly,B.C., Salmon,J.A., Ubatuba,F.B., Gryglewski, R.J. and Moncada,S.: Preparation and biochemical properties of $\mathrm{PGH}_{3}$. Prostaglandins 18: 423-438 (1979).

28. Van Dorp,D.A., van Evert,W.C. and van der Wolf,L.: 20-Methyl prostacyclin. A powerful 'unnatural' platelet aggregation inhibitor. Prostaglandins 16: 953-955 (1978).

29. Fitzpatrick,F.A., Wijnalda,M.A. and Kaiser,D.G.: Oximes for high performance liquid and electron capture gas chromatography of prostaglandins and thromboxanes. Anal.Chem. 49: 1032-1035 (1977).

30. Nugteren,D.H.: Arachidonate Tipoxygenase in blood platelets. Biochim. Biophys. Acta 380: 299-307 (1975).

31. Burch,J.W., Baenziger,N.L., Stanford,N. and Majerus,P.W.: Sensitivity of fatty acid cyclo-oxygenase from human aorta to acetylation by aspirin. Proc.Natl.Acad.Sci. USA 75: 5181-5184 (1978).

32. Masotti,G., Poggesi,L., Galanti,G., Abbate,R. and Neri Serneri,G.G.: Differential inhibition of prostacyclin production and platelet aggregation by aspirin. Lancet ii: 1213-1216 (1979).

33. Vallee,E. and Delahayes,J.F.: Role of phospholipase $A_{2}$ in inflammation and aggregation. Interest of inhibitors. Eur.J.Rheum. Inflamm. 1: 300-304 (1978).

34. Chignard,M., Le Couedic,J.P., Tence,M., Vargaftig,B.B. and Benveniste, J.: The role of platelet-activating factor in platelet aggregation. 
Nature 279: 799-800 (1979).

35. Benveniste,J., Henson,P.M. and Cochrane,C.G.: Leucocyte-dependent histamine release from rabbit platelets. The role of IgE, basophils and a platelet-activating factor. J.Exp.Med. 136: 1356-1377 (1971).

36. Henson,P.M. and Pinckard,R.N.: Platelet-activating factor (PAF). A possible direct mediator of anaphylaxis in the rabbit and a trigger for the vascular deposition of circulating immune complexes. Monogr. Allergy 12 : 13-26 (1977).

37. Pinckard,R.N., Farr,R.S. and Hanahan,D.J.: Physicochemial and functional identity of rabbit platelet-activating factor (PAF) released in vivo during IgE anaphylaxis with PAF, released in vitro from IgE sensitized basophils. J.Immunol.123 : 1847-1857 (1979).

38. Demopoulos,C.A., Pinckard,R.N. and Hanahan,D.J.: Platelet-activating factor. Evidence for 1-0-alkyl-2-acetyl-sn-glyceryl-3-phosphoryl-choline as the active component ( a new class of lipid mediators). J.Bio1.Chem. 254: 9355-9358 (1979).

39. Benveniste,J., Le Couedic,J.P. and Kamoun,P.: Aggregation of human platelets by platelet-activating factor. Lancet $i$ : 344-345 (1975).

40. O'Donne11,M.C., Henson,P.M. and Fiedel,B.A.: Activation of human platelets by platelet-activating factor (PAF) derived from sensitized rabbit basophils. Immunology 35: 953-958 (1979).

41. Cazenave,J.P., Benveniste,J. and Mustard,J.F.: Aggregation of rabbit platelets by platelet-activating factor is independent of the release reaction and the arachidonate pathway and inhibited by membrane-active drugs. Lab. Invest. 41: 275-285 (1979).

42. Nugteren,D.H.: Inhibition of prostaglandin biosynthesis by 8-cice, 12-trans, 14-cis-eicosatrienoic acid and 5-cis, 8-cis, 12-trens, 14-cis-eicosatetraenoic acid. Biochim. Biophys. Acta 210; 171-176 (1970).

43. Lands,W.E.M., LeTellier,P.R., Rome,L.H. and VanderHoek, J.Y.: Inhibition of prostaglandin biosynthesis. Adv.Biosc. 9., 15-28 (1973).

44. Dyerberg,J. and Bang,H.O.: Dietary fat and thrombosis. Lancet $i$ : 152 (1978).

45. Jakubowski,J.A. and Ardlie,N.G.: Evidence for the mechanism by which eicosapentaenoic acid inhibits human platelet aggregation and secretion - implications for the prevention of vascular disease. Thromb. Res. 16: 205-217 (1979).

46. Holman,R.T.: The ratio of trienoic:tetraenoic acids in tissue lipids as a measure of essential fatty acid requirement. J.Nutr. 70: 405-409 
(1960).

47. Brenner,R.R. and Peluffo,R.0.: Regulation of unsaturated fatty acid biosynthesis 1. Effect of unsaturated fatty acids of 18 carbons on the microsomal desaturation of 1 inoleic acid into $\gamma$-linolenic acid. Biochim. Biophys. Acta 176: 471-479 (1969).

48. Siess,W., Scherer,B., Böhlig,B., Roth,P., Kurzmann, I. and Weber,P.C.: Platelet membrane fatty acids, platelet aggregation and thromboxane -formation during a mackerel diet. Lancet $i$ : 441-444 (1980).

49. Dormandy, T.L.: Free radical oxidation and anti-oxidants. Lancet $i$ : 647-650 (1978).

50. Gryglewski,R.J., Bunting,S., Moncada,S., Flower,R.J. and Vane,J.R.: Arterial walls are protected against deposition of platelet thrombi by a substance (prostaglandin $X$ ) which they make from prostaglandin endoperoxides. Prostaglandins 12: 685-713 (1976).

51. Gudbjarnason,S.: Prostaglandins and polyunsaturated fatty acids in heart muscle. J.Mol.Cell.Cardiol. 7: 443-449 (1975).

52. Gudbjarnason,S. and Hallgrimsson, J.: The role of myocardial membrane lipids in the development of cardiac necrosis. Acta Med.Scand.Suppl. 587 : 17-27 (1976).

53. Gudbjarnason,S.: Pathophysiology of long-chain polyenoic fatty acids in heart muscle. Nutr. Metabol.Supplement. In press.

54. Jones, D., Gresham,G.A., Lloyd,H.G. and Howard,A.N.: Yellow fat in the wild rabbit. Nature 207: 205-206 (1965).

55. Kreneman,J. and Wensvoort,P.: Muscular dystrophy and yellow fat disease in Shetland pony foals. Neth.J.Vet.Sci. 1: 42-48 (1968).

56. Danse,L.H.J.C., Stolwijk,J. and Verschuren,P.M.: Fish oil-induced yellow fat disease in rats. IV. Functional studies in the reticuloendothelial system. Vet.Pathol. 16: 593-603 (1979).

57. Chambaz,J., Robert,A., Wolf,C., Béréziat,G. and Polonovski,J.: Different acylation and accumulation in free form of arachidonic acid or its sodium salt in human platelets. Thromb. Res. 15: 743-753 (1979).

58. Dembinska-Kiec,A., Gryglewska,T., Zmuda,A. and Gryglewski,R.J.: The generation of prostacyclin by arteries and by the coronary vascular bed is reduced in experimental atherosclerosis in rabbit. Prostaglandins 14: 1025-1034 (1977). 


\section{EFFECT OF DIFFERENT DIETARY FATS ON PLATELET LIPID PROFILE AND}

\section{FATTY ACID COMPOSITION. CONSEQUENCES FOR PLATELET PROSTAGLANDIN}

\section{PRODUCTION AND MEMBRANE FLUIDITY}

\subsection{Introduction}

From the previous chapters it can be concluded that the type of dietary fat significantly affects arterial thrombosis tendency in rats, most probably via a change in platelet aggregability. The dietary fat type also influences platelet thromboxane $\mathrm{A}_{2}\left(\mathrm{TXA}_{2}\right)$ - and vascular prostacyclin (prostaglandin $I_{2}, P I_{2}$ ) production in a strikingly similar way: although the amounts of the different compounds produced were greatiy affected by the type of dietary fat, the ratio between both products remained the same. This suggests that the type of dietary fat affects a 'common factor', which is equally important for $T \times A_{2}$ as it is for $P G I_{2}$ formation. For all enzymatic reactions, product formation is directly dependent upon enzyme activity and . dbstrate availability. In the process of $\mathrm{TXA}_{2}-$ and $\mathrm{PGI}_{2}$ formation, only the last step (conversion of the endoperoxide $\mathrm{PGH}_{2}$ ) requires a different enzyme. Consequently, the 'common factor' is most likely to be found before this particular step and will, therefore, be involved in the formation of $\mathrm{PGH}_{2}$ from arachidonic acid.

The formation of thromboxane $A_{2}$ and prostacyclin occurs in two strictly separated compartments ( $p$ latelets and vessel wall respectively, see Chapter 3 , section 3.3.3.). Since the type of dietary fat has repeatedly been shown to influence tissue lipid composition, including platelet lipids (3-10), it seems justified to suggest that a change in platelet- and vesselwall arachidonic acid (AA) contents constitutes the basis for the dietary-fat induced changes in $\mathrm{TXA}_{2}-$ and $P G I_{2}$ production. The fish oil experi.ment described in Chapter 9 , section 6 . suggested the same.

The results presented in Chapter 8 make it highly probable that AA-derivatives of platelets are of primary importance for arterial thrombus formation.in order to investigate whether platelet $\mathrm{TXA}_{2}$ formation is indeed correlated with the AA content of platelet phospholipids, we decided to measure the effect of the type of dietary fat on platelet arachidonate content and $T \times A_{2}$ production. We concentrated our fatty acid studies on the phospholipids because these 
compounds were shown to be the fatty acid donors for PG-synthesis $(1,2,65)$.

It is now fairly well established that $A A$-peroxidation is a membrane-bound process $(11,12)$. However, since the fatty acid composition of platelet membrane phospholipids appeared to be strikingly similar to that of whole platelet phospholipids (13) and because we did not want to sacrifice more animals than absolutely necessary, we confined our investigations to the phospholipids of whole platelets.

$\mathrm{TxA}_{2}$ formation was measured upon platelet activation with collagen. Since $\mathrm{TxA}_{2}$ is a highly unstable compound, we measured one of its stable metabolites, HHT (12-hydroxyheptadecatrienoic acid). Recently, also the platelet lipoxygenase (LPO-) pathway was suggested to be functionally important in platelet aggregation (14). Therefore, we also measured the final product of this pathway, HETE (12-hydroxyeicosatetraenoic acid).

The easiest way to measure these compounds is to incorporate some radioactive arachidonic acid into the platelet phospholipids, extract and separate the reaction products and quantify their amounts by liquid scintillation counting (15). However, the distribution of newly incorporated $A A$ in the various phospholipid classes is very much different from that of endogenous $A A(15,16)$. Consequently, its metabolism might be different as well and would not reflect the normal situation (17). This is the reason why we decided to measure the formation of endogenously formed compounds using gas chromatography combined with mass spectometry, which is the most specific technique available to-day.

\subsection{Experimental procedure}

10.2.1. Animals 2 diets_and_platelet_preparation

Six groups of 24 five-week-old male Wistar rats were fed an adequate diet (Table 6.1.) containing the following dietary fats (see Tables 6.2. and 9.1. for fatty acid compositions):

Group 1: 5 en\% sunflowerseed oil (SO). This is the control group. Group 2: 50 en $\%$ so. This diet is rich in linoleic acid $(18: 2(n-6))$. Group 3: 5 en: so (to prevent essential fatty acid deficiency) +45 en\% hydrogenated coconut oil ( $\mathrm{HCO}$ ), which is rich in saturated fatty acids. 
Group 4: 5 en\% S0 + 45 en\% linseed oil (LO). This diet is rich in $\alpha-1$ inolenic acid $(18: 3(n-3))$.

Group 5: 5 en\% S0 + 45 en\% cod-liver oil (CLO), providing the diet with considerable amounts of long-chain; polyunsaturated fatty acids of the $(n-3)$ family $(20: 5(n-3)$ and $22: 6(n-3))$.

Group 6: $5 \mathrm{en \%} \mathrm{HCO}$, which contains no essential fatty acids (EFA) and causes, therefore, essential fatty acid deficiency.

The diets were fed ad libitum for 15 weeks. Then, after one overnight fast, the ether-anesthesized animals were bled by puncturing the abdominal aorta and PRP and PPP were prepared as described in Chapter 7, section 2. and pooled per 4 animals. Of each pooled sample, the platelet count was determined (Coulter Counter) and some PRP was diluted with autologous PPP to obtain well over $4 \mathrm{mi}$ PRP with a platelet count of $10^{6}$ platelets.11 ${ }^{-1}$. The rest of the PRP was centrifuged $(10 \mathrm{~min}$ at $600 \times \mathrm{g})$ to produce a platelet pellet, which was carefully resuspended in phosphate-buffered saline ( $\mathrm{pH} 7.41)$ containing EDTA $\left(7.7 \mathrm{mmol} .1^{-1}\right.$, final concentration). Platelet loss appeared $; 0$ be negligible. Of these suspensions, the protein content was determined according to the Lowry technique (18). The suspensions were stored under nitrogen at $-70^{\circ} \mathrm{C}$ until analysis.

\subsubsection{HHT_and_HETE_me _.}

Platelet arachidonate peroxidation products formed upon activation with collagen were measured as follows.

One ml PRP, platelet count approximately $10^{6} . \mu l^{-1}$, was transferred into an aggregometer cuvette (Born/Michael MK IV) and pre-incubated for 3 min at $37.5^{\circ} \mathrm{C}$ and a stirring rate of 1,200 rev.min ${ }^{-1}$. The platelets were activated by adding 50, 75, 100 or $200 \mu 1$ of a collagen suspension in saline (prepared as described in Chapter 7, section 2.) containing 160 $\mu \mathrm{g}$ protein. $\mathrm{ml}^{-1}$. Aggregation was monitored by continuous recording of the change in optical density.

After $5 \mathrm{~min}$, the aggregated PRP was transferred into another tube, after which $2 \mathrm{ml}$ ethanol was added, containing $195 \mathrm{ng}$ deuterated HHT and $185 \mathrm{ng}$ deuterated HETE as internal standards. The reaction mixture was then acidified to $\mathrm{pH}$ 4-5 with $0.5 \mathrm{ml}$ citric acid $\left(0.2 \mathrm{~mol} .1^{-1}\right)$ after which $0.5 \mathrm{ml}$ distilled water was added. Following thorough mixing, the hydroxy acids were extracted with $5 \mathrm{ml}$ dichloromethane. After vigorous mixing and rapid centrifugation, the lower phase containing the hydroxy acids, 
was collected and the solvent evaporated under a stream of nitrogen. The : residue was taken up in $200 \mu 1$ of a chloroform-methanol mixture $(9: 1 \mathrm{v} / \mathrm{v})$ and spotted on a $20 \times 20 \mathrm{~cm}$ TLC plate (Merck, $0.5 \mathrm{~mm}$ ), together with HHT and HETE standards. The plate was developed in a chloroform/methanol/acetic acid/water mixture $(90: 8: 1: 0.75 \mathrm{v} / \mathrm{v} / \mathrm{v} / \mathrm{v})$ and air-dried. The parts of the plate containing the standard samples were sprayed with phosphomolybdate, dissolved in alcohol ( $100 \mathrm{~g}$ in $1 \mathrm{l}$ ethanol) and carefully warmed to visualize the spots. The corresponding parts of the plate containing the experimental samples were scraped off and collected in a glass tube.

The hydroxy acids were eluted from the gel twice, using $2 \mathrm{ml}$ of a dichloromethane-methanol mixture $(1: 1 \mathrm{v} / \mathrm{v})$. Both eluates were combined and evaporated under nitrogen. The residue was taken up in $0.6 \mathrm{ml}$ diethyl ether and $0.5 \mathrm{ml}$ acidified water $\left(\mathrm{pH} 4-4.5,25 \mathrm{ml} \mathrm{H}_{2} \mathrm{O}+0.05 \mathrm{ml}\right.$ citric acid, $0.2 \mathrm{~mol} . \mathrm{l}^{-1}$ ) was added. After thorough mixing and centrifugation, the upper layer was collected in a small glass tube. This ether extraction was repeated and both extracts were combined and evaporated under nitrogen. Subsequently, the residue was taken up in $0.2 \mathrm{ml}$ diethyl ether and the hydroxy acids were methylated with diazomethane. After $10 \mathrm{~min}$, the samples were evaporated under nitrogen and silylated with four drops of BSTFA (N,0-bis-(trimethylsilyl)trifluoroacetamide from Pierce Chemical Company, Rockford, I11. USA). After one hour, the reaction mixture was evaporated $\left(\mathrm{N}_{2}\right)$ and the residue taken up in $0.1 \mathrm{ml}$ diethyl ether and transferred into a GLC glass microvial. The rinsing procedure was repeated once, the combined solutions were evaporated under nitrogen and the residue obtained was taken up in $30 \mu \mathrm{T}$ ether for gas chromatography $(2 \% \mathrm{SE}-30$ column $1,5 \mathrm{~m}, 205^{\circ} \mathrm{C}$ ) combined with mass spectrometry (focusing at $\mathrm{m} / \mathrm{e} 295$ and 301). It appeared that this GC/MS method allows the reliable measurement of hydroxy acid levels as low as $10 \mathrm{ng} \cdot \mathrm{ml}^{-1}$.

\subsubsection{Plateletet_phospholipid_analys is}

Platelet phospholipid analyses were carried out as follows. To the frozen platelet suspensions (usually 2.5-3.5 $\mathrm{ml}$ containing $10-30 \times 10^{9}$ platelets), $2 \mathrm{ml} 2 \%(\mathrm{w} / \mathrm{v})$ EDTA solution was added after which they were allowed to thaw slowly with repeated mixing. This procedure was followed to minimize platelet phospholipase activation by $\mathrm{Ca}^{++}$, possibly released upon platelet lysis due to a temperature shock. After complete thawing, the diluted suspensions were homogenized by vigorous mixing after which 4-5 $\mathrm{ml}$ were 
extracted according to Bligh an Dyer (19), using a mixture of redistilled chloroform and methanol to which BHT $(0.05 \%$ w $/ \mathrm{v})$ had been added to prevent oxidation of the polyunsaturated fatty acids. The rest of the suspensions was added to measure the protein content (Lowry's method). The lipid residue was taken up in $10 \mathrm{ml}$ chloroform after which $0.5 \mathrm{ml}$ samples were taken for measuring total phospholipid- and cholesterol contents. The rest of the chloroform was evaporated and the residue dried over $\mathrm{P}_{2} \mathrm{O}_{5}$ under vacuum for at least one night. Phospholipid-class separation was performed by two-dimensional TLC using the method of Broekhuyse (20) which was slightly modified to attain optimum resolution. For 5 TLC plates $20 \times 20 \mathrm{~cm}$ ), $50 \mathrm{~g}$ silica gel (Merck, $60 \mathrm{G} \mathrm{HR}$ ) and $4 \mathrm{~g} \mathrm{Florisil}{ }^{(0)}$ (Merck, Darmstadt, FRG) were suspended in $120 \mathrm{ml}$ water. The slurry was spread over the plates (thickness of $0.75 \mathrm{~mm}$ ) and after air-drying, the plates were activated at $125^{\circ} \mathrm{C}$ for one night. Each lipid sample, taken up in 200 H chloroform, was spotted in equal amounts on two plates under a stream of nitrogen. The plates were developed in a chloroform/methanol/ $\mathrm{NH}_{4} \mathrm{OH} 25 \% /$ water mixture $(16.4 / 9.8 / 1 / 1, \mathrm{v} / \mathrm{v} / \mathrm{v} / \mathrm{v})$ and after careful drying in a flow of prewarmed nitrogen, they were developed in a direction perpendicular to the first, using a mixture of chloroform/methanol/acetic acid/water $(45 / 20 / 6 / 1, v / v / v / v)$. The duplicate $p l a t e s$ were developed in the same chamber, which had been pre-equilibrated for at least 1 hour. After the second development, the plates were again dried in a stream of warm nitrogen.

For phospholipid class determination, the spots were visualized with iodine vapour, scrapped off and collected in glass tubes. Half a ml $\mathrm{HClO}_{4}, 70 \%(\mathrm{~W} / \mathrm{V})$, was added and the phospholipids were destructed for $45 \mathrm{~min}$ at $180^{\circ} \mathrm{C}$ to obtain inorganic phosphorus (P). After cooling, $7.5 \mathrm{ml}$ of a solution of $0.22 \%(w / v)$ ammonium heptamolybdate in $2 \%$ suiphuric acid ( $v / v$ ) was added and then $0.3 \mathrm{ml}$ Fiske-Subbarov reagent (21), after which the tubes were heated at $100^{\circ} \mathrm{C}$ for $45 \mathrm{~min}$. After removal of the gel by centrifugation, the blue colour of the solution was measured spectrophotometrically at $830 \mathrm{~nm}$; the extinctions were converted into umol lipid-P, using a standard curve.

Simultaneously with each series of 6 samples, a blank $12 \mathrm{ml}$ redistilled water $+2 \mathrm{ml}$ EDTA) was extracted; all results were corrected for the blank values. Previously, all glassware had been carefully cleaned in chromosuiphuric acid (Merck).

Using methyl-PA as an interna? standard, phospholipid recovery by the TLC procedure applied was between 70 and $90 \%$. Starting from a mixture of 
known amounts of PC, PE, PS, PI and SPH, recovery variations were similar for all phospholipid classes. Therefore, variation in recovery did not interfere with phospholipid class distribution measurements.

\subsubsection{Phospholipid_fatty acid_composition}

For the determination of the fatty acid composition of the separate phospholipid classes, the spots were visualized by spraying the TLC plates with Rhodamine $6 \mathrm{G}(0.01 \%(\mathrm{w} / \mathrm{v})$ in methanol). The spots were marked under UV-light $(254 \mathrm{~nm})$, scraped off and collected in a glass tube. An amount of $0.5 \mathrm{ml}$ boron trifluoride $\left(\mathrm{BF}_{3}, 14 \%(\mathrm{w} / \mathrm{v})\right.$ in methanol) was added and the tubes were screw-capped under a stream of nitrogen. Phospholipids (see Table 2.1.) were hydrolyzed and the fatty acids methylated by heating the tubes at $100^{\circ} \mathrm{C}$ for $15 \mathrm{~min}$ (PE, PS and PI), $30 \mathrm{~min}$ (PC) or $90 \mathrm{~min}$ (SPH) as described by Morrison and Smith (22).

After cooling, $0.5 \mathrm{ml} \mathrm{H}_{2} \mathrm{O}$ was added and the fatty acid methyl esters were extracted three times with $1 \mathrm{ml}$ pentane $(+\mathrm{BHT}, 0.05 \% \mathrm{w} / \mathrm{v})$. The extracts were combined, evaporated under $\mathrm{N}_{2}$ and stored at $-15^{\circ} \mathrm{C}$ until analysis by GLC, for which a Perkin Elmer F17 unit with two glass columns (5\% DEGS, $0.2 \times 180 \mathrm{~cm})$ and $\mathrm{flame}$ ionisation detection was used. The injection temperature was $210^{\circ} \mathrm{C}$ and the detector temperature $250^{\circ} \mathrm{C}$. The analyses were performed using temperature programming, which had been optimized with a reference mixture containing most of the fatty acid inethyl esters of interest. This mixture was also used to identify the peaks. The samples to be analysed were taken up in 25-100 $\mu 1$ isooctane containing a known amount of 15:0 as an internal standard. The content of each fatty acid in the mixtures was calculated on the basis of peak height and width. After adjustment with respect to the 15:0 peak and correction for the blank samples, the proportional composition of the mixtures was calculated.

\subsection{HHT and HETE production of collagen-activated blood platelets}

10.3.1. Collagen-induced_aggregation

Platelet aggregation induced by various collagen doses, is given in Table 10.1. Statistical analysis (analysis of variance with Newman-Keuls conti- 
Table 10.1. Collagen-induced aggregation (tg $\alpha \pm$ SEM, see Fig.7.10.) in PRP of rats fed different dietary fats. $n=6$ pools of 4 animals.

\begin{tabular}{lllllll}
\hline Group & \multicolumn{5}{l}{ Collagen dose $(\mu l)$} \\
\hline No & Code & 50 & 75 & 100 & 200 \\
\hline 1 & Control & $1.0 \pm 0.56$ & $5.6 \pm 0.68$ & $7.4 \pm 0.40$ & $10.5 \pm 0.43$ \\
2 & SO & $4.4 \pm 0.37$ & $6.3 \pm 0.41$ & $7.9 \pm 0.31$ & $9.8 \pm 0.32$ \\
3 & HCO & $0.1 \pm 0.01$ & $2.3 \pm 0.91$ & $5.5 \pm 0.40$ & $8.5 \pm 0.21$ \\
4 & LO & $1.1 \pm 0.37$ & $5.7 \pm 0.15$ & $7.3 \pm 0.29$ & $9.2 \pm 0.00$ \\
5 & CL0 & $0.2 \pm 0.03$ & $5.4 \pm 0.58$ & $6.7 \pm 0.40$ & $9.0 \pm 0.29$ \\
6 & EFA-def. & $0.2 \pm 0.02$ & $0.5 \pm 0.11$ & $3.3 \pm 0.70$ & $7.6 \pm 0.53$ \\
\hline
\end{tabular}

nuation, see Table 10.2.) allowed the following conclusions. Only for the lowest collagen dose, is aggregation in the so-group significantly $\left(P_{2}<0.05\right)$ higher than in the other groups, indicating that the platelet -collagen 'activation treshold' is very low after feeding a diet enriched with sunflowerseed oil. However, once this treshold has been exceeded, So platelets no longer behave differently from the control platelets. Except for the lowest collagen dose, aggregation in the EFA-deficient group is significantly $\left(P_{2}<0.05\right)$ lower than in the other groups, which confirms earlier results obtained with PRP-saline dilutions (Chapier 8, section 2.2.3.). Aggregation of HCO platelets is clearly depressed as compared with that of the other high-fat and control platelets. As demonstrated in Chapter 7, section 3.1., this difference is also observed when aggregation is measured in a PRP-saline dilution. Using the latter system, the collagen-induced aggregation of CLO platelets was shown to be significantiy lower than that of So platelets (Chapter 9, section 3.),

Talite 10.2. Significance profile of differences between collagen-induced aggregations of platelets obtained from rats fed different dietary fats. $n=6$ pools of 4 animals. For explanation of group code: see Table 10.1. Groups not connected by the same line differ significantly from each other $\left(P_{2}<0.05\right)$.

\begin{tabular}{lllllll}
\hline Collagen dose $(\mu 1)$ & Profile & & & \\
\hline 50 & $\frac{2}{2}$ & $\frac{4}{4}$ & 1 & $\frac{3}{1}$ & 5 & 6 \\
75 & 2 & 4 & 5 & $\frac{3}{3}$ & 6 \\
100 & 2 & 1 & 4 & 5 & 3 & 6 \\
200 & 1 & 2 & 4 & $\overline{5}$ & $\underline{3}$ & 6
\end{tabular}


but this does not hold for the present situation where aggregation is measured in undiluted PRP. Although for all collagen doses, aggregation is lower in the CLO- than in the SO-group, the difference is only significant at the lowest dose.

\subsubsection{HHT production of collagen-activated blood platelets}

The effect of dietary composition on the production of HHT by platelets activated with four different collagen doses is illustrated in Fig.10.1. The values obtained for platelets from EFA-deficient animals were mostly below the levels of reliable quantification but always clearly above zero. Therefore, the HHT production of EFA-deficient platelets was arbitrarily taken as $5 \mathrm{ng} \cdot 10^{-9}$ platelets.

For the other groups, analysis of variance showed that increasing collagen doses caused platelet HHT production to increase dose-dependently. The dose-response relationships were not significantly different from rectilinearity, but the various slopes differed significantly $\left(P_{2}<0.001\right)$. HHT production is highest in the so group, followed by the control, HCO, LO, CLO and EFA-deficient groups in the order indicated.

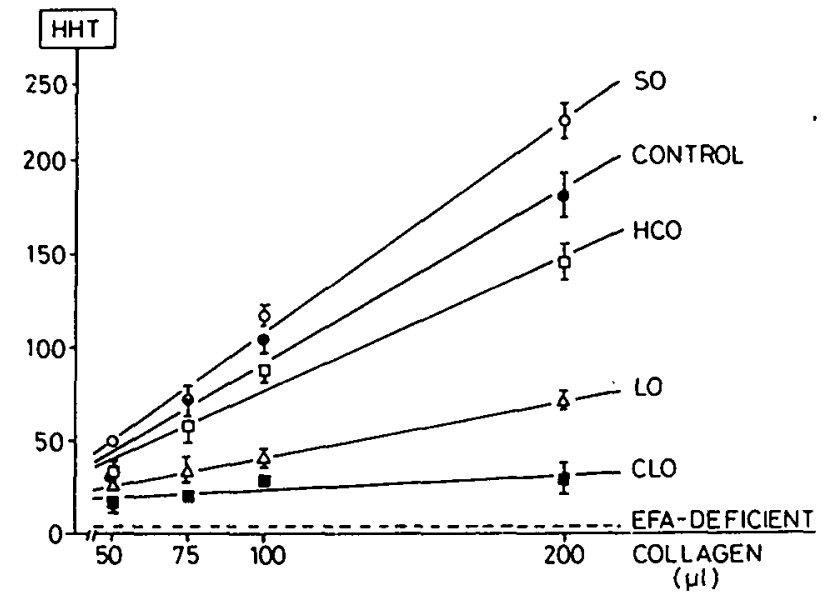

$\because i_{i} .10 .1$. Effect of different dietary fats on the HHT production $\left(\mathrm{ng} .10^{-9}\right.$ platelets) by collagen-activated blood platelets.Each point represents mean \pm SEM of 6 determinations carried out in PRP-pools each obtained from 4 animals. Regression equations for the various groups:

So: $Y=-6.99+1.155 \times(0)$; Control : $Y=-1.18+0.938 \times(\bullet)$;

HCO: $Y=3.98+0.730 \times(\square) ;$ LO : $Y=10.09+0.310 X(\Delta)$;

CLO: $Y=14.51+0.088 \times(\square)$. 


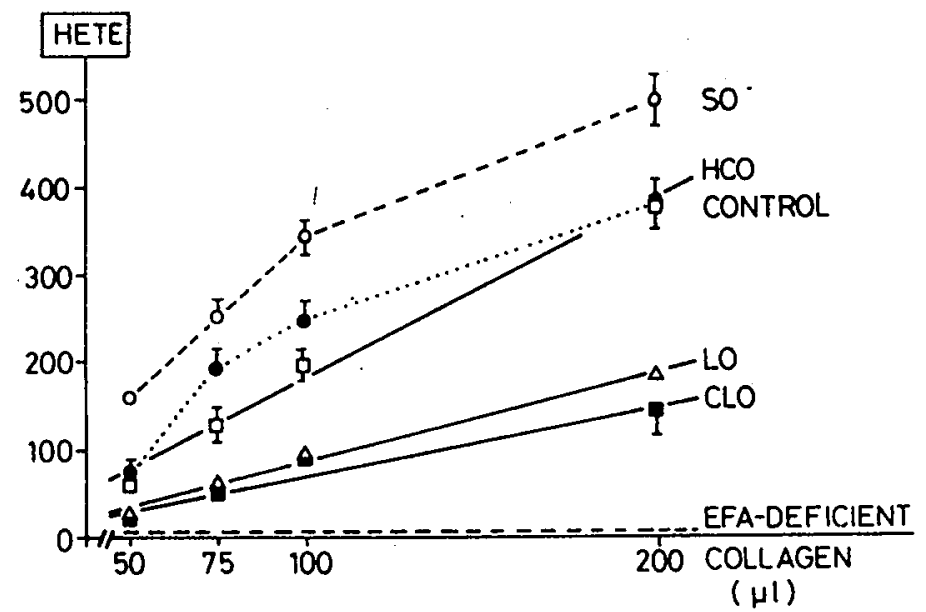

lig. 10. 2. Effect of different dietary fats on the HETE production (ng. $10^{-9}$ platelets) by collagen-activated blood platelets. Each point represents mean \pm SEM of 6 determinations carried out in PRP-pools, each obtained from 4 animals. Regression equations for the various groups:

S0: curvilinear $(0)$; Control: curvilinear $(\bullet)$;

HCO: $Y=-29.3+2.07 \times(\square) ; \quad$ LO: $Y=-13.5+0.99 X(\Delta)$;

CLO: $Y=-6.0+0.77 \times(\square)$.

\subsubsection{HEIE_production_of_collagen-acttivated_blood_platelelets}

Fig.10.2. Shows the HETE production of collagen-activated blood platelets. As was also the case for HHT, HETE formation increased significantly $\left(P_{2}<0.001\right)$ with increasing collagen dose (analysis of variance). For the control and SO groups, but not for the HCO, LO and CLO groups, the dose -response curves differed significantly from rectilinearity $\left(P_{2}<0.05\right)$.

Table 10. 0 . Effect of different dietary fats and trigger. strengths on HETE/HHT ratio (mean \pm SEM) of collagen-activated blood platelets. $n=6$ pools of 4 animals.

\begin{tabular}{|c|c|c|c|c|}
\hline \multirow{2}{*}{ Group } & \multicolumn{4}{|c|}{ Collagen dose $(\mu 1)$} \\
\hline & 50 & 75 & 100 & 200 \\
\hline $\begin{array}{l}\text { Control } \\
\text { SO } \\
\text { HCO } \\
\text { LO } \\
\text { CLO }\end{array}$ & $\begin{array}{l}2.2 \pm 0.23 \\
3.2 \pm 0.15 \\
1.9 \pm 0.12 \\
1.5 \pm 0.36 \\
1.6 \pm 0.63\end{array}$ & $\begin{array}{l}2.8 \pm 0.25 \\
3.6 \pm 0.47 \\
2.3 \pm 0.20 \\
2.4 \pm 0.57 \\
2.6 \pm 0.35\end{array}$ & $\begin{array}{l}2.4 \pm 0.25 \\
2.9 \pm 0.20 \\
2.3 \pm 0.21 \\
2.2 \pm 0.12 \\
3.5 \pm 0.24\end{array}$ & $\begin{array}{l}2.1 \pm 0.06 \\
2.2 \pm 0.13 \\
2.6 \pm 0.14 \\
2.6 \pm 0.11 \\
5.2 \pm 0.89\end{array}$ \\
\hline
\end{tabular}


HETE production in the EFA-deficient group was below the level of reliable quantification and was therefore taken as $5 \mathrm{ng} \cdot 10^{-9}$ platelets. Analysis of the regression slopes (Student-Newman-Keuls test) revealed no difference between the LO and CLO groups. These slopes were significantly $\left(P_{2}<0.05\right)$ less steep than those for the other groups, which, most probably, did not differ mutually, although HETE production in the so group is higher than that in the control and HCO groups. In general, the dietary effect on platelet-HETE formation is qualitatively similar to that observed for HHT production.

\subsubsection{Relationship between HHI and HETE formation}

The ratio between HETE and HHT produced by activated platelets depend on the reaction time: immediately after platelet triggering, more HHT than HETE is produced; after $5 \mathrm{~min}$, the production of both substances is about equal, whereas after $20 \mathrm{~min}$, the HETE/HHT ratio is about 2 (23). These different time courses or HETE and HHT formation probably explains the different ratios reported in the literature (24-27).

In our experiment, the HETE/HHT ratio not only differs for the different groups but for the various collagen doses as well (Table 10.3.). This collagen effect is difficult to explain, especially so because there seems to be an interaction with the type of diet. The time courses for HHT and HETE formation as described by Nugteren et al. (23), might proceed more quickly at a higher trigger strength. In this case, the HETE /HHT ratio is expected to increase with increasing collagen dose, but such a course is oniy observed for the CLO group, which is most probably due to other factors (vide: irrfiri).

The coilagen effect might also indicate that trigger strength determines how much of the released arachidonic acid enters the cyclo-oxygenase or the lipoxygenase pathway. An alternative explanation might be a 're-routing' of endoperoxides determined by the trigger strength: a higher HETE/HHT ratio might indicate that more $\mathrm{PGH}_{2}$ is used for the formation of 'classical' prostaglandins so that less $\mathrm{PGH}_{2}$ is available for HHT production. Finally, a trigger strength-dependent shift in $\mathrm{TxA}_{2}$ metabolism towards $\mathrm{TxB}_{2}$ instead of to HHT + MDA (see Fig.3.12.) might account for a lower HHT production, resulting in a higher HETE/HHT ratio. A detailed analysis of all arachidonic acid products formed upon collagen activation will be necessary to find the final answer. 
The most obvious dietary fat effect on the HETE/HHT ratio is that caused by CLO-feeding. It is very likely that this is due to the fact that the GC/MS procedure is unable to discriminate between products derived from arachidonic acid (the 2-series eicosanoids) and those derived from timnodonic acid (the 3 -series). As shown in Chapter 9 , section 7 , collagen activation of CLO platelets causes the release of endogenous timnodonic acid, which enters the 7 ipoxygenase pathway to form HEPE. Moreover, timnodonic acid does not serve as a substrate for the cyclo-oxygenase, but inhibits the conversion of arachidonic acid. This combined effect: the production of HEPE - measured as HETE - and the inhibition of HHT formation, results in an increase in the 'HETE'/HHT ratio.

The results, detailed in Table 10.3. and the explanation for the high HETE/HHT ratio in the CLO group mentioned above, strongly suggest that timnodonic acid is liberated from platelet phospholipids only at a high trigger strength because at lower collagen joses, the HETE/HHT ratio does not longer differ from that in the other groups.

Although platelets of animals fed the LO diet also contain a considerable amount of timnodonic acid (see under section 10.4.4.), their HETE/HHT ratios do not differ from those in the control group and are therefore lower than those for CLO platelets. This is a strong indication that timnodonic acid has not been liberated upon activation of the LO platelets, which suggests that only a certain pool of timnodonic acid is released on platelet activation whereas another, earlier 'filled' pool, is not (or less readily so).

\subsubsection{Relationship between platelet HHT formation and collagen-induced aggregation}

Platelets fro!n the So-group were shown to be very sensitive to a low cose of collagen: their aggregation response as well as their HHT production are significantly higher than those in the other groups. This observation supports the concept that collagen-induced aggregation is mediated by cyclo-oxygenase products of arachidonic acid (25). As can be seen from Fig.10.3, the type of dietary fat greatly affects the relationship between aggregation and HHT production: in the EFA-deficient-, the CLO- and the 1.0 groups, the collagen-induced aggregation is aimost independent of HHT formation whereas in the control-, SO- and HCO groups, there is a 


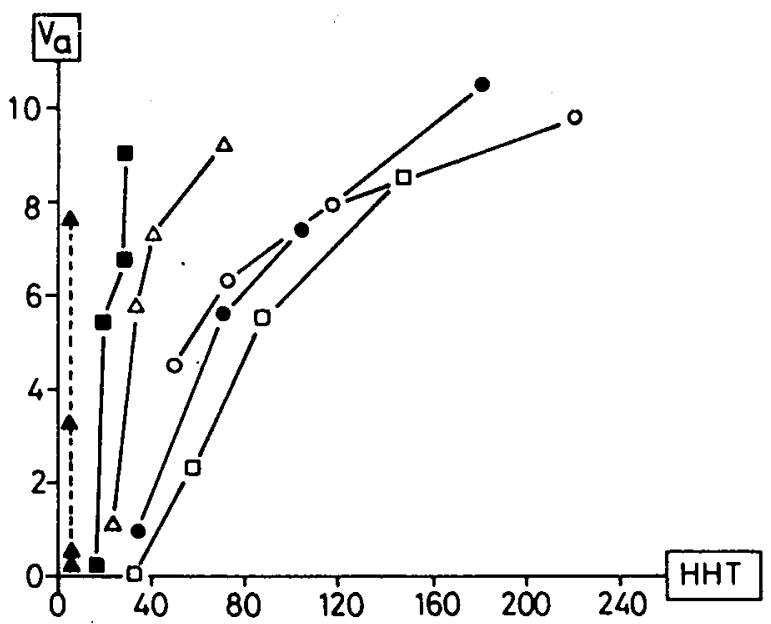

Fig. 10.3. Relationship between collagen-induced platelet HHT formation (ng. $10^{-9}$ platelets) and platelet aggregation $\left(V_{a}\right.$, see Fig.7.10.). Each point represents the mean of 6 determinations carried out in PRP-pools, each obtained from 4 animals.

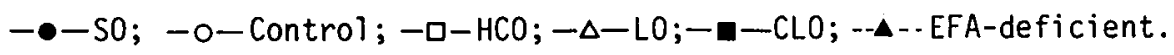

pronounced, although mutually different relationship between both parameters. As will be shown in more detail later (section 10.5.), HHT formation depends on the platelet arachidonic acid (AA) content and it is striking to note that collagen-induced aggregation is the more HHT-dependent, the higher the $A A$ content of platelet phospholipids. Thus, it seems highly probable that in the case of a diminished AA-peroxidation by cyclo -oxygenase, an alternative, $A A$-independent aggregation-mediating pathway takes over.

This aspect was investigated in more detail with platelets of another group of EFA-deficient rats in which MDA formation (Chapter 8 , section 3.) and ${ }^{14} \mathrm{C}-5 \mathrm{HT}$ release (Chapter 8 , section 2.2 .3 .) were measured upon triggering with collagen. Results were compared with those obtained for control platelets ( $5 \mathrm{en} \% \mathrm{~s} 0$ ). In a first series of experiments, a supramaximal dose of collagen was used and the reaction was interrupted after exposure times varying between $10 \mathrm{~s}$ and $3 \mathrm{~min}$. A second series was performed with different submaximal doses of collagen at a standard reaction time of $3 \mathrm{~min}$. If arachidonate peroxidation governs the release reaction, the relationship between ${ }^{14} \mathrm{C}-5 \mathrm{HT}$. release and MDA formation should be the same in both the EFA-deficient and the control group. This was not so: in EFA-deficient platelets, the same degree of release coin- 

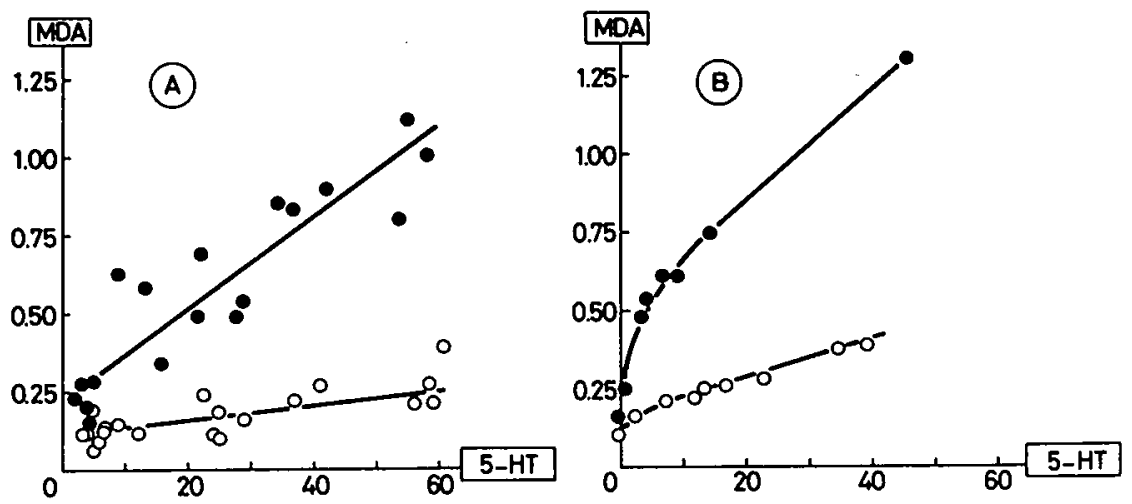

$\because 23.10 . a$. Relation between ${ }^{14} \mathrm{C}-5 \mathrm{HT}$ release (\%) and MDA production (nmol. $10^{-9}$ platelets) in control (•) and EFA-deficient (o) rat platelets. A: supramaximal collagen dose. Reaction interrupted after 10-180 s. Five experiments. B: different submaximal collagen doses. Reaction interrupted after $180 \mathrm{~s}$. Two experiments.

cides with a lower MDA formation than in control platelets (Fig.10.4.). Therefore, in EFA-deficient rat platelets, there must be an additional release mechanism inderendent of the arachidonate pathway. Bult and Bonta (28) arrived at the same conclusion.

Essentially similar results have been reported when blocking AA-peroxidation with aspirin: al though it irreversibly inactivates platelet cyclo -oxygenase $(\mathrm{CO})$ by acetylation $(29,30)$ and, as a result, inhibits secondary and collagen-induced aggregation (31-33), aggregation-inhibition can simply be overcome by increasing the trigger strength (33) without reactivation of CO-mediated AA peroxidation (34).

Collagen-induced aggregation of platelets of LO- and CLO-fed animals is hardly lower than that of control animals (section 10.3.1, Table 10.1.), whereas their HHT production is greatly depressed (Fig.10.1.). This provides a strong indication that these diets enhance the activity of an (the?) AA-independent release- and aggregation mechanism possibly by increasing the platelet sensitivity towards collagen, resulting in an effect analogous to that occurring upon increasing the trigger strength in aspirinated platelets.

In the case of EFA-deficiency, platelet HHT production and collagen-induced aggregation are reduced, indicating that the compensatory platelet-sensitivity increase observed for platelets of the LO and CLO groups, does not 
take place here. This might be ascribed to the diminished platelet-to -collagen adhesion, demonstrated in EFA-deficiency (Chapter 8, section 2.2.1.).

In the HCO group, triggering of platelets with collagen gives rise to a 'normal' HHT production in relation to the platelet AA content (see section 10.5.). Platelet aggregation, however, is definitely depressed, which strongly indicates that the sensitivity of $\mathrm{HCO}$-platelets towards the aggregating effect of $\mathrm{TXA}_{2}$ is diminished. This is also indicated by the results presented in Fig 10.3.

The present finding also suggests that the lower $\mathrm{PF}_{3}$ availability, observed with HCO platelets upon triggering with collagen (Chapter 7 , section 2.5.), is not due to a disturbance of the initial platelet-collagen interaction but to some secondary phenomenon.

Nothing is known yet about the alternative, $A A$-independent aggregation -mediating pathway, possibly implicated in the aggregation of LO-, CLOand EFA-deficient platelets. It would be interesting to investigate whether the platelet-activating factor (PAF, see ref. 35 and Chapter 9 , section 8.) plays a part here.

\subsection{Platelet phospholipid analysis}

\subsubsection{Plateletet protein content}

The platelet suspensions destined for phospholipid analyses, were prepared from $7.5 \mathrm{ml}$ (pooled) PRP, the platelet count of which had been determined beforehand. Since platelet loss during centrifugation for pellet preparation is known to be negligible, the total amount of platelets in the pellet could be calculated. After resuspending the pellet, a sample was taken for protein measurement and from the values obtained we were able to calculate the platelet protein content. The results are given in Table 10.4. and analysis of variance showed significant differences between the groups $\left(P_{2}<0.05\right)$. According to the Newman-Keuls test, the platelet protein content in the So group was probably higher $\left(P_{2}<0.10\right)$ than that in the HCO- and LO groups. The values of the other groups did not differ significantiy from each other.

Theoretically, the platelet suspensions might be contaminated with plasma, because we washed the platelets only once to minimize any phospholipase- 
Iall. 11.A. Protein content of platelets (mean \pm SEM) obtained from animals fed different dietary fats. $n=6$ pools of 4 animals.

\begin{tabular}{ll}
\hline Diet & $\begin{array}{l}\text { Prote in content } \\
\text { (mg. } 10^{-9} \text { platelets) }\end{array}$ \\
\hline Control & $1.49 \pm 0.024$ \\
SO & $1.67 \pm 0.083$ \\
HCO & $1.44 \pm 0.035$ \\
LO & $1.45 \pm 0.045$ \\
CLO & $1.50 \pm 0.065$ \\
EFA-def. & $1.62 \pm 0.076$ \\
\hline
\end{tabular}

activation during platelet handling (see section 10.4.3.). Contamination with significart amounts of plasma was unlikely, judging from the fact that the total protein content $(\mathrm{mg}, X)$ and total platelet counts $\left(\times 10^{9}, Y\right)$ of the suspensicns were related according to the equation $Y=0.56+$ $3.08 \times(r=0.88 ; n=24 ; P<0.001)$. When $Y=0$ (no platelets present), $X=-0.18$, indicating that protein is not present either. We may, therefore, conclude that platelets are the only source of protein in the suspensions. The platelet protein :ontent determined in our experiment are in good agreement with that of human platelets $(36,37)$.

\subsubsection{Platelet__ehospholipid_content}

Protein determinations were also carried out in suspensions diluted with EDTA immediately before extraction (section 10.2.2.). This enabled us to report platelet analyses in relation to platelet protein (cf. Table 10.5.). No significant differences were observed between the groups. As compared to human platelets $\left(0.20-0.30 \mu \mathrm{mol}\right.$ :ipid-P.mg ${ }^{-1}$ platelet protein $(5,13,38-40))$, the values for rat platelets are rather high. The same holds for the platelet cholesterol values (Table 10.15.) and is mos $\tau$ probably due to the low protein content of the platelet suspensions, measured immediately before lipid extraction. It is highly likely that the EDTA added to prevent phospholipase activity, interfered with the Lowry -technique used for the measurement of the platelet protein content.(68).

10.4.3. Platelet_phospholipid_class distribution

Table 10.6. gives the platelet phospholipid class distribution. These re- 
I'able 10.6. Total phospholipid content of platelets (mean \pm SEM) obtained from animals fed different dietary fats. $n=6$ pools of 4 animals.

\begin{tabular}{ll}
\hline Diet & $\begin{array}{l}\text { Platelet phospholipid } \\
\text { (umol iipid-P. mg protein }\end{array}$ \\
\hline Control & (um \\
SO & $0.44 \pm 0.022$ \\
HCO & $0.42 \pm 0.042$ \\
LO & $0.40 \pm 0.060$ \\
CLO & $0.43 \pm 0.018$ \\
EFA-def. & $0.50 \pm 0.047$ \\
\hline
\end{tabular}

sults are in good agreement with literature data $(5,6,13,39,40)$. The slight amount of LPE found in the platelet phospholipids means that only a minor activation of the platelets took place during preparation of the platelet suspensions. In pilot experiments, in which platelets had been washed twice, a considerable PE-hydrolysis was observed so that in the present experiment, we washed them only once.

As to the phospholipid class distribution, significant differences between the groups were observed for LPC only; this compound was considerably diminished in the EFA-deficient and CLO groups $\left(P_{2}<0.05\right)$. Whether this difference has any functional significance is difficult to establish. $L P C$ has been reported to be implicated in the regulation of platelet function by several investigators. Besterman and Gillet observed that LPC inhibits serotonin- and collagen-induced aggregation, whereas the second phase of ADP- and adrenaline-induced aggregation is also inhibited $(41,42)$. Joist and co-workers (43) also observed a dose-dependent inhibition of PRP aggregation induced by ADP, adrenaline, collagen and thrombin, which might be the result of a direct membrane-disturbing effect of LPC (which has deterging properties (44) and is reported to alter membrane structure (45)). LPC was shown to be taken up by platelets very efficiently (46); therefore, its effect might also be caused by an intracellular process. It inhibits stimulation of the adenyl cyclase system in various cell types and stimulates guanyl cyclase, possibly leading to enhancement of the cytoplasmatic $\mathrm{Ca}^{++}$level and, consequently, to phospholipase activation (47). However, it might well be that LPC serves a function in trapping free arachidonic acid before it can be converted to $\mathrm{TXA}_{2}$ so that the net result of a change in platelet $L P C$ is uncertain. The observation that platelet LPC is higher, the higher the platelet AA content (Fig.10.5.), may be explained by assuming that a high $A A$ content in the phospholipids creates a possible risk of free $A A$ and hence needs a high concentration 


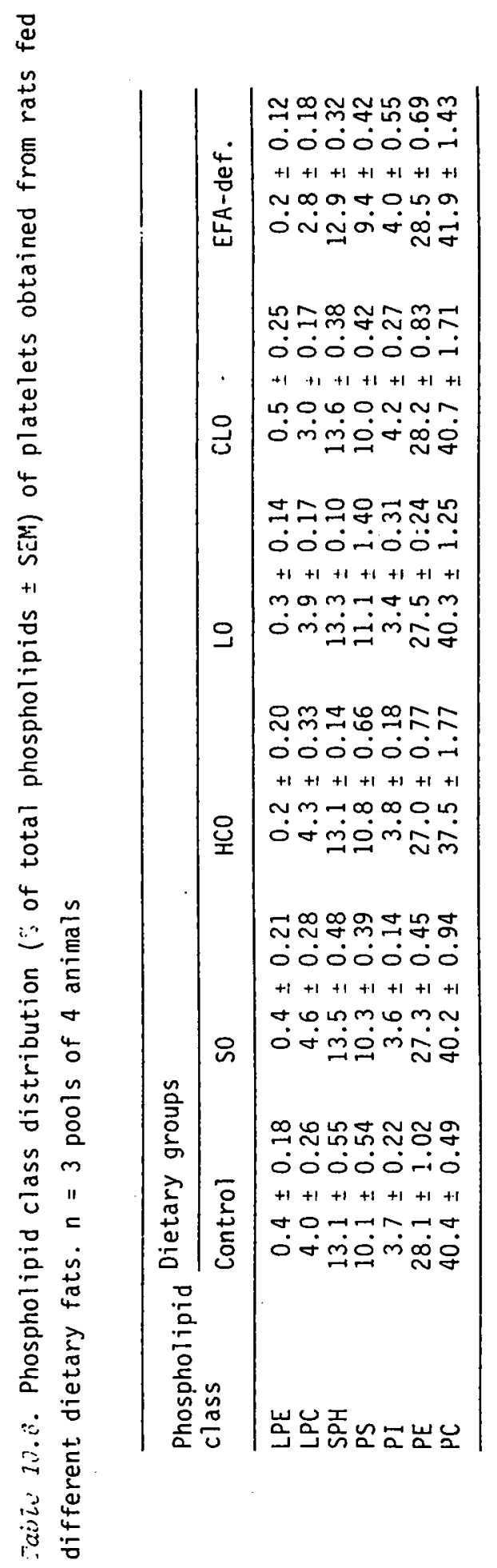




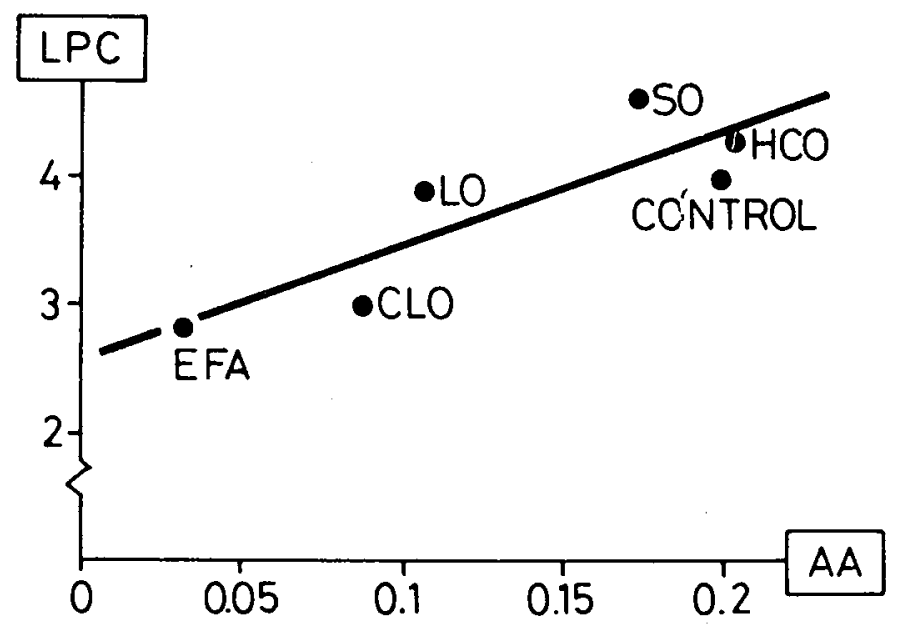

lig. 10... Relationship between platelet arachidonic acid content (AA, $\mu \mathrm{mol} . \mathrm{mg}$ protein ${ }^{-1}$ ) and the amount of lysolecithin in platelets (LPC, umol. mg protein $\left.{ }^{-1}\right)$. Data calculated from the results given in Tables $10.5,10.6$ and 10.12 .

$Y=2.56+9.01 X ; \quad r=0.87 ; P<0.05$.

of an effective free-AA scavenger. Further investigations into the role of platelet LPC seem justified.

Our TLC procedure did not allow discrimination between PE and PPE (plasmalogen form of PE, see Chapter 2, section 5.2.). A pilot study indicated that about $40 \%$ of PE was in the plasmalogen-form. Moreover, LPE found upon repeated platelet washing appeared to be due to PPE-breakdown.

\subsubsection{Fatty_acid_composition_of__latelelet_phospholigids}

The fatty acid composition of the different phospholipid classes is given in Tables 10.7.-10.11. From these results and those reported in Table 10.6. (phospholipid class distribution), the total phospholipid fatty acid composition was calculated (see Table 10.12.).

Apart from SPH, which has a very peculiar fatty acid composition ( $\because$ ide infra), the differences between the groups in regard to the fatty acid composition of total phospholipids, are a rerlection of those between the various phospholipid classes. The most prominent changes are observed with the long-chain polyunsaturated fatty acids. The arachidonic acid $(20: 4(n-6))$ content is almost similar in the control-, SO- and HCO groups, 
๓ก ๙ัญ

○ $0 \dot{0}$

$+1+1$

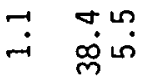

mon

षं $\dot{0}$

+

W

0 00ं 0 ․

m

$\dot{0}$

$+1+1+1+1$

$+1+$

$00-1$

$+1+1$

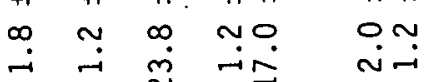

ํㅗㄷ

$\stackrel{0}{\Xi}$

$\dot{m} \dot{\dot{m}} \dot{0}-$

$\rightarrow$

m

눅융영

0ं一்

$+1+1+1+1+1+1$

$\because \infty m \sim m \infty$

오

लंखिंष्म

눈ํํำ

0ं0்

$+1+1+1+1$

?mo9?

migini

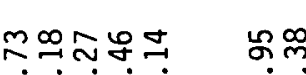

نंم்

$+1+1+1+1+1$

0ं

융요

சं

$+1+1+$

$+1$

mo $\cong 0$

ㅇ.

4

$\pm$

응

言

0

뭉

\%

ثे

¿?

둥 8 요

0ं $\dot{0}$

$+1+1+1+1$

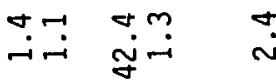

$+1$

$\stackrel{+}{5}$

iे

$\stackrel{\circ}{\circ}$

$\frac{1}{4}$

\&

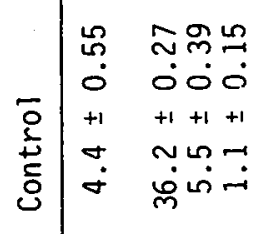

i.

$+1+1$

$\underset{v}{\square} \quad \dot{v}$

$\frac{n}{n}$

I

$\pm$

प)

客

a

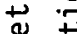

品

$+\frac{1}{4}$

$\bar{a}>$

$\therefore \bar{\delta}$ 


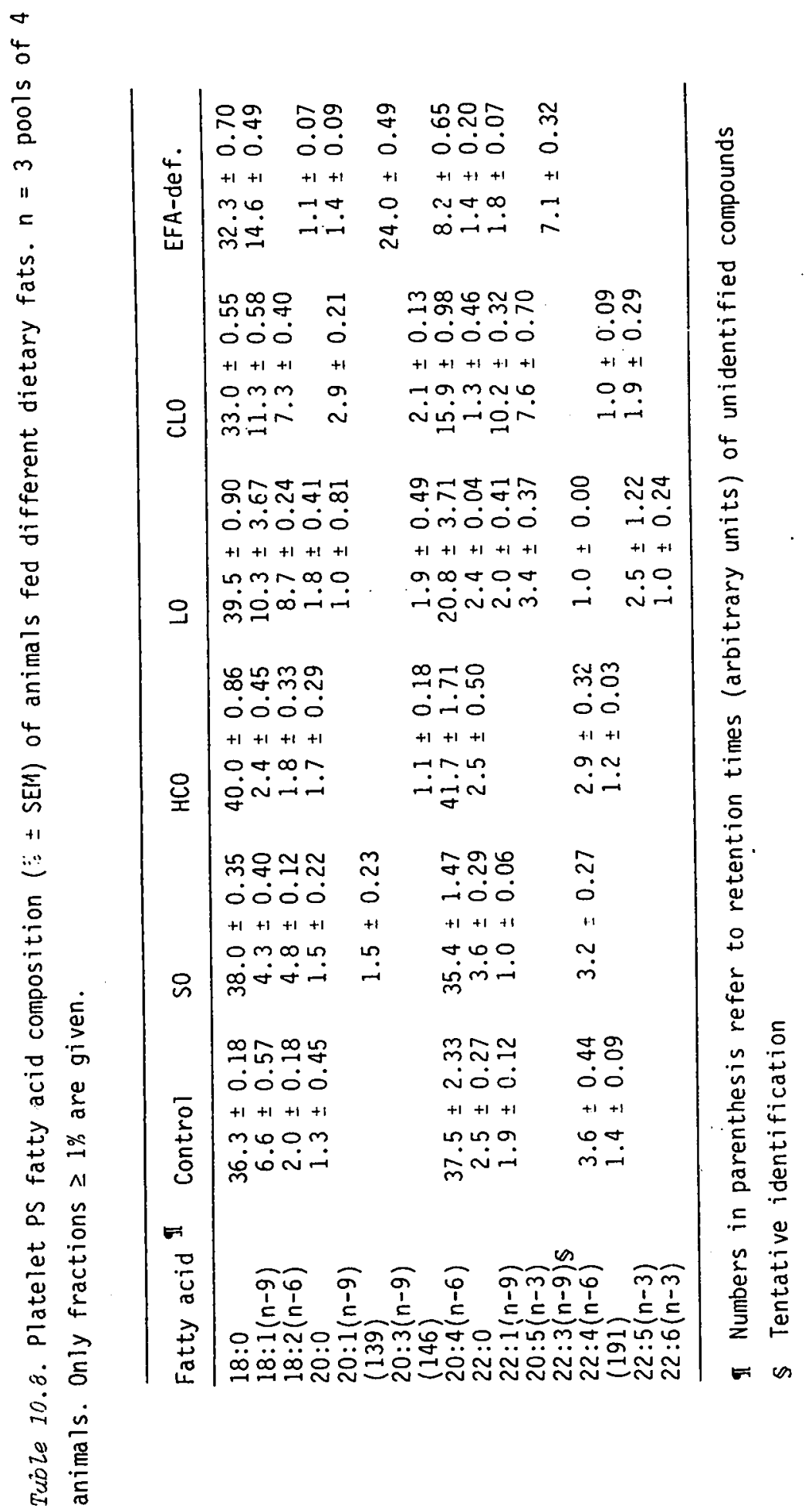


whereas it is significantly reduced in the LO, CLO and EFA-deficient groups. As to the latter group, this finding is not surprising because the dietary AA-precursor, linoleic acid (18:2 (n-6), LA) is lacking. "In the LO- and CLO groups, however, LA is fed in the same amounts as in the control group, so a (relative) precursor deficiency cannot be the reason for the reduced AA content observed in these groups. The most likely explanation for this is the inhibition of LA-desaturation (the key-step in $A A$ biosynthesis, see Chapter 2, section 2.2.) by $\alpha-1$ inolenic acid $(18: 3(n-3), a L A)$ in the LO-diet and by $20: 5(n-3)$ and $22: 5$ and $6(n-3)$ in the CLO-diet (Tables 6.2. and 9.1.). Due to this inhibition of the LA metabolism, the LA content is somewhat enhanced in the LO and CLO groups. The higher LA contenti in the SO group is most probabiy due to the large amount of LA in the SO diet.

Timnodonic acid $(20: 5(n-3), T A)$ and $22: 5(n-3)$ are increased in the LO group, which will be the result of the active desaturation and chain elongation of $\alpha-L A$ present in the $L 0$ diet. The enhanced concentrations of TA and 22:5(n-3) observed in the platelet phospholipids of CLO-fed animals are caused by the $r$-ther high content of these fatty acids in cod-liver oil (see Table 9.1.).

In EFA-deficiency, lack of LA and $\alpha-L A$ enables oleic acid to become desaturated and elongated, thus giving rise to the formation of mead acid (MA, 20:3(n-9), see Chapter 2, section 2.2.). Most probably, 22:3(n-9) is synthesized as well.

The higher contents of 14:0 and 18:0 observed in the HCO group are connected with the rather high dietary concentrations of these fatty acids.

The lower 16:0 content of the platelet phospholipids in this group cannot be explained from a dietary composition. Why this low platelet 16:0 level is not compensated for by a higher content of fatty acids of the $\left(r_{i}-7\right)$ family, cannot yet be accounted for.

In general, the fatty acid compositions of the different phospholipid classes are in agreement with those mentioned in the literature $(3-6,9$, $10,13,38$ ): the $A A$ content (or that of its 'replacers' $T A$ and MA) is highest in PI, PS and PE, where PE is the main phospholipid class of the long-chain (>20 C-atoms) polyunsaturated fatty acids and of the dimethylacetals (originating from PPE).

The fatty acid composition of SPH is greatly influenced by that of the diet. The diet-induced changes are only observed in the very long-chain 


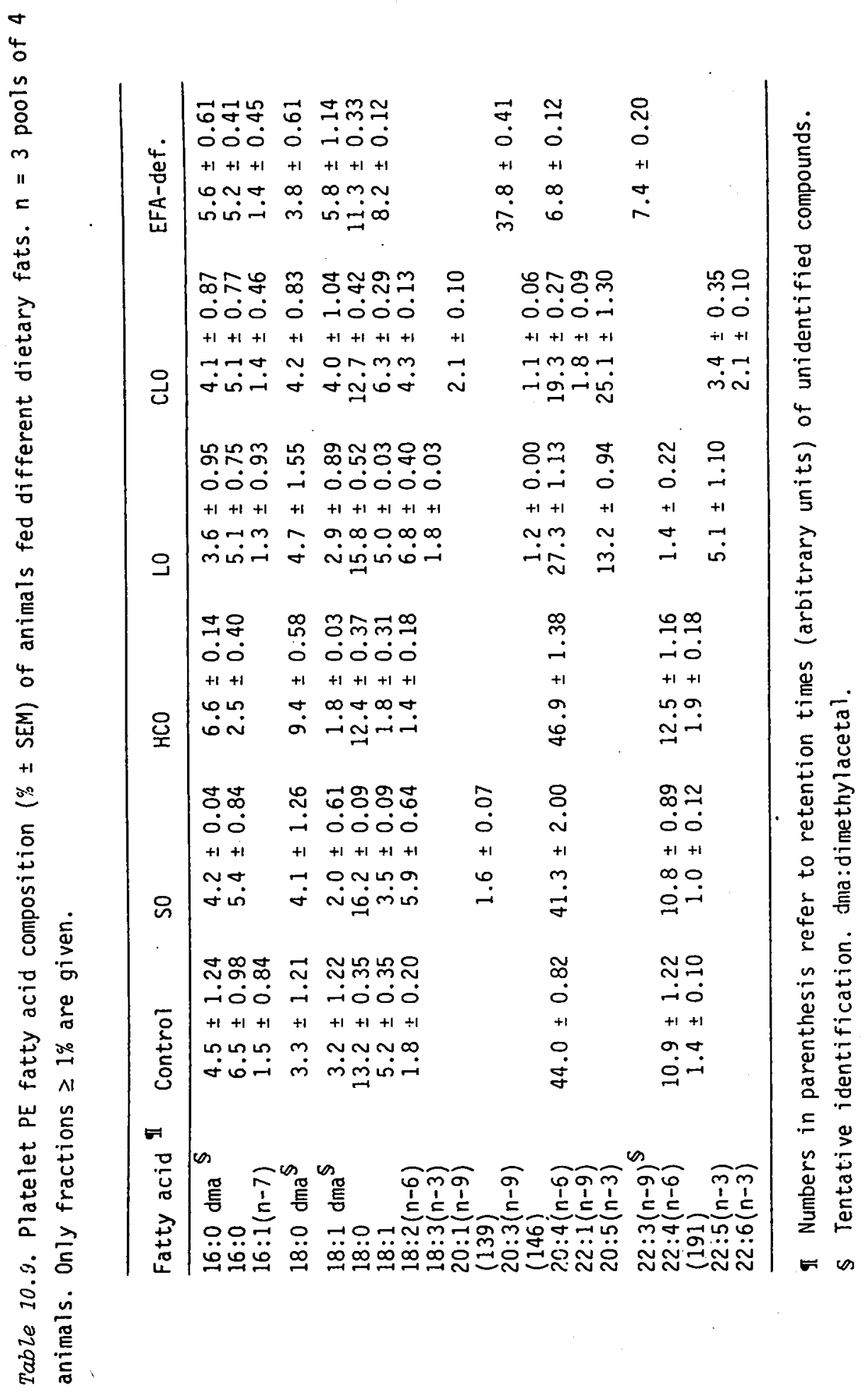




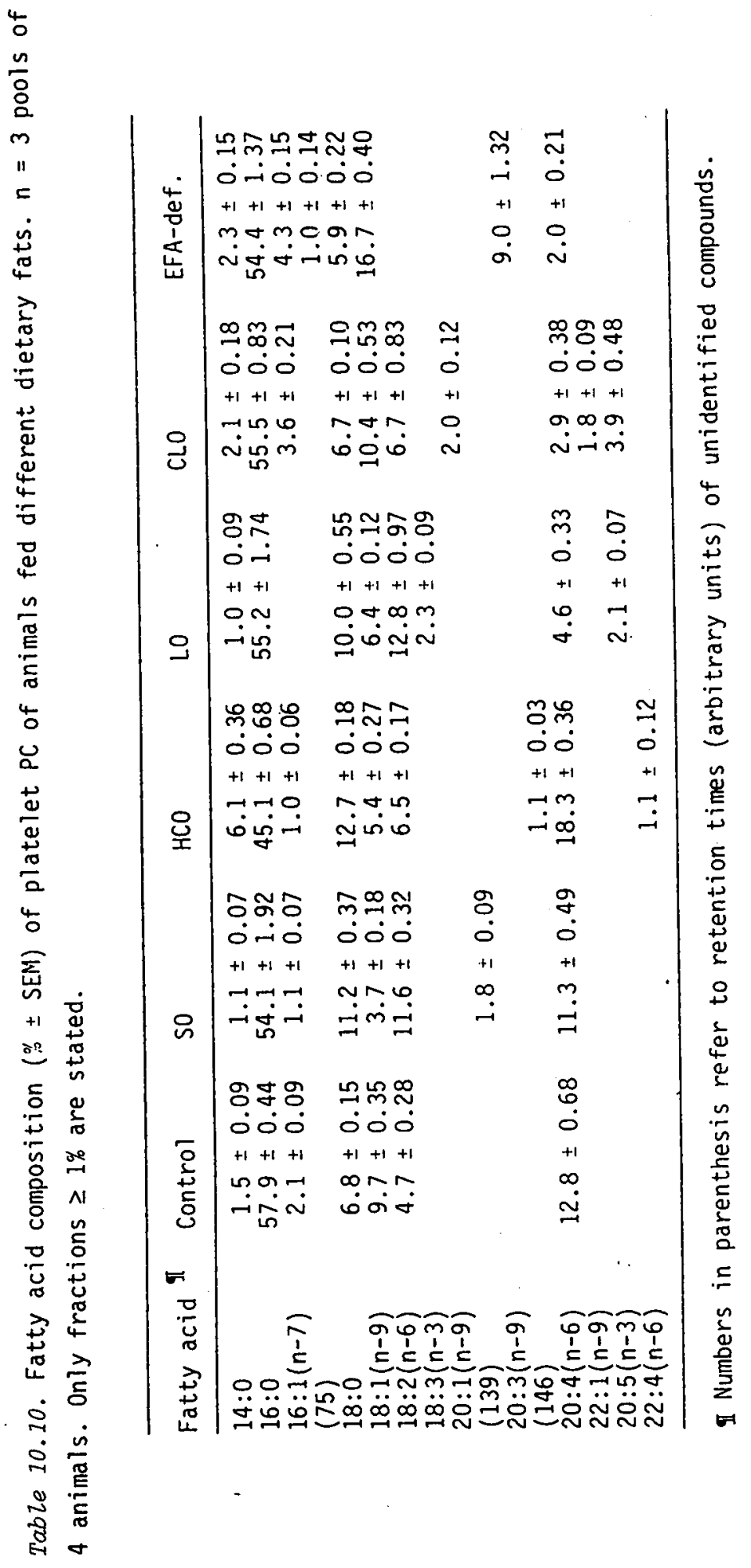




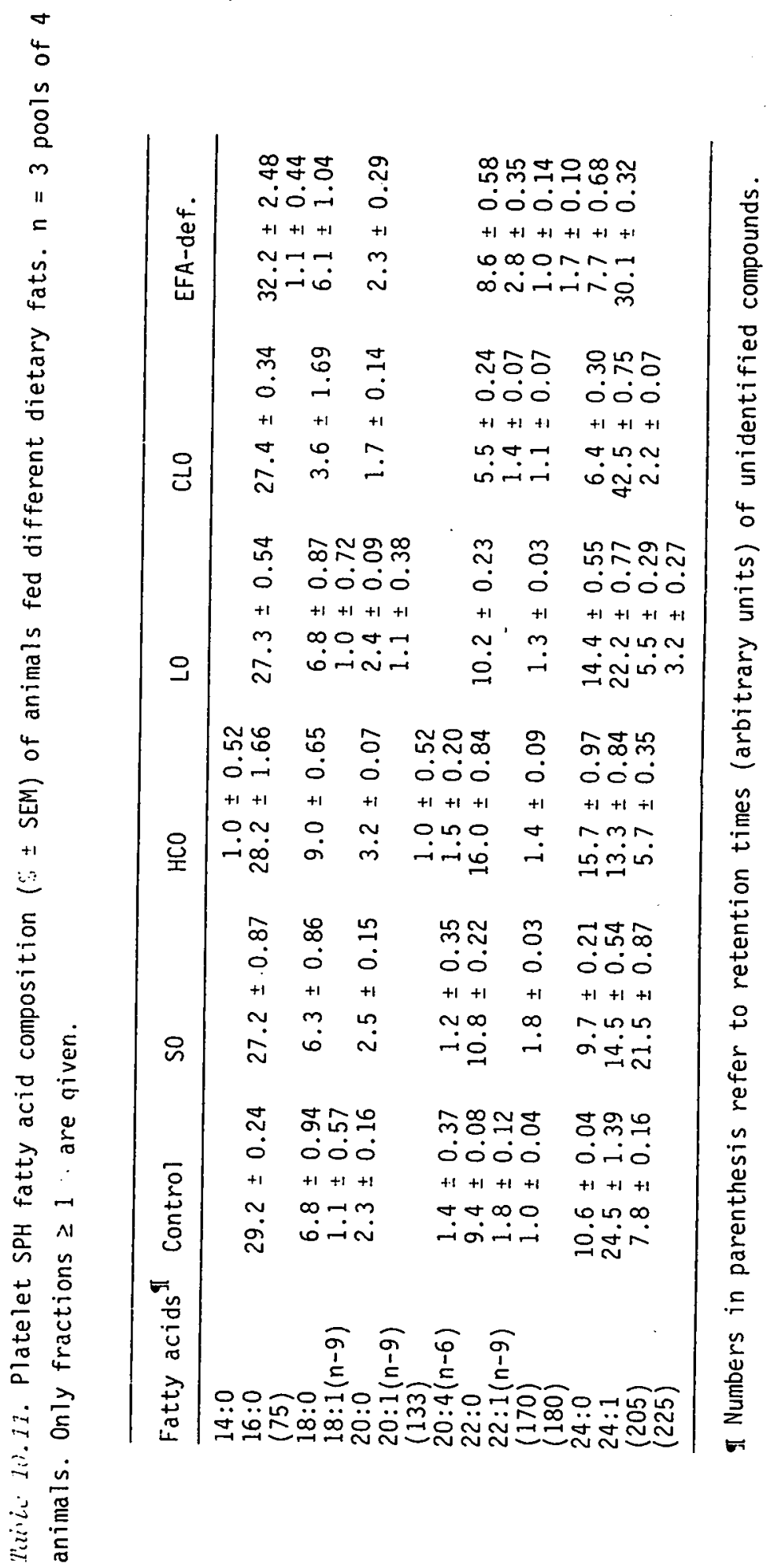


Table 10.12. Fatty acid composition ( $\% \pm$ SEM) of platelet total phospholipids. Only fractions $\geq 1 \%$ are mentioned.

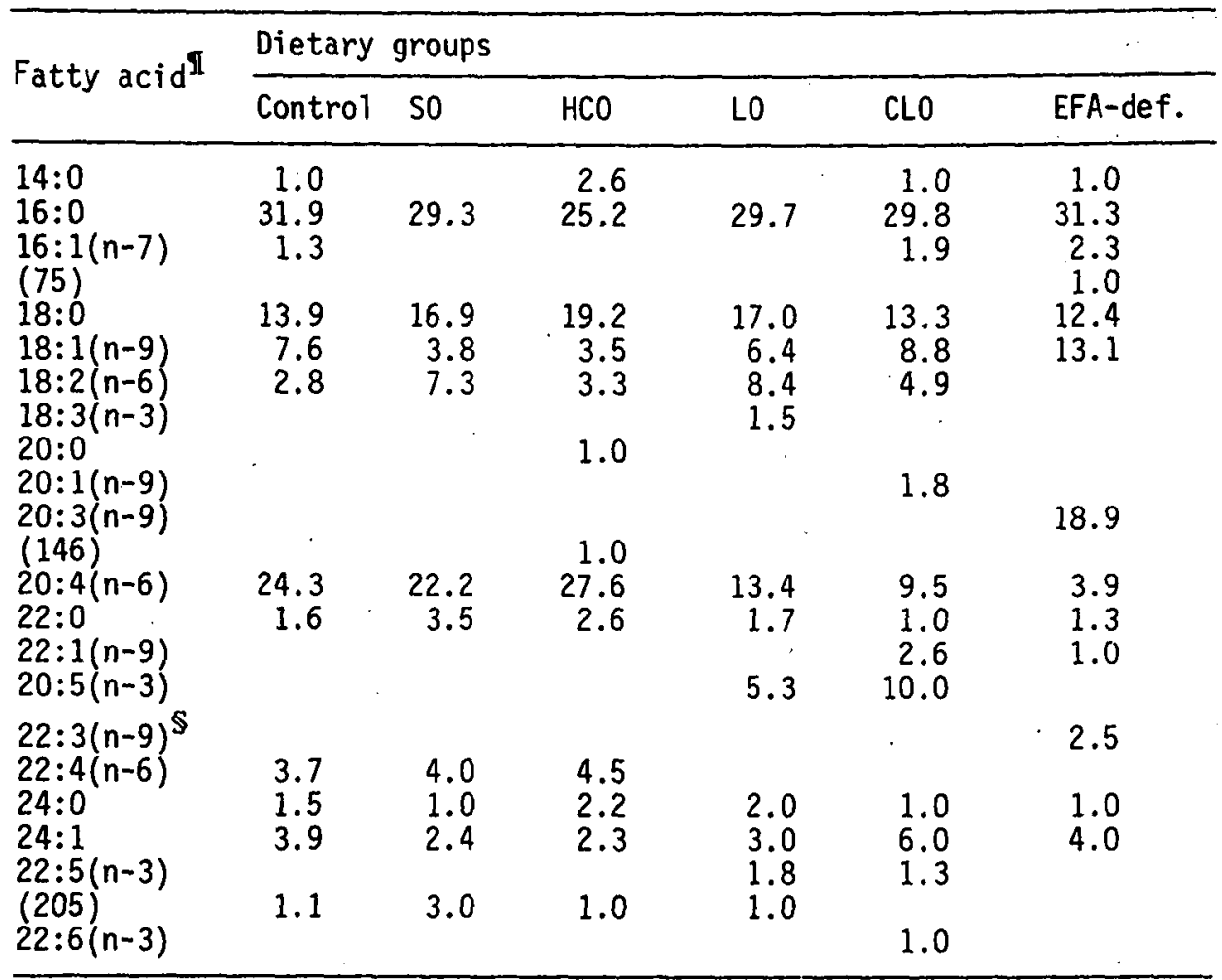

I Numbers in parenthesis refer to retention times (arbitrary units) of unidentified compounds.

$\$$ Tentative identification.

fatty acids 24:0 (increased in the HCO- and LO groups and decreased in the CLO- and EFA-deficient groups) and 24:1(n-9)(strikingly enhanced in EFA-deficiency and in the CLO group and considerably decreased upon SOand HCO feeding). SO feeding also causes a distinct increase in the content of an unidentified compound (retention time 205 arbitrary units) the functional role of which has not yet been investigated. 
10.5. Relationship between the arachidonic acid content of platelet phospholipids and the HHT production of activated platelets

\subsubsection{Absolute_AA_content}

Starting from the platelet phospholipid content (umol.mg ${ }^{-1}$ platelet protein), the phospholipid class distribution (\% of total phospholipids), the fact that 1 umol phospholipid equals 2 umol fatty acids (except for SPH, see Chapter 2, section 5.2.) and from the fatty acid composition of the different phospholipid classes, it is possible to give an estimate of the platelet phospholipid fatty acid composition (nmol. $\mathrm{mg}^{-1}$ pratelet protein). Results obtained in this way for arachidonic acid were plotted

(A)

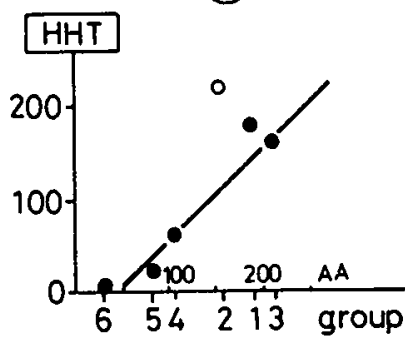

(C)

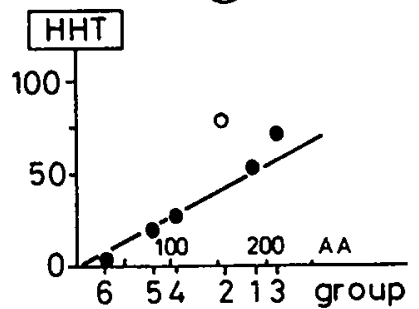

(B)

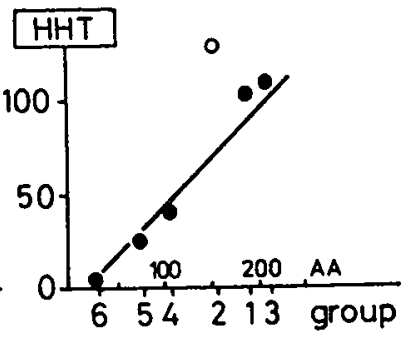

(D)

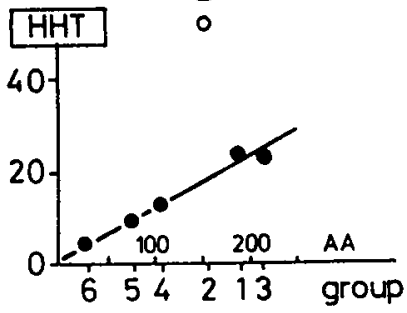

Fig.10.6. Relationship between arachidonic acid content of platelet total phospholipids (AA, nmol.mg platelet protein ${ }^{-1}$ ) and HHT production (ng.10 platelets) of platelets activated with different amounts of collagen. Each point represents the mean of 2-3 platelets pools, each obtained from 4 animals.

A: $200 \mu 1$ collagen; $Y=-42+1.0 X ; r=0.92 ; n=11$.

B: $100 \mu 1$ collagen; $Y=-17+0.6 x ; r=0.95 ; n=11$.

C: $75 \mu$ l collagen; $Y=-6.9+0.33 X ; r=0.85 ; n=11$.

$D: 50 \mu$ l collagen; $Y=1.1+0.11 X ; r=0.95 ; n=10$ :

SO group (Group 2, 0 ) not included for calculation of correlation.

Explanation of group code: 1: Control; 2: SO; 3: HCO; 4: LO; 5 : CLO;

6: EFA-deficient. 
against the HHT production (ng. $10^{9}$ platelets) of activated platelets to establish a possible relationship between these two parameters. Figs. 10.6. A-D show this relationship for the AA content of total platelet phospholipids and the HHT productions of these platelets upon their activation with four different collagen doses. From these figures it is evident that, in general, HHT production is higher, the larger the amount of arachidonic acid in platelet phospholipids. However, this relationship is not absolute, because platelets from the SO group produce mors HHT than might be expected from the relationships observed for the other groups. This is particularly clear at the lowest collagen dose.

Figs. 10.7.A-D show a qualitatively similar relationship between platelet HHT production upon activation with $100 \mu 1$ collagen and the AA content

(A)

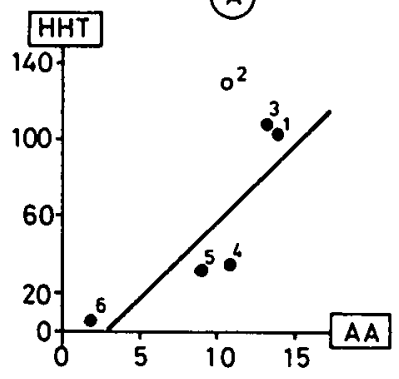

(c)

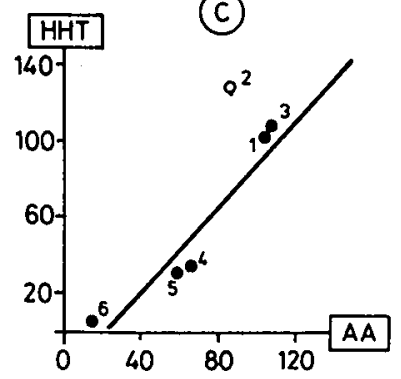

(B)

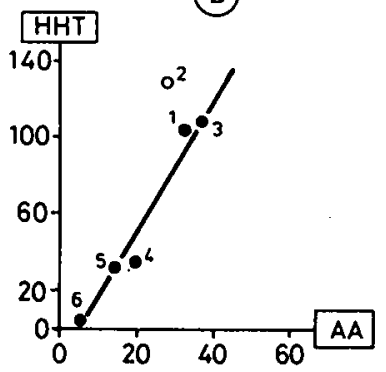

(D)

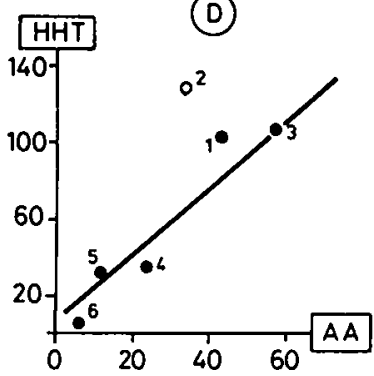

Fig. 10.7. Relationship between the arachidonic acid content of the various phospholipid classes (AA, nmol.mg platelet prote $i^{-1}$ ) and the HHT production (ng. $10^{-9}$ platelets) of platelets activated with $100 \mu l$ collagen.

Each point represents the mean of 2-3 platelet pools, each obtained from 4 animals.

A: $P I ; Y=-22.7+8.10 X ; r=0.87 ; n=14$.

B: PS; $Y=-17.7+3.49 X ; r=0.95 ; n=14$.

$C: P E ; Y=-23.0+1.13 X ; r=0.91 ; n=14$.

$D: P C ; Y=6.8+1.77 X ; r=0.87 ; n=15$.

Group $2(\mathrm{SO}, \mathrm{O})$ not included for calculation of correlations. For explanation of group codes, see legend of Fig.10.6. 
of the various AA-containing phospholipid classes. This is not surprising because there is a fairly close correlation between the AA contents of total phospholipids and those of the different phospholipid classes: any. increase in the $A A$ content of total phospholipids is proportionally distributed over the various $\mathrm{PL}$ classes, although there is a tendency for PI to become 'saturated' first and PC last (Fig.10.8.).

\subsubsection{Relative AA content}

Several long-chain polyunsaturated fatty acids have been shown to compete with $A A$ for the CO-enzyme system so that they inhibit AA conversion (48$50,67)$. Since these 'competitors' are also located at the 2-position of phospholipids, and the platelet phospholipase activity does not seem to be AA-specific (51, see also Chapter 9, section 7.2.2.), these fatty acids might be expected to become released simultaneously with AA. The following fatty acids are likely to affect AA conversion by $C 0: 22: 6(n-3)$; $22: 5(n-3) ; 20: 5(n-3) ; 18: 3(n-3) ; 22: 4(n-6) ; 18: 2(n-6) ; 22: 3(n-9)$ and $20: 3(n-9)$.

No detailed information is available on the mutual differences in affinity for the $C O$ enzyme system. Moreover, for most of these fatty acids the inhibition characteristics of $A A$ oxygenation have not been determined.

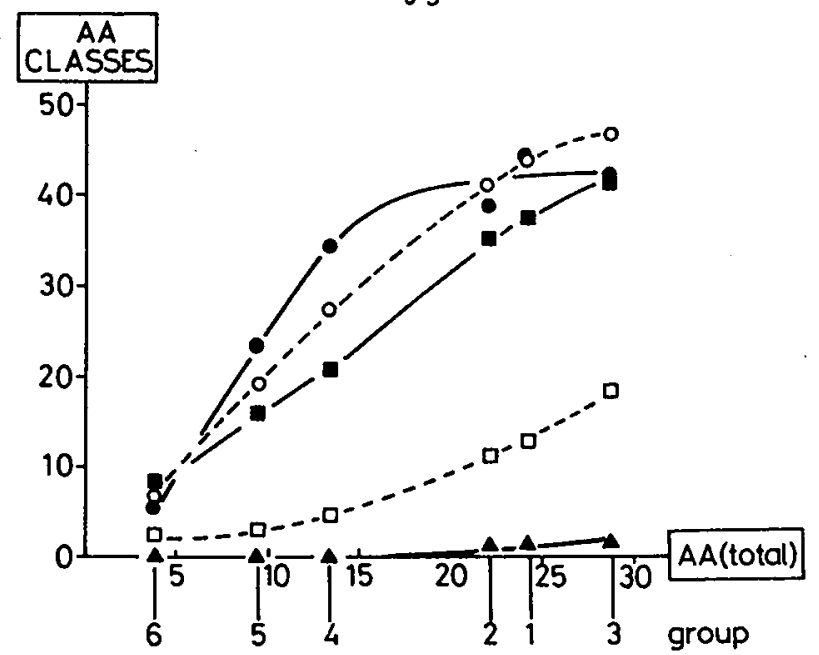

Fig. 10.8. Relationship between the AA content (\% of total fatty acids) of platelet total phospholipids (AA(total)) and that of the various phospholipid classes (AA classes). For explanation of group code, see legend of Fig.10.6. 
Therefore, it is supposed, as a first approximation, that for all fatty acids, the CO affinity is similar to that for $A A$ and that all 'competitors' are equally effective as inhibitors of $A A$ oxygenation. On the basis of these presumptions, a 'relative AA content' of platelet phospholipids can be calculated according the equation:

$$
\text { relative } A A \text { content }=\frac{\% A A}{\% A A+\sum \% \text { competitors }}
$$

Figs.10.9. and 10.10.A-D demonstrate the relationship between the relative $A A$ content $(A A(r e 1))$ of platelet phospholipids and the HHT production of these platelets following activation with collagen. In essence, the results are similar to those obtained for the uncorrected AA contents (Figs.10.6. and 10.7.). Also in the present case is a good linear correlation observed between both parameters for total phospholipids as well as for the various phospholipid classer and the values obtained for the SO group

(A)

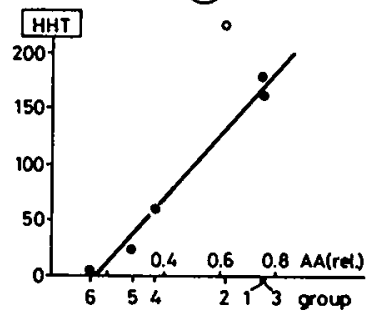

(C)

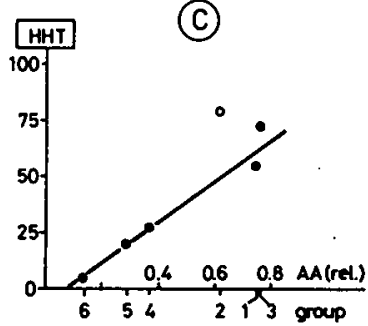

(B)

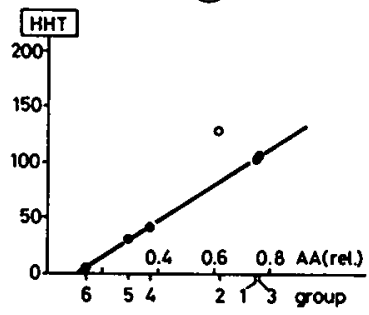

(D)

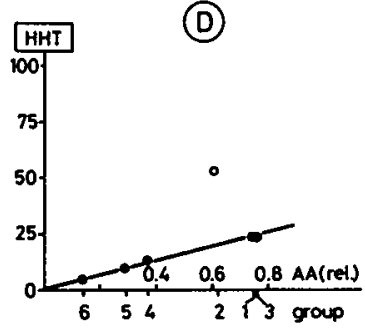

Fig. 10.9. Relationship between the relative arachidonic acid content of platelet total phospholipids (AA(rel), see text section 10.5.2.) and HHT production (ng. $10^{-9}$ platelets) of platelets activated with different amounts of collagen. Each point represents the mean of 2-3 platelet pools, each obtained from 4 animals.

A: 200 Hl collagen; $Y=-46+290.4 X ; r=0.94 ; n=11$.

B: $100 \mu$ l collagen; $Y=-17+163.6 X ; r=0.95 ; n=11$.

C: $75 \mu 1$ collagen; $Y=-6.6+90.1 X ; r=0.84 ; n=11$.

D: $50 \mu 1$ collagen; $Y=0.9+30.7 X ; r=0.95 ; n=10$.

So-group (Group 2, o) not included for calculation of correlations. For explanation of group code, see legend of Fig.10.6. 
again do not fit this relationship satisfactorily.

From the correlation coefficients, $r$, given in the legends to Figs. 10.6, $10.7,10.9$. and 10.10 , the coefficients of determination $\left(r^{2}\right)$ can be calculated, which are a measure of the fit of the regression calculated: the higher the $r^{2}$, the better the fit. Table 10.13. shows that correction of the $A A$ content of platelet phospholipids for the presence of Fatty acids competing with $A A$ for the $C O$ enzyme system, does not systematically improve the relationship with platelet HHT production. Even at the strongest platelet stimulus $(200 \mu 1$ collagen), this correction had no effect al though, under these conditions, competitors are the most likely to become liberated from the phospholipids (see section 10.3.4.). This lack of improvement

(A)

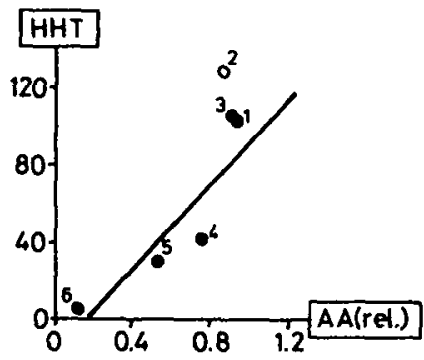

(C)

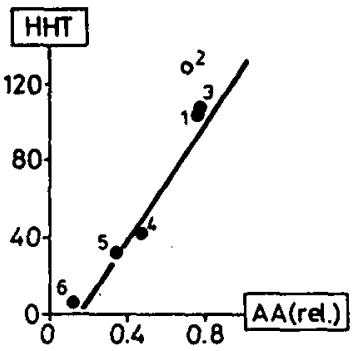

(B)

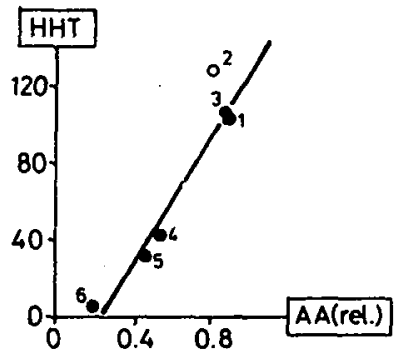

(0)

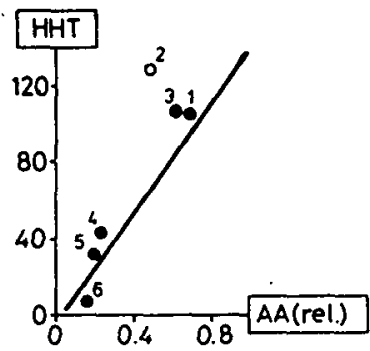

Fig. 10.10. Relationship between the relative arachidonic acid content ( $A A(r e 1)$, see text section 10.5.2.) of the various platelet phospholipid classes and the HHT production (ng. $10^{-9}$ platelets) of platelets activated with $100 \mu 1$ collagen. Each point represents the mean of 2-3 platelet pools, each obtained from 4 animals. For explanation of group code, see legend of Fig.10.6.

A: $P I ; Y=-18.5+114.2 X ; r=0.85 ; n=14$.

B: PS; $Y=-34.1+157.5 X ; r=0.95 ; n=13$.

$C: P E ; Y=-22.1+152.3 X ; r=0.90 ; n:=14$.

$D: P C ; Y=-2.9+146.7 X ; r=0.91 ; n=15$.

Group $2(50,0)$ not included for calculation of correlations. 
Table 10.13. Coefficients of determination $\left(r^{2}\right)$ of the correlation between the AA-content of platelet phospholipids and their HHT production upon activation with collagen. $A A(r e 1)$ : $A A$ content corrected for the presence of fatty acids known to compete with AA for cyclo-oxygenase (see section 10.6.).

\begin{tabular}{|c|c|c|c|c|c|}
\hline \multirow{2}{*}{$\begin{array}{l}\text { Phospholipid } \\
\text { class }\end{array}$} & \multirow{2}{*}{$\begin{array}{l}\text { Collagen } \\
\text { dose }(\mu 1)\end{array}$} & \multicolumn{2}{|c|}{$\begin{array}{l}\text { AA content } \\
\text { (nmol.mg protein }^{-1} \text { ) }\end{array}$} & \multicolumn{2}{|c|}{$A A(r e l)$} \\
\hline & & $n$ & $r^{2}$ & $\mathrm{n}$ & $r^{2}$ \\
\hline $\begin{array}{l}\text { Total } \\
\text { Total } \\
\text { Total } \\
\text { Total } \\
\text { PI } \\
\text { PS } \\
\text { PE } \\
\text { PC }\end{array}$ & $\begin{array}{r}200 \\
100 \\
75 \\
50 \\
100 \\
100 \\
100 \\
100\end{array}$ & $\begin{array}{l}11 \\
11 \\
11 \\
10 \\
14 \\
14 \\
14 \\
15\end{array}$ & $\begin{array}{l}0.85 \\
0.91 \\
0.73 \\
0.90 \\
0.76 \\
0.91 \\
0.83 \\
0.75\end{array}$ & $\begin{array}{l}11 \\
11 \\
11 \\
10 \\
14 \\
13 \\
14 \\
15\end{array}$ & $\begin{array}{l}0.88 \\
0.90 \\
0.71 \\
0.91 \\
0.72 \\
0.91 \\
0.82 \\
0.83\end{array}$ \\
\hline
\end{tabular}

might be due to the fact that there is a strong inverse relationship between the amounts of $A A$ and its competitors in the platelet phospholipids (Fig.10.11.). In fact, the various dietary treatments resulttd in a partial replacement of platelet $A A$ by the various competitors of the $(n-3 ;$ and the (n-9) families. Only for $P C$, the relationship is not significant and it is only for this phospholipid class that correction of platelet AA for the presence of competitors results in a moderate improvement of this relationship.

\subsubsection{Conclusions}

In general, there is a good, positive, linear relationship between the AA content of platelet phospholipids and the HHT formation by these platelets upon collagen activation. This relationship hardly improves when taking into account the presence of long-chain polyunsaturated fatty acids competing with $A A$ for the CO-enzyme system. The relationships are essentially similar for total phospholipids and the various phospholipid classes. In all cases, platelets obtained from animals fed an so-enriched diet, show a deviating behaviour: their HHT production upon activation with collagen is higher than expected on the basis of the relationships found for the other groups. 


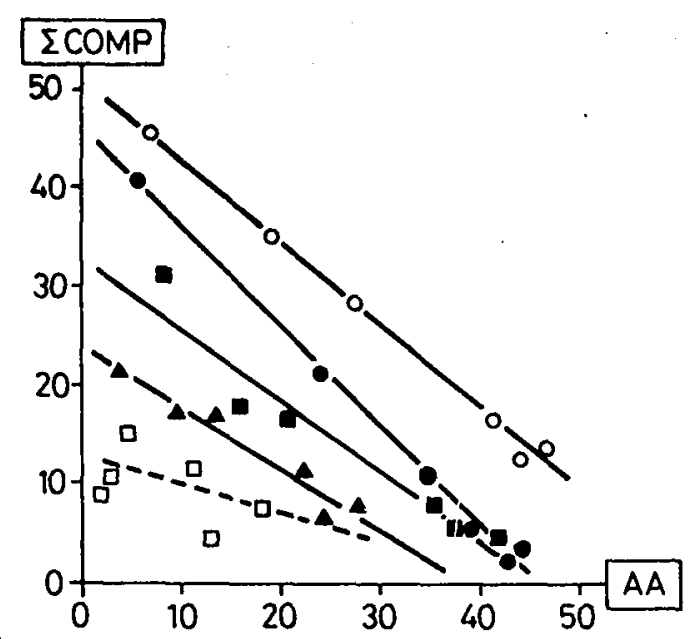

Fig. 10.11. Reiationship between the amounts (\% of total fatty acids) of $A A$ and its competitors for cyclo-oxygenase in platelet phospholipids.

-O- PI; $Y=45.9-1.01 X ; r=0.99$.

—- PS; $Y=33.1-0.72 X ; r=0.96$.

- $P$ - $; Y=50.6-0.82 X ; r=0.99$.

- - $--P C$; no significant correlation $(r=0.51)$

- $\Delta$ Total phospholipids $Y=23.9-0.62 x_{;} r=0.97$

10.6. Possible consequences of platelet lipid profile and fatty acid composition for membrane fluidity

The extracellular platelet-collagen interaction results in an intracellular series of events, leading to the formation of $\mathrm{TxA}_{2}$. This implies that a 'message' from the platelet exterior is transmitted towards the platelet interior. A higher collagen dose is likely to initiate a stronger transmembranal message because it results in the formation of more $\mathrm{TXA}_{2}$ (measured as HHT, šee section 10.3.). At a given trigger strength, however, also $\mathrm{TXA}_{2}$-formation might be expected to be modulated as a result of changes in the efficiency with which the message is transmitted across the membrane. There is ample evidence that the efficiency of such membrane-located processes is - at least in part- determined by membrane fluidity (see Chapter 2, section 3.1.). Moreover, it has recently been demonstrated that platelet orly adhere to fluid and not to crystalline phospholipid membranes (69).

In previous sections it was demonstrated that platelets of animals ted the so-enriched diet are very sensitive to the aggregating effect of a 
low dose of collagen as compared to platelets of other animals. This coincides with - and is probably caused by - an enhanced $\mathrm{TXA}_{2}$-formation (measured as HHT), which could not be explained on the basis of platelet AA-content. Therefore, a more efficient transmembranal message might be implicated, which may, for instance, result from an enhanced membrane fluidity.

As discussed in Chapter 2, biomembranes are composed of proteins, cholesterol and a mixture of phospholipids. These latter compounds contain a great variety of fatty acids as a result of which membranes do not show a sharp phase transition at a distinct temperature, as observed for pure phospholipid species, but a broad phase transition profile over a wide temperature range.

Because of their low phase transition temperatures, unsaturated fatty acids are likely to change this profile and, by affecting the ultimate state of the membrane, they may increase membrane fluidity thereby affecting membrane function.

Similar but opposite effects may be expected when increasing the saturated fatty acid content of biomembranes (52).

Above the phase transition temperature, the presence of cholesterol strikingly lowers the mobility of phospholipid-hydrocarbon groups as a result of an increase of the viscosity of their micro-environment. Under this condition, cholesterol lowers membrane fluidity, which has been shown to have functional consequences $(53-56)$. Below the phase transition temperature, cholesterol has an opposite effect since it decreases the hydrophcbic interactions between the hydrocarbon groups of membrane phos-

Table 10.14. Effect of different dietary fats on the unsaturation and saturation indices of platelet phospholipids. For methodological details: see section 10.6.).

\begin{tabular}{llrlll}
\hline \multirow{2}{*}{ Group } & \multicolumn{2}{l}{ Unsaturation index } & & \multicolumn{2}{l}{ Saturation index } \\
\cline { 2 - 3 } \cline { 5 - 6 } & index & $\%$ of control & & index & $\%$ of control \\
\hline Control & 130.4 & 100 & 0.38 & 100 \\
SO & 125.6 & 96.3 & 0.40 & 105.3 \\
HCO & 140.8 & 108.0 & 0.38 & 100.0 \\
LO & 119.8 & 91.9 & 0.42 & 110.5 \\
CLO & 131.4 & 100.8 & 0.35 & 92.1 \\
EFA-def. & 100.2 & 76.8 & 0.47 & 123.7 \\
\hline
\end{tabular}


pholipids and thus prevents a tight packing of the lipid molecules. Therefore, cholesterol may be regarded as a stabilizer of the plasticity of biomembranes.

Since the dietary fat type appeared to affect the fatty acid composition of platelet phospholipids (section 10.4.4.) and is also known to influence cholesterol metabolism (57) it may, as a result, change the fluidity of the platelet membrane and thereby its function. We therefore investigated the dietary influences on the unsaturation- and saturation indices of platelet phospholipids and on the platelet cholesterol content.

\subsubsection{Unșaturatation index}

The unsaturation index (U.I.) of the platelet phospholipids was calculated from table 10.12. according to the equation:

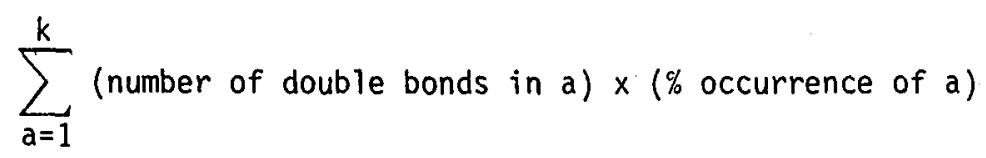

for each fatty acid in a group of $k$ fatty acids (58). This parameter relates to the classical chemico-biochemical term known as iodine value and can be taken as an indicator of membrane fluidity (59). The results (Table 10.14.) indicate that -as compared to the control group-only the EFA-deficient group shows a distinct deviation, the U.I. being considerably depressed. Platelets obtained from animals fed the fat-enriched diets show only small differences.

\subsubsection{Saturatation_index}

A saturation index was calculated by taking the sum of the proportional amounts of saturated fatty acids in platelet total phospholipids given in Table 10.12. ( $\Sigma$ SAFA) and correcting it for the degree of unsaturation indicated by the U.I., so that:

$$
\text { S.I: }=\frac{\Sigma \text { SAFA }}{\text { U.I. }}
$$

The results are given in Table 10.14. which again indicate that only platelets of the EFA-deficient groups show a considerable difference with respect to the control group. Platelets obtained from animals fed the 
fat-enriched diets show hardly any difference. The relative results $(\%$ of control group) remained essentially similar after taking into account the chain length of the fatty acids.

\subsubsection{Cholesterol-phospholipid_ratio}

For platelets it has been shown that increasing the cholesterol-phospholipid $(C / P)$ molar ratio to values above normal results, in an increased membrane microviscosity (as calculated from fluorescence probe analysis $(60,61))$, in an increase in platelet aggregability (53), in a resistance to the aggregation inhibitor $\mathrm{PGE}_{1}(55)$ and in an enhancement of $\mathrm{TxB}_{2}$ formation following standardized platelet activation (56). We calculated the $C / P$ ratio for the various dietary groups using the platelet phospholipid values of Table 10.5. and the results of cholesterol determinations (Catalase method) both measured in platelet total lipid extracts (Table 10.15.). The data obtained are given in Table 10.15. and although the value for the EFA-deficient group tends to be somewhat diminished, the difference between the groups was not significant $\left(P_{2}>0.20\right)$.

\subsubsection{Discusssion}

As mentioned already, our measurements were performed with lipid extracts of whole platelets and not with extracts of platelet membranes; therefore, the relevance of our findings might be doubted. However, Marcus et al. (13) showed that, at least for human platelets, there are only minor

Tabie 10.15. Effect of different dietary fats on platelet cholesterol content ( $\mu \mathrm{mol} . \mathrm{mg}$ protein ${ }^{-1}$ ) and the cholesterol-phospholipid molar ratio $(C / P)$ of platelet total lipids. Values are the mean \pm SEM of four platelet pools, each prepared from 4 animals.

\begin{tabular}{lll}
\hline Group & $\begin{array}{l}\text { Platelet cholesterol } \\
\left(\mu \mathrm{mol} . \mathrm{mg} \text { protein }^{-1} \text { ) }\right.\end{array}$ & C/P ratio \\
\hline Control & $0.239 \pm 0.0201$ & $0.54 \pm 0.052$ \\
SO & $0.224 \pm 0.0251$ & $0.54 \pm 0.031$ \\
HCO & $0.223 \pm 0.0204$ & $0.60 \pm 0.099$ \\
LO & $0.240 \pm 0.0094$ & $0.57 \pm 0.046$ \\
CLO & $0.271 \pm 0.0150$ & $0.53 \pm 0.066$ \\
EFA-def. & $0.202 \pm 0.0104$ & $0.46 \pm 0.047$ \\
\hline
\end{tabular}


differences between whole platelets and their membranes as far as the phospholipid fatty acid composition is concerned. Moreover, our C/P ratic -data (Table 10.15.) are in good agreement with those obtained by others for platelet membranes (62), which strongly suggests that also as regards the lipid profile, there are only minor differences between whole platelet lipids and membrane lipids.

Neither the degree of (un)saturation of the fatty acids of platelet total phospholipids nor their cholesterol/phospholipid molar ratio are considerably changed by the type of dietary fat. Only for EFA-deficient platelets, do changes in fatty acid composition indicate a decreased membrane fluidity. In EFA-deficiency, the cooperativity of various membrane-bound allosteric enzymes is significantly affected (59). Moreover, the activity of the sarcoplasmic calcium pump is diminished (63). Since these enzyme functions are likely to be regulated by membrane fluidity (52), the changes in platelet phospholipid (un)saturation as observed for EFA-deficient platelets, may indeed have certain implications in regard to their function.

Considering the other results, it seems rather unlikely that the dietary fat-induced changes in collagen-sensitivity of the blood platelets can be explained on the basis of changes in membrane microviscosity as far as could be ascertained by our measurements. However, it should be realized that the parameters we determined, only concern overall microviscosity at best. Consequently, local changes, e.g. as result of a redistribution of certain lipid domains (64), would not have been detected. Therefore, our negative findings do not necessarily imply that the changes in collagen sensitivity, as induced by the unsaturated fat-enriched diets, did not result from changes in membrane microviscosity. Only a more direct measurement of this parameter e.g. by fluorescence probe analys is (66), electron spin resonance or nuclear magnetic resonance techniques will give the final answer here.

\subsection{Summary}

Feeding rats different dietary fats did not cause major changes in platelet total phospholipid content and total phospholipid class distribution. The fatty acid compositions of the platelet phospholipids reflect that of the diet. Major changes were observed for the polyunsaturated fatty 
acids of the $(n-6)$ and $(n-3)$ families, which could be explained on the basis of the metabolic interactions between the dietary fatty acids of these families. Platelets from SO-fed animals showed a marked quantitative increase of an unidentified fatty acid in SPH. In general, there was a close relationship between the diet-induced changes in fatty acid composition of the total phospholipids and those of the various phospholipid classes. A striking, positive correlation was found between the LPC- and AA contents of blood platelets, which suggests a functional interaction between these two parameters. There was also a highly significant, positive correlation between the AA content of platelet phospholipids and the $\mathrm{TxA}_{2}$ production by these platelets (measured as HHT) upon collagen activation. Platelets from So-fed animals did not fit this relationship because their HHT-production was too high. The relationships observed did not chancje when taking into account the presence of other long-chain poly -unsaturated fatty acids, known to compete with AA for the CO enzyme system.

Nothwithstanding the great differences between the fatty acid compositions of platelet 'shospholipids caused by feeding different dietary fats, the average degree of (un)saturation of the phospholipids did not change. Only for EFA-deficient platelets was the degree of unsaturation considerably depressed as compared to that of control platelets. Changes in the cholesterol/phospholipid molar ratio of the platelets did not take place upon feeding different dietary fats, so that, except for the EFA-deficient group, changes in membrane fluidity may not have occurred either. However, more appropriate techniques to measure membrane microviscosity are required to establish whether changes in membrane microviscosity account for the explanation of the clear diet-induced differences in platelet functions, which, in the present experiment, were reflected by the significant differences observed in the collagen-induced aggregation of PRP.

This aggregation appeared to depend on platelet $T \times A_{2}$ production only, if the $A A$ content of platelet phospholipids was within a normal range (20-30\% of the total fatty acids). At lower AA levels, a TxA 2 -independent release- and aggregation pathway takes over. In EFA-deficient platelets, however, this mechanism is less efficient, possibly because of the diminished platelet-to-collagen adhesion. Evidence obtained indicate that diets high in unsaturated fatty acids, cause an enhancement of the collagen sensitivity of platelets. Platelets from animals fed a saturated fat-containing diet show a collagen response lower than that of control 
platelets, which is most probably due to a depressed sensitivity towards the aggregating effect of $\operatorname{TXA}_{2}$.

The production of $\mathrm{TXA}_{2}$ (measured as HHT) and HETE (the lipoxygenase product of AA) by platelets activated with collagen, is higher, the larger the collagen dose. The dose-response curves are significantly influenced by the type of dietary fat. The same holds for the HETE/HHT ratio which -at higher activation levels- is very high in animals fed cod-liver oil. This finding together with some other results reported in Chapter 9 , section 7.2.2. Ted us to assume that timnodonic acid (TA) is liberated from platelet phospholipids only after a strong stimulus. Moreover, indications were obtained for at least two different TA-pools, one of which was more easily released from platelet phospholipids than the other(s).

\subsection{References}

1. Lands,W.E.M. and Samuelsson,B.: Phospholipid precursors of prostaglandins. Biochim.Biophys. Acta 164 : 426-429 (1968).

2. Vonkeman,H. and van Dorp,D.A.: The action of prostaglandin synthetase on 2-arachidonyl-lecithin. Biochim.Biophys. Acta $164: 430-432$ (1968).

3. Nordøy,A., Haml in,J.T., Chandler,A.B. and Newland,H.: The influence of dietary fats on plasma and platelet lipids and ADP-induced platelet thrombosis in the rat. Scand.J.Haematol. 5: 458-473 (1968).

4. Renaud,S., Kuba,K., Goulet,C., Lemire,Y. and Allard,C.: Relationship between fatty acid composition of platelets and platelet aggregation in rat and man. Circ.Res. 26: 553-564 (1970).

5. Nord $\varnothing y, A$. and Rødset,J.M.: The influence of dietary fats on platelets in man. Acta Med.Scand. $190: 27-34$ (1971).

6. Andreoli,V.M., Maffei,F. and Tonon,G.C.: Platelet lipid modifications induced by fatty acids : experimental scudies and correlations with human neuropathology. Haemostasis 2: 118-140 (1973/74).

7. 0e1z,0., Seyberth,H.W., Knapp,H.R., Sweetman,B.J. and 0ates,J.A.: Effects of feeding ethyl-dihomo- $\gamma-1$ inolenate on prostaglandin biosynthesis and platelet aggregation in the rabbit. Biochim.Biophys. Acta 431: 268-277 (1976).

8. Jakubowski,J.A. and Ardlie,N.G.: Modification of human platelet function by a diet enriched in saturated or polyunsaturated fat. Atherosclerosis 31: $335-344$ (1978). 
9. Pitas,R.E., Nelson,G.J., Jaffe,R.M. and Mahley,R.W.: Effects of diets high in saturated fat and cholesterol on the lipid composition of canine platelets. Lipids 14: 469-477 (1979).

10. Siess,W., Scherer,B., Böhlig,B., Roth,P., Kurzman, I. and Weber,P.C.: Platelet membrane fatty acids, platelet aggregation and thromboxane -formation during a mackerel diet. Lancet i: 441-444 (1930).

11. Gerrard,J.M., White,J.G., Rao,G.H.R. and Townsend,D.: Localization of platelet prostaglandin production in the platelet dense tubular system. Am.J.Pathol. 83: 283-298 (1976).

12. Hong,S.L. and Levine,L.: Stimulation of prostaglandin synthesis by bradykinin and thrombin and their mechanisms of action on MC 5-5 fibroblasts. J.Biol.Chem 251: 5814-5816 (1976).

13. Marcus,A.J., Ullman,H.L. and Safier,L.B.: Lipid composition of subcellular particles of human blood platelets. J.Lipid Res. 10: 108-114 (1969).

14. Dutilh,C.E., Haddeman,E., Jouvenaz,G.H., ten Hoor, F. and Nugteren, D.H.: Study of the two pathways for arachidonate oxygenation in blood platelets. Lipids 14: 241-246 (1979).

15. Bills,T.K., Smith,J.B. and Silver,M.J.: Metabolism of ${ }^{14}$ C-arachidonic acid by human platelets. Biochim.Biophys. Acta 424: 303-314 (1976).

16. Bills,T.K., Smith,J.B. and Silver, M.J.: Selective release of arachidonic acid from the phospholipids of human platelets in response to thrombin. J.Clin. Invest. 60: 1-6 (1977).

17. Derksen, $A$. and Cohen, $P .:$ Patterns of fatty acid release from endogenous substrates by human platelet homogenates and membranes. J.Biol. Chem. 250: 9342-9347 (1975).

18. Lowry, O.H., Rosebrough,N.J., Farr,A.L. and Randall,R.J.: Protein measurement with the folin phenol reagent. J.Biol.Chem. 193:265-275 (1951).

19. Bligh,E.G. and Dyer,W.J.: A rapid method of total lipid extraction and purification. Can.J.Biochem. Physiol. 37: 911-917 (1959).

20. Broekhuyse,R.M.: Quantitative two-dimensional thin layer chromatography of blood phospholipids. Clin.Chim. Acta $23: 457-461$ (1969).

21. Böttcher,C.J.F., van Gent,C.M. and Pries,C.: A rapid and sensitive sub-micro phosphorus determination. Anal.Chim. Acta 24: 203-204 (1961).

22. Morrison,W.R. and Smith,L.M.: Preparation of fatty acid methyl esters and dimethylacetals from lipids with boron fluoride-methanol. J.Lipid Res. 5: 600-608 (1964).

23. Nugteren,D.H., Jouvenaz,G.H. and Dutilh,C.E.: Determination of pros- 
taglandins and other products of arachidonate oxygenation in perfusates and during platelet aggregation. Acta biol.med.germ. 37: 701-706 (1978).

24. Hamberg,M. and Samuelsson,B.: Prostaglandin endoperoxides. Novel transformations of arachidonic acid in human platelets. Proc.Nat1.Acad.Sci. USA 71: 3400-3404 (1974).

25. Hamberg, M., Svensson, J. and Samuelsson,B.: Prostaglandin endoperoxides. A new concept concerning the mode of action and release of prostaglandins. Proc.Nat1.Acad.Sci.USA 71: 3824-3828 (1974).

26. Lagarde,M., Charib,A. and Dechavanne,M.: A simple radiochemical assay of thromboxane $B_{2}$, 12-hydroxyeicosatetraenoic acid (HETE) and 12-hydroxy heptadecatrienoic acid (HHT) synthetized by human platelets. Clin.Chim. Acta 79: 255-259 (1977).

27. Diczfalusy,U. and Hammarström,S.: A structural requirement for the conversion of prostaglandin endoperoxides to thromboxanes. Febs Letts. 105: 291-295 (1979).

28. Bult,H. and Bonta,I.L.: Rat platelets aggregate in the absence of endogenous precursors of prostaglandin endoperoxides. Nature 264: 449-451 (1976).

29. Roth,G.J. and Majerus,P.W.: The mechanism of the effect of aspirin on human platelets. I. Acetylation of a particulate fraction protein. J.C1in. Invest. 56: 624-632 (1975).

30. Roth,G.J., Stanford,N. and Majerus,P.W.: Acetylation of prostaglandin synthase by aspirin. Proc.Nat1. Acad.Sci. USA 72: 3073-3076 (1975).

31. O'Brien,J.R.: Effects of salicylates on human platelets. Lancet $i$ : 779-783 (1968).

32. Weiss,H.J., Aledort,L.M. and Kochwa,S.: The effects of salicylates on the hemostatic properties of platelets in man. J.Clin. Invest. 47: 2169-2180 (1968).

33. Zucker,M.B. and Peterson,J.: Effect of acetylsalicylic acid, other nonsteroidal anti-inflammatory agents and dipyridamole on human blood platelets. J.Lab.Clin.Med. 76: 66-75 (1970).

34. Fukami,H.M., Holmsen,H. and Bauer, J.: Thrombin-induced oxygen consumption, malondialdehyde formation and serotonin secretion in human platelets. Biochim.Biophys. Acta 428: 253-256 (1976).

35. Benveniste,J., Le Couedic,J.P. and Kamoun,P.: Aggregation of human platelets by platelet-activating factor. Lancet i: 344-345 (1975).

36. Nachman,R.L.: Platelet proteins. In: Johnson,S.A.(Ed): The circulating platelet. Academic Press, New York and London (1971) pp. 207-224. 
37. Marcus,A.J., Safier,L.B. and UIIman,H.L.: Interactions between 5-hydroxytryptamine and platelet lipid fractions. In: Ciba Foundation Symposium 35 (new series): Biochemistry and pharmacology of platelets. Elsevisier.Exerpta Medica. North Holland. Amsterdam (1975) pp. 309-326, p.322 in particular.

38. Nord $\not y, A .$, Bjørge,J.M. and Strøm,E.: Comparison of the main lipids in platelets and plasina in man. Acta Med.Scand.193: 59-64 (1973).

39. Nord $\phi y, A$. and Lund, S.: Platelet factor 3 activity, platelet phospholipids and their fatty acid and aldehyde pattern in normal maje subjects. Scand.J.Clin.Lab. Invest. 22: 328-338 (1968).

40. Schick,P.K.: The role of platelet membrane lipids in platelet hemostatic activities. Sem. Hematol. 16: 221-233 (1979).

41. Besterman,E.M.M. and Gillet,M.P.T.: Inhibition of platelet aggregation by 1ysolecithin. Atherosclerosis 14: 323-330 (1971).

42. Besterman,E.M.M. and Gillet,M.P.T.: Influence of lysolecithin on platelet aggregation initiated by 5-hydroxytryptamine. Nature (New Biology) 241: 223-224 (1973).

43. Joist,J.H., Dolezel,G., Cucuianu,M.P., Nishizawa,E.E. and Mustard,J.F.: Inhibition and potentiation of platelet function by lysolecithin. Blood 49: 101-112 (1977).

44. Reman,F.C., Deme I,R.A., de Gier,J., van Deenen,L.L.M., Eibl,H. and Westphal,0.: Studies on the lysis of red cell and bimolecular lipid leaflets by synthetic lysolecithin, lecithins and structural analogs. Chem. Phys.Lipids 3: 221-224 (1969).

45. Poole,A.R., Howel1,J.I. and Lucy,J.A.: Lysolecithin and cellfusion. Nature 227: 810-814 (1970).

46. Joist,J.H., Dolezel,G., Lloyd,J.V. and Mustard,J.F.: Phospholipid transfer between plasma and platelets in vitro. Blood 48: 199-211 (1976).

47. Béréziat,G.: Comment les modifications des lipides plasmatiques constatées lors de l'athérosclerose peuvent - elles agir sur la physiologie plaquettaire ? Sem.Hôp. Paris 55: 753-754 (1979).

48. Lands,W.E.M., Le Tellier,P.R., Rome,L.H. and Vanderhoek,J.Y.: Inhibition of prostaglandin biosynthesis. Adv.Biosc. 9: 15-28 (1973).

49. Van Evert,W.C., Nugteren,D.H. and van Dorp,D.A.: Inhibition of prostaglandin biosynthesis by $c-5, c-8, c-11$-eicosatrienoic acid Prostaglandins 15 : 267-272 (1978).

50. Needleman, P., Raz,A., Minkes,M.S., Ferrendelli,J.A. and Sprecher,H.: Triene prostaglandins : prostacyclin and thromboxane biosynthesis 
and unique biological properties. Proc.Nat.Acad.Sci. USA 76: 944-948 (1979).

51. Bills,T.K., Smith,J.B., Kocsis,J.J. and Silver,M.J.: Metabolism of a potential anti-thrombotic agent $(8,11,14$-eicosatrienoic acid) by human platelets. Fed.Proc. 35: 755 (1976).

52. Cooper,R.A.: Abnormalities of cell-membrane fluidity in the pathogenesis of disease. New Engl.J.Med. 297: 371-377 (1977).

53. Shattil,S.J., Anaya-Galindo,R., Bennett,J., Colman,R.W. and Cooper, R.A.: PLatelet hypersensitivity induced by cholesterol incorporation. J.Clin. Invest. 55: 636-643 (1975).

54. Shattil,S.J. and Cooper,R.A.: Membrane microviscosity and human platelet function. Biochemistry 15: $4832-4837$ (1976).

55. Sirnha,A.K., Shatti],S:J. and Colman,R.W.: Cyclic AMP metabolism in cholesterol-rich platelets. J.Biol.Chem. 252: 3310-3314 (1977).

56. Stuart,M.J., Gerrard,J.M. and White,J.G.: Effect of cholesterol on production of thromboxane $B_{2}$ by platelets in vitro. New Engl.J.Med. 302: 6-10 (1980).

57. Jackson,R.L., Taunton,0.D., Morrisett,J.D. and Gotto,A.M.Jr.: The role of dietary polyunsaturated fat in lowering blood cholesterol in man. Circ. Res. 42: 447-453 (1978).

58. Williams,M.A., Stancliff,R.C., Packer,L. and Keith,A.D.: Relation of unsaturated fatty acid composition of rat liver mitochondria to oscillation period, spin label motion, permeability and oxidative phosphorylation. Biochim.Biophys.Acta 267 : 444-456 (1972).

59. Farias,R.N., Bloj,B., Morero,R.D., Siñeriz,F. and Trucco,R.E.: Regulation of allosteric membrane-bound enzymes through changes in membrane lipid composition. Biochim. Biophys.Acta 415: 231-251 (1975).

60. Vanderkooy,J., Fischkoff,S., Chance,B. and Cooper,R.A.: Fluorescent probe analysis of the lipid architecture of natural and experimental cholesterol-rich membranes. Biochemistry 13: 1589-1595 (1974).

61. Shinitzky,M. and Inbar,M.: Microviscosity parameters and protein mobility in biological membranes. Biochim. Biophys. Acta 433: 133-149 (1976).

62. Shatti1,S.J., Bennett,J.S., Colman,R.W. and Cooper,R.A.: Abnormalities of cholesterol-phospholipid composition in platelets and low density lipoproteins of human hyperbetalipoproteinemia. J.Lab.C1 in.Med. 89: 341-353 (1977).

63. Seiler,D. and Hasselbach: Essential fatty acids deficiency and the activity of the sarcoplasmic calcium pump. Eur.J.Biochem. 21: 385-387 
(1971).

64. Karnovski,M.J.: Lipid domains in biological membranes. Their structural and functional perturbation by free fatty acids and the regulation of receptor mobility. Am.J.Pathol. 97: 212-221 (1979).

65. Vogt,W., Suzuki,T. and Babilli,S.: Prostaglandins in S.RS-C and in Darmstoff preparation from frog intestinal dialysates. Mem.Soc. Endocrino1.14: 137-142 (1966).

66. Berlin,E. and Young,C.: Effects of dietary fat on the fluidity of platelet membranes. Biophys.J. 25: 64a (1979).

67. Nugteren,D.H.: Inhibition of prostaglandin biosynthesis by 8-cis, 12-trans, 14-cis-eicosatrienoic acid and 5-cis, 8-cis, 12-trans, 14-cis -eicosatetraenoic acid. Biochim.Biophys. Acta 210: 171-176 (1970).

68. Petersen,G.L.: Review of the fol in phenol protein quantitation method of Lowry, Rosebrough, Farr and Randall. Anal.Biochem. 100: 201-220 (1979).

69. Margolis,L.B., Tikhonov,A.N. and Vasilieva,E.Y.: Platelet adhesion to fluid and solid phospholipid membranes. Cell 19: 189-195 (1980). 


\section{EFFECT OF DIETARY LINOLEIC ACID ON PLATELET FUNCTION IN MEN}

\subsection{Introduction}

The studies reported in Chapters 6,7 and 8 show convincingly that replacing dietary saturated fatty acids by linoleic acid is beneficial in the prevention of arterial thrombosis in rats. Although these experimental results have been confirmed by many other investigators using a great variety of animal models (for reviews, see refs. 1 and 2), it is not justified to extrapolate these animal data to the human situation. Animal data only provide a guideline for human studies and therefore it is particularly worthwhile to investigate whether replacement of saturated fats by linoleic acid-rich oils has also an antithrombotic and antiatherosclerotic effect in human subjects. Epidemiological studies show this seems fairly likely because the intake of saturated fat is still the environmental factor most closely associated with coronary heart disease $(3,4)$.

The value of epidemiological studies is, however, rather limited because they only detect associations but do not prove any cause-effect relationships. For this purpose, prospective clinical trials have been performed, which all indicate a favourable effect brought about by a diet low in saturated fats and enriched with linoleic acid (5-7). The beneficial effects of these diets are not necessarily the results of their plasma lipid - lowering action only. As was shown for rats (Chapter 7), these effects may also be mediated by their influence on platelet thrombotic functions. Therefore, we decided to investigate the effect of a diet low in saturated fats and high in linoleic acid on human platelet aggregability.

\subsection{Methods}

\subsubsection{Experimental_groups_and diets}

The study was performed at the end of the 'Helsinki primary prevention trial' conducted by Turpeinen and co-workers in two mental hospitais in the Helsinki region (7). In one hospital the normal Finnish diet was given, which is rich in saturated fats and contains only $4 \%$ of digestible energy (en\%) as linoleic acid. In the other hospital, the diet was modi- 
Table 11.1. Approximate daily dietary intake and dietary lipid composition for both groups.

\begin{tabular}{llll}
\hline Parameter & Unit & $\begin{array}{c}\text { Hospital } \mathrm{N} \\
\text { (control) }\end{array}$ & $\begin{array}{c}\text { Hospital K } \\
\text { (experimenta)) }\end{array}$ \\
\hline Total energy & $10^{6} \mathrm{~J}$ & 11.5 & 11.7 \\
Total fats & $\mathrm{g}$ & 97 & 138 \\
Total fat energy & $\%$ & 31 & 44 \\
Cholesterol & $\mathrm{mg}$ & 556 & 275 \\
Saturated fatty acids & $\mathrm{g}$ & 48 & 31 \\
Polyunsaturated fatty acids & $\mathrm{g}$ & 14 & 58 \\
Energy from linoleic acid & $\%$ & 3.8 & 16.4 \\
\hline
\end{tabular}

fied: milk was replaced with soyabean oil-filled skim milk while butter and ordinary margarines were replaced with so-called 'soft' margarines, resulting in a dietary linoleic acid content of $16 \mathrm{en} \%$ (Table 11.1.). After six years, the diets were reversed, the total experimental period being 12 years. It then appeared that in men - not in women - the high AGE (YEARS) BODYWEIGHT (KG) CIGARETTES/DAY
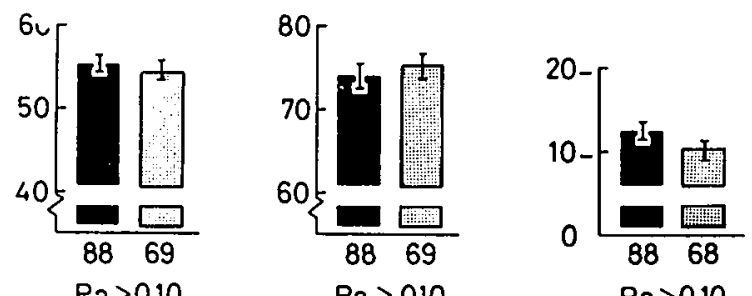

$P_{2}>0.10$

$P_{2}>0.10$

$P_{2}>0.10$

SERUMCHOL. SERUMTRIGLYC.

( $\mathrm{mg} \%, \log$ scale) (mmol. $\mathrm{l}^{-1}, \log$ scale)
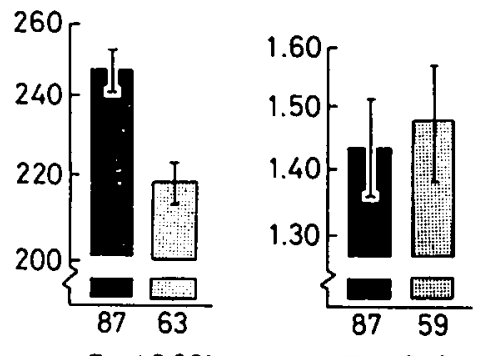

$P_{2}<0.001$

$\mathrm{P}_{2}>0.10$

Fiz.11.1. Characterization of both experimental groups (mean \pm SEM). diet containing 4 en\% linoleic acid; $\square$ diet containing 16 en\% linoleic acid.

Numbers under bars indicate number of subjects; $P_{2}$ : degree of significance (Student's two-sample test). 
-7 inoleic acid diet was associated with a $50 \%$ reduction in mortality from coronary heart disease. At the end of the second 6-year period, male subjects were random-selected from patients of both hospitals, the only reasons for exclusion being medication with aspirin-like drugs and expected difficulties in obtaining a clean venepuncture. Although a number of 88 men on the control diet (hospital N) and 69 men on the high-linoleic acid diet (hospital $\mathrm{K}$ ) were included in the study, data from a slightly smaller number of subjects are reported because of some technical difficulties. Both groups did not differ as to average age, body weight and cigarette smoking habits (Fig.11.1, data obtained from hospital records). All patients participating had been in hospital for at least four years.

\subsubsection{Exzerimental__procedure}

Subjects were studied between 7 a.m. and 11 a.m. after one overnight fast. First, the template bleeding time was measured (8), using an apparatus devised by Pras and co-workers (9). The subjects were then placed in a

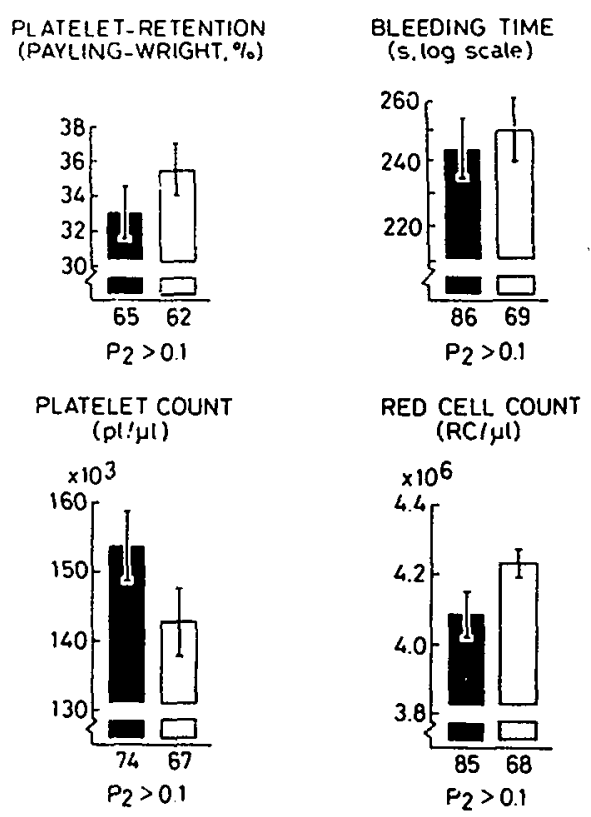

Fig.11.2. Effect of dietary linoleic acid content on several hematological parameters (mean \pm SEM).

4 en\% linoleic acid; $\square 16$ en\% linoleic acid.

Numbers under bars refer to number of subjects; $P_{2}$ : degree of significance (Student's two-sample test). 
recumbent position after which an indwelling catheter was inserted into an antecubital vein while applying minimum stasis. After some blood had drained away, samples were carefully taken for the following measurements: - platelet and red cell counts, (using a Celloscope ${ }^{\circledR}$ particle counter)

- serum triglyceride and serum cholesterol contents. These measurements were performer by Finnish colleagues and the results are given in Fig. 11.1 .

- platelet retention, using $2 \mathrm{ml}$ heparinized whole blood and the rotating -bulb technique, as described by Wright (10).

After completion of blood sampling, the indwelling catheter was connected to the filtragometer (Chapter 5, section 4 ) and platelet aggregation in flowing venous blood was measured as described in Chapter 5 , section 4.3 .

\subsection{Results}

Data on platelet retention, bleeding times and platelet- and red-cell counts are given in Fig.11.2. For none of these criteria, was a pronounced difference observed between the two groups. As shown in Fig.11.3, platelet aggregation measured with the filtragometer, is significantly decreased in the high-linoleic acid group: the aggregation time is longer,
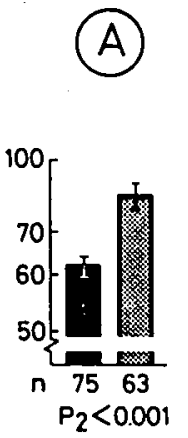
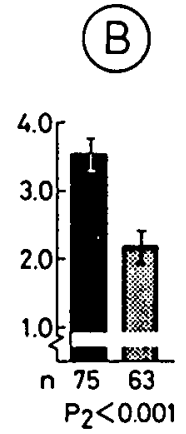
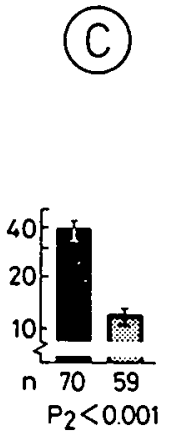
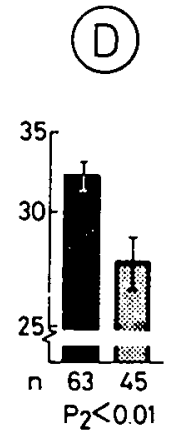

Fig.11.3. Effect of dietary linoleic acid content on platelet aggregation, measured with the filtragometer.

Q. 4 en\% linoleic acid; 16 en in linoleic acid.

A: Aggregation time ( $s$, reciprocal scale).

B: Aggregation velocity $\left(T_{s}\right.$, see Fig. 5.23.).

C: Maximum aggregation ( $\mathrm{mmHg}$, log scale).

$D$ : Disaggregation induction time (s, reciprocal scale).

Numbers under bars indicate number of subjects; $P_{2}$ : degree of significance (Student's two-sample test). 
aggregation velocity and maximum aggregation are lower and disaggregation occurs more quickly as compared with the control, low-linoleic acid group. Although the difference in filtragometer response between both groups is highly significant, there is a considerable overlap between the groups (Fig.11.4.).

\subsection{Discussion}

According to filtragometer measurements, platelet aggregation is distinctI
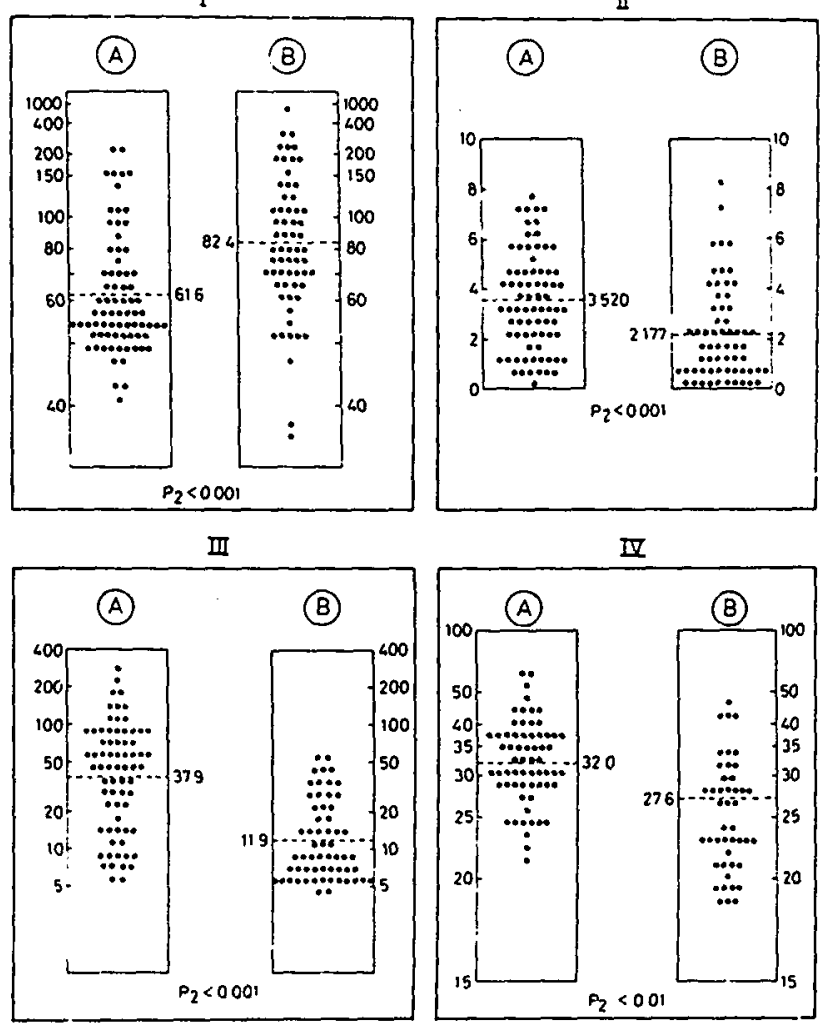

irg.11.4. Effect of dietary linoleic acid content on platelet aggregation in male subjects.

A: 4 en\% linoleic acid; B: 16 en\% linoleic acid.

I : Aggregation time (s, reciproral scale).

II : Aggregation velocity ( $T_{S}$, see Fig. 5.23.).

III: Maximum aggregation ( $\mathrm{mmH}$,, $13 \mathrm{~g}$ scale).

IV : Disaggregation induction time ( $s$, reciprocal scale).

$P_{2}$ : Degree of significance (Student's two-sample test); dashed lines are group means. 
ly lower in the high-linoleic acid group in relation to the low-linoleic acid control group. Since mortality from coronary artery disease is associated with occlusive coronary thrombosis -in which platelet aggregation is involved ( 11 , see also Chapter 1 )- it is conceivable that the lower. platelet aggregation observed in the present study, contributed to the reduced mortality from ischemic heart disease observed in the high-linoleic acid group.

The groups showed no difference in platelet retention, but it should be emphasized that there was a considerable time lapse between blood sampling and retention measurements (approximately $30 \mathrm{~min}$ ). During this period, unstable aggregation-modulating substances possibly present in blood, may have become inactivated.

Now it might be argued that the difference in platelet aggregation between both groups is not attributable to the diets but to other environmental differences between the hospitals. To be sure on this point, platelet aggregation was measured again one year later, which was three months after diet-normalization in hospital $K$. The results of this study are reported in the next section.

\subsection{Effect of decreasing the dietary linoleic acid content on platelet aggregation in men}

Three months after the high-linoleic acid diet (16 en:", code 16-LA) in hospital $K$ had been replaced by the normal Finnish diet ( 4 en:. linoleic acid, code 4-LA), platelet aggregation was measured again in both hospitals.

Several patients participating in the first study, were discharged so that they could not be measured again. As a result, only 38 patients from each hospital could be measured twice.

The results shown in Fig.11.5, demonstrate that the difference in aggregation observed between patients of the two hospitals during the first measurement, was greatly reduced 3 months after the dietary switch in hospital $K$, although it had not yet disappeared completely.

In connection with a technical molification to the filtragometer, which was still in an experimental stage at that time, platelet aggregation values during the second measurement were considerably lower as compared to those during the first measurement. Since in hospital $N$ (the control 
(A)

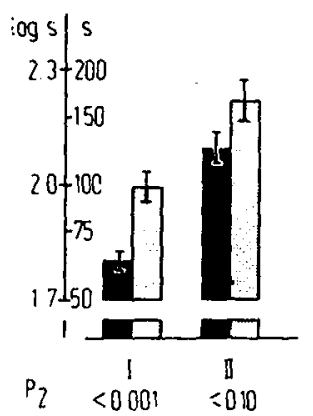

(B)

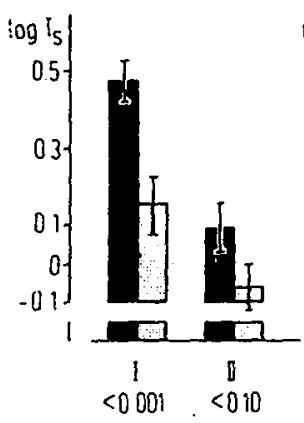

(c)

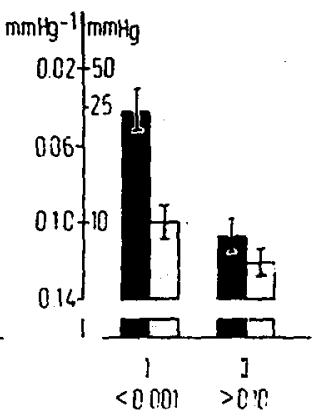

Fig.11.5. Platelet aggregation (filtragometer, mean \pm SEM), measured twice in the same subjects.

Hospital N, dietary linoleic acid content 4 en\% ( $n=38)$;

$\square$ Hospital $\mathrm{K}$, dietary 7 inoleic acid content 16 en\% ( $n=38)$.

I : Results of first measurement performed after a dietary period of 4-6 years.

II: Results of second measurement carried out one year later and tiree months after lowering the linoleic content of the diet in hospital $K$ towards that in hospital $\mathrm{N}$.

A : Aggregation time $\left(s, \log\right.$ scale); $B$ : Aggregation velocity $\left(T_{s}, \log \right.$ scale); $C$ : Maximum aggregation (mmHg, reciprocal scale).

$P_{2}$ : Degree of significance (Student's two-sample test).

hospital), no dietary switch had taken place, platelet aggregation values in this hospital were taken as $100 \%$ for both measurements. The results obtained in hospital $\mathrm{K}$ were expressed as a percentage of those measured in hospital $\mathrm{N}$, thereby correcting for the modification to the filtragometer. When computed in this way, the dietary switch in hospital $\mathrm{K}$ caused the aggregation time to become shorter (from 156 to 133\%), the aggregation velocity to increase from 58 to $70 \%$ and maximum aggregation to increase from 43 to $86 \%$ of those measured in the control hospital.

This slow response of platelet aggregation to the dietary switch was rather surprising because Fleischman and co-workers, who confirmed the anti-aggregating effect of dietary linoleic acid in humans, had shown that this beneficial effect is readily reversible when returning to a low-linoleic acid diet $(12,13)$. However, their high-linoleic acid feeding period lasted only 2-3 weeks whereas the subjects participating in our studies had been on the high-linoleic acid diet for at least 5 
years before their linoleic acid intake was reduced. This could indicate ihat long-term feeding of a high-linoleic acid diet provides a long-term thromboprotection.

Supporting evidence for this concept was obtained from aggregation values measured in subjects who were admitted to the hospitals in between both measurements. Those who had been hospitalized more than 3 months before the second investigation were included in this study. The new arrivals of hospital $K$ had been on the 16-LA diet for less than 9 months before they switched to the 8-LA regimen. As can be seen from Fig. 11.6, aggregation in these new arrivals of hospital $K$ tends to be higher than that in the original participants (shorter aggregation time and higher aggregation velocity). Moreover, the aggregation in the new arrivals of hospital $K$ does not differ from that in both groups in hospital $N$. This is in contrast to the aggregation in the initial participants of hospital $K$, which is significantly lower than that in both groups of hospital $N$. From this finding it seems justified to conclude that the anti-aggregating effect of a diet rich in LA persists longer, the longer the diet is eaten.

(A)

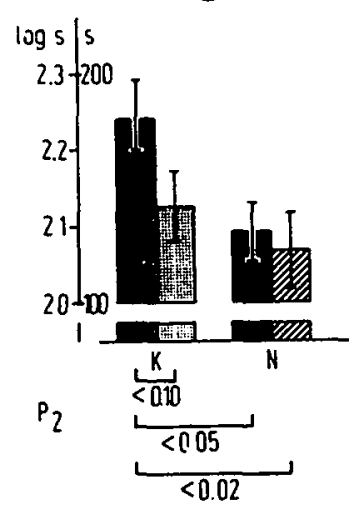

(B)

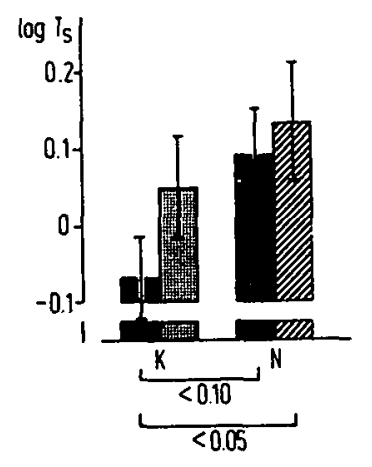

(C)

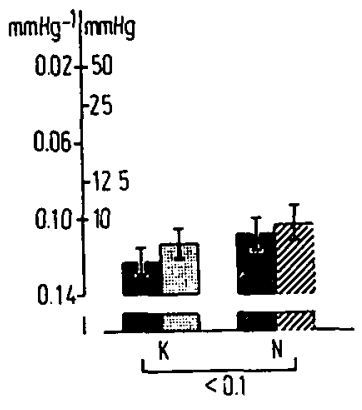

Pig.11.6. Platelet aggregation (filtragometer) 3 months after diet normalization in the experimental hospital (no change of diet).

a subjects participating in original trial;

subjects not participating in original trial eating the experimental diet for less than 9 months before diet normalization;

Wubjects not participating in original trial, eating the control diet all the time.

A: Aggregation time (s); B: Aggregation velocity $\left(T_{s}\right)$;

C: Maximum aggregation $(\mathrm{mmHg}) ; \mathrm{P}_{2}$ : Degree of significance. 
To be absolutely sure that the agreed dietary switch had indeed be carried through, the dietary composition was estimated after the switch by checking the lists of purchases of both hospitals. Unfortunately, this inspection showed that diet normalization in hospital $\mathrm{K}$ had occurred only partly: the soyabean oil-filled skim milk had been skipped, but the use of soft margarine instead of butter had been continued. This resulted in a dietary LA-content of 8 enc, which is still twice as high as that in the control group.

This finding means that eating an 8-LA diet for 3-12 months does not result in a lower platelet aggregation versus a 4-LA diet. This is not in agreement with results obtained by Fleischman and co-workers $(12,13)$, who noted an aggregation- inhibiting effect already within 4 days when increasing the dietary LA-content by amounts as low as 0.5-4 en\%. The reason for this discrepancy is not yet clear. Since they used a filtragometer giving results comparable to ours, a methodological reason seems unlikely.

11.6. The long-term thromboprotective effect of dietary linoleic acid. Hypothesis concerning a role of adipose tissue linoleate

As demonstrated in the previous section, subjects who had been on the 16-LA diet for almost 5 years, still showed a diminished aggregation tendency against the control group 3 months after they had switched to the 8-LA diet, although the latter diet did not appear to have an anti-aggregating effect. As discussed before, a possible explanation may be that long-term feeding of a high LA-diet provides a long-term protection after discontinuation. We tested this possibility in rats in an experiment which is reported in the next section.

\subsubsection{Modulation of the prothrombotic effect of a saturated fat diet} in_rats_by_erefeeding an antithrombotic_diet

Two groups of 60 young adult male Wistar rats were fed a diet containing 50 en\% sunflowerseed oil (SO). After 1 or 4 weeks, arterial thrombosis tendency was measured in 12 rats of each group. In the diet of the remaining animals, 45 en\% of the antithrombotic SO was replaced by prothrombotic hydrogenated coconut oil ( $\mathrm{HCO}) ; 1,2,3$, and 1 weeks later, arterial thrombosis tendency was measured in 12 rats of each group. If the sugges- 
tion emerging from the experiments described in the previous section is correct in that the beneficial effect of dietary linoleic acid may last longer if the feeding period is extended, the prothrombotic effect of hydrogenated coconut oil should become manifest later, if the animals had been prefed a linoleic acid-rich diet for a longer time. This indeed appeared to be so (fig.11.7.): the course of the thrombosis-promoting effect of dietary $\mathrm{HCO}$ greatly depends on the pre-experimental so-feeding period. This prothrombotic effect was maximal within 1 week if the animals had been prefed the antithrombotic so for one week only. After a 4-week pre-experimental so-period, it takes 3-4 weeks for the expression of the prothrombotic effect of HCO to become maximal, although the initial arterial trrombosis tendencies did not differ significantly. Therefore, it can be concluded that, at least in rats, the thromboprotective role of dietary so lasts longer, the longer the feeding period. This is in agreement with the suggestion obtained from the human experiment described in the previous section.

\subsubsection{The possible role of adipose tissue linoleate in long-term} thronboprotection. A hypothesis

Results reported in the previous sections show that the maximum dietary fat effects on arterial thrombosis tendency and platelet aggregation take

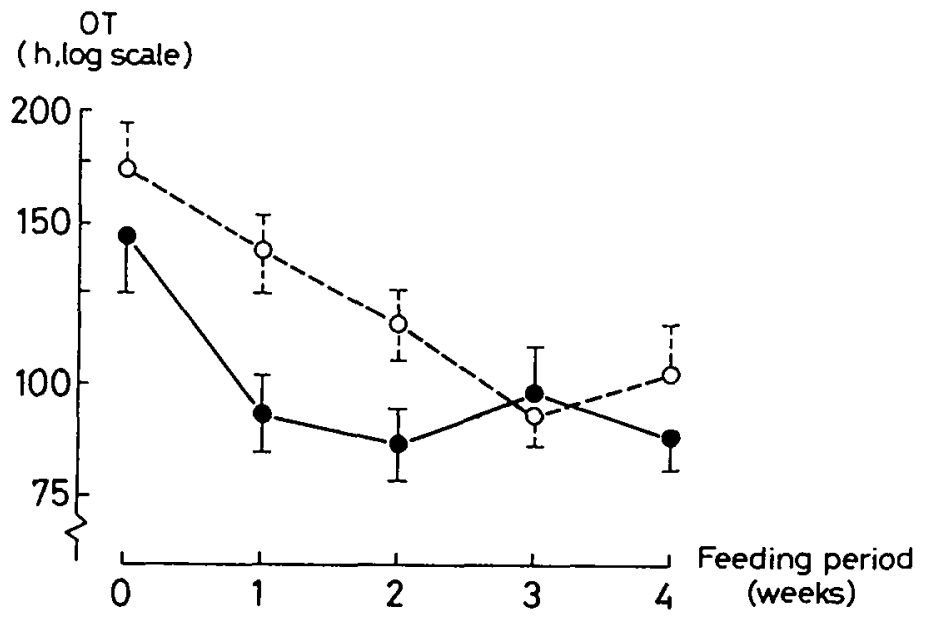

Eig.11.7. Effect of pre-experimental So-feeding (50 en\%; -1 week,

$0---04$ weeks) on the course of the prothrombotic effect of HCO (45 en\% +5 en\% SO) in rats. Results (OT \pm SEM) refer to arterial thrombosis tendencies as measured with the aorta loop (see Chapter 5, section 2.). 
much more time to become perceptible than the mean platelet life-span, which is approximately 10 and 3 days for man and rat respectively. Consequently, the long-term thromboprotective effect of dietary linoleate we observed cannot have been caused by a direct effect on the platelets but must be the result of some slowly changing factor in the platelet's environment.

Upon prolonged feeding, the linoleic acid content of the diet is known to be reflected by that of the adipose tissue. The Helsinki study showed that the LA-content of adipose tissue in the 16- and 4-LA groups was $26.9 \pm 3.06(n=31)$ and $10.2 \pm 1.93(n=35)$ respectively $(14)$. The turnover of adipose tissue triglycerides is rather slow as compared with plasma triglycerides $(15,16)$. Consequentiy, the adipose tissue LA-content might be expected to decrease only slowly when lowering the dietary LA-concentration. Since adipose tissue is the main source of plasma long-chain free fatty acids (Chapter 2), the composition of the latter will largely be determined by that of the adipose tissue.

In stress situations (prolonged fasting, myocardial infarction, fright, etc), a hormone-meciated rapid mobilization of adipose tissue fatty acids occurs, resulting in a rise of the plasma FFA-levels to such an extent that the FFA-binding capacity of plasma proteins is sometimes exceeded. It has been shown very convincingly that this situation causes hyperaggregability of blood platelets $(17,18)$. Moreover, it has been shown that these platelet reactions depend on the type of FFA: long-chain saturated fatty acids are much more active in this respect than linoleic acid $(19,20)$. The adipose tissue fatty acid composition may therefore be expected to affect the thrombotic functions of blood platelets through its effect on the plasma free fatiy acid composition.

In this respect, also the epidemiological findings by Logan and co-workers are of interest. They compared blood and adipose tissue lipid profiles of people from Stockholm and Edinburg and noted that the higher mortality from coronary artery disease in Edinburg is associated with a lower blood lipid- and adipose tissue linoleic acid content, whereas serum total and LDL cholesterol contents appeared to be similar (21). A thromboregulatory function of plasma FFA is also likely, considering the observation that FFA are able to perturb lipid domains in biological membranes, thereby influencing membrane receptor-mobility and-efficiency (22).

From these considerations it is clear that a possible thromboregulation 
through modulating plasma free fatty acid content and composition should be further investigated.

\subsection{Possible mechanisms by which linoleic acid lowers platelet aggregability and arterial thrombosis tendency}

Although feeding LA-rich sunflowerseed oil to rats causes various prothrombotic changes in vitro (stimulation of extrinsic clotting -Chapter 9, section 4.- an increase in collagen sensitivity -Chapter 10, section 3.1. - and an enhancement of platelet $\mathrm{TXA}_{2}$ formation -Chapter 10, section 5.) it lowers platelet aggregation in circulating arterial blood and reduces arterial thrombus formation in viino.

The diminishing effect of dietary linoleate on various thrombotic platelet functions has been confirmed by many investigators $(12,13,26,49-52)$, but little is known about the mechanisms underlying this effect. An increased dietary LA-concentration causes the platelet LA-content to increase as well (23-27, see also Chapter 10). Since endogenous LA may become released upon platelet activation (53) and because it competitively inhibits conversion of arachidonic acid by the cyclo-oxygenase enzyme system (28-30), an increase in platelet LA may result in a lower endoperoxide and $\mathrm{TXA}_{2}$ formation upon platelet activation and thus diminish the propagation of platelet aggregation.

Another way in which LA may inhibit platelet $T \times A_{2}$ formation is by inhibiting platelet phospholipase $A_{2}$, as demonstrated by Valee and co-workers (31). However, our experiments with rats demonstrated that feeding $L A$ -enriched diets did not diminish but stimulated platelet $T \times A_{2}$-formation. Admittedly, this does not necessarily apply to man as well, although it should be remembered that, as far as platelet-AA metabolisn is concerned, there is a striking similarity between rat and man ( $c f$. the effect of fish oil, Chapter 9).

The enhanced $A A$ metabolism upon feeding an LA-enriched diet, as described in Chapter 10 , is confirmed by findings that replacement of dietary saturated fatty acids by $L A$ results in an increased prostaglandin (PG) production of stimulated rat adipocytes (32) and in an enhanced PG-synthesizing potential of rat whole lung (33). Moreover, urinary excretion of PG-metabolites increased proportionally to LA-intake in rat (34) and man (35). This well-established stimulating effect of dietary LA on the peroxi- 
dation of arachidonic acid may give rise to an increased formation of $\mathrm{PGE}_{2}$ and $\mathrm{PGD}_{2}$, the latter being a very active aggregation inhibitor (36, $37)$ whereas the former has only weak aggregation-stimulating properties $(38,39)$. However, in rats, $\mathrm{PGD}_{2}$ is inactive as a platelet antiaggregant (40). Therefore, this explanation for the antiplatelet effect of dietary LA is also rather unlikely.

Recently, Lagarde and co-workers (41) reported that platelet FFA -although their levels are very low- are efficiently used in the formation of platelet prostaglandins. They also demonstrated that a small enhancement of the dihomo-r-linolenic acid level (D-LA) caused a much more increased formation of $\mathrm{PGE}_{1}$ (an dctive aggregation inhibitor) than a similar enhancement of the arachidonic acid (AA) level did with respect to stimulation of $\mathrm{PGE}_{2}$ production. Dietary $\mathrm{D}-\mathrm{LA}$ has been shown to decrease platelet aggregation in animals and man (42-45) although negative results have been published as well (46). Since D-LA is an intermediate in the conversion of $L A$ into $A A$ (Chapter 2), an enhanced LA-intake might be expected to increase D-LA synthesis, possibly leading to a higher platelet D-LA level. This was not obser.ed in our experiments with rats (Chapter 1C) but since the $\Delta_{5}$-desaturase (which mediates the conversion of $D-L A$ into $A A$, see Chapter 2) is much more active in rats than in man (47), we simply may not expect to observe it. Moreover, we did not investigate the composition of platelet FFA which -as indicated above- may be very important in this respect. Therefore, it seems worthwhile to investigate the role of $\mathrm{PGE}_{1}$ (from platelets or other sources) in the dietary LA-induced inhibition of platelet aggregation and thrombus formation.

Finally, the inhibiting effect of dietary LA on platelet aggregation may be an expression of the same LA-effect as that responsible for reduced cell-to-substrate adhesion, demonstrated in cultured BHK-cells which could not be reversed upon indomethacin addition and is, therefore, a prostaglandin-independent phenomenon (48).

\subsection{Summary}

Filtragometer measurements showed that a diet with 16 en\% linoleic acid given to human subjects for over 4 years produced a significant, $50 \%$ reduction in platelet aggregability as compared with a diet containing 
4 en\% linoleic acid. To attain the anti-platelet effect of dietary linoleic acid, ingestion of a rather high dose is required because 8 en: given for over 3 months, did not modify platelet aggregability. Indications that the thromboprotective effect of dietary linoleate lasts longer, the longer the feeding period, were confirmed in an experiment with rats. The results allow of the hypothesis that the long-term effect of dietary linoleate is mediated by linoleic acid, which is taken up in adipose tissue during the feeding period and slowly released into the plasma after withdrawal of the diet. In the mechanism(s) underlying the anti -aggregating effect of dietary linoleate, platelet $\mathrm{TxA}_{2}$-formation is most probably not involved. An enhanced formation of $P G E_{1}$ by platelets and/or other tissues seems plausible and is not incompatible with our results.

\subsection{References}

1. Renaud,S. and Gautheron,P.: Dietary fats and experimental (cardiac and venous) thrombosis. Haemostasis 2: 53-72 (1973/1974).

2. Hornstra,G.: Dietary fats and arterial thrombosis. Haemostasis 2: 21-52 (1973/1974).

3. Stamler,J.: Epidemiology of coronary heart disease. Med.Clin. North. Am. 57: 5-46 (1973).

4. Heyden,S.: Epidemiological data on dietary fat intake and atherosclerosis with an appendix on possible side effects. In: Vergroesen,A.J. (Ed.): The role of fats in human nutrition. Academic Press, London, New York, San Francisco (1975), pp. 44-113.

5. Leren,P.: The 0slo diet-heart study. Circulation 42: 935-942 (1970).

6. Dayton,S., Pearce,M.L., Hashimoto,S. and Dixon,W.J.: A controlled clinical trial of a diet high in unsaturated fat in preventing complications of atherosclerosis. Circulation 40, Supp 1.II: 1-63 (1969).

7. Miettinen,M., Turpeinen,0., Karvonen,M.J., Elosuo,R. and Paavilainen; E.: Effect of cholesterol lowering diet on mortality from coronary heart disease and other causes: a twelve-year clinical trial in men and women. The Lancet ii: 835-838 (1972).

8. Mielke,C.H., Ramos,J.C. and Britten,A.F.H.: Aspirin as an antiplatelet agent: template bleeding time as a monitor of therapy. Am.J.Clin. Pathol. 59: 236-242 (1973).

9. Praga,C., Valentini,L., Maiorano,M. and Cortellaro,M.: A new automated 
device for the standardized Ivy bleeding time. Adv.Exp.Med.Biol.34: 271-279 (1972).

10. Wright,H.P.: The adhesiveness of blood platelets in normal subjects with varying concentrations of anticoagulants. J.Pathol.Bact.53: 255-262 (1941).

11. Haerem,J.W.: Platelet aggregates and mural micro-thrombi in early stages of acute, fatal coronary disease. Thronb.Res. 5: 243-249 (1974).

12. Fleischman,A.I., Justice,D., Bierenbaum,M.L., Stier,A. and Sullivan, A.: Beneficial effect of increased dietary linoleate upon in vivo platelet function in man. J.Nutr. 105: 1286-1290 (1975).

13. Fleischmin,A.I., Bierenbaum,M.L., Justice,D., Stier,A., Sultivan,A. and Fleischman, M.: Titrating dietary linoleate to in vivo platelet function in man. Am.J.Clin. Nutr. 28: 601-605 (1975).

14. Turpeinen,0., Miettinen,M., Karvonen,M.J., Roine,P., Pekkarinen,M., Lehtosuo,E.J. and Alivirta,P.: Dietary prevention of coronary heart disease: long-term experiment. Am.J.Clin.Nutr. 21: 255-276 (1968).

15. Dayton, S.: Compnsition of lipids in human serum and adipose tissue during prolonged feeding of a diet high in unsaturated fat. J.Lipid Res. 7: 103-111 (1966).

16. Fleischman,A.I., Hayton,A. and Bierenbaum,M.L.: Objective biochemical determination of dietary adherence in the young coronary male. Am.J. Clin.Nutr. 20: 333-337 (1967).

17. Hoak,J.C., Poole,J.C.F. and Robinson,D.S.: Thrombosis associated with mobilization of fatty acids. Am.J.Pathol. 43: 987-997 (1963).

18. Connor,W.E., Hoak,J.C. and Warner,E.D.: Plasma free fatty acids, hypercoagulability and thrombosis. In: Sherry,S., Brinkhous, K.M., Genton,E. and Stengle,J.M. (Eds.): Thrombosis. Nat.Acad.Sci., Washington, D.C. (1969), pp. 355-373.

19. Hoak,J.C., Spector,A.A., Fry,G.L. and Warner,E.D.: Effect of free fatty acids on ADP-induced platelet aggregation. Nature 228: 1330 -1332 (1970).

20. Prost-Dvojakovic,R.J. and Samama,M.: Clot promoting and platelet-aggregating effects of fatty acids. Haemostasis 2: 73-84 (1973/1974).

21. Logan,R.L., Thomson,M., Riemersma,R.A., 01iver,M.F., 01sson,A.G., Rössner,S., Callmer,E., Walldius, G., Kaijser,L., Carlson,L.A., Lockerbie,L. and Lutz,W.: Risk factors for ischemic heart disease in normal men aged 40. Edingburgh-Stockholm study. Lancet i: 949-955 (1978).

22. Karnovsky,M.J.: Lipid domains in biological membranes. Their structural and functional perturbation by free fatty acids and the regulation 
of receptor mobility. Am.J.Pathol.97: 212-221 (1979).

23. Nord $\varnothing y, A$. , Haml in,J.T., Chandler,A.B. and Newland,H.: The influence. of dietary fats on plasma and platelet lipids and ADP-induced platelet thrombosis in the rat. Scand.J.Haemat. 5: 458-473 (1968).

24. Nord $\phi y, A$. and Rødset,J.M.: The influence of dietary fats on platelets in man. Acta Med.Scand. 190: 27-34 (1971).

25. Nord $\varnothing y, A ., S t r \phi m, E$. and Gjesdal,K.: The effect of alimentary hyperlipaemia and primary hypertriglyceridaemia on platelets in man. Scand. J.Haemat. 12: 329-340 (1974).

26. Renaud,S., Kuba,K., Goulet,C., Lemire,Y. and Allard,C.: Relationship between fatty acid composition of platelets and platelet aggregation in rat and man. Relation to thrombosis. Circ.Res. 26: 553-564 (1970).

27. Pitas,R.E., Nelson,G.J., Jaffe,R.M. and Mahley,R.W.: Effects of diets high in saturated fat and cholesterol on the lipid composition of canine platelets. Lipids 14: 469-477 (1979).

28. Pace-Asciak,C. and Wolfe,L.S.: Inhibition of prostaglandin synthesis by oleic, linoleic and linolenic acids. Biochim. Biophys.Acta 152: 784-787 (1968).

29. Lands,W.E.M., Leiellier,P.R., Rome,L.H. and Vanderhoek,Y.: Inhibition of prostaglandin biosynthesis. Adv.Biosci. 9: 15-28 (1973).

30. Gerrard,J.M., White,J.G. and Krivitt,W.: Labile aggregation-stimulating substance, free fatty acids and platelet aggregation. J.Lab.Clin. Med. 87: 73-82 (1976).

31. Vallee,E., Gougat,J. and Ageron,M.: Inhibition of platelet phospholipase- $A_{2}$ as a mechanism for the anti-aggregating effect of linoleic acid. Agents and Actions 10: 57-62 (1980).

32. Lipinski,B.A. and Mathias,M.M.: Prostaglandin production and lipolysis in isolated rat adipocytes as affected by dietary fat. Prostaglandins 16: 957-963 (1978).

33. Meydani,S.N., Mathias,M.M. and Schatte,C.L.: Dietary fat type and ambient oxygen tension influence pulmonary prostaglandin synthetic potential. Prost.Med. 1: 241-249 (1978).

34. Nugteren,D.H., van Evert,W.C., Soeting,W.J. and Spuy,J.H.: The effect of different amounts of linoleic acid in the diet on the excretion of urinary prostaglandin metabolites in the rat. Adv.Prost. Thromb. Res. 8: 1793-1796 (1980).

35. Zöllner, N., Adam,0. and Wolfram,G.: The influence of linoleic acid intake on the excretion of urinary prostaglandin metabolites. Res. Exp. Med. 175: 149-153 (1979). 
36. Smith,J.B., Ingerman,C.M. and Silver,M.J.: Formation of prostaglandin $\mathrm{D}_{2}$ during endoperoxide-induced platelet aggregation. Thromb.Res. 9: 413-418 (1976).

37. Oelz,0., Oelz,R., Knapp,H.R., Sweetman,B.J. and Oates,J.A.: Biosynthesis of prostaglandin $D_{2}$. I. Formation of prostaglandin $D_{2}$ by human platelets. Prostaglandins 12: 225-234 (1977).

38. Kloeze,J.: Influence of prostaglandins on platelet adhesiveness ard platelet aggregation. In: Bergström,S. and Samuelsson,B. (Eds.): Prostaglandins. Almquist and Wiksell, Stockholm (1967), pp. 241-252.

39. Shio,H. ard Ramwel1,P.: Effect of prostaglandin $E_{2}$ and aspirin on the secondary aggregation of human platelets. Nature (New Biology) 236: 45-46 (1972).

40. Whittle,B.J.R., Moncada,S. and Vane,J.R.: Comparison of effects of prostacyclin $\left(P \mathrm{CI}_{2}\right)$ prostaglandin $\mathrm{E}_{1}$ and $\mathrm{D}_{2}$ on platelet aggregation in different species. Prostaglandins 16: 373-388 (1978).

41. Lagarde,M., Guic'ardant,M. and Dechavanne,M.: Human platelet $P G E_{1}$ arid dihomogammalinolenic acid. Comparison to $\mathrm{PGE}_{2}$ and arachidonic acid. Progr. Lipid Res. (in press).

42. Willis,A.L., Comai,K., Kuhn,D.C. and Paulsrud,J.: Dihomo- $\gamma-1$ inolenate suppresses platelet aggregation when administered in vitro or in vivo. Prostaglandins 8: 509-519 (1974).

43. Sim,A.K. and MCCraw,A.P.: The activity of $\gamma$-linolenate and dihomo- $\gamma$ -1 inolenate methyl esters in vitro and in vivo on blood platelet function in non-human primates and in man. Thromb. Res. 10: 385-397 (1977).

44. Kernoff,P.B.A., Willis,A.L., Stone,K.J., Davies,J.A. and McNicol,G.P.: Antithrombotic potential of dihomo-gamma-linolenic acid in man. $\mathrm{Br}$. Med.J. 2: 1441-1444 (1977).

45. Willis,A.L. and Smith,J.B.: Some perspectives on platelets and prostaglandins. Progr.Lipid Res. (in press).

46. Oelz,0., Seyberth,H.W., Knapp,H.R.Jr., Sweetman,B.J. and Oates,J.A.: Effects of feeding ethyl-dihomo- $\gamma-1$ inolenate on prostaglandin biosynthesis and platelet aggregation in the rabbit. Biochim. Biophys. Acta 431: 268-277 (1976).

47. Willis,A.L.: Personal communication.

48. Hoover,R.L., Lynch,R.D., Karnovsky,M.J.: Decrease in adhesion of cells cultured in polyunsaturated fatty acids. Cell 12: 295-300 (1977).

49. O'Brien,J.R., Etherington,M.D. and Jamieson,S.: Acute platelet changes after large meals of saturated and unsaturated fats. Lancet $i: 878$ $-880(1976)$. 
50. O'Brien,J.R., Etherington,M.D., Jamieson,S., Vergroesen,A.J. and Ten Hoor,F.: Effect of a diet of polyunsaturated fats on some platelet function tests. Lancet ii: $995-997$ (1976).

51. Renaud,S., Morazain,R., McGregor,L. and Baudier,F.: Dietary fats and platelet functions in relation to atherosclerosis and coronary heart disease. Haemostasis 8: 234-251 (1979).

52. Jakubowski,J.A. and Ardlie,N.G.: Modification of human platelet function by a diet enriched in saturated or polyunsaturated fat. Atherosclerosis 31: 335-344 (1978).

53. Derksen,A. and Cohen,P.: Patterns of fatty acid release from endogenous substrates by human platelet homogenates and membranes. J.Biol.Chem. 250: 9342-9347 (1975). 


\section{SUMMARY AND CONCLUDING REMARKS}

Extensive animal experiments, human epidemiological studies and clinical trials all indicate that the type of dietary fat affects the genesis, course and complications of the atherosclerotic process.

Since arterial thrombosis is implicated in atherosclerosis, both as an initiating and a complicating factor, we investigated the effect of dietary fatty acid composition on arterial thrombogenesis and its underlying processes in animals and men, using some new-developed techniques.

In rats, diets rich in saturated fatty acids are thrombogenic. 0ils rich in mono-unsaturated fatty acids (olive oil, rapeseed oil) seem to behave neutrally and are antithrombotic only when replacing saturated fats. 0ils rich in polyunsaturated fatty acids (sunflowerseed $0 i 1$, safflower $0 i 1$, maize oil) have a distinct antithrombotic effect. This activity is most probably mediated by a change in the aggregation tendency of the blood platelets, whereas -except for certain fish oils-changes in blood coagulability do not seem to be involved. The antithrombotic effect of oils rich in polyunsaturated fatty acids of the (n-3) family (1inseed oil, certain fish oils), is explained by their decreasing influence on the production of a prothrombotic substance (thromboxane $A_{2}$ ) by activated blood platelets. The formation of vascular antithrombotic prostaglandin $I_{2}$ (prostacyclin) is, however, also inhibited. On the basis of this finding, the thromboregulatory theory based on the thromboxane/prostacycl in balance (Moncada,S. and Vane,J.R., Brit.Med.Bul1. 34, 129-135 (1978) is challenged. The studies reported also provide evidence against the highly elegant but insufficiently supported homoiostatic thromboregulatory theory, put forward by the same authors - which is based on an alleged transfer of platelet prostacyclin precursors to the vessel wall (Bunting,S., Gryglewski,R.J., Moncada,S. and Vane,J.R., Prostaglandins 12: 897-y13 (1976)). Moreover, evidence was obtained indicating that thrombin formed as a result of clotting, induced by vessel-wall damage, is of primary importance in platelet reactions following vascular injury.

The decreasing effect on the production of platelet thromboxane $A_{2}$ and vascular prostacyci in by dietary $(n-3)$ fatty acids is caused by their inhibiting influence on the conversion of linoleic acid into the prostaglandin precursor, arachidonic acid. The long-term use of oils rich in 
$(n-3)$ fatty acids will lead to a systemic depression of tissue arachidonic acid levels and, consequently, of the production of prostaglandins of the 2-series, which are important physiological modulators. This lower formation of the 2-series prostanoids is not compensated for by the production of prostaglandin-like substances of the 3-family. The ultimate effect of a continuous, generalized depression of prostaglandin formation is not yet known and should be investigated further before a general use of these oils can be recommended.

Linoleic acid (abundant in sunflower-, safflower- and maize oil) produces a distinct antithrombotic effect without lowering the formation of platelet and vessel-wall prostaglandin-like substances. The mechanism of this effect is not yet quite clear. A detailed study of the platelet lipid profile and fatty acid composition did not indicate the involvement of platelet membrane fluidity. However, more appropriate techniques are required to obtain a definitive answer to this question.

The involvement of prostaglandins from sources other than platelets and vascular tissue, which may be a factor in the explanation of the antithrombotic effect of dietary linoleic acid, is not incompatible with our results and deserves further investigation.

Replacing dietary saturated fats with linoleic acid-rich products, considerably reduces platelet aggregation in male human subjects. It is likely that this lower platelet aggregability contributed to the $50 \%$ decrease in mortality from coronary heart disease, which was associated with the high-linoleic acid diet. (Miettinen,M. et al. Lancet ii: 835-838 (1972). Indications obtained showed that the thromboprotective effect of dietary linoleate lasts longer, the longer the feeding period. It is assumed that this long-term effect of dietary linoleate is mediated by linoleic acid, which is taken up by adipose tissue during the feeding period and slowly released into the plasma after withdrawal from the diet.

After the onset of a myocardial infarct, about 50\% of the patients dies within a few hours, leaving too little time for successful intervention and/or secondary prevention. This implies that primary prevention of coronary disease is of major importance. Fewer calories, more physical exercise, no smoking and a more relaxed attitude are very important factors in this respect. Moreover, a change in dietary composition is likely to lower the risk of coronary thrombosis. Based on the results of 
the experimental studies in animals and man described in this thesis and also of those performed by others, a decreased intake of saturated fatty acids is recommended together with an increased consumption of polyunsaturated fatty acids, especially linoleic acid. This is not only $1 \mathrm{i}$ kely to lower arterial thrombosis tendency, but other atherosclerosis risk factors as we11, because dietary linoleic acid has been shown to decrease serum cholesterol, especially in low-density lipoproteins, lower 'borderline' hypertension and normalize biochemical abnormalities in obesity and maturity-onset diabetes. Moreover, animal studies clearly indicated that a linoleic acid-rich diet improves cardiac perfusion and work capacity. (Vergroesen et al., Compreh. Therap. 5: 19-30 (1979)). Besides, no major adverse effect of dietary linoleic acid has ever been reported, which after a careful screening of all pertinent data and sources, could not be disproved. (Heyden,S. in Vergroesen, A.J.(Ed): The role of fats in human nutrition. Academic Press, London, New York, San Francisco (1975) pp. 44-113). It cannot be denied that conclusive proof of the efficacy of the recommended dietary changes regarding the morbidity and mortality of atherosclerosis is difficult, if not impossible, to obtain. However, the experimental evidence already available does not allow any further delay in initiating these changes. In the meantime, more research work will have to be done, especially into the mechanism by which dietary linoleate affects the atherosclerotic process. 
Veel van wat er in dit proefschrift staat, is geschreven in de technische taal van de specialist. De uitkomsten van het onderzoek zullen daarom voor niet-vakgenoten moeilijk toegankelijk zijn. Omdat het onderwerp echter voor iedereen van belang is, is deze Nederlandse samenvatting voor een bredere lezerskring geschreven.

\section{Waar het in dit proefschrift over gaat}

Onze voeding bevat niet alleen vitaminen en mineralen, maar vooral bouwen brandstoffen. De bouwstoffen (voornamelijk eiwitten en mineralen) houden ons lichaam intakt en de brandstoffen (voornamelijk koolhydraten en vetten) leveren de nodige energie. Vitaminen zijn nodig om alle levensprocessen in ons lichaam goed gekoördineerd te laten verlopen.

Vetten zijn opgebouwd uit vetzuren die wat struktuur betreft onderling sterk kunnen verschillen. Daarom bestaan er ook grote verschillen tussen de diverse soorten vetten. Harde vetten (zoals boter, sommige margarines en frituurvet) bevatten veel verzadigde vetzuren terwijl zachte vetten (bijvoorbeeld dieetmargarines) en bepaalde oliën veel onverzadigde vetzuren bevatten.

Zoals gezegd is vet een brandstof voor ons lichaam. Vetzuren leveren echter niet alleen energie maar ze hebben nog heel andere funkties. Zo dienen ze bijvoorbeeld ook als bouwstenen voor celwanden en als uitgangsmateriaal voor de produktie van een hele serie regelstoffen, de prostaglandines, waarover later meer.

De meeste vetzuren kunnen door het lichaam zelf gemaakt worden. Bij sommige meervoudig-onverzadigde vetzuren lukt dat echter niet en het zijn juist deze vetzuren die we absoluut nodig hebben. Daarom moet ons voedsel een voldoende hoeveelheid van deze zogenaamde ssentiële vet:uuren bevatten.

Om alle ceilen van het lichaam van voldoende zuurstof en voedingsstoffen te voorzien, beschikt het lichaam over een bijzonder efficient transportsysteem: het bloed. Voortgestuwd door het hart, stroomt het via de slagaders (arteriën) naar alle delen van ons lichaam waar het zuurstof en voedingsstoffen aan de cellen afgeeft en afvalstoffen uit de cellen opneemt. Vandaar stroomt het via de aders (venen) terug naar het hart. 
Bloed is vloeibaar maar het wordt snel vast wanneer dit het lichaam verlaat: het stolt. Bloedstolling is een nuttig proces omdat bij een verwonding het bloedverlies binnen de perken gehouden wordt en het transportsysteem gehandhaafd blijft. Soms echter stolt het bloed in de bloedvaten. We spreken dan van thrombose en de bloedprop die ontstaat (de thrombus) kan de bloedstroom ernstig belemmeren of zelfs blokkeren. Thrombose kan in een ader voorkomen (dit is bijvoorbeeld het geval bij een 'thrombosebeen') maar ook in een slagader. In dit laatste geval hebben we te maken met arteriële thrombose.

Bij arteriële thrombose kan de zuurstof- en voedselvoorziening van weefsels in het gedrang komen als gevolg waarvan deze kunnen afsterven. Wanneer dit in de hartspier gebeurt, spreken we van een hartinfarct dat in Nederland jaarlijks ongeveer 30.000 mensen - óók jonge - het leven kost. Arteriële thrombose is dan ook de meest voorkomende doodsoorzaak in ons land. I

De arteriële thrombus die voor het hartinfarct verantwoordelijk is, ontstaat meestal in een slagader die daarvoór al in ernstige mate vernauwd was als gevolg van een ziekte die we atherosclerose noemen. Atherosclerose (vroeger spraken we van aderverkalking) is de belangrijkste van de hart- en vaatziekten en komt nagenoeg bij iedereen voor. De ziekte geeft pas in een laat stadium problemen. Als het eenmaal zover is, kan door allerlei matregelen het verdere verloop wel vertraagd en de kans op komplikaties verkleind worden, maar genezing is in feite uitgesloten. Daarom geldt hier wel heel in het bijzonder: voorkomen is beter dan genezen.

Bij het ontstaan van atherosclerose zijn verscheidene processen betrokken. Eén daarvan is óók weer arteriële thrombose: kleine stolsels kunnen door de slagaderwand ingekapseld worden, waardoor de wand dikker wordt en de doorgankelijkheid van het bloedvat afneemt. Een dergelijke vernauwde slagader heeft meer kans om door een thrombus te worden afgesloten dan een gezonde, wijde arterie. Vermindering van de thromboseneiging van het bloed zal dan ook niet alleen het ontstaan van atherosclerose kunnen vertragen maar kan wellicht ook het optreden van komplikaties ervan doen afnemen.

T Meer vitvoerige informatie over bloedstolling, thrombose en het hartinfarkt vindt $U$ in het boekje van die naam dat onlangs is uitgegeven door Natuur en Techniek (ISBN nr. 9070157063 ). 
Vergelijkende onderzoeken uitgevoerd onder verschillende bevolkingsgroepen hebben reeds geruime tijd geleden aangetoond dat er een verband bestaat tussen type voedingsvet en de sterfte als gevolg van atherosclerose. Mensen die veel harde (= verzadigde) vetten eten blijken meer kans te hebben om aan een hartinfarct te overlijden dan zij die weinig verzadigde vetten in hun voeding hebben. De werkelijke betekenis van een dergelijk verband moet echter niet worden overschat omdat het niet bewijst dat het één het gevolg is van het ander; om dat te kunnen aantonen zijn er goed opgezette proeven nodig. De uitkomsten van de vergelijkende bevolkingsonderzoeken hebben dan ook geleid tot het uitvoeren van een aantal voedingsexperimenten waarbij inderdaad werd vastgesteld dat langdurige vervanging van verzadigde- door meervoudig-onverzadigde vetten, een geringere sterfte aan hart- en vaatziekten tot gevolg heeft.

Op grond van deze onderzoekingen zou ons voedingspakket dus eigenlijk aangepast moeten worden: de verzadigde vetzuren zouden, althans voor een belangrijk deel, vervangen moeten worden door meervoudig-onverzadigde vetzuren. Dat dit nog nauwelijks gebeurt heeft twee oorzaken. In de eerste plaats bestaan er bij de meeste mensen nu eenmaal grote weerstanden om hun leefgewoonten te veranderen en ten tweede is er nogal wat kritiek op het onderzoek losgekomen. Hoewel hierbij gevestigde ekonomische belangen wellicht een grotere rol spelen dan wetenschappelijk gefundeerde bedenkingen, moet toch worden vastgesteld dat het definitieve bewijs voor het nut en de noodzaak van de aanbevolen aanpassing van ons voedingspakket nog niet geleverd is. Omdat het bovendien steeds duidelijker wordt dat een dergelijk bewijs om zowel praktische als ethische redenen hoogstwaarschijnlijk nooit verkregen zal kunnen worden, dreigen we in een situatie terecht te komen waarbij alles bij het oude blijft. De aanwijzingen voor een gunstig effekt van de aanbevolen dieetwijzigingen ten aanzien van de preventie van hart- en vaatziekten zijn echter zo veelbelovend, dat nader onderzoek wenselijk is. Het lijkt daarbij zinvol vooral de aandacht te richten op processen die bij het ontstaan en de komplikaties van atherosclerose betrokken zijn.

Zoals gezegd is arteriële thrombose niet alleen éen van de oorzaken van atherosclerose maar bovendien de belangrijkste dodelijke komplikatie van deze ziekte. De vraag die ten grondslag ligt aan het in dit proefschrift beschreven onderzoek luidde dan ook of het type voedingsvet op de arteriële thromboseneiging van invloed is. Toen dit inderdaad het 
geval bleek te zijn, werd het onderzoek vooral gericht op de vraag hoe deze beïnvloeding tot stand komt.

\section{Proeven met ratten}

Om de arteriële thromboseneiging te kunnen meten moet men thrombose in een slagader op een goed gestandaardiseerde manier kunnen opwekken. Een lage thromboseneiging uit zich dan in een langzame thrombusvorming en een hoge thromboseneiging in een snelle vorming en groei van een thrombus. Het is duidelijk dat deze direkte benadering niet bij mensen kan worden toegepast en daarom zijn de meeste proeven met ratten uitgevoerd. Ratten zijn, net als mensen, alleseters. Bovendien bleek het mogelijk in deze dieren op een goed gestandaardiseerde wijze een thrombus op te wekken die, in ontwikkeling en samenstelling, grote overeenkomst vertoont met een arteriële thrombus bij de mens. (Hoofdstuk 5.2.).

Hiertoe wordt de grote lichaamsslagader (aorta) met behulp van een doorzichtig slangetje (de aortalus), tot buiten het lichaam omgeleid. Op die plaatsen waar de lus aan de aorta is vastgemaakt vormt zich al snel een thrombus die sneller groeit naarmate de thromboseneiging hoger is en die na verloop van tijd de bloedstroom in de lus volledig blokkeert. Het moment waarop de lus volledig verstopt raakt, is vrij nauwkeurig vast te stellen omdat vanaf dat ogenblik het bloed in de lus snel van lichtrood tot donkerblauw verkleurt. De tijdsduur liggend tussen het aanleggen van de aortalus en de totale verstopping ervan wordt obstruktietijd genoemd en is korter naarmate het bloed een hogere thromboseneiging heeft.

Door ratten eerst gedurende een lange periode met allerlei vetten te voeden en daarna hun arteriële thromboseneiging te meten, kon worden nagegaan of die door het type voedingsvet wordt beinvloed. Het bleek dat vetten die veel verzadigde vetzuren bevatten (kokosvet, reuzel, boter, walvistraan) meestal een hoge arteriële thromboseneiging veroorzaken, terwijl oliën rijk aan (meervoudig-)onverzadigde vetzuren (zonnebloemolie, raapolie, levertraan enz.) de arteriële thromboseneiging doen afnemen (Hoofdstuk 6 en 9).

Op welke wijze beïnvloeden nu voedingsvetten de vorming van een arteriële thrombus. Om deze vraag to kunnen beantwoorden, dienen we de processen die bij arteriële thrombose een rol spelen, te kennen.

Dat bloedplaatjes hierbij centraal staan is al ruim 150 jaar bekend. Bloedplaatjes - of kortweg plaatjes-zijn de kleinste tot het bloed behorende 
cellen die, wanneer ze daartoe geprikkeld worden, plotseling aan de bloedvatwand en aan elkaar kunnen gaan kleven. Die prikkel is meestal een beschadiging van de binnenste bekleding van de bloedvatwand. Plaatjes hechten zich aan het beschadigde deel en worden hierdoor zodiniz geaktiveerd dat ze stoffen gaan produceren en uitscheiden die andere langsstromende bloedplaatjes aantrekken. Deze klonteren dan samen met de reeds aan de vaatwand gehechte plaatjes, waardoor ze zelf ook geaktiveerd worden en stoffen gaan uitscheiden die weer andere bloedplaatjes aantrekken, enz. Op deze wijze ontstaat een kettingreaktie die leidt tot de vorming van een prop van bloedplaatjes die tegen de beschadigde vaatwand gekleefd zit. Deze plaatjesprop is nog niet erg stevig, zodat de bloedstroom er gemakkelijk stukjes vanaf kan breken.

Beschadiging van de vaatwand brengt ook de bloedstolling op gang. Dit proces wordt door geaktiveerde bloedplaatjes bevorderd terwijl thrombine dat bij het stollingsproces vrijkomt, een sterke plaatjes-aktivator is. Onlangs hebben we duidelijke aanwijzingen verkregen dat in afwijking van de gangbare opvattingen, een normaal verlopend stollingsproces vocrwarde is voor de vorming van de losse plaatjesprop. (Hoofdstlik 3.2.).

Door de intensieve wisselwerking tussen bloedstolling en plaatjesaktivatie, verlopen beide processen op exakt dezelfde plaats. De bij de bloedstolling gevormde fibrinedraden raken daardoor met de losse platjesprop verweven met als gevoig dat de thrombus zo stevig wordt dat die ondanks een sterke bloedstroming, een slagader volledig kan verstoppen.

Uitgebreide proeven met ratten wezen uit dat de invloed van de meeste voedingsvetten op de arteriële thromboseneiging niet of naulvelijks tot stand komt via een direkt effekt op het bloedstollingsmechanisme. (Hoofdstuk 7.2.).

Om de invloed van voedingsvetten op het samenklonteren lan bloedplaatjes in stromend bloed te kunnen onderzoeken, werd een speciale meetmethode ontwikkeld. (Hoofdstuk 5.3.). Bij deze methode wordt eveneens gebruik gemaakt van de aortalus. Deze wordt doorgeknipt en verbonden met een filter waarvan de poriën groot genoeg zijn om het bloed ongehinderd te laten passeren. Vervolgens wordt er vlak vooór het filter een plaatjes-aktiverende stof geinjekteerd. Hierdoor gaan langsstromende bloedplaatjes samenklonteren (aggregeren) als gevolg waarvan het filter gedeeltelijk verstopt rakkt. De mate van verstopping wordt gemeten door bepaling van het verschil in bloeddruk vóór en achter het filter: naarmate dit verschil groter 
is, is het filter meer verstopt, zijn er dus meer aggregaten gevormd en is dus de aggregatieneiging van de bloedplaatjes groter. Met behulp van deze methode kon voor het merendeel van de onderzochte vetten een duidelijk verband worden aangetoond tussen de invloed van de verschillende voedingsvetten op de arteriële thromboseneiging enerzijds en de aggregatieneiging van de bloedplaatjes anderzijds. Op grond van deze en andere waarnemingen is dan ook gekonkludeerd dat de invloed van voedingsvetten op arteriële thrombusvorming tot stand komt via een effekt op de aggregatieneiging van bloedplaatjes (Hoofdstuk 7.3.).

\section{Proeven met mensen}

liet is natuurlijk wel aardig de invloed van voedingsvetten op de arteriële thromboseneiging bij ratten te kennen, maar het gaat er natuurlijk vooral om te weten hoe die bij de mens is. Uit de tot nu toe verkregen resultaten was het duidelijk geworden dat met name linolzuur een antithrombotisch effekt heeft en we wilden bijzonder graag nagaan of dit ook voor de mens geldt. De aortalus kan bij mensen natuurlijk niet worden toegepast maar de aggregatieneiging van bloedplaatjes - die bij ratten grote overeenkomst vertoonde met de thromboseneiging- zou misschien wel gemeten kunnen worden. We hebben daarom een instrument ontwikkeld waarmee de aggregatieneiging in het bloed van mensen kan worden gemeten volgens hetzelfde (suksesvolle) principe als bij ratten was toegepast.

Bloed -ditmaal uit een ader in de onderarm- wordt door een filter gezogen dat door in het bloed aanwezige aggregaten verstopt raakt. De mate van verstopping wordt afgeleid uit meting van het drukverschil over het filter dat sneller stijgt naarmate het bloed meer aggregaten bevat.

Tijdens de ontwikkeling van deze Filtragometer $\mathbb{B}$, kwamen we in kontakt met de Finse professor Turpeinen die in Helsinki een 12-jarige studie had verricht waaraan twee grote groepen mensen deeinamen: éēn groep kreeg het normale Finse dieet dat erg veel verzadigde vetzuren bevat terwijl de andere groep een dieet kreeg warin een deel van de verzadigde vetzuren door linolzuur was vervangen. We zijn toen met onze Filtragometer naar Helsinki gereisd en hebben bij ongeveer 70 mannen uit iedere groep de aggregatieneiging van de-bloedplaatjes gemeten. Die bleek in de groep met het linolzuurrijke voedsel slechts ongeveer de helft te zijn van de waarde die we in de kontrolegroep vonden. (Hoofdstuk 11). Dit kwam precies overeen 
met de bevindingen van Turpeinen dat bij mannen in de Tinolzuurrijke groep de sterfte als gevolg van hart- en vaatziekten ongeveer 50\% lager. was dan bij mannen die het normale Finse dieet kregen. Ongeveer 9 maanden nadat het linolzuurrijke dieet weer was vervangen door het (bijna) gewone Finse dieet, hebben we deze metingen herhaald. Toen bleek tot onze verrassing dat het verschil in aggregatieneiging wel kleiner geworden, maar beslist nog niet verdwenen wás. We hebben hieruit de konklusie getrokken dat een antithrombotisch dieet (vooropgesteld dat het gedurende een lange periode verstrekt wordt) een, lange nawerking heeft. Dit is later in een proef met ratten bevestigd en het vermoeden bestaat dat het linolzuur dat tijdens de experimentele voedingsperiode in het vetweefsel wordt opgeslagen en hieruit later weer langzaam vrijkomt, voor deze gunstige nawerking verantwoordelijk is (Hoofdstuk 11).

\section{Essentiële vetzuren, prostaglandines en arteriële thrombose}

Uit het tot dusver beschreven onderzoek is gebleken dat voeden met meervoudig onverzadigde vetzuren, de arteriële thromboseneiging doet afnemen als gevolg van een vermindering van de aggregatieneiging van bloedplaatjes. Met name linolzuur bleek eer sterke antithrombotische werking te hebben. Linolzuur is één van de zogenaamde essentiële vetzuren. Deze vetzuren werden vroeger wel vitamine $F$ genoemd; omdat het lichaam er niet buiten kan en deze zelf ook niet kan produceren, moeten ze met de voeding worden opgenomen.

Linolzuur wordt in het lichaam omgezet in een ander essentieel vetzuur, het arachidonzuur. Dit wordt onder meer gebruikt voor de produktie van prostaglamlinos - een serie stoffen die allerlei processen in ons lichaam voortdurend bijregelen. Prostaglandines zijn niet stabiel en worden dan ook meestal dáăr gemaakt waar ze hun werking moeten uitoefenen. De bloedplaatjes maken ook een soort prostaglandines, evenals de wand van de bloedvaten. De werking van deze stoffen is precies tegengesteld: de plaatjes maken een stof (thromboxaan $A_{2}$ ) die hen met andere bloedplaatjes doet samenklonteren terwijl de vaatwand een prostaglandine produceert (het prostacycline) dat die aggregatie juist tegengaar.

Deze ontdekkingen zijn nog maar kort geleden gedaan en leidden al gauw tot een aantal theorieën betreffende de regulering van de thromboseneiging. Deze theorieën waren zo aantrekkelijk dat ze overal direkt ingang vonden, hoewel er nog nauwelijks proeven gedaan waren om ze te kunnen bevestigen. 
Zoals reeds opgemerkt,kan het onderzoek naar de wijze waarop voedingsvetten de arteriële thromboseneiging beīnvioeden eerst dan met enige kans op sukses worden uitgevoerd wanneer precies bekend is hoe een arteriële thrombus ontstaat en op welke wijze dit proces wordt gereguleerd. Daartoe moest onder meer worden nagegaan of

- prostaglandines inderdaad een rol spelen bij de vorming van een arteriële thrombus,

- het inderdaad waar is dat de arteriële thromboseneiging bepald wordt door de balans tussen het thrombose-bevorderende thromboxaan $A_{2}$ uit de bloedplaatjes en het antithrombotische prostacycline uit de vaatwand, - geaktiveerde bloedplaatjes inderdaad hun eigen deelname aan het thrombotische proces tegengaan door de vaatwand tot het maken van meer prostacycline te stimuleren.

Zoals uitvoerig in Hoofdstuk 3.3.3. is uiteengezet, berust de laatste theorie op een foutieve interpretatie van een aantal niet goed gekontroleerde experimenten.

Om na te gaan of prostaglandines inderdaad een rol spelen bij het gebruikte thrombosemodel, werden ratten gedurende een lange periode met een dieet gevoed dat geen essentiële vetzuren bevatte. Op deze wijze kon de prostaglandineproduktie bijna volledig worden onderdrukt. Het bleek toen dat de thromboseneiging bij deze dieren buitengewoon laag was en dit maakt het erg aannemelijk dat prostaglandines bij de vorming van de arteriële thrombus en bepaalde rol spelen (Hoofdstuk 8.2.). Het huidige onderzoek heeft echter ook sterke aanwijzingen opgeleverd dat er nog andere thromboseregulerende mechanismen bestaan dan de tot nu toe bekende.

Het was opmerkelijk dat voeding met een dieet zonder essentiële vetzuren de vorming van het antithrombotische prostacycline door de vaatwand even sterk doet dalen als de produktie van het thrombosebevorderende thromboxaan $A_{2}$. De balans tussen beide stoffen verandert dus niet en toch wordt de thromboseneiging beduidend lager.

Soortgelijke resultaten kregen we na voedingsproeven met lijnolie en levertraan en toen er ook nog een keurig verband bleek te bestaan tussen de arteriële thromboseneiging en de mate waarin bloedplaatjes in staat zijn het thrombose-bevorderende thromboxaan te maken, werd het duidelijk dat de balanshypothese -hoe elegant ook- niet klopte maar dat voor de regulering van de thromboseneiging van het bloed, het thromboxaan uit de bloedplaatjes veel belangrijker is dan het prostacycline uit de vaatwand (Hoofdstuk 8.3.). 
Dit onderzoek gaf ook meteen een antwoord op de vraag waarom voeding met lijnolie en levertraan de arteriële thromboseneiging doet afnemen. Het veroorzaakte immers een vermindering van het vermogen van de bloedplaatjes om thromboxaan te maken. Dit bleek te berusten op een vermindering in de bloedplaatjes (maar ook in andere weefsels) van de hoeveelheid arachidonzuur -het essentiële vetzuur waaruit thromboxaan wordt gemaakt- en dat kon weer worden verklaard uit het feit dat bepaalde vetzuren die in lijnolie en levertraan voorkomen, de vorming van arachidonzuur uit linolzuur remmen (Hoofdstuk 10).

Andere onderzoekers veronderstelden dat het antithrombotische effekt van visoliën werd veroorzaakt door de produktie van een speciaal soort prostaglandines maar deze theorie bleek niet juist: in een uitgebreid onderzoek, waarbij zeer gevoelige technieken gebruikt zijn, hebben we aangetoond dat deze prostaglandines niet gevormd worden (Hoofdstuk 9). Onze resultaten zijn inmiddels (door andere onderzoekers) bij mensen ten dele bevestigd. Tot op dit moment heeft men nog niet ontdekt op welke wijze de thrombosebevorderende werking van verzadigde vetzuren en het antithrombotisch effekt van linolzuur tot stand komen. De prostaglandines van bloedplaatjes en vaatwand spelen hierbij geen rol, want de produktie van deze stoffen bleek door voeden met verzadigde vetten of met oliën rijk aan linolzuur niet beïnvloed te worden. Bij de verklaring van het effekt van linolzuur, kunnen mogelijk andere prostaglandines nog een rol spelen want de uitscheiding van prostaglandine-afbraakprodukten neemt sterk toe bij voeding met een' dieet dat rijk aan linolzuur is. Ook zijn er aanwijzingen dat de funktie van het bloedplaatjesmembraan door een linolzuurrijke voeding wordt beînvloed, maar het onderzoek in deze richting staat nog in de kinderschoenen.

\section{Wat betekent dit onderzoek voor onze voeding}

De belangrijkste resultaten komen in het kort of het volgende neer.

- Arteriële thrombose is een belangrijke oorzaak van hart- en vaatziekten en meestal verantwoordelijk voor de dood die deze ziekten veroorzaken.

- Verzadigde vetzuren bevorderen de arteriële thromboseneiging, terwijl meervoudig-onverzadigde vetzuren de vorming van een arteriële thrombus juist afremmen.

- Het antithrombotische effekt van de meervoudig-onverzadigde vetzuren uit lijnolie en visoliën komt tot stand via een algemene verlaging van de prostaglandineproduktie in het lichaam. 
- Linolzuur dat in belangrijke hoeveelheden in zonnebloem-, saffloer- en maisoilie voorkomt, heeft ook een sterke antithrombotische werking maar het vermindert de vorming van prostaglandines niet.

op grond van deze bevindingen verdient het aanbeveling verzadigde vetzuren in de voeding te vervangen door meervoudig-onverzadigde vetzuren. Linolzuur heeft hierbij de voorkeur omdat het de produktie van een groep belangrijke regelstoffen, de prostaglandines, niet vermindert. Bovendien worden de meervoudig-onverzadigde vetzuren uit lijnolie en visoliën als minder smakelijk ervaren. Deze oliën worden gauw ranzig. Tenslotte weten we dat door een veelvuldig gebruik van visoliën, veranderingen in de hartspier en in andere weefsels veroorzaakt worden waarvan de exakte betekenis momenteel nog niet duidelijk is.

Er zijn nog meer redenen waarom het gebruik van linolzuur kan worden aanbevolen. Zo is bijvoorbeeld aangetoond dat het naast een verlagend effekt op het serumcholesterolgehalte, ook een gunstige invloed heeft op bepaalde vormen van hoge bloeddruk, terwijl dierproeven een positief effekt van linolzuur op de hartwerking hebben aangetoond. Tenslotte is het onlangs ook duidelijk geworden dat linolzuur een gunstige invloed heeft op die komplikaties bij suikerziekte (diabetes mellitus) die ook een rol spelen bij het verhoogde risiko van atherosclerose bij diabetespatienten.

Linolzuur is een natuurprodukt, maar het moet heel wat bewerkingen ondergaan voordat het voor konsumptie geschikt is. Op geen enkele wijze is tot nu toe aangetoond dat hierdoor het gebruik van linolzuur op de duur schadelijk zou zijn, maar dat neemt niet weg dat we altijd attent moeten blijven op verdere ontwikkelingen. Dat geldt echter ook voor andere voedingsmiddelen die met een veel geringere wetenschappelijke achtergrond en vaak alleen op historische gronden als veilig en gezond worden beschouwd.

Ons levenspatroon heeft de laatste 30 jaar grote veranderingen ondergaan, die onder meer geleid hebben tot een verhoogd risiko voor hart- en vaatziekten. Daarom zijn risikoverlagende matregelen nu meer dan ooit nodig. Naast minder eten en meer bewegen, niet meer roken en meer ontspannen, kan een verandering van ons voedingspakket ook een van die maatregelen zijn. Een dergelijke verandering hoeft niet ingrijpend te zijn en kan vrij eenvoudig worden gerealiseerd, vooropgesteld dat het produkten-assortiment wordt aangepast. Die aanpassing dient niet alleen te bestaan uit de produktie van steeds meer linolzuurrijke voedingsmiddelen, maar ook uit de vervaardiging van steeds minder produkten die veel verzadigde vetzuren 
bevatten. Dit vereist ingrijpende strukturele maatregelen waarvoor we. gezamenlijk de verantwoording moeten willen dragen. Het is mijn wens dat de onderzoekingen die in dit proefschrift zijn beschreven, een positieve bijdrage mogen leveren tot de politieke wil om tot dergelijke maatregelen te komen. 


\section{CURRICULUM VITAE}

De schrijver van dit proefschrift is op 31 maart 1938 in Wolvega geboren. Na 6 klassen lager onderwijs, werd eerst het diploma U.L.O. B en vervolgens het getuigschrift H.B.S. B verkregen waarna hij een jaar als aspirant-laborant op een bedrijfslaboratorium in Zwolle werkte. $\mathrm{Na}$ zijn militaire dienstplicht te hebben vervuld, trad hij in 1959 als aspirant-analist in dienst van het Unilever Research Laboratorium te Vlaardingen, waar hij het voedingsfysiologisch onderzoek in al zijn facetten leerde kennen. Inmiddels behaalde hij het analistendiploma $G$ (zoölogie).

Omstreeks 1970 begon hij aan het in dit proefschrift beschreven onderzoek. Vanaf 1974 studeerde $h^{i} j$, daartoe door zijn werkgever in staat gesteld, geneeskunde aan de Medische Fakulteit van de Erasmus Universiteit te Rotterdam. Het kandidaatsexamen werd in 1977 afgelegd, waarna hij zich aan de Rijksuniversiteit van Leiden voorbereidde op het doktoraalexamen geneeskunde, vrije studierichting, met als hoofdvak biochemie en als bijvakken fysiologie, pathologische anatomie, hematologie, kindergeneeskunde, cardiologie, endocrinologie en voedingsleer. In het kader van deze studie werd een stage gevolgd bij de Capaciteitsgroep Biochemie van de Rijksuniversiteit Limburg te Maastricht.

Op 29 juni 1979 volgde het doktoraalexamen; het diploma werd hem cum laude toegekend.

$\mathrm{Na}$ een dienstverband van ruim 20 jaar, verliet hij onlangs het Unilever Research Laboratorium om het daar begonnen en in dit proefschrift beschreven onderzoek voort te zetten aan de Algemene Fakulteit van de Rijksuniversiteit Limburg in Mastricht. 


\section{'t En is niet kant en claer of ' $t$ haepert hier en daer....}

Oudhollandse zegswijze 